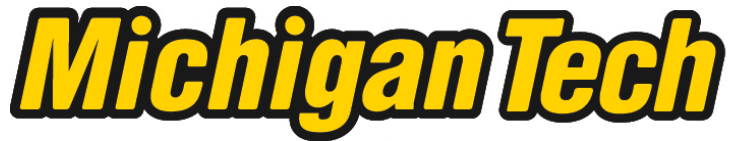 \\ Michigan Technological University Create the Future Digital Commons @ Michigan Tech
}

2015

\section{MECHANICAL PROPERTIES OF GRAPHENE NANOPLATELET/ EPOXY COMPOSITES}

Danielle René Klimek-McDonald

Michigan Technological University

Follow this and additional works at: https://digitalcommons.mtu.edu/etds

Part of the Chemical Engineering Commons

Copyright 2015 Danielle René Klimek-McDonald

\section{Recommended Citation}

Klimek-McDonald, Danielle René, "MECHANICAL PROPERTIES OF GRAPHENE NANOPLATELET/EPOXY COMPOSITES", Dissertation, Michigan Technological University, 2015.

https://doi.org/10.37099/mtu.dc.etds/1014

Follow this and additional works at: https://digitalcommons.mtu.edu/etds

Part of the Chemical Engineering Commons 


\title{
MECHANICAL PROPERTIES OF GRAPHENE NANOPLATELET/EPOXY COMPOSITES
}

\author{
By \\ Danielle René Klimek-McDonald
}

\begin{abstract}
A DISSERTATION
Submitted in partial fulfillment of the requirements for the degree of

DOCTOR OF PHILOSOPHY

In Chemical Engineering
\end{abstract}

MICHIGAN TECHNOLOGICAL UNIVERSITY

2015

(C) 2015 Danielle René Klimek-McDonald 
This dissertation has been approved in partial fulfillment of the requirements for the Degree of DOCTOR OF PHILOSOPHY in Chemical Engineering

\section{Department of Chemical Engineering}
Dissertation Advisor:
Dr. Julia A. King
Committee Member:
Dr. Timothy Eisele
Committee Member:
Dr. Gregory Odegard
Committee Member:
Dr. Ibrahim Miskioglu
Department Chair:
Dr. S. Komar Kawatra 


\section{Table of Contents}

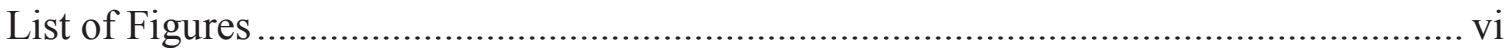

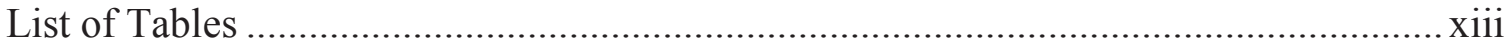

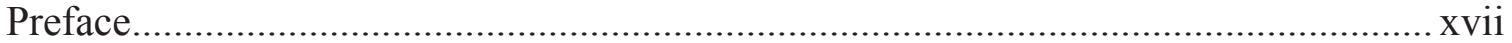

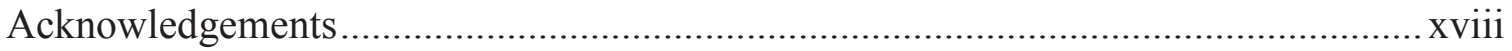

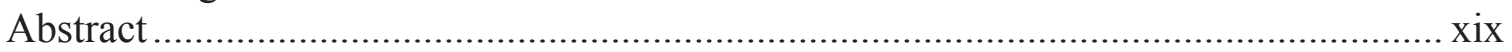

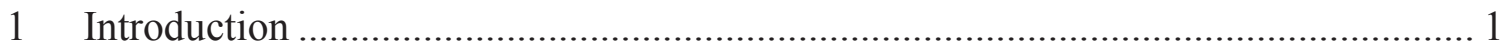

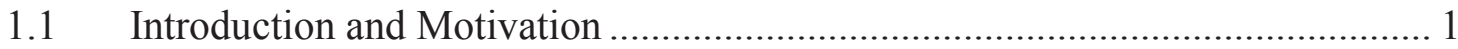

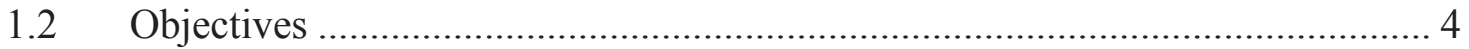

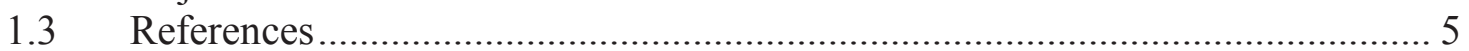

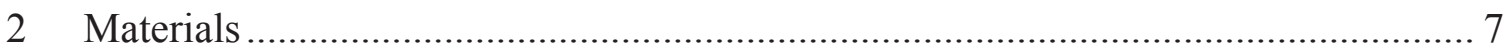

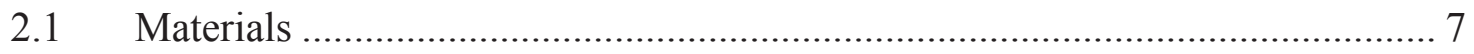

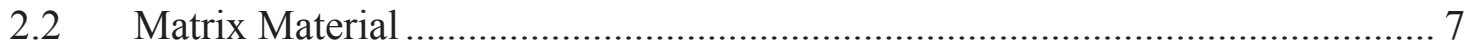

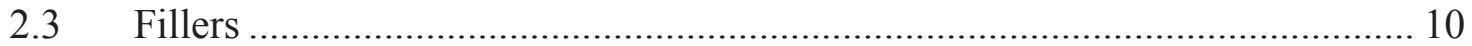

2.3.1 Graphene Nanoplatelets (GNP) ........................................................... 10

2.3.2 Hexcel HexTow ${ }^{\circledR}$ AS4-GP-3K Continuous Carbon Fiber............................. 12

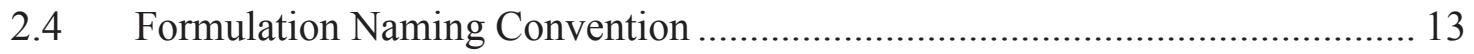

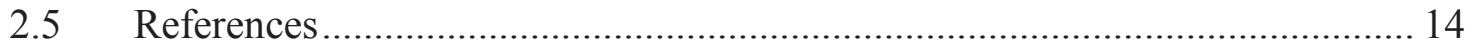

3 Fabrication and Experimental Methods............................................................ 15

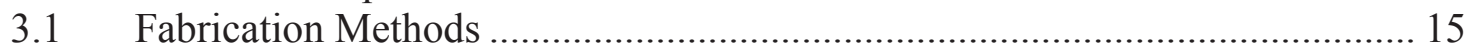

3.1.1 Neat epoxy test specimen fabrication ........................................................ 16

3.1.2 $\mathrm{xGnP}^{\circledR}$-M-15/epoxy test specimen fabrication ............................................ 16

3.1.3 $\mathrm{xGnP}^{\circledR}-\mathrm{M}-5 /$ epoxy test specimen fabrication ………................................... 17

3.1.4 $\mathrm{xGnP}^{\circledR}-\mathrm{C}-300 /$ epoxy test specimen fabrication .......................................... 18

3.1.5 Asbury TC307/epoxy test specimen fabrication......................................... 19

3.1.6 AS4 carbon fiber/epoxy test specimen fabrication ....................................... 20

3.1.7 AS4 carbon fiber/ $\mathrm{xGnP}^{\circledR}{ }_{-} \mathrm{C}-300$ /epoxy test specimen fabrication................. 21

3.2 Experimental Test Methods ................................................................. 22

3.2.1 Neat Epoxy and GNP/Epoxy Mechanical Tensile Property Test Method.... 22

3.2.2 Continuous Carbon Fiber Mechanical Tensile Property Test Method .......... 23

3.2.3 Nanoindentation Test Method.................................................................... 24

3.2.4 Mounting Samples in Epoxy Puck .............................................................. 26

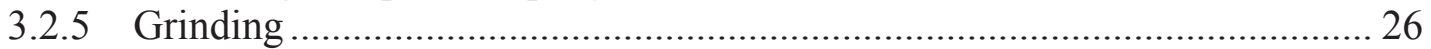

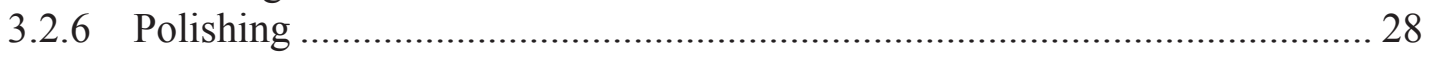

3.2.7 Through-Plane Electrical Resistivity Test Method........................................ 32

3.2.8 In-Plane Electrical Resistivity Test Method …………………….................. 33

3.2.9 Differential Scanning Calorimeter (DSC) Test Method .................................. 33

3.2.10 Dynamic Mechanical Analyzer (DMA) Test Method .................................. 35

3.2.11 Field Emission Scanning Electron Microscopy (FE-SEM) Test Method..... 38

3.2.12 Environmental Scanning Electron Microscopy (ESEM) Test Method.......... 40

3.2.13 Optical Microscope Test Method................................................................. 41

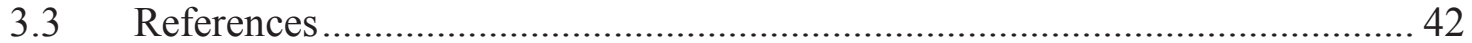

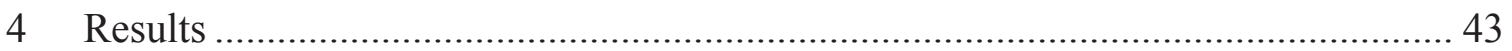

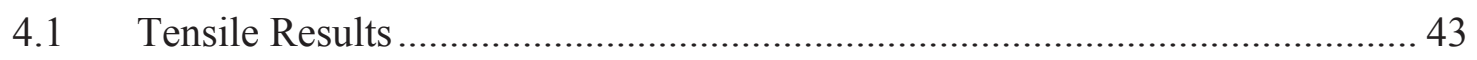




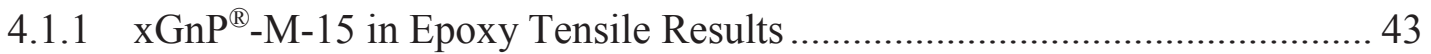

4.1.2 $\mathrm{xGnP}^{\circledR}-\mathrm{M}-5$ in Epoxy and $\mathrm{xGnP}^{\circledR}-\mathrm{C}-300$ in Epoxy Tensile Results ............ 46

4.1.3 Asbury Carbon's TC307 in Epoxy Tensile Results.......................................5 50

4.1.4 $\mathrm{xGnP}^{\circledR}-\mathrm{C}-300$ with Carbon Fiber in Epoxy Tensile Results.......................... 52

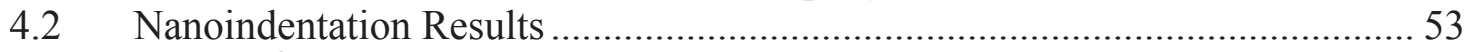

4.2.1 $\mathrm{xGnP}^{\circledR}-\mathrm{M}-15$ in Epoxy Nanoindentation Results .......................................... 53

4.2.2 $\mathrm{xGnP}^{\circledR}-\mathrm{M}-5$ in Epoxy and $\mathrm{xGnP}^{\circledR}-\mathrm{C}-300$ in Epoxy Nanoindentation Results 58

4.2.3 Asbury TC307 in Epoxy Nanoindentation Results........................................... 63

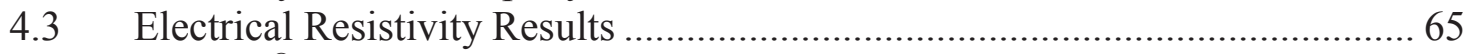

4.3.1 $\mathrm{xGnP}^{\circledR}-\mathrm{M}-15$ in Epoxy Electrical Resistivity Results .................................... 65

4.3.2 $\mathrm{xGnP}^{\circledR}-\mathrm{M}-5$ in Epoxy and $\mathrm{xGnP}^{\mathbb{B}}-\mathrm{C}-300$ in Epoxy Electrical Resistivity

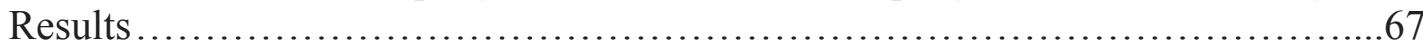

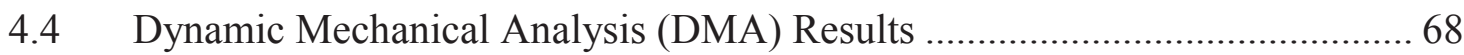

4.5 Differential Scanning Calorimeter (DSC) Results.............................................. 69

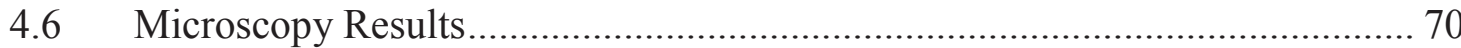

4.6.1 $\mathrm{xGnP}^{\circledR}-\mathrm{M}-15$ in Epoxy Microscopy Results............................................... 70

4.6.2 $\mathrm{xGnP}^{\circledR}-\mathrm{M}-5$ in Epoxy and $\mathrm{xGnP}^{\circledR}-\mathrm{C}-300$ in Epoxy Microscopy Results..... 72

4.6.3 $\mathrm{xGnP}^{\circledR}$-C-300 with Continuous Carbon Fiber in Epoxy Microscopy Results 74

4.6.4 Asbury TC307 in Epoxy Microscopy Results …………………………….... 75

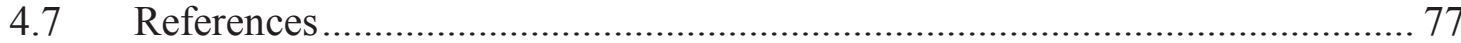

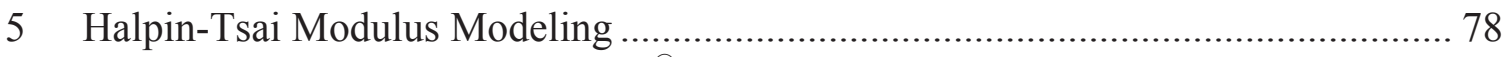

5.1 Halpin-Tsai Model for $\mathrm{xGnP}^{\circledR}-\mathrm{M}-15$ in Epoxy ………………………........... 79

5.2 Halpin-Tsai Model for $\mathrm{xGnP}^{\circledR}-\mathrm{M}-5$ in Epoxy ……………….......................... 80

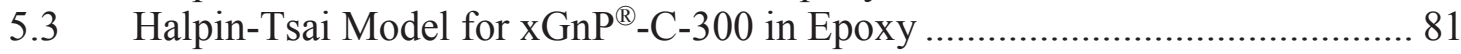

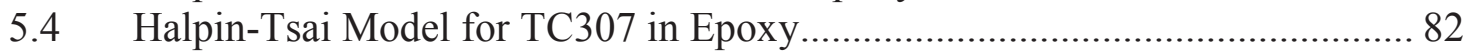

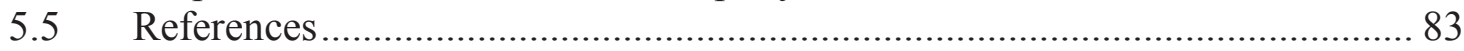

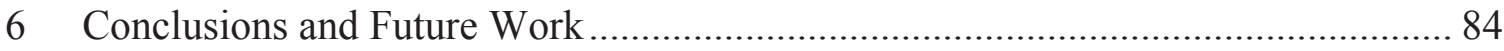

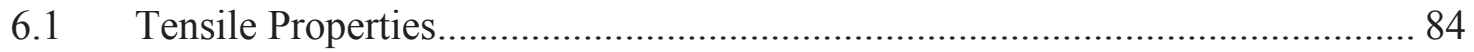

6.1.1 Neat Epoxy and GNP/Epoxy Composite Tensile Properties ......................... 84

6.1.2 Continuous Carbon Fiber/Epoxy and Continuous Carbon Fiber/xGnP®-C-

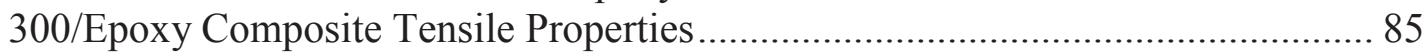

6.1.3 Tensile Property Summary ………………………................................... 85

6.2 Nanoindentation Properties for Neat Epoxy and GNP/Epoxy Composites...... 86

6.3 Electrical Resistivity Properties for Neat Epoxy and GNP/Epoxy Composites 87

6.4 Glass Transition Temperature $\left(\mathrm{T}_{\mathrm{g}}\right)$ for Neat Epoxy and GNP/Epoxy

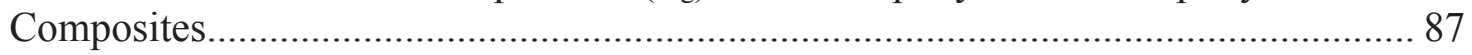

6.5 Halpin-Tsai Modeling for Neat Epoxy and GNP/Epoxy Composites .............. 88

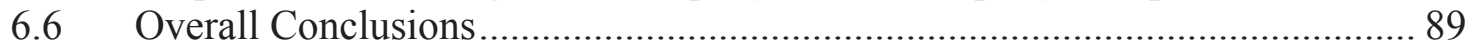

6.7 Recommendations for Future Work......................................................... 90

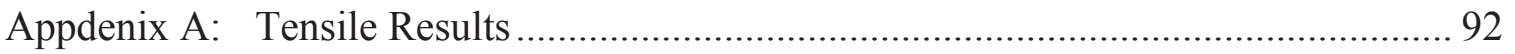

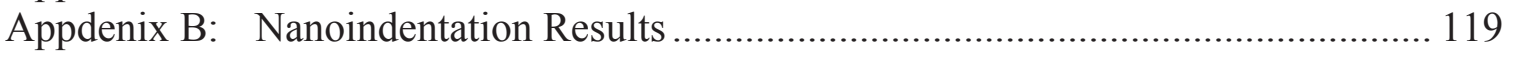

Appdenix C： Electrical Resistivity Results ................................................................ 165 


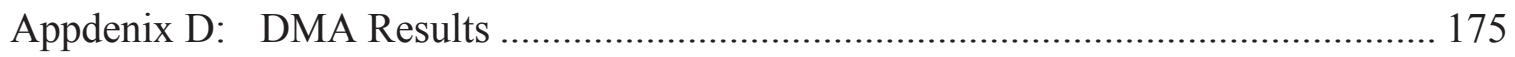

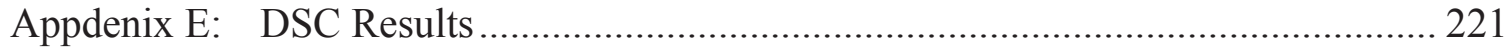

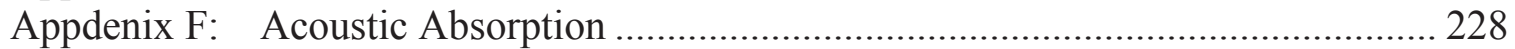

F.1 Impedance Tube Method ................................................................. 228

F.2 Dynamic Mechanical Analysis Method ..................................................... 229

F.3 Acoustic Absorption Results............................................................... 230

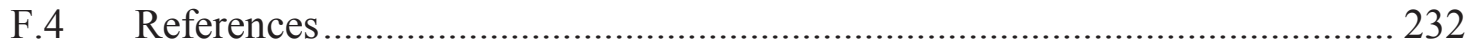

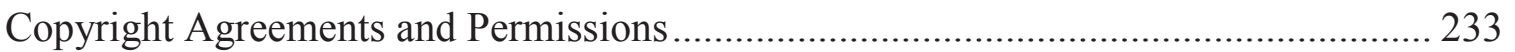

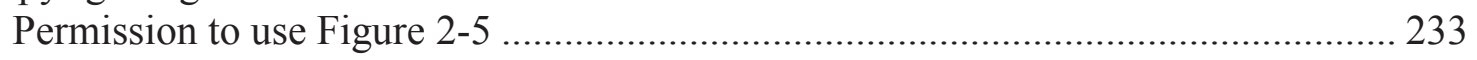

Permission to use Figure 2-6 .......................................................................... 234

Permission for Sections 4.1.1, 4.2.1, 4.3.1, 4.6.1, and 5.1................................. 235

Permission for Sections 4.1.2, 4.2.2, 4.6.2, 5.2, and 5.3 ..................................... 242 


\section{List of Figures}

Figure 2-1: EPON ${ }^{\mathrm{TM}}$ Resin 862 and EPIKRUE Curing Agent W Structures..................... 8

Figure 2-2: $\mathrm{EPON}^{\mathrm{TM}}$ Resin 862 formation from Bisphenol $\mathrm{F}$......................................... 8

Figure 2-3: Crosslinking of EPON ${ }^{\mathrm{TM}}$ Resin 862 with EPIKURE Curing Agent W ........... 9

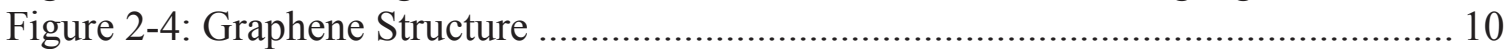

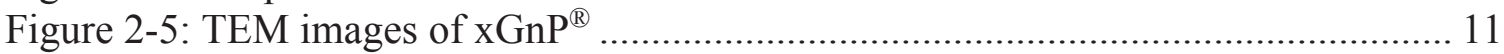

Figure 2-6: Transmission Electron Micrograph of Asbury TC307 ................................. 12

Figure 3-1: (left) Ross high shear mixer HSM-100 LSK-I with (right) 2" dispersion

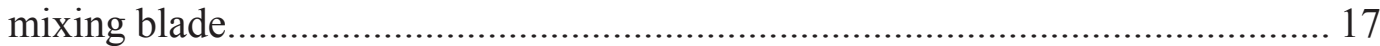

Figure 3-2: Branson Bath Sonicator CPX2800H........................................................ 19

Figure 3-3: Wabash Compression Molding Machine Vantage Series Model V75H-18-

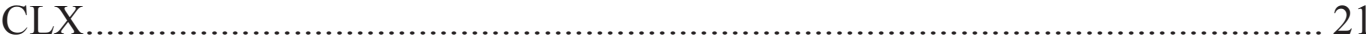

Figure 3-4: Instru-Met Sintech mechanical testing machine with tensile apparatus

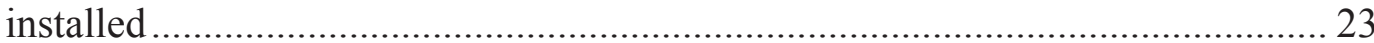

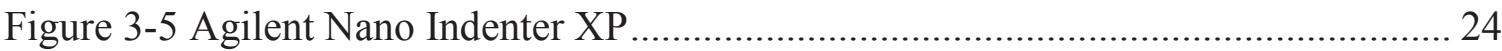

Figure 3-6: Diamond Pacific rotating lap with water drip apparatus................................. 27

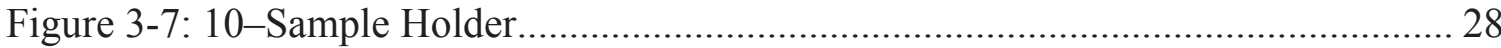

Figure 3-8: Buhler Ecomet 4 variable speed grinder-polisher........................................ 29

Figure 3-9: (left) Keithley 6517A Electrometer/High Resistance Meter, (right) Keithley 8009 Resistivity Test Fixture ............................................................................. 32

Figure 3-10: Metter Toledo 823E Differential Scanning Calorimeter................................ 34

Figure 3-11: left) TA Instruments Q800 DMA right) Dual/single cantilever clamp........ 36

Figure 3-12: Amplitude test for neat CTC Resin 310-008/Hardener 320-009, showing that

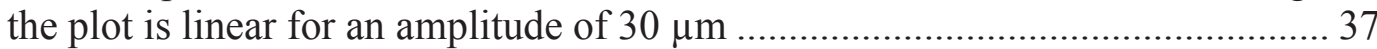

Figure 3-13: Hitachi S-4700 Field Emission Scanning Electron Microscope (FE-SEM) 39

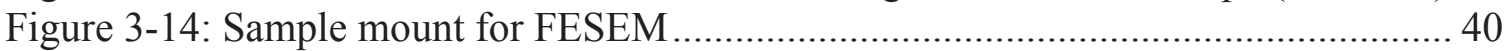

Figure 3-15: FEI/Phillips XL40 Environmental Scanning Electron Microscope.............. 41

Figure 4-1: Modulus for $\mathrm{xGnP}^{\circledR}-\mathrm{M}-15 /$ epoxy composites................................................. 44

Figure 4-2: Ultimate tensile strength and strain at ultimate tensile strength for $\mathrm{xGnP}^{\circledR}-\mathrm{M}$ -

15/epoxy composites.

Figure 4-3: Tensile modulus for $\mathrm{xGnP}^{\circledR}-\mathrm{M}-5 /$ epoxy and $\mathrm{xGnP}^{\circledR}-\mathrm{C}-300$ /epoxy composites

Figure 4-4: Ultimate tensile strength for $\mathrm{xGnP}^{\circledR}-\mathrm{M}-5 /$ epoxy and $\mathrm{xGnP}{ }^{\circledR}-\mathrm{C}-300$ /epoxy

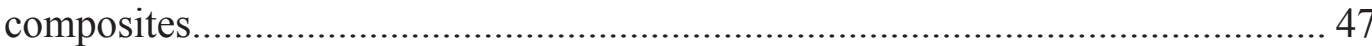

Figure 4-5: Strain at ultimate tensile strength for $\mathrm{xGnP}^{\circledR}-\mathrm{M}-5 /$ epoxy and $\mathrm{xGnP}^{\circledR}-\mathrm{C}-$

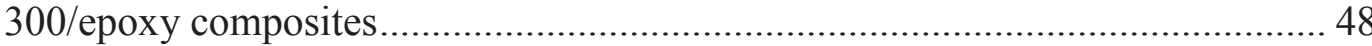

Figure 4-6: Modulus for TC307/epoxy composites...................................................... 51

Figure 4-7: Ultimate tensile strength and strain at ultimate tensile strength TC307/epoxy

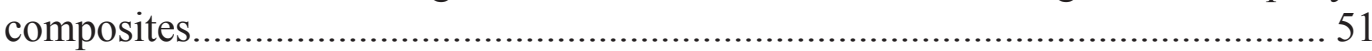

Figure 4-8: Modulus and hardness determined by nanoindentation for $5 \mathrm{wt} \% \mathrm{xGnP}^{\circledR}-\mathrm{M}$ 15 in epoxy..... 53

Figure 4-9: Modulus determined by nanoindentation for $\mathrm{xGnP}^{\circledR}-\mathrm{M}-15 /$ epoxy composites 
Figure 4-10: Nanoindentation penetration depth curves at various loads for $5 \mathrm{wt} \%$ $\mathrm{xGnP}^{\circledR}-\mathrm{M}-15$ in epoxy .......................................................................... 56

Figure 4-11: Creep compliance for $5 \mathrm{wt} \% \mathrm{xGnP}^{\circledR}-\mathrm{M}-15$ in epoxy at various loads ........ 57 Figure 4-12: Creep compliance at a load of $2 \mathrm{mN}$ for neat epoxy and $\mathrm{xGnP}^{\circledR}-\mathrm{M}-15 / \mathrm{epoxy}$

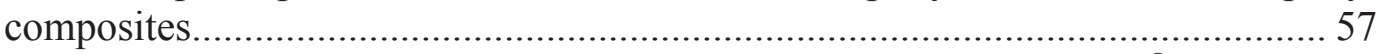

Figure 4-13: Creep compliance at a load of $25 \mathrm{mN}$ for neat epoxy and $\mathrm{xGnP}^{\circledR}-\mathrm{M}$ -

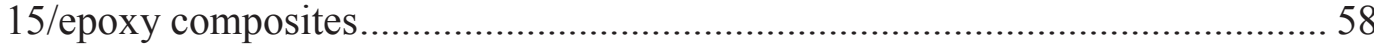

Figure 4-14: Creep Compliance for $5 \mathrm{wt} \% \mathrm{xGnP}^{\circledR}-\mathrm{C}-300$ in Epoxy at Various Loads ... 61 Figure 4-15: Creep Compliance for Neat Epoxy, 2 and $5 \mathrm{wt} \% \mathrm{xGnP}^{\circledR}-\mathrm{C}-300$ in Epoxy at $25 \mathrm{mN}$. 62

Figure 4-16: Modulus as Determined by Nanoindentation for TC307/Epoxy Composites 65

Figure 4-17: $\log$ (electrical resistivity) results for $\mathrm{xGnP}^{\circledR}-\mathrm{M}-15 /$ epoxy composites ....... 66 Figure 4-18: Optical Microscope micrograph of $5 \mathrm{wt} \%$ graphene nanoplatelets in epoxy 71

Figure 4-19: Field emission scanning electron microscope micrograph of $5 \mathrm{wt} \%$ graphene

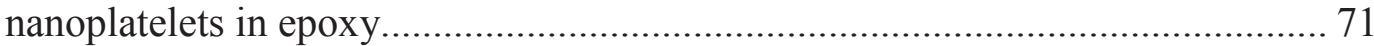

Figure 4-20: Environmental scanning electron microscope micrograph of $5 \mathrm{wt} \% \mathrm{xGnP}^{\circledR}$ -

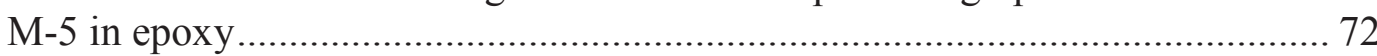

Figure 4-21: Field emission scanning electron microscope micrograph of $5 \mathrm{wt} \% \mathrm{xGnP}^{\circledR}$ -

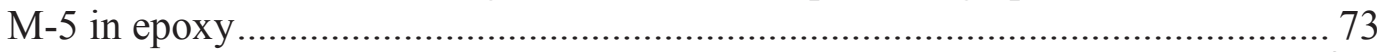

Figure 4-22: Environmental scanning electron microscope micrograph of $4 \mathrm{wt} \% \mathrm{xGnP}^{\circledR}$ C-300 in epoxy ................................................................................... 73

Figure 4-23: Field emission scanning electron microscope micrograph of $4 \mathrm{wt} \% \mathrm{xGnP}^{\circledR}$ -

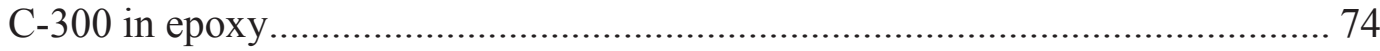

Figure 4-24: Field Emission Scanning Electron Microscope Image of the Fracture Surface of $\mathrm{xGnP}^{\circledR}-\mathrm{C}-300 /$ Carbon Fiber/Epoxy Composite ................................. 75

Figure 4-25: Field Emission Scanning Electron Micrograph of 4 wt\% TC307 in Epoxy 76 Figure 4-26: Field Emission Scanning Electron Micrograph of 4 wt\% TC307 in Epoxy at Higher Magnification................................................................................. 76

Figure 5-1: Tensile Modulus, Scaled Nanoindentation Modulus, and Halpin-Tsai Models for $\mathrm{xGnP}^{\circledR}-\mathrm{M}-15$ in Epoxy ........................................................................... 80

Figure 5-2: Tensile Modulus, Scaled Nanoindentation Modulus, and Halpin-Tsai Models for $\mathrm{xGnP}^{\circledR}-\mathrm{M}-5$ in Epoxy 81

Figure 5-3: Tensile Modulus, Scaled Nanoindentation Modulus, and Halpin-Tsai Models for $\mathrm{xGnP}^{\circledR}-\mathrm{C}-300$ in Epoxy ........................................................................ 82

Figure 5-4: Tensile Modulus, Scaled Nanoindentation Modulus, and Halpin-Tsai Models for TC307 in Epoxy ................................................................................. 83

Figure A-1: Tensile Results for Neat Epoxy............................................................ 92

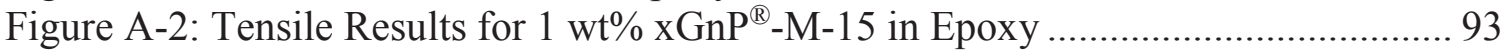

Figure A-3: Tensile Results for $2 \mathrm{wt} \% \mathrm{xGnP}^{\circledR}-\mathrm{M}-15$ in Epoxy .................................... 94

Figure A-4: Tensile Results for $3 \mathrm{wt} \% \mathrm{xGnP}^{\circledR}$-M-15 in Epoxy ................................... 95

Figure A-5: Tensile Results for $4 \mathrm{wt} \% \mathrm{xGnP}^{\circledR}-\mathrm{M}-15$ in Epoxy ................................... 96

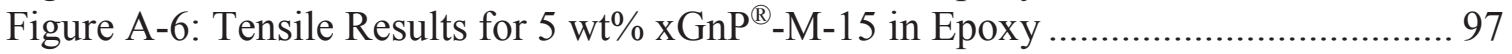


Figure A-7: Tensile Results for $6 \mathrm{wt} \% \mathrm{xGnP}^{\circledR}-\mathrm{M}-15$ in Epoxy .................................... 98

Figure A-8: Tensile Results for $1 \mathrm{wt} \% \mathrm{xGnP}^{\circledR}-\mathrm{M}-5$ in Epoxy ...................................... 99

Figure A-9: Tensile Results for $2 \mathrm{wt} \% \mathrm{xGnP}^{\circledR}-\mathrm{M}-5$ in Epoxy .................................... 100

Figure A-10: Tensile Results for $3 \mathrm{wt} \% \mathrm{xGnP}^{\circledR}-\mathrm{M}-5$ in Epoxy ................................. 101

Figure A-11: Tensile Results for $4 \mathrm{wt} \% \mathrm{xGnP}^{\circledR}-\mathrm{M}-5$ in Epoxy .................................. 102

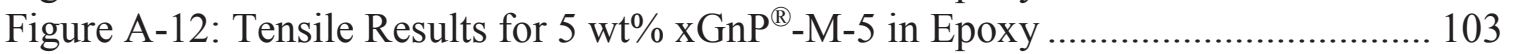

Figure A-13: Tensile Results for $6 \mathrm{wt} \% \mathrm{xGnP}^{\circledR}-\mathrm{M}-5$ in Epoxy …................................. 104

Figure A-14: Tensile Results for $1 \mathrm{wt} \% \mathrm{xGnP}^{\circledR}-\mathrm{C}-300$ in Epoxy ................................. 105

Figure A-15: Tensile Results for $2 \mathrm{wt} \% \mathrm{xGnP}^{\circledR}{ }_{-} \mathrm{C}-300$ in Epoxy ................................. 106

Figure A-16: Tensile Results for $3 \mathrm{wt} \% \mathrm{xGnP}^{\circledR}-\mathrm{C}-300$ in Epoxy ................................ 107

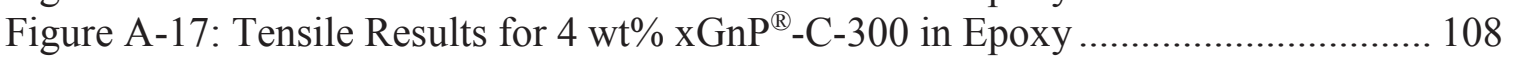

Figure A-18: Tensile Results for $5 \mathrm{wt} \% \mathrm{xGnP}^{\circledR}-\mathrm{C}-300$ in Epoxy ................................ 109

Figure A-19: Tensile Results for $6 \mathrm{wt} \% \mathrm{xGnP}^{\circledR}-\mathrm{C}-300$ in Epoxy ................................ 110

Figure A-20: Tensile Results for $1 \mathrm{wt} \%$ TC307 in Epoxy........................................... 111

Figure A-21: Tensile Results for 2 wt\% TC307 in Epoxy......................................... 112

Figure A-22: Tensile Results for 3 wt\% TC307 in Epoxy.......................................... 113

Figure A-23: Tensile Results for 4 wt\% TC307 in Epoxy.......................................... 114

Figure A-24: Tensile Results for AS4 Carbon Fiber in Epoxy..................................... 115

Figure A-25: Tensile Results for $1 \mathrm{wt} \% \mathrm{xGnP}^{\circledR}-\mathrm{C}-300$ with AS4 Carbon Fiber in Epoxy

116

Figure A-26: Tensile Results for $2 \mathrm{wt} \% \mathrm{xGnP}^{\circledR}-\mathrm{C}-300$ with AS4 Carbon Fiber in Epoxy

Figure A-27: Tensile Results for $3 \mathrm{wt} \% \mathrm{xGnP}^{\circledR}-\mathrm{C}-300$ with AS4 Carbon Fiber in Epoxy

Figure B-1: Load vs. Displacement curve for Neat Epoxy Test 16 .............................. 120

Figure B-2: Modulus vs. Displacement curve for Neat Epoxy Test 16...................... 120

Figure B-3: Hardness vs. Displacement curve for Neat Epoxy Test 16 ....................... 120

Figure B-4: Load vs. Displacement curve for $1 \mathrm{wt} \%$ xGnP ${ }^{\circledR}-\mathrm{M}-15$ in Epoxy Test $16 \ldots 122$

Figure B-5: Modulus vs. Displacement curve for $1 \mathrm{wt} \% \mathrm{xGnP}^{\circledR}-\mathrm{M}-15$ in Epoxy Test 16

Figure B-6: Hardness vs. Displacement curve 1 wt $\%$ xGnP ${ }^{\circledR}-\mathrm{M}-15$ in Epoxy Test 16.. 122 Figure B-7: Load vs. Displacement curve for $2 \mathrm{wt} \% \mathrm{xGnP}^{\circledR}-\mathrm{M}-15$ in Epoxy Test $6 \ldots . .124$ Figure B-8: Modulus vs. Displacement curve for $2 \mathrm{wt} \% \mathrm{xGnP}^{\circledR}-\mathrm{M}-15$ in Epoxy Test 6

Figure B-9: Hardness vs. Displacement curve 2 wt\% xGnP ${ }^{\circledR}-\mathrm{M}-15$ in Epoxy Test $6 . . .124$ Figure B-10: Load vs. Displacement curve for $3 \mathrm{wt} \% \mathrm{xGnP}^{\circledR}-\mathrm{M}-15$ in Epoxy Test 15. 126 Figure B-11: Modulus vs. Displacement curve for $3 \mathrm{wt} \% \mathrm{xGnP}^{\circledR}-\mathrm{M}-15$ in Epoxy Test 15

Figure B-12: Hardness vs. Displacement curve 3 wt \% xGnP ${ }^{\circledR}-\mathrm{M}-15$ in Epoxy Test 15126 Figure B-13: Load vs. Displacement curve for $4 \mathrm{wt} \% \mathrm{xGnP}^{\circledR}-\mathrm{M}-15$ in Epoxy Test 29. 128 Figure B-14: Modulus vs. Displacement curve for $4 \mathrm{wt} \% \mathrm{xGnP}^{\circledR}-\mathrm{M}-15$ in Epoxy Test 29

Figure B-15: Hardness vs. Displacement curve 4 wt\% xGnP ${ }^{\circledR}-\mathrm{M}-15$ in Epoxy Test 29128 Figure B-16: Load vs. Displacement curve for $5 \mathrm{wt} \% \mathrm{xGnP}^{\circledR}-\mathrm{M}-15$ in Epoxy Test 13. 130 
Figure B-17: Modulus vs. Displacement curve for 5 wt $\%$ xGnP ${ }^{\circledR}-M-15$ in Epoxy Test 13

Figure B-18: Hardness vs. Displacement curve $5 \mathrm{wt} \%$ xGnP ${ }^{\circledR}-\mathrm{M}-15$ in Epoxy Test 13130 Figure B-19: Load vs. Displacement curve for $6 \mathrm{wt} \% \mathrm{xGnP}^{\circledR}-\mathrm{M}-15$ in Epoxy Test 32.132 Figure B-20: Modulus vs. Displacement curve for $6 \mathrm{wt} \% \mathrm{xGnP}^{\circledR}-\mathrm{M}-15$ in Epoxy Test 32

Figure B-21: Hardness vs. Displacement curve 6 wt\% xGnP ${ }^{\circledR}-\mathrm{M}-15$ in Epoxy Test 32132 Figure B-22: Load vs. Displacement curve for $1 \mathrm{wt} \% \mathrm{xGnP}^{\circledR}-\mathrm{M}-5$ in Epoxy Test $31 \ldots 134$ Figure B-23: Modulus vs. Displacement curve for $1 \mathrm{wt} \% \mathrm{xGnP}^{\circledR}-\mathrm{M}-5$ in Epoxy Test 31

Figure B-24: Hardness vs. Displacement curve for $1 \mathrm{wt} \% \mathrm{xGnP}^{\circledR}-\mathrm{M}-5$ in Epoxy Test 31

Figure B-25: Load vs. Displacement curve for $2 \mathrm{wt} \% \mathrm{xGnP}^{\circledR}-\mathrm{M}-5$ in Epoxy Test 26... 136 Figure B-26: Modulus vs. Displacement curve for $2 \mathrm{wt} \% \mathrm{xGnP}^{\circledR}-\mathrm{M}-5$ in Epoxy Test 26 136

Figure B-27: Hardness vs. Displacement curve for $2 \mathrm{wt} \% \mathrm{xGnP}^{\circledR}-\mathrm{M}-5$ in Epoxy Test 26

Figure B-28: Load vs. Displacement curve for $3 \mathrm{wt} \% \mathrm{xGnP}^{\circledR}-\mathrm{M}-5$ in Epoxy Test $32 \ldots 138$ Figure B-29: Modulus vs. Displacement curve for $3 \mathrm{wt} \% \mathrm{xGnP}^{\circledR}-\mathrm{M}-5$ in Epoxy Test 32 138

Figure B-30: Hardness vs. Displacement curve for $3 \mathrm{wt} \% \mathrm{xGnP}^{\circledR}-\mathrm{M}-5$ in Epoxy Test 32

Figure B-31: Load vs. Displacement curve for $4 \mathrm{wt} \% \mathrm{xGnP}^{\circledR}-\mathrm{M}-5$ in Epoxy Test $22 \ldots 140$ Figure B-32: Modulus vs. Displacement curve for $4 \mathrm{wt} \% \mathrm{xGnP}^{\circledR}-\mathrm{M}-5$ in Epoxy Test 22 140

Figure B-33: Hardness vs. Displacement curve for $4 \mathrm{wt} \% \mathrm{xGnP}^{\circledR}-\mathrm{M}-5$ in Epoxy Test 22

Figure B-34: Load vs. Displacement curve for $5 \mathrm{wt} \% \mathrm{xGnP}^{\circledR}-\mathrm{M}-5$ in Epoxy Test 28... 142 Figure B-35: Modulus vs. Displacement curve for $5 \mathrm{wt} \% \mathrm{xGnP}^{\circledR}-\mathrm{M}-5$ in Epoxy Test 28 142

Figure B-36: Hardness vs. Displacement curve for $5 \mathrm{wt} \% \mathrm{xGnP}^{\circledR}-\mathrm{M}-5$ in Epoxy Test 28

Figure B-37: Load vs. Displacement curve for $6 \mathrm{wt} \% \mathrm{xGnP}^{\circledR}-\mathrm{M}-5$ in Epoxy Test 18... 144 Figure B-38: Modulus vs. Displacement curve for $6 \mathrm{wt} \% \mathrm{xGnP}^{\circledR}-\mathrm{M}-5$ in Epoxy Test 18

Figure B-39: Hardness vs. Displacement curve for $6 \mathrm{wt} \% \mathrm{xGnP}^{\circledR}-\mathrm{M}-5$ in Epoxy Test 18

Figure B-40: Load vs. Displacement curve for $1 \mathrm{wt} \% \mathrm{xGnP}^{\circledR}-\mathrm{C}-300$ in Epoxy Test 36146 Figure B-41: Modulus vs. Displacement curve for $1 \mathrm{wt} \% \mathrm{xGnP}^{\circledR}-\mathrm{C}-300 /$ Epoxy Test 36

Figure B-42: Hardness vs. Displacement curve for $1 \mathrm{wt} \% \mathrm{xGnP}^{\circledR}-\mathrm{C}-300 /$ Epoxy Test 36

Figure B-43: Load vs. Displacement curve for $2 \mathrm{wt} \% \mathrm{xGnP}^{\circledR}-\mathrm{C}-300$ in Epoxy Test 35148 
Figure B-44: Modulus vs. Displacement curve for $2 \mathrm{wt} \% \mathrm{xGnP}^{\circledR}-\mathrm{C}-300 /$ Epoxy Test 35 148

Figure B-45: Hardness vs. Displacement curve for $2 \mathrm{wt} \% \mathrm{xGnP}^{\circledR}-\mathrm{C}-300 /$ Epoxy Test 35 148

Figure B-46: Load vs. Displacement curve for $3 \mathrm{wt} \% \mathrm{xGnP}^{\circledR}-\mathrm{C}-300$ in Epoxy Test 35150 Figure B-47: Modulus vs. Displacement curve for $3 \mathrm{wt} \% \mathrm{xGnP}^{\circledR}-\mathrm{C}-300 /$ Epoxy Test 35

Figure B-48: Hardness vs. Displacement curve for $3 \mathrm{wt} \% \mathrm{xGnP}^{\circledR}-\mathrm{C}-300 /$ Epoxy Test 35

Figure B-49: Load vs. Displacement curve for $4 \mathrm{wt} \% \mathrm{xGnP}^{\circledR}-\mathrm{C}-300$ in Epoxy Test 35152 Figure B-50: Modulus vs. Displacement curve for $4 \mathrm{wt} \% \mathrm{xGnP}^{\circledR}-\mathrm{C}-300 /$ Epoxy Test 35

Figure B-51: Hardness vs. Displacement curve for $4 \mathrm{wt} \% \mathrm{xGnP}^{\circledR}-\mathrm{C}-300 /$ Epoxy Test 35

Figure B-52: Load vs. Displacement curve for $5 \mathrm{wt} \% \mathrm{xGnP}^{\circledR}-\mathrm{C}-300$ in Epoxy Test 36154

Figure B-53: Modulus vs. Displacement curve for $5 \mathrm{wt} \% \mathrm{xGnP}^{\circledR}-\mathrm{C}-300 /$ Epoxy Test 36

Figure B-54: Hardness vs. Displacement curve for $5 \mathrm{wt} \% \mathrm{xGnP}^{\circledR}-\mathrm{C}-300 /$ Epoxy Test 36

Figure B-55: Load vs. Displacement curve for $6 \mathrm{wt} \% \mathrm{xGnP}^{\circledR}-\mathrm{C}-300$ in Epoxy Test 35156

Figure B-56: Modulus vs. Displacement curve for $6 \mathrm{wt} \% \mathrm{xGnP}^{\circledR}-\mathrm{C}-300 /$ Epoxy Test 35

Figure B-57: Hardness vs. Displacement curve for $6 \mathrm{wt} \% \mathrm{xGnP}^{\circledR}-\mathrm{C}-300 /$ Epoxy Test 35

Figure B-58: Load vs. Displacement curve for 1 wt \% TC307 in Epoxy Test 36.......... 158

Figure B-59: Modulus vs. Displacement curve for $1 \mathrm{wt} \%$ TC307 in Epoxy Test 36.... 158

Figure B-60: Hardness vs. Displacement curve for 1 wt $\%$ TC307 in Epoxy Test 36 .... 158

Figure B-61: Load vs. Displacement curve for $2 \mathrm{wt} \%$ TC307 in Epoxy Test 36.......... 160

Figure B-62: Modulus vs. Displacement curve for 2 wt $\%$ TC307 in Epoxy Test $36 \ldots . .160$

Figure B-63: Hardness vs. Displacement curve for 2 wt $\%$ TC307 in Epoxy Test 36 ... 160

Figure B-64: Load vs. Displacement curve for 3 wt\% TC307 in Epoxy Test 36.......... 162

Figure B-65: Modulus vs. Displacement curve for 3 wt \% TC307 in Epoxy Test 36.... 162

Figure B-66: Hardness vs. Displacement curve for 3 wt \% TC307 in Epoxy Test 36 .... 162

Figure B-67: Load vs. Displacement curve for 4 wt \% TC307 in Epoxy Test 36.......... 164

Figure B-68: Modulus vs. Displacement curve for 4 wt \% TC307 in Epoxy Test 36.... 164

Figure B-69: Hardness vs. Displacement curve for 4 wt\% TC307 in Epoxy Test 36 ... 164

Figure D-1: Storage Modulus for Neat Epoxy Test 3 ............................................... 175

Figure D-2: Loss Modulus for Neat Epoxy Test 3 ................................................. 176

Figure D-3: Tan Delta for Neat Epoxy Test 3 .......................................................... 176

Figure D-4: Storage Modulus for $1 \mathrm{wt} \% \mathrm{xGnP}^{\circledR}-\mathrm{M}-15$ in Epoxy Test 3...................... 177

Figure D-5: Loss Modulus for $1 \mathrm{wt} \% \mathrm{xGnP}^{\circledR}-\mathrm{M}-15$ in Epoxy Test 3 .......................... 178

Figure D-6: Tan Delta for $1 \mathrm{wt}^{\mathrm{t}} \mathrm{xG \textrm {xnP }}{ }^{\circledR}-\mathrm{M}-15$ in Epoxy Test 3 ................................ 178

Figure D-7: Storage Modulus for $2 \mathrm{wt} \% \mathrm{xGnP}^{\circledR}-\mathrm{M}-15$ in Epoxy Test 3...................... 179

Figure D-8: Loss Modulus for $2 \mathrm{wt} \% \mathrm{xGnP}^{\circledR}-\mathrm{M}-15$ in Epoxy Test 3 .......................... 180 
Figure D-9: Tan Delta for $2 \mathrm{wt} \% \mathrm{xGnP}^{\circledR}-\mathrm{M}-15$ in Epoxy Test 3 ............................... 180

Figure D-10: Storage Modulus for $3 \mathrm{wt} \% \mathrm{xGnP}^{\mathbb{R}}-\mathrm{M}-15$ in Epoxy Test 2.................... 181

Figure D-11: Loss Modulus for $3 \mathrm{wt} \% \mathrm{xGnP}^{\circledR}-\mathrm{M}-15$ in Epoxy Test 2 ........................ 182

Figure D-12: Tan Delta for $3 \mathrm{wt} \% \mathrm{xGnP}^{\circledR}-\mathrm{M}-15$ in Epoxy Test 2 .............................. 182

Figure D-13: Storage Modulus for $4 \mathrm{wt} \% \mathrm{xGnP}^{\circledR}-\mathrm{M}-15$ in Epoxy Test 1 ..................... 183

Figure D-14: Loss Modulus for 4 wt \% xGnP ${ }^{\circledR}-\mathrm{M}-15$ in Epoxy Test 1 ........................ 184

Figure D-15: Tan Delta for $4 \mathrm{wt} \% \mathrm{xGnP}^{\circledR}-\mathrm{M}-15$ in Epoxy Test 1 ............................... 184

Figure D-16: Storage Modulus for $5 \mathrm{wt} \% \mathrm{xGnP}^{\circledR}-\mathrm{M}-15$ in Epoxy Test 1 ..................... 185

Figure D-17: Loss Modulus for $5 \mathrm{wt} \% \mathrm{xGnP}^{\circledR}-\mathrm{M}-15$ in Epoxy Test 1 ........................ 186

Figure D-18: Tan Delta for $5 \mathrm{wt} \% \mathrm{xGnP}^{\circledR}-\mathrm{M}-15$ in Epoxy Test 1 ............................... 186

Figure D-19: Storage Modulus for $6 \mathrm{wt} \% \mathrm{xGnP}^{\circledR}-\mathrm{M}-15$ in Epoxy Test 3.................... 187

Figure D-20: Loss Modulus for $6 \mathrm{wt} \% \mathrm{xGnP}^{\circledR}-\mathrm{M}-15$ in Epoxy Test 3 ......................... 188

Figure D-21: Tan Delta for $6 \mathrm{wt} \% \mathrm{xGnP}^{\circledR}-\mathrm{M}-15$ in Epoxy Test 3 .............................. 188

Figure D-22: Storage Modulus for $1 \mathrm{wt} \% \mathrm{xGnP}^{\circledR}-\mathrm{M}-5$ in Epoxy Test 1 ....................... 189

Figure D-23: Loss Modulus for $1 \mathrm{wt} \% \mathrm{xGnP}^{\circledR}-\mathrm{M}-5$ in Epoxy Test 1 .......................... 190

Figure D-24: Tan Delta for $1 \mathrm{wt} \% \mathrm{xGnP}^{\circledR}{ }_{-} \mathrm{M}-5$ in Epoxy Test 1 ................................ 190

Figure D-25: Storage Modulus for $2 \mathrm{wt} \% \mathrm{xGnP}^{\circledR}-\mathrm{M}-5$ in Epoxy Test 1 ...................... 191

Figure D-26: Loss Modulus for $2 \mathrm{wt} \% \mathrm{xGnP}^{\circledR}-\mathrm{M}-5$ in Epoxy Test 1 ........................... 192

Figure D-27: Tan Delta for $2 \mathrm{wt} \% \mathrm{xGnP}^{\circledR}-\mathrm{M}-5$ in Epoxy Test 1 ................................ 192

Figure D-28: Storage Modulus for $3 \mathrm{wt} \% \mathrm{xGnP}^{\circledR}-\mathrm{M}-5$ in Epoxy Test 1 ....................... 193

Figure D-29: Loss Modulus for 3 wt \% xGnP ${ }^{\circledR}-\mathrm{M}-5$ in Epoxy Test 1 ............................ 194

Figure D-30: Tan Delta for $3 \mathrm{wt} \% \mathrm{xGnP}^{\circledR}-\mathrm{M}-5$ in Epoxy Test 1 .................................. 194

Figure D-31: Storage Modulus for $4 \mathrm{wt} \% \mathrm{xGnP}^{\circledR}{ }^{-\mathrm{M}-5}$ in Epoxy Test 1 ....................... 195

Figure D-32: Loss Modulus for 4 wt\% xGnP ${ }^{\circledR}-\mathrm{M}-5$ in Epoxy Test 1 ........................... 196

Figure D-33: Tan Delta for 4 wt $\% \mathrm{xGnP}^{\circledR}-\mathrm{M}-5$ in Epoxy Test 1 ................................. 196

Figure D-34: Storage Modulus for 5 wt\% xGnP ${ }^{\circledR}-\mathrm{M}-5$ in Epoxy Test 1....................... 197

Figure D-35: Loss Modulus for $5 \mathrm{wt} \% \mathrm{xGnP}^{\circledR}-\mathrm{M}-5$ in Epoxy Test 1 .......................... 198

Figure D-36: Tan Delta for $5 \mathrm{wt} \% \mathrm{xGnP}^{\circledR}-\mathrm{M}-5$ in Epoxy Test 1 ................................. 198

Figure D-37: Storage Modulus for $6 \mathrm{wt} \% \mathrm{xGnP}^{\circledR}-\mathrm{M}-5$ in Epoxy Test 1 ....................... 199

Figure D-38: Loss Modulus for $6 \mathrm{wt} \% \mathrm{xGnP}^{\circledR}-\mathrm{M}-5$ in Epoxy Test 1 ........................... 200

Figure D-39: Tan Delta for $6 \mathrm{wt} \% \mathrm{xGnP}^{\circledR}-\mathrm{M}-5$ in Epoxy Test 1 ................................. 200

Figure D-40: Storage Modulus for $1 \mathrm{wt} \% \mathrm{xGnP}^{\circledR}-\mathrm{C}-300$ in Epoxy Test 1 .................... 201

Figure D-41: Loss Modulus for $1 \mathrm{wt} \% \mathrm{xGnP}^{\circledR}{ }_{-} \mathrm{C}-300$ in Epoxy Test 1 ........................ 202

Figure D-42: Tan Delta for $1 \mathrm{wt} \% \mathrm{xGnP}^{\circledR}-\mathrm{C}-300$ in Epoxy Test 1 .............................. 202

Figure D-43: Storage Modulus for $2 \mathrm{wt} \% \mathrm{xGnP}^{\circledR}-\mathrm{C}-300$ in Epoxy Test 1 ................... 203

Figure D-44: Loss Modulus for $2 \mathrm{wt} \% \mathrm{xGnP}^{\circledR}-\mathrm{C}-300$ in Epoxy Test 1 ........................ 204

Figure D-45: Tan Delta for $2 \mathrm{wt}^{\%} \% \mathrm{xGnP}^{\circledR}-\mathrm{C}-300$ in Epoxy Test 1 ............................... 204

Figure D-46: Storage Modulus for $3 \mathrm{wt} \% \mathrm{xGnP}^{\circledR}-\mathrm{C}-300$ in Epoxy Test 1 ................... 205

Figure D-47: Loss Modulus for $3 \mathrm{wt} \% \mathrm{xGnP}^{\circledR}-\mathrm{C}-300$ in Epoxy Test 1 ....................... 206

Figure D-48: Tan Delta for $3 \mathrm{wt} \% \mathrm{xGnP}^{\circledR}-\mathrm{C}-300$ in Epoxy Test 1 .............................. 206

Figure D-49: Storage Modulus for $4 \mathrm{wt} \% \mathrm{xGnP}^{\circledR}-\mathrm{C}-300$ in Epoxy Test 1 .................. 207

Figure D-50: Loss Modulus for $4 \mathrm{wt} \% \mathrm{xGnP}^{\circledR}-\mathrm{C}-300$ in Epoxy Test 1 ....................... 208

Figure D-51: Tan Delta for $4 \mathrm{wt} \% \mathrm{xGnP}^{\circledR}-\mathrm{C}-300$ in Epoxy Test 1 ............................. 208

Figure D-52: Storage Modulus for $5 \mathrm{wt} \% \mathrm{xGnP}^{\circledR}-\mathrm{C}-300$ in Epoxy Test 1 ................... 209 
Figure D-53: Loss Modulus for $5 \mathrm{wt} \% \mathrm{xGnP}^{\circledR}-\mathrm{C}-300$ in Epoxy Test 1 ......................... 210

Figure D-54: Tan Delta for $5 \mathrm{wt} \% \mathrm{xGnP}^{\circledR}$ - C-300 in Epoxy Test 1 ............................. 210

Figure D-55: Storage Modulus for $6 \mathrm{wt} \% \mathrm{xGnP}^{\circledR}-\mathrm{C}-300$ in Epoxy Test 1 ................... 211

Figure D-56: Loss Modulus for $6 \mathrm{wt} \% \mathrm{xGnP}^{\circledR}-\mathrm{C}-300$ in Epoxy Test 1 ....................... 212

Figure D-57: Tan Delta for $6 \mathrm{wt} \% \mathrm{xGnP}^{\circledR}$ - C-300 in Epoxy Test 1 ............................. 212

Figure D-58: Storage Modulus for $1 \mathrm{wt} \%$ TC307 in Epoxy Test 1 ............................... 213

Figure D-59: Loss Modulus for 1 wt \% TC307 in Epoxy Test 1 ................................. 214

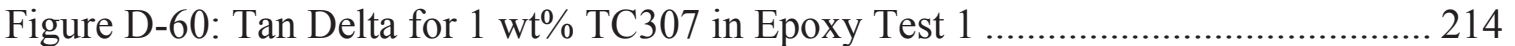

Figure D-61: Storage Modulus for $2 \mathrm{wt} \%$ TC307 in Epoxy Test 1............................. 215

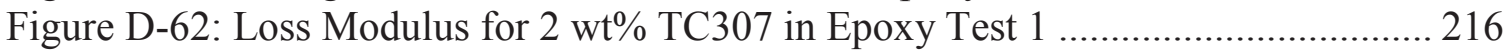

Figure D-63: Tan Delta for $2 \mathrm{wt} \%$ TC307 in Epoxy Test 1 ....................................... 216

Figure D-64: Storage Modulus for 3 wt \% TC307 in Epoxy Test 1.............................. 217

Figure D-65: Loss Modulus for 3 wt\% TC307 in Epoxy Test 1 .................................. 218

Figure D-66: Tan Delta for $3 \mathrm{wt} \%$ TC307 in Epoxy Test 1 ....................................... 218

Figure D-67: Storage Modulus for 4 wt \% TC307 in Epoxy Test 1.............................. 219

Figure D-68: Loss Modulus for 4 wt \% TC307 in Epoxy Test 1 ................................. 220

Figure D-69: Tan Delta for 4 wt\% TC307 in Epoxy Test 1 ...................................... 220

Figure E-1: DSC for Neat Epoxy (A862-9-30-11) Run 1 vs. Time................................ 221

Figure E-2: DSC for $1 \mathrm{wt} \% \mathrm{xGnP}^{\circledR}-\mathrm{M}-15$ in Epoxy (A862-M15-1-12-12-11) Run 1 vs.

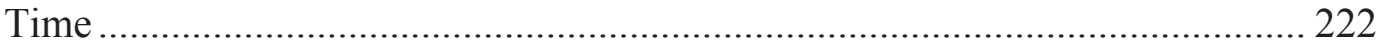

Figure E-3: DSC for $2 \mathrm{wt} \% \mathrm{xGnP}^{\circledR}$-M-15 in Epoxy (A862-M15-2-12-13-11) Run 1 vs.

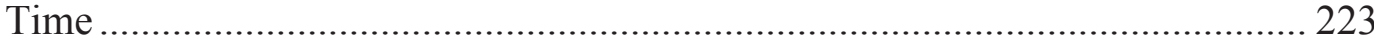

Figure E-4: DSC for 3 wt\% xGnP ${ }^{\circledR}$-M-15 in Epoxy (A862-M15-3-10-11-11) Run 2 vs.

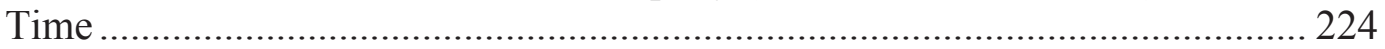

Figure E-5: DSC for 4 wt\% xGnP ${ }^{\circledR}$-M-15 in Epoxy (A862-M15-4-12-15-11) Run 1 vs.

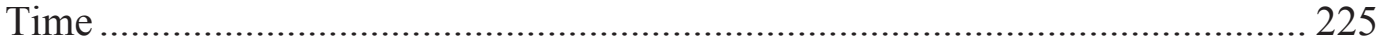

Figure E-6: DSC for 5 wt\% xGnP ${ }^{\circledR}$-M-15 in Epoxy (A862-M15-5-12-16-11) Run 2 vs.

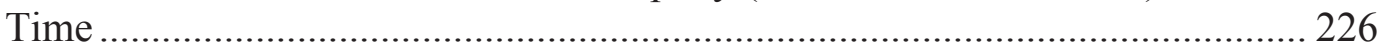

Figure E-7: DSC for 6 wt\% xGnP ${ }^{\circledR}-M-15$ in Epoxy (A862-M15-6-1-19-12) Run 2 vs.

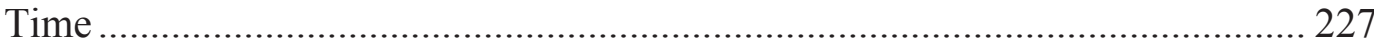




\section{List of Tables}

Table 2-1: Properties of Momentive's EPON ${ }^{\mathrm{TM}}$ Resin 862 and EPIKURE Curing Agent

$\mathrm{W}$

Table 2-2: Properties of Hexcel HexTow ${ }^{\circledR}$ AS4-GP-3K continuous carbon fiber............. 13

Table 3-1: Grinding and Polishing Steps .................................................................. 31

Table 4-1: $\mathrm{xGnP}^{\circledR}{ }^{\circledR} \mathrm{M}-15$ loading levels in epoxy and tensile results obtained from ASTM

D638 test method ...................................................................................... 45

Table 4-2: $\mathrm{xGnP}^{\circledR}$-M-5 and $\mathrm{xGnP}^{\circledR}$-C-300 loading levels in epoxy, tensile results obtained from ASTM D638 test method ........................................................ 49

Table 4-3: Asbury TC307 loading levels in epoxy, tensile results obtained from ASTM

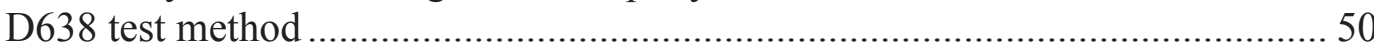

Table 4-4: Tensile Modulus results for $x \mathrm{GnP}^{\circledR}-\mathrm{C}-300 /$ carbon fiber/epoxy composites ... 52

Table 4-5: Modulus as Determined by Nanoindentation for $\mathrm{xGnP}^{\circledR}-\mathrm{M}-5$ in Epoxy and

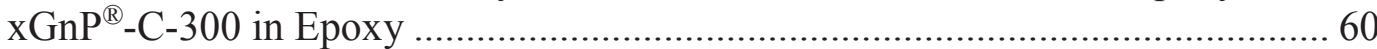

Table 4-6: Nanoindentation Results for TC307 in Epoxy ............................................... 64

Table 4-7: Electrical resistivity results for $\mathrm{xGnP}^{\circledR}$-M-5/epoxy and $\mathrm{xGnP}^{\circledR}-\mathrm{C}-300 /$ epoxy

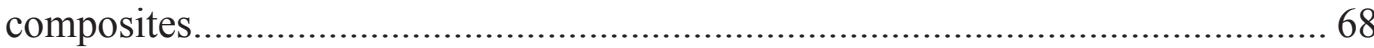

Table 4-8: DMA results for $\mathrm{xGnP}^{\circledR}-\mathrm{M}-15$ in epoxy, $\mathrm{xGnP}^{\circledR}-\mathrm{M}-5$ in epoxy and $\mathrm{xGnP}^{\circledR}-\mathrm{C}-$

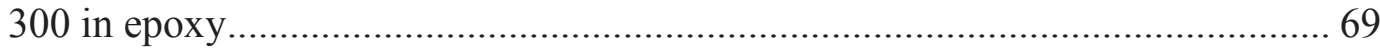

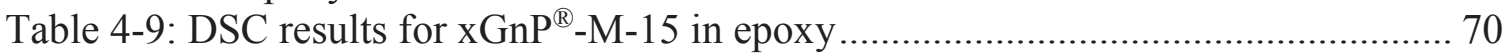

Table A-1: Tensile Results for Neat Epoxy .................................................................... 92

Table A-2: Tensile Results for $1 \mathrm{wt} \% \mathrm{xGnP}^{\circledR}-\mathrm{M}-15$ in Epoxy......................................... 93

Table A-3: Tensile Results for $2 \mathrm{wt} \% \mathrm{xGnP}^{\circledR}-\mathrm{M}-15$ in Epoxy......................................... 94

Table A-4: Tensile Results for $3 \mathrm{wt} \% \mathrm{xGnP}^{\circledR}-\mathrm{M}-15$ in Epoxy........................................ 95

Table A-5: Tensile Results for $4 \mathrm{wt} \% \mathrm{xGnP}^{\circledR}-\mathrm{M}-15$ in Epoxy........................................ 96

Table A-6: Tensile Results for $5 \mathrm{wt} \% \mathrm{xGnP}^{\circledR}-\mathrm{M}-15$ in Epoxy........................................ 97

Table A-7: Tensile Results for $6 \mathrm{wt} \% \mathrm{xGnP}^{\circledR}-\mathrm{M}-15$ in Epoxy......................................... 98

Table A-8: Tensile Results for $1 \mathrm{wt} \% \mathrm{xGnP}^{\circledR}-\mathrm{M}-5$ in Epoxy............................................ 99

Table A-9: Tensile Results for $2 \mathrm{wt} \% \mathrm{xGnP}^{\circledR}-\mathrm{M}-5$ in Epoxy.......................................... 100

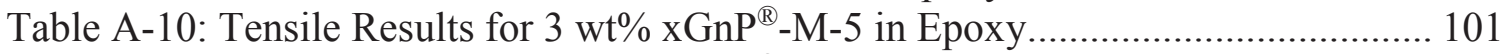

Table A-11: Tensile Results for $4 \mathrm{wt} \% \mathrm{xGnP}^{\circledR}-\mathrm{M}-5$ in Epoxy...................................... 102

Table A-12: Tensile Results for $5 \mathrm{wt} \% \mathrm{xGnP}^{\circledR}-\mathrm{M}-5$ in Epoxy.......................................... 103

Table A-13: Tensile Results for $6 \mathrm{wt} \% \mathrm{xGnP}^{\circledR}-\mathrm{M}-5$ in Epoxy.......................................... 104

Table A-14: Tensile Results for $1 \mathrm{wt} \% \mathrm{xGnP}^{\circledR}-\mathrm{C}-300$ in Epoxy..................................... 105

Table A-15: Tensile Results for $2 \mathrm{wt} \% \mathrm{xGnP}^{\circledR}-\mathrm{C}-300$ in Epoxy..................................... 106

Table A-16: Tensile Results for $3 \mathrm{wt} \% \mathrm{xGnP}^{\circledR}-\mathrm{C}-300$ in Epoxy.................................... 107

Table A-17: Tensile Results for $4 \mathrm{wt} \% \mathrm{xGnP}^{\circledR}-\mathrm{C}-300$ in Epoxy.................................... 108

Table A-18: Tensile Results for $5 \mathrm{wt} \% \mathrm{xGnP}^{\circledR}$-C-300 in Epoxy..................................... 109

Table A-19: Tensile Results for $6 \mathrm{wt} \% \mathrm{xGnP}^{\circledR}-\mathrm{C}-300$ in Epoxy.................................... 110

Table A-20: Tensile Results for $1 \mathrm{wt} \%$ TC307 in Epoxy............................................... 111

Table A-21: Tensile Results for 2 wt\% TC307 in Epoxy............................................... 112

Table A-22: Tensile Results for 3 wt\% TC307 in Epoxy.............................................. 113

Table A-23: Tensile Results for 4 wt\% TC307 in Epoxy.............................................. 114

Table A-24: Tensile Results for AS4 Carbon Fiber in Epoxy ……………………......... 115 
Table A-25: Tensile Results for $1 \mathrm{wt}^{\%} \% \mathrm{xGnP}^{\circledR}-\mathrm{C}-300$ with AS4 Carbon Fiber in Epoxy

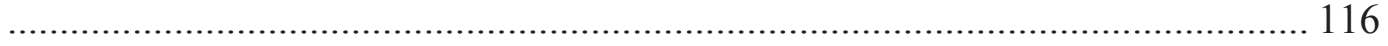

Table A-26: Tensile Results for $2 \mathrm{wt} \% \mathrm{xGnP}^{\circledR}-\mathrm{C}-300$ with AS4 Carbon Fiber in Epoxy 117

Table A-27: Tensile Results for 3 wt $\%$ xGnP $^{\circledR}-\mathrm{C}-300$ with AS4 Carbon Fiber in Epoxy 118

Table B-1: Nanoindentation Averages Between 500 and $1500 \mathrm{~nm}$ Depth for Neat Epoxy 119

Table B-2: Nanoindentation Averages Between 500 and $1500 \mathrm{~nm}$ Depth for $1 \mathrm{wt} \%$ $\mathrm{xGnP}^{\circledR}-\mathrm{M}-15$ in Epoxy................................................................................ 121

Table B-3: Nanoindentation Averages Between 500 and $1500 \mathrm{~nm}$ Depth for $2 \mathrm{wt} \%$ $x^{x G n P}{ }^{\circledR}-\mathrm{M}-15$ in Epoxy............................................................................... 123

Table B-4: Nanoindentation Averages Between 500 and $1500 \mathrm{~nm}$ Depth for $3 \mathrm{wt} \%$ $\mathrm{xGnP}^{\circledR}-\mathrm{M}-15$ in Epoxy. 125

Table B-5: Nanoindentation Averages Between 500 and $1500 \mathrm{~nm}$ Depth for $4 \mathrm{wt} \%$ $\mathrm{xGnP}^{\circledR}-\mathrm{M}-15$ in Epoxy.

Table B-6: Nanoindentation Averages Between 500 and $1500 \mathrm{~nm}$ Depth for $5 \mathrm{wt} \%$ $\mathrm{xGnP}^{\circledR}-\mathrm{M}-15$ in Epoxy.

Table B-7: Nanoindentation Averages Between 500 and $1500 \mathrm{~nm}$ Depth for $6 \mathrm{wt} \%$ $\mathrm{xGnP}^{\circledR}-\mathrm{M}-15$ in Epoxy.

Table B-8: Nanoindentation Averages Between 500 and $1500 \mathrm{~nm}$ Depth for $1 \mathrm{wt} \%$ $\mathrm{xGnP}^{\circledR}-\mathrm{M}-5$ in Epoxy

Table B-9: Nanoindentation Averages Between 500 and $1500 \mathrm{~nm}$ Depth for $2 \mathrm{wt} \%$ $\mathrm{xGnP}^{\circledR}-\mathrm{M}-5$ in Epoxy.

Table B-10: Nanoindentation Averages Between 500 and $1500 \mathrm{~nm}$ Depth for $3 \mathrm{wt} \%$ $\mathrm{xGnP}^{\circledR}-\mathrm{M}-5$ in Epoxy.

Table B-11: Nanoindentation Averages Between 500 and $1500 \mathrm{~nm}$ Depth for $4 \mathrm{wt} \%$ $\mathrm{xGnP}^{\circledR}-\mathrm{M}-5$ in Epoxy.

Table B-12: Nanoindentation Averages Between 500 and $1500 \mathrm{~nm}$ Depth for $5 \mathrm{wt} \%$ $\mathrm{xGnP}{ }^{\circledR}-\mathrm{M}-5$ in Epoxy.

Table B-13: Nanoindentation Averages Between 500 and $1500 \mathrm{~nm}$ Depth for $6 \mathrm{wt} \%$ $\mathrm{xGnP}{ }^{\circledR}-\mathrm{M}-5$ in Epoxy.

Table B-14: Nanoindentation Averages Between 500 and $1500 \mathrm{~nm}$ Depth for $1 \mathrm{wt} \%$ $\mathrm{xGnP}^{\circledR}-\mathrm{C}-300$ in Epoxy

Table B-15: Nanoindentation Averages Between 500 and $1500 \mathrm{~nm}$ Depth for $2 \mathrm{wt} \%$ $\mathrm{xGnP}^{\circledR}-\mathrm{C}-300$ in Epoxy

Table B-16: Nanoindentation Averages Between 500 and $1500 \mathrm{~nm}$ Depth for $3 \mathrm{wt} \%$ $\mathrm{xGnP}^{\circledR}-\mathrm{C}-300$ in Epoxy

Table B-17: Nanoindentation Averages Between 500 and $1500 \mathrm{~nm}$ Depth for $4 \mathrm{wt} \%$ $\mathrm{xGnP}^{\circledR}-\mathrm{C}-300$ in Epoxy

Table B-18: Nanoindentation Averages Between 500 and $1500 \mathrm{~nm}$ Depth for $5 \mathrm{wt} \%$ $\mathrm{xGnP}^{\circledR}-\mathrm{C}-300$ in Epoxy

Table B-19: Nanoindentation Averages Between 500 and $1500 \mathrm{~nm}$ Depth for $6 \mathrm{wt} \%$ $\mathrm{xGnP}^{\circledR}-\mathrm{C}-300$ in Epoxy 
Table B-20: Nanoindentation Averages Between 500 and $1500 \mathrm{~nm}$ Depth for $1 \mathrm{wt} \%$ TC307 in Epoxy.....

Table B-21: Nanoindentation Averages Between 500 and $1500 \mathrm{~nm}$ Depth for $2 \mathrm{wt} \%$ TC307 in Epoxy.

Table B-22: Nanoindentation Averages Between 500 and $1500 \mathrm{~nm}$ Depth for $3 \mathrm{wt} \%$ TC307 in Epoxy.

Table B-23: Nanoindentation Averages Between 500 and $1500 \mathrm{~nm}$ Depth for $4 \mathrm{wt} \%$ TC307 in Epoxy....

Table C-1: ASTM D257 Thru-Plane Electrical Resistivity Results for Neat Epoxy ..... 165

Table C-2: ASTM D257 Thru-Plane Electrical Resistivity Results for $1 \mathrm{wt} \% \mathrm{xGnP}^{\circledR}$-M15 in Epoxy 165

Table C-3: ASTM D4496 Two Point In-Plane Electrical Resistivity Results for $2 \mathrm{wt} \%$ $\mathrm{xGnP}^{\circledR}$-M-15 in Epoxy............................................................................... 166

Table C-4: ASTM D4496 Two Point In-Plane Electrical Resistivity Results for 3 wt\% $\mathrm{xGnP}^{\circledR}-\mathrm{M}-15$ in Epoxy............................................................................... 166

Table C-5: ASTM D4496 Two Point In-Plane Electrical Resistivity Results for 4 wt\% $\mathrm{xGnP}^{\circledR}$-M-15 in Epoxy............................................................................... 167

Table C-6: ASTM D4496 Two Point In-Plane Electrical Resistivity Results for 5 wt\% $\mathrm{xGnP}{ }^{\circledR}-\mathrm{M}-15$ in Epoxy. 167

Table C-7: ASTM D4496 Two Point In-Plane Electrical Resistivity Results for 6 wt\%

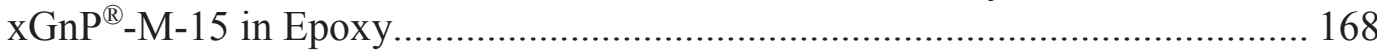

Table C-8: ASTM D257 Thru-Plane Electrical Resistivity Results for $1 \mathrm{wt} \% \mathrm{xGnP}^{\circledR}-\mathrm{M}-5$ in Epoxy …............................................................................................ 168

Table C-9: ASTM D257 Thru-Plane Electrical Resistivity Results for 2 wt\% xGnP ${ }^{\circledR}$-M-5 in Epoxy.... 169

Table C-10: ASTM D257 Thru-Plane Electrical Resistivity Results for $3 \mathrm{wt} \%$ xGnP ${ }^{\circledR}$-M5 in Epoxy ............................................................................................. 169

Table C-11: ASTM D4496 Two Point In-Plane Electrical Resistivity Results for 4 wt \% $\mathrm{xGnP}^{\circledR}-\mathrm{M}-5$ in Epoxy

Table C-12: ASTM D4496 Two Point In-Plane Electrical Resistivity Results for 5 wt\% $\mathrm{xGnP}^{\circledR}-\mathrm{M}-5$ in Epoxy

Table C-13: ASTM D4496 Two Point In-Plane Electrical Resistivity Results for 6 wt\% $\mathrm{xGnP}^{\circledR}-\mathrm{M}-5$ in Epoxy.

Table C-14: ASTM D257 Thru-Plane Electrical Resistivity Results for $1 \mathrm{wt} \% \mathrm{xGnP}^{\circledR}$-C300 in Epoxy....

Table C-15: ASTM D257 Thru-Plane Electrical Resistivity Results for $2 \mathrm{wt} \% \mathrm{xGnP}^{\circledR}-\mathrm{C}-$ 300 in Epoxy.

Table C-16: ASTM D257 Thru-Plane Electrical Resistivity Results for $3 \mathrm{wt} \% \mathrm{xGnP}^{\circledR}-\mathrm{C}-$ 300 in Epoxy....

Table C-17: ASTM D4496 Two Point In-Plane Electrical Resistivity Results for 4 wt\% $\mathrm{xGnP}^{\circledR}-\mathrm{C}-300$ in Epoxy .............................................................................. 173

Table C-18: ASTM D4496 Two Point In-Plane Electrical Resistivity Results for 5 wt \% $\mathrm{xGnP}^{\circledR}-\mathrm{C}-300$ in Epoxy 
Table C-19: ASTM D4496 Two Point In-Plane Electrical Resistivity Results for $6 \mathrm{wt} \%$

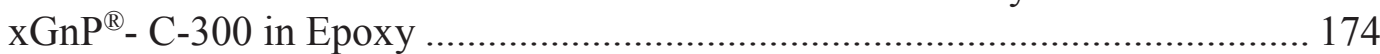

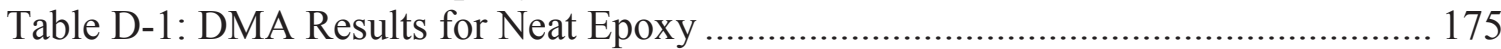

Table D-2: DMA Results for $1 \mathrm{wt} \% \mathrm{xGnP}^{\circledR}-\mathrm{M}-15$ in Epoxy ………………………...... 177

Table D-3: DMA Results for $2 \mathrm{wt} \% \mathrm{xGnP}^{\circledR}-\mathrm{M}-15$ in Epoxy …………………................ 179

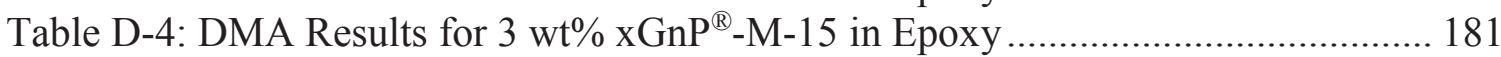

Table D-5: DMA Results for $4 \mathrm{wt} \% \mathrm{xGnP}^{\circledR}-\mathrm{M}-15$ in Epoxy ………………................... 183

Table D-6: DMA Results for $5 \mathrm{wt} \% \mathrm{xGnP}^{\circledR}-\mathrm{M}-15$ in Epoxy ……………........................ 185

Table D-7: DMA Results for $6 \mathrm{wt} \% \mathrm{xGnP}^{\circledR}-\mathrm{M}-15$ in Epoxy ......................................... 187

Table D-8: DMA Results for $1 \mathrm{wt} \% \mathrm{xGnP}^{\circledR}-\mathrm{M}-5$ in Epoxy .......................................... 189

Table D-9: DMA Results for $2 \mathrm{wt} \% \mathrm{xGnP}^{\circledR}-\mathrm{M}-5$ in Epoxy ………………......................... 191

Table D-10: DMA Results for $3 \mathrm{wt} \% \mathrm{xGnP}^{\circledR}-\mathrm{M}-5$ in Epoxy ……………………............ 193

Table D-11: DMA Results for $4 \mathrm{wt} \% \mathrm{xGnP}^{\circledR}-\mathrm{M}-5$ in Epoxy ………………………...... 195

Table D-12: DMA Results for $5 \mathrm{wt} \% \mathrm{xGnP}^{\circledR}-\mathrm{M}-5$ in Epoxy ....................................... 197

Table D-13: DMA Results for $6 \mathrm{wt} \% \mathrm{xGnP}^{\circledR}-\mathrm{M}-5$ in Epoxy ......................................... 199

Table D-14: DMA Results for $1 \mathrm{wt} \% \mathrm{xGnP}^{\circledR}-\mathrm{C}-300$ in Epoxy …………………….......... 201

Table D-15: DMA Results for $2 \mathrm{wt} \% \mathrm{xGnP}^{\circledR}-\mathrm{C}-300$ in Epoxy ……………………........ 203

Table D-16: DMA Results for $3 \mathrm{wt} \% \mathrm{xGnP}^{\circledR}{ }^{\circledR} \mathrm{C}-300$ in Epoxy ……………………........ 205

Table D-17: DMA Results for $4 \mathrm{wt} \% \mathrm{xGnP}^{\circledR}-\mathrm{C}-300$ in Epoxy ....................................... 207

Table D-18: DMA Results for $5 \mathrm{wt} \% \mathrm{xGnP}^{\circledR}{ }^{\circledR}$ C-300 in Epoxy ..................................... 209

Table D-19: DMA Results for $6 \mathrm{wt} \% \mathrm{xGnP}^{\circledR}{ }^{\circledR} \mathrm{C}-300$ in Epoxy …………….................... 211

Table D-20: DMA Results for $1 \mathrm{wt} \%$ TC307 in Epoxy …………………........................ 213

Table D-21: DMA Results for $2 \mathrm{wt} \%$ TC307 in Epoxy …………................................ 215

Table D-22: DMA Results for $3 \mathrm{wt} \%$ TC307 in Epoxy ………………....................... 217

Table D-23: DMA Results for $4 \mathrm{wt} \%$ TC307 in Epoxy ............................................... 219

Table E-1: DSC Results for Neat Epoxy ..................................................................... 221

Table E-2: DSC Results for $1 \mathrm{wt} \% \mathrm{xGnP}^{\circledR}-\mathrm{M}-15$ in Epoxy ......................................... 222

Table E-3: DSC Results for $2 \mathrm{wt} \% \mathrm{xGnP}^{\circledR}-\mathrm{M}-15$ in Epoxy .......................................... 223

Table E-4: DSC Results for $3 \mathrm{wt} \% \mathrm{xGnP}^{\circledR}-\mathrm{M}-15$ in Epoxy ........................................... 224

Table E-5: DSC Results for $4 \mathrm{wt} \% \mathrm{xGnP}^{\circledR}-\mathrm{M}-15$ in Epoxy ......................................... 225

Table E-6: DSC Results for $5 \mathrm{wt} \% \mathrm{xGnP}^{\circledR}-\mathrm{M}-15$ in Epoxy ............................................ 226

Table E-7: DSC Results for $6 \mathrm{wt} \% \mathrm{xGnP}^{\circledR}-\mathrm{M}-15$ in Epoxy .......................................... 227 


\section{Preface}

The work contained in this dissertation was conducted in the department of Chemical Engineering at Michigan Technological University from August 2011 to August 2015. This dissertation is a compilation of published journal articles, journals articles accepted for publication, and journal articles to be submitted. The layout of the journal articles have been edited to present a flow of topics throughout the dissertation.

Material contained in Sections 4.1.1, 4.2.1, 4.3.1, 4.6.1, and 5.1 have been published in the following peer reviewed article:

J. A. King, D. R. Klimek, I. Miskioglu, G. Odegard; "Mechanical Properties of Graphene Nanoplatelet/Epoxy Composites" Journal of Applied Polymer Science, Vol 128, No. 6, pp.4217-4223, June 2013.

Content in Sections 4.1.2, 4.2.2, 4.6.2, 5.2, and 5.3 have been published in the following peer reviewed article:

J. A. King, D. R. Klimek, I. Miskioglu, G. Odegard; "Mechanical Properties of Graphene Nanoplatelet/Epoxy Composites” Journal of Composite Materials, Vol 49, No. 6, pp.659-668, March 2015.

Portions of Chapter 4 (4.1.4 and 4.6.3) have been submitted to Carbon. Parts of Chapter 4 and 5 (4.1.3, 4.2.3, 4.6.4, and 5.4) will be submitted for publication in Polymer Composites in August 2015.

This dissertation was written by Danielle Klimek-McDonald. All experiments and measurements discussed within this dissertation were performed by Danielle KlimekMcDonald with the assistance of the undergraduate researchers acknowledged in the acknowledgement section of this dissertation.

Additional contributions included writing formatting, journal article submissions and technical advice from Dr. Julia King. Dr. Gregory Odegard provided project guidance and technical advice throughout this project. Technical advice was obtained from Dr. Ibrahim Miskioglu with regard to nanoindentation and tensile properties. 


\section{Acknowledgements}

I would first like to thank my advisor Dr. Julia King for all of her guidance and insight throughout this project. I also want to thank my committee members Drs. Gregory Odegard, Ibrahim Miskioglu, and Timothy Eisele for taking time out of their busy schedules to be on my committee.

This research was funded by NASA under the Subsonic Fixed Wing Program (Grant NNX11AO72A), without it this project would not have been made possible. I would like to thank XG Sciences Inc. and Asbury Carbons for donating the graphene nanoplatelets used for this work.

Thank you to all of the undergraduate student researchers that have worked with me over the last 4 years. I could not have done it without all of the help from the $\sim 60$ students that helped with the various aspects of this project.

I would like to thank my family, especially my parents, for all their love and support throughout the years. I would not be where I am today without their guidance. Despite being so far away they always found a way to give me support when I needed it.

Lastly, I would like to thank my loving husband, Jacob McDonald, for all of his help and support on this project. If I needed an extra set of hands he would always come to help. 


\begin{abstract}
Due to their high specific stiffness, carbon-filled polymer composites are commonly used in the construction of structural components of subsonic fixed-wing aircrafts, such as the fuselage and control surfaces. In this work, neat epoxy (EPON 862 with EPIKURE Curing Agent W) was fabricated along with 1- $6 \mathrm{wt} \%$ of three types of GNP available from XG Sciences Inc. and 1-4 wt $\%$ of another type of GNP available from Asbury Carbons added to epoxy. The curing cycle for this epoxy was $121^{\circ} \mathrm{C}$ for 2 hours followed by $177^{\circ} \mathrm{C}$ for two hours.

GNP are short stacks of individual layers of graphite that are newly developed and available at a low cost. XG Sciences Inc. $\mathrm{XGnP}^{\circledR}-\mathrm{M}-15$ has a platelets diameter of 15 $\mu \mathrm{m}$ and a thickness of $7 \mathrm{~nm} . \mathrm{xGnP}^{\circledR}-\mathrm{M}-5$ has a diameter of $5 \mu \mathrm{m}$ and a thickness of 7 $\mathrm{nm}$. The specific surface area for both $\mathrm{M}$-grades is $130 \mathrm{~m}^{2} / \mathrm{g}$. $\mathrm{xGnP}^{\circledR}-\mathrm{C}-300$ has a diameter of $2 \mu \mathrm{m}$ and a thickness of $2 \mathrm{~nm}$ with a specific surface area of $300 \mathrm{~m}^{2} / \mathrm{g}$. Asbury Carbon's TC307 GNP has a particle size $<1 \mu \mathrm{m}$ diameter and $\sim 8$ layers $(1.1 \mathrm{~nm})$ thick and a specific surface area of $350 \mathrm{~m}^{2} / \mathrm{g}$.
\end{abstract}

Development of good dispersion techniques was the most important contribution of this project. Proper dispersion is very important for obtaining a good composite. For each of the four types of GNP used in this study, a unique dispersion method was developed. High shear mixing was used in combination with sonication to exfoliate the GNP and disperse it into the epoxy matrix. An optical microscope was used to monitor the dispersion during mixing progression.

The composites were tested for their mechanical properties using typical macroscopic tensile testing, nanoindentation, and dynamic mechanical analysis. The addition of any of the four types of GNP resulted in an increase in the modulus (stiffness). The modulus can be predicted using the Halpin-Tsai model. The Halpin-Tsai model takes into account the mechanical properties of the polymer and the filler and also the filler geometry. The 2D randomly oriented filler Halpin-Tsai model was useful for predicting the modulus for $\mathrm{xGnP}^{\circledR}-\mathrm{M}-15$ in epoxy and $\mathrm{xGnP}^{\circledR}-\mathrm{M}-5$ in epoxy, this was confirmed visually through microscopy. The 3D randomly oriented filler Halpin-Tsai model predicted the modulus well for the $\mathrm{xGnP}^{\circledR}-\mathrm{C}-300$ and the TC307, microscopy visually confirmed that the filler was oriented in all three planes.

From the mechanical properties, one type of GNP was chosen for use in a unidirectional carbon fiber composite. The continuous carbon fiber composites were tested via macroscopic tensile tests. The GNP chosen did not have an effect on the composite's axial modulus, but increased the transverse modulus. The carbon fiber's mechanical properties dominate over the GNP/epoxy properties in the axial direction. As far as current literature available, continuous carbon fiber has never been used as a reinforcement for GNP/epoxy composites. 


\section{Introduction}

\subsection{Introduction and Motivation}

Structural components of sub-sonic fixed wing aircrafts, such as fuselage and control surfaces, are commonly constructed using carbon-filled polymer composites. Polymer composites are used for aerospace applications because they have high specific (per unit mass) mechanical properties. There are many types of carbon available for use in carbon-filled polymer composites. Carbon nanotubes (CNT), carbon black, and graphite are a few of the common carbon materials used in polymer composites.

Carbon consists of laminar structure of carbon hexahedral lattice planes. There are two general classes of carbons, turbostratic (disordered laminar structure) and graphitic (ordered laminar structure). Graphite is a three dimensional allotrope of carbon. Graphite is the crystalline (ordered) form of elemental carbon and is derived from two sources, natural and synthetic. Natural graphite is mined from the earth. Synthetic graphite is manufactured carbonaceous material that is heat treated to temperatures above $2500{ }^{\circ} \mathrm{C}$. There are three major types of synthetic graphite: primary graphite (such as electrodes for the electric arc furnace steel-making process), secondary graphite (typically recycled primary graphite), and carbon fibers. Two types of carbon fibers exist, petroleum pitchbased carbon fiber and polyacrylonitrile (PAN) -based carbon fiber, which differ in the feedstock used to produce them [1].

Individual layers of graphite, called graphene, have recently become commercially available. Graphite is made out of individual layers of graphene layers that are weakly bonded by van der Waals forces. Graphene nanoplatelets (GNPs) are short stacks of 
graphene sheets. GNP's are a low cost carbon filler $(\$ 15-\$ 50 / \mathrm{lb})$ that can be used to improve the composites tensile modulus and conductivity properties [2]. Carbon nanotubes can also be used to increase the tensile modulus, but have a much higher cost associated with them $(\sim \$ 50-\$ 500 / \mathrm{g})[1-6]$. Improved composite mechanical properties are related to the fillers' aspect ratio as well as its surface-to-volume ratio [3]. GNP has a higher surface-to-volume ratio than carbon nanotubes due to lack of access to the inner surface of the nanotube [4].

The element carbon has the following orbitals: $1 \mathrm{~s}^{2}, 2 \mathrm{~s}^{2}, 2 \mathrm{p}^{2}$ (6 electrons total). Graphene has unique electronic orbitals: $1 \mathrm{~s}^{2} 2 \mathrm{~s}^{1} 2 \mathrm{p}_{\mathrm{x}}{ }^{1} 2 \mathrm{p}_{\mathrm{y}}{ }^{1} 2 \mathrm{p}_{\mathrm{z}}{ }^{1}$. In the graphene hexagonal lattice, each carbon atom is bonded to 3 other carbon atoms by the overlap of three $\mathrm{sp}^{2}$ hybrid bonds. The $\mathrm{sp}^{2}$ hybridization between the $\mathrm{s}$ orbital and the two $\mathrm{p}$ orbitals leads to a trigonal planar structure with a formation of a sigma bond between carbon atoms separated by 1.42 angstroms. These bands have a filled shell. The $\mathrm{sp}^{2}$ orbitals arise from the hybridization of $2 \mathrm{~s}^{1}, 2 \mathrm{p}_{\mathrm{x}}{ }^{1}$ and $2 \mathrm{p}_{\mathrm{y}}{ }^{1}$ electrons. Thus, each carbon keeps a pure $\mathrm{p}_{z}$ orbital (perpendicular to the planar structure) that can bind covalently with neighboring carbon atoms, causing the formation of a pi bond. This hybridization results in the following electron orbitals: $1 \mathrm{~s}^{2}\left(\mathrm{sp}^{2}\right)^{3} 2 \mathrm{p}_{\mathrm{z}}{ }^{1}$. Often functional groups containing oxygen, nitrogen, etc. can be added to the edges of graphite $[1,5]$.

The unique electron orbitals of graphene is important for the load transfer between the filler and the matrix. Load transfer can occur when there is micromechanical interlocking of the filler and the matrix, chemical bonding between the filler and the matrix, or is there is van der Waals bonding between the filler and the matrix. Interfacial 
shear results in load transfer. If the load transfer is poor then the other mechanical properties will suffer. Nanostructured materials have been shown the increase the stiffness of a composite, but they also can reduce the strength and elongation of a composite.

There are two primary nanostructured carbon fillers, carbon nanotubes and graphene nanoplatelets. Nanostructured materials are characterized by having at least one constituent whose character length that is tens of nanometers or smaller. The literature contains many references concerning adding carbon nanotubes to epoxy to increase the tensile modulus [6-9]. GNP is a newly developed low cost material that is a very promising alternative to carbon nanotubes that also increases the tensile modulus [2, 10-15]. Specifically, Fukushima et al. demonstrated that the tensile modulus from $\sim 2.75$ GPa to $\sim 3.1 \mathrm{GPa}$ for 3 vol $\% \mathrm{GNP} / 97$ vol\% epoxy. Schadler et al. showed an increase from $3.1 \mathrm{GPa}$ for neat epoxy to $3.71 \mathrm{GPa}$ for $5 \mathrm{wt} \% \mathrm{CNT} / 95 \mathrm{wt} \%$ epoxy.

Tensile modulus models are useful predicting the behavior of a composite. The Halpin-Tsai model is a widely accepted model for predicting the tensile modulus for discontinuous carbon fibers. The model can be adapted for many different filler geometries, platelets being one of them. The Halpin-Tsai model takes into account the tensile properties of the polymer matrix and the filler as well as the filler geometry [1619]. It is useful to have models that will predict the mechanical properties of composites so that time and money is not wasted on fabrication and testing.

In order to make aircrafts more fuel efficient, the material used for their fabrication needs to be lighter. Carbon-filled polymer composites are lighter than the 
metals they replace, and have the potential to be just as strong. This research was funded by NASA under the Subsonic Fixed Wing Program (Grant NNX11AO72A). The epoxy (polymer) chosen for this study was Momentive EPON ${ }^{\mathrm{TM}}$ Resin 862 with EPIKURE Curing Agent W with GNP as the carbon filler and continuous carbon fiber for structural reinforcement. Very few studies have been conducted on this particular epoxy with this curing agent. The mechanical properties of GNP added to this particular epoxy composites have not been determined. As far as current literature available, continuous carbon fiber has never been used as a reinforcement for GNP/epoxy composites. It is believed that adding GNP to epoxy will increase the tensile modulus. This should also increase the overall stiffness of a continuous carbon fiber composite.

\subsection{Objectives}

There is one primary goal for this project, to characterize GNP/epoxy and continuous $\mathrm{CF} / \mathrm{GNP} /$ epoxy composites in terms of their tensile properties (stress, strain, and modulus). The specific objectives of this project are listed below.

- Objective 1: Graphene nanoplatelet (GNP)/epoxy composites were fabricated and tested for mechanical properties (measured by ASTM D638 and nanoindentation).

- Objective 2: Continuous carbon fiber/GNP/epoxy composites were fabricated and tested for mechanical properties (measured by ASTM D3039).

- Objective 3: Based on the data collected in Objectives 1 and 2, Halpin-Tsai models will be were applied to predict the tensile modulus. 


\subsection{References}

[1] Marsh, H. and Rodrigues, F. Reinoso, Sciences of Carbon Materials, Publicaciones da la Universidad de Alicante, Spain, (2010).

[2] XG Sciences Inc. $x G n P^{\circledR}$ Brand Graphene Nanoplatelets Product Information, 3101 Grand Oak Drive, Lansing, MI 48911 (2010).

[3] Stankovich, S., Dikin, D., Dommett, et al. Nature, 442, 282-286 (2006).

[4] Du, J. and Cheng, H. Macromol. Chem. Phys., 213, 1060-1077 (2012).

[5] Castro Neto, A.H., et al., Reviews of Modern Physics, 81(1), 109-162 (2009).

[6] Gojny, F., Wichmann, M., et al., "Influence of different carbon nanotubes on the mechanical properties of epoxy matrix composites- A comparative study" Composites Science and Technology, 2005, 65 (15-16). 2300-2313.

[7] Sandler, J, Shaffer, M, et al., "Development of dispersion process for carbon nanotubes in an epoxy matrix and the resulting electrical properties" Polymer, 1999, $40(21), 5967-5971$.

[8] Gojny, F., Nastalczyk, J., et al., "Surface modified multi-walled carbon nanotubes in CNT/epoxy-composites" Chemical Physics Letters, 2003, 370 (5-6) 820-824.

[9] Allaoui, A., Bai, S., et al., "Mechanical and electrical proeprteis of MWNT/epoxy composite" Composites Science and Technology, 2002, 62 (15) 1993-1998.

[10] Asbury Carbons, ThermoCarb Graphite TC-Series Product Information, 405 Old Main Street, Asbury, NJ 08802 (2013).

[11] Kalaitzidou, K., Fukushima, H., and Drzal, L. T. Composites Part A, 38, 16751682 (2007).

[12] Fukushima, H., Drzal, L. T., Rook, B. P., and Rich, M. J., J. Therm. Anal. Calorim., $85,235-238$ (2006).

[13] Kalaitzidou, K., Fukushima, H., Miyagawa, H., and Drzal, L. T., Polym. Eng. Sci., 47, 1796-1803 (2007).

[14] Kalaitzidou, K., Fukushima, H., and Drzal, L. T., Compos. Sci. Technol., 67, 20452051 (2007). 
[15] Schadler, L. S., Giannaris, S. C., and Ajayan, P. M., App. Phys. Let., 73 (26), $3842-$ 3844 (1998).

[16] Halpin, J.C., and Kardos, J. L. The Halpin-Tsai equations: A review. Polymer Engineering and Science 1976; 16: 344-352.

[17] Agarwal, B.D. and Broutman, L. J. Analysis and Performance of Fiber Composites. Wiley, New York, NY, 1980.

[18] Mallick, P. K. Composites Engineering Handbook, Marcel Dekker, Inc., New York, NY, 1997.

[19] Halpin, J. C., J. Compos. Mater., 3, $732-734$ (1969). 


\section{Materials}

\subsection{Materials}

For this project there were four different graphene nanoplatelets, one continuous carbon fiber, and one epoxy matrix studied. The epoxy matrix analyzed was Momentive EPON $^{\mathrm{TM}}$ Resin 862 with EPIKURE Curing Agent W. The carbon fillers studied were: $\mathrm{XG}$ Sciences $\mathrm{xGnP}{ }^{\circledR}-\mathrm{M}-15, \mathrm{xGnP}^{\circledR}-\mathrm{M}-5, \mathrm{xGnP}^{\circledR}-\mathrm{C}-300$ graphene nanoplatelets, Asbury Carbons ThermoCarb TC307 graphene nanoplatelets, and Hexcel HexTow ${ }^{\circledR}$ AS4-GP-3K Continuous Carbon Fiber. The following sections will cover each material in more detail.

\subsection{Matrix Material}

The epoxy matrix used in this study was Momentive EPON ${ }^{\mathrm{TM}}$ Resin 862 (diglycidyl ether of bisphenol F, DGEBF) with EPIKURE Curing Agent W (diethyltoluenediamine, DETDA) (EPON 862/EPIKURE W). The chemical structures of $\mathrm{EPON}^{\mathrm{TM}}$ Resin 862 and EPIKURE Curing Agent $\mathrm{W}$ are shown in Figure 2-1. EPON ${ }^{\mathrm{TM}}$ Resin 862 is a low viscosity, liquid epoxy resin manufactured from epichlorohydrin and bisphenol F [1]. The formation of EPON ${ }^{\mathrm{TM}}$ Resin 862 from Bisphenol $\mathrm{F}$ is shown in Figure 2-2. The amine groups on the EPIKURE Curing Agent $\mathrm{W}$ react with the epoxide groups on the EPON ${ }^{\mathrm{TM}}$ Resin 862 as the reaction continues the system becomes a branched crosslinked structure as shown in Figure 2-3. EPON 862/EPIKURE W is a thermoset epoxy system with a curing cycle of $121^{\circ} \mathrm{C}$ for 2 hours followed by $177^{\circ} \mathrm{C}$ for 
2 hours. Table 2-1 contains physical properties of the EPON ${ }^{\mathrm{TM}}$ Resin 862 and EPIKURE Curing Agent W.

Table 2-1: Properties of Momentive's EPON ${ }^{T M}$ Resin 862 and EPIKURE Curing Agent $W[1]$

\begin{tabular}{|c|c|}
\hline Tensile Strength & $78.6 \mathrm{MPa}$ \\
\hline Tensile Modulus & $2.72 \mathrm{GPa}$ \\
\hline Tensile Strain & $7.1 \%$ \\
\hline Density & $1.20 \mathrm{~g} / \mathrm{cm}^{3}$ \\
\hline
\end{tabular}

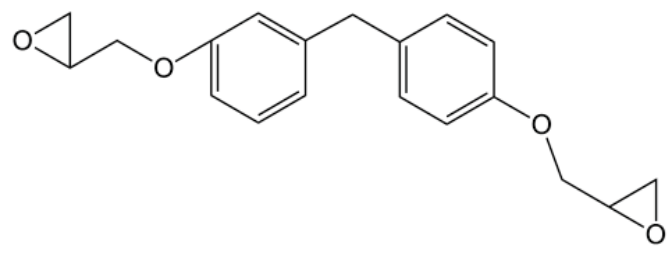

EPON $^{\mathrm{TM}}$ Resin 862

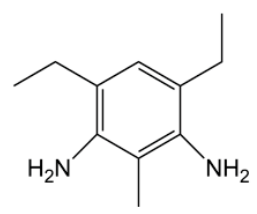

EPIKURE Curing Agent W

Figure 2-1: EPON ${ }^{T M}$ Resin 862 and EPIKRUE Curing Agent W Structures -drawn from chemical name given in vendor literature [1]

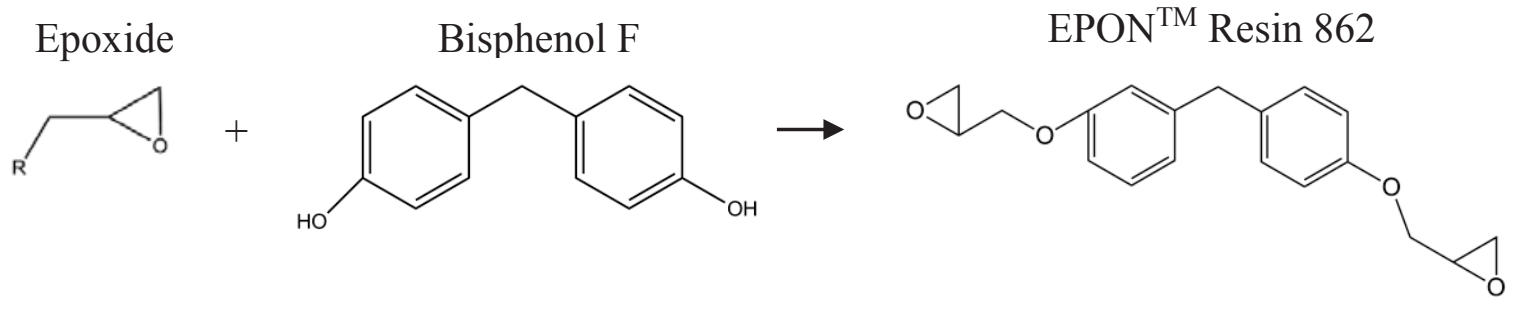

Figure 2-2: EPON ${ }^{T M}$ Resin 862 formation from Bisphenol $F$ 

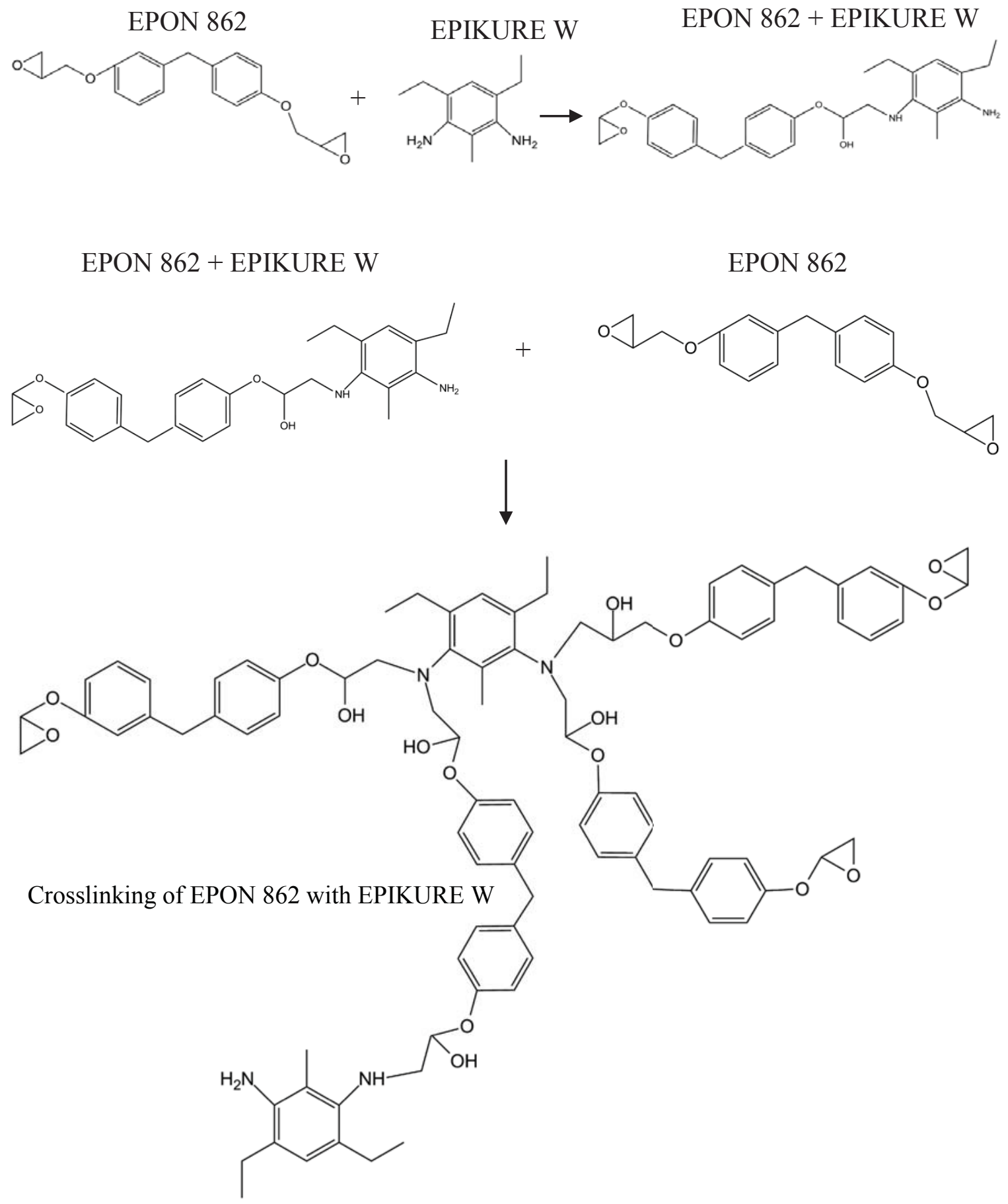

Figure 2-3: Crosslinking of EPON ${ }^{T M}$ Resin 862 with EPIKURE Curing Agent W 


\subsection{Fillers}

\subsubsection{Graphene Nanoplatelets (GNP)}

Graphene nanoplatelets (GNP) are short stacks of graphene sheets. A graphene sheet is defined as a single layer of graphite. GNPs are available in many different particle diameters and thicknesses, they can have various surface areas and surface modifications. The structure of graphene can be seen in Figure 2-4.

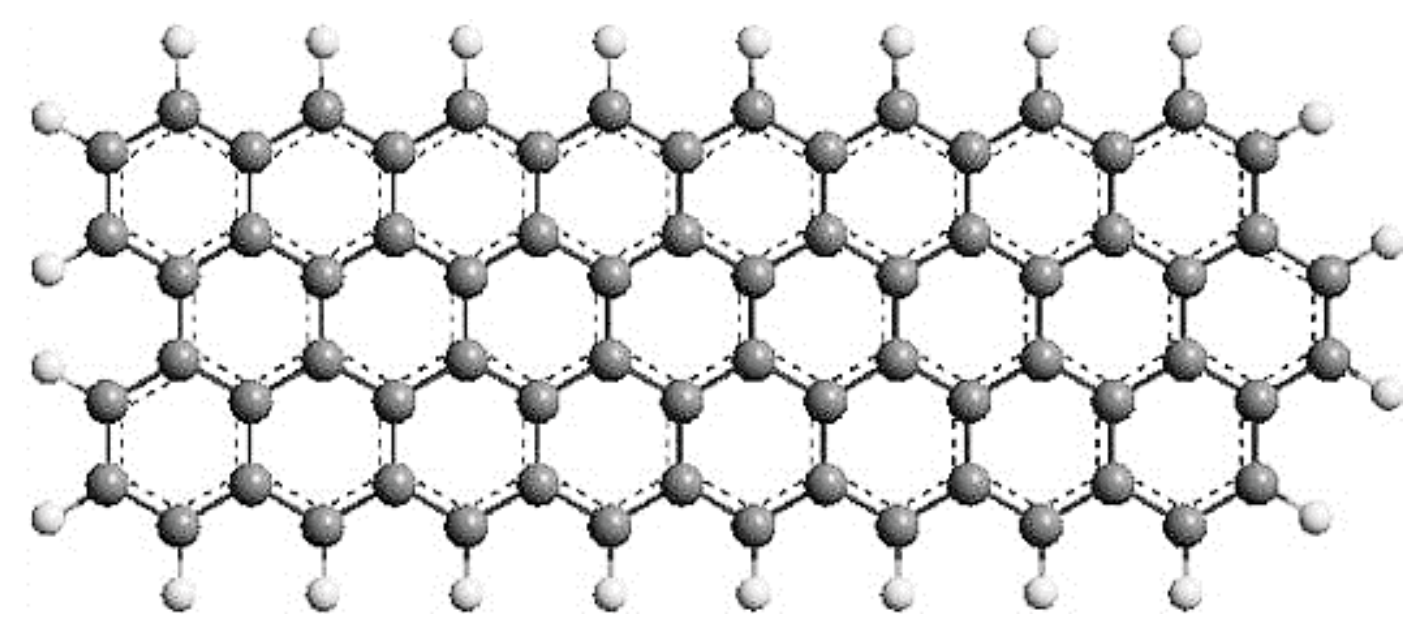

Figure 2-4: Graphene Structure

Three of the four GNPs are from XG Sciences. XG Sciences has two different grades of GNP. The first type is M grade, which are manufactured by heating Graphite Intercalated Compounds (GIC). First, the GICs were fabricated by intercalating mixtures of acids into natural graphite flakes. Then the GIC samples were produced thermally. After the treatment, these graphite flakes showed significant expansions due to the vaporization of intercalated acids in between the graphite layers. The expanded graphite flakes were then pulverized to a specific size. The average thickness and size of the $\mathrm{xGnP}^{\circledR}$ can be controlled by changing the process conditions. Two types of M Grade 
$\mathrm{xGnP}^{\circledR}$ were used. The first type is $\mathrm{xGnP}^{\circledR}-\mathrm{M}-15$, which has an average particle diameter of 15 microns and a thickness of $7 \mathrm{~nm}$. The second type is $\mathrm{xGnP}^{\circledR}-\mathrm{M}-5$, which has an average diameter of 5 microns, and a thickness of $7 \mathrm{~nm}$. The specific surface area of both M grade materials is $120-130 \mathrm{~m}^{2} / \mathrm{g}$.

The second grade that $\mathrm{XG}$ Sciences manufactures is, $\mathrm{C}$ grade $\mathrm{xGnP}^{\circledR}$, which is made by a different proprietary process. The type used for this study was $\mathrm{xGnP}{ }^{\circledR}-\mathrm{C}-300$, which has an average particle diameter of 2 microns and $\sim 2 \mathrm{~nm}$ thickness, the specific surface area is $\sim 300 \mathrm{~m}^{2} / \mathrm{g}$. C grade materials are smaller and thinner, because of this they have more edge groups present so there are more functional groups [2]. TEM images of $\mathrm{xGnP}^{\circledR}$ can be seen in Figure 2-5.

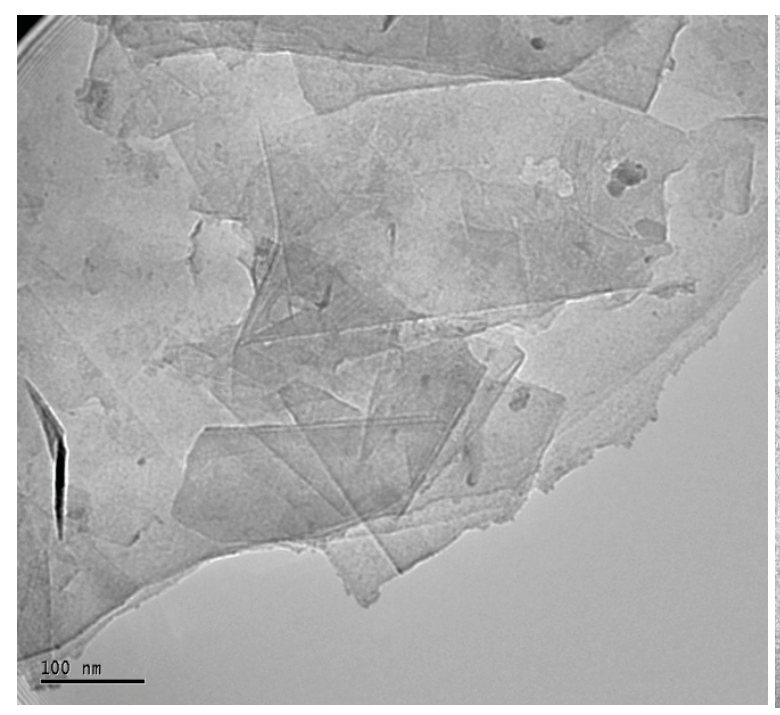

A: Scale bar $=100 \mathrm{~nm}$

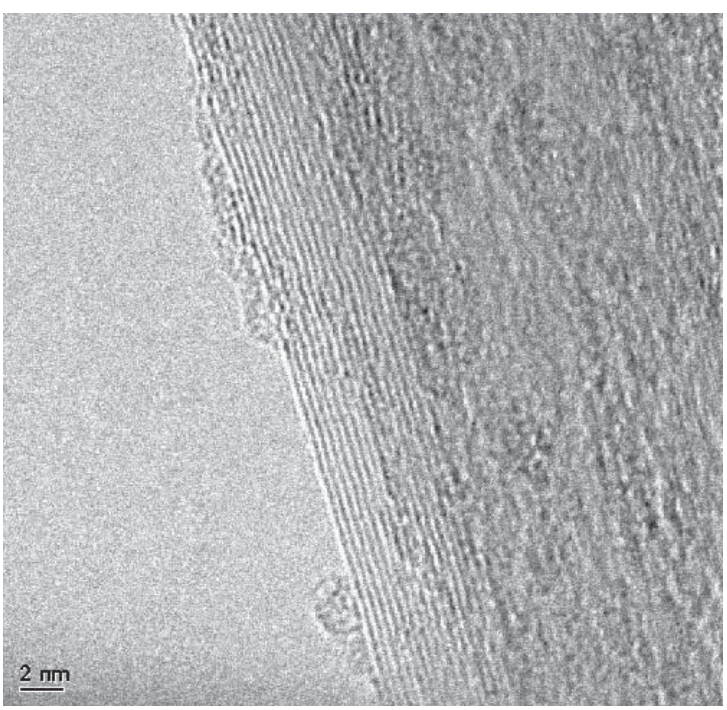

B: Scale bar $=2 \mathrm{~nm}$

Figure 2-5: TEM images of $x G n P^{\circledR}[2]$

The last GNP used is available from Asbury. Asbury TC307 GNP are manufactured using a proprietary process. The parent carbon used in this particular GNP 
material is a high quality calcined needle coke, which is heat treated to temperatures above $2500{ }^{\circ} \mathrm{C}$ to effect graphitization. A transmission electron micrograph of TC307 can be seen in Figure 2-6. TC307 has an average primary particle diameter of below $1 \mu \mathrm{m}$, a density of $\sim 2 \mathrm{~g} / \mathrm{mL}$, and a nominal specific surface area of $350 \mathrm{~m}^{2} / \mathrm{g}$. TC307 has a nominal primary lamella thickness of $\sim 8(\sim 1.1 \mathrm{~nm})$ graphene layers [3].

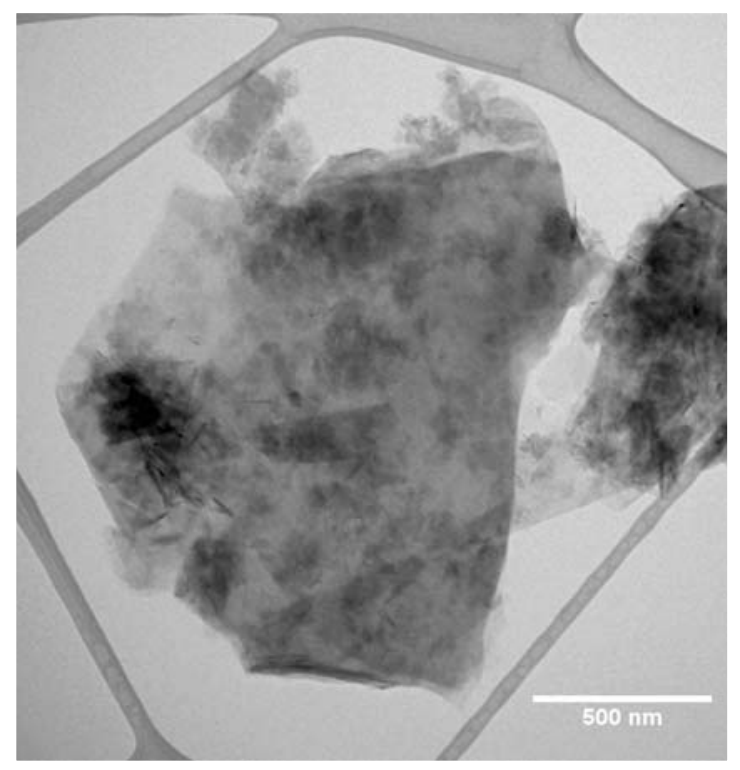

Scale bar $=500 \mathrm{~nm}$

Figure 2-6: Transmission Electron Micrograph of Asbury TC307 [4]

\subsubsection{Hexcel HexTow ${ }^{\circledR}$ AS4-GP-3K Continuous Carbon Fiber}

The continuous carbon fiber used in this analysis is fabricated by Hexcel. Hexcel's HexTow ${ }^{\circledR}$ AS4-GP-3K is a PAN (polyacrylonitrile) based carbon fiber, containing 3,000 fibers per bundle (3K tow) [5]. There is $1 \mathrm{wt} \%$ sizing consisting of a proprietary, uncured epoxy resin. The properties are shown in Table 2-2. 
Table 2-2: Properties of Hexcel HexTow ${ }^{\circledR}$ AS4-GP-3K continuous carbon fiber [5]

\begin{tabular}{|l|c|}
\hline Tensile Strength & $4,620 \mathrm{MPa}$ \\
\hline Tensile Modulus & $231 \mathrm{GPa}$ \\
\hline Density & $1.76-1.82 \mathrm{~g} / \mathrm{cm}^{3}$ \\
\hline Fiber Diameter & $7.3 \mathrm{microns}$ \\
\hline
\end{tabular}

\subsection{Formulation Naming Convention}

To make sample identification simpler, a naming convention has been created. Most samples look very similar to one another so it is important to label every sample with a unique name. Labels were applied after fabrication. The naming system is as follows:

A862-AS4- b-w - date - z - \#

Where:

$\mathrm{A}=$ project description (NASA project)

AS4 $=$ HexTow $^{\circledR}$ AS4-GP-3K, if not used in the composite then do not use in naming $\mathrm{b}=$ filler type $\left(\mathrm{M} 15=\mathrm{xGnP}^{\circledR}-\mathrm{M}-15, \mathrm{M} 5=\mathrm{xGnP}^{\circledR}-\mathrm{M}-5, \mathrm{C} 300=\mathrm{xGnP}^{\circledR}-\mathrm{C}-300\right.$, TC307 $=$ Asbury TC307), if none are contained in the composites then do not use in naming $\mathrm{w}=$ weight percent of $\mathrm{xGnP}^{\circledR}$ graphene nanoplatelets.

date $=$ date of specimen fabrication

$\mathrm{z}=$ specimen type $(\mathrm{T}=$ tensile bar, $\mathrm{D}=$ electrical resistivity disks $)$

\#= specimen number

An example of the naming system would be A862-AS4-C300-2-11-8-13-T-8. This would represent the $8^{\text {th }}$ tensile bar containing HexTow ${ }^{\circledR}$ AS4-GP-3K continuous carbon fiber and 2 wt \% xGnP ${ }^{\circledR}-\mathrm{C} 300$ fabricated on November 8, 2013. 


\subsection{References}

[1] Momentive Specialty Chemicals, Inc. EPON 862 /EPIKURE Curing Agent W System Product Literature, 180 E. Broad Street, Columbus, OH, 43215 (2011).

[2] XG Sciences Inc. $x G n P^{\circledR}$ Brand Graphene Nanoplatelets Product Information, 3101 Grand Oak Drive, Lansing, MI 48911 (2010).

[3] Asbury Carbons, ThermoCarb Graphite TC-Series Product Information, 405 Old Main Street, Asbury, NJ 08802 (2013).

[4] A. V. Tamashausky, Asbury Carbons, micrograph of TC307, personal correspondence on Aug 13, 2014.

[5] Hexcel. HexTow Continuous Carbon Fiber Product Literature. Stamford, CT, 2011. 


\section{Fabrication and Experimental Methods}

\subsection{Fabrication Methods}

For each type of GNP an optimum mixing procedure had to be developed. In the earlier stages this was done through trial and error. The mixing speed and time were varied and samples were tested to see if the optimum properties were obtained. This is how the mixing procedures for the $\mathrm{xGnP}^{\circledR}-\mathrm{M}-15$ and $\mathrm{xGnP}^{\circledR}-\mathrm{M}-5$ were found. The $\mathrm{xGnP}^{\circledR}-\mathrm{C}-300$ proved to be a challenge for mixing. The $\mathrm{xGnP}^{\circledR}-\mathrm{C}-300$ size properties were drastically different from the two M-grades that the trial and error method would not work.

For the $\mathrm{xGnP}^{\circledR}-\mathrm{C}-300$ the mixing rate was set as high as it would go before the mixture began to splatter out of the beaker $(3500 \mathrm{rpm})$. To find the optimal mixing time for the $\mathrm{xGnP}^{\circledR}-\mathrm{C}-300$ an optical microscope was used. Samples were taken from the batch as it was mixing at 10 min time intervals. A pea sized sample was flattened between two microscope slides and the $\mathrm{xGnP}^{\circledR}-\mathrm{C}-300$ was viewed under the microscope at 500x magnification. Once the GNP was no longer getting visibly smaller, the mixing was complete. It was also found that sonication helped to exfoliate the GNP further. Sonication was tried on the M-grade GNPs, but it did not make a difference. The same procedure used for the $\mathrm{xGnP}^{\circledR}-\mathrm{C}-300$ was then applied to disperse the TC307 GNP in epoxy. The finalized mixing procedures are described in the following subsections. 


\subsubsection{Neat epoxy test specimen fabrication}

To fabricate the neat epoxy, $100 \mathrm{~g}$ of EPON 862 was added to $26.4 \mathrm{~g}$ of EPIKURE Curing Agent $\mathrm{W}$ at $23^{\circ} \mathrm{C}$ and mixed by hand for 3 minutes. The mixture was degassed inside an oven at $90^{\circ} \mathrm{C}$ and 29 inches $\mathrm{Hg}$ vacuum for $30 \mathrm{~min}$ and then poured into rectangular molds. The molds were heated in an oven to $121^{\circ} \mathrm{C}$ over $30 \mathrm{~min}$, held at $121^{\circ} \mathrm{C}$ for $2 \mathrm{~h}$, heated to $177^{\circ} \mathrm{C}$ over $30 \mathrm{~min}$, held for another $2 \mathrm{~h}$ at $177^{\circ} \mathrm{C}$, and finally cooled to ambient temperature [1-3].

\subsection{2 $x G n P^{\circledR}-M-15 / e p o x y$ test specimen fabrication}

To produce the $\mathrm{xGnP}^{\circledR}-\mathrm{M}-15 /$ epoxy composites, the appropriate amount of $\mathrm{xGnP} \mathrm{P}^{\circledR}-\mathrm{M}-15$ was added to EPON 862 and mixed using a 2 in diameter disperser blade in a Ross high shear mixer HSM-100 LSK-I (see Figure 3-1) at 2500 rpm for 40 minutes. The corresponding amount of EPIKURE Curing Agent W (100 g EPON 862 added to 26.4 $\mathrm{g}$ of EPIKURE Curing Agent $\mathrm{W}$ ) was added to the $\mathrm{xGnP}^{\circledR}-\mathrm{M}-15 / \mathrm{EPON}$ mixture and stirred with the Ross mixer at $1000 \mathrm{rpm}$ for 3 minutes at $23^{\circ} \mathrm{C}$. The mixture was degassed inside an oven at $90^{\circ} \mathrm{C}$ and 29 inches $\mathrm{Hg}$ vacuum for 30 min and then poured into rectangular- and disc-shaped molds. The same curing cycle was used as described for the neat epoxy. For the neat epoxy and the $\mathrm{xGnP}^{\circledR}-\mathrm{M}-15 /$ epoxy systems, the fabricated samples were rectangular bars (165 $\mathrm{mm}$ long by $19 \mathrm{~mm}$ wide by $3.3 \mathrm{~mm}$ thick) [4]. 


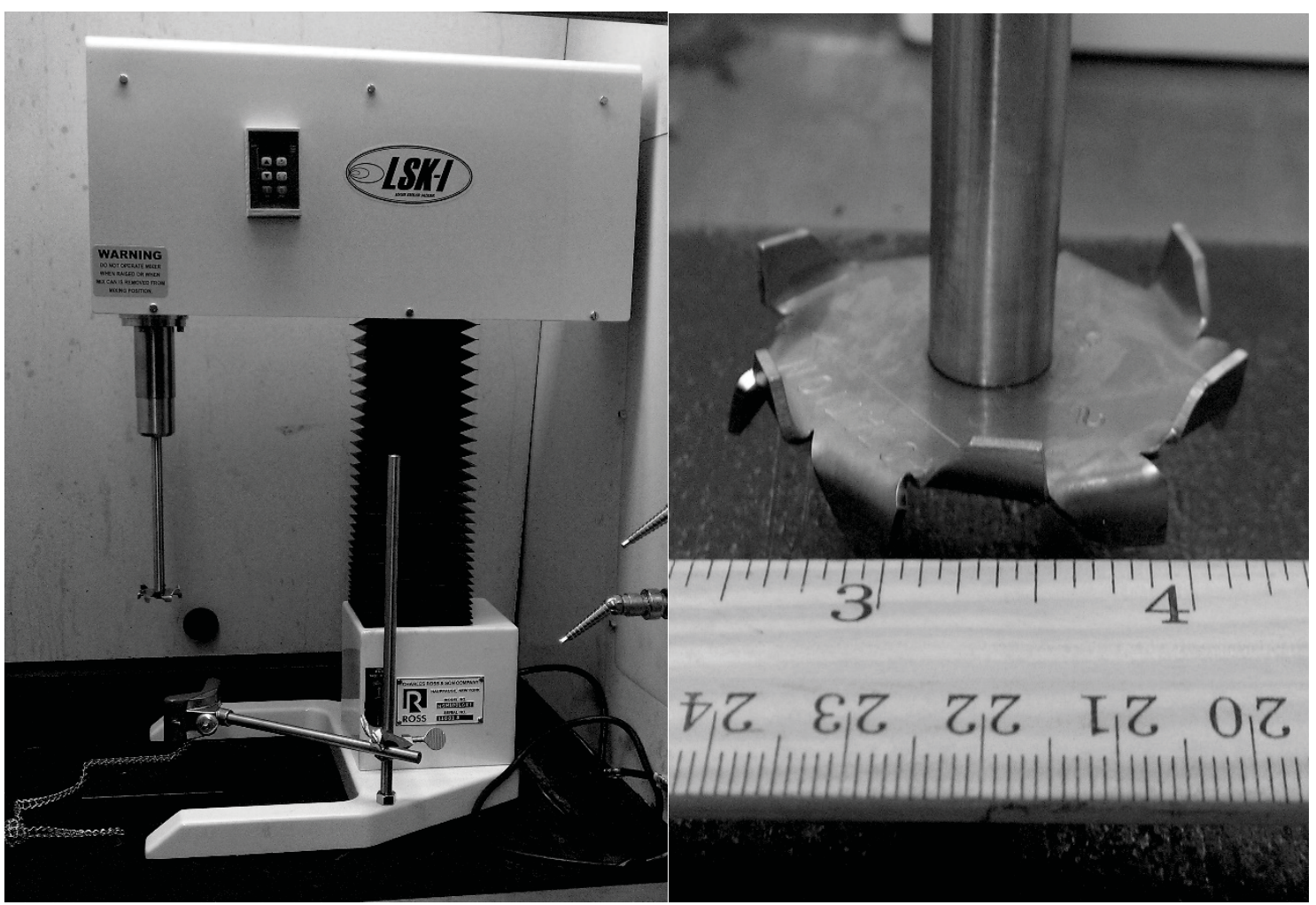

Figure 3-1: (left) Ross high shear mixer HSM-100 LSK-I with (right) 2" dispersion mixing blade

\subsection{3 $x G n P^{\circledR}-M-5 / e p o x y$ test specimen fabrication}

To produce the $\mathrm{xGnP}^{\circledR}-\mathrm{M}-5 /$ epoxy composites, the appropriate amount of $\mathrm{xGnP}^{\circledR}$ M-5was added to EPON 862 and mixed using a 2 in diameter disperser blade in a Ross high shear mixer HSM-100 LSK-I at 2500 rpm for 20 minutes. The corresponding amount of EPIKURE Curing Agent W (100 g EPON 862 added to $26.4 \mathrm{~g}$ of EPIKURE Curing Agent W) was added to the $\mathrm{xGnP}^{\circledR}-\mathrm{M}-5 / \mathrm{EPON}$ mixture and stirred with the Ross mixer at $1000 \mathrm{rpm}$ for 3 minutes at $23^{\circ} \mathrm{C}$. The mixture was degassed inside an oven at $90^{\circ} \mathrm{C}$ and 29 inches $\mathrm{Hg}$ vacuum for $30 \mathrm{~min}$ and then poured into rectangular- and discshaped molds. The same curing cycle was used as described for the neat epoxy. For the 
$\mathrm{xGnP}^{\circledR}-\mathrm{M}-5 /$ epoxy system the fabricated samples were rectangular bars (165 $\mathrm{mm}$ long by $19 \mathrm{~mm}$ wide by $3.3 \mathrm{~mm}$ thick) [5].

\subsection{4 $x G n P^{\circledR}-C-300 / e p o x y$ test specimen fabrication}

To produce the $\mathrm{xGnP}^{\circledR}-\mathrm{C}-300 /$ epoxy composites, the appropriate amount of xGnP ${ }^{\circledR}$-C-300 was added to EPIKURE Curing Agent W (100 g EPON 862 added to 26.4 g of EPIKURE Curing Agent W) and mixed using a 2 in diameter disperser blade in a Ross high shear mixer HSM-100 LSK-I at $3500 \mathrm{rpm}$ for 150 minutes. The mixture was then placed in a Branson Bath Sonicator CPX2800H (see Figure 3-2) operating at $40 \mathrm{kHz}$ for 60 minutes at $23^{\circ} \mathrm{C}$. The corresponding amount of EPON 862 was added to the xGnP ${ }^{\circledR}$-C-300/Curing Agent W mixture and stirred with the Ross mixer at $1000 \mathrm{rpm}$ for 3 minutes at $23^{\circ} \mathrm{C}$. The mixture was degassed inside an oven at $90^{\circ} \mathrm{C}$ and 29 inches $\mathrm{Hg}$ vacuum for $30 \mathrm{~min}$ and then poured into rectangular- and disc-shaped molds. The same curing cycle was used as described for the neat epoxy. For the $\mathrm{xGnP}^{\circledR}-\mathrm{C}-300$ /epoxy system the fabricated samples were rectangular bars (165 mm long by $19 \mathrm{~mm}$ wide by 3.3 mm thick) [5]. 


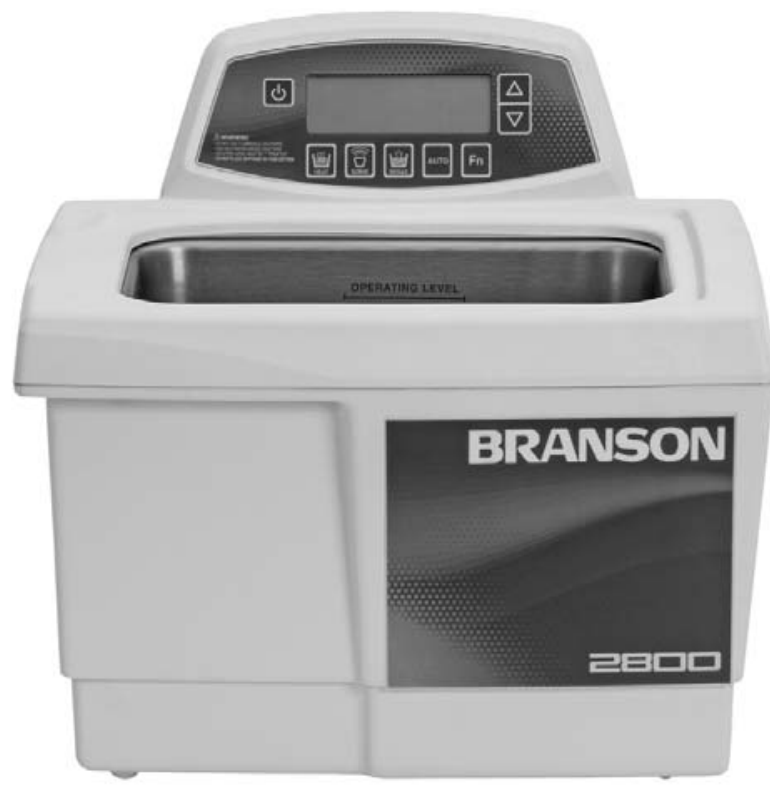

Figure 3-2: Branson Bath Sonicator CPX2800H

\subsubsection{Asbury TC307/epoxy test specimen fabrication}

To produce the Asbury TC307/epoxy composites, the appropriate amount of TC307 was added to EPON 862 and mixed using a 2 in diameter disperser blade in a Ross high shear mixer HSM-100 LSK-I at $3000 \mathrm{rpm}$ for 60 minutes. The mixture was then placed in a Branson Bath Sonicator CPX2800H operating at $40 \mathrm{kHz}$ for 60 minutes at $23^{\circ} \mathrm{C}$. The corresponding amount of EPIKURE Curing Agent W $(100 \mathrm{~g}$ EPON 862 added to $26.4 \mathrm{~g}$ of EPIKURE Curing Agent W) was added to the TC307/Curing Agent W mixture and stirred with the Ross mixer at $1200 \mathrm{rpm}$ for 10 minutes at $23^{\circ} \mathrm{C}$. The mixture was degassed inside an oven at $90^{\circ} \mathrm{C}$ and 29 inches $\mathrm{Hg}$ vacuum for $30 \mathrm{~min}$ and then poured into rectangular- and disc-shaped molds. The same curing cycle was used as 
described for the neat epoxy. For the TC307 /epoxy system the fabricated samples were rectangular bars ( $165 \mathrm{~mm}$ long by $19 \mathrm{~mm}$ wide by $3.3 \mathrm{~mm}$ thick).

\subsubsection{AS4 carbon fiber/epoxy test specimen fabrication}

To fabricate the continuous unidirectional carbon fiber/epoxy composites, $100 \mathrm{~g}$ of EPON 862 was added to $26.4 \mathrm{~g}$ of EPIKURE Curing Agent $\mathrm{W}$ at $23{ }^{\circ} \mathrm{C}$ and mixed by hand for 3 minutes. The corresponding amount of epoxy (100 g EPON 862 added to 26.4 $\mathrm{g}$ of EPIKURE Curing Agent $\mathrm{W}$ ) and carbon fiber were mixed to produce a unidirectional composite containing $67 \mathrm{wt} \%$ carbon fiber and $33 \mathrm{wt} \%$ epoxy. The uncured epoxy/carbon fiber was cut into sheets $(248 \mathrm{~mm}$ by $248 \mathrm{~mm})$ and placed in a picture frame mold. To fabricate the unidirectional composite plate, five plies were placed with the carbon fiber in the $0^{\circ}$ direction. A Wabash Compression Molding Machine Vantage Series Model V75H-18-CLX (see Figure 3-3) was used. Initially, the composite plate was heated to $121{ }^{\circ} \mathrm{C}$ and held at a constant pressure of $30 \mathrm{psi}$ for 2 hours. The press was then ramped up to $177{ }^{\circ} \mathrm{C}$ and held at a constant pressure of 1000 psi for 2 hours. Cooling water was used to cool the press until the platen temperature was $30^{\circ} \mathrm{C}$, then the composite plate $(1.7 \mathrm{~mm}$ thick) was removed [6]. 


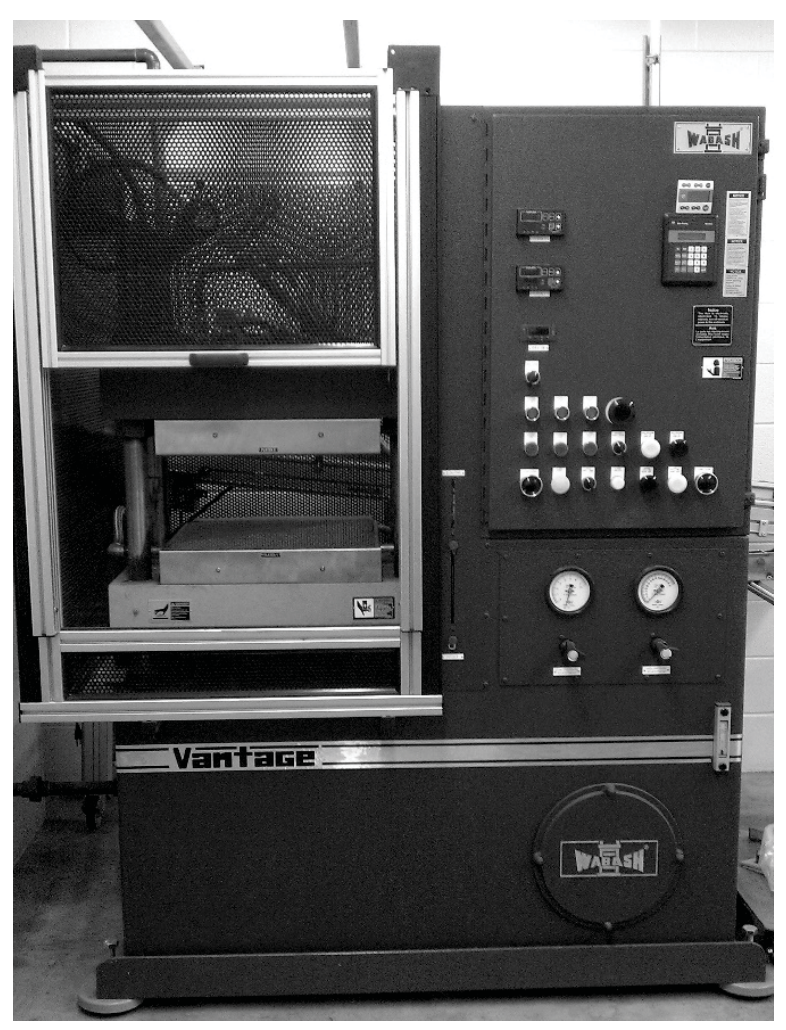

Figure 3-3: Wabash Compression Molding Machine Vantage Series Model V75H-18CLX

\subsubsection{AS4 carbon fiber/ $x G n P^{\circledR}-C-300 /$ epoxy test specimen fabrication}

To fabricate the $\mathrm{xGnP}^{\circledR}$-C-300/carbon fiber/epoxy hybrid composites, the appropriate amount of $\mathrm{xGnP}^{\circledR}-\mathrm{C}-300$ was added to $26.4 \mathrm{~g}$ EPIKURE Curing Agent W and mixed using a 2 in diameter disperser blade in a Ross high shear mixer HSM-100 LSK-I at 3500 rpm for 150 minutes. Next the mixture was placed in a Branson Sonicator CPX2800H operating at $40 \mathrm{kHz}$ for 60 minutes at $23^{\circ} \mathrm{C}$. The corresponding amount of epoxy $(100 \mathrm{~g}$ EPON 862 added to $26.4 \mathrm{~g}$ of EPIKURE Curing Agent W) was added to the $\mathrm{xGnP}^{\circledR}-\mathrm{C}$ 300/ Curing Agent W mixture and stirred with the Ross mixer at $1000 \mathrm{rpm}$ for 3 minutes at $23^{\circ} \mathrm{C}$. The carbon fiber was strung through a resin bath containing $\mathrm{xGnP}^{\circledR}-\mathrm{C}-300$ / 
epoxy to produce a unidirectional continuous carbon fiber composite containing the following compositions:

- $1 \mathrm{wt} \% \mathrm{xGnP}^{\circledR}-\mathrm{C}-300 / 67 \mathrm{wt} \%$ carbon fiber $/ 32 \mathrm{wt} \%$ epoxy

- $2 \mathrm{wt} \% \mathrm{xGnP}^{\circledR}-\mathrm{C}-300 / 67 \mathrm{wt} \%$ carbon fiber $/ 31 \mathrm{wt} \%$ epoxy

- $3 \mathrm{wt} \% \mathrm{xGnP}{ }^{\circledR}-\mathrm{C}-300 / 67 \mathrm{wt} \%$ carbon fiber $/ 30 \mathrm{wt} \%$ epoxy

The uncured $x G n P^{\circledR}-C-300 /$ carbon fiber/epoxy composite was cut into sheets and cured as described for the neat epoxy [6].

\subsection{Experimental Test Methods}

\subsubsection{Neat Epoxy and GNP/Epoxy Mechanical Tensile Property Test Method}

The neat epoxy and GNP/epoxy composites were tested for tensile properties at ambient conditions according to ASTM D638 at a crosshead rate of $1 \mathrm{~mm} / \mathrm{min}$. The test specimens are ASTM Type I sample geometry, $165 \mathrm{~mm}$ length with $3.3 \mathrm{~mm}$ thickness. An InstruMet Sintech screw-driven mechanical testing machine was used, shown in Figure 3-4. Stress results are recorded by the testing machine and an extensometer was used to collect the strain values. 


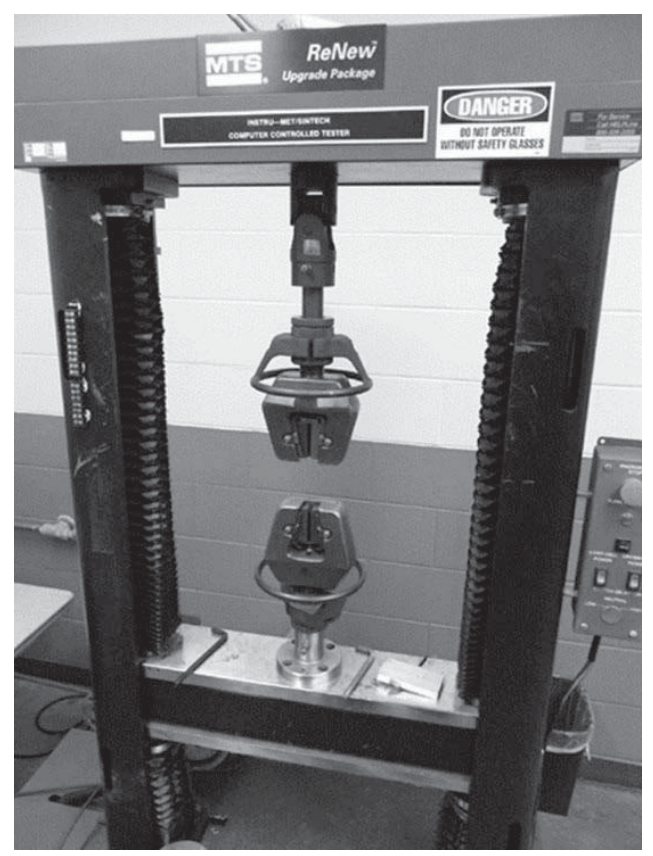

Figure 3-4: Instru-Met Sintech mechanical testing machine with tensile apparatus installed

ASTM D638 was used to determine the tensile strength, strain, and modulus [7]. Modulus is determined by the initial slope of the stress-strain curve. At least 5 samples of each composite were tested. The samples were conditioned at $23{ }^{\circ} \mathrm{C}$ and $50 \%$ relative humidity for 2 days prior to testing.

\subsubsection{Continuous Carbon Fiber Mechanical Tensile Property Test Method}

The continuous carbon fiber composites were tested for tensile properties at ambient conditions according to ASTM D3039 at a crosshead rate of $2 \mathrm{~mm} / \mathrm{min}$ [8]. The samples were cut to $165 \mathrm{~mm}$ length, $12.5 \mathrm{~mm}$ width, and $3.3 \mathrm{~mm}$ thickness. An InstruMet Sintech screw-driven mechanical testing machine was used. Stress results are recorded by the testing machine and an extensometer was used to collect the strain values. 
ASTM D3039 was used to determine the tensile strength, strain, and modulus. Modulus is determined by the initial slope of the stress-strain curve. At least 6 samples of each composite were tested. The samples were conditioned at $23{ }^{\circ} \mathrm{C}$ and $50 \%$ relative humidity for 2 days prior to testing.

\subsubsection{Nanoindentation Test Method}

Nanoindentation tests were performed on samples cut from untested tensile specimens for all composite formulations, $10 \mathrm{~mm}$ x $10 \mathrm{~mm} \times 3.3 \mathrm{~mm}$. The samples were mounted in an epoxy puck and tested with an Agilent Nano Indenter XP, shown in Figure 3-5. The typical test was run to a depth of $1500 \mathrm{~nm}$ and data was recorded at a rate of 5 Hz.

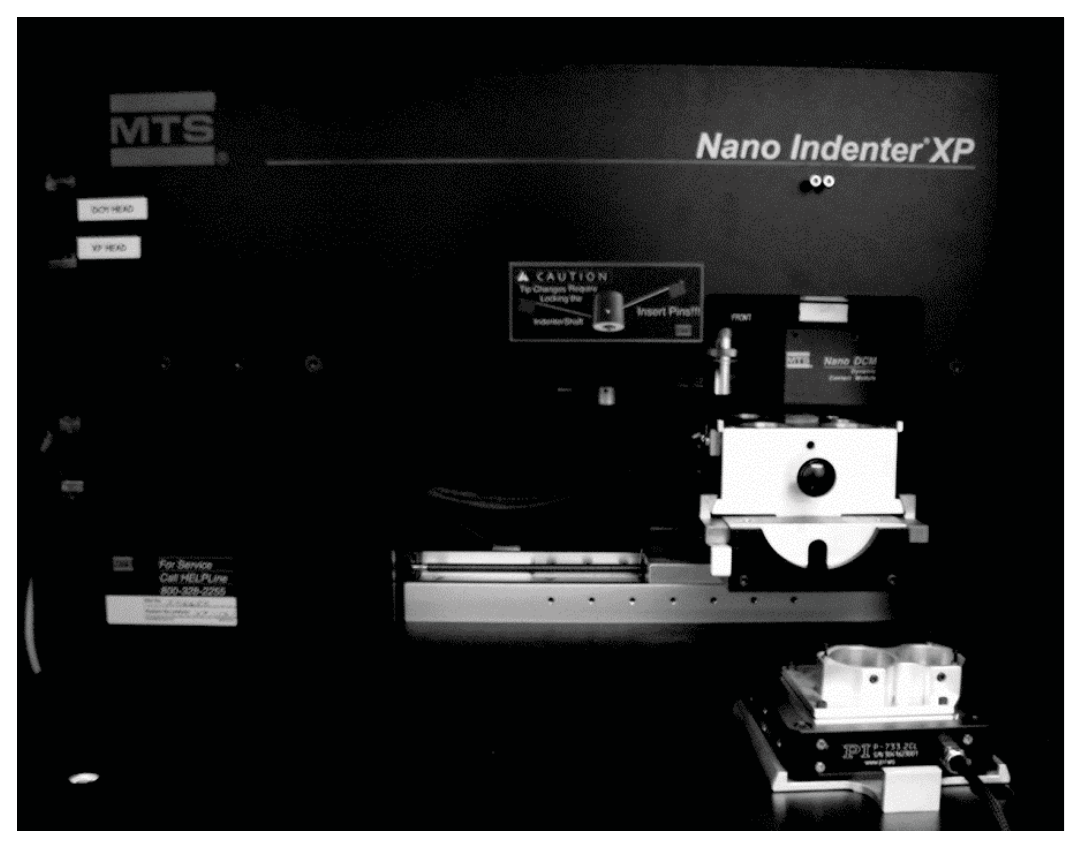

Figure 3-5 Agilent Nano Indenter XP 
For each sample, 36 indents were made in a $6 \times 6$ pattern with $50 \mu \mathrm{m}$ spacing in both directions. A Berkovich indenter was used for the tests. Data collected included load on the sample, penetration of the indenter, hardness of the sample, and modulus. The modulus (E) and hardness $(\mathrm{H})$ of the sample was calculated using the contact stiffness per Oliver-Pharr method [9]. In general, the modulus was obtained from the slope of the load-displacement curve during unloading. The approach results in the calculation of $\mathrm{E}$ and $\mathrm{H}$ at the maximum indentation depth. Data collected was also accomplished by the continuous stiffness method (CSM), in which a small oscillation was superimposed on the primary loading. This method allows determination of $\mathrm{E}$ and $\mathrm{H}$ as a continuous function of the indenter penetration. The frequency of the oscillations was set at $45 \mathrm{~Hz}$ for the CSM method.

Creep tests were also conducted on all composite formulations. The creep loads were set at $2,5,10,15,25,35$, and $45 \mathrm{mN}$. The load was increased to the creep load at a rate of $1 \mathrm{mN} / \mathrm{s}$ and held at the creep load for $150 \mathrm{~s}$. The creep data was analyzed following the method proposed by Tehrani et al. [10]. The relation between strain and the creep load is described in Equation 3-1.

$$
\varepsilon(t)=\sigma_{0} J(t)
$$

where $J(t)$ is the creep compliance and is defined in Equation 3-1.

$$
J(t)=\frac{A(t)}{(1-v) P_{0} \tan (\theta)}
$$

In Equation 3-2, $A(t)$ is the contact area, $v$ is Poisson's ratio $=0.35$ for epoxy [9-10], $\mathrm{P}_{0}$ is the constant applied load $(2,5,10,15,25,35$, and $45 \mathrm{mN})$, and $\theta$ is the effective cone 
angle $\left(70.3^{\circ}\right.$ for Berkovich indenter). The approach takes into account how the contact area under the Berkovich indenter changes as displacement into the surface changes.

\subsubsection{Mounting Samples in Epoxy Puck}

A sample must be cut to the size desired to be mounted in epoxy. To prepare the mold cups, mold cups are sprayed with Mann Ease Release 300 (mold release) then aluminum foil is pressed smoothly into the bottom of the cup. Carefully remove the bottom of the cup with the aluminum foil taking care not to add wrinkles to the aluminum foil. A small piece of carpet (double stick) tape is placed onto the aluminum foil. A Buehler ${ }^{\circledR}$ Sampl-Klip ${ } I$ is wrapped around the cut sample and the face of interest is placed face down on the tape. Carefully replace the top part of the mold cup.

To mix up the epoxy $12 \mathrm{~g}$ of Aka-Cure is added to $100 \mathrm{~g}$ of Aka-Resin. These are weighed into a paper cup and mixed by hand until no streaks are visible. Approximate 15 $\mathrm{g}$ of epoxy is poured into each mold cup and are allowed to cure at room temperature overnight. To remove the epoxy mounts, open the bottom and peel the aluminum foil and tape off. Place the mold cups upside down and use the handle of a screwdriver and press firmly until the epoxy mount releases.

\subsubsection{Grinding}

Using a 320 grit $\mathrm{SiC}$ paper on a Diamond Pacific rotating lap with a water drip (See Figure 3-6) grind the edges of the epoxy mount to a smooth finish so that there are no sharp edges. If a meniscus was formed then grind the sample flat. Using the same grit, 
grind the epoxy mounts down until the sample surface is exposed. Once all the samples surfaces are exposed, place all the epoxy mounts into a ten sample holder shown in Figure 3-7. If there are not ten samples to fill the holder use 'blank' samples to fill the sample holder.

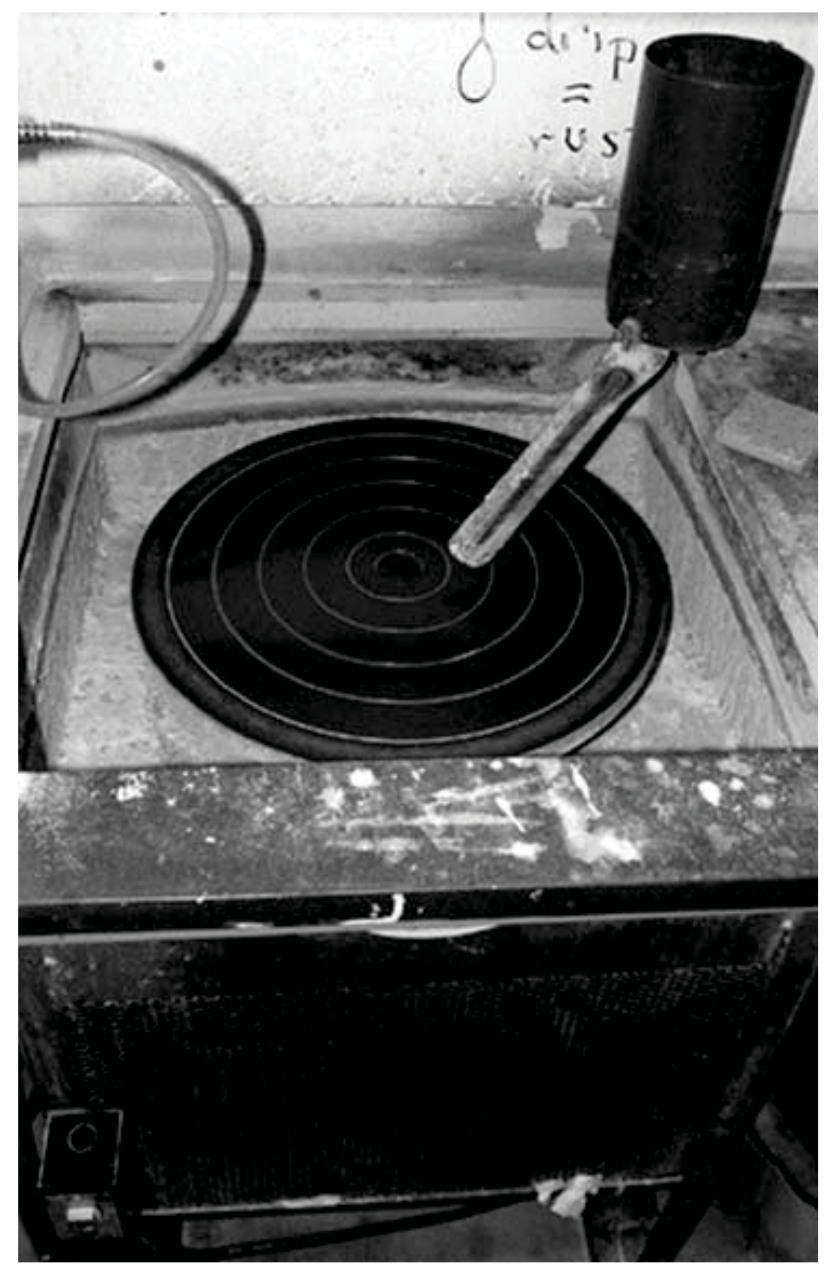

Figure 3-6: Diamond Pacific rotating lap with water drip apparatus 


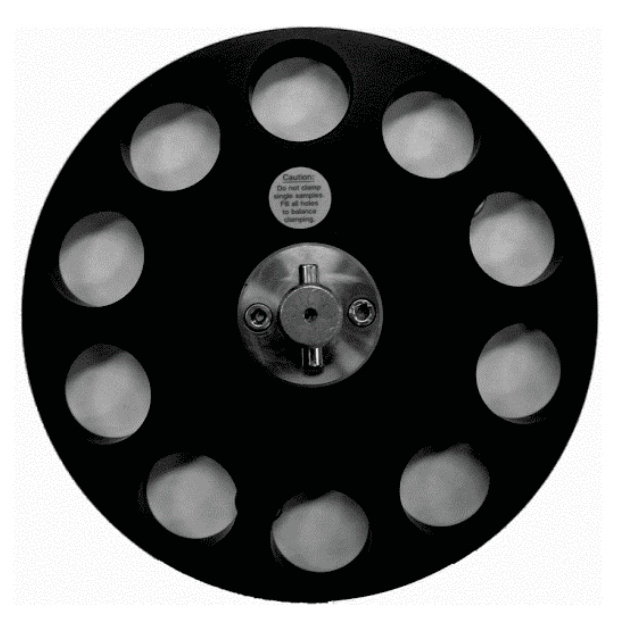

\section{Figure 3-7: 10-Sample Holder}

Once the samples are secured in the holder grind them until all the surfaces are at the same level. Place sample holder in a bath sonicator for about $5 \mathrm{~min}$. Meanwhile, remove the 320 grit paper and replace with a 600 grit $\mathrm{SiC}$ paper. Grind samples with a water drip on the 600 grit paper until no more visible scratches from the 320 grit paper. Place the sample holder in the bath sonicator again for about 5 min. Remove the 600 grit paper and replace with a 1200 grit $\mathrm{SiC}$ paper. Grind samples once more with the water drip until no more visible scratches from the 600 grit paper. Put the sample holder back in the sonicator and run for about 10-15 $\mathrm{min}$.

\subsubsection{Polishing}

After sonication rinse the samples with distilled water. Place the $9 \mu \mathrm{m}$ (red) platen on the Buhler Ecomet 4 variable speed grinder-polisher (Figure 3-8), shake the $9 \mu \mathrm{m}$ (red) diamond suspension until no more diamonds are visible on the bottom of the spray bottle. Spray on platen and then insert the sample holder into the head. Set the rotation 
speed to $150 \mathrm{rpm}$, set the force to $6 \mathrm{lb}$ and use the counter clockwise rotation for the head. Run the 9 micron polish until no more visible scratches from the 1200 grit paper.

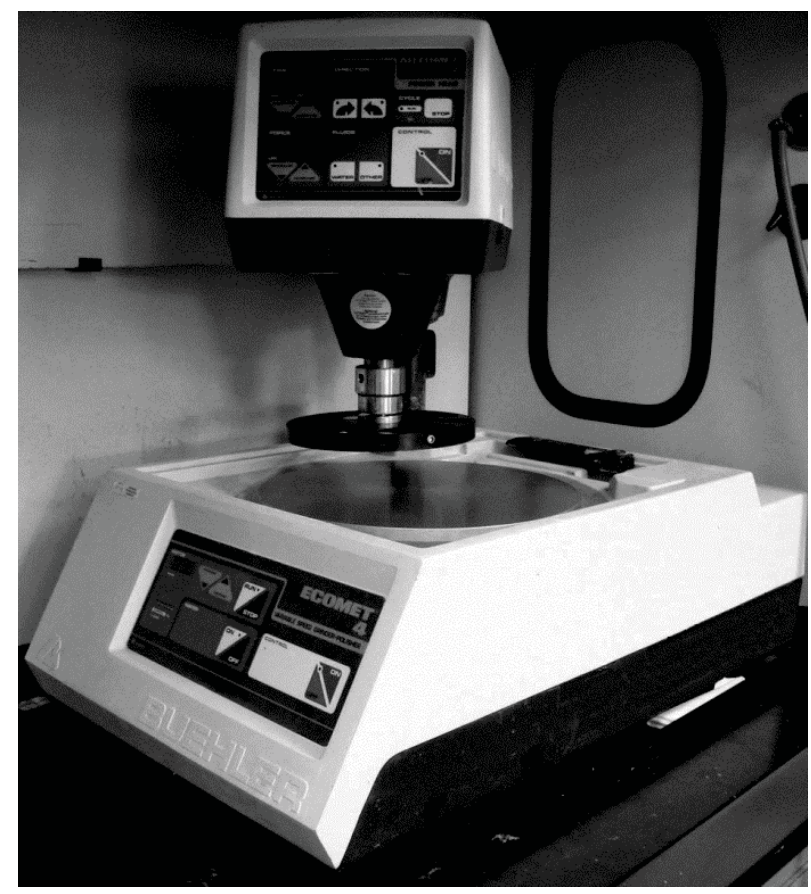

\section{Figure 3-8: Buhler Ecomet 4 variable speed grinder-polisher}

Rinse the sample holder with distilled water and place into bath sonicator (be sure to replace water and clean the grit out before this step). Remove the $9 \mu \mathrm{m}$ (red) platen and replace with the $3 \mu \mathrm{m}$ (green) platen. Shake the $3 \mu \mathrm{m}$ (green) diamond suspension until there are no more visible diamonds on the bottom of the spray bottle. Spray on platen and then insert the sample holder into the head. Set the rotation speed to $120 \mathrm{rpm}$, set the force to $5 \mathrm{lb}$ and use the counter clockwise rotation for the head. Run the 3 micron polish until no more visible scratches from the 9 micron polish. 
Rinse the sample holder with distilled water and place into bath sonicator. Remove the $3 \mu \mathrm{m}$ (green) platen and replace with the $1 \mu \mathrm{m}$ (white) platen. Shake the 1 $\mu \mathrm{m}$ (white) alumina suspension until well mixed. Squirt on platen and then insert the sample holder into the head. Set the rotation speed to $120 \mathrm{rpm}$, set the force to $5 \mathrm{lb}$ and use the counter clockwise rotation for the head. Run the 1 micron polish until no more visible scratches from the 3 micron polish.

Remove the samples from the sample holder and rinse with distilled water and place into bath sonicator taking care to place the wrong side of the samples face to face and the polished sides face to face in a repeating pattern. Remove the $1 \mu \mathrm{m}$ (white) platen. Shake the $0.05 \mu \mathrm{m}$ (white) alumina suspension until well mixed. Place a MasterTex cloth on a Buehler Vibromet 1 vibratory polisher. (Note: May have to clean the Kerosene from the Vibromet first). Pour 0.05 micron slurry onto the cloth, place the samples into the Vibromet single sample holders (can only run 4 at a time). Put the samples face down into the slurry and put the cover over the Vibromet. Turn up the intensity of the table slowly with the knob until about 7-8 on the dial. Let the samples 'dance' around the edge for about 2 hours.

Remove the samples from the sample holders and rinse with distilled water. Clean the bath sonicator once more and replace with fresh water. Put the samples in the sonicator as mentioned before (face to face and end to end) sonicate for $15 \mathrm{~min}$. Remove the samples and rinse with distilled water, then rinse well with ethanol, and allow to dry. Place a red cap on top so that the surface will not get scratched in transport. 


\begin{tabular}{|c|c|c|c|c|c|c|c|}
\hline 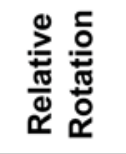 & & & & 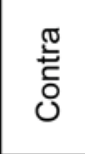 & $\begin{array}{l}\text { 뜐 } \\
\text { O }\end{array}$ & $\begin{array}{l}\text { 뜐 } \\
\text { O }\end{array}$ & \\
\hline 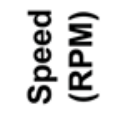 & & & & $\stackrel{\circ}{\circ}$ & ঙ্ & 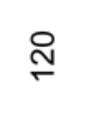 & \\
\hline 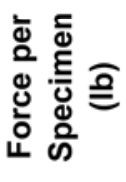 & & & & 6 & م & م & \\
\hline 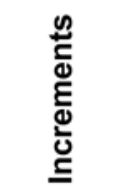 & $\begin{array}{l}\stackrel{ }{E} \\
\stackrel{ }{\circ}\end{array}$ & $\begin{array}{l}\stackrel{ }{\bar{E}} \\
\text { 음 }\end{array}$ & 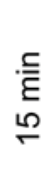 & $\begin{array}{l}. \frac{c}{E} \\
\qquad\end{array}$ & $\underset{6}{\stackrel{C}{E}}$ & $\frac{.}{E}$ & 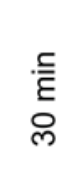 \\
\hline$\stackrel{\stackrel{\oplus}{\xi}}{\underline{E}}$ & 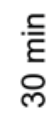 & 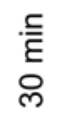 & 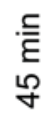 & $\begin{array}{l}. \subseteq \\
\text { E } \\
\text { O) }\end{array}$ & 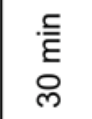 & 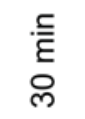 & $\stackrel{z}{v}$ \\
\hline 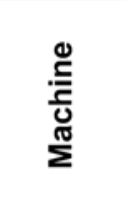 & 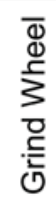 & 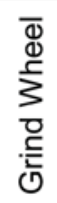 & 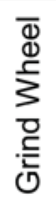 & 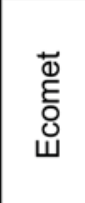 & $\begin{array}{l}\vec{\Phi} \\
\bar{\delta} \\
\text { ய }\end{array}$ & 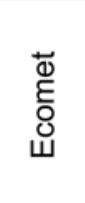 & $\begin{array}{l}\overleftarrow{\Phi} \\
\stackrel{+}{0} \\
\frac{0}{3} \\
\stackrel{5}{>}\end{array}$ \\
\hline $\begin{array}{l}\text { 동 } \\
\frac{0}{0} \\
\frac{0}{0} \\
\frac{0}{0}\end{array}$ & $\begin{array}{l}\text { U } \\
\text { क } \\
\text { ज्ञ } \\
\text { స్ }\end{array}$ & 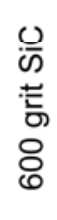 & 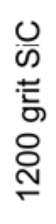 & 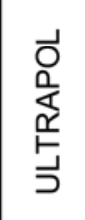 & 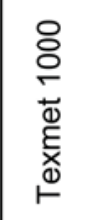 & $\begin{array}{l}\text { 등 } \\
\frac{0}{0} \\
\text { 일 }\end{array}$ & 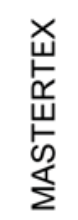 \\
\hline 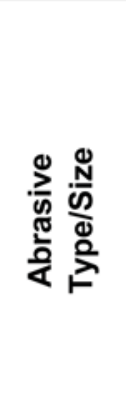 & $\begin{array}{l}\text { 늠 } \\
\text { O } \\
\text { ల్ } \\
1 \\
\text { 心 }\end{array}$ & $\begin{array}{l}\text { 늠 } \\
8 \\
8 \\
0 \\
1 \\
0 \\
\text { 心 }\end{array}$ & 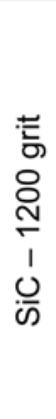 & 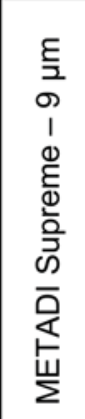 & 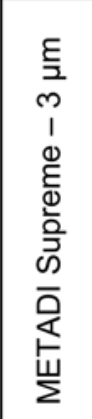 & 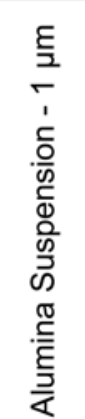 & 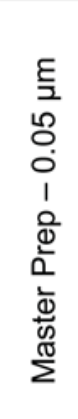 \\
\hline 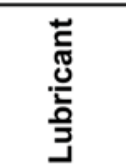 & $\frac{\frac{1}{\Phi}}{3}$ & $\frac{\bar{\Phi}}{\frac{1}{\pi}}$ & $\frac{\bar{\Phi}}{\frac{1}{\pi}}$ & 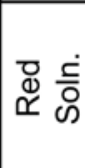 & 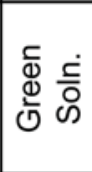 & 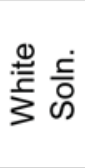 & 売 \\
\hline
\end{tabular}




\subsubsection{Through-Plane Electrical Resistivity Test Method}

For samples with an electrical resistivity $>10^{10} \Omega$-cm, ASTM D257 was used to measure the volumetric electrical resistivity at $23^{\circ} \mathrm{C}$ [12]. In this method a constant voltage, typically $100 \mathrm{~V}$, was applied to the test specimen. Resistivity was measured using a Keithley 6517A Electrometer/High Resistance Meter with an 8009 Resistivity Test Fixture (see Figure 3-9). The test specimen tested were disks that were cut to $6.4 \mathrm{~cm}$ in diameter and $3 \mathrm{~mm}$ thick. At least 4 samples were tested for each formulation. Two days prior to testing, the samples were conditioned at $23{ }^{\circ} \mathrm{C}$ and $50 \%$ relative humidity.

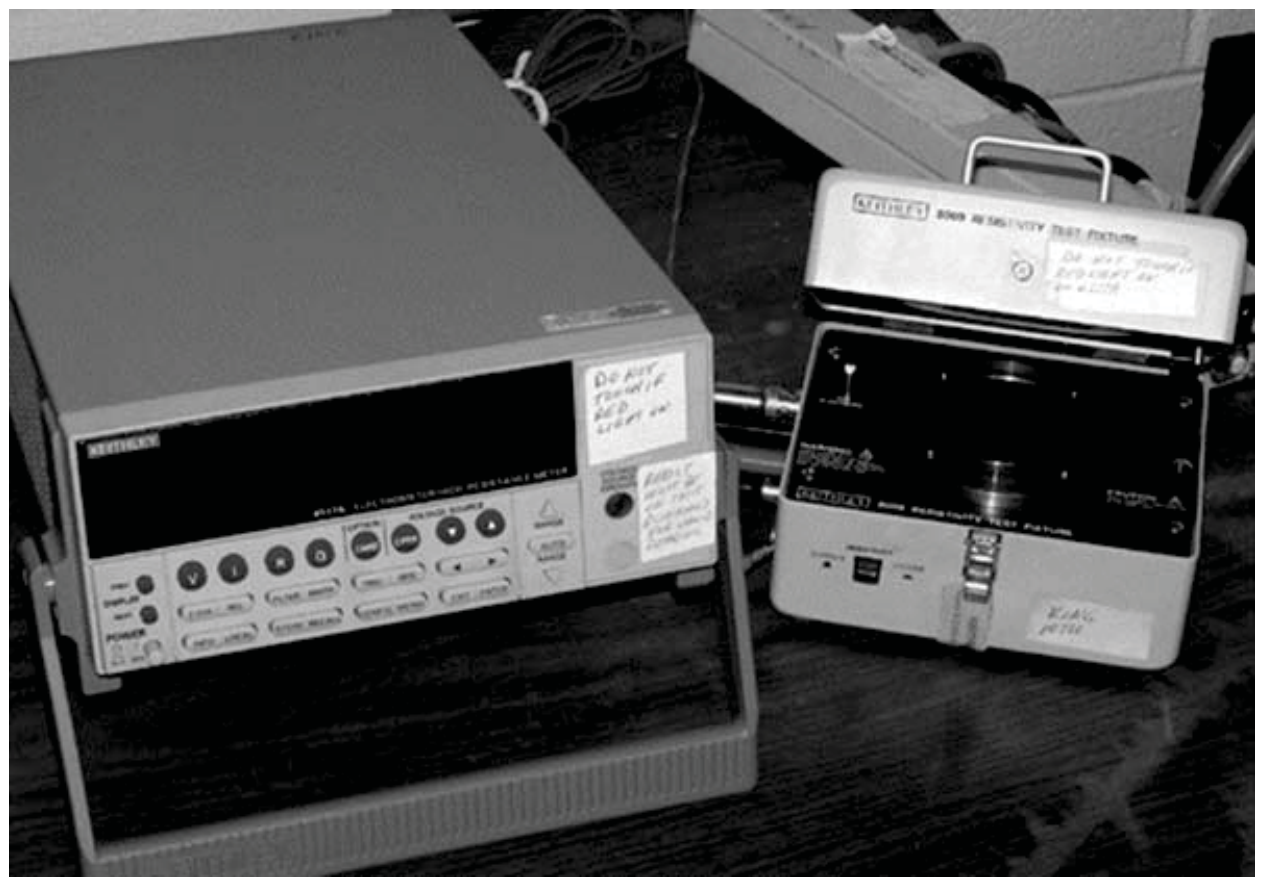

Figure 3-9: (left) Keithley 6517A Electrometer/High Resistance Meter, (right) Keithley 8009 Resistivity Test Fixture 


\subsubsection{In-Plane Electrical Resistivity Test Method}

For samples with an electrical resistivity $<10^{10} \Omega$-cm, ASTM D4496 was used to measure the in-plane volumetric electrical resistivity of a rectangular bar at $23^{\circ} \mathrm{C}[13]$. Two probes were used to conduct the tests. The test specimen tested were bars $(12.5 \mathrm{~mm}$ wide and $3 \mathrm{~mm}$ thick) that were cryogenically broken to $60 \mathrm{~mm}$ long, this creates a fracture surface at both ends. The fracture surfaces were painted with silver paint. At least 4 samples were tester for each formulation. Two days prior to testing, the samples were conditioned at $23{ }^{\circ} \mathrm{C}$ and $50 \%$ relative humidity. One probe was placed on each silver-painted fracture surface, and a constant voltage was applied. The voltage source was a Keithley 2400 Source Meter. The resulting current was measured and the volume electrical resistivity was calculated using Equation 3-3.

$$
\mathrm{ER}=\frac{(\Delta \mathrm{V})(\mathrm{w})(\mathrm{t})}{(\mathrm{i})(\mathrm{L})}
$$

Where ER is the volume electrical resistivity $(\Omega-\mathrm{cm}), \Delta \mathrm{V}$ is the voltage (volts), $\mathrm{w}$ is the sample width $(\mathrm{cm}), \mathrm{t}$ is the sample thickness $(\mathrm{cm}), \mathrm{i}$ is the current (amps), and $\mathrm{L}$ is the length which $\Delta \mathrm{V}$ is measured across $(\mathrm{cm})$.

\subsubsection{Differential Scanning Calorimeter (DSC) Test Method}

A Metter Toledo 823E differential scanning calorimeter (see Figure 3-10) was used to measure the glass transition temperature ( $\mathrm{Tg}$ ) of every composite. Approximately $10 \mathrm{mg}$ of 'crushed' epoxy sample was placed in a sealed aluminum pan with a 'vent hole' in the lid. Nitrogen purge gas was used. The following heating cycle was used and Tg 
was determined on the second heating cycle. Tg was determined by a change in heat flow (i.e. heat capacity).

The following heating method was used:

1) Heat $40^{\circ} \mathrm{C}$ to $180^{\circ} \mathrm{C}$ at $10^{\circ} \mathrm{C} / \mathrm{min}$

2) $\mathrm{Cool} 180^{\circ} \mathrm{C}$ to $40^{\circ} \mathrm{C}$ at $10^{\circ} \mathrm{C} / \mathrm{min}$

3) Hold $40^{\circ} \mathrm{C}$ and hold for $5 \mathrm{~min}$

4) Heat $40^{\circ} \mathrm{C}$ to $180^{\circ} \mathrm{C}$ at $10^{\circ} \mathrm{C} / \mathrm{min}$

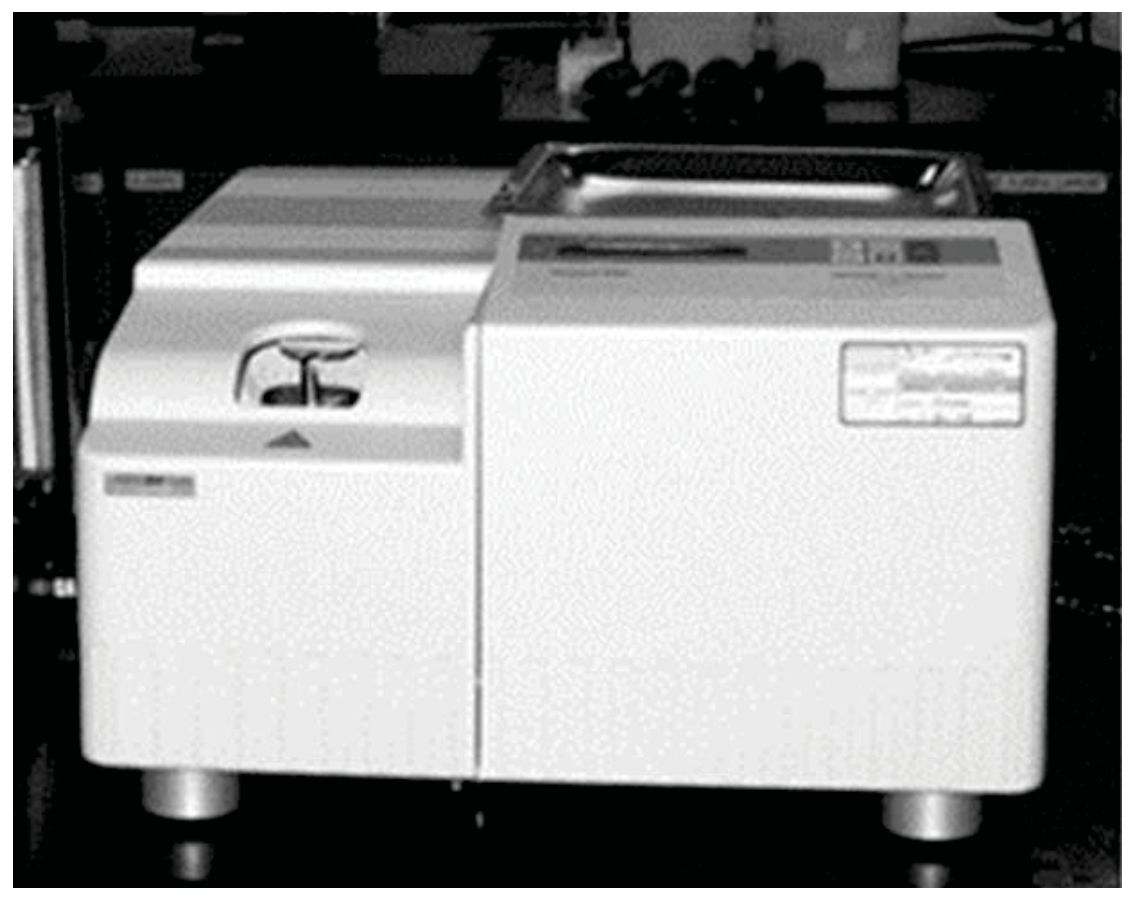

Figure 3-10: Metter Toledo 823E Differential Scanning Calorimeter 


\subsubsection{Dynamic Mechanical Analyzer (DMA) Test Method}

The DMA applies a sinusoidal deformation to a sample of known geometry and measures the stiffness and dampening which it reports as modulus and tan delta. The storage modulus is a representation of the stored energy and shows the elastic portion of the epoxy resin. The loss modulus measures the energy dissipated as heat which represents the viscous portion of the epoxy resin. The ratio comparison of the two moduli is known as the tan delta, which can be used to determine the glass transition temperature. The glass transition temperature is the transition of a polymer from the "glassy" state to the "rubbery" state. This is represented as a range of temperatures determined from the storage modulus onset, peak of the loss modulus curve, and the peak of the tan delta curve. The following equations (Equations 3-4, 3-5, and 3-6) are used to calculate the storage modulus, loss modulus, and tan delta for the epoxy resin.

$$
\begin{array}{ll}
\text { Storage Modulus: } & \mathrm{E}^{\prime}=\frac{\sigma_{\mathrm{o}}}{\varepsilon_{\mathrm{o}}} \cos (\delta) \\
\text { Loss Modulus: } & \mathrm{E}^{\prime \prime}=\frac{\sigma_{\mathrm{o}}}{\varepsilon_{\mathrm{o}}} \sin (\delta) \\
\text { Tan Delta: } & \tan (\delta)=\frac{\mathrm{E}^{\prime \prime}}{\mathrm{E}^{\prime}}
\end{array}
$$

$\sigma=$ stress $\quad \varepsilon=$ strain $\quad \delta=$ phase lag between stress and strain

The sample tests were completed on the TA Instruments Q800 DMA (see Figure 3-11 left) using the dual/single cantilever clamp (Figure 3-11 right), for testing the single cantilever was used. The sample thickness and width was measured with calipers and entered into the program along with a set length of $17.5 \mathrm{~mm}$ (distance between clamps). The actual sample dimensions were $3 \mathrm{~mm}$ thick, $12 \mathrm{~mm}$ wide, and $35 \mathrm{~mm}$ long, cut from 
bars with $3 \mathrm{~mm}$ thickness, $25 \mathrm{~mm}$ width, and $150 \mathrm{~mm}$ long. Using tweezers so as not to touch the sample, it was carefully loaded into the clamps and tightened down using 9 inlbs of torque. The tweezers were used to prevent oil from getting on the sample due to contact with hands and fingers.

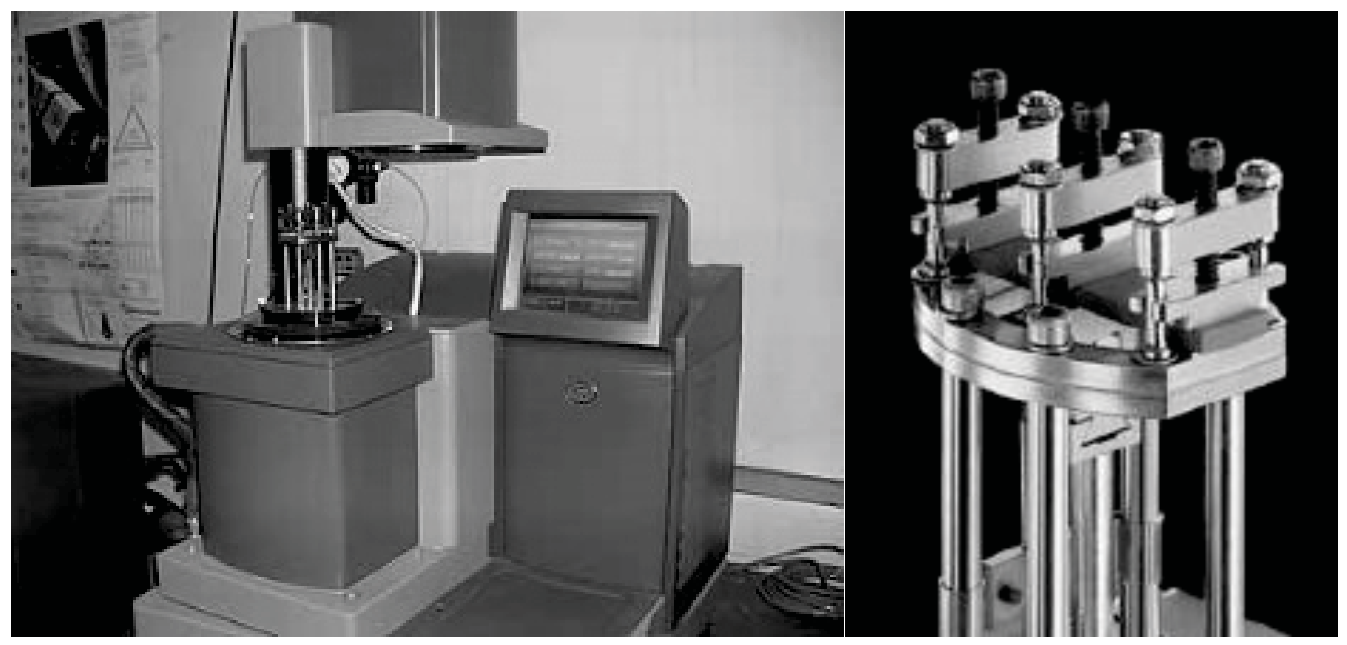

Figure 3-11: left) TA Instruments Q800 DMA right) Dual/single cantilever clamp

Once the sample was in place in the clamps, an amplitude test was performed to determine if the machine and program were operating correctly. The test mode was chosen to be "DMA Multi Strain" with the test set to "Strain Sweep". The frequency was kept at $1 \mathrm{~Hz}$ with the isothermal temperature at $35^{\circ} \mathrm{C}$ and a soak time of 5 minutes, the amplitude was swept from $5 \mu \mathrm{m}$ to $50 \mu \mathrm{m}$. Following the test, the graph of amplitude versus loss modulus was analyzed to determine the amplitude needed for the temperature sweep test. The amplitude that is chosen should be in the linear portion of the amplitude loss modulus plot. This linearity is shown in Figure 3-12, along with the $30 \mu \mathrm{m}$ amplitude chosen, this amplitude was used for all formulations. 


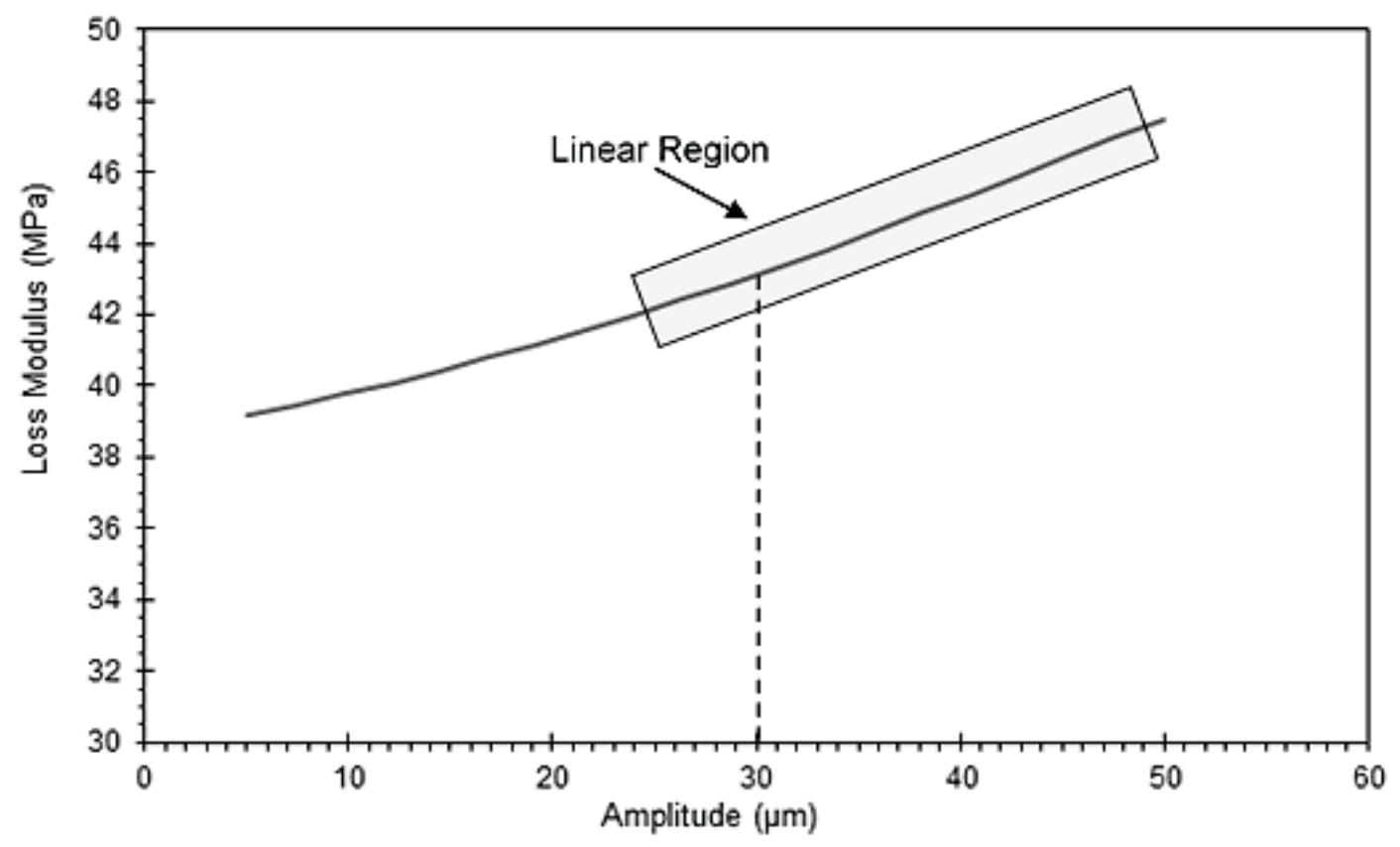

Figure 3-12: Amplitude test for neat CTC Resin 310-008/Hardener 320-009, showing that the plot is linear for an amplitude of $30 \mu \mathrm{m}$

The sample parameters entered into the software for the test to determine the modulus and tan delta were similar to that of the amplitude test. The thickness and width were entered along with a fixed length of $17.5 \mathrm{~mm}$. The program mode was set to "DMA multi frequency strain" and the test was "temp ramp/frequency sweep". The procedure parameters were an amplitude of $30 \mu \mathrm{m}$, an initial temperature of $50{ }^{\circ} \mathrm{C}$ with a soak time of 5 minutes, a temperature ramp rate of $3{ }^{\circ} \mathrm{C} / \mathrm{min}$, and a final temperature of $290{ }^{\circ} \mathrm{C}$ with a hold time of 5 minutes. The frequency was held at $1 \mathrm{~Hz}$ for the entire duration of the test. Once the test was completed, the data was analyzed to determine the storage modulus, loss modulus, and tan delta graphs, which were then used to find the glass transition temperature $\left(\mathrm{T}_{\mathrm{g}}\right)$. 
The $T_{g}$ found using the storage modulus is the onset temperature. This is found from the intersection of the line tangent to the temperatures below the glass transition and the tangent of the inflection point of the storage modulus. The $\mathrm{T}_{\mathrm{g}}$ for loss modulus and tan delta is the temperature where the maximum of the loss modulus and the tan delta occurs.

\subsubsection{Field Emission Scanning Electron Microscopy (FE-SEM) Test Method}

A Hitachi S-4700 Filed Emission Scanning Electron Microscope (FE-SEM), shown in Figure 3-13, was used to image the composites. Imaging was done at $2 \mathrm{kV}$ accelerating voltage with a working distance of $1.9 \mathrm{~mm}$. The upper secondary electron

detector was used to collect the images. FE-SEM is useful for high resolution imaging. The higher resolution allows the sample surface topography to be imaged. 


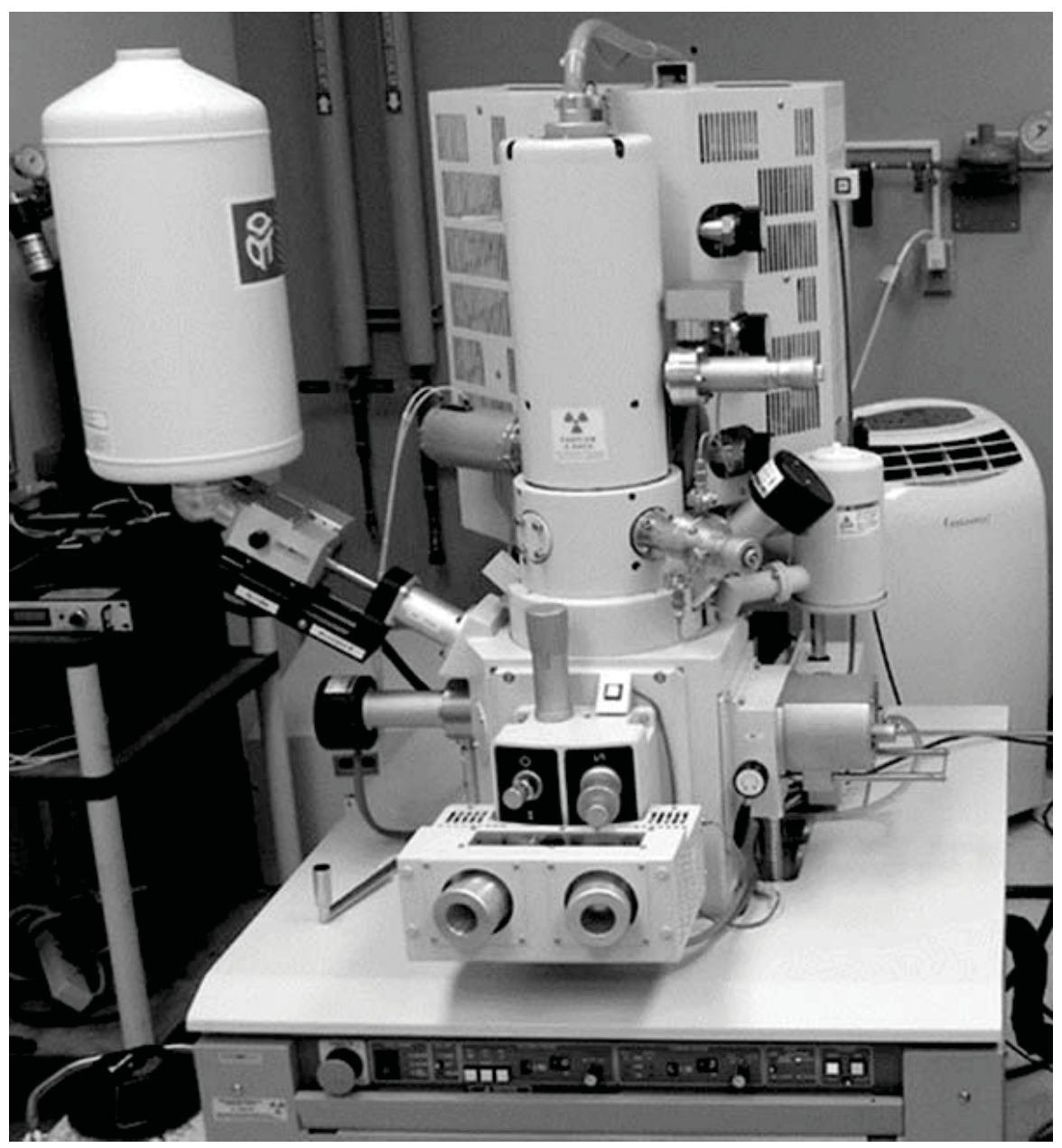

Figure 3-13: Hitachi S-4700 Field Emission Scanning Electron Microscope (FE-SEM)

Samples were cut from tested tensile specimen. The samples were cut to $2 \mathrm{~mm} \mathrm{x}$ $2 \mathrm{~mm}$ x $10 \mathrm{~mm}$ using a scroll saw. The fracture surfaces were sputtered with platinum using an Anatech Hummer 6.2 Sputtering System, the platinum thickness was $2 \mathrm{~nm}$ to 5 nm depending on the GNP size. The samples were placed fracture surface up in a sample holder, as shown in Figure 3-14. Carbon tape was used to ground the samples with the sample holder. 


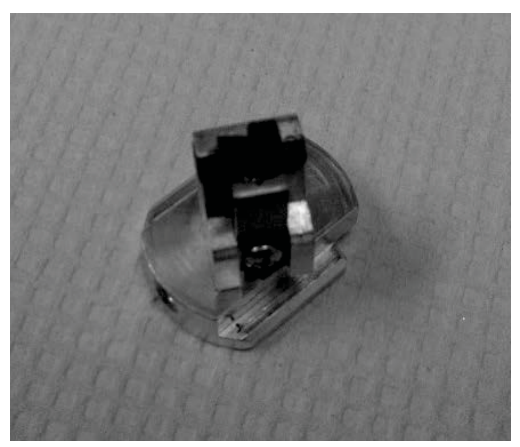

Figure 3-14: Sample mount for FESEM

\subsubsection{Environmental Scanning Electron Microscopy (ESEM) Test Method}

A FEI/Phillips XL40 Environmental Scanning Electron Microscope (see Figure

3-15) was used to view the surface of the GNP/epoxy composite. A $10 \mathrm{~mm} \times 3 \mathrm{~mm} \times 10$ mm sample was cut from a molded rectangular bar. The sample was prepared for observation by mounting the composite in a cast epoxy puck and then was polished. The sample was sputtered with platinum using an Anatech Hummer 6.2 Sputtering System. ESEM is useful for imaging under a low vacuum environment (close to atmospheric). The image obtained using ESEM is similar to an optical microscope, but at a higher magnification than optical imaging. 


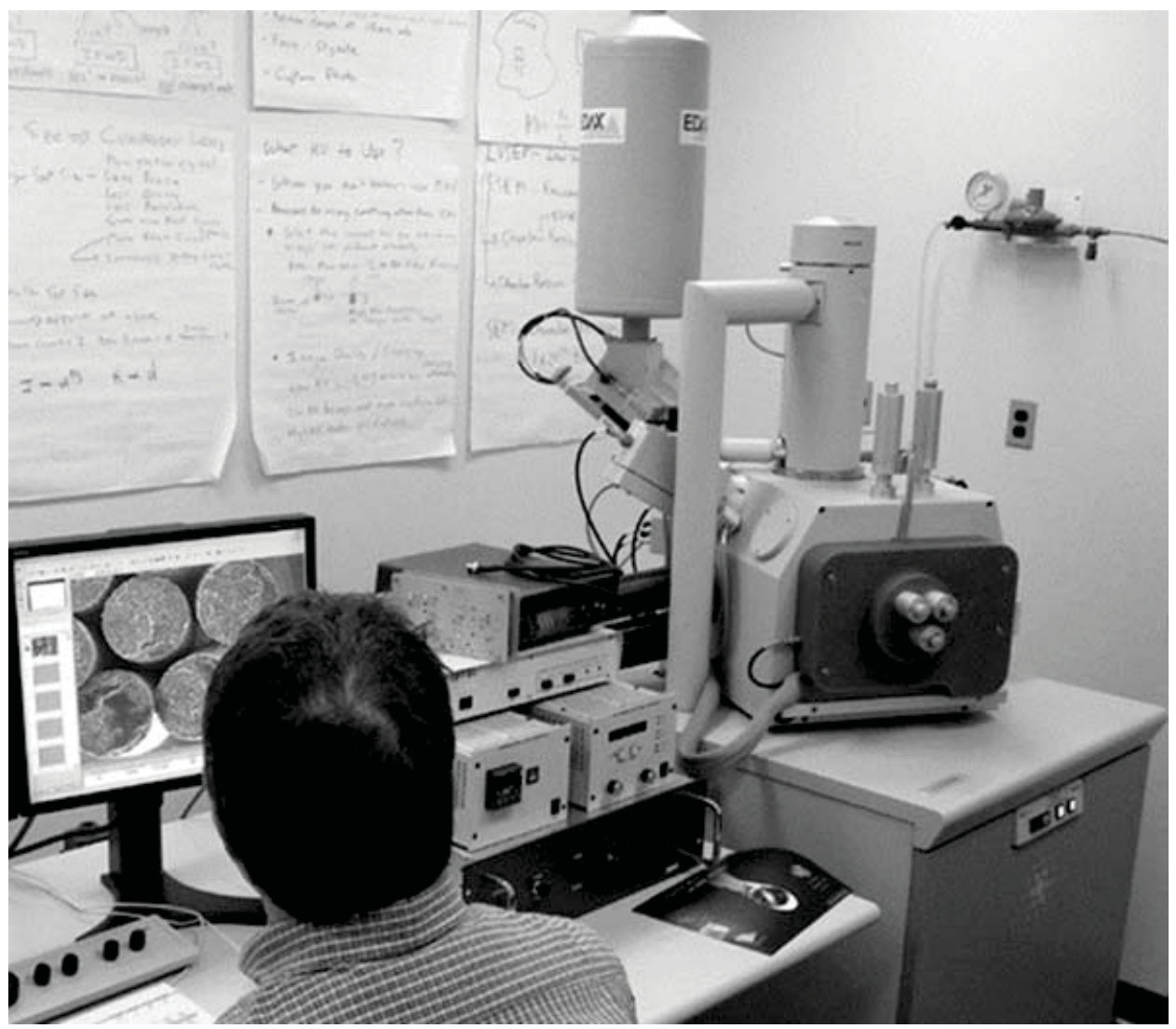

Figure 3-15: FEI/Phillips XL40 Environmental Scanning Electron Microscope

\subsubsection{Optical Microscope Test Method}

An Olympus PMG3 Metallograh optical microscope equipped with a Leica EC3 digital camera and Leica Application Suite EZ image capture software was used to view the surface of the GNP/epoxy composite. A $10 \mathrm{~mm}$ x $3 \mathrm{~mm} \times 10 \mathrm{~mm}$ sample was cut from a molded rectangular bar. The sample was prepared for observation by mounting the composite in a cast epoxy puck and then was polished. 


\subsection{References}

[1] Momentive Specialty Chemicals, Inc. EPON 862 /EPIKURE Cureing Agent W System Product Literature, 180 E. Broad Street, Columbus, OH, 43215 (2011).

[2] Zhou, Y.; Pervin, F.; Lewis, L.; Jeelani, S. Mater. Sci. Eng. A 2008, 475, 157.

[3] Chen, C.; Curliss, D. Nanotechnology 2003, 14, 643.

[4] J. A. King, D. R. Klimek, I. Miskioglu, G. Odegard; "Mechanical Properties of Graphene Nanoplatelet/Epoxy Composites" Journal of Applied Polymer Science, Vol 128, No. 6, pp.4217-4223, June 2013.

[5] J.A. King, D. R. Klimek, I. Miskioglu, G. Odegard; "Mechanical Properties of Graphene Nanoplatelet/Epoxy Composites" Journal of Composite Materials, Vol 49, No. 6, pp. 659-668, February 2015.

[6] C. M. Hadden, D. R. Klimek-McDonald, E. J. Paneda, J. A. King, A. M. Reichandadter, I. Miskioglu, S. Gowtham, G. Odegard; "Mechanical Properties of Graphene Nanoplatelet/Carbon Fiber/Epoxy Hybrid Composites: Multiscale Modeling and Experiments" Carbon, submitted February 2015.

[7] Standard Test Method for Tensile Properties of Plastics, ASTM Standard D638, American Society for Testing and Materials, Philadelphia, PA (2008).

[8] Standard Test Method for Tensile Properties of Plastics, ASTM Standard D3039, American Society for Testing and Materials, Philadelphia, PA (2008).

[9] Oliver, W. C.; Pharr, G. M. Mater. Res. Soc. 1992, 7, 1564.

[10] Tehrani, M.; Safdari, M.; Al-Halik, M. S. Int. J. Plast. 2011, 27, 887.

[11] Tack, J. L. Thermodynamic and Mechanical Properties of EPON 862 with Curing Agent DETDA by Molecular Simulation, M. S. Thesis, Texas A\&M University, College Station, TX (2006).

[12] Standard Test Methods for DC Resistance or Conductance of Insulating Materials, ASTM Standard D257-91, American Society for Testing and Materials, Philadelphia, PA (1998).

[13] Standard Test Methods for DC Resistance or Conductance of Moderately Conductive Materials, ASTM Standard D4496-04, American Society for Testing and Materials, Philadelphia, PA (2008). 


\section{Results}

\subsection{Tensile Results}

The tensile modulus measured for the neat epoxy was $2.72 \mathrm{GPa}$. The ultimate tensile stress was measured to be $77.6 \mathrm{MPa}$, and the strain at ultimate tensile stress was measured to be $8.0 \%$. These values are shown in Table $4-1$.

\subsection{1 xGnP ${ }^{\circledR}-M-15$ in Epoxy Tensile Results ${ }^{1}$}

Figure 4-1 and Figure 4-2 show the mean [along with error bars \pm 1 SD (standard deviation)] tensile modulus, ultimate tensile strength, and strain at ultimate tensile strength for the $\mathrm{xGnP}^{\circledR}$-M-15/epoxy composites measured according to ASTM D638. Error bars are not shown for formulations where one standard deviation is less than the marker size. Table 4-1 also shows these results (mean, standard deviation, and number of samples tested). Adding GNP caused the tensile modulus to increase as well as the tensile strength and strain to decrease. The modulus increases from $2.72 \mathrm{GPa}$ for neat epoxy to 3.36 GPa for the sample containing 6 wt \% (3.7 vol \%) GNP in epoxy. The ultimate tensile strength decreases from 77.6 (neat epoxy) to $35.5 \mathrm{MPa}$ for the formulation containing $6 \mathrm{wt} \%(3.7 \mathrm{vol} \%)$ GNP in epoxy. The strain at ultimate tensile strength decreases from 8.0 (neat epoxy) to $1.5 \%$ for the formulation containing $6 \mathrm{wt} \%$ (3.7 vol

\footnotetext{
${ }^{1}$ The material contained within this section has been published in the journal "Journal of Applied Polymer Science." Citation:

J. A. King, D. R. Klimek, I. Miskioglu, G. Odegard; "Mechanical Properties of Graphene Nanoplatelet/Epoxy Composites” Journal of Applied Polymer Science, Vol 128, No. 6, pp.4217-4223, June 2013.
} 
\%) GNP in epoxy. These results compare well with those of Fukushima for graphene (15 $\mu \mathrm{m}$ average particle diameter) in Shell EPON 828 with curing agent Jeffamine T403 from Hunstman Petrochemical [1]. In Fukushima's work, he reported an increase in tensile modulus from $\sim 2.75$ (neat epoxy) to $\sim 3.1 \mathrm{GPa}$ for 3 vol $\%$ GNP/97 vol $\%$ epoxy [compared to our result of $3.3 \mathrm{GPa}$ for $5 \mathrm{wt} \% \mathrm{GNP}(\sim 3 \mathrm{vol} \% \mathrm{GNP})$ ] [1]. For tensile strength, Fukushima reported $\sim 35 \mathrm{MPa}$ for 3 vol \% NP/97 vol \% epoxy [compared to our result of $37 \mathrm{MPa}$ for $5 \mathrm{wt} \% \mathrm{GNP}(\sim 3 \mathrm{vol} \% \mathrm{GNP})$ ] [1]. This suggests that the load transfer between the GNP and the epoxy is satisfactory. The stiffness increases, but the strength and elongation decreases.

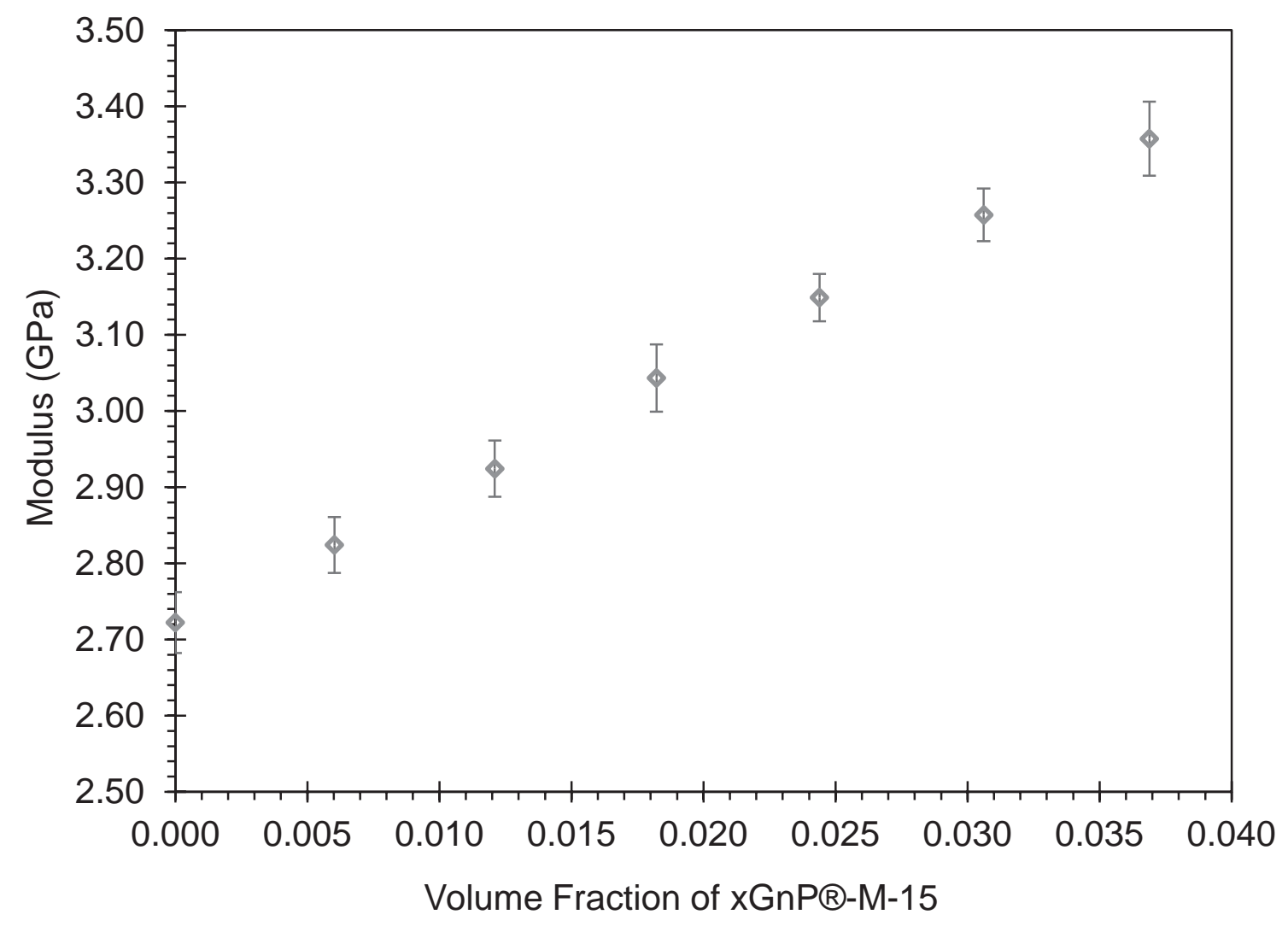

Figure 4-1: Modulus for $x G n P^{\circledR}-M-15 /$ epoxy composites 


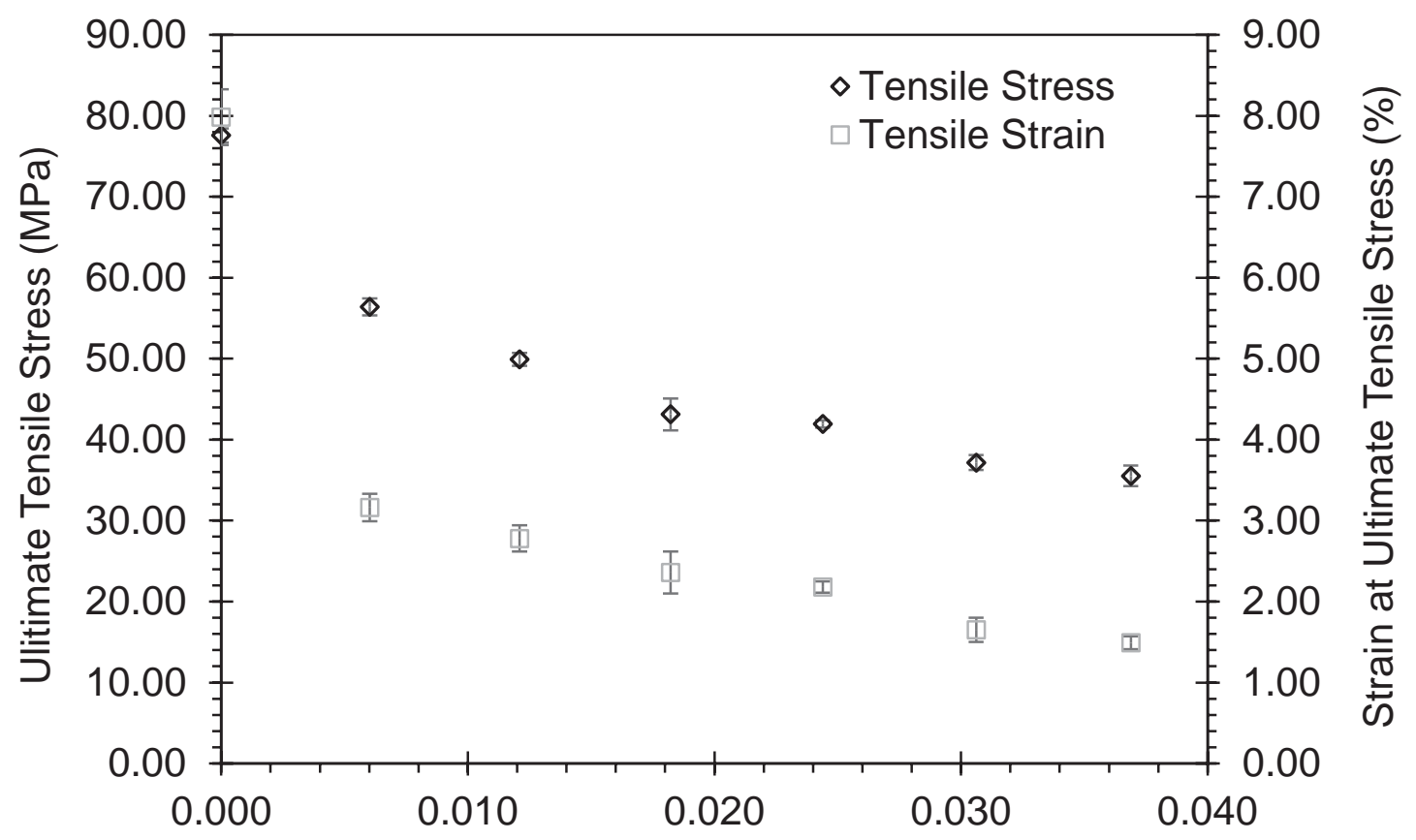

Volume Fraction of $x \mathrm{GnP} \circledast \mathrm{P}-\mathrm{M}-15$

Figure 4-2: Ultimate tensile strength and strain at ultimate tensile strength for $x G n P^{\circledR}$ M-15/epoxy composites

Table 4-1: $x G n P^{\circledR}-M-15$ loading levels in epoxy and tensile results obtained from ASTM D638 test method

\begin{tabular}{|c|c|c|c|c|c|}
\hline Formulation & $\begin{array}{c}\text { GNP } \\
\text { wt\% }\end{array}$ & $\begin{array}{c}\text { GNP } \\
\text { vol \% }\end{array}$ & $\begin{array}{c}\text { Tensile } \\
\text { Modulus } \\
(\mathbf{G P a})\end{array}$ & $\begin{array}{c}\text { Ultimate } \\
\text { tensile strength } \\
(\mathbf{M P a})\end{array}$ & $\begin{array}{c}\text { Strain at ultimate } \\
\text { tensile strength } \\
(\mathbf{\%})\end{array}$ \\
\hline Epoxy & 0 & 0.00 & $2.72 \pm 0.04 \mathrm{n}=6$ & $77.6 \pm 0.9 \mathrm{n}=6$ & $7.89 \pm 0.35 \mathrm{n}=6$ \\
\hline $1 \mathrm{M} 15$ & 1 & 0.60 & $2.82 \pm 0.04 \mathrm{n}=7$ & $56.4 \pm 1.0 \mathrm{n}=7$ & $3.16 \pm 2.78 \mathrm{n}=7$ \\
\hline $2 \mathrm{M} 15$ & 2 & 1.21 & $2.92 \pm 0.04 \mathrm{n}=7$ & $49.9 \pm 0.8 \mathrm{n}=7$ & $2.78 \pm 0.16 \mathrm{n}=7$ \\
\hline 3M15 & 3 & 1.82 & $3.04 \pm 0.03 \mathrm{n}=6$ & $43.1 \pm 2.0 \mathrm{n}=6$ & $2.36 \pm 0.26 \mathrm{n}=6$ \\
\hline 4M15 & 4 & 2.44 & $3.15 \pm 0.04 \mathrm{n}=6$ & $41.9 \pm 0.5 \mathrm{n}=6$ & $2.18 \pm 0.07 \mathrm{n}=6$ \\
\hline 5M15 & 5 & 3.06 & $3.26 \pm 0.03 \mathrm{n}=6$ & $37.2 \pm 0.9 \mathrm{n}=6$ & $1.65 \pm 0.15 \mathrm{n}=6$ \\
\hline $6 \mathrm{M} 15$ & 6 & 3.69 & $3.36 \pm 0.05 \mathrm{n}=6$ & $35.5 \pm 1.3 \mathrm{n}=6$ & $1.49 \pm 0.08 \mathrm{n}=6$ \\
\hline
\end{tabular}




\subsection{2 $x G n P^{\circledR}-M-5$ in Epoxy and $x G n P^{\circledR}-C-300$ in Epoxy Tensile Results ${ }^{2}$}

Figure 4-3, Figure 4-4, and Figure 4-5 show the mean (along with error bars $= \pm$ one standard deviation) tensile modulus, ultimate tensile strength, and strain at ultimate tensile strength for the $\mathrm{xGnP}^{\circledR}-\mathrm{M}-5 /$ epoxy and $\mathrm{xGnP}^{\circledR}-\mathrm{C}-300 /$ epoxy composites measured according to ASTM D638. Error bars are not shown for formulations where one standard deviation is less than the marker size. Table 4-2 also shows these results (mean, standard deviation, and number of samples tested). First, the $\mathrm{xGnP}^{\circledR}-\mathrm{M}-5 /$ epoxy composites will be discussed. As expected adding $\mathrm{xGnP}^{\circledR}$-M-5 causes the tensile modulus to increase, as well as the tensile strength and ductility to decrease. The modulus increases from 2.72 GPa for neat epoxy to $3.35 \mathrm{GPa}$ for the sample containing $6 \mathrm{wt} \%(3.7 \mathrm{vol} \%) \times \mathrm{GnP}^{\circledR}-\mathrm{M}-5$ in epoxy. The ultimate tensile strength decreases from $77.6 \mathrm{MPa}$ (neat epoxy) to $36.4 \mathrm{MPa}$ for the formulation containing $6 \mathrm{wt} \%(3.7 \mathrm{vol} \%) \mathrm{xGnP}^{\circledR}-\mathrm{M}-5$ in epoxy. The strain at ultimate tensile strength decreases from $8.0 \%$ (neat epoxy) to $1.4 \%$ for the formulation containing $6 \mathrm{wt} \%$ (3.7 vol\%) GNP in epoxy. These results are almost identical to those obtained previously by our research group for $\mathrm{xGnP}^{\circledR}-\mathrm{M}-15 /$ epoxy composites [2]. $\mathrm{xGnP}^{\circledR}-\mathrm{M}-15$ is also produced by $\mathrm{XG}$ Sciences and has a $15 \mathrm{~mm}$ average particle diameter, a thickness of $7 \mathrm{~nm}$, a surface area of $\sim 130 \mathrm{~m}^{2} / \mathrm{g}$, and a density of $\sim 2.0 \mathrm{~g} / \mathrm{mL}$ [3].

\footnotetext{
${ }^{2}$ The material contained within this section has been published in the journal "Journal of Composite Materials."

Citation:

J. A. King, D. R. Klimek, I. Miskioglu, G. Odegard; "Mechanical Properties of Graphene Nanoplatelet/Epoxy Composites” Journal of Composite Materials, Vol 49, No. 6, pp.659-668, March 2015.
} 


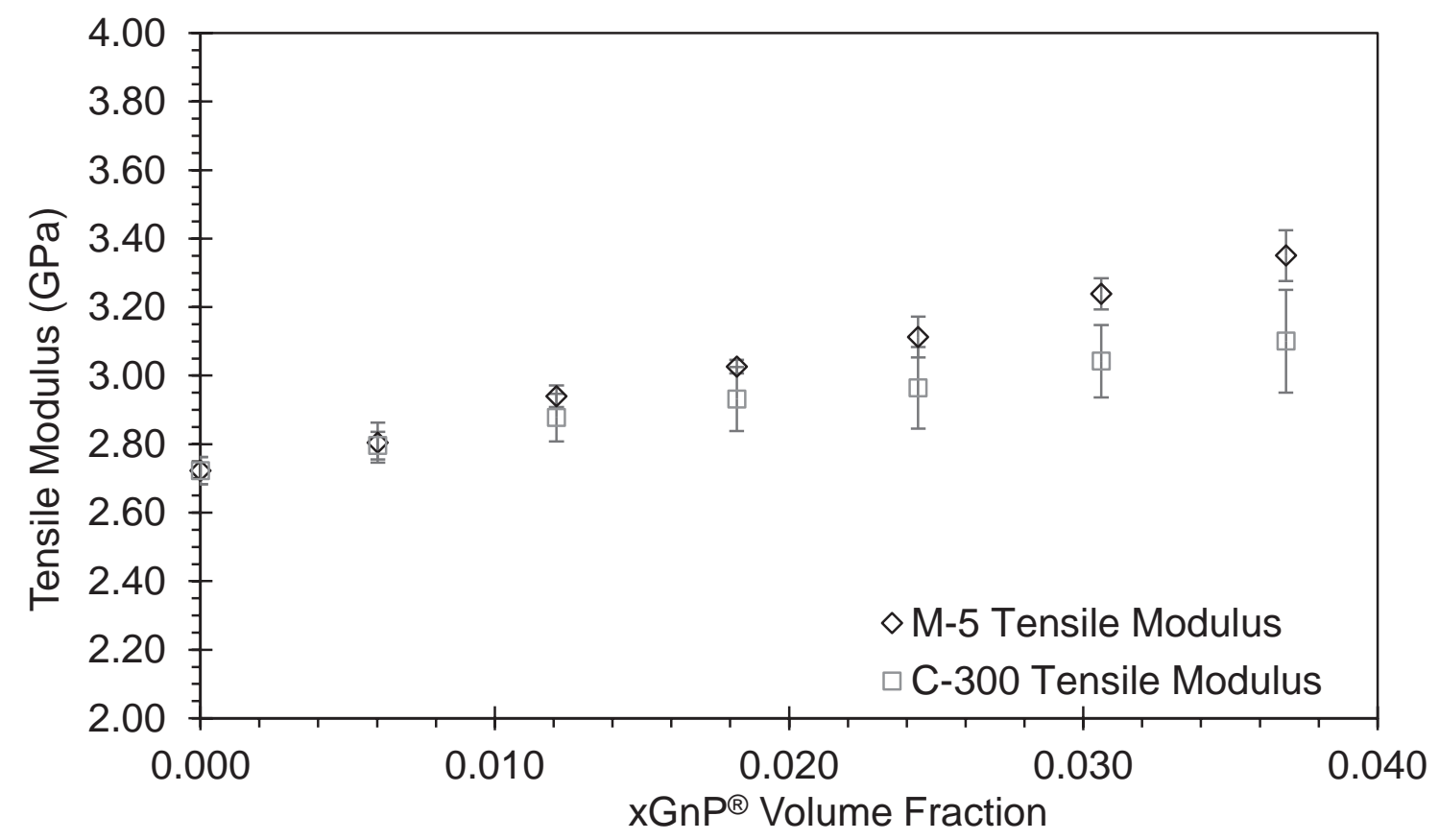

Figure 4-3: Tensile modulus for $x G n P^{\circledR}-M-5 /$ epoxy and $x G n P^{\circledR}-C-300 /$ epoxy composites

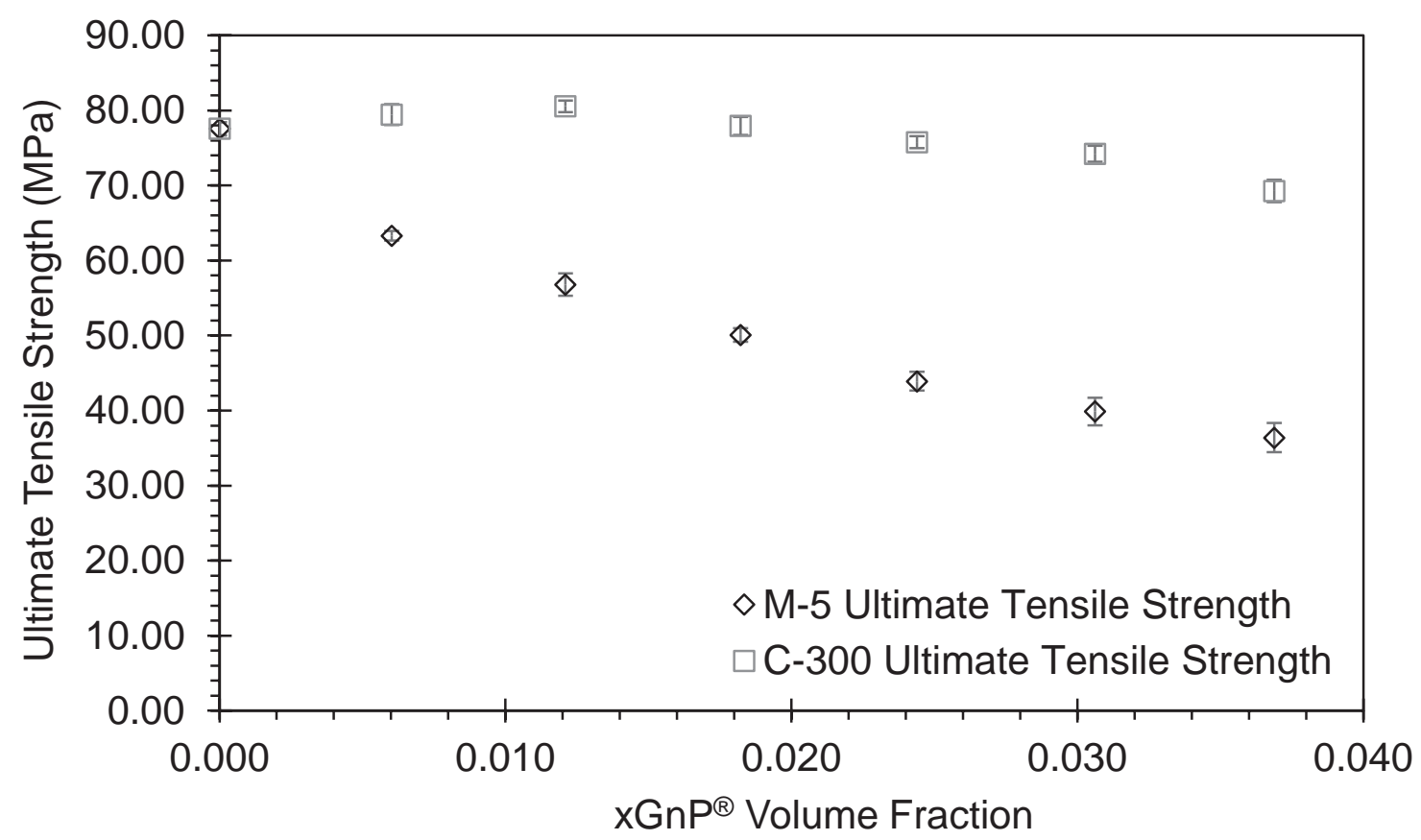

Figure 4-4: Ultimate tensile strength for $x G n P^{\circledR}-M-5 /$ epoxy and $x G n P^{\circledR}-C-300 /$ epoxy composites 


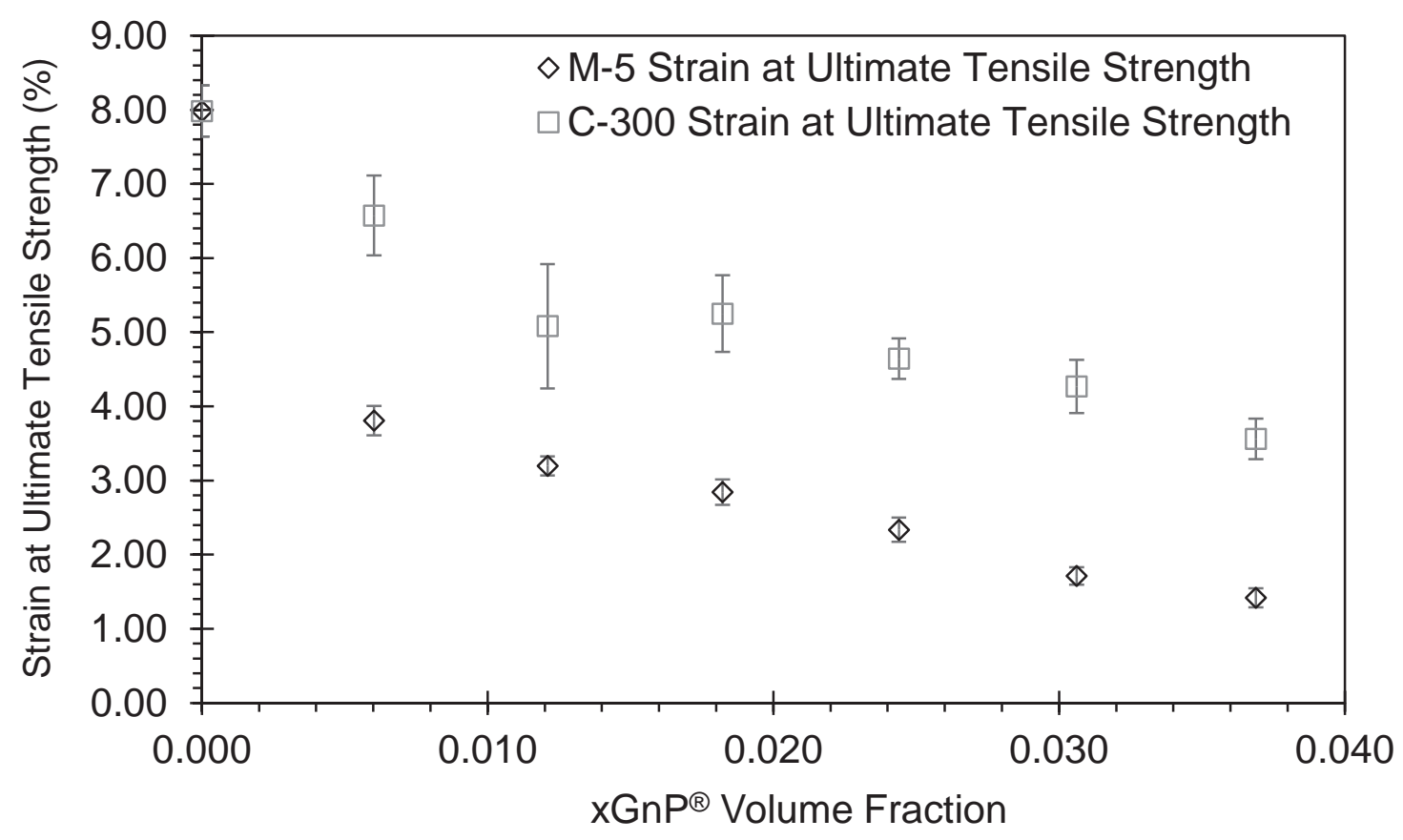

Figure 4-5: Strain at ultimate tensile strength for $x G n P^{\circledR}{ }_{-} M-5 /$ epoxy and $x G n P^{\circledR}-C$ 300/epoxy composites

At this point, it is important to address the observed trend of decreasing tensile strength with increasing levels of $\mathrm{xGnP}^{\circledR}-\mathrm{M}-5$. Of course, it is desired to design composite materials where the strength increases with increasing filler content. However, the trends described above suggest that the GNP reinforcement serves to decrease the overall strength of the composite relative to the neat resin. This observation can be physically explained using the results from Molecular Dynamics simulation conducted by Hadden et al of this same material system (graphene- reinforced EPON 862 with Curing Agent W) [4]. Hadden et al demonstrated that the molecular structure of the epoxy monomer and hardener molecules at the interface is distinctly different than that in the bulk resin in this particular material system [4]. In fact, this interfacial zone is about 1 $\mathrm{nm}$ wide and has a density that varies continuously with respect to the bulk density. As a result, it is anticipated that this structural disturbance may adversely affect the strength 
properties of the composite system, thus potentially explaining the strength observations described herein. The results suggest that the load transfer between the M-grade GNPs and the epoxy is satisfactory. If the load transfer is poor then the GNP acts like a void and weakens the composite.

Table 4-2: $x G n P^{\circledR}-M-5$ and $x G n P^{\circledR}-C-300$ loading levels in epoxy, tensile results obtained from ASTM D638 test method

\begin{tabular}{|c|c|c|c|c|c|}
\hline Formulation & $\begin{array}{l}\text { GNP } \\
\text { Wt \% }\end{array}$ & $\begin{array}{c}\text { GNP } \\
\text { Vol \% }\end{array}$ & $\begin{array}{l}\text { Tensile Modulus } \\
\text { (GPa) }\end{array}$ & $\begin{array}{c}\text { Ultimate } \\
\text { Tensile } \\
\text { Strength } \\
\text { (MPa) }\end{array}$ & $\begin{array}{c}\text { Strain at Ultimate } \\
\text { Tensile Strength } \\
(\%)\end{array}$ \\
\hline Epoxy & 0 & 0.0 & $2.72 \pm 0.04 \mathrm{n}=6$ & $77.6 \pm 0.9 \mathrm{n}=6$ & $7.98 \pm 0.35 \mathrm{n}=6$ \\
\hline \multicolumn{6}{|l|}{ xGnP ${ }^{\circledR}-M-5$} \\
\hline $1 \mathrm{M} 5$ & 1 & 0.60 & $2.80 \pm 0.06 \mathrm{n}=6$ & $63.3 \pm 1.4 \mathrm{n}=6$ & $3.81 \pm 0.20 \mathrm{n}=6$ \\
\hline $2 \mathrm{M} 5$ & 2 & 1.21 & $2.94 \pm 0.03 \mathrm{n}=9$ & $56.8 \pm 0.8 \mathrm{n}=9$ & $3.20 \pm 0.13 \mathrm{n}=9$ \\
\hline $3 \mathrm{M} 5$ & 3 & 1.82 & $3.03 \pm 0.02 n=7$ & $50.1 \pm 1.2 \mathrm{n}=7$ & $2.84 \pm 0.17 n=7$ \\
\hline 4M5 & 4 & 2.44 & $3.11 \pm 0.06 \mathrm{n}=6$ & $43.9 \pm 0.8 \mathrm{n}=6$ & $2.34 \pm 0.16 \mathrm{n}=6$ \\
\hline $5 \mathrm{M} 5$ & 5 & 3.06 & $3.24 \pm 0.05 \mathrm{n}=7$ & $39.9 \pm 1.1 \mathrm{n}=7$ & $1.71 \pm 0.12 \mathrm{n}=7$ \\
\hline $6 \mathrm{M} 5$ & 6 & 3.69 & $3.35 \pm 0.07 \mathrm{n}=8$ & $36.4 \pm 1.4 \mathrm{n}=8$ & $1.42 \pm 0.13 \mathrm{n}=8$ \\
\hline \multicolumn{6}{|l|}{$x G n P^{\circledR}-C-300$} \\
\hline $1 \mathrm{C} 300$ & 1 & 0.60 & $2.80 \pm 0.04 \mathrm{n}=7$ & $79.5 \pm 0.7 \mathrm{n}=7$ & $6.57 \pm 0.54 n=7$ \\
\hline $2 \mathrm{C} 300$ & 2 & 1.21 & $2.88 \pm 0.07 \mathrm{n}=8$ & $80.6 \pm 1.5 \mathrm{n}=8$ & $5.08 \pm 0.84 \mathrm{n}=8$ \\
\hline $3 \mathrm{C} 300$ & 3 & 1.82 & $2.93 \pm 0.09 \mathrm{n}=8$ & $77.9 \pm 0.9 \mathrm{n}=8$ & $5.25 \pm 0.52 \mathrm{n}=8$ \\
\hline $4 \mathrm{C} 300$ & 4 & 2.44 & $2.96 \pm 0.12 \mathrm{n}=7$ & $75.8 \pm 1.3 \mathrm{n}=7$ & $4.64 \pm 0.27 \mathrm{n}=7$ \\
\hline $5 \mathrm{C} 300$ & 5 & 3.06 & $3.04 \pm 0.11 \mathrm{n}=8$ & $74.2 \pm 1.8 \mathrm{n}=8$ & $4.27 \pm 0.36 n=8$ \\
\hline $6 \mathrm{C} 300$ & 6 & 3.69 & $3.10 \pm 0.15 \mathrm{n}=8$ & $69.3 \pm 2.0 \mathrm{n}=8$ & $3.56 \pm 0.27 \mathrm{n}=8$ \\
\hline
\end{tabular}

For the $\mathrm{xGnP}^{\circledR}-\mathrm{C}-300 /$ epoxy composites, the tensile modulus is slightly lower than the $\mathrm{xGnP}^{\circledR}-\mathrm{M}-5 /$ epoxy and $\mathrm{xGnP}^{\circledR}-\mathrm{M}-15 /$ epoxy composites. The ultimate tensile strength (UTS) for the $\mathrm{xGnP}^{\circledR}$-C-300/epoxy composites stays fairly constant between 74 and $81 \mathrm{MPa}$ for those containing $\leq 5 \mathrm{wt} \%(3.1 \mathrm{vol} \%) \mathrm{xGnP}^{\circledR}-\mathrm{C}-300$. This observation is in contrast to the decreasing ultimate tensile strength as $\mathrm{xGnP}^{\circledR}-\mathrm{M}-5$ and $\mathrm{xGnP}^{\circledR}-\mathrm{M}-15$ is added to epoxy. The strain at UTS also follows this same trend. Apparently, the smaller size of the $\mathrm{xGnP}^{\circledR}-\mathrm{C}-300$ in epoxy produces a composite with higher strength and 
ductility compared to the $\mathrm{xGnP}^{\circledR}-\mathrm{M}-5 /$ epoxy composites. Since the $\mathrm{xGnP}{ }^{\circledR}-\mathrm{C}-300$ maintains its strength and strain, this suggests that the GNP and epoxy has a better load transfer than the M-grade GNPs.

\subsubsection{Asbury Carbon's TC307 in Epoxy Tensile Results}

Figure 4-6 and Figure 4-7 show the average tensile modulus, ultimate tensile strength, and strain at ultimate tensile strength for the TC307/epoxy composites measured according to ASTM D638. Error bars shown are \pm 1 standard deviation (SD). The average tensile modulus, ultimate tensile strength, and stain at ultimate tensile strength with standard deviation and number of samples tested for each is summarized in Table 4-3. Adding the TC 307 to the epoxy increases the tensile modulus and decreases the tensile strength and strain. The neat epoxy has a tensile modulus of $2.72 \mathrm{GPa}$ with a strength of $77.6 \mathrm{MPa}$ and a strain of $7.98 \%$. The $4 \mathrm{wt} \%$ (2.44 vol\%) TC307 in epoxy has a tensile modulus of $2.92 \mathrm{GPa}$ with a strength of $75.8 \mathrm{MPa}$ and a strain of $5.25 \%$. It has been observed that GNP increases tensile modulus, Chatterjee et al. reported an increase from $\sim 2.65 \mathrm{GPa}$ for neat epoxy to $\sim 3.08 \mathrm{GPa}$ for $2 \mathrm{wt} \% \mathrm{GNP}$ in epoxy [5].

Table 4-3: Asbury TC307 loading levels in epoxy, tensile results obtained from ASTM D638 test method

\begin{tabular}{|c|c|c|c|c|c|}
\hline Formulation & $\begin{array}{c}\text { GNP } \\
\text { wt\% }\end{array}$ & $\begin{array}{c}\text { GNP } \\
\text { vol \% }\end{array}$ & $\begin{array}{c}\text { Tensile Modulus } \\
(\mathbf{G P a})\end{array}$ & $\begin{array}{c}\text { Ultimate tensile } \\
\text { strength } \\
\text { (MPa) }\end{array}$ & $\begin{array}{c}\text { Strain at ultimate } \\
\text { tensile strength } \\
(\boldsymbol{\%})\end{array}$ \\
\hline Epoxy & 0 & 0.00 & $2.72 \pm 0.04 \mathrm{n}=6$ & $77.6 \pm 0.9 \mathrm{n}=6$ & $7.98 \pm 0.35 \mathrm{n}=6$ \\
\hline $1 \mathrm{TC} 307$ & 1 & 0.60 & $2.84 \pm 0.08 \mathrm{n}=6$ & $81.2 \pm 1.6 \mathrm{n}=6$ & $5.94 \pm 0.82 \mathrm{n}=6$ \\
\hline $2 \mathrm{TC} 307$ & 2 & 1.21 & $2.88 \pm 0.07 \mathrm{n}=7$ & $80.9 \pm 1.9 \mathrm{n}=7$ & $5.91 \pm 0.51 \mathrm{n}=7$ \\
\hline $3 \mathrm{TC} 307$ & 3 & 1.82 & $2.91 \pm 0.05 \mathrm{n}=8$ & $78.1 \pm 0.8 \mathrm{n}=8$ & $4.74 \pm 0.24 \mathrm{n}=8$ \\
\hline 4TC307 & 4 & 2.44 & $2.93 \pm 0.09 \mathrm{n}=7$ & $75.8 \pm 1.8 \mathrm{n}=7$ & $4.55 \pm 0.31 \mathrm{n}=7$ \\
\hline
\end{tabular}




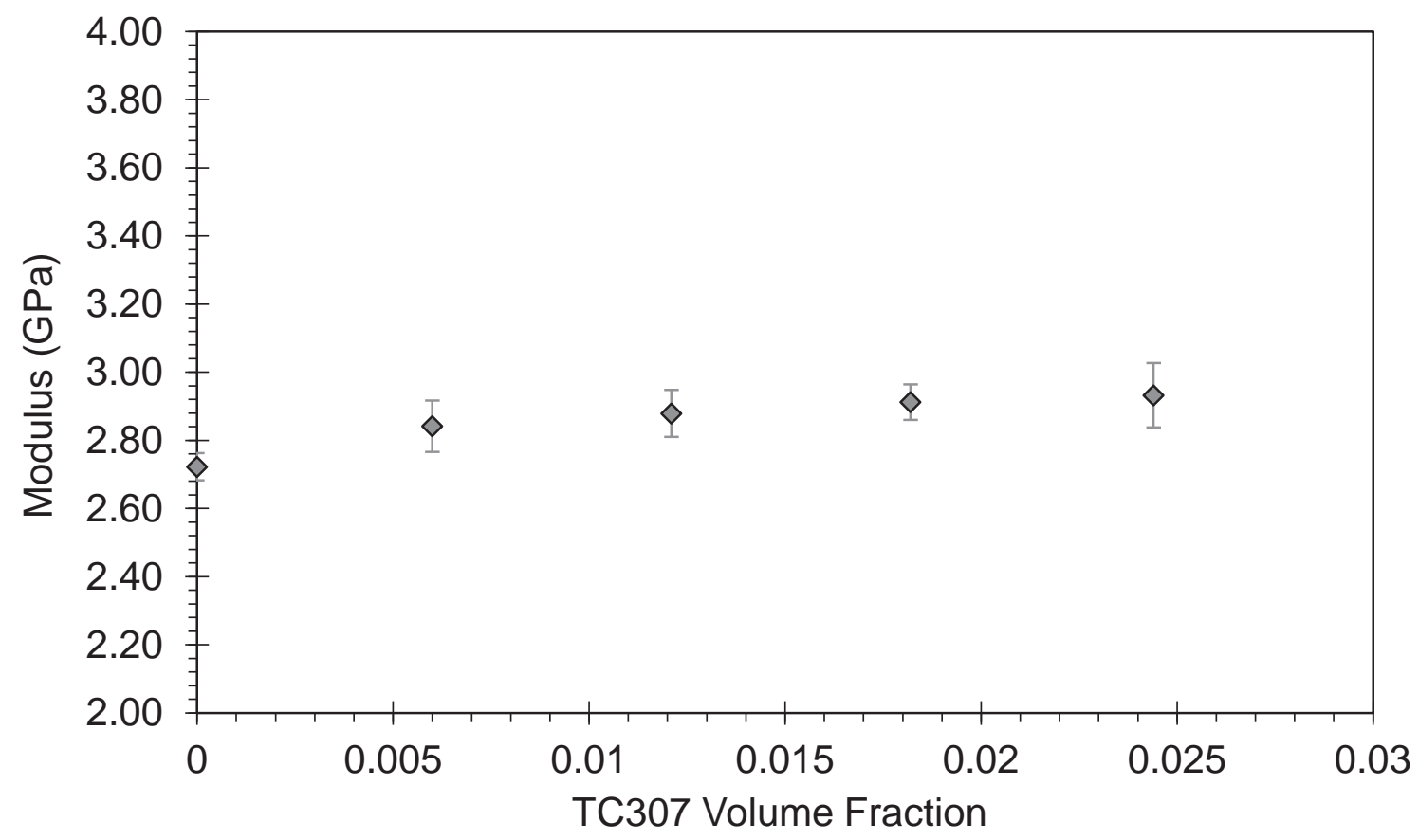

Figure 4-6: Modulus for TC307/epoxy composites

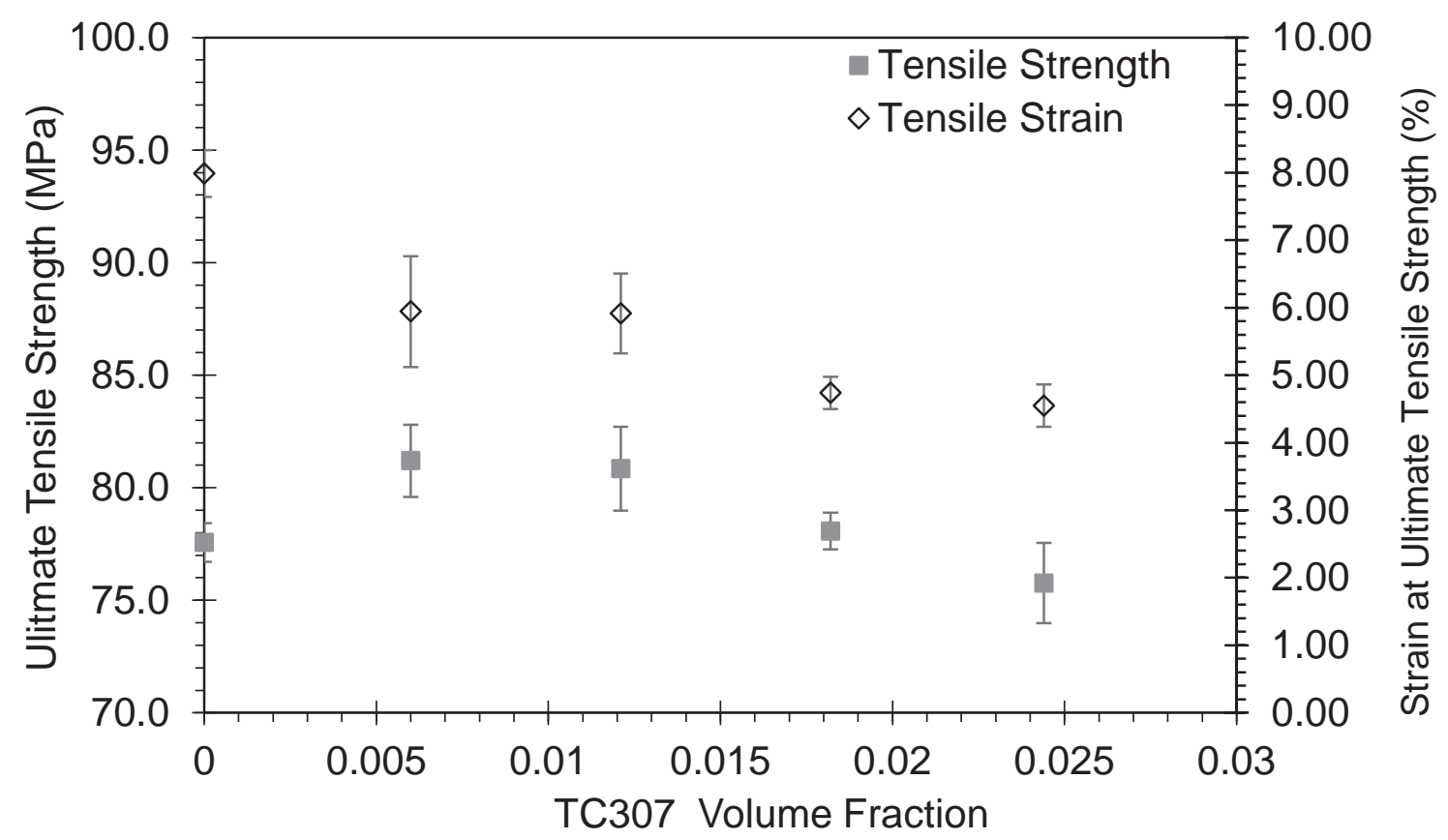

Figure 4-7: Ultimate tensile strength and strain at ultimate tensile strength TC307/epoxy composites 


\subsection{4 $x G n P^{\circledR}-C-300$ with Carbon Fiber in Epoxy Tensile Results}

Table 4-4 shows the tensile results (mean, standard deviation, and number of samples tested) for the carbon fiber/epoxy and $\mathrm{xGnP}^{\circledR}$-C-300/carbon fiber/epoxy composites. From the data it is clear that adding 1 to $3 \mathrm{wt} \% \mathrm{xGnP}^{\circledR}-\mathrm{C}-300$ to carbon fiber/epoxy composites did not cause an the axial modulus to change significantly, but caused an increase in the transverse modulus. The carbon fiber dominates in the axial direction, this is expected due to the high axial modulus of the carbon fiber. The epoxy matrix serves to transfer the load between the fibers, this occurs primarily through interfacial shear.

Table 4-4: Tensile Modulus results for $x G n P^{\circledR}-C-300 /$ carbon fiber/epoxy composites

\begin{tabular}{|c|c|c|c|c|}
\hline Material system & $\begin{array}{c}\text { Filler } \\
\text { Wt \% }\end{array}$ & $\begin{array}{c}\text { Filler } \\
\text { Vol \% }\end{array}$ & $\begin{array}{c}\text { Axial Modulus } \\
(\mathbf{G P a})\end{array}$ & $\begin{array}{c}\text { Transverse Modulus } \\
\text { (GPa) }\end{array}$ \\
\hline carbon fiber/epoxy & $\begin{array}{c}\mathrm{GNP}-0 \\
\mathrm{CF}-67\end{array}$ & $\begin{array}{c}\mathrm{GNP}-0 \\
\mathrm{CF}-58\end{array}$ & $134.29 \pm 9.27 \mathrm{n}=6$ & $7.81 \pm 0.81 \mathrm{n}=5$ \\
\hline $\begin{array}{c}\mathrm{xGnP}^{\circledR}-\mathrm{C}-300 / \text { carbon } \\
\text { fiber/epoxy }\end{array}$ & $\begin{array}{c}\mathrm{GNP}-1 \\
\mathrm{CF}-67\end{array}$ & $\begin{array}{c}\mathrm{GNP}-0.8 \\
\mathrm{CF}-58\end{array}$ & $137.5 \pm 9.33 \mathrm{n}=15$ & $7.89 \pm 0.13 \mathrm{n}=3$ \\
\hline $\begin{array}{c}\mathrm{xGnP}^{\circledR}-\mathrm{C}-300 / \text { carbon } \\
\text { fiber/epoxy }\end{array}$ & $\begin{array}{c}\mathrm{GNP}-2 \\
\mathrm{CF}-67\end{array}$ & $\begin{array}{c}\mathrm{GNP}-1.6 \\
\mathrm{CF}-58\end{array}$ & $137.0 \pm 6.53 \mathrm{n}=15$ & $8.29 \pm 0.14 \mathrm{n}=3$ \\
\hline $\begin{array}{c}\mathrm{xGnP}^{\circledR}-\mathrm{C}-300 / \text { carbon } \\
\text { fiber/epoxy }\end{array}$ & $\begin{array}{c}\mathrm{GNP}-3 \\
\mathrm{CF}-67\end{array}$ & $\begin{array}{c}\mathrm{GNP}-2.3 \\
\mathrm{CF}-58\end{array}$ & $137.1 \pm 9.75 \mathrm{n}=11$ & --- \\
\hline
\end{tabular}




\subsection{Nanoindentation Results}

\subsection{1 $x G n P^{\circledR}-M-15$ in Epoxy Nanoindentation Results ${ }^{3}$}

Typical curves for $\mathrm{E}$ and $\mathrm{H}$ as a function of indenter penetration are shown in Figure 4-8 for $5 \mathrm{wt} \%$ GNP in epoxy. The $\mathrm{E}$ and $\mathrm{H}$ values reported are the average of $\mathrm{E}$ and $\mathrm{H}$ determined over the range of indenter penetration from 500 to $1500 \mathrm{~nm}$. Figure 6 shows that hardness is $0.26 \mathrm{GPa}$. Table I shows a constant hardness value $(\sim 0.24-0.26$ GPa) for neat epoxy and 1-6 wt \% GNP in epoxy.

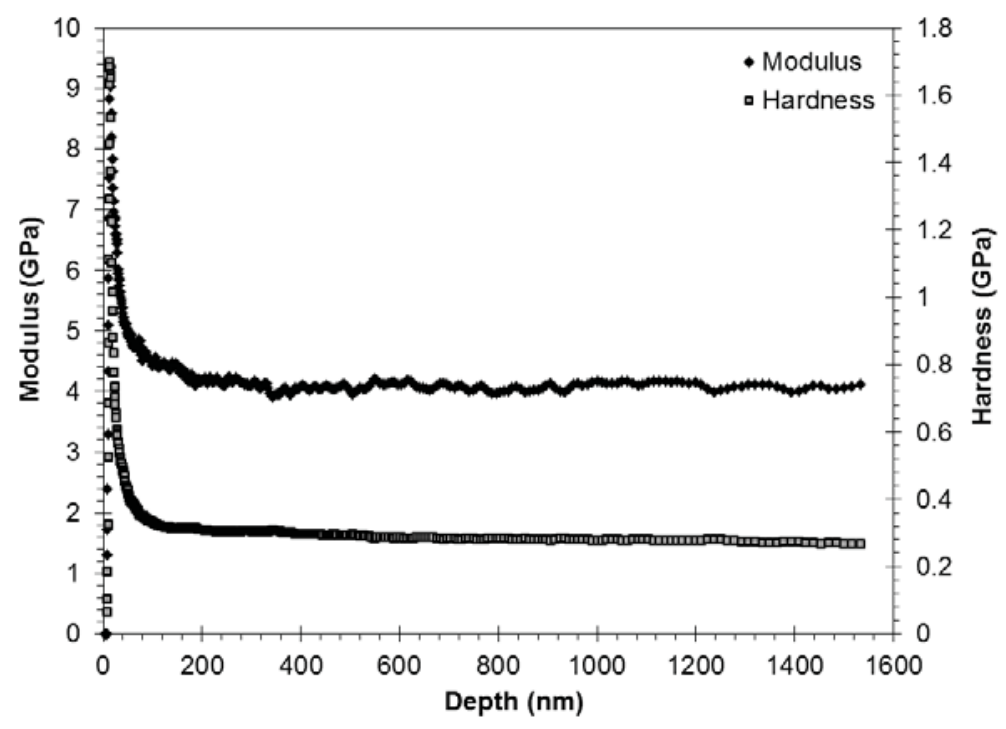

Figure 4-8: Modulus and hardness determined by nanoindentation for $5 \mathrm{wt} \%$ xGnP ${ }^{\Theta_{-}}$ M-15 in epoxy

\footnotetext{
${ }^{3}$ The material contained within this section has been published in the journal "Journal of Applied Polymer Science."

Citation:

J. A. King, D. R. Klimek, I. Miskioglu, G. Odegard; "Mechanical Properties of Graphene Nanoplatelet/Epoxy Composites" Journal of Applied Polymer Science, Vol 128, No. 6, pp.4217-4223, June 2013.
} 
Figure 4-9 shows the mean modulus as determined by the nanoindentation test. The error bars that are shown represent \pm 1 SD. Whether or not the Berkovich indenter encounters a GNP rich area or a matrix rich area on the sample will introduce error into this test method. Thus, as the amount of GNP increases, the error bars become larger, because more GNP is present in the sample. Several researchers have shown for polymers and polymer-based composites that modulus as determined by nanoindentation is higher than that reported by macroscopic tensile tests [6-8]. These ratios have been found to be 1.70 for polystyrene and 1.64 for polycarbonate [6]. This difference is likely due to pile up of material around the contact impression and viscoelasticity of the polymer and polymer based composites that is not accounted for by the modulus as determined by the Oliver-Pharr method [6-8]. The mean modulus from nanoindentation for the neat epoxy was 3.61 GPa (see Figure 4-9) when compared with 2.72 GPa (see Table 4-1) from the macroscopic D638 tensile test. Hence, a ratio of 1.33 was seen for our neat epoxy composites. This ratio was then used as a scaling factor for all moduli for the GNP/epoxy composites, and these mean results are also shown in Figure 4. The modulus as determined from nanoindentation showed a similar trend to the tensile modulus determined by a macroscopic method. 


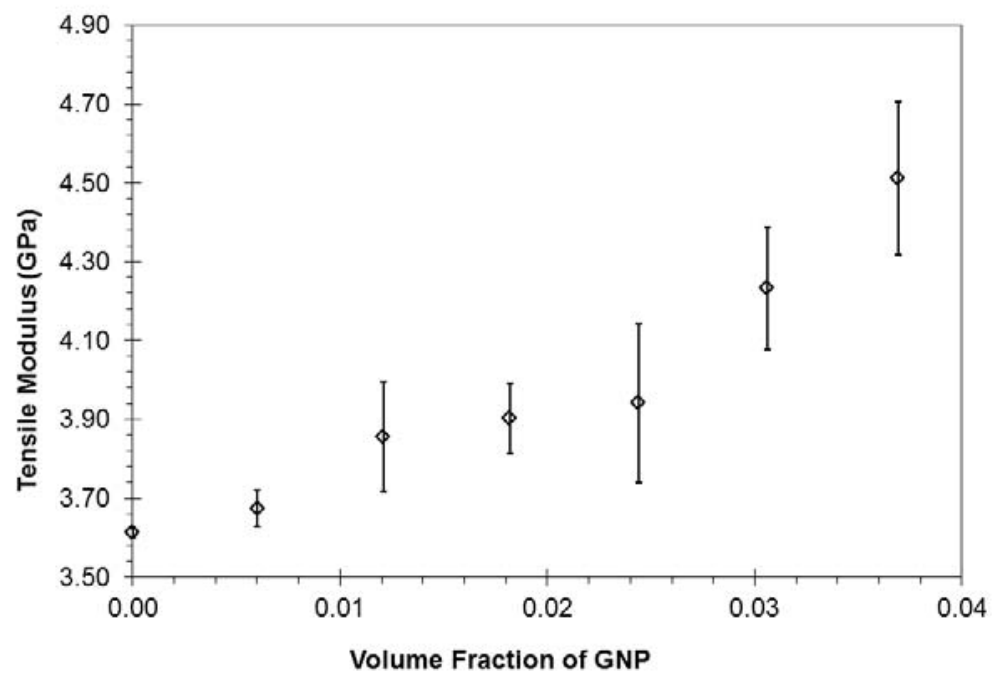

\section{Figure 4-9: Modulus determined by nanoindentation for $x G n P^{\circledR}-M-15 / e p o x y$ composites}

Figure 4-10 shows typical displacement (also called depth) curves as a function of time for $5 \mathrm{wt} \%$ (3.1 vol \%) GNP in epoxy at varying loads from 2 to $45 \mathrm{mN}$. Figure 4-10 shows that a steady state creep stage is observed almost as soon as the creep load was reached. Figure 4-11 shows the creep compliance for the 5 wt \% GNP in epoxy composite at all loads. The creep compliance calculated varies very little with the loads between 15 and $45 \mathrm{mN}$ in the steady-state creep range. For loads of 2, 5, and $10 \mathrm{mN}$, the creep compliance increases with load. Figure 4-12 displays the creep compliance results at $2 \mathrm{mN}$ for all the formulations. Figure 4-12 shows that the creep compliance for the neat epoxy is slightly higher than that of the GNP/epoxy composites. This result was also observed for the $5 \mathrm{mN}$ loading. For loadings from 10 to $45 \mathrm{mN}$, the creep compliance was the same for all formulations (neat epoxy and GNP/epoxy). As an example, Figure 4-13 illustrates the creep compliance results at $25 \mathrm{mN}$ for all the formulations. Tehrani et al. reported for neat epoxy (room temperature cure) and for $3 \mathrm{wt} \%$ multiwall carbon 
nanotube (MWCNT) in epoxy composites similar creep compliance curves tested at 1 $\mathrm{mN}$ and $25{ }^{\circ} \mathrm{C}$ [9]. At $25^{\circ} \mathrm{C}$ and $3 \mathrm{mN}$, Tehrani et al. observed reduced creep compliance in the MWCNT/epoxy composite as opposed to the neat epoxy [9]. Our results reported in this work indicate that for $10-45 \mathrm{mN}$, creep compliance is the same for the neat epoxy and GNP/epoxy composites.

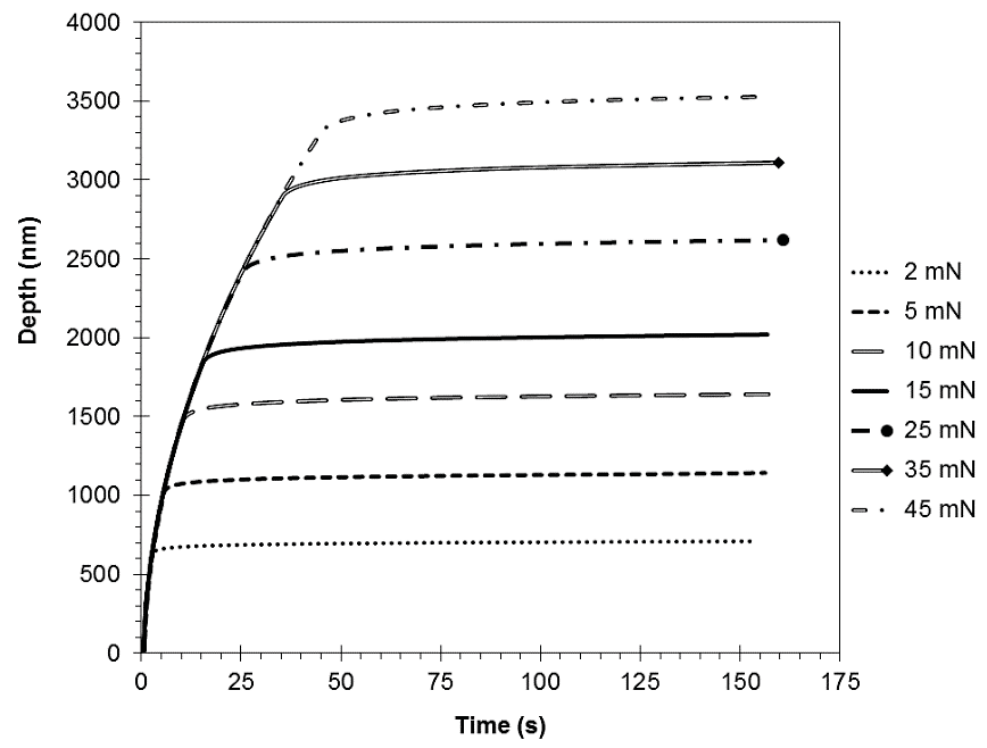

Figure 4-10: Nanoindentation penetration depth curves at various loads for 5 wt\% $x G n P^{\circledR}-M-15$ in epoxy 


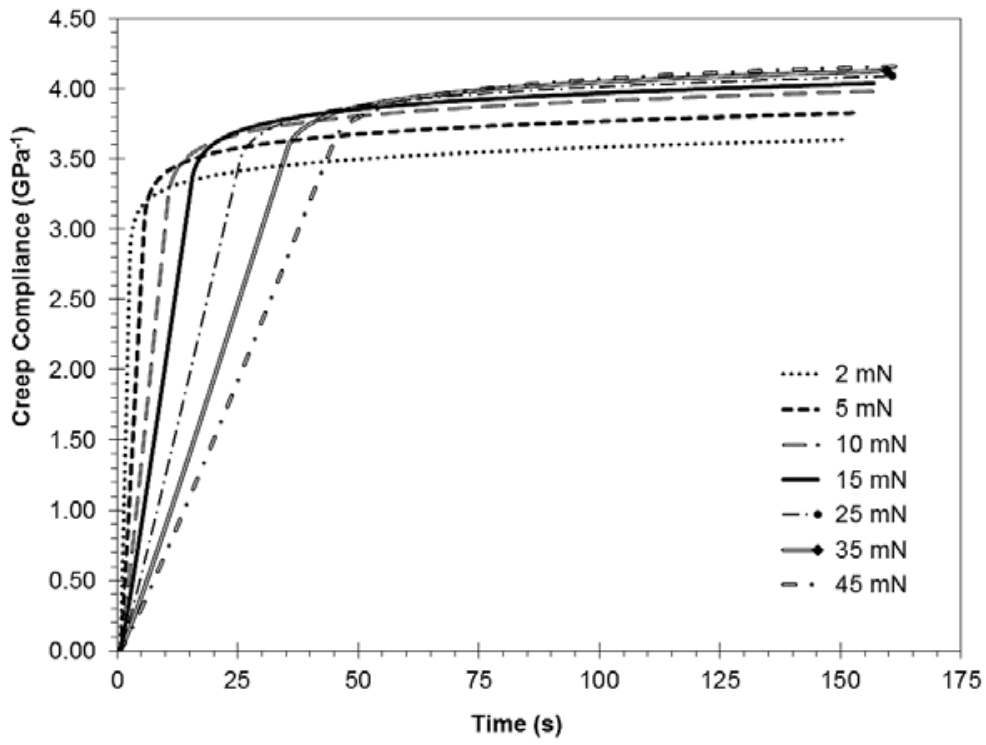

Figure 4-11: Creep compliance for $5 w t \% x G n P^{\circledR}-M-15$ in epoxy at various loads

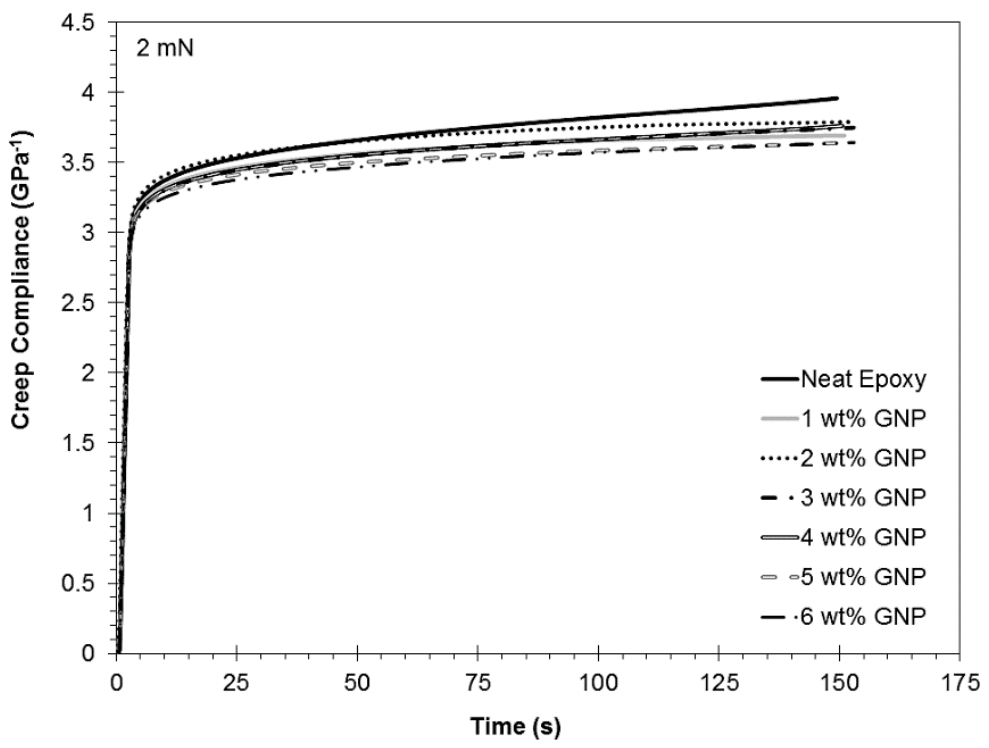

Figure 4-12: Creep compliance at a load of $2 m N$ for neat epoxy and $x G n P^{\circledR}-M-$ 15/epoxy composites 


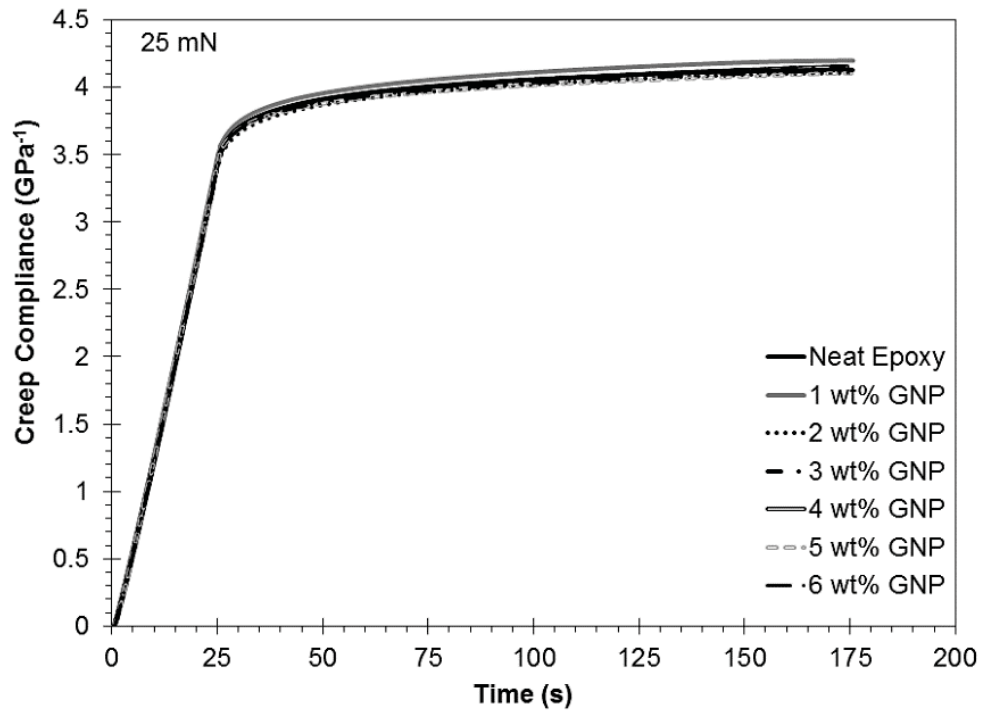

Figure 4-13: Creep compliance at a load of $25 \mathrm{~m} N$ for neat epoxy and $x G n P^{\circledR}-M-$ 15/epoxy composites

\subsection{2 $x G n P^{\circledR}-M-5$ in Epoxy and $x G n P^{\circledR}-C-300$ in Epoxy Nanoindentation Results $^{4}$}

The modulus $(\mathrm{E})$ and hardness $(\mathrm{H})$ values reported are the average of $\mathrm{E}$ and $\mathrm{H}$ determined over the range of indenter penetration from $500 \mathrm{~nm}$ to $1500 \mathrm{~nm}$ using the CSM method. Table 1 shows a constant hardness value of 0.25 to $0.27 \mathrm{GPa}$ for neat epoxy, 1 to 6wt $\%$ xGnP-M-5/epoxy, and 1-6wt $\%$ xGnP-C-300/epoxy composites. Typical curves for

\footnotetext{
${ }^{4}$ The material contained within this section has been published in the journal "Journal of Composite Materials.”

Citation:

J. A. King, D. R. Klimek, I. Miskioglu, G. Odegard; "Mechanical Properties of Graphene Nanoplatelet/Epoxy Composites” Journal of Composite Materials, Vol 49, No. 6, pp.659-668, March 2015.
} 
$\mathrm{E}$ and $\mathrm{H}$ as a function of indenter penetration have been published previously in King et al [2].

Several researchers have shown for polymers and polymer-based composites that modulus as determined by nanoindentation is higher than that reported by macroscopic tensile tests [6-8]. Tranchida et al. reported that for polystyrene the modulus obtained from nanoindentation was 1.70 times the modulus obtained from macroscopic tensile tests [6]. This difference is likely due to pile-up of material around the contact impression and viscoelasticity of the polymer and polymer-based composites that is not accounted for by the modulus as determined by the Oliver-Pharr Method [6-8]. The mean modulus from nanoindentation for the neat epoxy was $3.61 \mathrm{GPa}$ as compared to $2.72 \mathrm{GPa}$ from the macroscopic tensile test. Hence, the ratio of nanoindentation to macroscopic tensile modulus was found to be 1.33 . This ratio was then used as a scaling factor for all moduli for the $\mathrm{xGn}-\mathrm{M}-5 /$ epoxy and $\mathrm{xGnP}-\mathrm{C}-300 /$ epoxy composites and these mean results are also shown in Table 4-5 (standard deviation and number of samples tested are also shown). The modulus as determined from nanoindentation showed a similar trend to the tensile modulus determined by the macroscopic method for all composite systems. 
Table 4-5: Modulus as Determined by Nanoindentation for $x G n P^{\circledR}-M-5$ in Epoxy and $x G n P^{\circledR}-C-300$ in Epoxy

\begin{tabular}{|c|c|c|c|c|c|c|}
\hline Formulation & $\begin{array}{l}\text { GNP } \\
\text { Wt } \\
\%\end{array}$ & $\begin{array}{c}\text { GNP } \\
\text { Vol } \\
\%\end{array}$ & $\begin{array}{l}\text { Nano } \\
\text { Modulus } \\
\text { (GPa) }\end{array}$ & $\begin{array}{c}\text { Scaled } \\
\text { Nano } \\
\text { Modulus } \\
\text { (MPa) }\end{array}$ & $\begin{array}{c}\text { Hardness } \\
\text { (GPa) }\end{array}$ & $\begin{array}{l}\text { Stress Exponent } \\
\text { (m) for } 25 \mathrm{mN} \\
\text { Creep Load }\end{array}$ \\
\hline Epoxy & 0 & 0.0 & $\begin{array}{c}3.61 \pm 0.02 \\
n=16\end{array}$ & $\begin{array}{c}2.72 \pm 0.02 \\
\mathrm{n}=16\end{array}$ & $\begin{array}{c}0.255 \pm 0.003 \\
\mathrm{n}=16\end{array}$ & $\begin{array}{c}30.45 \pm 1.62 \\
n=36\end{array}$ \\
\hline \multicolumn{7}{|l|}{ xGnP ${ }^{\circledR}-M-5$} \\
\hline $1 \mathrm{M} 5$ & 1 & 0.60 & $\begin{array}{c}3.75 \pm 0.04 \\
n=24\end{array}$ & $\begin{array}{c}2.82 \pm 0.04 \\
n=24\end{array}$ & $\begin{array}{c}0.261 \pm 0.005 \\
n=24\end{array}$ & $\begin{array}{c}29.14 \pm 0.82 \\
n=36\end{array}$ \\
\hline $2 \mathrm{M} 5$ & 2 & 1.21 & $\begin{array}{c}3.89 \pm 0.07 \\
\mathrm{n}=24\end{array}$ & $\begin{array}{c}2.92 \pm 0.07 \\
\mathrm{n}=24\end{array}$ & $\begin{array}{c}0.259 \pm 0.006 \\
n=24\end{array}$ & $\begin{array}{c}28.77 \pm 1.67 \\
\mathrm{n}=36\end{array}$ \\
\hline $3 \mathrm{M} 5$ & 3 & 1.82 & $\begin{array}{c}3.95 \pm 0.11 \\
\mathrm{n}=24\end{array}$ & $\begin{array}{c}2.97 \pm 0.11 \\
\mathrm{n}=24\end{array}$ & $\begin{array}{c}0.256 \pm 0.010 \\
n=24\end{array}$ & $\begin{array}{c}30.65 \pm 1.32 \\
n=36\end{array}$ \\
\hline $4 \mathrm{M} 5$ & 4 & 2.44 & $\begin{array}{c}4.08 \pm 0.15 \\
\mathrm{n}=24\end{array}$ & $\begin{array}{c}3.07 \pm 0.15 \\
\mathrm{n}=24\end{array}$ & $\begin{array}{c}0.252 \pm 0.013 \\
\mathrm{n}=24\end{array}$ & $\begin{array}{c}29.85 \pm 1.40 \\
\mathrm{n}=36\end{array}$ \\
\hline 5M5 & 5 & 3.06 & $\begin{array}{c}4.32 \pm 0.15 \\
n=24\end{array}$ & $\begin{array}{c}3.25 \pm 0.15 \\
\mathrm{n}=24\end{array}$ & $\begin{array}{c}0.254 \pm 0.016 \\
n=24\end{array}$ & $\begin{array}{c}31.47 \pm 1.55 \\
\mathrm{n}=36\end{array}$ \\
\hline $6 \mathrm{M} 5$ & 6 & 3.69 & $\begin{array}{c}4.45 \pm 0.14 \\
\mathrm{n}=24\end{array}$ & $\begin{array}{c}3.35 \pm 0.14 \\
\mathrm{n}=24\end{array}$ & $\begin{array}{c}0.255 \pm 0.012 \\
n=24\end{array}$ & $\begin{array}{c}30.47 \pm 1.20 \\
n=36\end{array}$ \\
\hline \multicolumn{7}{|l|}{$\mathrm{xGnP}^{\circledR}-\mathrm{C}-\mathbf{3 0 0}$} \\
\hline $1 \mathrm{C} 300$ & 1 & 0.60 & $\begin{array}{c}3.65 \pm 0.04 \\
n=35\end{array}$ & $\begin{array}{c}2.74 \pm 0.04 \\
n=35\end{array}$ & $\begin{array}{c}0.261 \pm 0.004 \\
\mathrm{n}=35\end{array}$ & $\begin{array}{c}27.13 \pm 0.43 \\
n=36\end{array}$ \\
\hline $2 \mathrm{C} 300$ & 2 & 1.21 & $\begin{array}{c}3.79 \pm 0.03 \\
\mathrm{n}=25\end{array}$ & $\begin{array}{c}2.85 \pm 0.03 \\
\mathrm{n}=25\end{array}$ & $\begin{array}{c}0.265 \pm 0.007 \\
\mathrm{n}=25\end{array}$ & $\begin{array}{c}28.47 \pm 0.46 \\
n=36\end{array}$ \\
\hline $3 \mathrm{C} 300$ & 3 & 1.82 & $\begin{array}{c}3.79 \pm 0.03 \\
\mathrm{n}=29\end{array}$ & $\begin{array}{c}2.85 \pm \\
0.03 \mathrm{n}=29\end{array}$ & $\begin{array}{c}0.263 \pm 0.007 \\
n=29\end{array}$ & $\begin{array}{c}29.52 \pm 0.68 \\
\mathrm{n}=36\end{array}$ \\
\hline $4 C 300$ & 4 & 2.44 & $\begin{array}{c}3.83 \pm 0.04 \\
\mathrm{n}=30\end{array}$ & $\begin{array}{c}2.88 \pm 0.04 \\
\mathrm{n}=30\end{array}$ & $\begin{array}{c}0.265 \pm 0.005 \\
\mathrm{n}=30\end{array}$ & $\begin{array}{c}28.57 \pm 0.56 \\
\mathrm{n}=36\end{array}$ \\
\hline $5 C 300$ & 5 & 3.06 & $\begin{array}{c}3.90 \pm 0.09 \\
n=24\end{array}$ & $\begin{array}{c}2.93 \pm 0.09 \\
\mathrm{n}=24\end{array}$ & $\begin{array}{c}0.263 \pm 0.007 \\
n=24\end{array}$ & $\begin{array}{c}28.50 \pm 0.64 \\
n=36\end{array}$ \\
\hline $6 C 300$ & 6 & 3.69 & $\begin{array}{c}3.91 \pm 0.08 \\
n=24\end{array}$ & $\begin{array}{c}2.94 \pm 0.08 \\
\mathrm{n}=24\end{array}$ & $\begin{array}{c}0.267 \pm 0.004 \\
n=24\end{array}$ & $\begin{array}{c}29.62 \pm 0.87 \\
\mathrm{n}=36\end{array}$ \\
\hline
\end{tabular}

Creep tests were conducted at the following loads: $2,5,10,15,25,35$, and 45 $\mathrm{mN}$. Typical displacement (also called depth) curves as a function of time were previously shown in King et al [2]. At $2 \mathrm{mN}$, the maximum depth observed was 740nm for neat epoxy and 706nm for $6 \mathrm{wt} \% \mathrm{xGnP}-\mathrm{M}-5 /$ epoxy and $6 \mathrm{wt} \% \mathrm{xGnP}-\mathrm{C}-300 /$ epoxy composites ( $4.6 \%$ decrease in the maximum penetration depth). At the highest load of 45 
$\mathrm{mN}$, the maximum depth was 3539nm for neat epoxy and 3486nm for $6 \mathrm{wt} \% \mathrm{xGnP}-\mathrm{M}-$ 5/epoxy and 6wt\% xGnP-C-300/epoxy composites (1.5\% decrease in maximum penetration depth). Figure 4-14 shows the creep compliance for the $5 \mathrm{wt} \% \mathrm{xGnP}-\mathrm{C}$ 300/epoxy composite. The creep compliance varies very little with loads between 15 and $45 \mathrm{mN}$ in the steady-state creep range. For loads of 2,5 , and $10 \mathrm{mN}$, the creep compliance increases with load. A similar creep response was also observed for the neat epoxy, 1 to 4 and $6 \mathrm{wt} \% \mathrm{xGnP}-\mathrm{C}-300 /$ epoxy, and 1 to $6 \mathrm{wt} \% \mathrm{xGnP}-\mathrm{M}-5 /$ epoxy composites. As an example, Figure 4-15 shows the creep compliance at the $25 \mathrm{mN}$ load for neat epoxy, 2 and 5wt $\%$ xGnP-M-5/epoxy, and 2 and 5wt $\%$ xGnP-C-300/epoxy composites. These figures show that the steady-state creep compliance remains constant for neat epoxy, $1-6 w t \%$ wt $\%$ xGnP-C-300/epoxy composites, and 1 to $6 \mathrm{wt} \%$ xGnP-M-5/epoxy composites.

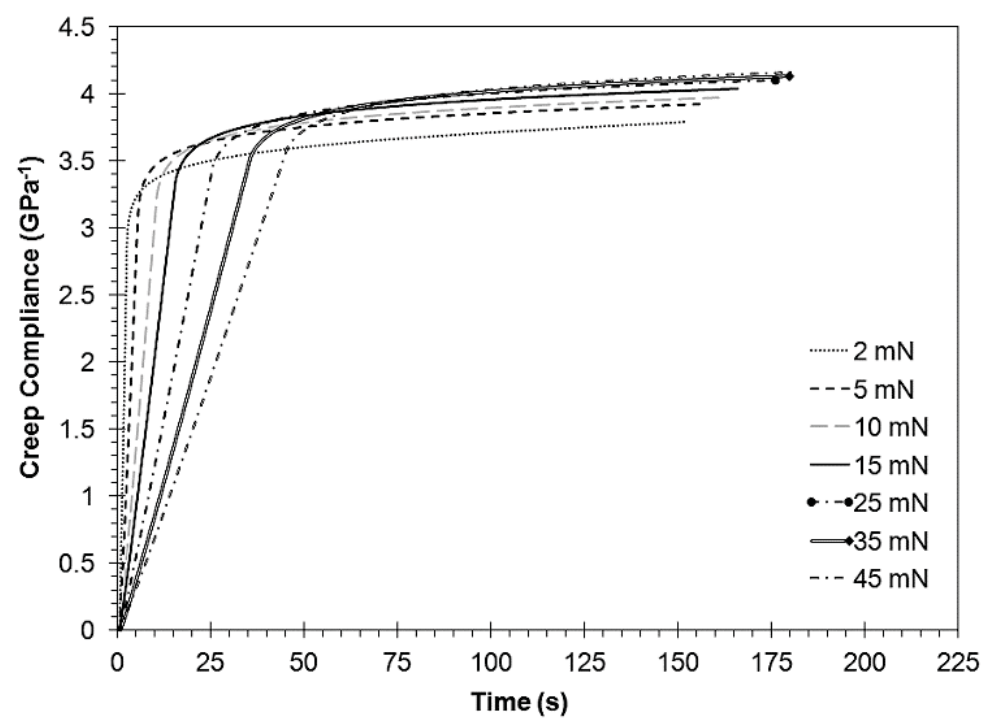

Figure 4-14: Creep Compliance for $5 w t \% x G n P^{\circledR}-C-300$ in Epoxy at Various Loads 


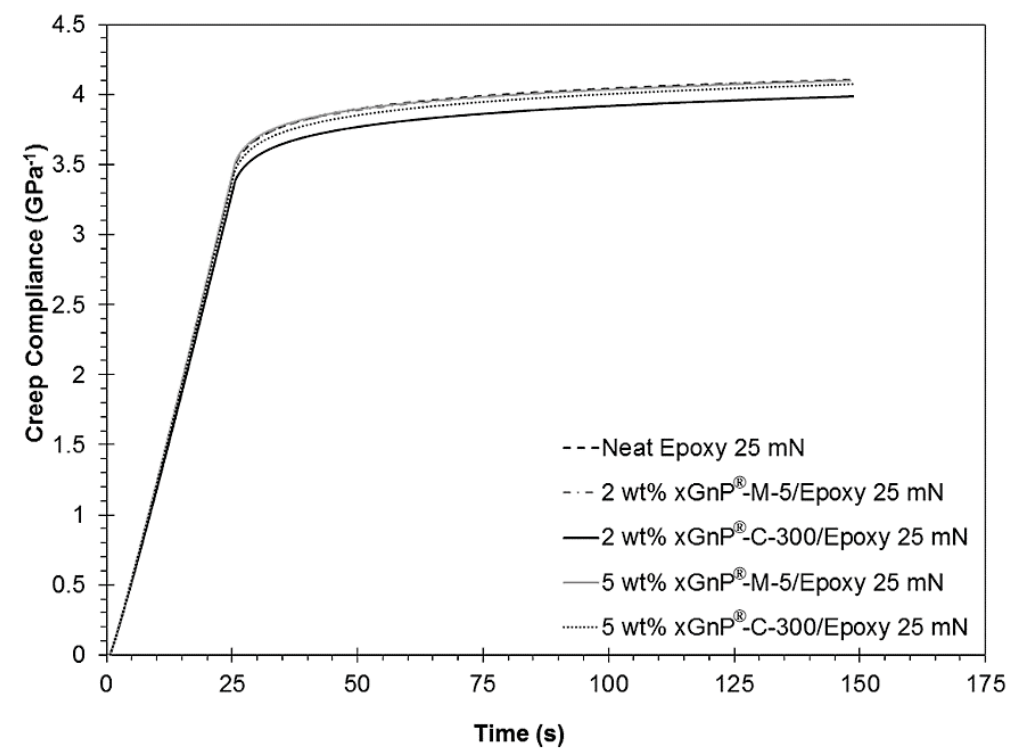

Figure 4-15: Creep Compliance for Neat Epoxy, 2 and $5 w t \% x G n P^{\circledR}-C-300$ in Epoxy at $25 \mathrm{mN}$

A simplified relationship between the strain rate $(\dot{\varepsilon})$ and stress $(\sigma)$ during steady state creep can be given as

$$
\dot{\varepsilon}=\mathrm{B} \sigma^{\mathrm{m}}
$$

Where $\mathrm{B}$ and $\mathrm{m}$ are constants. Strain rate is calculated from the displacement of the indenter as

$$
\dot{\varepsilon}=\left[\frac{(\text { displacement })_{\mathrm{i}}-(\text { displacement })_{\mathrm{i}-1}}{(\text { displacement })_{\mathrm{i}}}\right] /\left(\mathrm{t}_{\mathrm{i}}-\mathrm{t}_{\mathrm{i}-1}\right)
$$


and stress is

$$
\sigma=\frac{\mathrm{P}_{0}}{\mathrm{~A}(\mathrm{t})}
$$

where $\mathrm{A}(\mathrm{t})$ is the contact area (see Equation 3-2). The calculations for $\dot{\varepsilon}, \sigma$, and the stress exponent $\mathrm{m}$ are performed at the conclusion of the creep test. The stress exponent $\mathrm{m}$ can be interpreted as the sensitivity of the material to creep [10]. The stress exponent $\mathrm{m}$ was calculated for neat epoxy, 1-6wt $\%$ xGnP-C-300/ epoxy composites, and 1 to $6 \mathrm{wt} \% \mathrm{xGnP}-\mathrm{M}-5 /$ epoxy composites at $2,5,10,15,25,35$, and $45 \mathrm{mN}$. The $\mathrm{m}$ values in all formulations at all loadings were similar. Table 1 shows the values for $\mathrm{m}$ at $25 \mathrm{mN}$ for all the formulations. The constant value for stress exponent $\mathrm{m}$ agrees with the constant creep compliance curves. In addition, Zandiastashbar et al. reported similar creep results for graphene platelet/epoxy nanocomposites [11].

\subsubsection{Asbury TC307 in Epoxy Nanoindentation Results}

The modulus (E) and hardness $(\mathrm{H})$ shown in Table 4-6 were determined by taking the average $\mathrm{E}$ and $\mathrm{H}$ over a penetration depth of $500 \mathrm{~nm}$ to $1500 \mathrm{~nm}$ as per the continuous stiffness method. Table 4-6 shows a hardness of $\sim 0.26 \mathrm{GPa}$ for neat epoxy and $\sim 0.28$ for $4 \mathrm{wt} \%$ TC307 in epoxy. Figure 4-16 shows the modulus as determined by nanoindentation as a function of volume fraction of TC307, error bars shown are \pm 1 SD. 
It has been observed that the modulus as determined by nanoindentation is higher than the modulus as determined by macroscopic tensile test (ASTM D638) for polymer-based composites [6-8]. A possible cause for this difference is pile-up of material around the point of contact. The polymer viscoelasticity is not accounted for in the modulus as determined by Oliver-Pharr method [6-8]. The modulus as determined by nanoindentation for neat epoxy was found to be $3.61 \mathrm{GPa}$ which is 1.33 times greater than that measured by the macroscopic tensile test. This ratio was then applied to the moduli of all formulations and the result is shown in Table 4-6 as 'scaled nano modulus'. The scaled nanoindentation modulus shows the same trend as the macroscopic tensile modulus.

Table 4-6: Nanoindentation Results for TC307 in Epoxy

\begin{tabular}{|c|c|c|c|c|}
\hline $\begin{array}{c}\text { Material } \\
\text { system }\end{array}$ & $\begin{array}{c}\text { Filler } \\
\text { Wt \% } \\
\text { (Vol \%) }\end{array}$ & $\begin{array}{c}\text { Nano } \\
\text { Modulus } \\
\text { (GPa) }\end{array}$ & $\begin{array}{c}\text { Scaled } \\
\text { Nano } \\
\text { Modulus } \\
(\text { GPa }) \\
\end{array}$ & $\begin{array}{l}\text { Hardness } \\
\text { (GPa) }\end{array}$ \\
\hline $\begin{array}{l}\text { Neat } \\
\text { Epoxy }\end{array}$ & $\begin{array}{c}0 \\
(0.00) \\
\end{array}$ & $\begin{array}{c}3.61 \pm 0.02 \\
n=16\end{array}$ & $\begin{array}{c}2.72 \pm 0.02 \\
n=16\end{array}$ & $\begin{array}{c}0.255 \pm 0.003 \\
\mathrm{n}=16\end{array}$ \\
\hline 1TC307 & $\begin{array}{c}1 \\
(0.60)\end{array}$ & $\begin{array}{c}3.70 \pm 0.03 \\
n=33\end{array}$ & $\begin{array}{c}2.78 \pm 0.03 \\
n=33\end{array}$ & $\begin{array}{c}0.273 \pm 0.005 \\
n=33\end{array}$ \\
\hline $2 \mathrm{TC} 307$ & $\begin{array}{c}2 \\
(1.21) \\
\end{array}$ & $\begin{array}{c}3.74 \pm 0.07 \mathrm{n} \\
=33\end{array}$ & $\begin{array}{c}2.81 \pm 0.07 \\
\mathrm{n}=33\end{array}$ & $\begin{array}{c}0.273 \pm 0.009 \\
n=33\end{array}$ \\
\hline 3ТC307 & $\begin{array}{c}3 \\
(1.82)\end{array}$ & $\begin{array}{c}3.81 \pm 0.06 \\
\mathrm{n}=34\end{array}$ & $\begin{array}{c}2.87 \pm 0.06 \\
n=34\end{array}$ & $\begin{array}{c}0.278 \pm 0.006 \\
n=34\end{array}$ \\
\hline 4TC307 & $\begin{array}{c}4 \\
(2.44)\end{array}$ & $\begin{array}{c}3.85 \pm 0.07 \\
\mathrm{n}=33\end{array}$ & $\begin{array}{c}2.89 \pm 0.07 \\
n=33\end{array}$ & $\begin{array}{c}0.281 \pm 0.009 \\
n=33\end{array}$ \\
\hline
\end{tabular}




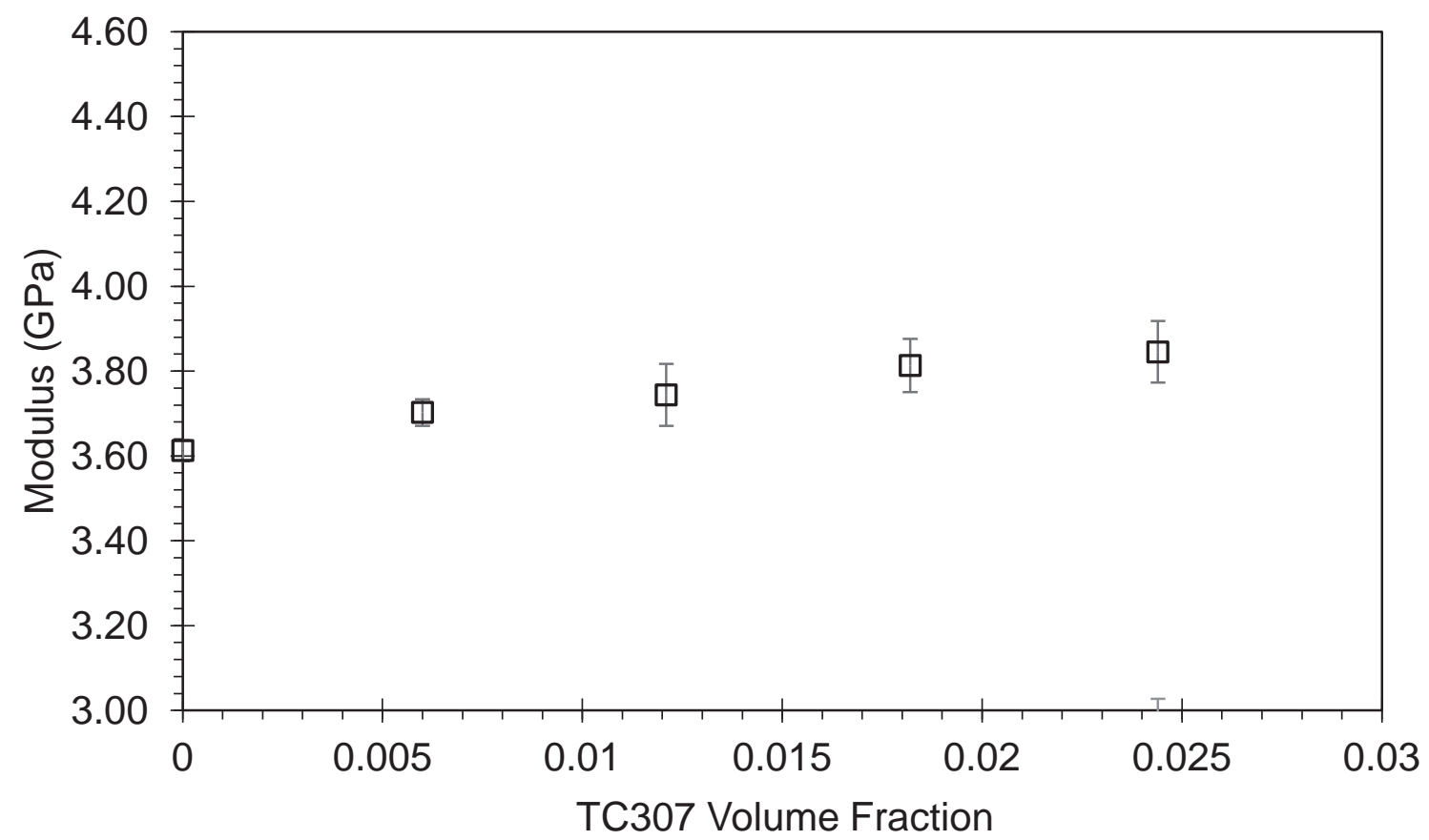

Figure 4-16: Modulus as Determined by Nanoindentation for TC307/Epoxy Composites

\subsection{Electrical Resistivity Results}

\subsection{1 xGn $P^{\circledR}-M-15$ in Epoxy Electrical Resistivity Results ${ }^{5}$}

Figure 4-17 shows the $\log$ (electrical resistivity in $\Omega$-cm) as a function of filler volume fraction. All the data points have been plotted in this figure. At low-filler loadings, the electrical resistivity remains similar to that of the pure polymer. Then, at a point called the percolation threshold, the resistivity decreases dramatically over a very

\footnotetext{
${ }^{5}$ The material contained within this section has been published in the journal "Journal of Applied Polymer Science."

Citation:

J. A. King, D. R. Klimek, I. Miskioglu, G. Odegard; "Mechanical Properties of Graphene Nanoplatelet/Epoxy Composites” Journal of Applied Polymer Science, Vol 128, No. 6, pp.4217-4223, June 2013.
} 
narrow range of filler concentrations $[12,13]$. Figure 4-17 illustrates that the percolation threshold occurs at $\sim 0.99$ vol \% ( 1.6 wt \%) for GNP. Enough formulations were tested to determine the percolation threshold, because this will be discussed later for tensile modulus models.

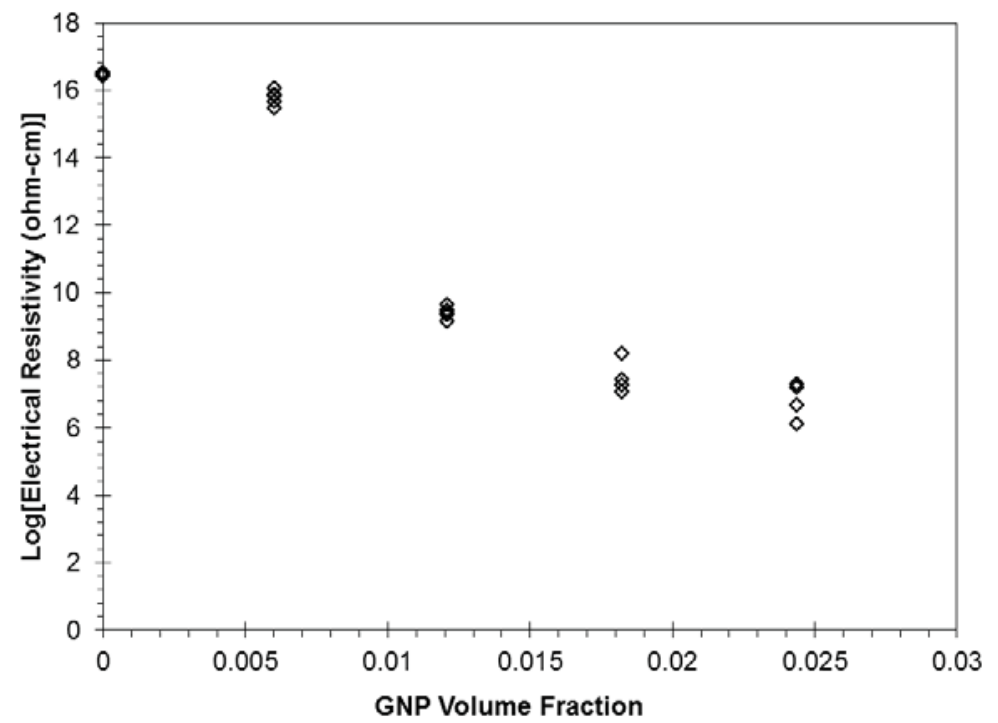

Figure 4-17: Log (electrical resistivity) results for $x G n P^{\circledR}-M-15 /$ epoxy composites

The percolation threshold for GNP has been recently modeled using a similar analytical method using the interparticle distance concept [14]. This model postulates that conductive particles can be separated by a distance equal to the electron tunneling distance through the nonconductive matrix and still have conduction between the particles. The model assumes high-aspect ratio disc-like morphology for GNP and uses this assumption to determine cubic elements containing a single GNP and then uses these elements to determine a percolation threshold. The resulting analytical formula for the percolation threshold for GNP/PC composites is given by Equation 4-4 below [14]. 


$$
\phi_{C}=\frac{27 \pi D^{2} t}{4(D+I P D)^{3}}
$$

In Equation 4-4, $\phi_{\mathrm{c}}$ is the filler volume fraction at the percolation threshold, 0.0099; $\mathrm{t}$ is the thickness of the platelet, $7 \mathrm{~m}$; IPD is the electron tunneling distance, $10 \mathrm{~nm}$ for many polymer systems [14]; and D is the diameter of the platelet. Using Equation 4-4, the diameter of the platelet was then calculated to be $15,000 \mathrm{~nm}(15 \mu \mathrm{m})$, which agrees with the vendor literature [3].

\subsection{2 $x G n P^{\circledR}-M-5$ in Epoxy and $x G n P^{\circledR}-C-300$ in Epoxy Electrical Resistivity Results}

Table 4-7 shows the volume electrical resistivity for all formulations for both types of GNP. At low-filler loadings, the electrical resistivity remains similar to that of the pure polymer. Then, at the percolation threshold, the resistivity decreases dramatically over a very narrow range of filler concentrations $[12,13]$. The percolation

threshold occurs at $\sim 2.53 \mathrm{vol} \%(\sim 4.1 \mathrm{wt} \%)$ for $\mathrm{xGnP}^{\circledR}-\mathrm{M}-5$ and $\sim 2.09 \mathrm{vol} \%(\sim 3.4 \mathrm{wt} \%)$ for $\mathrm{xGnP}^{\circledR}{ }_{-} \mathrm{C}-300$. Enough formulations were tested to determine the percolation threshold, because this will be used later for tensile modulus models. Both of these values match the as received aspect ratio that is used to solve for $\phi_{C}$ in Equation 4-4. 
Table 4-7: Electrical resistivity results for $x G n P^{\circledR}-M-5 /$ epoxy and $x G n P^{\circledR}-C-300 /$ epoxy composites

\begin{tabular}{|c|c|}
\hline Formulation & Storage Modulus Onset $\left({ }^{\circ} \mathbf{C}\right)$ \\
\hline Neat Epoxy & $2.88 \times 10^{16} \pm 3.20 \times 10^{15} \mathrm{n}=6$ \\
\hline \multicolumn{2}{|l|}{$\mathrm{xGnP}^{\circledR}-\mathrm{M}-5$} \\
\hline $1 \mathrm{M5}$ & $2.72 \times 10^{15} \pm 1.02 \times 10^{15} \mathrm{n}=5$ \\
\hline $2 M 5$ & $4.71 \times 10^{15} \pm 1.86 \times 10^{15} \mathrm{n}=4$ \\
\hline $3 \mathrm{M5}$ & $9.73 \times 10^{14} \pm 6.50 \times 10^{14} \mathrm{n}=4$ \\
\hline $4 \mathrm{M5}$ & $3.78 \times 10^{9} \pm 2.55 \times 10^{9} \mathrm{n}=5$ \\
\hline 5M5 & $6.06 \times 10^{8} \pm 8.88 \times 10^{9} \mathrm{n}=5$ \\
\hline 6M5 & $2.14 \times 10^{8} \pm 3.36 \times 10^{8} n=5$ \\
\hline \multicolumn{2}{|l|}{$\mathrm{xGnP}{ }^{\circledR}-\mathrm{C}-300$} \\
\hline $1 \mathrm{C300}$ & $2.63 \times 10^{16} \pm 1.58 \times 10^{16} \mathrm{n}=6$ \\
\hline $2 \mathrm{C300}$ & $5.07 \times 10^{15} \pm 2.27 \times 10^{15} \mathrm{n}=6$ \\
\hline $3 C 300$ & $5.85 \times 10^{15} \pm 1.99 \times 10^{15} \mathrm{n}=5$ \\
\hline $4 C 300$ & $3.48 \times 10^{8} \pm 6.32 \times 10^{7} \mathrm{n}=5$ \\
\hline $5 C 300$ & $1.99 \times 10^{8} \pm 1.40 \times 10^{8} \mathrm{n}=5$ \\
\hline $6 C 300$ & $4.35 \times 10^{7} \pm 6.49 \times 10^{7} \mathrm{n}=5$ \\
\hline
\end{tabular}

\subsection{Dynamic Mechanical Analysis (DMA) Results}

The glass transition temperature $\left(\mathrm{T}_{\mathrm{g}}\right)$ for the neat epoxy was found to be about 156 ${ }^{\circ} \mathrm{C}$ (determined by the peak of the tan delta curve). Table 4-8 shows the average temperature for the storage modulus onset, the peak of the loss modulus, and the peak of the tan delta for all formulations of $\mathrm{xGnP}^{\circledR}-\mathrm{M}-15$ in epoxy, $\mathrm{xGnP}^{\circledR}-\mathrm{M}-5$ in epoxy, and $\mathrm{xGnP}^{\circledR}-\mathrm{C}-300$ in epoxy. The storage modulus onset, the peak of the loss modulus and the peak of the tan delta all follow a similar trend. The $\mathrm{T}_{\mathrm{g}}$ decreases until it hits the approximate percolation threshold and then begins to increase again, this is true for all three types of GNP. 
Table 4-8: DMA results for $x G n P^{\circledR}-M-15$ in epoxy, $x G n P^{\circledR}-M-5$ in epoxy and $x G n P^{\circledR}-C-300$ in epoxy

\begin{tabular}{|c|c|c|c|}
\hline Formulation & $\begin{array}{c}\text { Storage Modulus } \\
\text { Onset }\left({ }^{\circ} \mathbf{C}\right)\end{array}$ & $\begin{array}{c}\text { Loss Modulus } \\
\text { Peak }\left({ }^{\circ} \mathbf{C}\right) \\
\end{array}$ & $\begin{array}{c}\text { Tan Delta Peak } \\
\left({ }^{\circ} \mathbf{C}\right)\end{array}$ \\
\hline Neat Epoxy & $139.3 \pm 0.5 n=6$ & $149.8 \pm 0.3 n=6$ & $155.8 \pm 0.4 n=6$ \\
\hline \multicolumn{4}{|l|}{$\mathrm{xGnP}^{\circledR}-\mathrm{M}-15$} \\
\hline $1 \mathrm{M15}$ & $131.9 \pm 0.8 n=3$ & $145.3 \pm 0.3 \mathrm{n}=3$ & $153.5 \pm 0.5 \mathrm{n}=3$ \\
\hline $2 \mathrm{M15}$ & $130.2 \pm 0.7 n=5$ & $143.6 \pm 0.8 \mathrm{n}=5$ & $152.6 \pm 0.8 \mathrm{n}=5$ \\
\hline 3M15 & $130.4 \pm 0.5 n=3$ & $143.1 \pm 0.2 n=3$ & $150.4 \pm 0.3 n=3$ \\
\hline 4M15 & $131.5 \pm 0.6 n=3$ & $144.1 \pm 0.5 \mathrm{n}=3$ & $152.4 \pm 0.3 n=3$ \\
\hline $5 \mathrm{M} 15$ & $137.1 \pm 0.3 n=3$ & $149.1 \pm 0.4 n=3$ & $156.0 \pm 0.4 \mathrm{n}=3$ \\
\hline 6M15 & $136.0 \pm 1.0 \mathrm{n}=5$ & $148.4 \pm 0.6 \mathrm{n}=5$ & $155.9 \pm 0.5 \mathrm{n}=5$ \\
\hline \multicolumn{4}{|l|}{$\mathrm{xGnP}^{\circledR}-\mathrm{M}-5$} \\
\hline $1 \mathrm{M5}$ & $136.2 \pm 0.4 \mathrm{n}=3$ & $147.6 \pm 0.3 n=3$ & $154.3 \pm 0.3 n=3$ \\
\hline $2 \mathrm{M5}$ & $134.7 \pm 0.5 \mathrm{n}=3$ & $145.8 \pm 0.2 \mathrm{n}=3$ & $153.1 \pm 0.4 n=3$ \\
\hline $3 M 5$ & $137.4 \pm 0.2 n=3$ & $148.14 \pm 0.4 n=3$ & $154.7 \pm 0.3 n=3$ \\
\hline $4 \mathrm{M5}$ & $139.6 \pm 0.3 n=3$ & $150.0 \pm 0.5 \mathrm{n}=3$ & $156.5 \pm 0.4 n=3$ \\
\hline $5 \mathrm{M5}$ & $140.9 \pm 0.1 \mathrm{n}=3$ & $150.7 \pm 0.3 \mathrm{n}=3$ & $157.2 \pm 0.4 n=3$ \\
\hline $6 \mathrm{M5}$ & $139.3 \pm 0.3 n=3$ & $149.8 \pm 0.1 \mathrm{n}=3$ & $156.4 \pm 0.1 \mathrm{n}=3$ \\
\hline \multicolumn{4}{|l|}{$\mathrm{xGnP}^{\circledR}-\mathrm{C}-300$} \\
\hline $1 C 300$ & $132.2 \pm 0.4 n=3$ & $145.3 \pm 0.2 n=3$ & $152.7 \pm 0.3 \mathrm{n}=3$ \\
\hline $2 \mathrm{C300}$ & $120.6 \pm 0.5 n=3$ & $134.8 \pm 0.1 \mathrm{n}=3$ & $143.4 \pm 0.2 n=3$ \\
\hline $3 \mathrm{C300}$ & $132.5 \pm 0.6 \mathrm{n}=3$ & $145.1 \pm 0.1 \mathrm{n}=3$ & $152.7 \pm 0.4 \mathrm{n}=3$ \\
\hline $4 \mathrm{C300}$ & $135.0 \pm 0.9 \mathrm{n}=3$ & $147.4 \pm 0.3 n=3$ & $154.9 \pm 0.3 n=3$ \\
\hline $5 C 300$ & $133.0 \pm 0.7 n=3$ & $145.6 \pm 0.1 \mathrm{n}=3$ & $153.3 \pm 0.3 n=3$ \\
\hline $6 C 300$ & $132.8 \pm 0.5 \mathrm{n}=3$ & $145.4 \pm 0.1 \mathrm{n}=3$ & $153.4 \pm 0.2 \mathrm{n}=3$ \\
\hline \multicolumn{4}{|l|}{ TC307 } \\
\hline 1TC307 & $132.7 \pm 0.6 n=4$ & $146.2 \pm 0.4 n=4$ & $154.0 \pm 0.3 n=4$ \\
\hline 2 2TC307 & $134.6 \pm 0.4 n=4$ & $148.3 \pm 0.4 n=4$ & $155.7 \pm 0.3 \mathrm{n}=4$ \\
\hline 3TC307 & $132.4 \pm 0.5 n=4$ & $145.5 \pm 0.0 \mathrm{n}=4$ & $153.3 \pm 0.1 \mathrm{n}=4$ \\
\hline 4TC307 & $135.4 \pm 0.3 \mathrm{n}=4$ & $148.8 \pm 0.1 \mathrm{n}=4$ & $156.4 \pm 0.1 \mathrm{n}=4$ \\
\hline
\end{tabular}

\subsection{Differential Scanning Calorimeter (DSC) Results}

The glass transition temperature $\left(\mathrm{T}_{\mathrm{g}}\right)$ for the neat epoxy was found to be about 143

${ }^{\circ} \mathrm{C}$. Table 4-9 shows the average glass transition temperature for all formulations of

$\mathrm{xGnP}^{\circledR}-\mathrm{M}-15$ in epoxy. The $\mathrm{T}_{\mathrm{g}}$ follows a similar trend as the storage modulus onset, peak of the loss modulus and peak of the tan delta for the DMA test. The $\mathrm{T}_{\mathrm{g}}$ decreases until it hits the approximate percolation threshold and then begins to increase again. 
Table 4-9: DSC results for $x G n P^{\circledR}-M-15$ in epoxy

\begin{tabular}{|c|c|}
\hline Formulation & $\mathbf{T}_{\mathbf{g}}\left({ }^{\circ} \mathbf{C}\right)$ \\
\hline Neat Epoxy & $143.3 \pm 0.7 \mathrm{n}=7$ \\
\hline $1 \mathrm{M} 15$ & $145.3 \pm 1.5 \mathrm{n}=8$ \\
\hline $2 \mathrm{M} 15$ & $143.3 \pm 1.0 \mathrm{n}=8$ \\
\hline $3 \mathrm{M} 15$ & $138.7 \pm 2.4 \mathrm{n}=8$ \\
\hline $4 \mathrm{M} 15$ & $144.3 \pm 1.0 \mathrm{n}=8$ \\
\hline $5 \mathrm{M} 15$ & $145.2 \pm 1.9 \mathrm{n}=8$ \\
\hline $6 \mathrm{M} 15$ & $145.6 \pm 2.4 \mathrm{n}=8$ \\
\hline
\end{tabular}

\subsection{Microscopy Results}

\subsection{1 xGnP ${ }^{\circledR}-M-15$ in Epoxy Microscopy Results ${ }^{6}$}

Figure 4-18 shows the random dispersion of $5 \mathrm{wt} \%$ GNP (see white nanoplatelet geometry) in epoxy. Figure 4-19 shows the FESEM image of a tensile fracture surface for the $5 \mathrm{wt} \%$ GNP in epoxy composite. This figure clearly shows the platelet shape of the GNP coming out of the fracture surface ( $\mathrm{z}$ direction). The epoxy is seen in the " $\mathrm{x}-\mathrm{y}$ plane"' of Figure 4-19.

\footnotetext{
${ }^{6}$ The material contained within this section has been published in the journal "Journal of Applied Polymer Science." Citation:

J. A. King, D. R. Klimek, I. Miskioglu, G. Odegard; "Mechanical Properties of Graphene Nanoplatelet/Epoxy Composites” Journal of Applied Polymer Science, Vol 128, No. 6, pp.4217-4223, June 2013.
} 


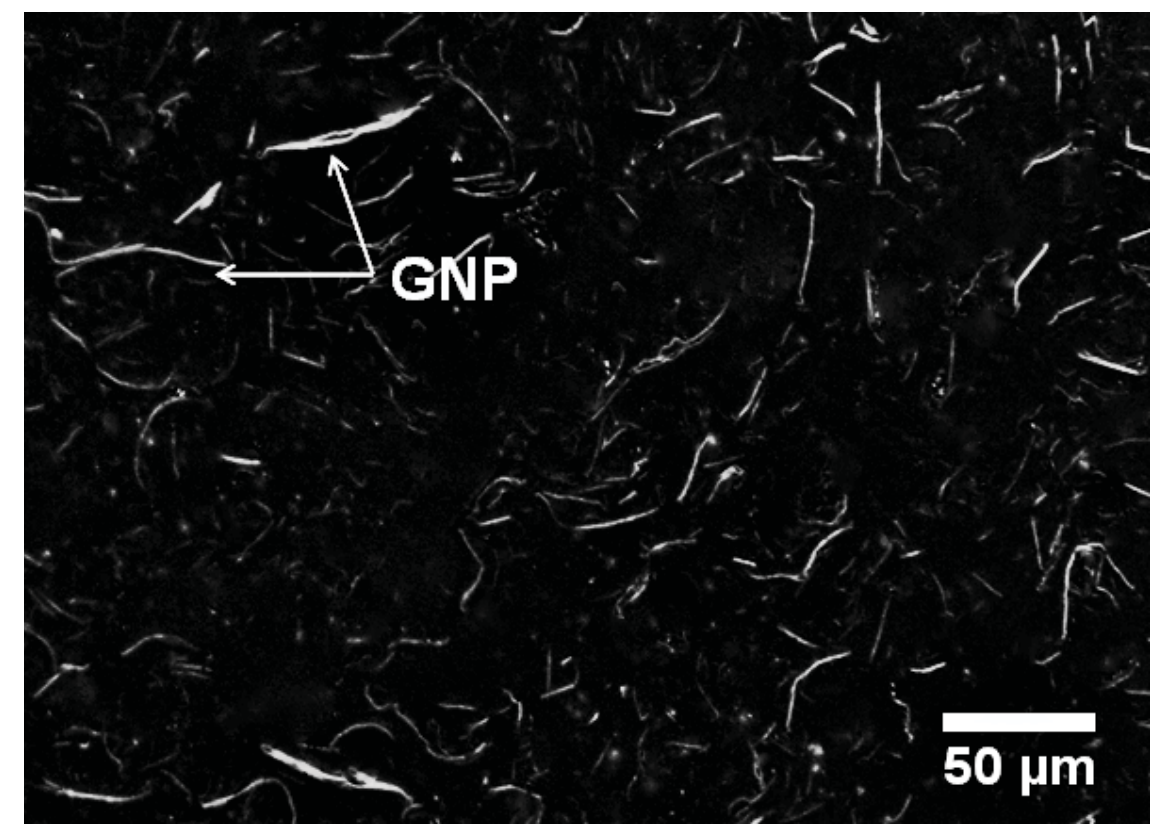

Figure 4-18: Optical Microscope micrograph of 5 wt\% graphene nanoplatelets in epoxy

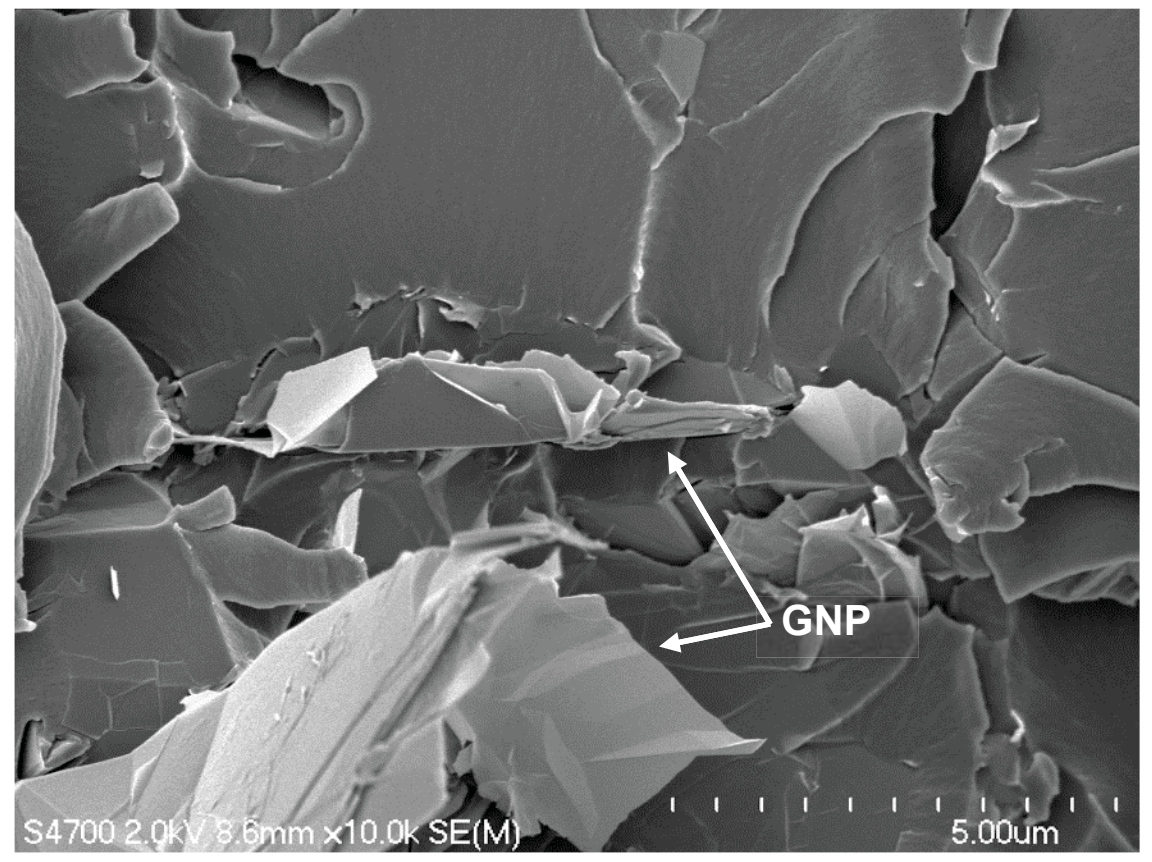

Figure 4-19: Field emission scanning electron microscope micrograph of 5 wt\% graphene nanoplatelets in epoxy 


\subsection{2 $x G n P^{\circledR}-M-5$ in Epoxy and $x G n P^{\circledR}-C-300$ in Epoxy Microscopy Results ${ }^{7}$}

Figure 4-20 shows the random dispersion of $5 \mathrm{wt}^{2} \% \mathrm{xGnP}^{\circledR}-\mathrm{M}-5$ (see white nanoplatelet geometry) in epoxy. Figure 4-21 shows the FESEM image of a tensile fracture surface for the $5 \mathrm{wt} \% \mathrm{xGnP}^{\circledR}-\mathrm{M}-5$ in epoxy composite. This figure clearly shows the platelet shape of the GNP coming out of the fracture surface (z direction). Figure 4-22 shows the random dispersion of $4 \mathrm{wt} \% \mathrm{xGnP}^{\circledR}-\mathrm{C}-300$ in epoxy. Figure 4-23 shows the FESEM image of a tensile fracture surface for the $4 \mathrm{wt} \% \mathrm{xGnP}^{\circledR}-\mathrm{C}-300$ in epoxy. As expected, the $\mathrm{xGnP}^{\circledR}-\mathrm{C}-300$ flake $(\sim 2 \mathrm{~mm})$ is smaller than the $\mathrm{xGnP}^{\circledR}-\mathrm{M}-5(\sim 5 \mathrm{~mm})$ flake shown in Figure 4-21.

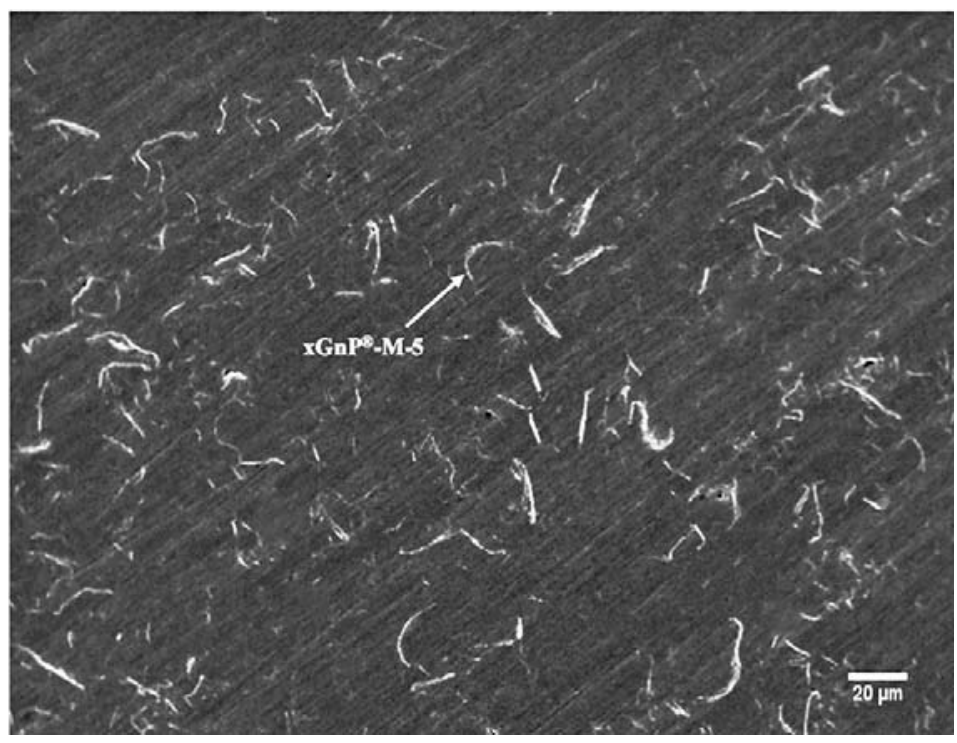

Figure 4-20: Environmental scanning electron microscope micrograph of $5 \mathrm{wt} \%$ $x G n P^{\circledR}-M-5$ in epoxy

\footnotetext{
${ }^{7}$ The material contained within this section has been published in the journal "Journal of Composite Materials."

Citation:

J. A. King, D. R. Klimek, I. Miskioglu, G. Odegard; "Mechanical Properties of Graphene Nanoplatelet/Epoxy Composites” Journal of Composite Materials, Vol 49, No. 6, pp.659-668, March 2015.
} 


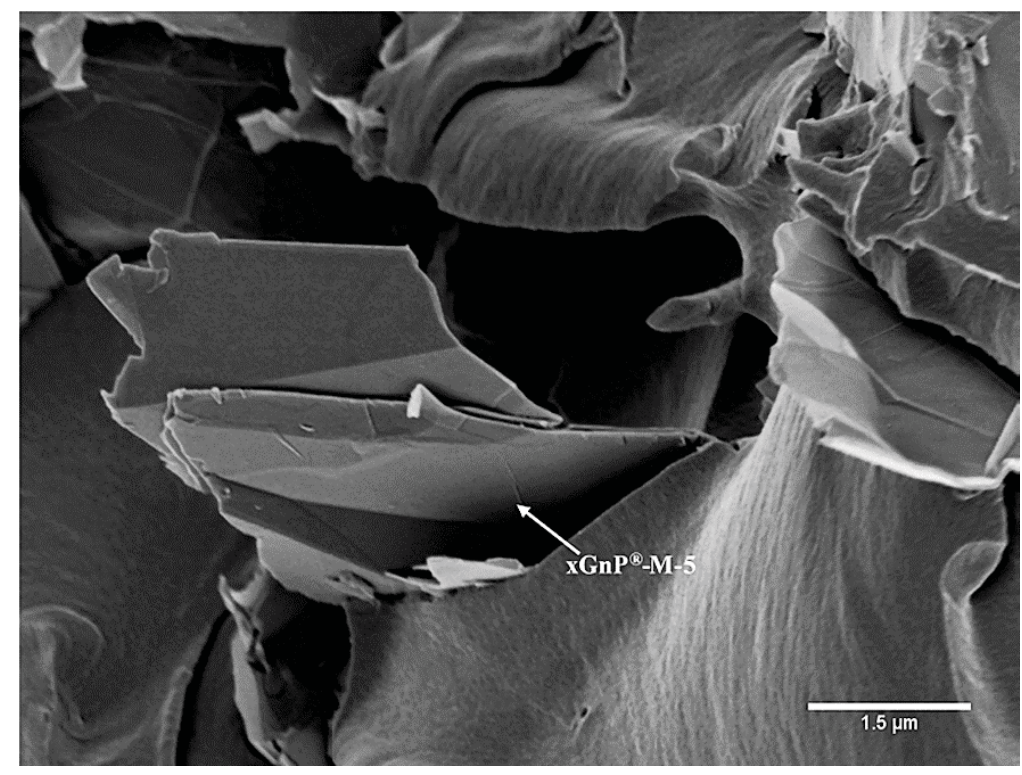

Figure 4-21: Field emission scanning electron microscope micrograph of 5 wt\% $x G n P^{\circledR}-M-5$ in epoxy

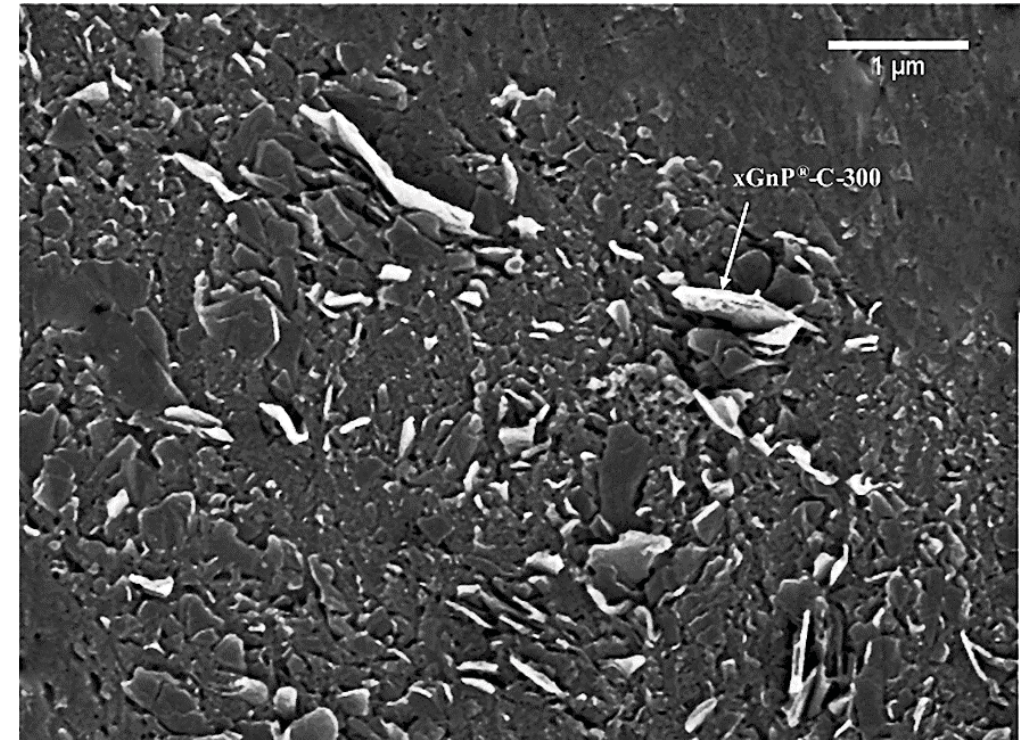

Figure 4-22: Environmental scanning electron microscope micrograph of 4 wt\% $x G n P^{\circledR}-C-300$ in epoxy 


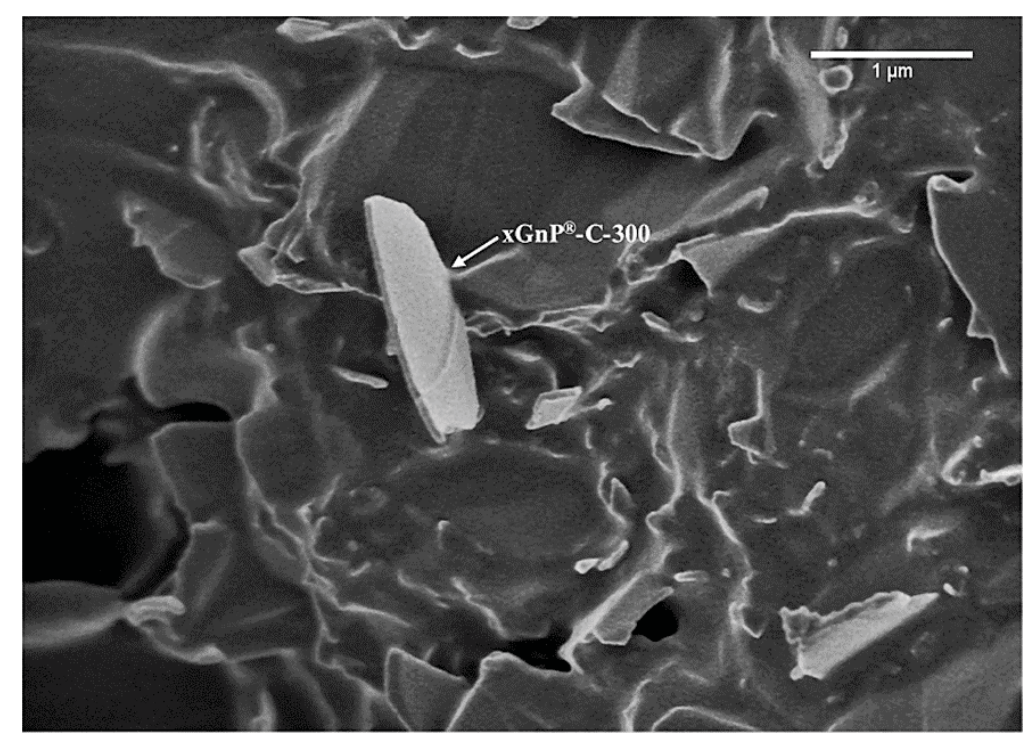

Figure 4-23: Field emission scanning electron microscope micrograph of 4 wt\% $x G n P^{\circledR}-C-300$ in epoxy

\subsection{3 $x G n P^{\circledR}-C-300$ with Continuous Carbon Fiber in Epoxy Microscopy Results}

Samples were cut to view the transverse tensile fracture surface. Figure 4-24 shows the transverse tensile fracture of $2 \mathrm{wt} \% \mathrm{xGnP}^{\circledR}-\mathrm{C}-300 / 68 \mathrm{wt} \%$ carbon fiber/ 30 $\mathrm{wt} \%$ epoxy composite. This figure clearly shows the $\mathrm{xGnP}^{\circledR}-\mathrm{C}-300$ on top of a carbon fiber. 


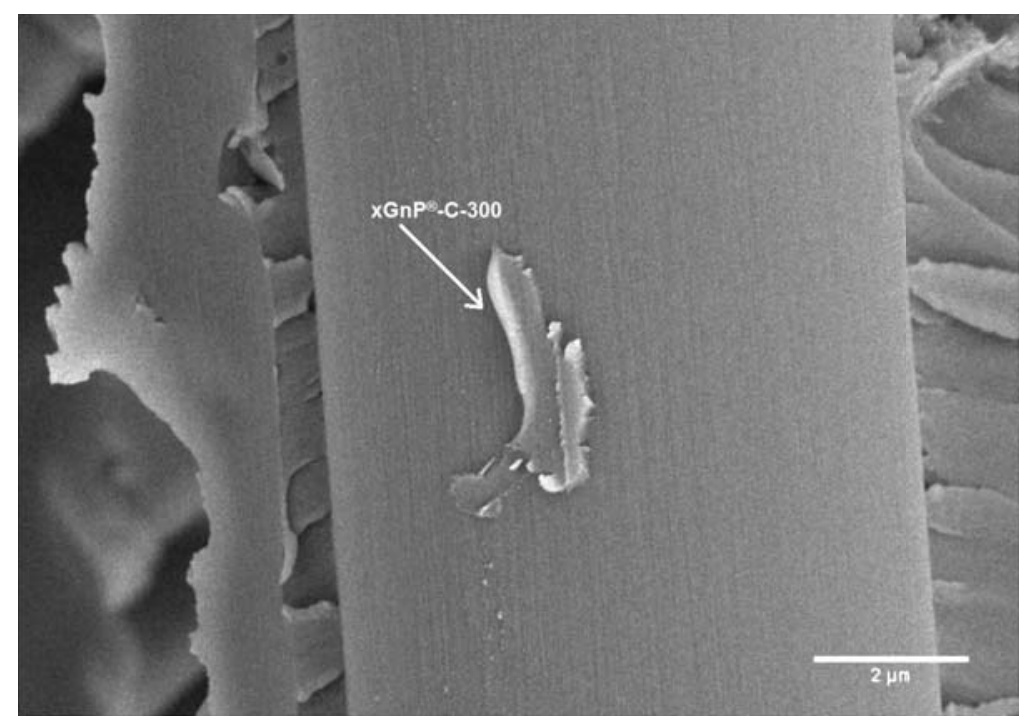

Figure 4-24: Field Emission Scanning Electron Microscope Image of the Fracture Surface of $x G n P^{\circledR}-C-300 / C a r b o n$ Fiber/Epoxy Composite

\subsubsection{Asbury TC307 in Epoxy Microscopy Results}

Figure 4-25 shows a FESEM image of a tensile fracture surface for $4 \mathrm{wt} \%$ TC307 in epoxy. This figure appears to shows a three-dimensional random arrangement of TC307 in epoxy. Figure 4-26 is also a FESEM image of the same fracture surface using

a higher magnification. This figure shows the platelet shape of GNP protruding out of the fracture surface (z-direction). 


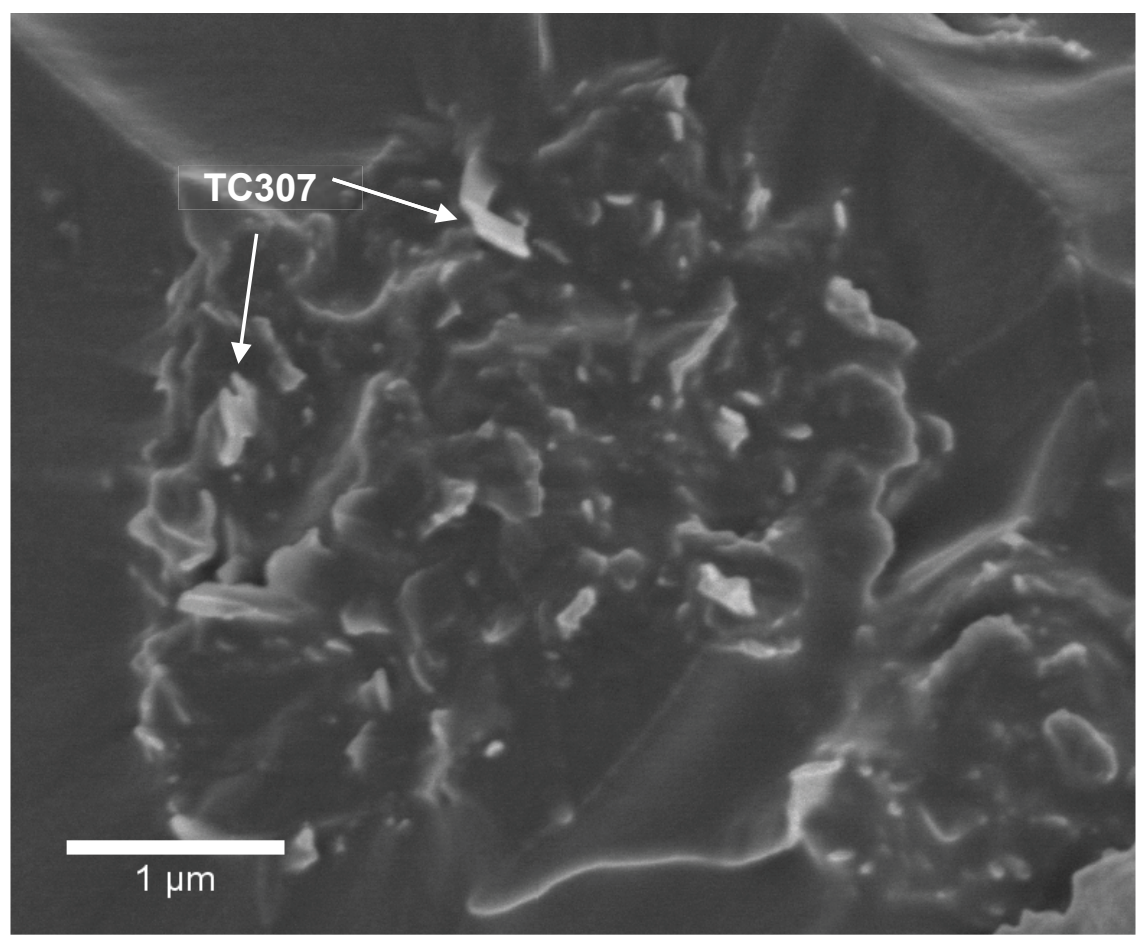

Figure 4-25: Field Emission Scanning Electron Micrograph of 4 wt\% TC307 in Epoxy

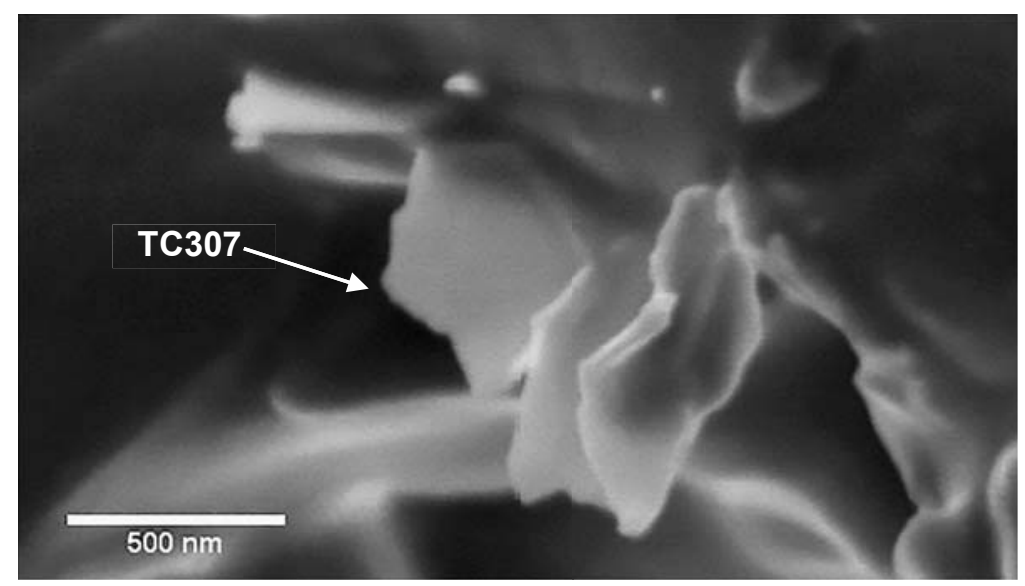

Figure 4-26: Field Emission Scanning Electron Micrograph of 4 wt\% TC307 in Epoxy at Higher Magnification 


\subsection{References}

[1] Fukushima, H. Graphite nanoreinforcements in polymer nanocomposites, Ph.D. Dissertation, Michigan State University, East Lansing, MI, 2003.

[2] J. A. King, D. R. Klimek, I. Miskioglu, G. Odegard; "Mechanical Properties of Graphene Nanoplatelet/Epoxy Composites" Journal of Applied Polymer Science, Vol 128, No. 6, pp.4217-4223, June 2013.

[3] XG Sciences Inc. $x G n P^{\circledR}$ Brand Graphene Nanoplatelets Product Information, 3101 Grand Oak Drive, Lansing, MI 48911 (2010).

[4] Hadden CM, Jensen BD, Bandyopadhyay A, et al. Molecular modeling of EPON862/graphite composites: interfacial characteristics for multiple crosslink densities. Compos Sci Technol 2013; 76: 92-99.

[5] Chatterjee, S., Wang, J., Kuo, W., et al. Chem. Phys. Lett., 531, 6-10 (2012).

[6] Tranchida, D.; Piccarolo, S.; Loos, J.; Alexeev, A. Macromolecules 2007, 40, 1259.

[7] Lagoudas, D.; Thakre, P. R.; Benzerga, A. A. Fract. Nano Eng. Mater. Struct. 2006, 1,649 .

[8] Tranchida, D.; Piccarolo, S.; Loos, J.; Alexeev, A. Appl. Phys. Lett. 2006, 89, 171905.

[9] Tehrani, M.; Safdari, M.; Al-Halik, M. S. Int. J. Plast. 2011, 27, 887.

[10] Dowling NE. Mechanical behavior of materials, $3^{\text {rd }}$ ed. Upper Saddle River, NJ: Pearson Prentice Hall, 2007.

[11] Zandiastashbar A, Ricu CR and Koratkar N. Control of epoxy creep using graphene. Small 2012; 8: 1676-1682.

[12] Narkis, M.; Lidor, G.; Vaxman, A.; Zuri, L. J. Electrostat. 1999, 47, 201.

[13] Weber, M.; Kamal, M. R. Polym. Compos. 1997, 18, 711.

[14] Li, J.; Kim, J. K. Compos. Sci. Technol. 2007, 67, 2114. 


\section{Halpin-Tsai Modulus Modeling}

The Halpin-Tsai model predicts the tensile modulus of composite materials using the aspect ratio and volume fraction of the filler as well as the tensile moduli of the matrix and filler. For unidirectional, discontinuous filler composites, the Halpin-Tsai model predicts the composite tensile modulus in both the longitudinal direction and the transverse direction using Equations 5-1 and 5-2 shown below:

$$
\begin{aligned}
& \frac{\mathrm{E}_{\mathrm{L}}}{\mathrm{E}_{\mathrm{M}}}=\frac{1+\xi \eta_{\mathrm{L}} \mathrm{V}_{\mathrm{f}}}{1-\eta_{\mathrm{L}} \mathrm{V}_{\mathrm{f}}} \\
& \frac{\mathrm{E}_{\mathrm{T}}}{\mathrm{E}_{\mathrm{M}}}=\frac{1+2 \eta_{\mathrm{T}} \mathrm{V}_{\mathrm{f}}}{1-\eta_{\mathrm{T}} \mathrm{V}_{\mathrm{f}}}
\end{aligned}
$$

where $\mathrm{E}_{\mathrm{L}}$ is the longitudinal composite tensile modulus, $\mathrm{E}_{\mathrm{T}}$ is the transverse composite tensile modulus, $\mathrm{E}_{\mathrm{M}}$ is the tensile modulus of the matrix, $\mathrm{L} / \mathrm{d}$ is the filler aspect ratio, $\mathrm{V}_{\mathrm{f}}$ is the volume fraction of filler, and $\xi$ is the filler shape factor [1-4]. The parameters $\eta_{L}$ and $\eta_{\mathrm{T}}$ are given in Equations 5-3 and 5-4 shown below:

$$
\begin{gathered}
\eta_{\mathrm{L}}=\frac{\left(\frac{E_{f}}{E_{M}}\right)-1}{\left(\frac{E_{f}}{E_{M}}\right)+\xi} \\
\eta_{\mathrm{T}}=\frac{\left(\frac{E_{f}}{E_{M}}\right)-1}{\left(\frac{E_{f}}{E_{M}}\right)+2}
\end{gathered}
$$

where $\mathrm{E}_{\mathrm{f}}$ is the tensile modulus of the filler [6-9]. Equations 5-5 and 5-6 are used for the two-dimensional (2D) random orientation of fillers and the three-dimensional (3D) random orientation of fillers are shown below: 


$$
\begin{aligned}
& E_{C}=\frac{3}{8} E_{L}+\frac{5}{8} E_{T} \quad \text { 2D Randomly oriented filler } \\
& E_{C}=\frac{1}{5} E_{L}+\frac{4}{5} E_{T} \quad \text { 3D Randomly oriented filler }
\end{aligned}
$$

where $\mathrm{E}_{\mathrm{C}}$ is the composite tensile modulus [2,3].

For all formulations, $\mathrm{E}_{\mathrm{M}}$, the tensile modulus of the matrix was measured experimentally to be $2.72 \mathrm{GPa}$. To model the GNP/epoxy system, filler information is needed. Graphene sheets have a tensile modulus of $1060 \mathrm{GPa}$ in the plane of the sheet [5]. GNP is made up of multiple sheets stacked on each other. When tensile loads are transferred to the GNP particles from the polymer, the van der Waals's dispersion bonding between layers is likely to fail before graphitic carbon-carbon bonding within the sheets fails, leading to further exfoliation of the particle. Hence, for the Halpin-Tsai model, the tensile modulus of GNP was equal to the modulus of exfoliation in the graphite c-axis (through-the-plane) of $36.5 \mathrm{GPa}[6]$. For platelets, the filler shape factor, $\xi$, is equal to 0.667 (L/d) [7]. In prior work, Kalaitzidou et al. used the Halpin-Tsai model with $\xi$ is equal to $0.667(\mathrm{~L} / \mathrm{d})$ to successfully model the tensile modulus of GNP/polypropylene composites that were produced by extrusion and then injection molding [8].

\subsection{Halpin-Tsai Model for $x G n P^{\circledR}-M-15$ in Epoxy}

Figure 5-1 shows the tensile modulus, the scaled nanoindentation modulus, the 2D and 3D Halpin-Tsai Models for $\mathrm{xGnP}^{\circledR}-\mathrm{M}-15$. The $\mathrm{L} / \mathrm{d}$ ratio used was equal to 2143 
(length $=15,000 \mathrm{~nm}$ and thickness $=7 \mathrm{~nm}$, same as 'as received'). The 2D Halpin-Tsai model fits the experimental data well. It is likely that during composite fabrication, a random 2D filler orientation was obtained (see Figure 4-18). This figure shows a random dispersion of the GNP in the $\mathrm{x}-\mathrm{y}$ plane. The GNP flakes are sticking out in the $\mathrm{z}$ plane.

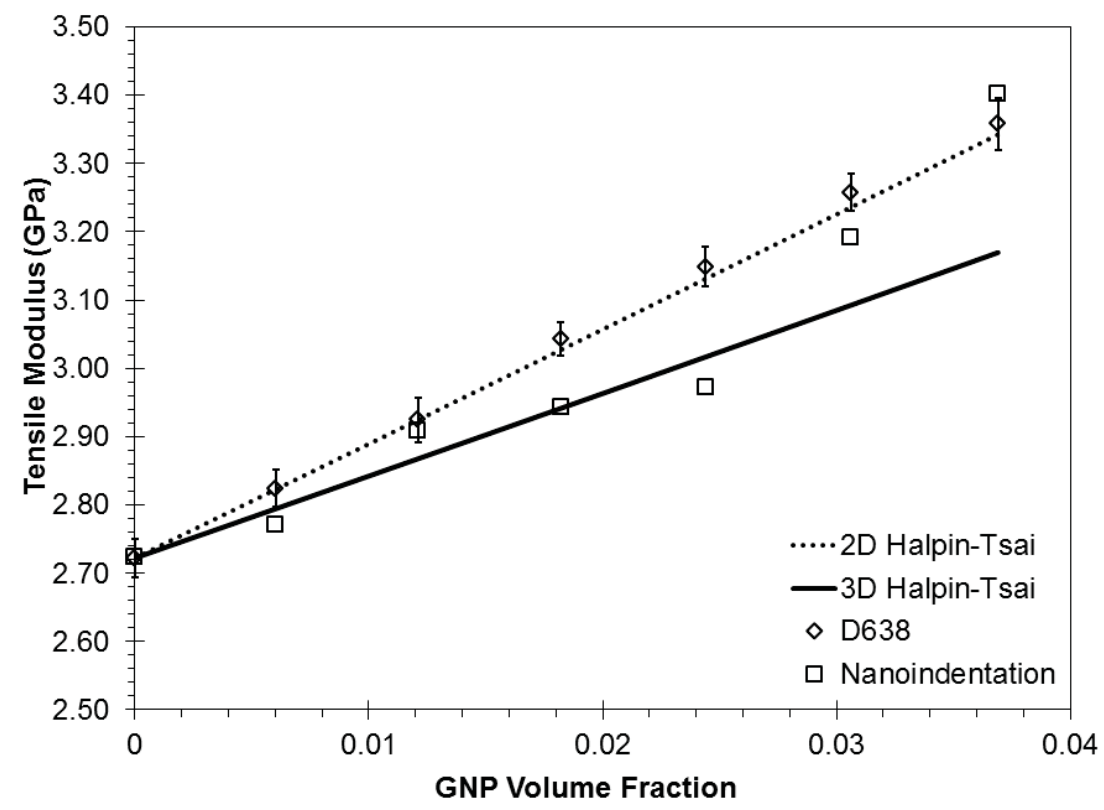

Figure 5-1: Tensile Modulus, Scaled Nanoindentation Modulus, and Halpin-Tsai Models for $x G n P^{\circledR}-M-15$ in Epoxy

\subsection{Halpin-Tsai Model for $\mathrm{xGnP}^{\circledR}-\mathrm{M}-5$ in Epoxy}

Figure 5-2 shows the tensile modulus, the scaled nanoindentation modulus, the 2D and 3D Halpin-Tsai Models for $\mathrm{xGnP}^{\circledR}-\mathrm{M}-15$. The $\mathrm{L} / \mathrm{d}$ ratio used was equal to 714.3 (length $=5,000 \mathrm{~nm}$ and thickness $=7 \mathrm{~nm}$, same as 'as received'). The 2D Halpin-Tsai model fits the experimental data well. It is likely that during composite fabrication, a 
random 2D filler orientation was obtained (see Figure 4-20). This figures also shows a random dispersion in the $\mathrm{x}-\mathrm{y}$ plane, with the GNP sticking out in the $\mathrm{z}$ direction.

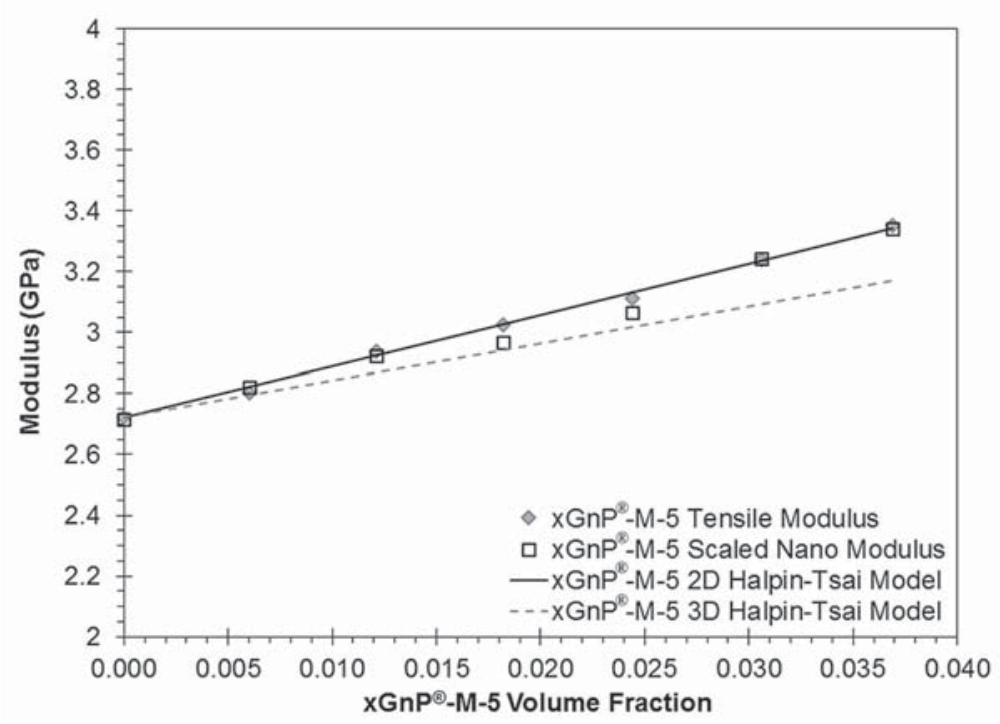

Figure 5-2: Tensile Modulus, Scaled Nanoindentation Modulus, and Halpin-Tsai Models for $x G n P^{\circledR}-M-5$ in Epoxy

\subsection{Halpin-Tsai Model for $\mathrm{xGnP}^{\circledR}-\mathrm{C}-300$ in Epoxy}

Figure 5-3 shows the tensile modulus, the scaled nanoindentation modulus, the $2 \mathrm{D}$ and 3D Halpin-Tsai Models for $\mathrm{xGnP}^{\circledR}-\mathrm{C}-300$ in epoxy. The $\mathrm{L} / \mathrm{d}$ ratio used was equal to 1000 (length $=2,000 \mathrm{~nm}$ and thickness $=2 \mathrm{~nm}$, same as 'as received'). The 3D HalpinTsai model fits the experimental data well. It is likely that during composite fabrication, a random 3D filler orientation was obtained (see Figure 4-22). This figure shows a random dispersion in all three planes (x-y-z). 


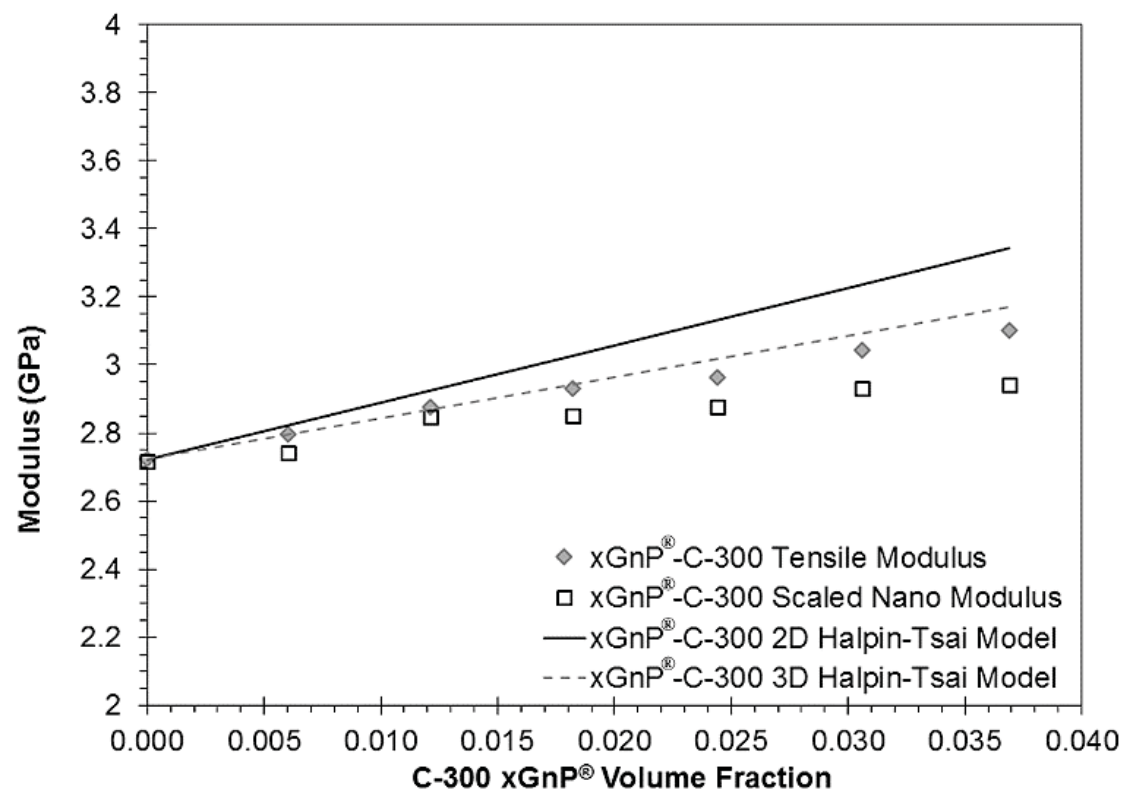

Figure 5-3: Tensile Modulus, Scaled Nanoindentation Modulus, and Halpin-Tsai Models for $x G n P^{\circledR}-C-300$ in Epoxy

\subsection{Halpin-Tsai Model for TC307 in Epoxy}

Figure 5-4 shows the tensile modulus, the scaled nanoindentation modulus, the 2D and 3D Halpin-Tsai Models for TC307 in epoxy. The L/d ratio used was equal to 500 (length $=1,000 \mathrm{~nm}$ and thickness $=2 \mathrm{~nm}$, same as 'as received'). The 3D Halpin-Tsai model fits the experimental data well. It is likely that during composite fabrication, a random 3D filler orientation was obtained (see Figure 4-25). This figure also shows a random dispersion in three-dimensions, thus visually confirming the 3D Halpin-Tsai model. 


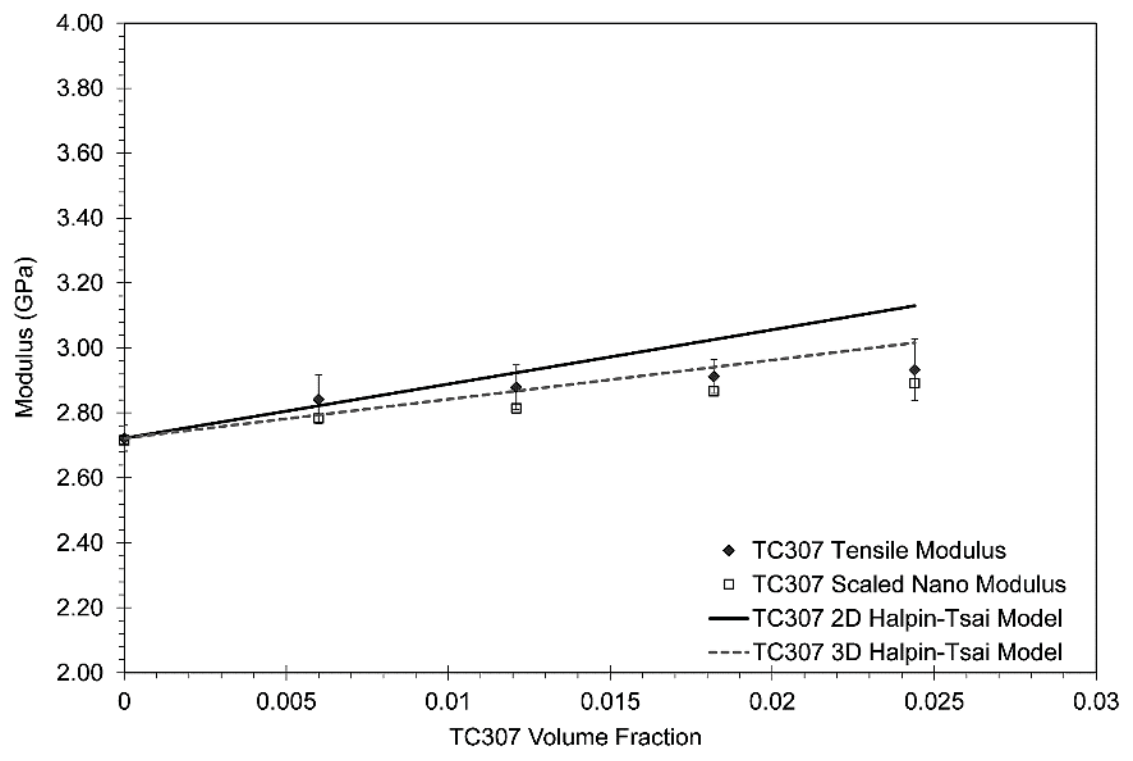

Figure 5-4: Tensile Modulus, Scaled Nanoindentation Modulus, and Halpin-Tsai Models for TC307 in Epoxy

\subsection{References}

[1] Stankovich, S., Dikin, D., Dommett, et al. Nature, 442, 282-286 (2006).

[2] Du, J. and Cheng, H. Macromol. Chem. Phys., 213, 1060-1077 (2012).

[3] Halpin, J.C., and Kardos, J. L. The Halpin-Tsai equations: A review. Polymer Engineering and Science 1976; 16: 344-352.

[4] Agarwal, B.D. and Broutman, L. J. Analysis and Performance of Fiber Composites. Wiley, New York, NY, 1980.

[5] Marsh, H.; Rodriguez-Reinoso, F. Sciences of carbon materials, Universidad de Alicante, San Vicente del Raspeig, Alicante, Spain, 2001.

[6] Tranchida, D.; Piccarolo, S.; Loos, J.; Alexeev, A. Appl. Phys. Lett. 2006, 89, 171905.

[7] Van Es, M. Polymer-clay nanocomposites: The importance of particle dimensions, Ph.D. Dissertation, Delft University of Technology, Delft, Netherlands, 2001.

[8] Kalaitzidou, K.; Fukushima, H.; Miyagawa, H.; Drzal, L. T. Polym. Eng. Sci. 2007, 47, 1796. 


\section{Conclusions and Future Work}

\subsection{Tensile Properties}

\subsubsection{Neat Epoxy and GNP/Epoxy Composite Tensile Properties}

Adding carbon fillers to a polymer will often change the mechanical properties. It was observed that the addition of any type of GNP will increase the tensile modulus. The modulus for the neat epoxy was measured to be $\sim 2.72 \mathrm{GPa}$. The addition of $6 \mathrm{wt} \%$ (3.69 vol\%) $\mathrm{xGnP}^{\circledR}-\mathrm{M}-15$ in epoxy increased the tensile modulus to $\sim 3.36 \mathrm{GPa}$. $6 \mathrm{wt} \%$ (3.69 vol\%) $\mathrm{xGnP}^{\circledR}-\mathrm{M}-5$ in epoxy was very close to $\mathrm{xGnP}^{\circledR}$-M-15 with a modulus of $\sim 3.35$ GPa. Where $6 \mathrm{wt} \%$ (3.69 vol\%) $\mathrm{xGnP}^{\circledR}$-C-300 in epoxy only increased the modulus to $\sim 3.10 \mathrm{GPa}$. The maximum amount of TC307 added to epoxy was $4 \mathrm{wt} \%$ (2.44 vol\%), this increased the tensile modulus to $\sim 2.93 \mathrm{GPa}$.

The stress and strain for the $\mathrm{xGnP}^{\circledR}-\mathrm{M}-15$ in epoxy and $\mathrm{x} G n \mathrm{P}^{\circledR}-\mathrm{M}-5$ in epoxy decreased rapidly as more GNP was added. The stress and strain for $\mathrm{xGnP}^{\circledR}-\mathrm{C}-300$ and TC307 stays constant until about $4 \mathrm{wt} \%$ and then begins to decrease slowly as more GNP is added. The ultimate tensile stress and strain at ultimate tensile stress for neat epoxy was measured to be $\sim 77.6 \mathrm{MPa}$ and $\sim 8.0 \%$ respectively. For $4 \mathrm{wt} \%$ (2.44 vol \%) $\mathrm{xGnP}^{\circledR}$ M-15 in epoxy, stress was measured to be $\sim 41.9 \mathrm{MPa}$ with $\sim 2.2 \%$ strain. For $4 \mathrm{wt} \%$ (2.44 vol \%) xGnP ${ }^{\circledR}-\mathrm{M}-5$ in epoxy, stress was found to be $\sim 43.9 \mathrm{MPa}$, and strain was $\sim 2.3 \%$. For $4 \mathrm{wt} \%$ (2.44 vol \%) $\mathrm{xGnP}^{\circledR}-\mathrm{C}-300$ in epoxy, strength was measured to be $\sim 75.8 \mathrm{MPa}$ and $\sim 4.6 \%$ (closer to neat epoxy than the M grade GNPs). For $4 \mathrm{wt} \%$ (2.44 vol \%) TC307 in epoxy, $75.8 \mathrm{MPa}$ was found for stress and $\sim 4.6 \%$ for strain. 
The two M-grade GNPs showed very similar properties to one another, the only difference between the two M-grades was the platelet diameter. The larger one $\left(\mathrm{xGnP}^{\circledR}\right.$ M-15) had a diameter of $\sim 3$ times that of the than the smaller $\left(\mathrm{xGnP}^{\circledR}-\mathrm{M}-5\right)$. The $\mathrm{xGnP}^{\circledR}-$ C-300 and the TC307 showed similar properties to one another. The size, shape, and surface area for the two GNPs were very similar, it was expected to get similar tensile properties.

\subsubsection{Continuous Carbon Fiber/Epoxy and Continuous Carbon Fiber/xGnP®- C-300/Epoxy Composite Tensile Properties}

For the $\mathrm{xGnP}^{\circledR}-\mathrm{C}-300$ with continuous carbon fiber in epoxy composites, the $\mathrm{xGnP}^{\circledR}-\mathrm{C}-300$ did not appear to have an effect on the tensile modulus in the axial direction, but increased the tensile modulus in the transverse direction. The axial modulus for the unidirectional continuous carbon fiber/epoxy composite was found to be $134 \pm 9 \mathrm{GPa}$. For the $3 \mathrm{wt} \% \mathrm{xGnP}^{\circledR}-\mathrm{C}-300$ with unidirectional continuous carbon fiber/epoxy, the modulus was measured to be $137 \pm 9 \mathrm{GPa}$. The continuous carbon fiber tensile properties dominate over the GNP/epoxy tensile properties in the axial direction. The transverse modulus increases from $7.81 \mathrm{GPa}$ for CCF/epoxy to $8.29 \mathrm{GPa}$ for $2 \mathrm{wt} \%$ $\mathrm{xGnP}^{\circledR}-\mathrm{C}-300$ with $\mathrm{CCF} / \mathrm{epoxy}$.

\subsubsection{Tensile Property Summary}

Based on the tensile properties obtained for all four types of GNP added to epoxy, the optimal GNP to use would be the $\mathrm{xGnP}^{\circledR}-\mathrm{C}-300$ or TC307. These GNPs had 
approximately the same effect on the tensile properties of the composite. It is

recommended that $2 \mathrm{wt} \%$ of either $\mathrm{xGnP}^{\circledR}-\mathrm{C}-300$ or $\mathrm{TC} 307$ be added to epoxy. At this filler loading the strength and strain of the composite are still close to that of the neat epoxy, and the tensile modulus increases slightly. This suggests that the load transfer between the GNP and the epoxy is better than the two M-grade GNPs.

\subsection{Nanoindentation Properties for Neat Epoxy and GNP/Epoxy Composites}

The modulus as determined by nanoindentation for all four types of GNP was 1.33 times greater than the macroscopic tensile modulus. This was thus used as a scaling factor, a similar trend has been noticed for most polymer composites. It is likely due to pile-up of material around the indenter tip, the Oliver-Pharr method does not take into account the viscoelasticity of polymer based materials. The modulus measured by nanoindentation for the neat epoxy before scaling was measured to be $\sim 3.61 \mathrm{GPa}$. $6 \mathrm{wt} \%$ $\mathrm{xGnP}^{\circledR}-\mathrm{M}-15$ in epoxy had a modulus of $\sim 4.44 \mathrm{GPa}$. The modulus measured for $6 \mathrm{wt} \%$ $\mathrm{xGnP}{ }^{\circledR}-\mathrm{M}-5$ in epoxy was $\sim 4.45 \mathrm{GPa}$. For $6 \mathrm{wt} \% \mathrm{xGnP}^{\circledR}-\mathrm{C}-300$ in epoxy the modulus was found to be $\sim 3.91 \mathrm{GPa}$. And for $4 \mathrm{wt} \% \mathrm{TC} 307$ in epoxy $3.85 \mathrm{GPa}$ was measured. The modulus as determine by nanoindentation for all the GNPs showed a similar trend to the modulus as determined by macroscopic tensile tests. 


\subsection{Electrical Resistivity Properties for Neat Epoxy and GNP/Epoxy Composites}

Electrical resistivity (ER) tests were conducted for all three types of XG Sciences Inc GNPs. This data was useful for finding the percolation threshold (the point at which the electrical resistivity decreases dramatically). The percolation threshold equation is a function of $\mathrm{L} / \mathrm{d}$ (the aspect ratio), the aspect ratio is used in the Halpin-Tsai model. The neat epoxy has an ER of $2.88 \times 10^{16} \Omega$-cm. The ER for $2 \mathrm{wt} \% \mathrm{xGnP}^{\circledR}-\mathrm{M}-15$ in epoxy dropped to $2.61 \times 10^{9} \Omega-\mathrm{cm}$, the percolation threshold for $\mathrm{xGnP}^{\circledR}-\mathrm{M}-15$ was approximated to be $\sim 0.99$ vol $\%(\sim 1.6 \mathrm{wt} \%)$. The ER for $4 \mathrm{wt}^{\%} \% \mathrm{xGnP}^{\circledR}-\mathrm{M}-5$ in epoxy dropped to $3.78 \times 10^{9} \Omega$-cm. The percolation threshold was approximated to be $\sim 2.53$ vol $\%(\sim 4.1$ wt \%) for $\mathrm{xGnP}^{\circledR}-\mathrm{M}-5$ and $\sim 2.09$ vol\% $(\sim 3.4 \mathrm{wt} \%)$ for $\mathrm{xGnP}^{\circledR}-\mathrm{C}-300$. For $4 \mathrm{wt} \% \mathrm{xGnP}^{\circledR}{ }_{-}$ C-300 in epoxy the ER dropped to $3.48 \times 10^{8} \Omega-\mathrm{cm}$. The approximated percolation threshold matched the filler loading that produced a drop in the electrical resistivity of the composite for all three types of GNP. Since the approximated percolation threshold matched the actual percolation threshold, the vendor given aspect ratios were used for the Halpin-Tsai model.

\subsection{Glass Transition Temperature $\left(T_{g}\right)$ for Neat Epoxy and GNP/Epoxy Composites}

The glass transition temperature is the transition of a polymer from the "glassy" state to the "rubbery" state. A composite in the "rubbery state is more pliable than one in the "glassy" state, this makes the composite less brittle. The glass transition temperature 
for $\mathrm{xGnP}^{\circledR}-\mathrm{M}-15$ in epoxy was measured two different ways, DSC and DMA tests. The $\mathrm{T}_{\mathrm{g}}$ from DMA for neat epoxy (determined from the peak of the tan delta curve) was found to be $155.8{ }^{\circ} \mathrm{C} \pm 0.4{ }^{\circ} \mathrm{C}(\mathrm{n}=6)$. At around the percolation threshold $(\sim 3 \mathrm{wt} \%)$ the $\mathrm{T}_{\mathrm{g}}$ for $\mathrm{xGnP} \mathrm{P}^{\circledR}-\mathrm{M}-15$ in epoxy drops to about $150.4{ }^{\circ} \mathrm{C} \pm 0.3{ }^{\circ} \mathrm{C}(\mathrm{n}=3)$. The $\mathrm{T}_{\mathrm{g}}$ after this point increased and $155.9^{\circ} \mathrm{C} \pm 0.5^{\circ} \mathrm{C}(\mathrm{n}=5)$ at $6 \mathrm{wt} \% \mathrm{xGnP} \mathrm{P}^{\circledR}-\mathrm{M}-15$ in epoxy. This same trend was observed with the $\mathrm{T}_{\mathrm{g}}$ determined by DSC. The neat epoxy $\mathrm{T}_{\mathrm{g}}$ was measured to be $143.3{ }^{\circ} \mathrm{C} \pm 0.7{ }^{\circ} \mathrm{C}(\mathrm{n}=7)$ and decreases to $138.7^{\circ} \mathrm{C} \pm 2.4{ }^{\circ} \mathrm{C}(\mathrm{n}=8)$ at $3 \mathrm{wt} \% \mathrm{xGnP}{ }^{\circledR}-\mathrm{M}-$ 15 in epoxy. It then increased to $145.6^{\circ} \mathrm{C} \pm 2.4^{\circ} \mathrm{C}(\mathrm{n}=8)$ for $6 \mathrm{wt} \% \mathrm{xGnP}^{\circledR}-\mathrm{M}-15$ in epoxy.

DMA was used to find the $T_{g}$ for $\mathrm{xGnP}^{\circledR}-\mathrm{M}-5$ in epoxy and $\mathrm{xGnP}^{\circledR}-\mathrm{C}-300$ in epoxy. For $\mathrm{xGnP}^{\circledR}-\mathrm{M}-5$ in epoxy $\mathrm{T}_{\mathrm{g}}$ drops to $153.1{ }^{\circ} \mathrm{C} \pm 0.4{ }^{\circ} \mathrm{C}(\mathrm{n}=3)$, this occurs at $2 \mathrm{wt} \%$ and it increases to $156.4^{\circ} \mathrm{C} \pm 0.1^{\circ} \mathrm{C}(\mathrm{n}=3)$ for $6 \mathrm{wt} \% \mathrm{xGnP}^{\circledR}-\mathrm{M}-5$ in epoxy. For $\mathrm{xGnP}{ }^{\circledR}-\mathrm{C}-300$ in epoxy at $2 \mathrm{wt} \%$, the $\mathrm{T}_{\mathrm{g}}$ decreases to $143.4{ }^{\circ} \mathrm{C} \pm 0.2{ }^{\circ} \mathrm{C}(\mathrm{n}=3)$. The $\mathrm{T}_{\mathrm{g}}$ increased to $153.4{ }^{\circ} \mathrm{C} \pm 0.2{ }^{\circ} \mathrm{C}(\mathrm{n}=3)$ for $6 \mathrm{wt} \% \mathrm{xGnP}^{\circledR}-\mathrm{C}-300$ in epoxy. Since $2 \mathrm{wt} \% \mathrm{xGnP}^{\circledR}-\mathrm{C}-300$ in epoxy has the lowest glass transition temperature, it is the optimum formulation.

\subsection{Halpin-Tsai Modeling for Neat Epoxy and GNP/Epoxy Composites}

The Halpin-Tsai model is an existing model that takes into account the tensile properties and volume fractions of the matrix and the filler material. It also accounts for the composite filler geometry. A modified shape factor was used to predict the modulus behavior of a platelet shaped filler geometry. For the two larger GNPs $\left(\mathrm{xGnP}^{\circledR}-\mathrm{M}-15\right.$ and $\mathrm{xGnP}^{\circledR}-\mathrm{M}-5$ ), the two-dimensional randomly oriented filler Halpin-Tsai model fit the 
best. By looking at images of the GNP in epoxy it was apparent that a 2D dispersion was obtained. Since the platelet diameter is much larger than the thickness it was expected to see this $2 \mathrm{D}$ dispersion.

For the two smaller GNPs $\left(\mathrm{xGnP}^{\circledR}-\mathrm{C}-300\right.$ and TC307) the platelet diameter is closer to the platelet thickness and it is believed that a 3D dispersion was obtained. This is visible through looking at images of the two types of GNP in epoxy. Thus, a threedimensional randomly oriented Halpin-Tsai model fit the data the best.

\subsection{Overall Conclusions}

Four types of GNP were added to an epoxy matrix to produce polymer composites. The composites were tested for mechanical properties. A different mixing method was developed for each of the four types of GNP to ensure that good dispersion was achieved. Tensile properties were measured and the fracture surface produced was imaged to see

the dispersion in the composite. From tensile testing results, $2 \mathrm{wt} \%$ of $\mathrm{xGnP}^{\circledR}-\mathrm{C}-300$ or TC307 in epoxy is recommended. This formulation increases the composite tensile modulus without sacrificing the strength and strain dramatically.

When $\mathrm{xGnP}^{\circledR}-\mathrm{C}-300$ is added to a unidirectional continuous carbon fiber composite, there is no change in the composite tensile modulus. The carbon fiber dominates the tensile properties for a unidirectional carbon fiber composite. 


\subsection{Recommendations for Future Work}

This project showed that adding GNP to an epoxy can increase the tensile modulus, it would be beneficial to see if the GNP has a similar effect on a different aerospace epoxy system. There are also many other different types of GNP available from XG Sciences Inc., Asbury Carbons, and others. Different surface treatments on the GNP may allow for chemical bonding between the Epoxy and the GNP. If the chemical bond created between the GNP and epoxy is strong then load transfer between the filler and the matrix will occur.

Load transfer between the GNP and epoxy should be investigated. It is important to have good load transfer between the filler and the matrix, this allows for enhanced mechanical properties and not just increased stiffness. If the load transfer is not good then the filler is like a void space in the epoxy and will create a weak point in the composite. For GNP with a higher specific surface area, it appears as though the load transfer between the GNP and epoxy is better.

The surface area of the platelets seems to play in important role in the tensile properties. The larger the surface area, the better the ultimate tensile stress and strain at ultimate tensile stress of the composite. Only by having a controlled set of tests (hold diameter and thickness constant but change surface areas) can the effect of surface area on the tensile properties be determined. Specifically XG Sciences Inc. has an H-Grade GNP, the dimensions for the H-Grade are similar to the M-Grade the only difference is the surface area $\left(\sim 60 \mathrm{~m}^{2} / \mathrm{g}\right.$ for $\mathrm{H}-$-Grade). $1-6 \mathrm{wt} \%$ of $\mathrm{xGnP}^{\circledR}-\mathrm{H}-15$ and $\mathrm{xGnP}{ }^{\circledR}-\mathrm{H}-5$ in EPON 862/EPIKURE Curing Agent W should be fabricated and tested. 
All of the mechanical properties were determined at room temperature. It is not likely that these composites would be used at ambient conditions. For aircrafts, they are usually exposed to high temperatures. It is recommended that the tensile properties at elevated temperatures (just below and above the $\mathrm{T}_{\mathrm{g}}$ ) be measured to determine if the composite can withstand higher temperatures.

For carbon fiber composites, stiffness only tells part of the mechanical story. Fracture toughness testing can tell more about the failure mechanisms associated with a $\mathrm{CCF} /$ epoxy composite. It is important to ensure that there is good adhesion between the carbon fiber and the epoxy matrix. Delamination is one of the main modes of failure for a continuous carbon fiber composite. It is recommended that fracture toughness tests be conducted to better understand the failure mechanisms for the continuous carbon fiber/epoxy composites. 


\section{Appdenix A: Tensile Results}

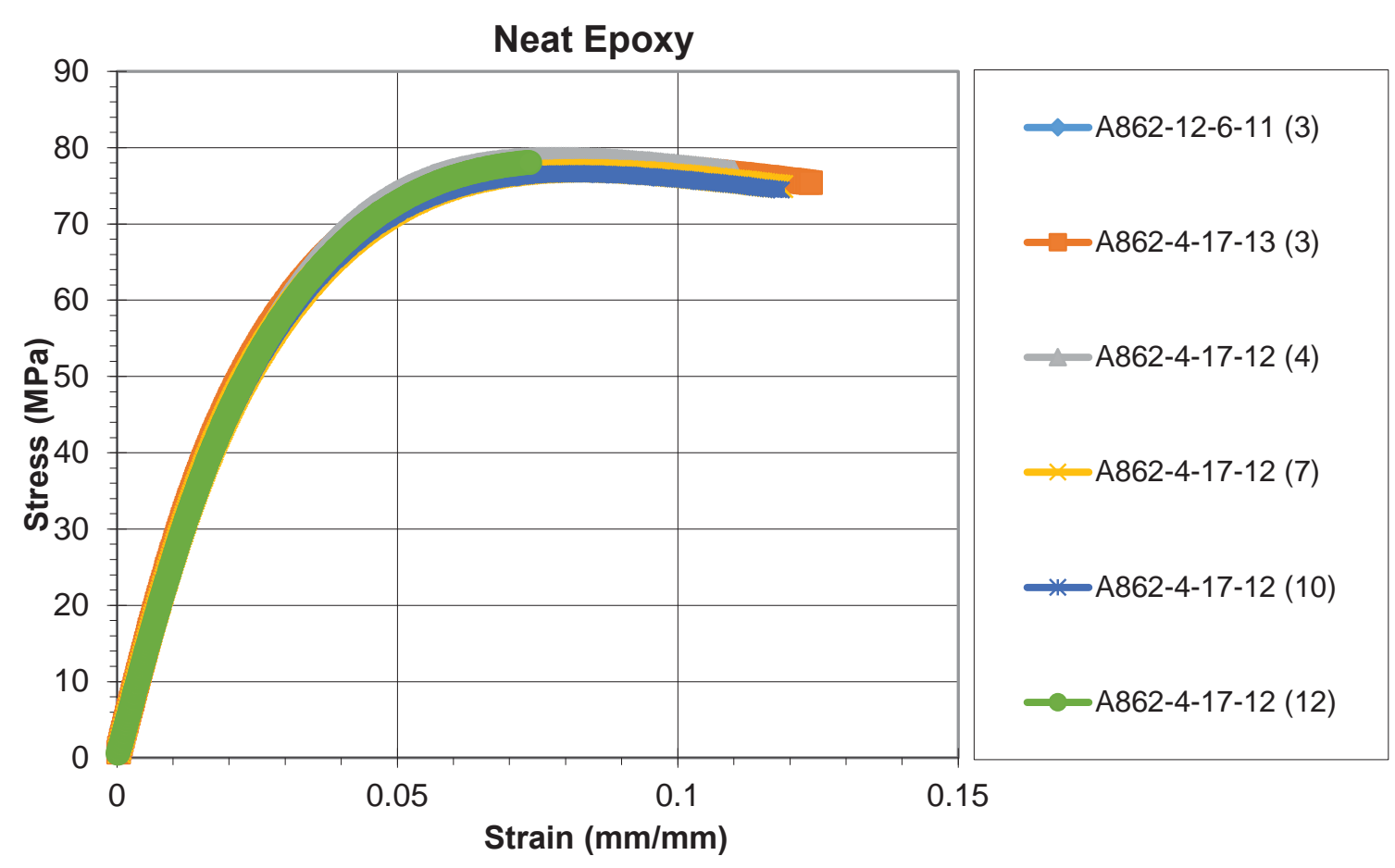

Figure A-1: Tensile Results for Neat Epoxy

Table A-1: Tensile Results for Neat Epoxy

\begin{tabular}{|l|c|c|c|c|c|c|}
\hline \multicolumn{1}{|c|}{ Sample } & No. & $\begin{array}{c}\text { Ultimate } \\
\text { Tensile } \\
\text { Stress } \\
\text { (MPa) }\end{array}$ & $\begin{array}{c}\text { Strain at } \\
\text { Ultimate } \\
\text { Tensile } \\
\text { Stress (\%) }\end{array}$ & $\begin{array}{c}\text { Tensile } \\
\text { Fracture } \\
\text { Stress } \\
\text { (MPa) }\end{array}$ & $\begin{array}{c}\text { Strain at } \\
\text { Tensile } \\
\text { Fracture } \\
\text { Stress (\%) }\end{array}$ & $\begin{array}{c}\text { Tensile } \\
\text { Modulus } \\
\text { (GPa) }\end{array}$ \\
\hline A862-12-6-11 & 3 & 76.998 & 8.013 & 76.986 & 8.189 & 2.717 \\
\hline A862-4-17-12 & 3 & 77.854 & 8.180 & 75.559 & 12.209 & 2.757 \\
\hline A862-4-17-12 & 4 & 78.900 & 7.898 & 77.279 & 10.858 & 2.782 \\
\hline A862-4-17-12 & 7 & 76.976 & 8.272 & 74.873 & 11.852 & 2.710 \\
\hline A862-4-17-12 & 10 & 76.591 & 8.201 & 74.569 & 11.701 & 2.691 \\
\hline A862-4-17-12 & 12 & 78.065 & 7.335 & 78.065 & 7.335 & 2.678 \\
\hline Average & & $\mathbf{7 7 . 5 6}$ & $\mathbf{7 . 9 8}$ & $\mathbf{7 6 . 2 2}$ & $\mathbf{1 0 . 3 6}$ & $\mathbf{2 . 7 2}$ \\
\hline Standard Deviation & $\mathbf{0 . 8 6}$ & $\mathbf{0 . 3 5}$ & $\mathbf{1 . 4 2}$ & $\mathbf{2 . 0 8}$ & $\mathbf{0 . 0 4}$ \\
\hline Count & & $\mathbf{6}$ & $\mathbf{6}$ & $\mathbf{6}$ & $\mathbf{6}$ & $\mathbf{6}$ \\
\hline
\end{tabular}




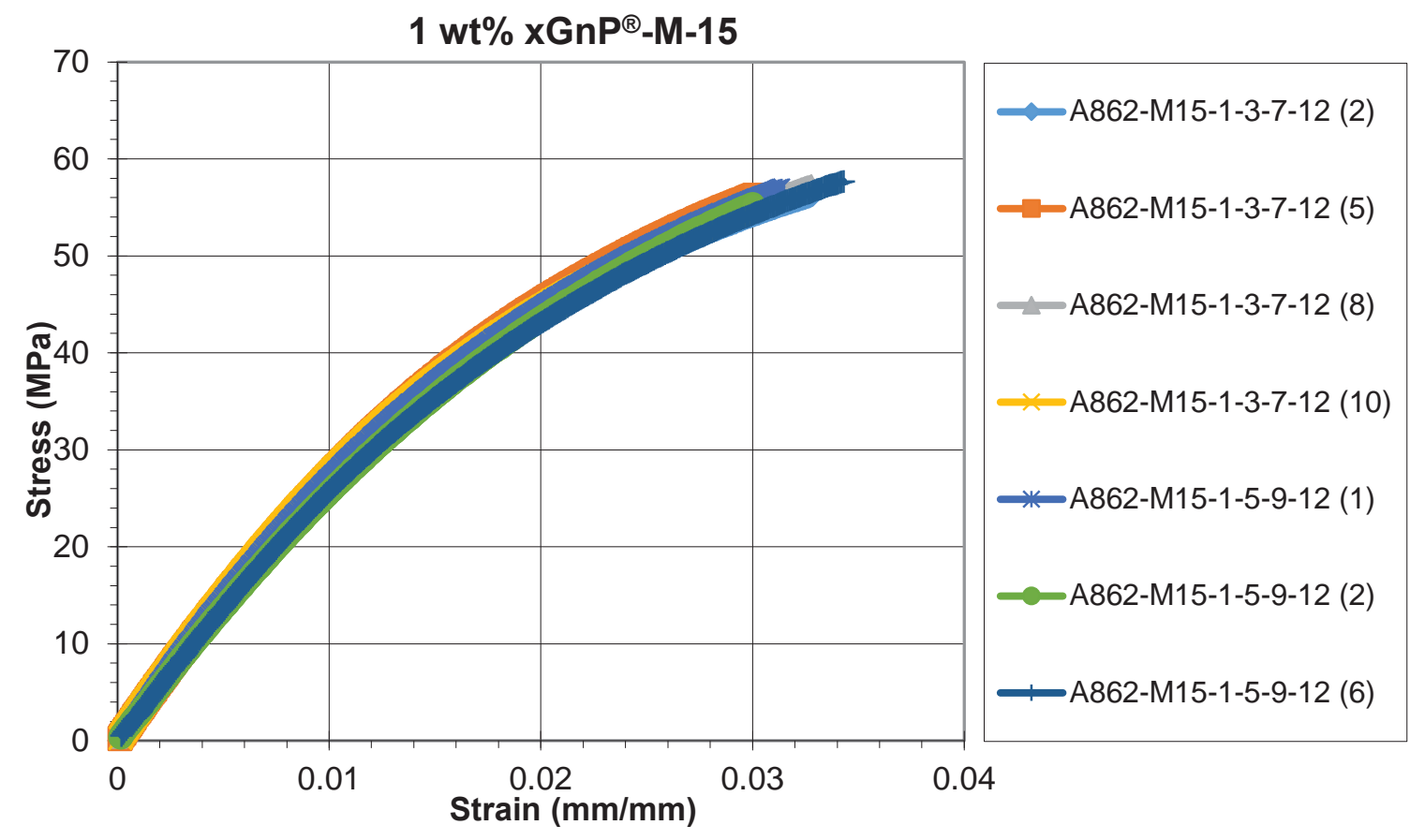

Figure A-2: Tensile Results for 1 wt\% $x G n P^{\circledR}-M-15$ in Epoxy

Table A-2: Tensile Results for 1 wt\% $x G n P^{\circledR}-M-15$ in Epoxy

\begin{tabular}{|l|c|c|c|c|c|c|}
\hline \multicolumn{1}{|c|}{ Sample } & No. & $\begin{array}{c}\text { Ultimate } \\
\text { Tensile } \\
\text { Stress } \\
\text { (MPa) }\end{array}$ & $\begin{array}{c}\text { Strain at } \\
\text { Ultimate } \\
\text { Tensile } \\
\text { Stress (\%) }\end{array}$ & $\begin{array}{c}\text { Tensile } \\
\text { Fracture } \\
\text { Stress } \\
\text { (MPa) }\end{array}$ & $\begin{array}{c}\text { Strain at } \\
\text { Tensile } \\
\text { Fracture } \\
\text { Stress (\%) }\end{array}$ & $\begin{array}{c}\text { Tensile } \\
\text { Modulus } \\
\text { (MPa) }\end{array}$ \\
\hline A862-M15-1-3-7-12 & 2 & 56.001 & 3.282 & 56.001 & 3.282 & 2.842 \\
\hline A862-M15-1-3-7-12 & 5 & 56.244 & 3.010 & 56.244 & 3.010 & 2.829 \\
\hline A862-M15-1-3-7-12 & 8 & 57.461 & 3.278 & 57.461 & 3.278 & 2.802 \\
\hline A862-M15-1-3-7-12 & 10 & 55.000 & 3.007 & 55.000 & 3.007 & 2.869 \\
\hline A862-M15-1-5-9-12 & 1 & 57.118 & 3.138 & 57.118 & 3.138 & 2.863 \\
\hline A862-M15-1-5-9-12 & 2 & 55.279 & 3.001 & 55.279 & 3.001 & 2.791 \\
\hline A862-M15-1-5-9-12 & 6 & 57.676 & 3.430 & 57.676 & 3.430 & 2.773 \\
\hline Average & & $\mathbf{5 6 . 4 0}$ & $\mathbf{3 . 1 6}$ & $\mathbf{5 6 . 4 0}$ & $\mathbf{3 . 1 6}$ & $\mathbf{2 . 8 2}$ \\
\hline Standard Deviation & & $\mathbf{1 . 0 5}$ & $\mathbf{0 . 1 7}$ & $\mathbf{1 . 0 5}$ & $\mathbf{0 . 1 7}$ & $\mathbf{0 . 0 4}$ \\
\hline Count & & $\mathbf{7}$ & $\mathbf{7}$ & $\mathbf{7}$ & $\mathbf{7}$ & $\mathbf{7}$ \\
\hline
\end{tabular}




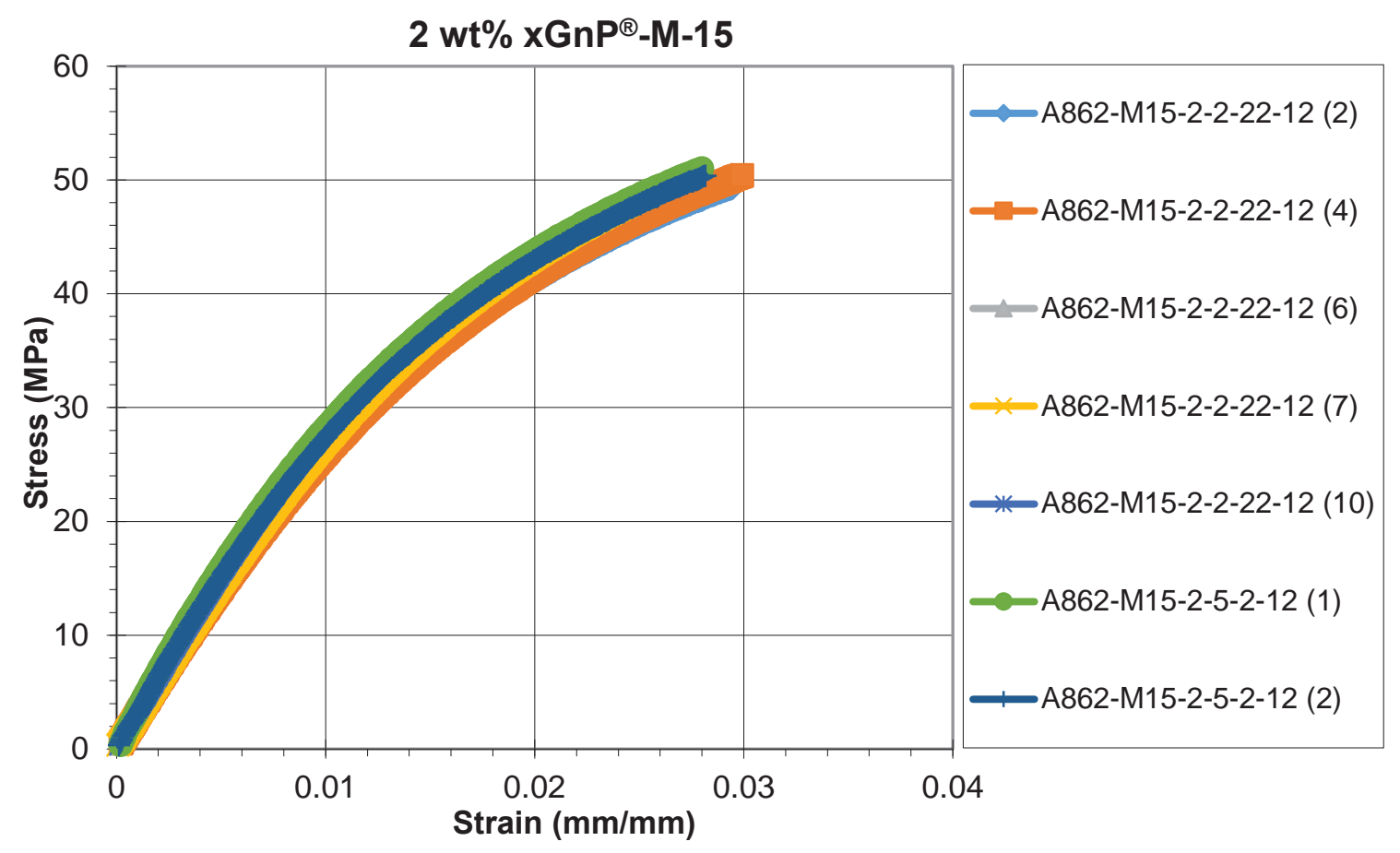

Figure A-3: Tensile Results for $2 w t \% x G n P^{\circledR}-M-15$ in Epoxy

Table A-3: Tensile Results for 2 wt\% $x G n P^{\circledR}-M-15$ in Epoxy

\begin{tabular}{|l|c|c|c|c|c|c|}
\hline \multicolumn{1}{|c|}{ Sample } & No. & $\begin{array}{c}\text { Ultimate } \\
\text { Tensile } \\
\text { Stress } \\
\text { (MPa) }\end{array}$ & $\begin{array}{c}\text { Strain at } \\
\text { Ultimate } \\
\text { Tensile } \\
\text { Stress (\%) }\end{array}$ & $\begin{array}{c}\text { Tensile } \\
\text { Fracture } \\
\text { Stress } \\
\text { (MPa) }\end{array}$ & $\begin{array}{c}\text { Strain at } \\
\text { Tensile } \\
\text { Fracture } \\
\text { Stress (\%) }\end{array}$ & $\begin{array}{c}\text { Tensile } \\
\text { Modulus } \\
\text { (GPa) }\end{array}$ \\
\hline A862-M15-2-2-22-12 & 2 & 49.046 & 2.946 & 49.046 & 2.946 & 2.889 \\
\hline A862-M15-2-2-22-12 & 4 & 50.384 & 2.991 & 50.384 & 2.991 & 2.899 \\
\hline A862-M15-2-2-22-12 & 6 & 49.505 & 2.616 & 49.505 & 2.616 & 2.862 \\
\hline A862-M15-2-2-22-12 & 7 & 48.838 & 2.561 & 48.838 & 2.561 & 2.914 \\
\hline A862-M15-2-2-22-12 & 10 & 50.130 & 2.704 & 50.130 & 2.704 & 2.971 \\
\hline A862-M15-2-5-2-12 & 1 & 50.999 & 2.799 & 50.999 & 2.799 & 2.973 \\
\hline A862-M15-2-5-2-12 & 2 & 50.383 & 2.816 & 50.383 & 2.816 & 2.962 \\
\hline Average & & $\mathbf{4 9 . 9 0}$ & $\mathbf{2 . 7 8}$ & $\mathbf{4 9 . 9 0}$ & $\mathbf{2 . 7 8}$ & $\mathbf{2 . 9 2}$ \\
\hline Standard Deviation & & $\mathbf{0 . 7 9}$ & $\mathbf{0 . 1 6}$ & $\mathbf{0 . 7 9}$ & $\mathbf{0 . 1 6}$ & $\mathbf{0 . 0 4}$ \\
\hline Count & & $\mathbf{7}$ & $\mathbf{7}$ & $\mathbf{7}$ & $\mathbf{7}$ & $\mathbf{7}$ \\
\hline
\end{tabular}




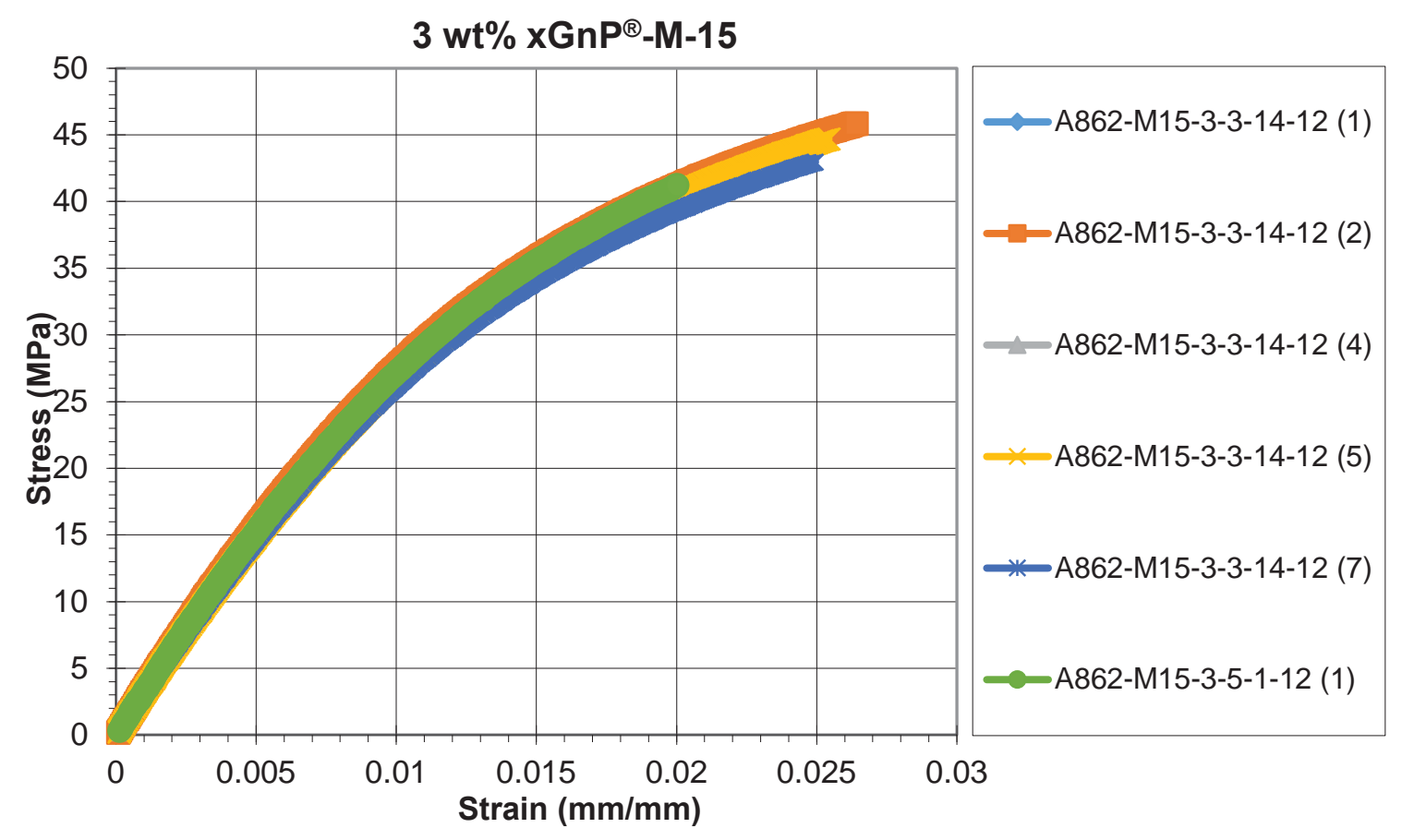

Figure A-4: Tensile Results for 3 wt\% $x G n P^{\circledR}-M-15$ in Epoxy

Table A-4: Tensile Results for 3 wt\% $x G n P^{\circledR}-M-15$ in Epoxy

\begin{tabular}{|l|c|c|c|c|c|c|}
\hline \multicolumn{1}{|c|}{ Sample } & No. & $\begin{array}{c}\text { Ultimate } \\
\text { Tensile } \\
\text { Stress } \\
\text { (MPa) }\end{array}$ & $\begin{array}{c}\text { Strain at } \\
\text { Ultimate } \\
\text { Tensile } \\
\text { Stress (\%) }\end{array}$ & $\begin{array}{c}\text { Tensile } \\
\text { Fracture } \\
\text { Stress } \\
(\mathbf{M P a})\end{array}$ & $\begin{array}{c}\text { Strain at } \\
\text { Tensile } \\
\text { Fracture } \\
\text { Stress (\%) }\end{array}$ & $\begin{array}{c}\text { Tensile } \\
\text { Modulus } \\
\text { (GPa) }\end{array}$ \\
\hline A862-M15-3-3-14-12 & 1 & 40.724 & 2.096 & 40.724 & 2.096 & 3.054 \\
\hline A862-M15-3-3-14-12 & 2 & 45.829 & 2.642 & 45.829 & 2.642 & 3.074 \\
\hline A862-M15-3-3-14-12 & 4 & 43.314 & 2.384 & 43.314 & 2.384 & 3.008 \\
\hline A862-M15-3-3-14-12 & 5 & 44.690 & 2.544 & 44.690 & 2.544 & 3.043 \\
\hline A862-M15-3-3-14-12 & 7 & 42.955 & 2.495 & 42.955 & 2.495 & 3.004 \\
\hline A862-M15-3-5-1-12 & 1 & 41.217 & 2.002 & 41.217 & 2.002 & 3.076 \\
\hline Average & & $\mathbf{4 3 . 1 2}$ & $\mathbf{2 . 3 6}$ & $\mathbf{4 3 . 1 2}$ & $\mathbf{2 . 3 6}$ & $\mathbf{3 . 0 4}$ \\
\hline Standard Deviation & & $\mathbf{1 . 9 6}$ & $\mathbf{0 . 2 6}$ & $\mathbf{1 . 9 6}$ & $\mathbf{0 . 2 6}$ & $\mathbf{0 . 0 3}$ \\
\hline Count & $\mathbf{6}$ & $\mathbf{6}$ & $\mathbf{6}$ & $\mathbf{6}$ & $\mathbf{6}$ \\
\hline
\end{tabular}




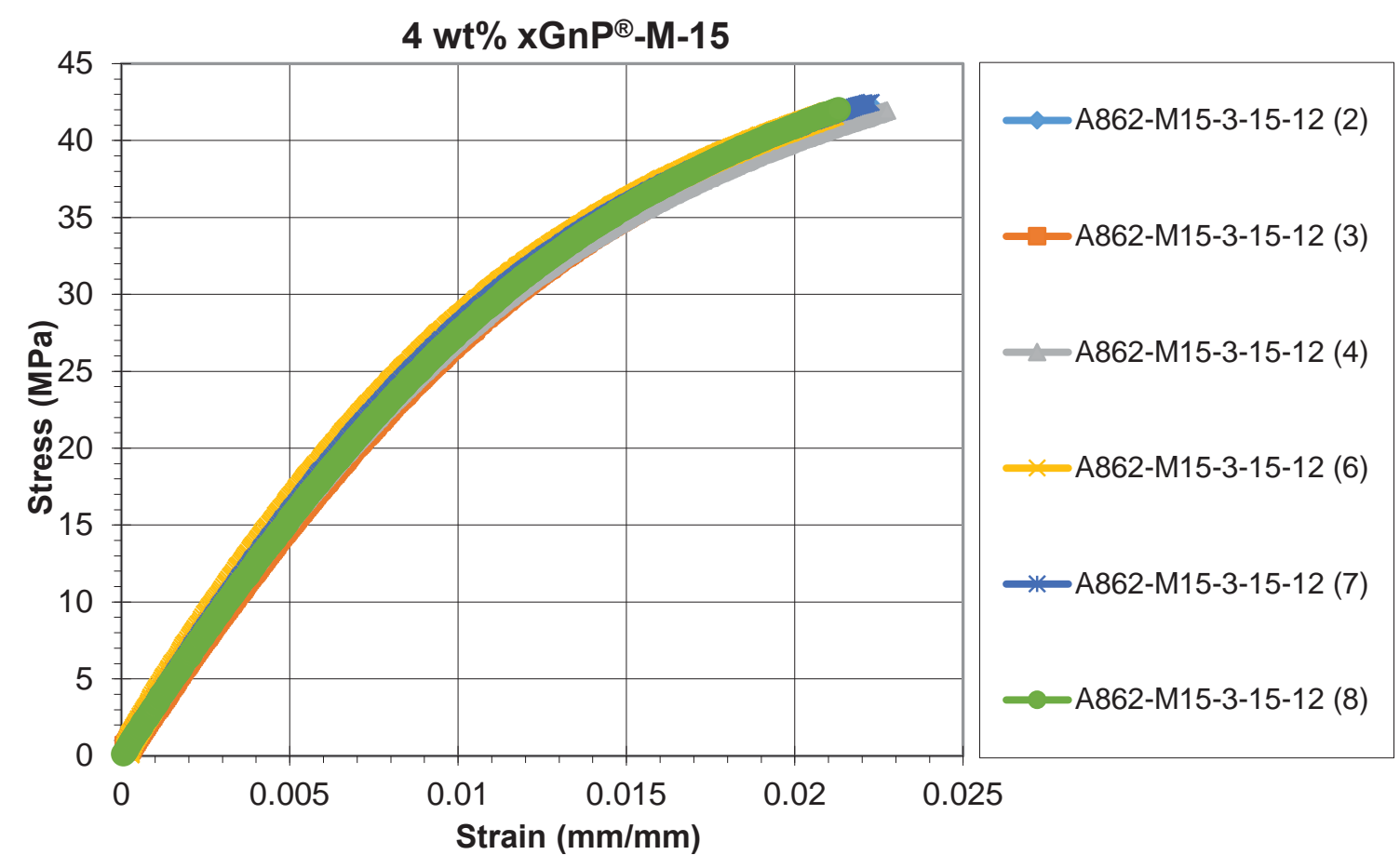

Figure A-5: Tensile Results for 4 wt\% $x G n P^{\circledR}-M-15$ in Epoxy

Table A-5: Tensile Results for 4 wt\% $x G n P^{\circledR}-M-15$ in Epoxy

\begin{tabular}{|l|c|c|c|c|c|c|}
\hline \multicolumn{1}{|c|}{ Sample } & No. & $\begin{array}{c}\text { Ultimate } \\
\text { Tensile } \\
\text { Stress } \\
(\mathbf{M P a})\end{array}$ & $\begin{array}{c}\text { Strain at } \\
\text { Ultimate } \\
\text { Tensile } \\
\text { Stress (\%) }\end{array}$ & $\begin{array}{c}\text { Tensile } \\
\text { Fracture } \\
\text { Stress } \\
(\mathbf{M P a})\end{array}$ & $\begin{array}{c}\text { Strain at } \\
\text { Tensile } \\
\text { Fracture } \\
\text { Stress (\%) }\end{array}$ & $\begin{array}{c}\text { Tensile } \\
\text { Modulus } \\
\text { (MPa) }\end{array}$ \\
\hline A862-M15-4-3-15-12 & 2 & 42.289 & 2.230 & 42.289 & 2.230 & 3.169 \\
\hline A862-M15-4-3-15-12 & 3 & 41.170 & 2.096 & 41.170 & 2.096 & 3.104 \\
\hline A862-M15-4-3-15-12 & 4 & 41.961 & 2.274 & 41.961 & 2.274 & 3.124 \\
\hline A862-M15-4-3-15-12 & 6 & 41.743 & 2.111 & 41.743 & 2.111 & 3.193 \\
\hline A862-M15-4-3-15-12 & 7 & 42.469 & 2.226 & 42.469 & 2.226 & 3.180 \\
\hline A862-M15-4-3-15-12 & 8 & 42.016 & 2.130 & 42.016 & 2.130 & 3.124 \\
\hline Average & & $\mathbf{4 1 . 9 4}$ & $\mathbf{2 . 1 8}$ & $\mathbf{4 1 . 9 4}$ & $\mathbf{2 . 1 8}$ & $\mathbf{3 . 1 5}$ \\
\hline Standard Deviation & & $\mathbf{0 . 4 6}$ & $\mathbf{0 . 0 7}$ & $\mathbf{0 . 4 6}$ & $\mathbf{0 . 0 7}$ & $\mathbf{0 . 0 4}$ \\
\hline Count & $\mathbf{6}$ & $\mathbf{6}$ & $\mathbf{6}$ & $\mathbf{6}$ & $\mathbf{6}$ \\
\hline
\end{tabular}




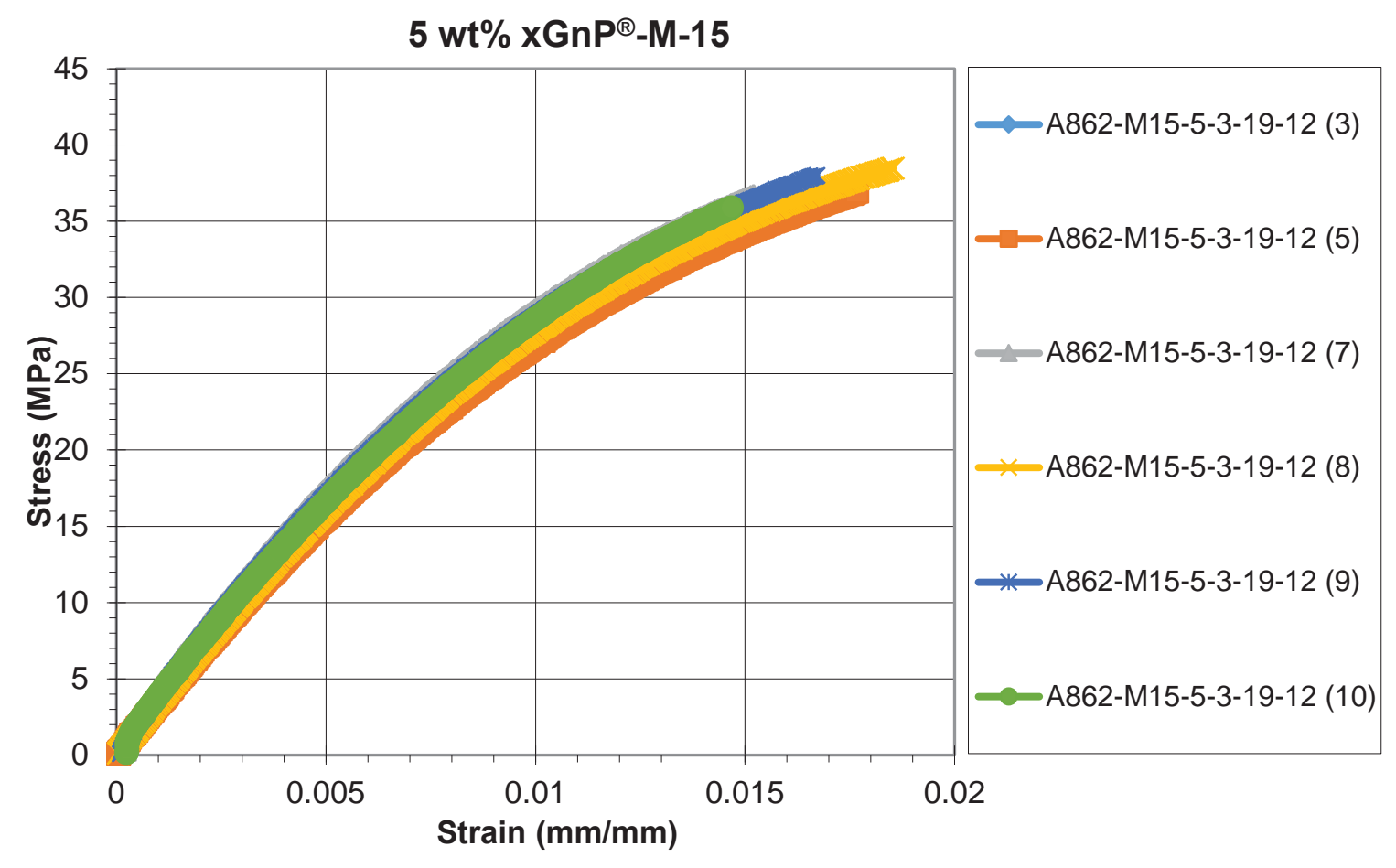

Figure A-6: Tensile Results for 5 wt\% $x G n P^{\circledR}-M-15$ in Epoxy

Table A-6: Tensile Results for 5 wt\% $x G n P^{\circledR}-M-15$ in Epoxy

\begin{tabular}{|l|c|c|c|c|c|c|}
\hline \multicolumn{1}{|c|}{ Sample } & No. & $\begin{array}{c}\text { Ultimate } \\
\text { Tensile } \\
\text { Stress } \\
\text { (MPa) }\end{array}$ & $\begin{array}{c}\text { Strain at } \\
\text { Ultimate } \\
\text { Tensile } \\
\text { Stress (\%) }\end{array}$ & $\begin{array}{c}\text { Tensile } \\
\text { Fracture } \\
\text { Stress } \\
\text { (MPa) }\end{array}$ & $\begin{array}{c}\text { Strain at } \\
\text { Tensile } \\
\text { Fracture } \\
\text { Stress (\%) }\end{array}$ & $\begin{array}{c}\text { Tensile } \\
\text { Modulus } \\
(\mathbf{G P a})\end{array}$ \\
\hline A862-M15-5-3-19-12 & 3 & 36.797 & 1.626 & 36.797 & 1.626 & 3.238 \\
\hline A862-M15-5-3-19-12 & 5 & 36.940 & 1.767 & 36.940 & 1.767 & 3.197 \\
\hline A862-M15-5-3-19-12 & 7 & 36.818 & 1.521 & 36.818 & 1.521 & 3.291 \\
\hline A862-M15-5-3-19-12 & 8 & 38.478 & 1.853 & 38.478 & 1.853 & 3.266 \\
\hline A862-M15-5-3-19-12 & 9 & 38.060 & 1.674 & 38.060 & 1.674 & 3.278 \\
\hline A862-M15-5-3-19-12 & 10 & 35.902 & 1.468 & 35.902 & 1.468 & 3.275 \\
\hline Average & & $\mathbf{3 7 . 1 7}$ & $\mathbf{1 . 6 5}$ & $\mathbf{3 7 . 1 7}$ & $\mathbf{1 . 6 5}$ & $\mathbf{3 . 2 6}$ \\
\hline Standard Deviation & & $\mathbf{0 . 9 4}$ & $\mathbf{0 . 1 5}$ & $\mathbf{0 . 9 4}$ & $\mathbf{0 . 1 5}$ & $\mathbf{0 . 0 3}$ \\
\hline Count & $\mathbf{6}$ & $\mathbf{6}$ & $\mathbf{6}$ & $\mathbf{6}$ & $\mathbf{6}$ \\
\hline
\end{tabular}




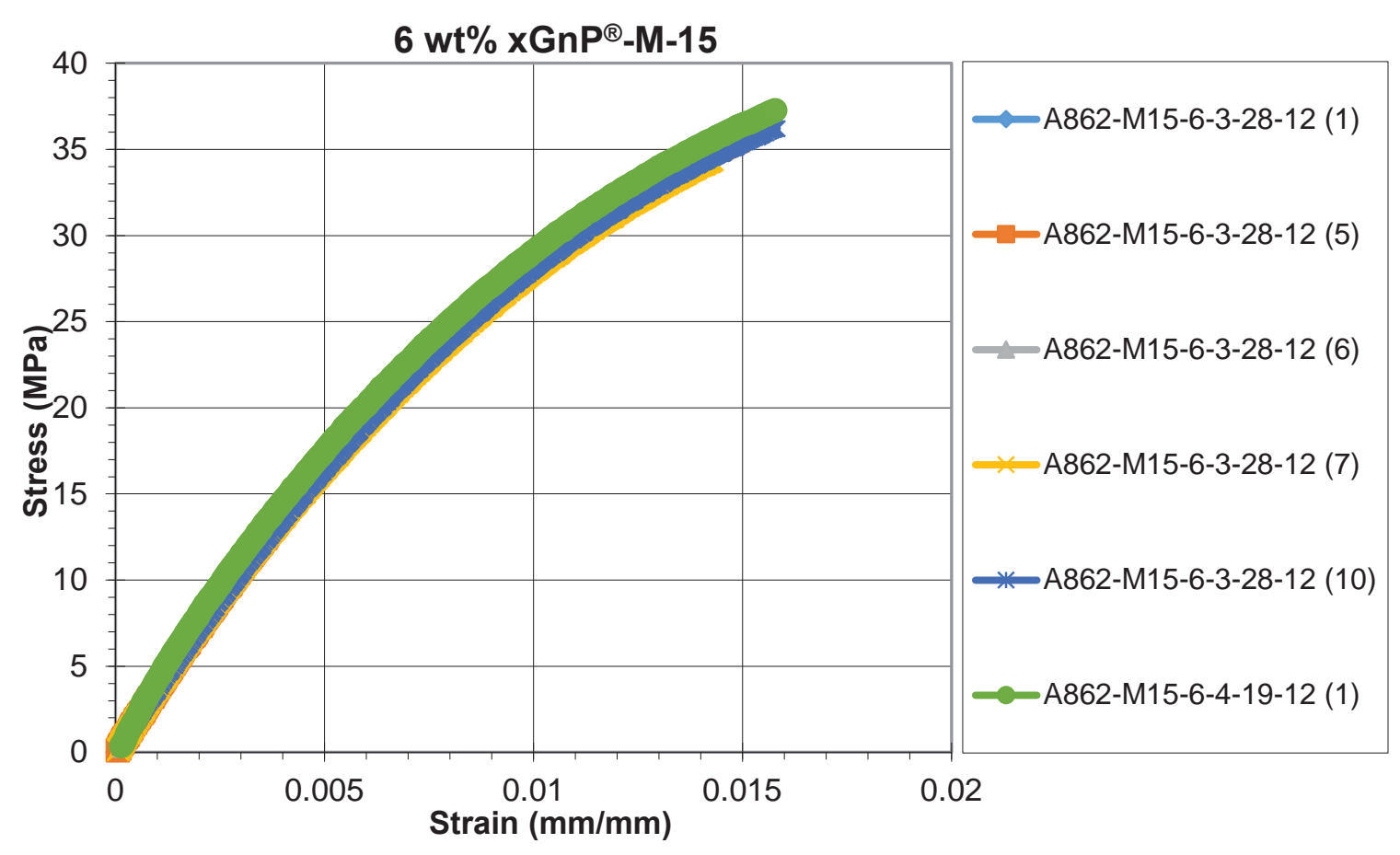

Figure A-7: Tensile Results for 6 wt\% $x G n P^{\circledR}-M-15$ in Epoxy

Table A-7: Tensile Results for 6 wt\% xGnP ${ }^{\circledR}-M-15$ in Epoxy

\begin{tabular}{|l|c|c|c|c|c|c|}
\hline \multicolumn{1}{|c|}{ Sample } & No. & $\begin{array}{c}\text { Ultimate } \\
\text { Tensile } \\
\text { Stress } \\
\text { (MPa) }\end{array}$ & $\begin{array}{c}\text { Strain at } \\
\text { Ultimate } \\
\text { Tensile } \\
\text { Stress (\%) }\end{array}$ & $\begin{array}{c}\text { Tensile } \\
\text { Fracture } \\
\text { Stress } \\
\text { (MPa) }\end{array}$ & $\begin{array}{c}\text { Strain at } \\
\text { Tensile } \\
\text { Fracture } \\
\text { Stress (\%) }\end{array}$ & $\begin{array}{c}\text { Tensile } \\
\text { Modulus } \\
\text { (GPa) }\end{array}$ \\
\hline A862-M15-6-3-28-12 & 1 & 33.728 & 1.369 & 33.728 & 1.369 & 3.284 \\
\hline A862-M15-6-3-28-12 & 5 & 35.621 & 1.491 & 35.621 & 1.491 & 3.376 \\
\hline A862-M15-6-3-28-12 & 6 & 35.888 & 1.497 & 35.888 & 1.497 & 3.385 \\
\hline A862-M15-6-3-28-12 & 7 & 34.405 & 1.428 & 34.405 & 1.428 & 3.313 \\
\hline A862-M15-6-3-28-12 & 10 & 36.205 & 1.583 & 36.205 & 1.583 & 3.373 \\
\hline A862-M15-6-4-19-12 & 1 & 37.267 & 1.578 & 37.267 & 1.578 & 3.413 \\
\hline Average & & $\mathbf{3 5 . 5 2}$ & $\mathbf{1 . 4 9}$ & $\mathbf{3 5 . 5 2}$ & $\mathbf{1 . 4 9}$ & $\mathbf{3 . 3 6}$ \\
\hline Standard Deviation & & $\mathbf{1 . 2 7}$ & $\mathbf{0 . 0 8}$ & $\mathbf{1 . 2 7}$ & $\mathbf{0 . 0 8}$ & $\mathbf{0 . 0 5}$ \\
\hline Count & $\mathbf{6}$ & $\mathbf{6}$ & $\mathbf{6}$ & $\mathbf{6}$ & $\mathbf{6}$ \\
\hline
\end{tabular}




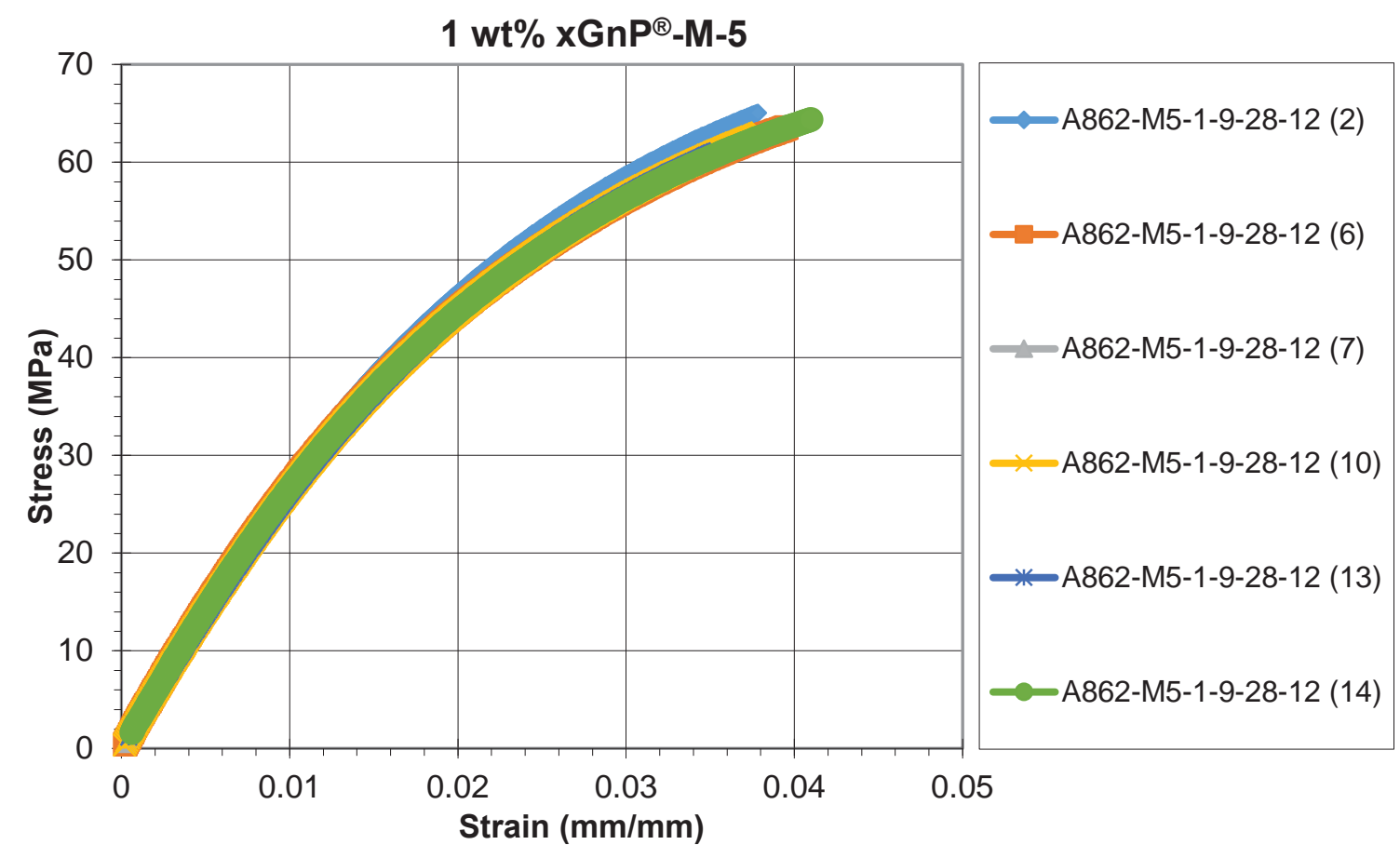

Figure A-8: Tensile Results for 1 wt\% $x G n P^{\circledR}-M-5$ in Epoxy

Table A-8: Tensile Results for 1 wt\% $x G n P^{\circledR}-M-5$ in Epoxy

\begin{tabular}{|l|c|c|c|c|c|c|}
\hline \multicolumn{1}{|c|}{ Sample } & No. & $\begin{array}{c}\text { Ultimate } \\
\text { Tensile } \\
\text { Stress } \\
\text { (MPa) }\end{array}$ & $\begin{array}{c}\text { Strain at } \\
\text { Ultimate } \\
\text { Tensile } \\
\text { Stress (\%) }\end{array}$ & $\begin{array}{c}\text { Tensile } \\
\text { Fracture } \\
\text { Stress } \\
\text { (MPa) }\end{array}$ & $\begin{array}{c}\text { Strain at } \\
\text { Tensile } \\
\text { Fracture } \\
\text { Stress (\%) }\end{array}$ & $\begin{array}{c}\text { Tensile } \\
\text { Modulus } \\
\text { (GPa) }\end{array}$ \\
\hline A862-M5-1-9-28-12 & 2 & 65.072 & 3.783 & 65.072 & 3.783 & 2.907 \\
\hline A862-M5-1-9-28-12 & 6 & 63.537 & 3.951 & 63.537 & 3.951 & 2.824 \\
\hline A862-M5-1-9-28-12 & 7 & 62.614 & 3.660 & 62.614 & 3.660 & 2.771 \\
\hline A862-M5-1-9-28-12 & 10 & 62.980 & 3.809 & 62.980 & 3.809 & 2.787 \\
\hline A862-M5-1-9-28-12 & 13 & 61.167 & 3.541 & 61.167 & 3.541 & 2.734 \\
\hline A862-M5-1-9-28-12 & 14 & 64.375 & 4.100 & 64.375 & 4.100 & 2.803 \\
\hline Average & & $\mathbf{6 3 . 2 9}$ & $\mathbf{3 . 8 1}$ & $\mathbf{6 3 . 2 9}$ & $\mathbf{3 . 8 1}$ & $\mathbf{2 . 8 0}$ \\
\hline Standard Deviation & & $\mathbf{1 . 3 8}$ & $\mathbf{0 . 2 0}$ & $\mathbf{1 . 3 8}$ & $\mathbf{0 . 2 0}$ & $\mathbf{0 . 0 6}$ \\
\hline Count & $\mathbf{6}$ & $\mathbf{6}$ & $\mathbf{6}$ & $\mathbf{6}$ & $\mathbf{6}$ \\
\hline
\end{tabular}




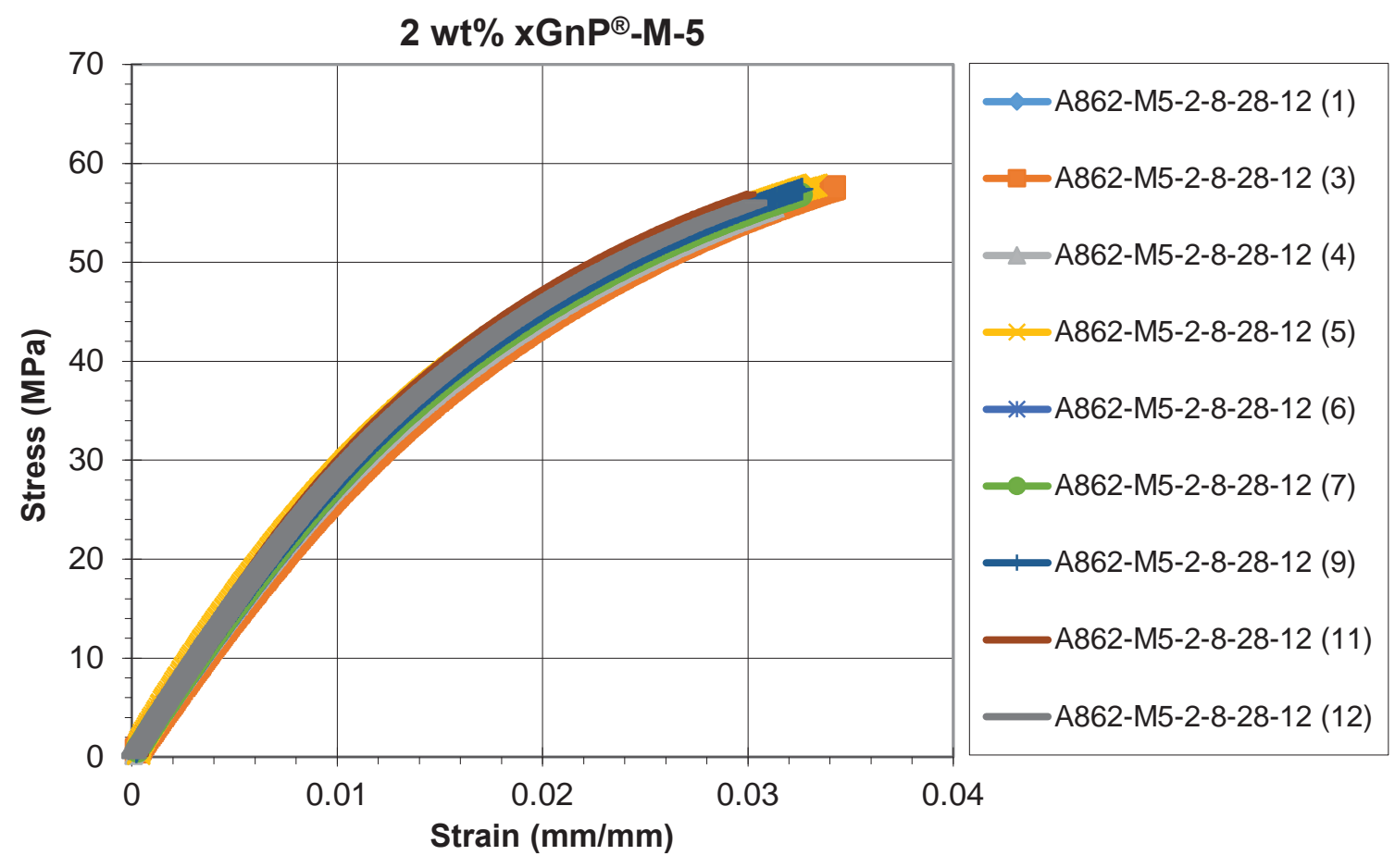

Figure A-9: Tensile Results for $2 w t \% x G n P^{\circledR}-M-5$ in Epoxy

Table A-9: Tensile Results for $2 w t \% x G n P^{\circledR}-M-5$ in Epoxy

\begin{tabular}{|l|c|c|c|c|c|c|}
\hline \multicolumn{1}{|c|}{ Sample } & No. & $\begin{array}{c}\text { Ultimate } \\
\text { Tensile } \\
\text { Stress } \\
\text { (MPa) }\end{array}$ & $\begin{array}{c}\text { Strain at } \\
\text { Ultimate } \\
\text { Tensile } \\
\text { Stress (\%) }\end{array}$ & $\begin{array}{c}\text { Tensile } \\
\text { Fracture } \\
\text { Stress } \\
\text { (MPa) }\end{array}$ & $\begin{array}{c}\text { Strain at } \\
\text { Tensile } \\
\text { Fracture } \\
\text { Stress (\%) }\end{array}$ & $\begin{array}{c}\text { Tensile } \\
\text { Modulus } \\
\text { (GPa) }\end{array}$ \\
\hline A862-M5-2-8-28-12 & 1 & 56.471 & 3.115 & 56.471 & 3.115 & 2.953 \\
\hline A862-M5-2-8-28-12 & 3 & 57.562 & 3.418 & 57.562 & 3.418 & 2.874 \\
\hline A862-M5-2-8-28-12 & 4 & 55.470 & 3.135 & 55.470 & 3.135 & 2.915 \\
\hline A862-M5-2-8-28-12 & 5 & 57.814 & 3.332 & 57.814 & 3.332 & 2.942 \\
\hline A862-M5-2-8-28-12 & 6 & 56.470 & 3.152 & 56.470 & 3.152 & 2.931 \\
\hline A862-M5-2-8-28-12 & 7 & 56.832 & 3.257 & 56.832 & 3.257 & 2.942 \\
\hline A862-M5-2-8-28-12 & 9 & 57.419 & 3.265 & 57.419 & 3.265 & 2.951 \\
\hline A862-M5-2-8-28-12 & 11 & 57.285 & 3.054 & 57.285 & 3.054 & 2.987 \\
\hline A862-M5-2-8-28-12 & 12 & 56.004 & 3.034 & 56.004 & 3.034 & 2.961 \\
\hline Average & & $\mathbf{5 6 . 8 1}$ & $\mathbf{3 . 2 0}$ & $\mathbf{5 6 . 8 1}$ & $\mathbf{3 . 2 0}$ & $\mathbf{2 . 9 4}$ \\
\hline Standard Deviation & & $\mathbf{0 . 7 8}$ & $\mathbf{0 . 1 3}$ & $\mathbf{0 . 7 8}$ & $\mathbf{0 . 1 3}$ & $\mathbf{0 . 0 3}$ \\
\hline Number & & $\mathbf{9}$ & $\mathbf{9}$ & $\mathbf{9}$ & $\mathbf{9}$ & $\mathbf{9}$ \\
\hline
\end{tabular}




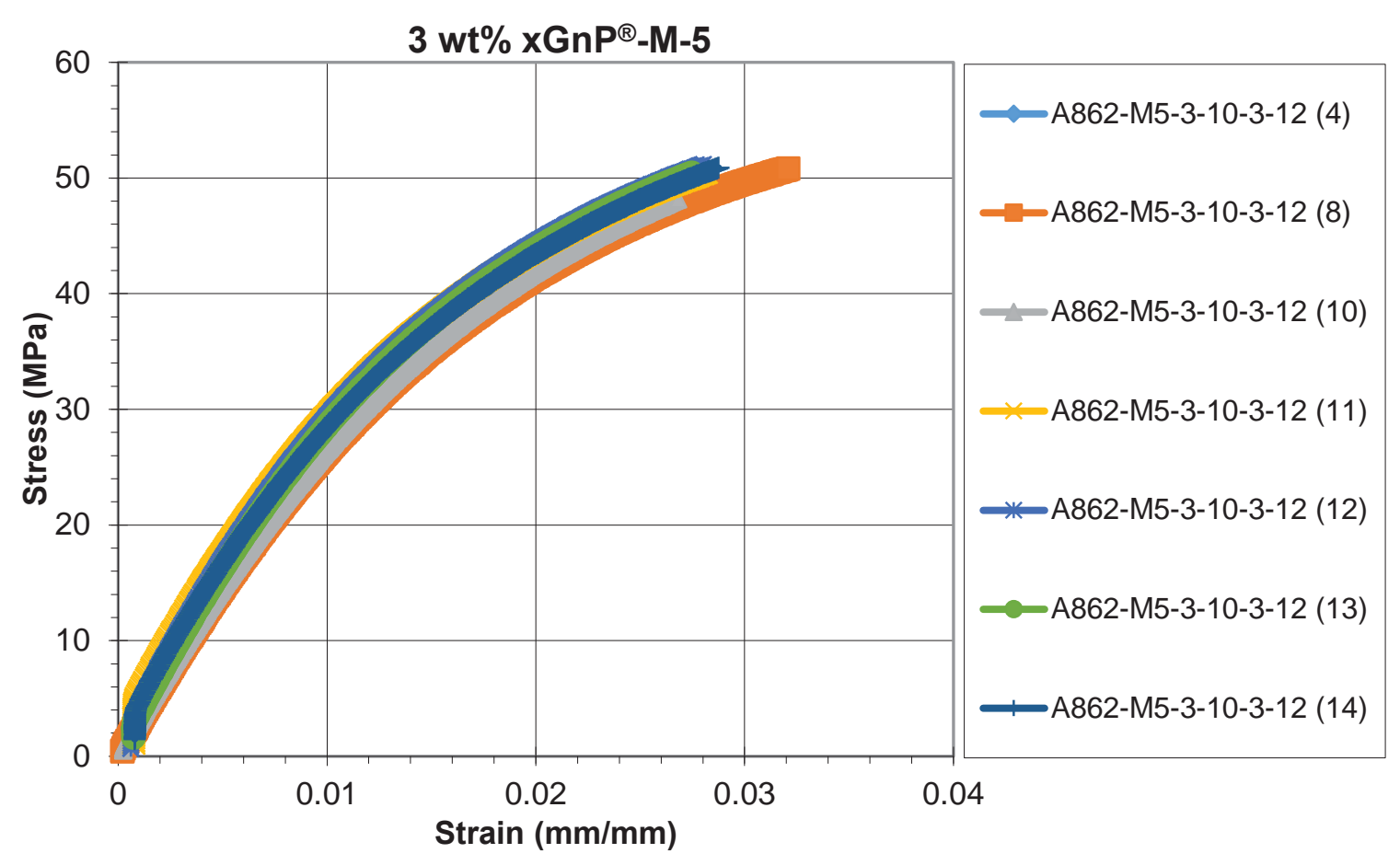

Figure A-10: Tensile Results for 3 wt\% $x G n P^{\circledR}-M-5$ in Epoxy

Table A-10: Tensile Results for 3 wt\% $x G n P^{\circledR}-M-5$ in Epoxy

\begin{tabular}{|l|c|c|c|c|c|c|}
\hline \multicolumn{1}{|c|}{ Sample } & No. & $\begin{array}{c}\text { Ultimate } \\
\text { Tensile } \\
\text { Stress } \\
\text { (MPa) }\end{array}$ & $\begin{array}{c}\text { Strain at } \\
\text { Ultimate } \\
\text { Tensile } \\
\text { Stress (\%) }\end{array}$ & $\begin{array}{c}\text { Tensile } \\
\text { Fracture } \\
\text { Stress } \\
\text { (MPa) }\end{array}$ & $\begin{array}{c}\text { Strain at } \\
\text { Tensile } \\
\text { Fracture } \\
\text { Stress (\%) }\end{array}$ & $\begin{array}{c}\text { Tensile } \\
\text { Modulus } \\
\text { (GPa) }\end{array}$ \\
\hline A862-M5-3-10-3-12 & 4 & 48.540 & 2.8 & 48.540 & 2.773 & 3.016 \\
\hline A862-M5-3-10-3-12 & 8 & 50.809 & 3.2 & 50.809 & 3.208 & 3.023 \\
\hline A862-M5-3-10-3-12 & 10 & 48.165 & 2.7 & 48.165 & 2.682 & 2.986 \\
\hline A862-M5-3-10-3-12 & 11 & 50.479 & 2.8 & 50.479 & 2.818 & 3.037 \\
\hline A862-M5-3-10-3-12 & 12 & 51.173 & 2.8 & 51.173 & 2.803 & 3.045 \\
\hline A862-M5-3-10-3-12 & 13 & 50.457 & 2.7 & 50.457 & 2.747 & 3.039 \\
\hline A862-M5-3-10-3-12 & 14 & 50.883 & 2.9 & 50.883 & 2.875 & 3.035 \\
\hline Average & & $\mathbf{5 0 . 0 7}$ & $\mathbf{2 . 8 4}$ & $\mathbf{5 0 . 0 7}$ & $\mathbf{2 . 8 4}$ & $\mathbf{3 . 0 3}$ \\
\hline Standard Deviation & & $\mathbf{1 . 2 0}$ & $\mathbf{0 . 1 7}$ & $\mathbf{1 . 2 0}$ & $\mathbf{0 . 1 7}$ & $\mathbf{0 . 0 2}$ \\
\hline Number & & $\mathbf{7}$ & $\mathbf{7}$ & $\mathbf{7}$ & $\mathbf{7}$ & $\mathbf{7}$ \\
\hline
\end{tabular}




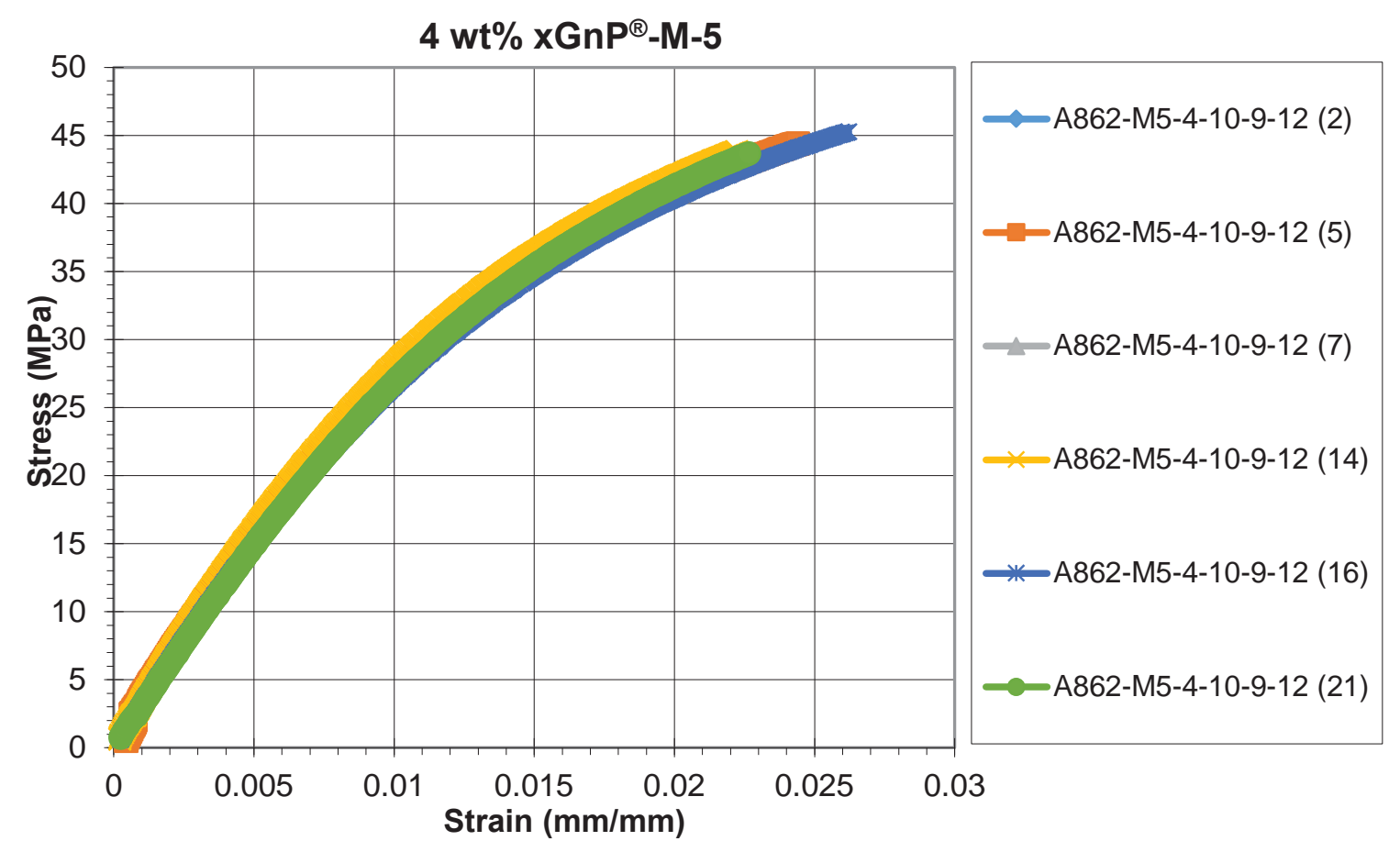

Figure A-11: Tensile Results for 4 wt\% $x G n P^{\circledR}-M-5$ in Epoxy

Table A-11: Tensile Results for 4 wt\% $x G n P^{\circledR}-M-5$ in Epoxy

\begin{tabular}{|l|c|c|c|c|c|c|}
\hline \multicolumn{1}{|c|}{ Sample } & No. & $\begin{array}{c}\text { Ultimate } \\
\text { Tensile } \\
\text { Stress } \\
\text { (MPa) }\end{array}$ & $\begin{array}{c}\text { Strain at } \\
\text { Ultimate } \\
\text { Tensile } \\
\text { Stress (\%) }\end{array}$ & $\begin{array}{c}\text { Tensile } \\
\text { Fracture } \\
\text { Stress } \\
\text { (MPa) }\end{array}$ & $\begin{array}{c}\text { Strain at } \\
\text { Tensile } \\
\text { Fracture } \\
\text { Stress (\%) }\end{array}$ & $\begin{array}{c}\text { Tensile } \\
\text { Modulus } \\
\text { (GPa) }\end{array}$ \\
\hline A862-M5-4-10-9-12 & 2 & 43.139 & 2.193 & 43.139 & 2.193 & 3.136 \\
\hline A862-M5-4-10-9-12 & 5 & 44.412 & 2.440 & 44.412 & 2.440 & 3.069 \\
\hline A862-M5-4-10-9-12 & 7 & 43.224 & 2.276 & 43.224 & 2.276 & 3.146 \\
\hline A862-M5-4-10-9-12 & 14 & 43.804 & 2.223 & 43.804 & 2.223 & 3.194 \\
\hline A862-M5-4-10-9-12 & 16 & 45.263 & 2.622 & 45.263 & 2.622 & 3.087 \\
\hline A862-M5-4-10-9-12 & 21 & 43.667 & 2.266 & 43.667 & 2.266 & 3.023 \\
\hline Average & & $\mathbf{4 3 . 9 2}$ & $\mathbf{2 . 3 4}$ & $\mathbf{4 3 . 9 2}$ & $\mathbf{2 . 3 4}$ & $\mathbf{3 . 1 1}$ \\
\hline Standard Deviation & & $\mathbf{0 . 8 0}$ & $\mathbf{0 . 1 6}$ & $\mathbf{0 . 8 0}$ & $\mathbf{0 . 1 6}$ & $\mathbf{0 . 0 6}$ \\
\hline Count & $\mathbf{6}$ & $\mathbf{6}$ & $\mathbf{6}$ & $\mathbf{6}$ & $\mathbf{6}$ \\
\hline
\end{tabular}




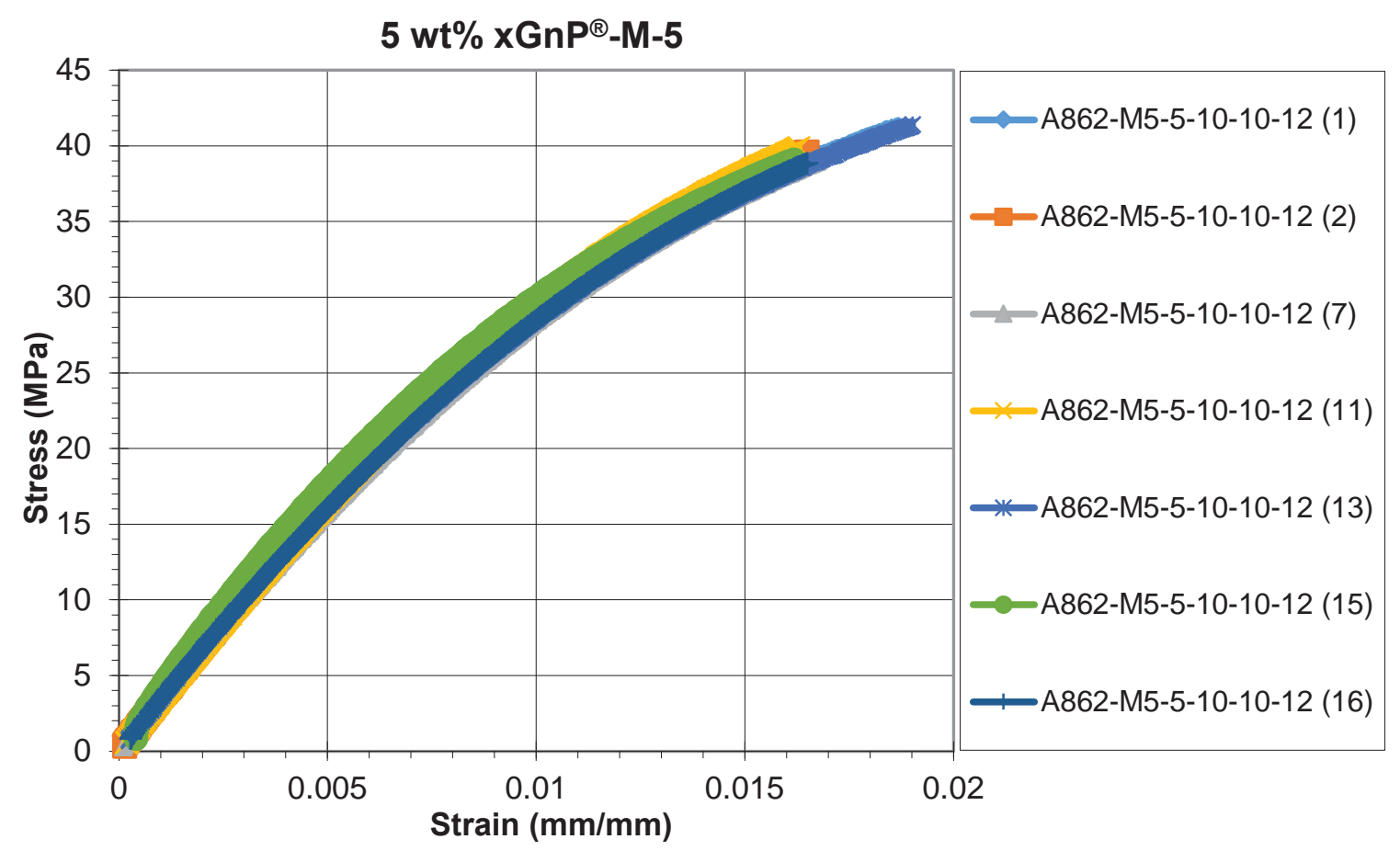

Figure A-12: Tensile Results for 5 wt\% $x G n P^{\circledR}-M-5$ in Epoxy

Table A-12: Tensile Results for 5 wt\% $x G n P^{\circledR}-M-5$ in Epoxy

\begin{tabular}{|l|c|c|c|c|c|c|}
\hline \multicolumn{1}{|c|}{ Sample } & No. & $\begin{array}{c}\text { Ultimate } \\
\text { Tensile } \\
\text { Stress } \\
\text { (MPa) }\end{array}$ & $\begin{array}{c}\text { Strain at } \\
\text { Ultimate } \\
\text { Tensile } \\
\text { Stress (\%) }\end{array}$ & $\begin{array}{c}\text { Tensile } \\
\text { Fracture } \\
\text { Stress } \\
\text { (MPa) }\end{array}$ & $\begin{array}{c}\text { Strain at } \\
\text { Tensile } \\
\text { Fracture } \\
\text { Stress (\%) }\end{array}$ & $\begin{array}{c}\text { Tensile } \\
\text { Modulus } \\
\text { (GPa) }\end{array}$ \\
\hline A862-M5-5-10-10-12 & 1 & 41.304 & 1.866 & 41.304 & 1.866 & 3.252 \\
\hline A862-M5-5-10-10-12 & 2 & 39.607 & 1.650 & 39.607 & 1.650 & 3.280 \\
\hline A862-M5-5-10-10-12 & 7 & 39.034 & 1.676 & 39.034 & 1.676 & 3.161 \\
\hline A862-M5-5-10-10-12 & 11 & 39.886 & 1.630 & 39.886 & 1.630 & 3.282 \\
\hline A862-M5-5-10-10-12 & 13 & 41.401 & 1.902 & 41.401 & 1.902 & 3.208 \\
\hline A862-M5-5-10-10-12 & 15 & 39.088 & 1.618 & 39.088 & 1.618 & 3.275 \\
\hline A862-M5-5-10-10-12 & 16 & 38.857 & 1.649 & 38.857 & 1.649 & 3.215 \\
\hline Average & & 39.88 & $\mathbf{1 . 7 1}$ & $\mathbf{3 9 . 8 8}$ & $\mathbf{1 . 7 1}$ & $\mathbf{3 . 2 4}$ \\
\hline Standard Deviation & & $\mathbf{1 . 0 6}$ & $\mathbf{0 . 1 2}$ & $\mathbf{1 . 0 6}$ & $\mathbf{0 . 1 2}$ & $\mathbf{0 . 0 5}$ \\
\hline Count & & $\mathbf{7}$ & $\mathbf{7}$ & $\mathbf{7}$ & $\mathbf{7}$ & $\mathbf{7}$ \\
\hline
\end{tabular}




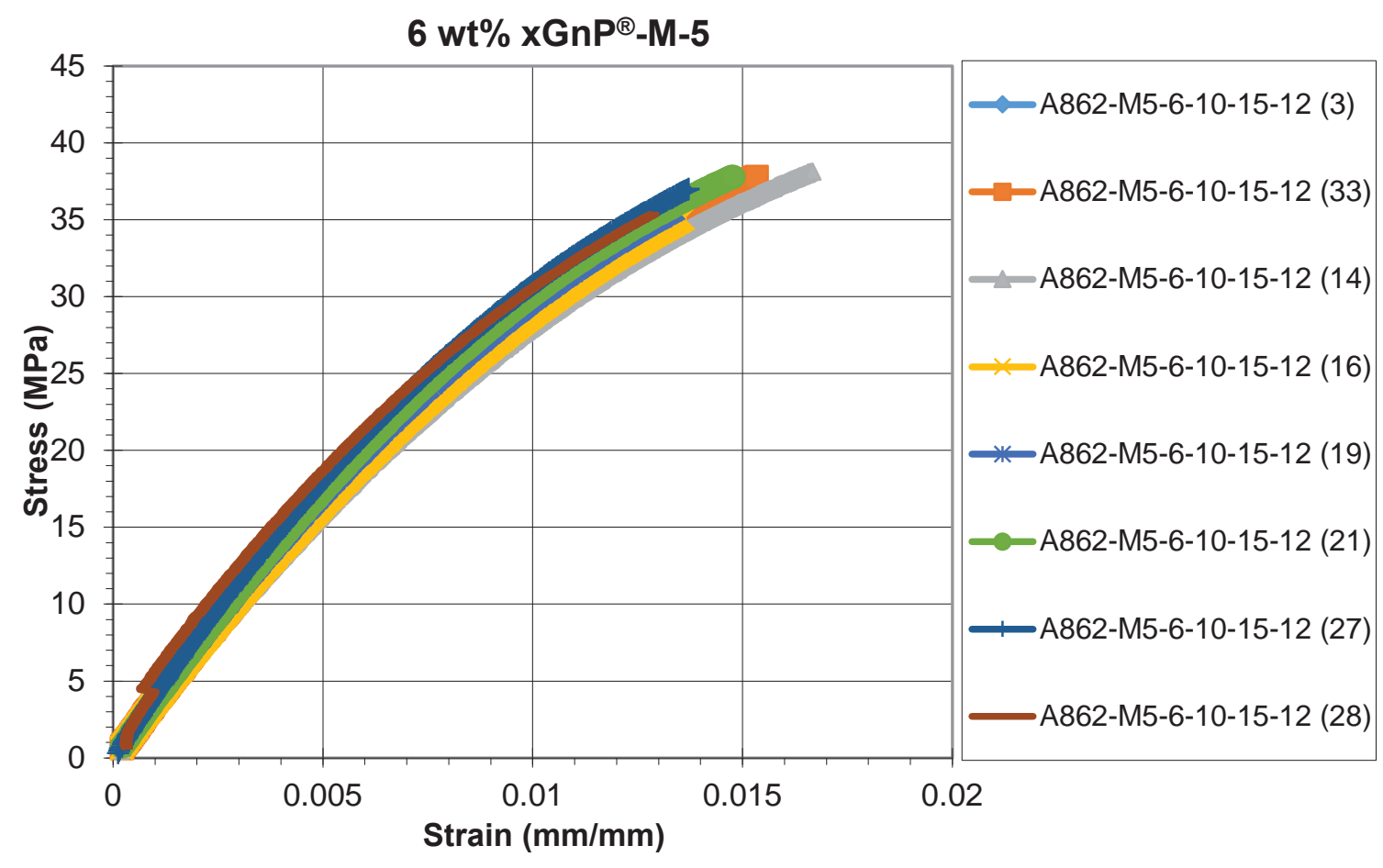

Figure A-13: Tensile Results for 6 wt\% $x G n P^{\circledR}-M-5$ in Epoxy

Table A-13: Tensile Results for 6 wt\% $x G n P^{\circledR}-M-5$ in Epoxy

\begin{tabular}{|l|c|c|c|c|c|c|}
\hline \multicolumn{1}{|c|}{ Sample } & No. & $\begin{array}{c}\text { Ultimate } \\
\text { Tensile } \\
\text { Stress } \\
\text { (MPa) }\end{array}$ & $\begin{array}{c}\text { Strain at } \\
\text { Ultimate } \\
\text { Tensile } \\
\text { Stress (\%) }\end{array}$ & $\begin{array}{c}\text { Tensile } \\
\text { Fracture } \\
\text { Stress } \\
\text { (MPa) }\end{array}$ & $\begin{array}{c}\text { Strain at } \\
\text { Tensile } \\
\text { Fracture } \\
\text { Stress (\%) }\end{array}$ & $\begin{array}{c}\text { Tensile } \\
\text { Modulus } \\
\text { (MPa) }\end{array}$ \\
\hline A862-M5-6-10-15-12 & 3 & 34.104 & 1.294 & 34.104 & 1.294 & 3.305 \\
\hline A862-M5-6-10-15-12 & 13 & 37.783 & 1.534 & 37.783 & 1.534 & 3.330 \\
\hline A862-M5-6-10-15-12 & 14 & 38.144 & 1.667 & 38.144 & 1.667 & 3.241 \\
\hline A862-M5-6-10-15-12 & 16 & 35.081 & 1.359 & 35.081 & 1.359 & 3.304 \\
\hline A862-M5-6-10-15-12 & 19 & 35.515 & 1.343 & 35.515 & 1.343 & 3.366 \\
\hline A862-M5-6-10-15-12 & 21 & 37.782 & 1.474 & 37.782 & 1.474 & 3.421 \\
\hline A862-M5-6-10-15-12 & 27 & 37.096 & 1.378 & 37.096 & 1.378 & 3.480 \\
\hline A862-M5-6-10-15-12 & 28 & 35.726 & 1.304 & 35.726 & 1.304 & 3.357 \\
\hline Average & & $\mathbf{3 6 . 4 0}$ & $\mathbf{1 . 4 2}$ & $\mathbf{3 6 . 4 0}$ & $\mathbf{1 . 4 2}$ & $\mathbf{3 . 3 5}$ \\
\hline Standard Deviation & & $\mathbf{1 . 4 9}$ & $\mathbf{0 . 1 3}$ & $\mathbf{1 . 4 9}$ & $\mathbf{0 . 1 3}$ & $\mathbf{0 . 0 7}$ \\
\hline Count & & $\mathbf{8}$ & $\mathbf{8}$ & $\mathbf{8}$ & $\mathbf{8}$ & $\mathbf{8}$ \\
\hline
\end{tabular}




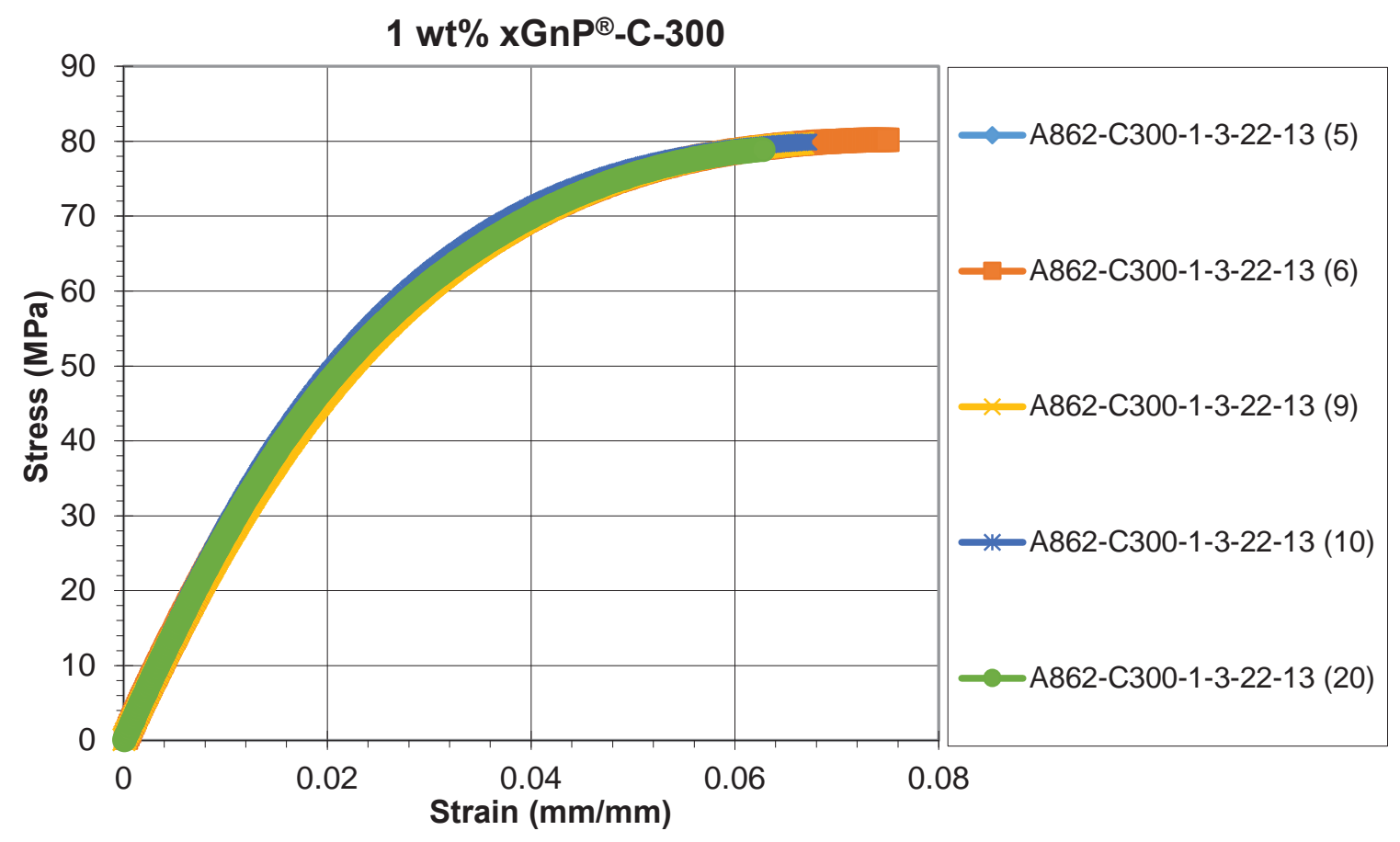

Figure A-14: Tensile Results for 1 wt\% $x G n P^{\circledR}-C-300$ in Epoxy

Table A-14: Tensile Results for 1 wt\% $x G n P^{\circledR}-C-300$ in Epoxy

\begin{tabular}{|l|c|c|c|c|c|c|}
\hline \multicolumn{1}{|c|}{ Sample } & No. & $\begin{array}{c}\text { Ultimate } \\
\text { Tensile } \\
\text { Stress } \\
\text { (MPa) }\end{array}$ & $\begin{array}{c}\text { Strain at } \\
\text { Ultimate } \\
\text { Tensile } \\
\text { Stress (\%) }\end{array}$ & $\begin{array}{c}\text { Tensile } \\
\text { Fracture } \\
\text { Stress } \\
\text { (MPa) }\end{array}$ & $\begin{array}{c}\text { Strain at } \\
\text { Tensile } \\
\text { Fracture } \\
\text { Stress (\%) }\end{array}$ & $\begin{array}{c}\text { Tensile } \\
\text { Modulus } \\
\text { (GPa) }\end{array}$ \\
\hline A862-C300-1-3-22-13 & 5 & 78.989 & 6.540 & 78.989 & 6.540 & 2.738 \\
\hline A862-C300-1-3-22-13 & 6 & 80.209 & 7.448 & 80.209 & 7.448 & 2.804 \\
\hline A862-C300-1-3-22-13 & 7 & 80.006 & 6.738 & 80.006 & 6.738 & 2.825 \\
\hline A862-C300-1-3-22-13 & 9 & 79.739 & 6.666 & 79.739 & 6.666 & 2.781 \\
\hline A862-C300-1-3-22-13 & 10 & 79.892 & 6.705 & 79.892 & 6.705 & 2.861 \\
\hline A862-C300-1-3-22-13 & 20 & 78.931 & 6.262 & 78.931 & 6.262 & 2.800 \\
\hline Average & & $\mathbf{7 9 . 6 3}$ & $\mathbf{6 . 7 3}$ & $\mathbf{7 9 . 6 3}$ & $\mathbf{6 . 7 3}$ & $\mathbf{2 . 8 0}$ \\
\hline Standard Deviation & & $\mathbf{0 . 5 4}$ & $\mathbf{0 . 3 9}$ & $\mathbf{0 . 5 4}$ & $\mathbf{0 . 3 9}$ & $\mathbf{0 . 0 4}$ \\
\hline Count & $\mathbf{6}$ & $\mathbf{6}$ & $\mathbf{6}$ & $\mathbf{6}$ & $\mathbf{6}$ \\
\hline
\end{tabular}




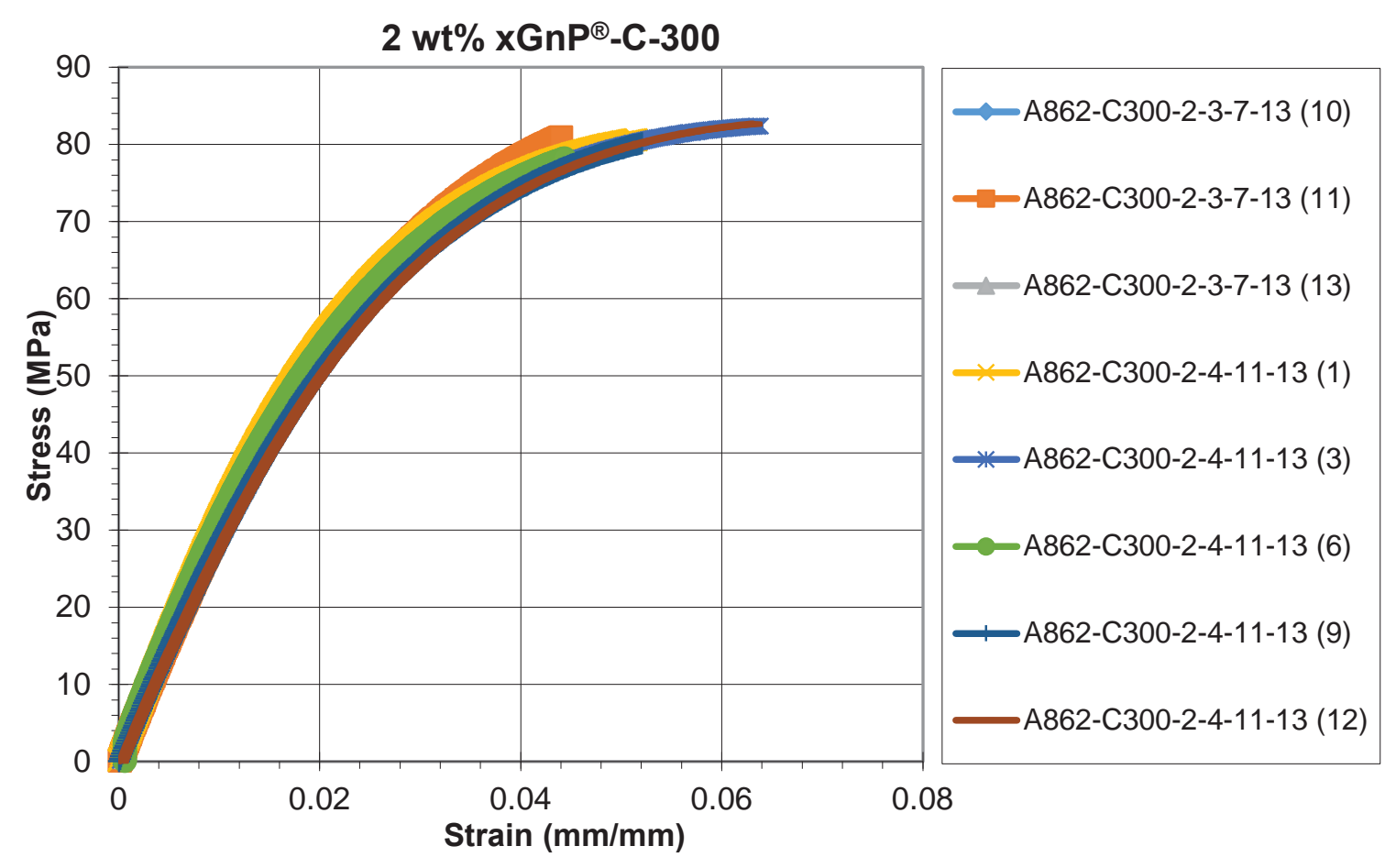

Figure A-15: Tensile Results for $2 w t \% x G n P^{\circledR}-C-300$ in Epoxy

Table A-15: Tensile Results for 2 wt\% $x G n P^{\circledR}-C-300$ in Epoxy

\begin{tabular}{|l|c|c|c|c|c|c|}
\hline \multicolumn{1}{|c|}{ Sample } & No. & $\begin{array}{c}\text { Ultimate } \\
\text { Tensile } \\
\text { Stress } \\
\text { (MPa) }\end{array}$ & $\begin{array}{c}\text { Strain at } \\
\text { Ultimate } \\
\text { Tensile } \\
\text { Stress (\%) }\end{array}$ & $\begin{array}{c}\text { Tensile } \\
\text { Fracture } \\
\text { Stress } \\
\text { (MPa) }\end{array}$ & $\begin{array}{c}\text { Strain at } \\
\text { Tensile } \\
\text { Fracture } \\
\text { Stress (\%) }\end{array}$ & $\begin{array}{c}\text { Tensile } \\
\text { Modulus } \\
\text { (GPa) }\end{array}$ \\
\hline A862-C300-2-3-7-13 & 10 & 80.361 & 4.327 & 80.361 & 4.327 & 2.804 \\
\hline A862-C300-2-3-7-13 & 11 & 80.898 & 4.399 & 80.898 & 4.399 & 2.816 \\
\hline A862-C300-2-3-7-13 & 13 & 79.099 & 4.461 & 79.099 & 4.461 & 2.836 \\
\hline A862-C300-2-4-11-13 & 1 & 80.621 & 5.148 & 80.621 & 5.148 & 2.975 \\
\hline A862-C300-2-4-11-13 & 3 & 82.373 & 6.342 & 82.373 & 6.342 & 2.860 \\
\hline A862-C300-2-4-11-13 & 6 & 78.184 & 4.435 & 78.184 & 4.435 & 2.990 \\
\hline A862-C300-2-4-11-13 & 9 & 80.233 & 5.236 & 80.233 & 5.236 & 2.871 \\
\hline A862-C300-2-4-11-13 & 12 & 82.655 & 6.296 & 82.655 & 6.296 & 2.870 \\
\hline Average & & 80.55 & 5.08 & 80.55 & 5.08 & 2.88 \\
\hline Standard Deviation & & 1.50 & 0.84 & 1.50 & 0.84 & 0.07 \\
\hline Count & & 8 & 8 & 8 & 8 & 8 \\
\hline
\end{tabular}




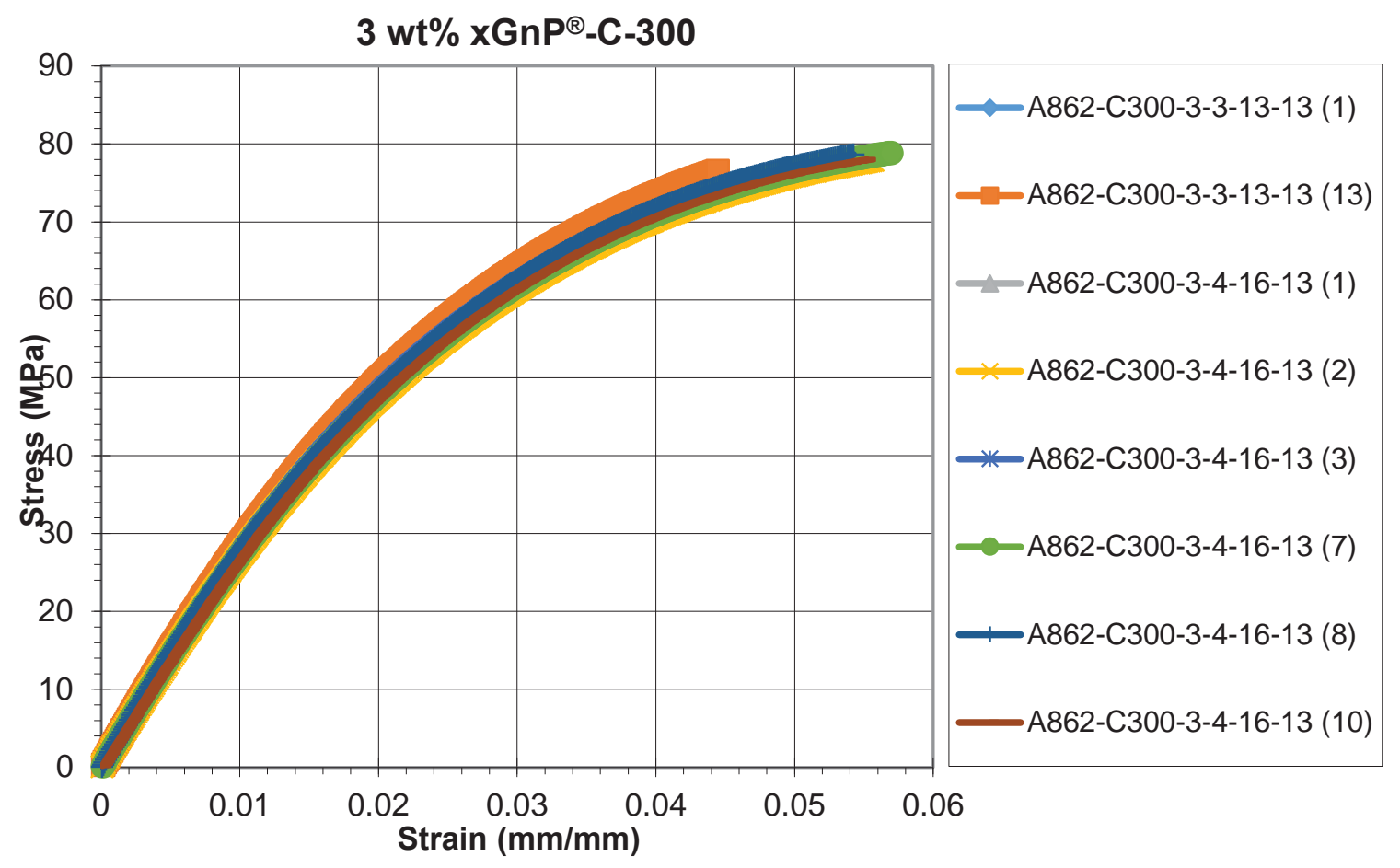

Figure A-16: Tensile Results for 3 wt\% $x G n P^{\circledR}-C-300$ in Epoxy

Table A-16: Tensile Results for $3 w t \% x G n P^{\circledR}-C-300$ in Epoxy

\begin{tabular}{|l|c|c|c|c|c|c|}
\hline \multicolumn{1}{|c|}{ Sample } & No. & $\begin{array}{c}\text { Ultimate } \\
\text { Tensile } \\
\text { Stress } \\
\text { (MPa) }\end{array}$ & $\begin{array}{c}\text { Strain at } \\
\text { Ultimate } \\
\text { Tensile } \\
\text { Stress (\%) }\end{array}$ & $\begin{array}{c}\text { Tensile } \\
\text { Fracture } \\
\text { Stress } \\
\text { (MPa) }\end{array}$ & $\begin{array}{c}\text { Strain at } \\
\text { Tensile } \\
\text { Fracture } \\
\text { Stress (\%) }\end{array}$ & $\begin{array}{c}\text { Tensile } \\
\text { Modulus } \\
\text { (GPa) }\end{array}$ \\
\hline A862-C300-3-3-13-13 & 1 & 76.509 & 4.436 & 76.509 & 4.436 & 3.099 \\
\hline A862-C300-3-3-13-13 & 13 & 76.535 & 4.445 & 76.535 & 4.445 & 3.013 \\
\hline A862-C300-3-4-16-13 & 1 & 78.457 & 5.469 & 78.457 & 5.469 & 2.970 \\
\hline A862-C300-3-4-16-13 & 2 & 77.887 & 5.565 & 77.887 & 5.565 & 2.835 \\
\hline A862-C300-3-4-16-13 & 3 & 78.253 & 5.300 & 78.253 & 5.300 & 2.917 \\
\hline A862-C300-3-4-16-13 & 7 & 78.844 & 5.699 & 78.844 & 5.699 & 2.875 \\
\hline A862-C300-3-4-16-13 & 8 & 78.739 & 5.456 & 78.739 & 5.456 & 2.924 \\
\hline A862-C300-3-4-16-13 & 10 & 78.321 & 5.642 & 78.321 & 5.642 & 2.820 \\
\hline Average & & $\mathbf{7 7 . 9 4}$ & $\mathbf{5 . 2 5}$ & $\mathbf{7 7 . 9 4}$ & $\mathbf{5 . 2 5}$ & $\mathbf{2 . 9 3}$ \\
\hline Standard Deviation & $\mathbf{0 . 9 3}$ & $\mathbf{0 . 5 2}$ & $\mathbf{0 . 9 3}$ & $\mathbf{0 . 5 2}$ & $\mathbf{0 . 0 9}$ \\
\hline Number & $\mathbf{8}$ & $\mathbf{8}$ & $\mathbf{8}$ & $\mathbf{8}$ & $\mathbf{8}$ \\
\hline
\end{tabular}




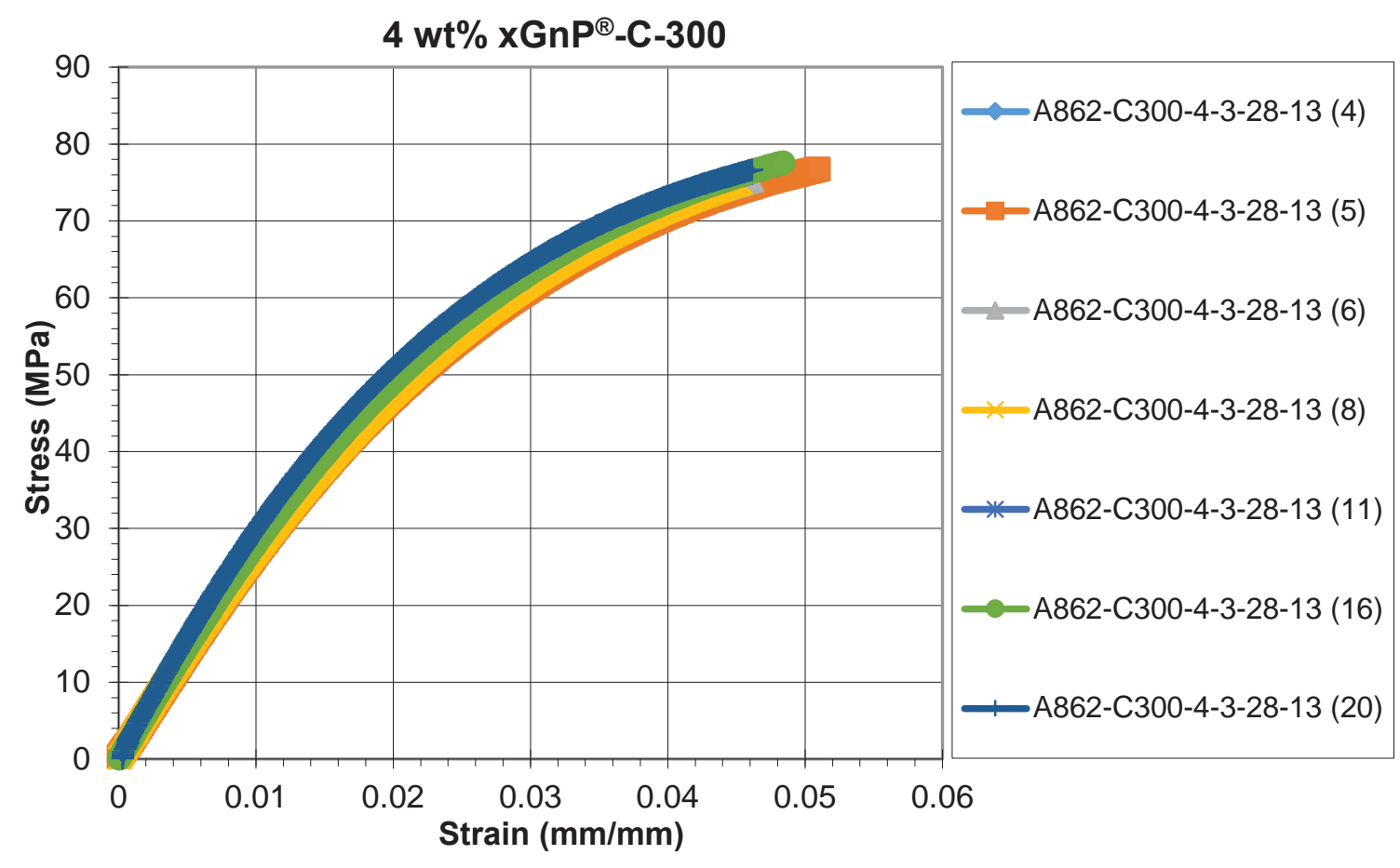

Figure A-17: Tensile Results for 4 wt\% $x G n P^{\circledR}-C-300$ in Epoxy

Table A-17: Tensile Results for 4 wt\% $x G n P^{\circledR}-C-300$ in Epoxy

\begin{tabular}{|l|c|c|c|c|c|c|}
\hline \multicolumn{1}{|c|}{ Sample } & No. & $\begin{array}{c}\text { Ultimate } \\
\text { Tensile } \\
\text { Stress } \\
\text { (MPa) }\end{array}$ & $\begin{array}{c}\text { Strain at } \\
\text { Ultimate } \\
\text { Tensile } \\
\text { Stress (\%) }\end{array}$ & $\begin{array}{c}\text { Tensile } \\
\text { Fracture } \\
\text { Stress } \\
\text { (MPa) }\end{array}$ & $\begin{array}{c}\text { Strain at } \\
\text { Tensile } \\
\text { Fracture } \\
\text { Stress (\%) }\end{array}$ & $\begin{array}{c}\text { Tensile } \\
\text { Modulus } \\
\text { (GPa) }\end{array}$ \\
\hline A862-C300-4-3-28-13 & 4 & 73.910 & 4.217 & 73.910 & 4.217 & 2.991 \\
\hline A862-C300-4-3-28-13 & 5 & 76.747 & 5.095 & 76.747 & 5.095 & 2.766 \\
\hline A862-C300-4-3-28-13 & 6 & 74.937 & 4.637 & 74.937 & 4.637 & 3.000 \\
\hline A862-C300-4-3-28-13 & 8 & 74.934 & 4.537 & 74.934 & 4.537 & 2.865 \\
\hline A862-C300-4-3-28-13 & 11 & 75.810 & 4.562 & 75.810 & 4.562 & 3.086 \\
\hline A862-C300-4-3-28-13 & 16 & 77.557 & 4.840 & 77.557 & 4.840 & 2.943 \\
\hline A862-C300-4-3-28-13 & 20 & 76.632 & 4.612 & 76.632 & 4.612 & 3.100 \\
\hline Average & & $\mathbf{7 5 . 7 9}$ & $\mathbf{4 . 6 4}$ & $\mathbf{7 5 . 7 9}$ & $\mathbf{4 . 6 4}$ & $\mathbf{2 . 9 6}$ \\
\hline Standard Deviation & & $\mathbf{1 . 2 7}$ & $\mathbf{0 . 2 7}$ & $\mathbf{1 . 2 7}$ & $\mathbf{0 . 2 7}$ & $\mathbf{0 . 1 2}$ \\
\hline Number & $\mathbf{7}$ & $\mathbf{7}$ & $\mathbf{7}$ & $\mathbf{7}$ & $\mathbf{7}$ \\
\hline
\end{tabular}




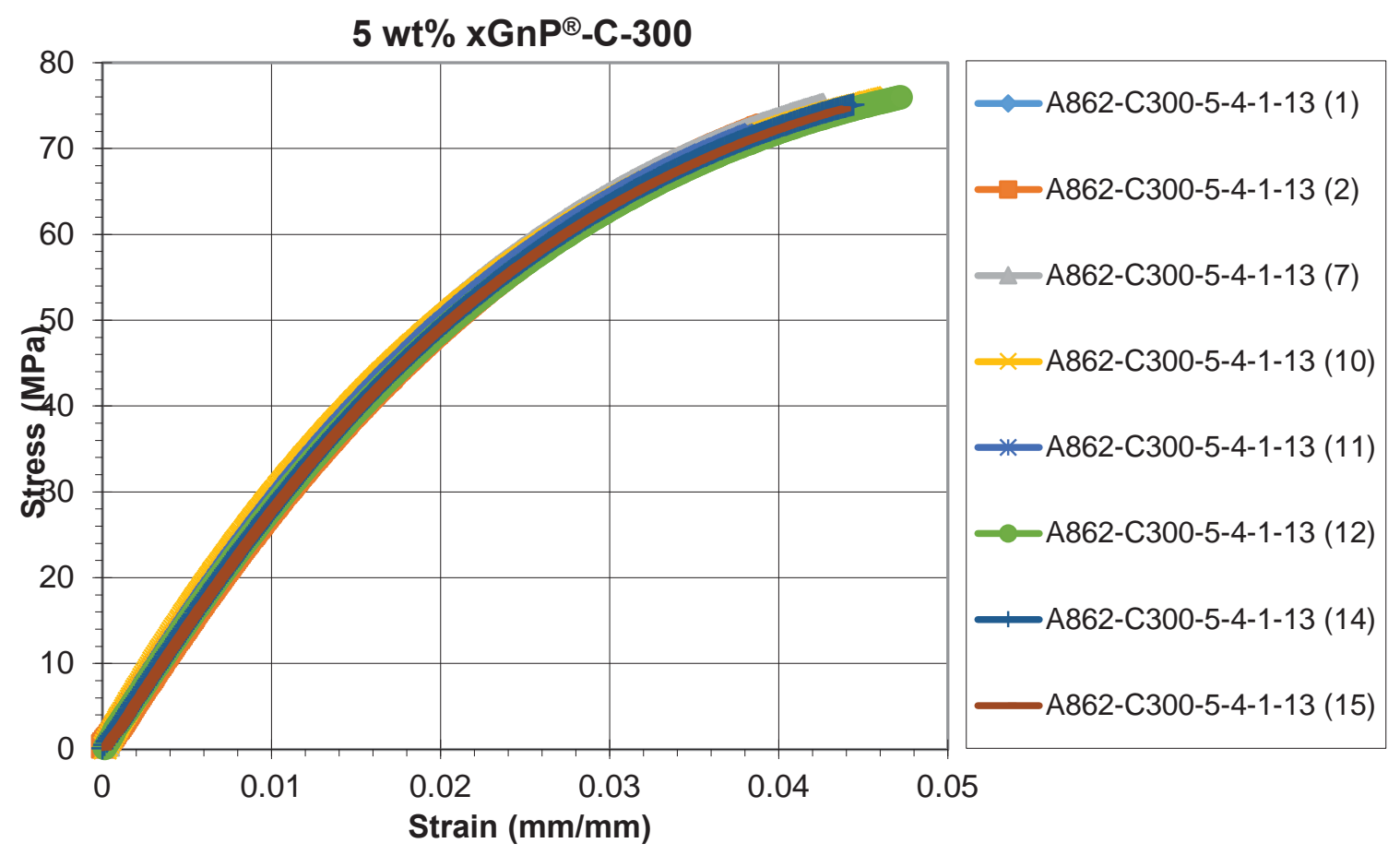

Figure A-18: Tensile Results for 5 wt\% $x G n P^{\circledR}-C-300$ in Epoxy

Table A-18: Tensile Results for 5 wt\% $x G n P^{\circledR}-C-300$ in Epoxy

\begin{tabular}{|l|c|c|c|c|c|c|}
\hline \multicolumn{1}{|c|}{ Sample } & No. & $\begin{array}{c}\text { Ultimate } \\
\text { Tensile } \\
\text { Stress } \\
(\mathbf{M P a})\end{array}$ & $\begin{array}{c}\text { Strain at } \\
\text { Ultimate } \\
\text { Tensile } \\
\text { Stress } \mathbf{( \% )}\end{array}$ & $\begin{array}{c}\text { Tensile } \\
\text { Fracture } \\
\text { Stress } \\
(\mathbf{M P a})\end{array}$ & $\begin{array}{c}\text { Strain at } \\
\text { Tensile } \\
\text { Fracture } \\
\text { Stress (\%) }\end{array}$ & $\begin{array}{c}\text { Tensile } \\
\text { Modulus } \\
(\mathbf{G P a})\end{array}$ \\
\hline A862-C300-5-4-1-13 & 1 & 71.597 & 3.84 & 71.597 & 3.84 & 3.0715 \\
\hline A862-C300-5-4-1-13 & 2 & 72.679 & 3.93 & 72.679 & 3.93 & 2.9547 \\
\hline A862-C300-5-4-1-13 & 7 & 75.442 & 4.26 & 75.442 & 4.26 & 3.1686 \\
\hline A862-C300-5-4-1-13 & 10 & 75.918 & 4.66 & 75.918 & 4.66 & 3.2026 \\
\hline A862-C300-5-4-1-13 & 11 & 71.979 & 3.84 & 71.979 & 3.84 & 3.0867 \\
\hline A862-C300-5-4-1-13 & 12 & 75.984 & 4.72 & 75.984 & 4.72 & 2.9747 \\
\hline A862-C300-5-4-1-13 & 14 & 75.193 & 4.45 & 75.193 & 4.45 & 2.92 \\
\hline A862-C300-5-4-1-13 & 15 & 75.098 & 4.46 & 75.098 & 4.46 & 2.96 \\
\hline Average & & $\mathbf{7 4 . 2 4}$ & $\mathbf{4 . 2 7}$ & $\mathbf{7 4 . 2 4}$ & $\mathbf{4 . 2 7}$ & $\mathbf{3 . 0 4}$ \\
\hline Standard Deviation & $\mathbf{1 . 8 3}$ & $\mathbf{0 . 3 6}$ & $\mathbf{1 . 8 3}$ & $\mathbf{0 . 3 6}$ & $\mathbf{0 . 1 1}$ \\
\hline Count & $\mathbf{8}$ & $\mathbf{8}$ & $\mathbf{8}$ & $\mathbf{8}$ & $\mathbf{8}$ \\
\hline
\end{tabular}




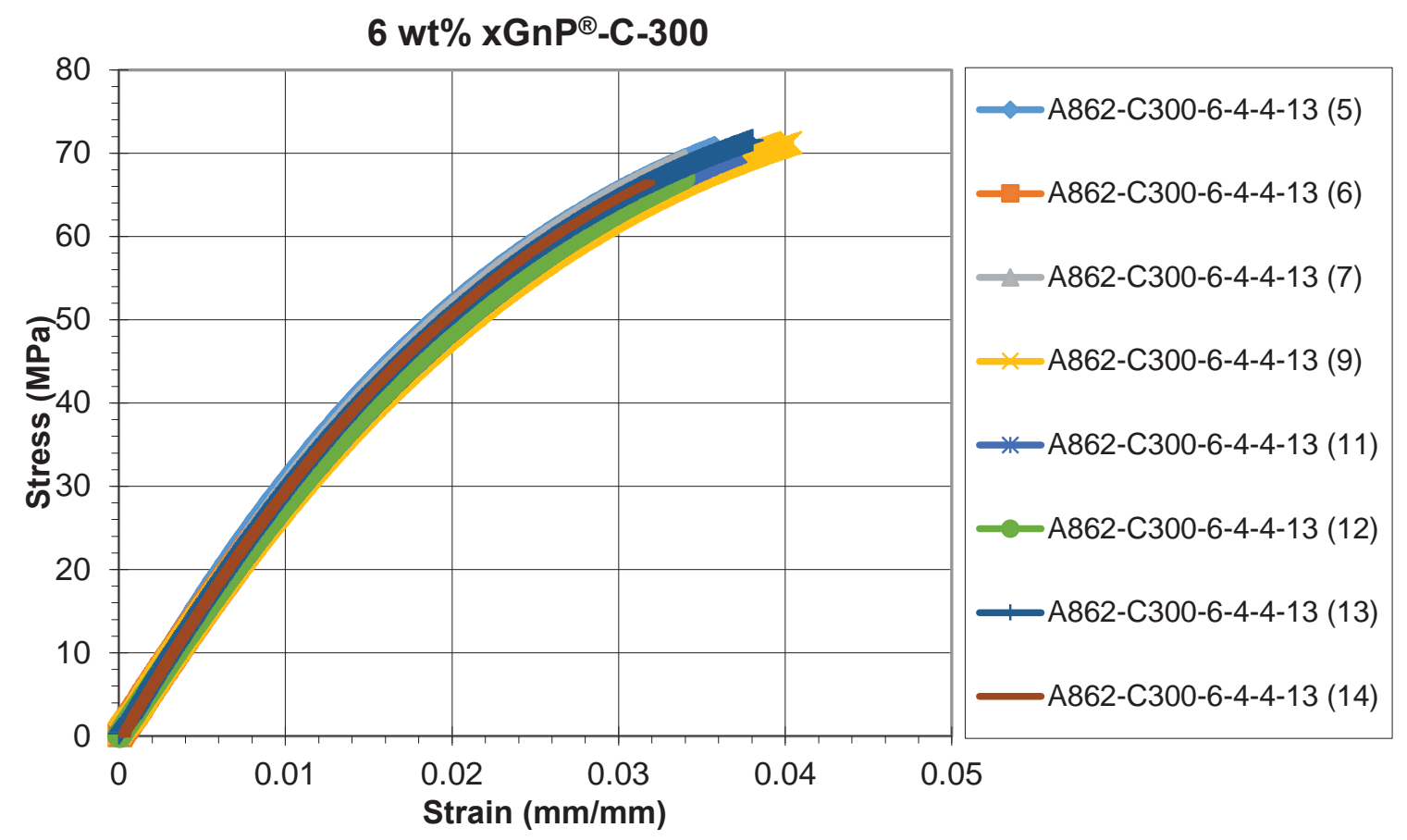

Figure A-19: Tensile Results for 6 wt\% $x G n P^{\circledR}-C-300$ in Epoxy

Table A-19: Tensile Results for 6 wt\% $x G n P^{\circledR}-C-300$ in Epoxy

\begin{tabular}{|l|c|c|c|c|c|c|}
\hline \multicolumn{1}{|c|}{ Sample } & No. & $\begin{array}{c}\text { Ultimate } \\
\text { Tensile } \\
\text { Stress } \\
\text { (MPa) }\end{array}$ & $\begin{array}{c}\text { Strain at } \\
\text { Ultimate } \\
\text { Tensile } \\
\text { Stress (\%) }\end{array}$ & $\begin{array}{c}\text { Tensile } \\
\text { Fracture } \\
\text { Stress } \\
(\mathbf{M P a})\end{array}$ & $\begin{array}{c}\text { Strain at } \\
\text { Tensile } \\
\text { Fracture } \\
\text { Stress (\%) }\end{array}$ & $\begin{array}{c}\text { Tensile } \\
\text { Modulus } \\
\text { (GPa) }\end{array}$ \\
\hline A862-C300-6-4-4-13 & 5 & 70.973 & 3.576 & 70.973 & 3.576 & 3.302 \\
\hline A862-C300-6-4-4-13 & 6 & 67.176 & 3.348 & 67.176 & 3.348 & 2.998 \\
\hline A862-C300-6-4-4-13 & 7 & 69.391 & 3.400 & 69.391 & 3.400 & 3.295 \\
\hline A862-C300-6-4-4-13 & 9 & 71.270 & 4.033 & 71.270 & 4.033 & 2.978 \\
\hline A862-C300-6-4-4-13 & 11 & 69.814 & 3.723 & 69.814 & 3.723 & 2.940 \\
\hline A862-C300-6-4-4-13 & 12 & 67.038 & 3.387 & 67.038 & 3.387 & 2.970 \\
\hline A862-C300-6-4-4-13 & 13 & 71.574 & 3.803 & 71.574 & 3.803 & 3.121 \\
\hline A862-C300-6-4-4-13 & 14 & 67.020 & 3.221 & 67.020 & 3.221 & 3.201 \\
\hline Average & & $\mathbf{6 9 . 2 8}$ & $\mathbf{3 . 5 6}$ & $\mathbf{6 9 . 2 8}$ & $\mathbf{3 . 5 6}$ & $\mathbf{3 . 1 0}$ \\
\hline Standard Deviation & & $\mathbf{1 . 9 6}$ & $\mathbf{0 . 2 7}$ & $\mathbf{1 . 9 6}$ & $\mathbf{0 . 2 7}$ & $\mathbf{0 . 1 5}$ \\
\hline Count & & $\mathbf{8}$ & $\mathbf{8}$ & $\mathbf{8}$ & $\mathbf{8}$ & $\mathbf{8}$ \\
\hline
\end{tabular}




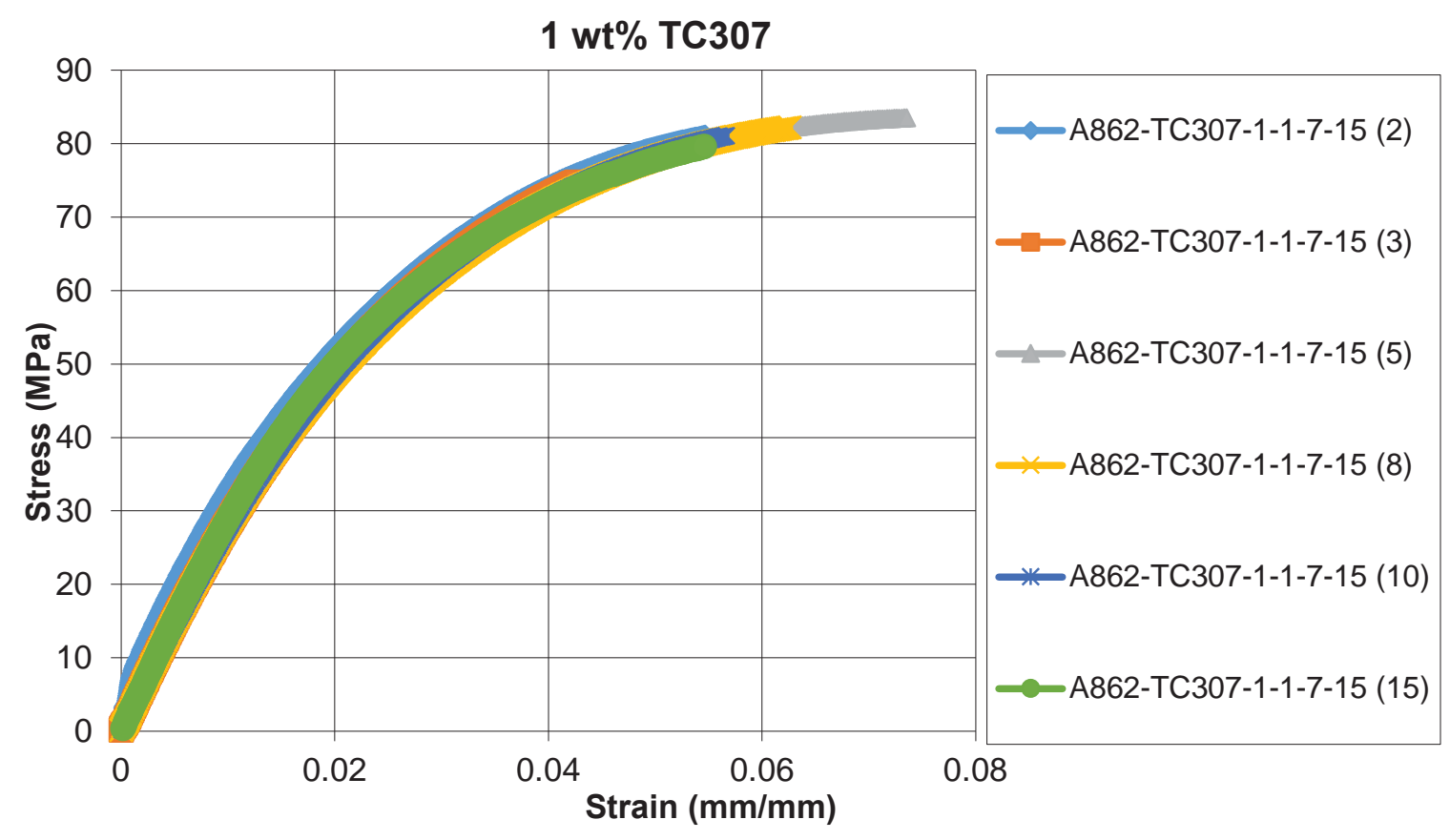

Figure A-20: Tensile Results for 1 wt\% TC307 in Epoxy

Table A-20: Tensile Results for 1 wt\% TC307 in Epoxy

\begin{tabular}{|l|c|c|c|c|c|c|}
\hline \multicolumn{1}{|c|}{ Sample } & No. & $\begin{array}{c}\text { Ultimate } \\
\text { Tensile } \\
\text { Stress } \\
\text { (MPa) }\end{array}$ & $\begin{array}{c}\text { Strain at } \\
\text { Ultimate } \\
\text { Tensile } \\
\text { Stress (\%) }\end{array}$ & $\begin{array}{c}\text { Tensile } \\
\text { Fracture } \\
\text { Stress } \\
\text { (MPa) }\end{array}$ & $\begin{array}{c}\text { Strain at } \\
\text { Tensile } \\
\text { Fracture } \\
\text { Stress (\%) }\end{array}$ & $\begin{array}{c}\text { Tensile } \\
\text { Modulus } \\
\text { (GPa) }\end{array}$ \\
\hline A862-TC307-1-1-7-15 & 2 & 81.283 & 5.719 & 81.283 & 5.719 & 2.9528 \\
\hline A862-TC307-1-1-7-15 & 3 & 79.200 & 5.047 & 79.200 & 5.047 & 2.8246 \\
\hline A862-TC307-1-1-7-15 & 5 & 83.530 & 7.399 & 83.530 & 7.399 & 2.7576 \\
\hline A862-TC307-1-1-7-15 & 8 & 82.270 & 6.294 & 82.270 & 6.294 & 2.8231 \\
\hline A862-TC307-1-1-7-15 & 10 & 81.170 & 5.693 & 81.170 & 5.693 & 2.7821 \\
\hline A862-TC307-1-1-7-15 & 15 & 79.715 & 5.492 & 79.715 & 5.492 & 2.9091 \\
\hline Average & & 81.19 & 5.94 & 81.19 & 5.94 & 2.84 \\
\hline Standard Deviation & & 1.60 & 0.82 & 1.60 & 0.82 & 0.08 \\
\hline Count & 6 & 6 & 6 & 6 & 6 \\
\hline
\end{tabular}




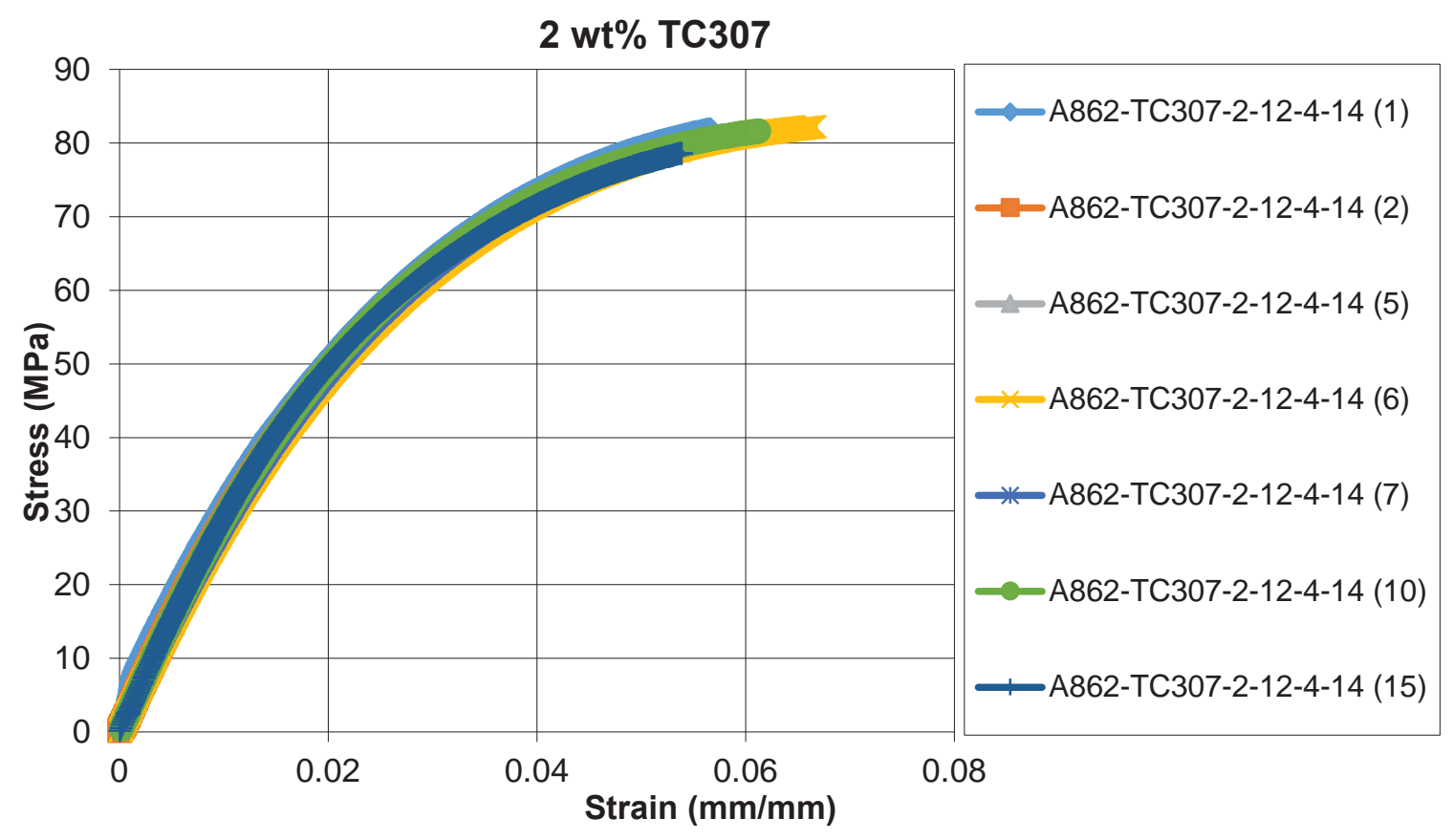

Figure A-21: Tensile Results for 2 wt\% TC307 in Epoxy

Table A-21: Tensile Results for 2 wt\% TC307 in Epoxy

\begin{tabular}{|l|c|c|c|c|c|c|}
\hline \multicolumn{1}{|c|}{ Sample } & No. & $\begin{array}{c}\text { Ultimate } \\
\text { Tensile } \\
\text { Stress } \\
\text { (MPa) }\end{array}$ & $\begin{array}{c}\text { Strain at } \\
\text { Ultimate } \\
\text { Tensile } \\
\text { Stress (\%) }\end{array}$ & $\begin{array}{c}\text { Tensile } \\
\text { Fracture } \\
\text { Stress } \\
\text { (MPa) }\end{array}$ & $\begin{array}{c}\text { Strain at } \\
\text { Tensile } \\
\text { Fracture } \\
\text { Stress (\%) }\end{array}$ & $\begin{array}{c}\text { Tensile } \\
\text { Modulus } \\
(\mathbf{G P a})\end{array}$ \\
\hline A862-TC307-2-12-4-14 & 1 & 82.237 & 5.917 & 82.237 & 5.917 & 2.807 \\
\hline A862-TC307-2-12-4-14 & 2 & 77.648 & 4.894 & 77.648 & 4.894 & 2.886 \\
\hline A862-TC307-2-12-4-14 & 5 & 82.008 & 6.213 & 82.008 & 6.213 & 2.870 \\
\hline A862-TC307-2-12-4-14 & 6 & 82.244 & 6.704 & 82.244 & 6.704 & 2.823 \\
\hline A862-TC307-2-12-4-14 & 7 & 81.351 & 6.085 & 81.351 & 6.085 & 2.826 \\
\hline A862-TC307-2-12-4-14 & 10 & 81.706 & 6.166 & 81.706 & 6.166 & 2.960 \\
\hline A862-TC307-2-12-4-14 & 1 & 82.237 & 5.417 & 78.734 & 5.417 & 2.982 \\
\hline Average & & $\mathbf{8 0 . 8 5}$ & $\mathbf{5 . 9 1}$ & $\mathbf{8 0 . 8 5}$ & $\mathbf{5 . 9 1}$ & $\mathbf{2 . 8 8}$ \\
\hline Standard Deviation & & $\mathbf{1 . 8 7}$ & $\mathbf{0 . 5 9}$ & $\mathbf{1 . 8 7}$ & $\mathbf{0 . 5 9}$ & $\mathbf{0 . 0 7}$ \\
\hline Number & $\mathbf{7}$ & $\mathbf{7}$ & $\mathbf{7}$ & $\mathbf{7}$ & $\mathbf{7}$ \\
\hline
\end{tabular}




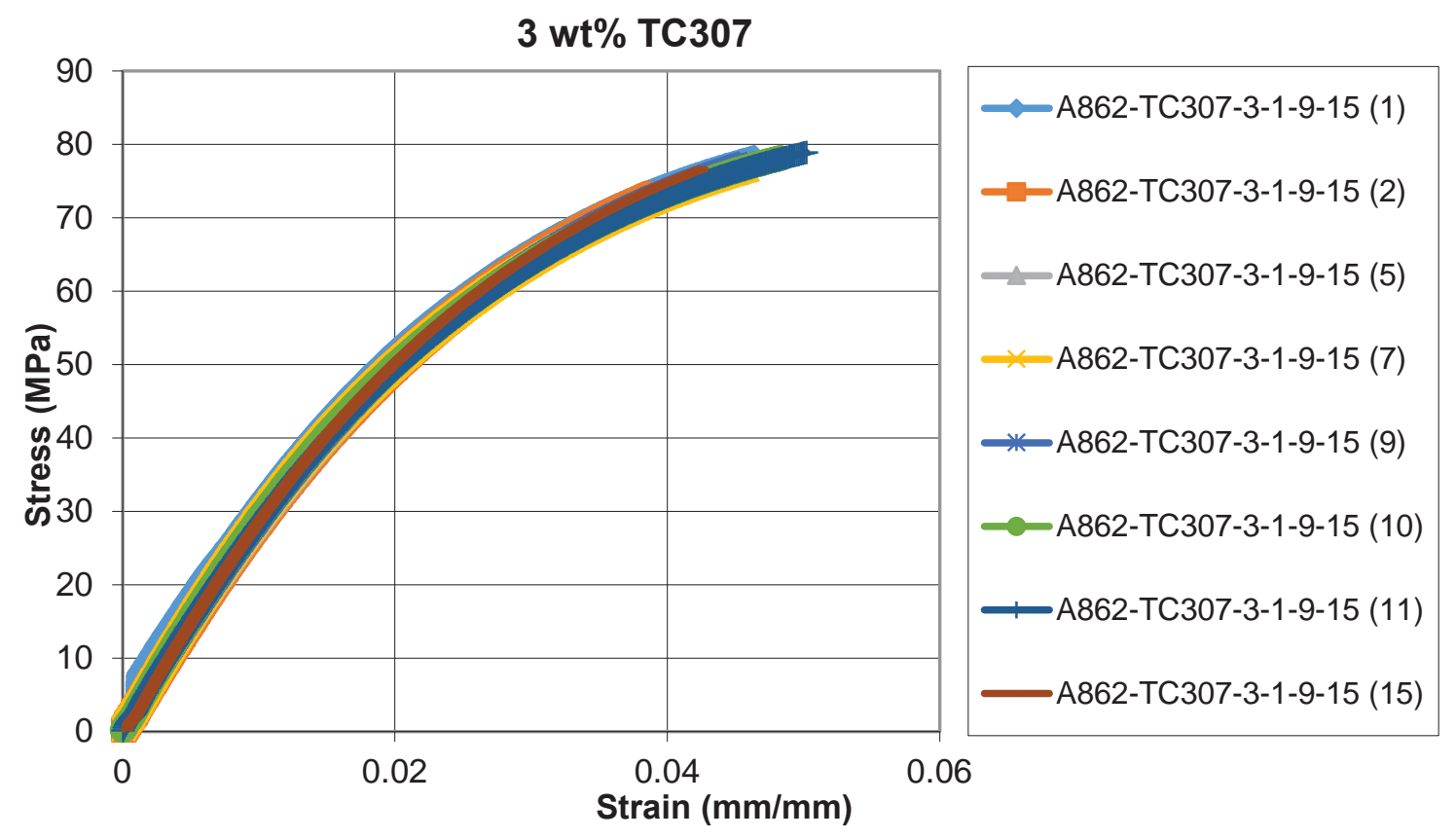

Figure A-22: Tensile Results for 3 wt\% TC307 in Epoxy

Table A-22: Tensile Results for 3 wt\% TC307 in Epoxy

\begin{tabular}{|l|c|c|c|c|c|c|}
\hline \multicolumn{1}{|c|}{ Sample } & No. & $\begin{array}{c}\text { Ultimate } \\
\text { Tensile } \\
\text { Stress } \\
\text { (MPa) }\end{array}$ & $\begin{array}{c}\text { Strain at } \\
\text { Ultimate } \\
\text { Tensile } \\
\text { Stress (\%) }\end{array}$ & $\begin{array}{c}\text { Tensile } \\
\text { Fracture } \\
\text { Stress } \\
\text { (MPa) }\end{array}$ & $\begin{array}{c}\text { Strain at } \\
\text { Tensile } \\
\text { Fracture } \\
\text { Stress (\%) }\end{array}$ & $\begin{array}{c}\text { Tensile } \\
\text { Modulus } \\
\text { (GPa) }\end{array}$ \\
\hline A862-TC307-3-1-9-15 & 1 & 79.039 & 4.94 & 79.039 & 4.94 & 2.886 \\
\hline A862-TC307-3-1-9-15 & 2 & 78.367 & 4.68 & 78.367 & 4.68 & 2.903 \\
\hline A862-TC307-3-1-9-15 & 5 & 78.095 & 4.86 & 78.095 & 4.86 & 2.839 \\
\hline A862-TC307-3-1-9-15 & 7 & 76.717 & 4.61 & 76.717 & 4.61 & 2.974 \\
\hline A862-TC307-3-1-9-15 & 9 & 77.977 & 4.60 & 77.977 & 4.60 & 2.884 \\
\hline A862-TC307-3-1-9-15 & 10 & 78.259 & 4.85 & 78.259 & 4.85 & 2.973 \\
\hline A862-TC307-3-1-9-15 & 11 & 79.023 & 5.05 & 79.023 & 5.05 & 2.874 \\
\hline A862-TC307-3-1-9-15 & 15 & 77.137 & 4.30 & 77.137 & 4.30 & 2.969 \\
\hline Average & & $\mathbf{7 8 . 0 8}$ & $\mathbf{4 . 7 4}$ & $\mathbf{7 8 . 0 8}$ & $\mathbf{4 . 7 4}$ & $\mathbf{2 . 9 1}$ \\
\hline Standard Deviation & $\mathbf{0 . 8 2}$ & $\mathbf{0 . 2 4}$ & $\mathbf{0 . 8 2}$ & $\mathbf{0 . 2 4}$ & $\mathbf{0 . 0 5}$ \\
\hline Count & $\mathbf{8}$ & $\mathbf{8}$ & $\mathbf{8}$ & $\mathbf{8}$ & $\mathbf{8}$ \\
\hline
\end{tabular}




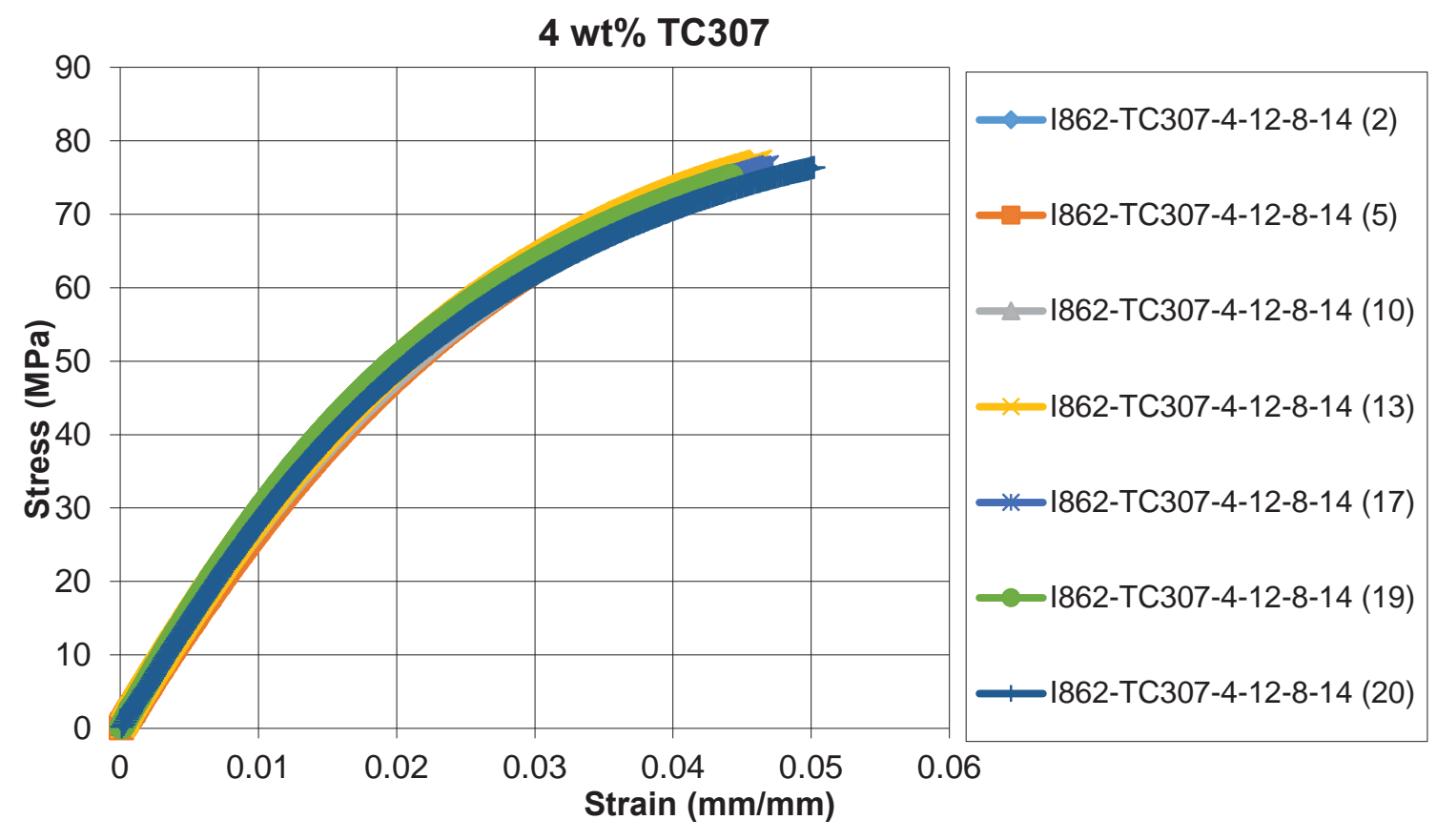

Figure A-23: Tensile Results for 4 wt\% TC307 in Epoxy

Table A-23: Tensile Results for 4 wt\% TC307 in Epoxy

\begin{tabular}{|l|c|c|c|c|c|c|}
\hline \multicolumn{1}{|c|}{ Sample } & $\begin{array}{c}\text { Ultimate } \\
\text { Tensile } \\
\text { Stress } \\
\text { (MPa) }\end{array}$ & $\begin{array}{c}\text { Strain at } \\
\text { Ultimate } \\
\text { Tensile } \\
\text { Stress }\end{array}$ & $\begin{array}{c}\text { Tensile } \\
\text { Fracture } \\
\text { Stress } \\
\text { (MPa) }\end{array}$ & $\begin{array}{c}\text { Strain at } \\
\text { Tensile } \\
\text { Fracture } \\
\text { Stress (\%) }\end{array}$ & $\begin{array}{c}\text { Tensile } \\
\text { Modulus } \\
(\mathbf{G P a})\end{array}$ \\
\hline A862-TC307-2-12-4-14 & 2 & 76.719 & 4.508 & 76.719 & 4.508 & 2.914 \\
\hline A862-TC307-2-12-4-14 & 5 & 75.668 & 4.460 & 75.668 & 4.460 & 2.828 \\
\hline A862-TC307-2-12-4-14 & 10 & 72.036 & 4.015 & 72.036 & 4.015 & 2.838 \\
\hline A862-TC307-2-12-4-14 & 13 & 77.183 & 4.630 & 77.183 & 4.630 & 2.964 \\
\hline A862-TC307-2-12-4-14 & 17 & 76.997 & 4.729 & 76.997 & 4.729 & 3.039 \\
\hline A862-TC307-2-12-4-14 & 19 & 75.282 & 4.444 & 75.282 & 4.444 & 3.068 \\
\hline A862-TC307-2-12-4-14 & 20 & 76.471 & 5.046 & 76.471 & 5.046 & 2.879 \\
\hline Average & & $\mathbf{7 5 . 7 7}$ & $\mathbf{4 . 5 5}$ & $\mathbf{7 5 . 7 7}$ & $\mathbf{4 . 5 5}$ & $\mathbf{2 . 9 3}$ \\
\hline Standard Deviation & & $\mathbf{1 . 7 8}$ & $\mathbf{0 . 3 1}$ & $\mathbf{1 . 7 8}$ & $\mathbf{0 . 3 1}$ & $\mathbf{0 . 0 9}$ \\
\hline Number & $\mathbf{7}$ & $\mathbf{7}$ & $\mathbf{7}$ & $\mathbf{7}$ & $\mathbf{7}$ \\
\hline
\end{tabular}




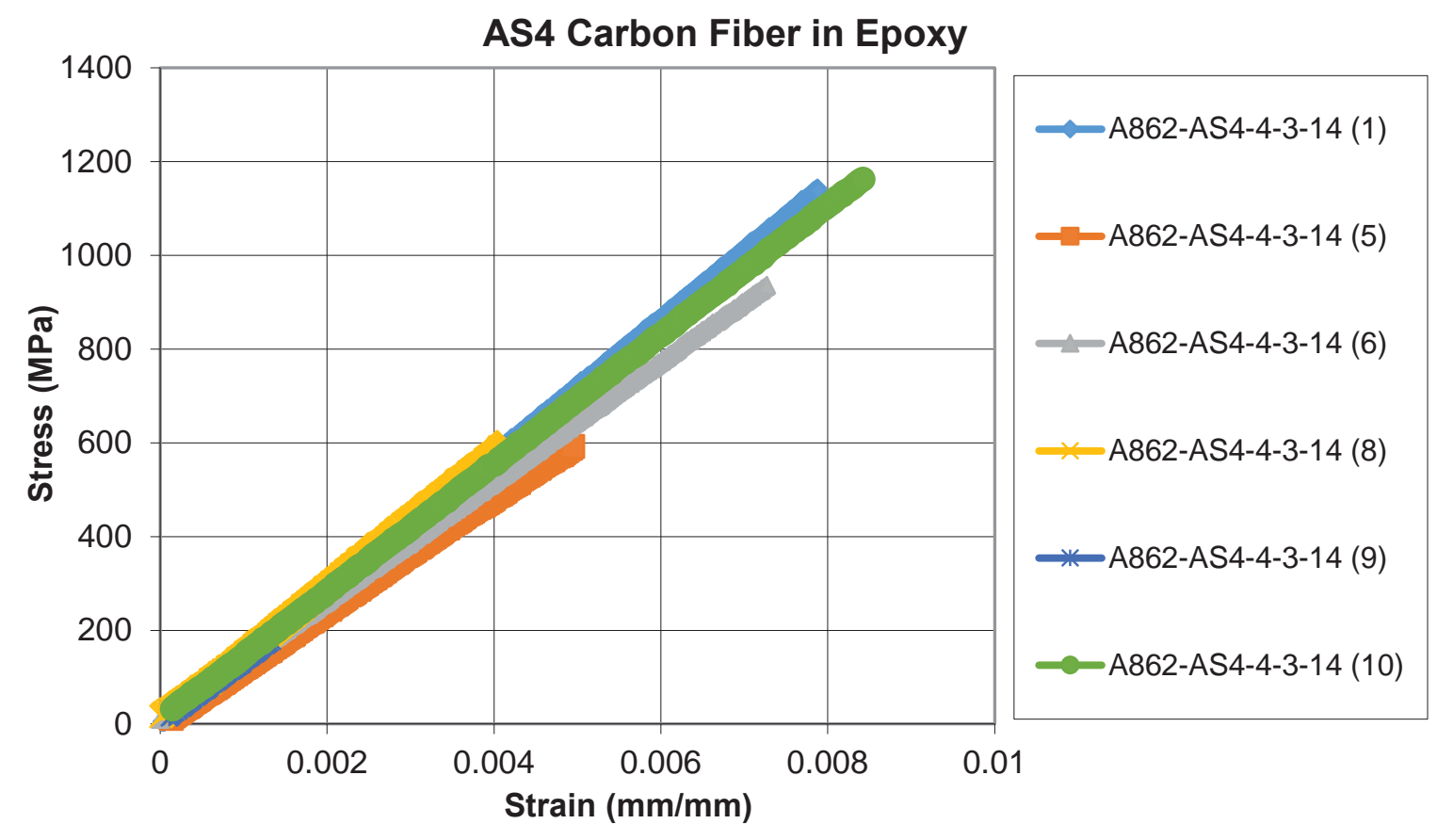

Figure A-24: Tensile Results for AS4 Carbon Fiber in Epoxy

Table A-24: Tensile Results for AS4 Carbon Fiber in Epoxy

\begin{tabular}{|l|c|c|}
\hline \multicolumn{1}{|c|}{ Sample } & No. & $\begin{array}{c}\text { Tensile } \\
\text { Modulus } \\
\text { (GPa) }\end{array}$ \\
\hline A862-AS4-4-3-14 & 1 & 144.847 \\
\hline A862-AS4-4-3-14 & 5 & 120.89 \\
\hline A862-AS4-4-3-14 & 6 & 127.263 \\
\hline A862-AS4-4-3-14 & 8 & 143.104 \\
\hline A862-AS4-4-3-14 & 9 & 132.278 \\
\hline A862-AS4-4-3-14 & 10 & 137.053 \\
\hline Average & & 134.24 \\
\hline Standard Deviation & & $\mathbf{9 . 2 7}$ \\
\hline Number & $\mathbf{6}$ \\
\hline
\end{tabular}




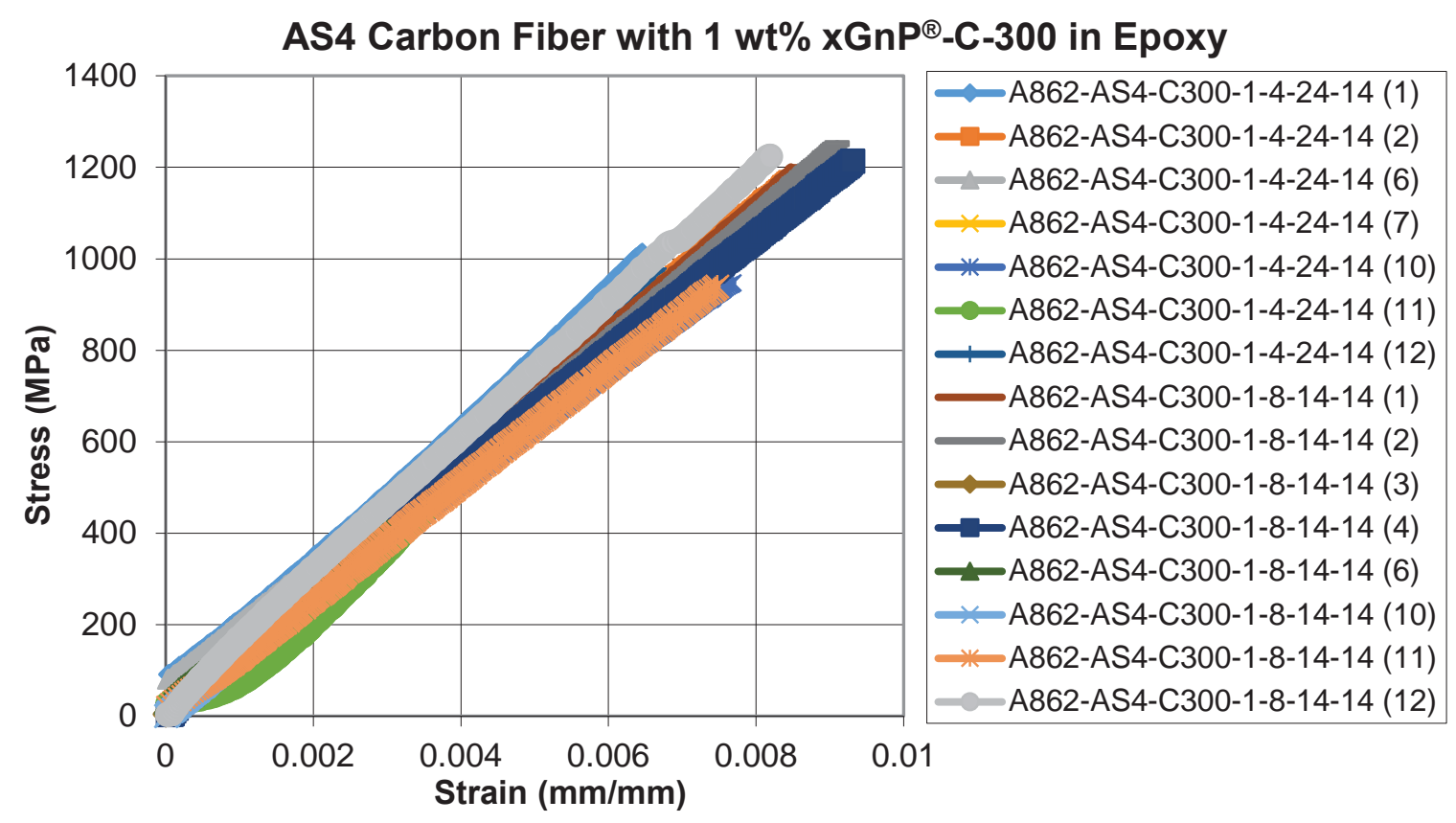

Figure A-25: Tensile Results for 1 wt\% $x$ GnP $^{\circledR}-C-300$ with AS4 Carbon Fiber in Epoxy

Table A-25: Tensile Results for 1 wt\% $x$ GnP $^{\circledR}-C-300$ with AS4 Carbon Fiber in Epoxy

\begin{tabular}{|l|c|c|}
\hline \multicolumn{1}{|c|}{ Sample } & No. & $\begin{array}{c}\text { Tensile } \\
\text { Modulus } \\
\text { (GPa) }\end{array}$ \\
\hline A862-AS4-C300-1-4-24-14 & 1 & 144.359 \\
\hline A862-AS4-C300-1-4-24-14 & 2 & 136.662 \\
\hline A862-AS4-C300-1-4-24-14 & 6 & 123.901 \\
\hline A862-AS4-C300-1-4-24-14 & 7 & 135.517 \\
\hline A862-AS4-C300-1-4-24-14 & 10 & 123.261 \\
\hline A862-AS4-C300-1-4-24-14 & 11 & 153.901 \\
\hline A862-AS4-C300-1-4-24-14 & 12 & 147.364 \\
\hline A862-AS4-C300-1-8-14-14 & 1 & 140.661 \\
\hline A862-AS4-C300-1-8-14-14 & 2 & 136.581 \\
\hline A862-AS4-C300-1-8-14-14 & 3 & 133.940 \\
\hline A862-AS4-C300-1-8-14-14 & 4 & 129.347 \\
\hline A862-AS4-C300-1-8-14-14 & 6 & 136.521 \\
\hline A862-AS4-C300-1-8-14-14 & 10 & 146.469 \\
\hline A862-AS4-C300-1-8-14-14 & 11 & 125.681 \\
\hline A862-AS4-C300-1-8-14-14 & 12 & 147.647 \\
\hline Average & & $\mathbf{1 3 7 . 4 5}$ \\
\hline Standard Deviation & & $\mathbf{9 . 3 3}$ \\
\hline Number & & $\mathbf{1 5}$ \\
\hline
\end{tabular}




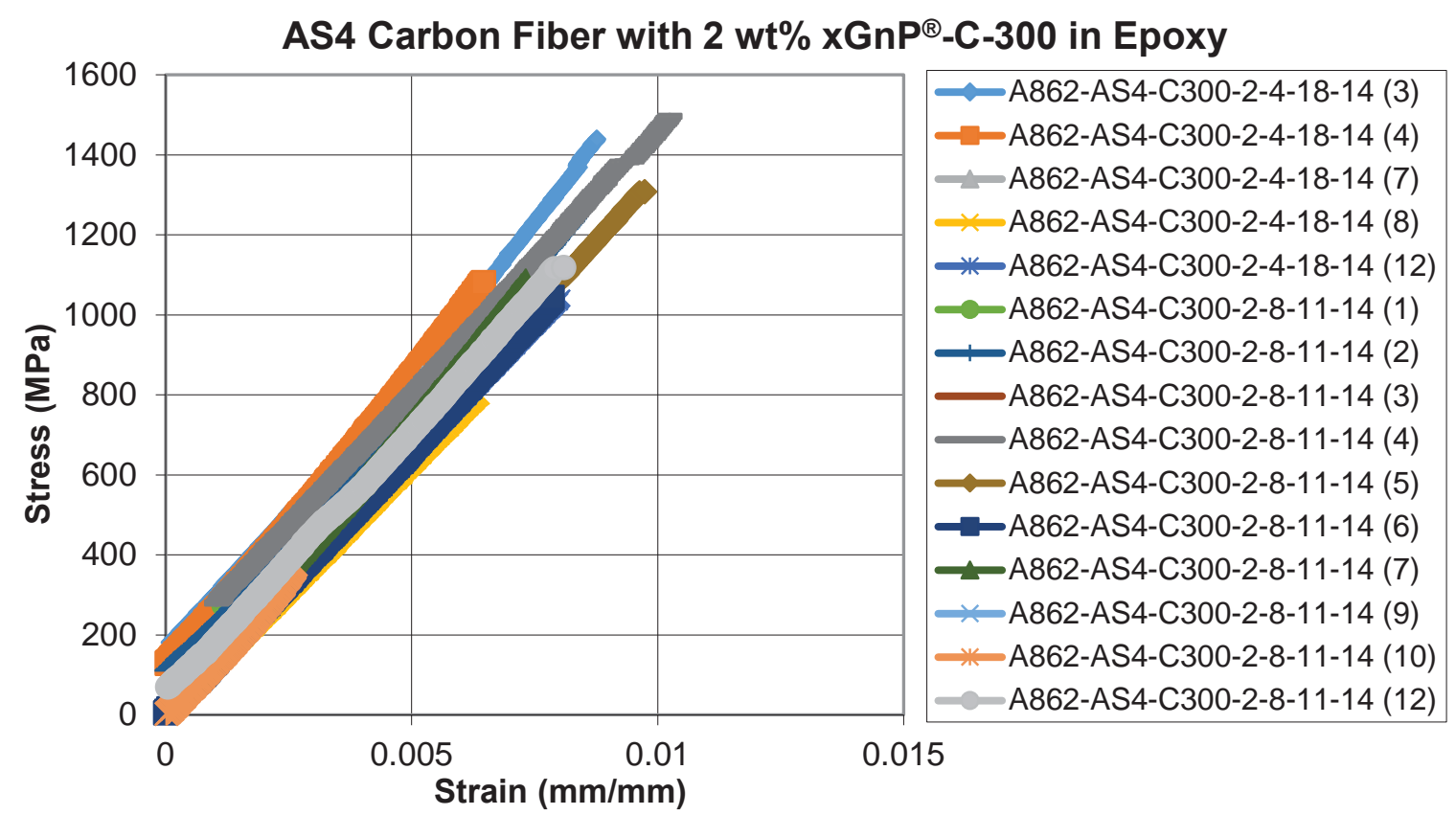

Figure A-26: Tensile Results for 2 wt\% xGnP ${ }^{\circledR}-C-300$ with AS4 Carbon Fiber in Epoxy

Table A-26: Tensile Results for 2 wt\% $x$ GnP $^{\circledR}-C-300$ with AS4 Carbon Fiber in Epoxy

\begin{tabular}{|l|c|c|}
\hline \multicolumn{1}{|c|}{ Sample } & No. & $\begin{array}{c}\text { Tensile } \\
\text { Modulus } \\
\text { (GPa) }\end{array}$ \\
\hline A862-AS4-C300-2-4-18-14 & 3 & 144.101 \\
\hline A862-AS4-C300-2-4-18-14 & 4 & 148.060 \\
\hline A862-AS4-C300-2-4-18-14 & 7 & 142.403 \\
\hline A862-AS4-C300-2-4-18-14 & 8 & 125.484 \\
\hline A862-AS4-C300-2-4-18-14 & 12 & 128.794 \\
\hline A862-AS4-C300-2-8-11-14 & 1 & 137.983 \\
\hline A862-AS4-C300-2-8-11-14 & 2 & 138.185 \\
\hline A862-AS4-C300-2-8-11-14 & 3 & 133.256 \\
\hline A862-AS4-C300-2-8-11-14 & 4 & 132.438 \\
\hline A862-AS4-C300-2-8-11-14 & 5 & 132.908 \\
\hline A862-AS4-C300-2-8-11-14 & 6 & 132.537 \\
\hline A862-AS4-C300-2-8-11-14 & 7 & 145.506 \\
\hline A862-AS4-C300-2-8-11-14 & 9 & 142.301 \\
\hline A862-AS4-C300-2-8-11-14 & 10 & 138.923 \\
\hline A862-AS4-C300-2-8-11-14 & 12 & 132.816 \\
\hline Average & & 137.046 \\
\hline Standard Deviation & & $\mathbf{6 . 5 3}$ \\
\hline Number & & 15 \\
\hline
\end{tabular}




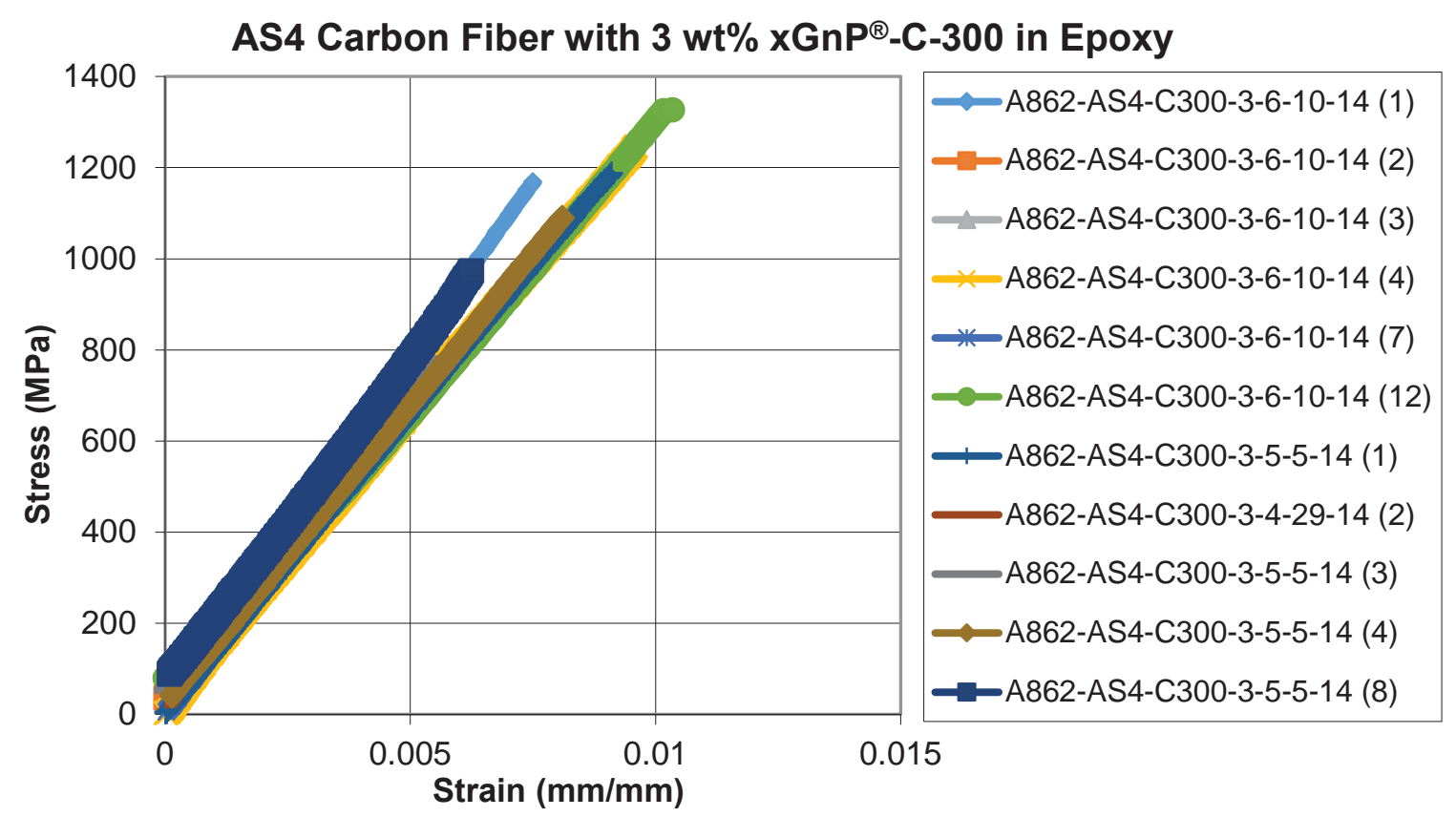

Figure A-27: Tensile Results for 3 wt\% xGnP ${ }^{\circledR}-C-300$ with AS4 Carbon Fiber in Epoxy

Table A-27: Tensile Results for 3 wt\% $x$ GnP $^{\circledR}-C-300$ with AS4 Carbon Fiber in Epoxy

\begin{tabular}{|l|c|c|}
\hline \multicolumn{1}{|c|}{ Sample } & No. & $\begin{array}{c}\text { Tensile } \\
\text { Modulus } \\
\text { (GPa) }\end{array}$ \\
\hline A862-AS4-C300-3-6-10-14 & 1 & 149.417 \\
\hline A862-AS4-C300-3-6-10-14 & 2 & 148.111 \\
\hline A862-AS4-C300-3-6-10-14 & 3 & 131.460 \\
\hline A862-AS4-C300-3-6-10-14 & 4 & 129.898 \\
\hline A862-AS4-C300-3-6-10-14 & 7 & 142.461 \\
\hline A862-AS4-C300-3-6-10-14 & 12 & 122.110 \\
\hline A862-AS4-C300-3-5-5-14 & 1 & 131.016 \\
\hline A862-AS4-C300-3-5-5-14 & 2 & 150.472 \\
\hline A862-AS4-C300-3-5-5-14 & 3 & 128.631 \\
\hline A862-AS4-C300-3-5-5-14 & 4 & 131.955 \\
\hline A862-AS4-C300-3-5-5-14 & 8 & 142.267 \\
\hline Average & & $\mathbf{1 3 7 . 0 7 3}$ \\
\hline Standard Deviation & & $\mathbf{9 . 7 5}$ \\
\hline Number & & $\mathbf{1 1}$ \\
\hline
\end{tabular}




\section{Appdenix B: Nanoindentation Results}

Table B-1: Nanoindentation Averages Between 500 and 1500 nm Depth for Neat Epoxy

\begin{tabular}{|c|c|c|c|c|}
\hline Test & $\begin{array}{c}\text { Average } \\
\text { Modulus } \\
(\mathbf{G P a})\end{array}$ & $\begin{array}{c}\text { Modulus } \\
\text { Std Dev }\end{array}$ & $\begin{array}{c}\text { Average } \\
\text { Hardness } \\
(\mathbf{G P a})\end{array}$ & $\begin{array}{c}\text { Hardness } \\
\text { Std Dev }\end{array}$ \\
\hline 1 & 3.6021 & 0.0499 & 0.2579 & 0.0032 \\
\hline 2 & 3.6090 & 0.0553 & 0.2521 & 0.0022 \\
\hline 3 & 3.5960 & 0.0567 & 0.2586 & 0.0049 \\
\hline 4 & 3.6054 & 0.0567 & 0.2556 & 0.0021 \\
\hline 5 & 3.5958 & 0.0548 & 0.2554 & 0.0023 \\
\hline 6 & 3.6466 & 0.0557 & 0.2629 & 0.0048 \\
\hline 7 & 3.6063 & 0.0510 & 0.2533 & 0.0022 \\
\hline 8 & 3.6040 & 0.0642 & 0.2542 & 0.0027 \\
\hline 9 & 3.5531 & 0.0362 & 0.2518 & 0.0016 \\
\hline 10 & 3.6174 & 0.0620 & 0.2570 & 0.0029 \\
\hline 11 & 3.6495 & 0.0701 & 0.2541 & 0.0035 \\
\hline 12 & 3.6547 & 0.0567 & 0.2500 & 0.0021 \\
\hline 13 & 3.6042 & 0.0542 & 0.2544 & 0.0022 \\
\hline 14 & 3.6113 & 0.0554 & 0.2583 & 0.0036 \\
\hline 15 & 3.6299 & 0.0465 & 0.2509 & 0.0015 \\
\hline 16 & 3.6125 & 0.0512 & 0.2542 & 0.0031 \\
\hline Average & 3.61 & --- & $\mathbf{0 . 2 5 5}$ & --- \\
\hline Std. Dev. & $\mathbf{0 . 0 2}$ & --- & $\mathbf{0 . 0 0 3}$ & --- \\
\hline Count & 16 & $\mathbf{1 6}$ & $\mathbf{1 6}$ & $\mathbf{1 6}$ \\
\hline & & & & \\
\hline
\end{tabular}




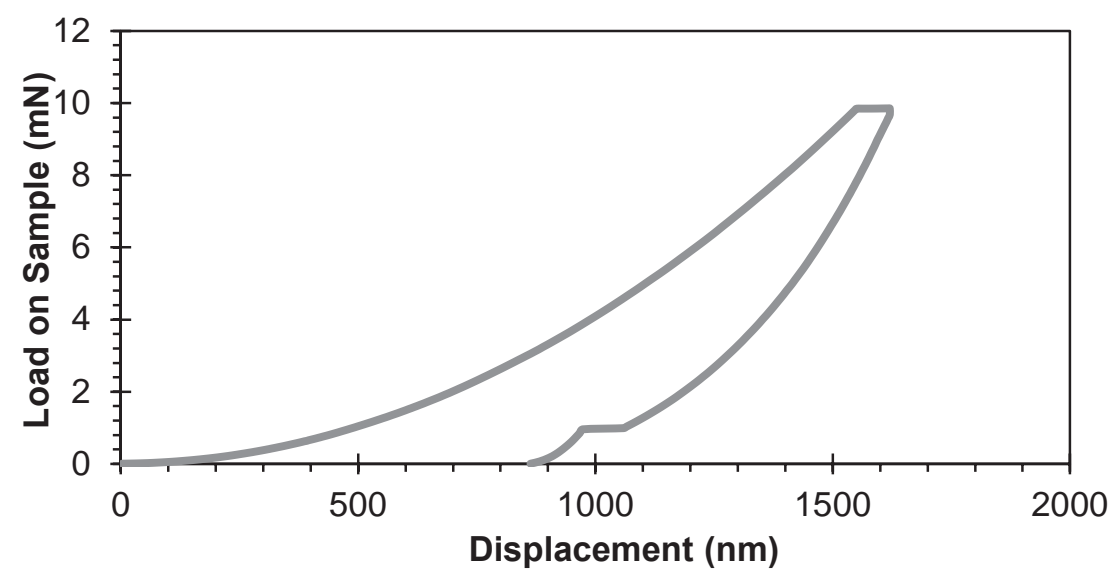

Figure B-1: Load vs. Displacement curve for Neat Epoxy Test 16

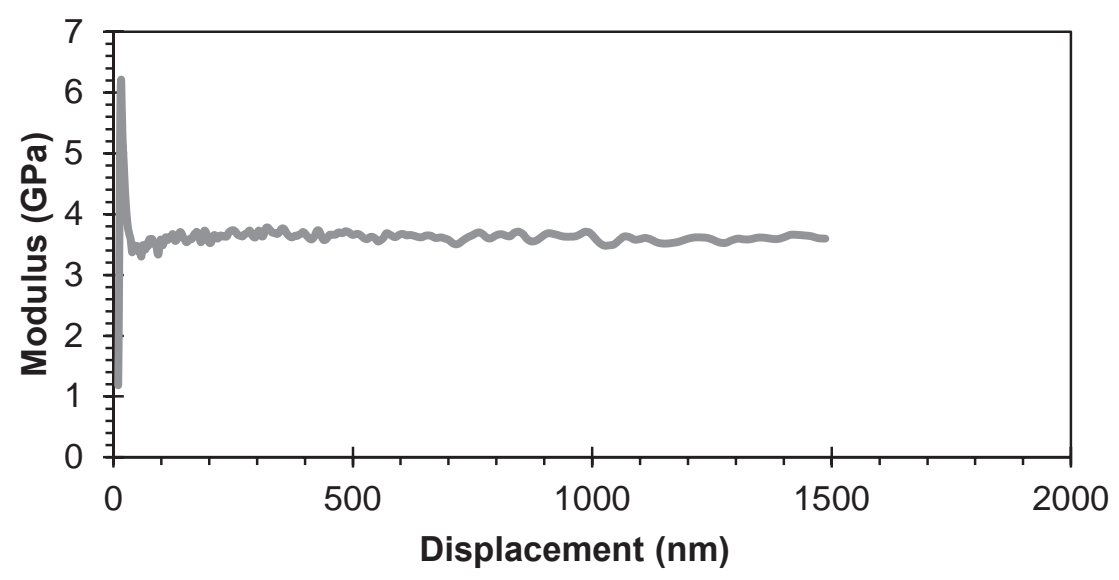

Figure B-2: Modulus vs. Displacement curve for Neat Epoxy Test 16

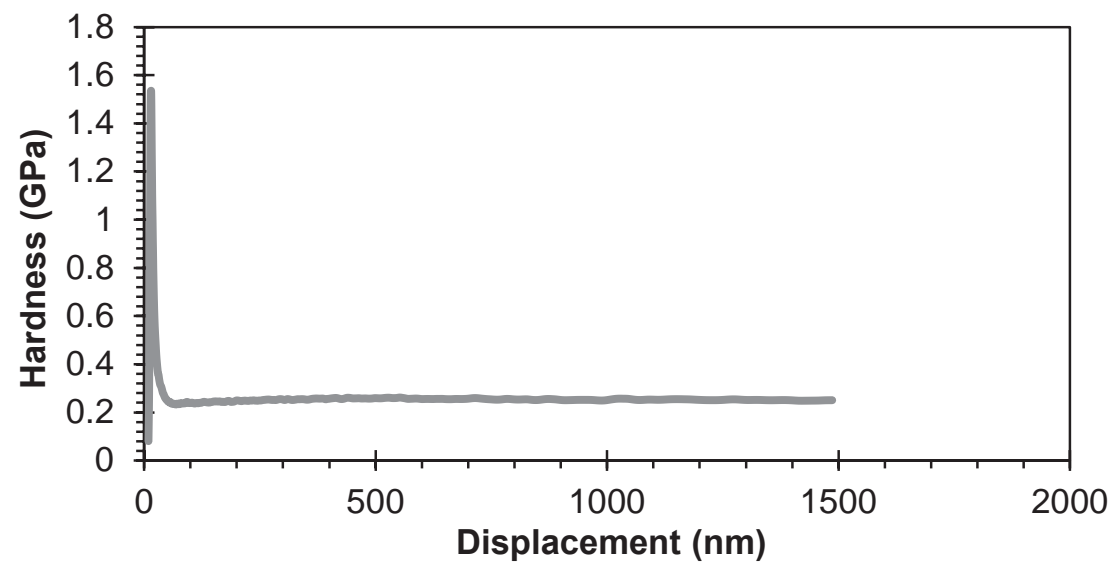

Figure B-3: Hardness vs. Displacement curve for Neat Epoxy Test 16 
Table B-2: Nanoindentation Averages Between 500 and 1500 nm Depth for 1 wt\% $x G n P^{\circledR}-M-15$ in Epoxy

\begin{tabular}{|c|c|c|c|c|}
\hline Test & $\begin{array}{c}\text { Average } \\
\text { Modulus } \\
(\mathrm{GPa})\end{array}$ & $\begin{array}{l}\text { Modulus } \\
\text { Std Dev }\end{array}$ & $\begin{array}{c}\text { Average } \\
\text { Hardness } \\
\text { (GPa) }\end{array}$ & $\begin{array}{l}\text { Hardness } \\
\text { Std Dev }\end{array}$ \\
\hline 2 & 3.7515 & 0.0717 & 0.2647 & 0.0086 \\
\hline 3 & 3.6896 & 0.0649 & 0.2635 & 0.0059 \\
\hline 7 & 3.8334 & 0.0823 & 0.2598 & 0.0029 \\
\hline 10 & 3.7979 & 0.0731 & 0.2555 & 0.0027 \\
\hline 13 & 3.7343 & 0.0735 & 0.2676 & 0.0059 \\
\hline 15 & 3.6954 & 0.0494 & 0.2578 & 0.0022 \\
\hline 16 & 3.8412 & 0.0577 & 0.2716 & 0.0023 \\
\hline 17 & 3.7092 & 0.0588 & 0.2638 & 0.0037 \\
\hline 20 & 3.7000 & 0.0595 & 0.2621 & 0.0043 \\
\hline 21 & 3.7377 & 0.0519 & 0.2647 & 0.0037 \\
\hline 23 & 3.8076 & 0.0752 & 0.2558 & 0.0022 \\
\hline 26 & 3.7485 & 0.0573 & 0.2661 & 0.0021 \\
\hline 29 & 3.7551 & 0.0549 & 0.2655 & 0.0029 \\
\hline 31 & 3.8318 & 0.0456 & 0.2734 & 0.0025 \\
\hline 34 & 3.7121 & 0.0593 & 0.2557 & 0.0029 \\
\hline 35 & 3.7437 & 0.0553 & 0.2591 & 0.0051 \\
\hline 36 & 3.7957 & 0.0678 & 0.2648 & 0.0034 \\
\hline 37 & 3.7519 & 0.0587 & 0.2690 & 0.0069 \\
\hline 39 & 3.7250 & 0.0518 & 0.2557 & 0.0039 \\
\hline 40 & 3.7429 & 0.0449 & 0.2663 & 0.0039 \\
\hline 42 & 3.8244 & 0.0826 & 0.2772 & 0.0064 \\
\hline 43 & 3.6823 & 0.0445 & 0.2552 & 0.0025 \\
\hline 45 & 3.7100 & 0.0969 & 0.2391 & 0.0030 \\
\hline 46 & 3.7566 & 0.0939 & 0.2573 & 0.0035 \\
\hline 47 & 3.6548 & 0.0513 & 0.2555 & 0.0022 \\
\hline 50 & 3.7396 & 0.0566 & 0.2659 & 0.0033 \\
\hline 51 & 3.7119 & 0.0604 & 0.2597 & 0.0035 \\
\hline 52 & 3.8312 & 0.0430 & 0.2750 & 0.0072 \\
\hline Mean & 3.75 & --- & 0.262 & -- \\
\hline Std Dev & 0.05 & --- & 0.008 & --- \\
\hline Count & 28 & 28 & 28 & 28 \\
\hline
\end{tabular}




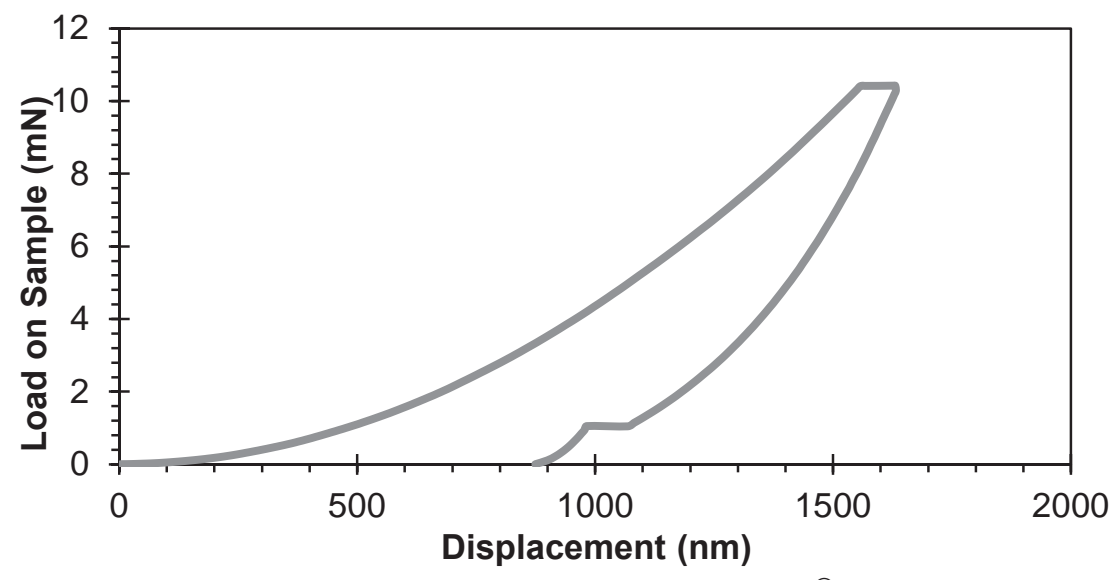

Figure B-4: Load vs. Displacement curve for 1 wt\% $x G n P^{\circledR}-M-15$ in Epoxy Test 16

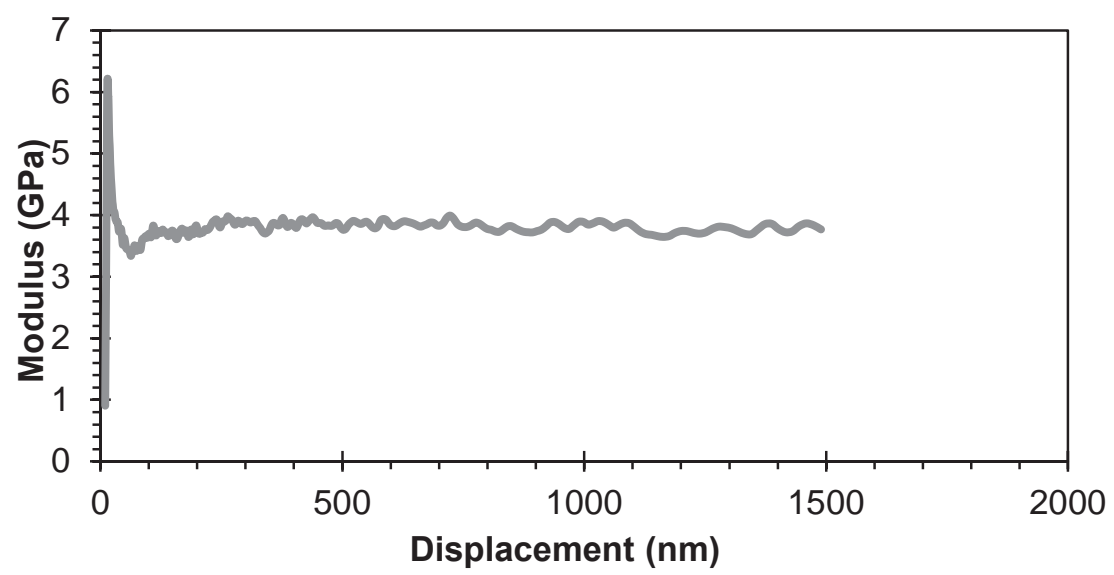

Figure B-5: Modulus vs. Displacement curve for 1 wt\% xGnP ${ }^{\circledR}-M-15$ in Epoxy Test 16

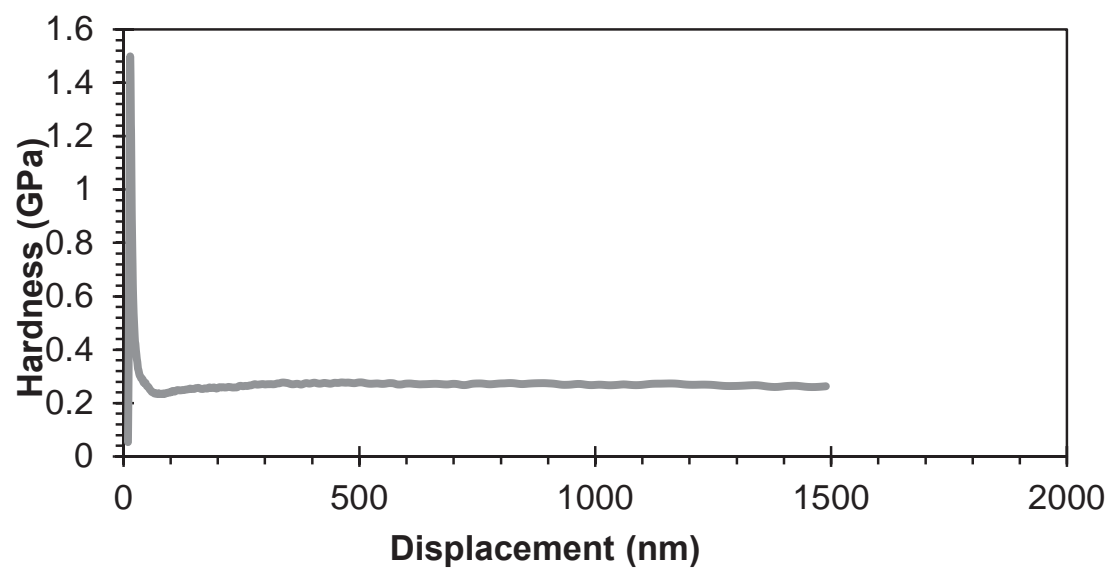

Figure B-6: Hardness vs. Displacement curve 1 wt\% xGnP ${ }^{\circledR}-M-15$ in Epoxy Test 16 
Table B-3: Nanoindentation Averages Between 500 and $1500 \mathrm{~nm}$ Depth for $2 \mathrm{wt} \%$ $x G n P^{\circledR}-M-15$ in Epoxy

\begin{tabular}{|l|c|c|c|c|}
\hline Test & $\begin{array}{c}\text { Average } \\
\text { Modulus } \\
\text { (GPa) }\end{array}$ & $\begin{array}{c}\text { Modulus } \\
\text { Std Dev }\end{array}$ & $\begin{array}{c}\text { Average } \\
\text { Hardness } \\
\text { (GPa) }\end{array}$ & $\begin{array}{c}\text { Hardness } \\
\text { Std Dev }\end{array}$ \\
\hline 1 & 3.7333 & 0.0405 & 0.2325 & 0.0094 \\
\hline 5 & 3.7643 & 0.0670 & 0.2571 & 0.0039 \\
\hline 6 & 3.7372 & 0.0604 & 0.2566 & 0.0053 \\
\hline 8 & 4.0044 & 0.0620 & 0.2596 & 0.0023 \\
\hline 9 & 4.0137 & 0.0612 & 0.2786 & 0.0046 \\
\hline 13 & 3.8790 & 0.0871 & 0.2652 & 0.0047 \\
\hline 23 & 3.9598 & 0.0655 & 0.2574 & 0.0016 \\
\hline 25 & 3.9367 & 0.1068 & 0.2525 & 0.0075 \\
\hline 29 & 3.8653 & 0.0641 & 0.2313 & 0.0076 \\
\hline 33 & 3.9276 & 0.0835 & 0.2389 & 0.0062 \\
\hline 36 & 3.8161 & 0.0680 & 0.2424 & 0.0040 \\
\hline 37 & 3.9291 & 0.0597 & 0.2564 & 0.0023 \\
\hline 38 & 3.9886 & 0.0603 & 0.2645 & 0.0032 \\
\hline 40 & 4.0002 & 0.1087 & 0.2639 & 0.0060 \\
\hline 41 & 3.9691 & 0.0789 & 0.2608 & 0.0053 \\
\hline 42 & 3.9908 & 0.0630 & 0.2675 & 0.0036 \\
\hline 43 & 3.9642 & 0.0689 & 0.2574 & 0.0069 \\
\hline 44 & 3.7499 & 0.1185 & 0.2166 & 0.0134 \\
\hline 46 & 3.9399 & 0.0767 & 0.2438 & 0.0108 \\
\hline 47 & 3.9336 & 0.0594 & 0.2449 & 0.0070 \\
\hline 48 & 3.7338 & 0.1108 & 0.2280 & 0.0137 \\
\hline 49 & 3.9682 & 0.0601 & 0.2547 & 0.0040 \\
\hline 50 & 3.9191 & 0.0875 & 0.2384 & 0.0137 \\
\hline 51 & 3.8861 & 0.0606 & 0.2614 & 0.0040 \\
\hline Mean & $\mathbf{3 . 9 0}$ & --- & $\mathbf{0 . 2 5 1}$ & --- \\
\hline Std Dev & $\mathbf{0 . 0 9}$ & --- & $\mathbf{0 . 0 1 5}$ & -- \\
\hline Count & $\mathbf{2 4}$ & $\mathbf{2 4}$ & $\mathbf{2 4}$ & $\mathbf{2 4}$ \\
\hline & & & & \\
\hline
\end{tabular}




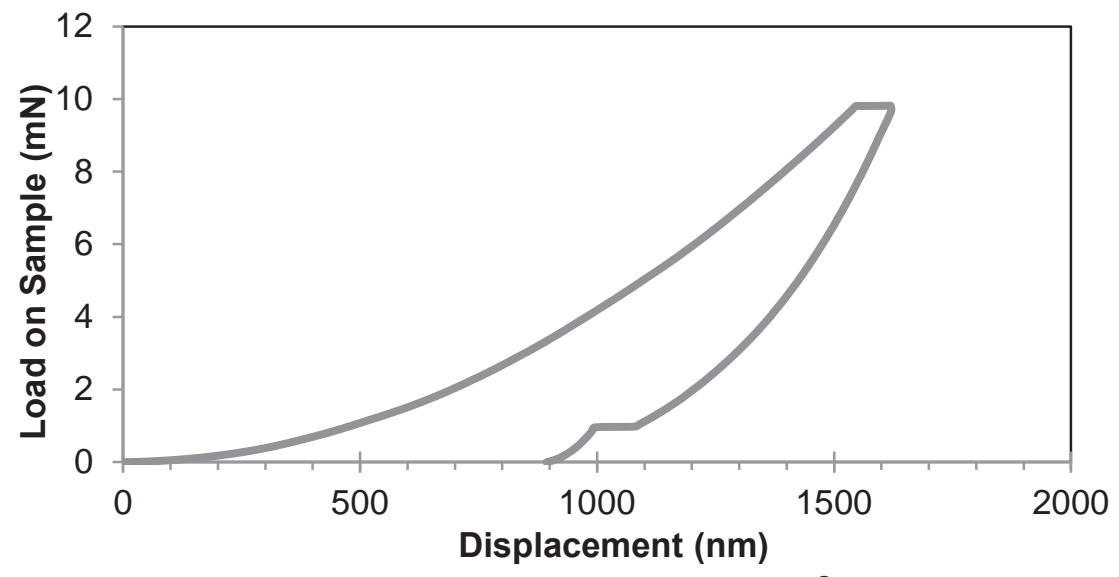

Figure B-7: Load vs. Displacement curve for $2 w t \% x G n P^{\circledR}-M-15$ in Epoxy Test 6

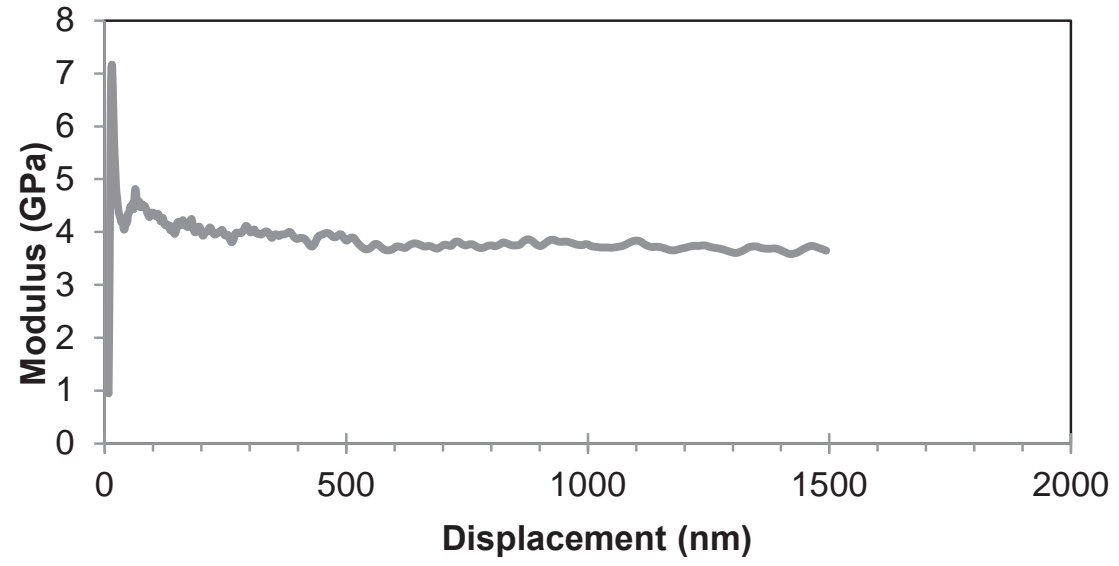

Figure B-8: Modulus vs. Displacement curve for 2 wt\% $x G n P^{\circledR}-M-15$ in Epoxy Test 6

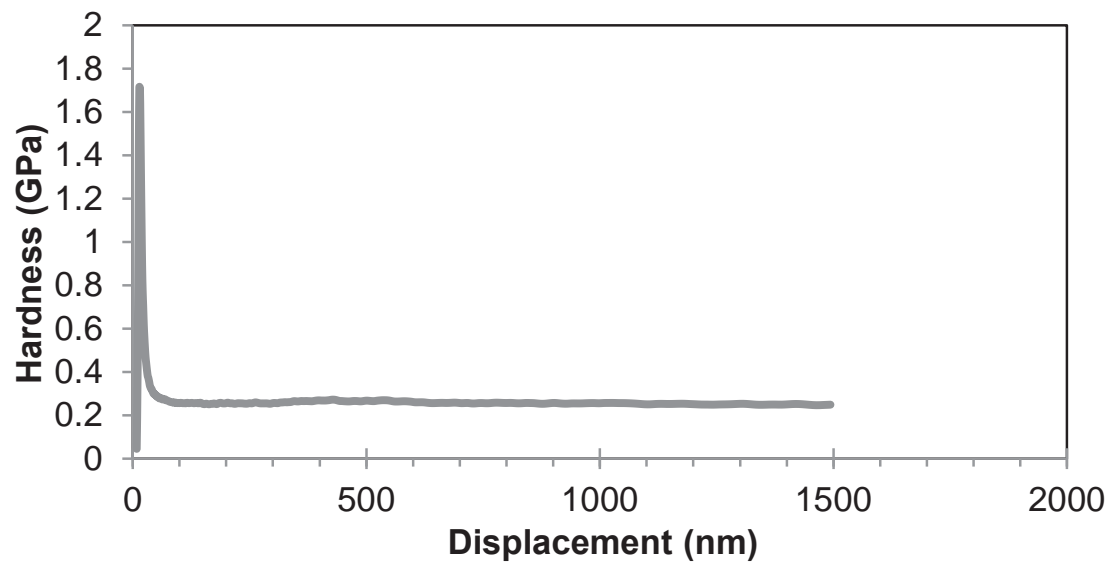

Figure B-9: Hardness vs. Displacement curve 2 wt\% xGnP ${ }^{\circledR}-M-15$ in Epoxy Test 6 
Table B-4: Nanoindentation Averages Between 500 and 1500 nm Depth for 3 wt\% $x G n P^{\circledR}-M-15$ in Epoxy

\begin{tabular}{|c|c|c|c|c|}
\hline Test & $\begin{array}{c}\text { Average } \\
\text { Modulus } \\
\text { (GPa) }\end{array}$ & $\begin{array}{l}\text { Modulus } \\
\text { Std Dev }\end{array}$ & $\begin{array}{c}\text { Average } \\
\text { Hardness } \\
\text { (GPa) }\end{array}$ & $\begin{array}{l}\text { Hardness } \\
\text { Std Dev }\end{array}$ \\
\hline 4 & 4.1321 & 0.0688 & 0.2336 & 0.0029 \\
\hline 8 & 3.9474 & 0.0911 & 0.2291 & 0.0022 \\
\hline 11 & 4.1595 & 0.0769 & 0.2745 & 0.0081 \\
\hline 12 & 4.0522 & 0.0940 & 0.2670 & 0.0080 \\
\hline 15 & 4.1636 & 0.0709 & 0.2486 & 0.0075 \\
\hline 18 & 3.9821 & 0.0664 & 0.2656 & 0.0075 \\
\hline 19 & 4.1566 & 0.0650 & 0.2747 & 0.0122 \\
\hline 22 & 4.1279 & 0.0518 & 0.2911 & 0.0112 \\
\hline 24 & 4.1511 & 0.0845 & 0.2595 & 0.0093 \\
\hline 25 & 3.9612 & 0.0514 & 0.2769 & 0.0060 \\
\hline 26 & 3.9516 & 0.1239 & 0.2503 & 0.0037 \\
\hline 28 & 3.9229 & 0.0629 & 0.2594 & 0.0069 \\
\hline 30 & 4.0410 & 0.0670 & 0.2525 & 0.0035 \\
\hline 33 & 4.0726 & 0.0790 & 0.2688 & 0.0082 \\
\hline 34 & 3.9586 & 0.0863 & 0.2543 & 0.0032 \\
\hline 38 & 3.9646 & 0.0674 & 0.2690 & 0.0041 \\
\hline 39 & 3.9696 & 0.0511 & 0.2705 & 0.0073 \\
\hline 41 & 4.0447 & 0.0437 & 0.2665 & 0.0018 \\
\hline 42 & 3.9581 & 0.0745 & 0.2510 & 0.0043 \\
\hline 43 & 4.0768 & 0.0826 & 0.2604 & 0.0108 \\
\hline 44 & 4.0330 & 0.0666 & 0.2761 & 0.0102 \\
\hline 47 & 3.9367 & 0.0583 & 0.2719 & 0.0048 \\
\hline 48 & 3.9161 & 0.0561 & 0.2603 & 0.0062 \\
\hline 51 & 3.9962 & 0.0646 & 0.2699 & 0.0084 \\
\hline Mean & 4.03 & --- & 0.263 & --- \\
\hline Std Dev & 0.08 & --- & 0.014 & --- \\
\hline Count & 24 & 24 & 24 & 24 \\
\hline
\end{tabular}




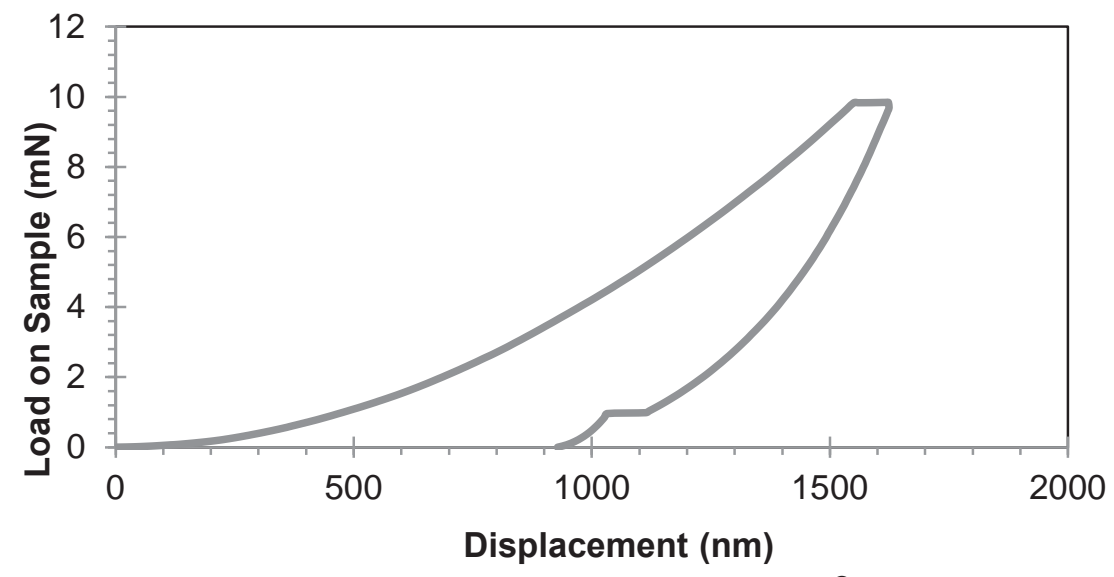

Figure B-10: Load vs. Displacement curve for 3 wt\% $x$ GnP ${ }^{\circledR}-M-15$ in Epoxy Test 15

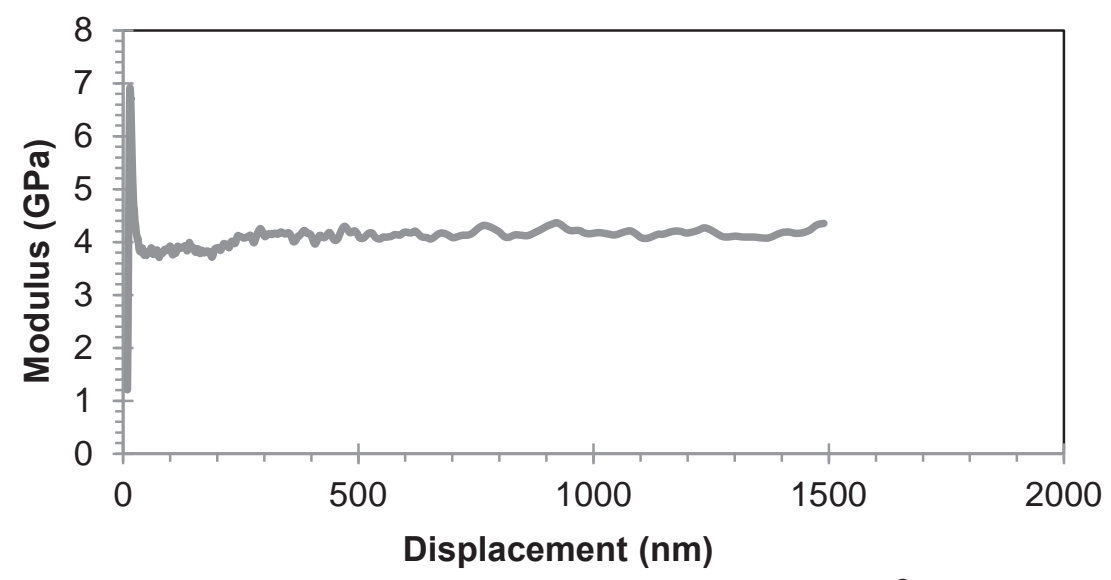

Figure B-11: Modulus vs. Displacement curve for 3 wt\% xGnP ${ }^{\circledR}$-M-15 in Epoxy Test 15

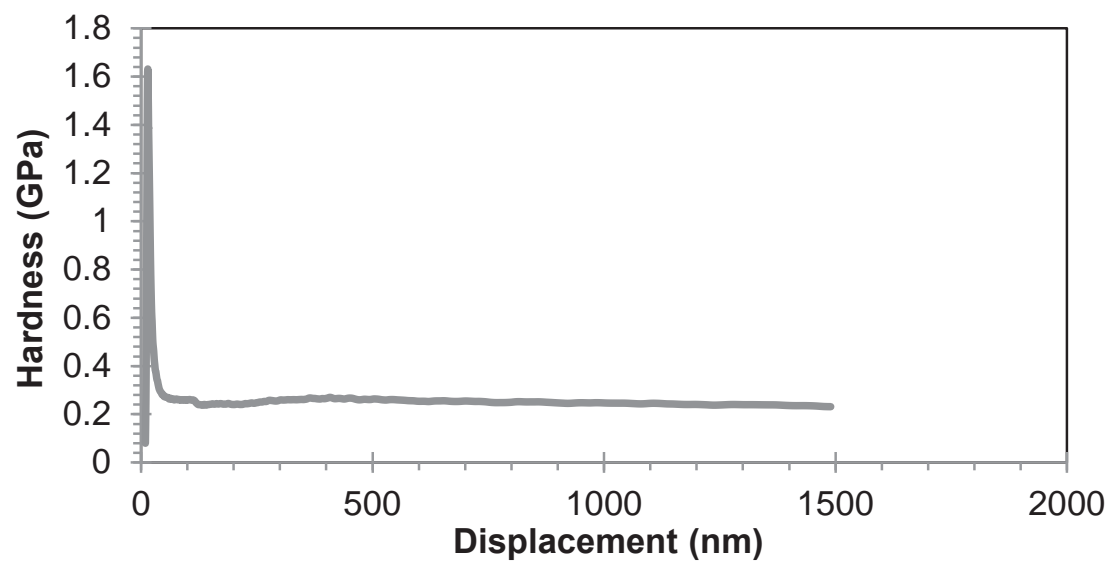

Figure B-12: Hardness vs. Displacement curve 3 wt\% xGnP ${ }^{\circledR}-M-15$ in Epoxy Test 15 
Table B-5: Nanoindentation Averages Between 500 and $1500 \mathrm{~nm}$ Depth for $4 \mathrm{wt} \%$ $x$ GnP $^{\circledR}-M-15$ in Epoxy

\begin{tabular}{|l|c|c|c|c|}
\hline Test & $\begin{array}{c}\text { Average } \\
\text { Modulus } \\
\text { (GPa) }\end{array}$ & $\begin{array}{c}\text { Modulus } \\
\text { Std Dev }\end{array}$ & $\begin{array}{c}\text { Average } \\
\text { Hardness } \\
\text { (GPa) }\end{array}$ & $\begin{array}{c}\text { Hardness } \\
\text { Std Dev }\end{array}$ \\
\hline 2 & 4.4609 & 0.0485 & 0.2090 & 0.0027 \\
\hline 3 & 4.1866 & 0.0497 & 0.2347 & 0.0012 \\
\hline 7 & 3.9969 & 0.0785 & 0.2444 & 0.0030 \\
\hline 10 & 4.4360 & 0.0676 & 0.2290 & 0.0065 \\
\hline 12 & 4.5263 & 0.1226 & 0.2399 & 0.0041 \\
\hline 13 & 3.9860 & 0.0650 & 0.2647 & 0.0052 \\
\hline 16 & 4.2842 & 0.1022 & 0.2414 & 0.0035 \\
\hline 20 & 4.1050 & 0.0779 & 0.2161 & 0.0146 \\
\hline 23 & 4.0215 & 0.0574 & 0.2565 & 0.0071 \\
\hline 29 & 3.9922 & 0.0457 & 0.2516 & 0.0066 \\
\hline 31 & 4.1114 & 0.0543 & 0.2469 & 0.0094 \\
\hline 33 & 3.9774 & 0.0474 & 0.2709 & 0.0052 \\
\hline 35 & 4.4175 & 0.0723 & 0.2402 & 0.0087 \\
\hline 42 & 3.9818 & 0.0656 & 0.2641 & 0.0069 \\
\hline 43 & 3.9863 & 0.0627 & 0.2661 & 0.0040 \\
\hline 46 & 3.9764 & 0.0641 & 0.2699 & 0.0057 \\
\hline 49 & 4.0506 & 0.0489 & 0.2590 & 0.0038 \\
\hline 50 & 4.4769 & 0.1315 & 0.2509 & 0.0019 \\
\hline 51 & 3.9995 & 0.0623 & 0.2607 & 0.0039 \\
\hline 56 & 4.0076 & 0.0592 & 0.2714 & 0.0016 \\
\hline 59 & 4.5152 & 0.0822 & 0.2595 & 0.0033 \\
\hline 60 & 4.5241 & 0.1659 & 0.2599 & 0.0030 \\
\hline 62 & 4.0560 & 0.0725 & 0.2656 & 0.0059 \\
\hline 63 & 4.1370 & 0.0830 & 0.2582 & 0.0084 \\
\hline 66 & 4.1357 & 0.0644 & 0.2680 & 0.0035 \\
\hline 67 & 4.0085 & 0.0723 & 0.2649 & 0.0093 \\
\hline Mean & 4.17 & --- & $\mathbf{0 . 2 5 2}$ & --- \\
\hline Std Dev & $\mathbf{0 . 2 1}$ & --- & $\mathbf{0 . 0 1 7}$ & --- \\
\hline Count & $\mathbf{2 6}$ & $\mathbf{2 6}$ & $\mathbf{2 6}$ & $\mathbf{2 6}$ \\
\hline & & & & \\
\hline
\end{tabular}




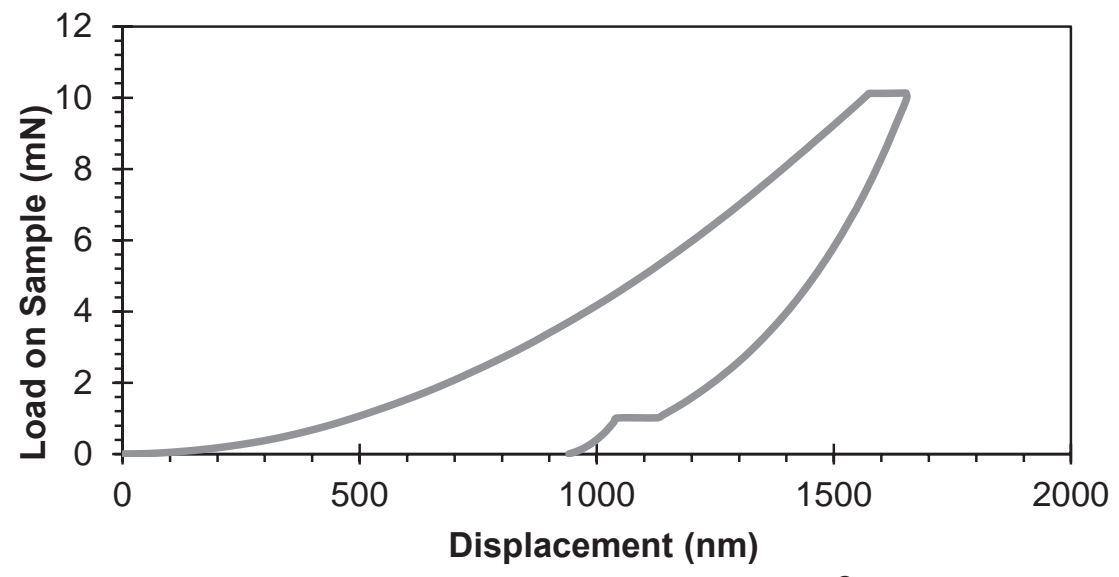

Figure B-13: Load vs. Displacement curve for 4 wt\% $x G n P^{\circledR}-M-15$ in Epoxy Test 29

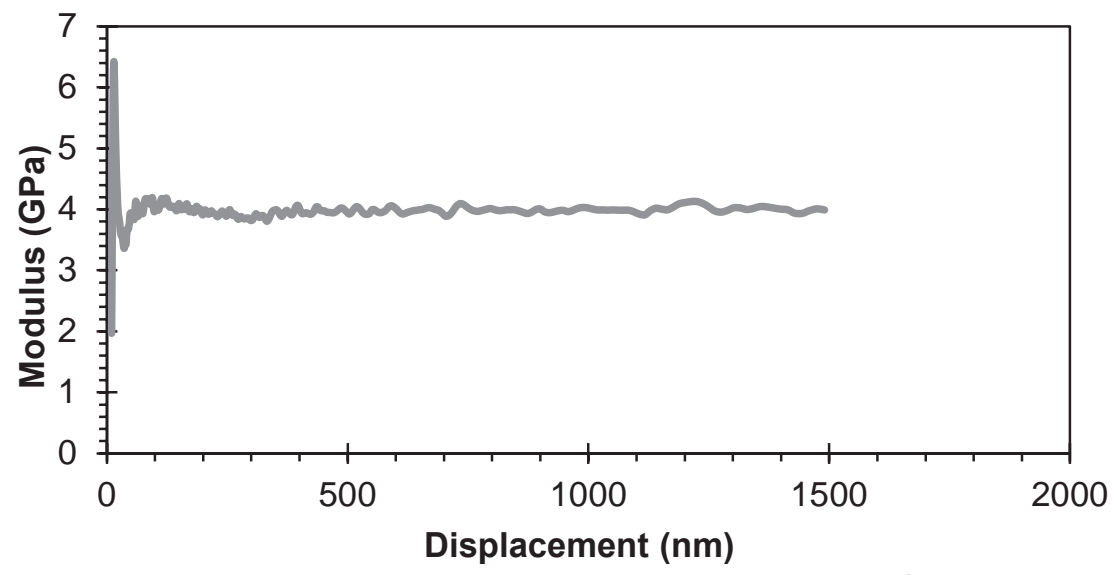

Figure B-14: Modulus vs. Displacement curve for 4 wt\% $x G n P^{\circledR}-M-15$ in Epoxy Test 29

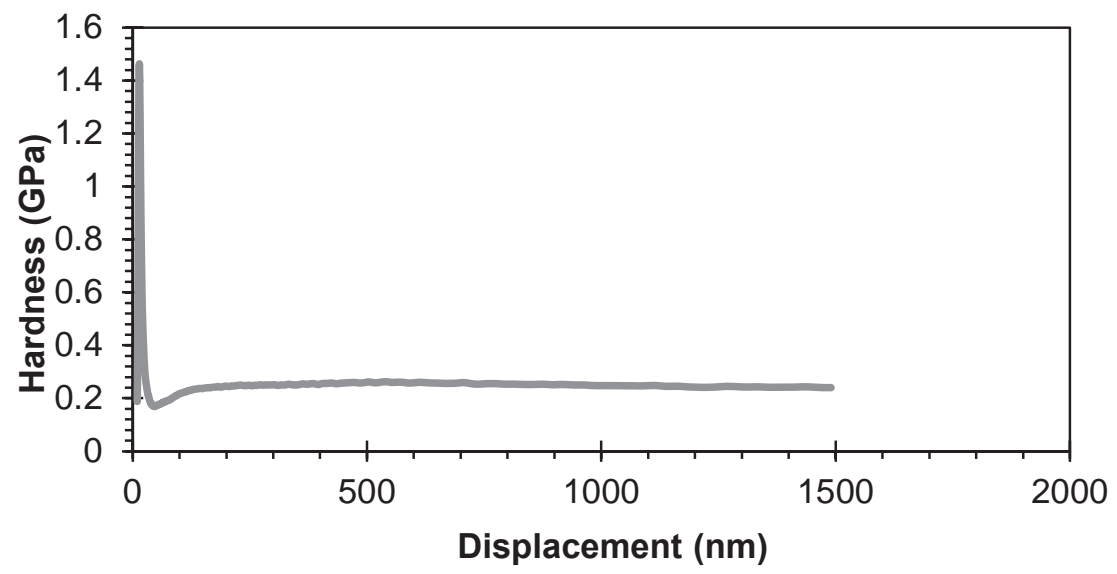

Figure B-15: Hardness vs. Displacement curve 4 wt\% $x G_{n} P^{\circledR}-M-15$ in Epoxy Test 29 
Table B-6: Nanoindentation Averages Between 500 and 1500 nm Depth for 5 wt\% $x$ GnP $^{\circledR}-M-15$ in Epoxy

\begin{tabular}{|c|c|c|c|c|}
\hline Test & $\begin{array}{c}\text { Average } \\
\text { Modulus } \\
\text { (GPa) }\end{array}$ & $\begin{array}{l}\text { Modulus } \\
\text { Std Dev }\end{array}$ & $\begin{array}{c}\text { Average } \\
\text { Hardness } \\
\text { (GPa) }\end{array}$ & $\begin{array}{l}\text { Hardness } \\
\text { Std Dev }\end{array}$ \\
\hline 3 & 4.5986 & 0.1462 & 0.2776 & 0.0092 \\
\hline 4 & 4.3252 & 0.0543 & 0.2570 & 0.0036 \\
\hline 6 & 4.2933 & 0.0813 & 0.2591 & 0.0078 \\
\hline 8 & 4.3528 & 0.0435 & 0.2589 & 0.0041 \\
\hline 9 & 4.1655 & 0.1682 & 0.2443 & 0.0024 \\
\hline 11 & 4.0861 & 0.0589 & 0.2812 & 0.0054 \\
\hline 13 & 4.0650 & 0.1111 & 0.2622 & 0.0054 \\
\hline 16 & 4.3298 & 0.0588 & 0.2514 & 0.0056 \\
\hline 17 & 4.5582 & 0.1144 & 0.2339 & 0.0064 \\
\hline 27 & 4.3044 & 0.0751 & 0.2606 & 0.0048 \\
\hline 28 & 4.2106 & 0.0767 & 0.2565 & 0.0068 \\
\hline 29 & 4.1950 & 0.1303 & 0.2525 & 0.0034 \\
\hline 30 & 4.3151 & 0.1071 & 0.2599 & 0.0031 \\
\hline 32 & 4.4128 & 0.1417 & 0.2540 & 0.0071 \\
\hline 35 & 4.3599 & 0.2252 & 0.2594 & 0.0099 \\
\hline 36 & 4.0779 & 0.1449 & 0.2663 & 0.0074 \\
\hline 41 & 4.4275 & 0.0962 & 0.2409 & 0.0067 \\
\hline 42 & 4.2676 & 0.1694 & 0.2209 & 0.0200 \\
\hline 43 & 4.4628 & 0.1103 & 0.2641 & 0.0035 \\
\hline 44 & 4.2379 & 0.0814 & 0.2537 & 0.0043 \\
\hline 45 & 4.5075 & 0.2410 & 0.2537 & 0.0034 \\
\hline 46 & 4.2218 & 0.1227 & 0.2613 & 0.0051 \\
\hline 50 & 4.2896 & 0.1252 & 0.2677 & 0.0083 \\
\hline 52 & 4.1670 & 0.0556 & 0.2611 & 0.0044 \\
\hline Mean & 4.30 & --- & 0.257 & --- \\
\hline Std Dev & 0.14 & --- & 0.013 & --- \\
\hline Count & 24 & 24 & 24 & 24 \\
\hline
\end{tabular}




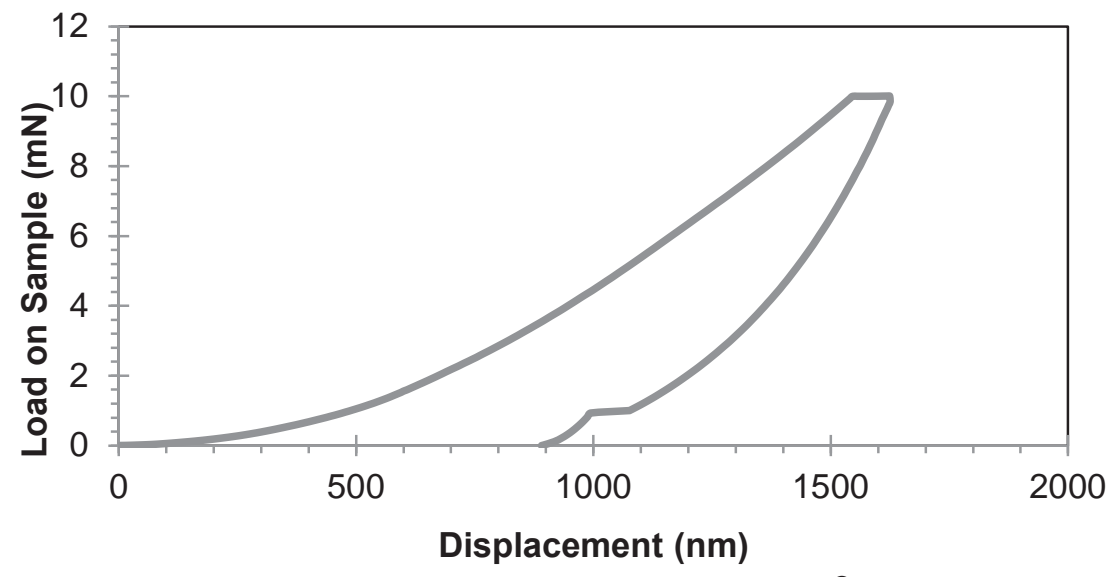

Figure B-16: Load vs. Displacement curve for 5 wt\% $x G n P^{\circledR}-M-15$ in Epoxy Test 13

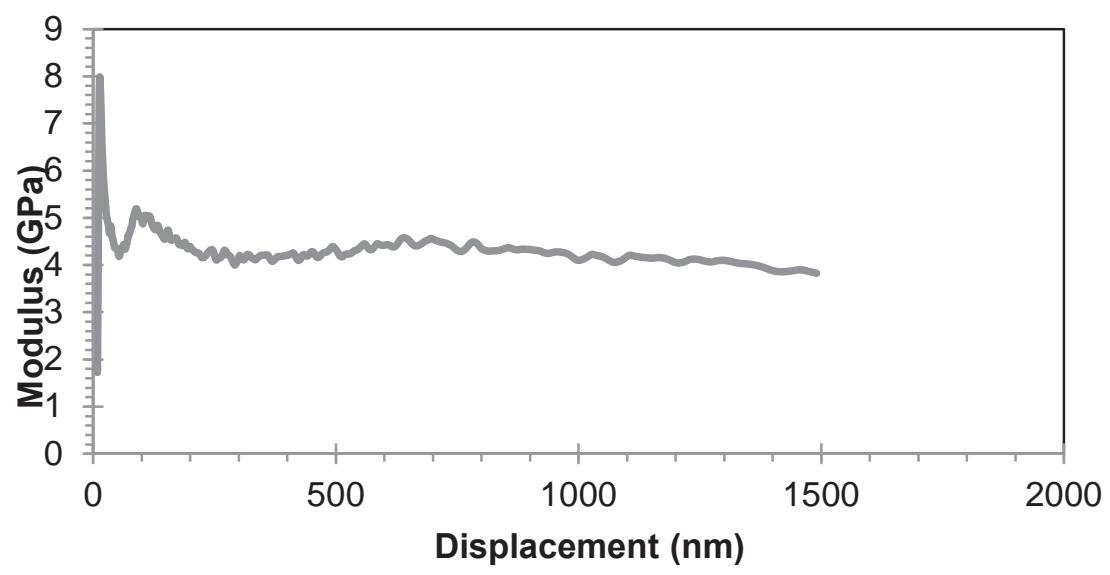

Figure B-17: Modulus vs. Displacement curve for 5 wt\% xGnP ${ }^{\circledR}-M-15$ in Epoxy Test 13

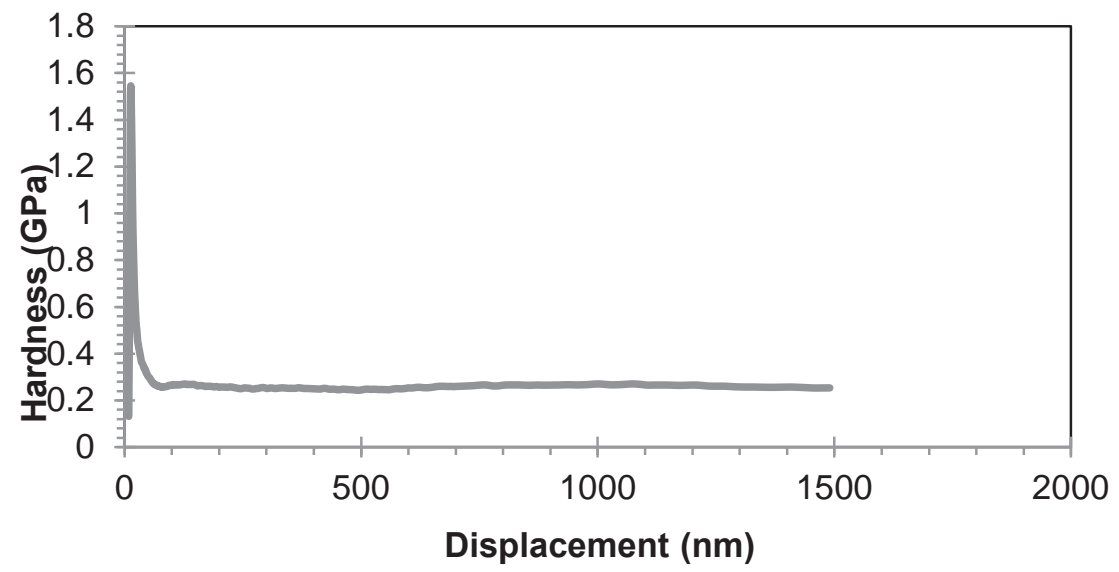

Figure B-18: Hardness vs. Displacement curve 5 wt\% xGnP ${ }^{\circledR}-M-15$ in Epoxy Test 13 
Table B-7: Nanoindentation Averages Between 500 and $1500 \mathrm{~nm}$ Depth for $6 \mathrm{wt} \%$ $x$ GnP $^{\circledR}-M-15$ in Epoxy

\begin{tabular}{|l|c|c|c|c|}
\hline Test & $\begin{array}{c}\text { Average } \\
\text { Modulus } \\
\text { (GPa) }\end{array}$ & $\begin{array}{c}\text { Modulus } \\
\text { Std Dev }\end{array}$ & $\begin{array}{c}\text { Average } \\
\text { Hardness } \\
\text { (GPa) }\end{array}$ & $\begin{array}{c}\text { Hardness } \\
\text { Std Dev }\end{array}$ \\
\hline 12 & 4.6885 & 0.1412 & 0.2374 & 0.0042 \\
\hline 13 & 4.5265 & 0.0948 & 0.2693 & 0.0121 \\
\hline 14 & 4.3266 & 0.0874 & 0.2401 & 0.0045 \\
\hline 17 & 4.2921 & 0.1027 & 0.2472 & 0.0032 \\
\hline 20 & 4.5124 & 0.0668 & 0.2701 & 0.0017 \\
\hline 29 & 4.4587 & 0.0750 & 0.2385 & 0.0036 \\
\hline 32 & 4.4128 & 0.1560 & 0.2390 & 0.0063 \\
\hline 33 & 4.4180 & 0.2779 & 0.2565 & 0.0103 \\
\hline 34 & 4.2569 & 0.1005 & 0.2670 & 0.0049 \\
\hline 35 & 4.4733 & 0.0758 & 0.2656 & 0.0112 \\
\hline 37 & 4.4523 & 0.1277 & 0.2623 & 0.0040 \\
\hline 38 & 4.3739 & 0.0894 & 0.2693 & 0.0065 \\
\hline 39 & 4.2221 & 0.0850 & 0.2652 & 0.0085 \\
\hline 42 & 4.6196 & 0.1825 & 0.2589 & 0.0036 \\
\hline 44 & 4.5049 & 0.0827 & 0.2531 & 0.0018 \\
\hline 45 & 4.6817 & 0.0847 & 0.2686 & 0.0090 \\
\hline 46 & 4.2799 & 0.0934 & 0.2714 & 0.0044 \\
\hline 47 & 4.6403 & 0.1154 & 0.2621 & 0.0027 \\
\hline 56 & 4.5913 & 0.1084 & 0.2682 & 0.0067 \\
\hline 60 & 4.5126 & 0.1242 & 0.2687 & 0.0078 \\
\hline 62 & 4.2329 & 0.0824 & 0.2627 & 0.0040 \\
\hline 64 & 4.6169 & 0.0895 & 0.2645 & 0.0089 \\
\hline 66 & 4.2466 & 0.1245 & 0.2722 & 0.0064 \\
\hline 68 & 4.2044 & 0.1540 & 0.2438 & 0.0027 \\
\hline Mean & 4.44 & --- & $\mathbf{0 . 2 5 9}$ & --- \\
\hline Std Dev & $\mathbf{0 . 1 6}$ & --- & $\mathbf{0 . 0 1 2}$ & --- \\
\hline Count & $\mathbf{2 4}$ & $\mathbf{2 4}$ & $\mathbf{2 4}$ & $\mathbf{2 4}$ \\
\hline & & & & \\
\hline
\end{tabular}




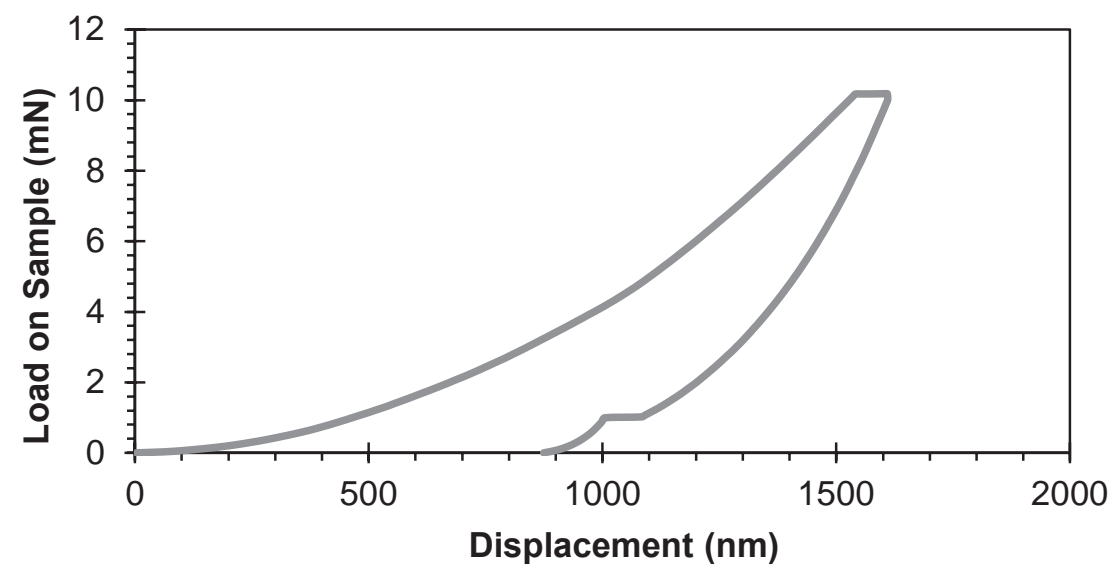

Figure B-19: Load vs. Displacement curve for 6 wt\% $x G n P^{\circledR}-M-15$ in Epoxy Test 32

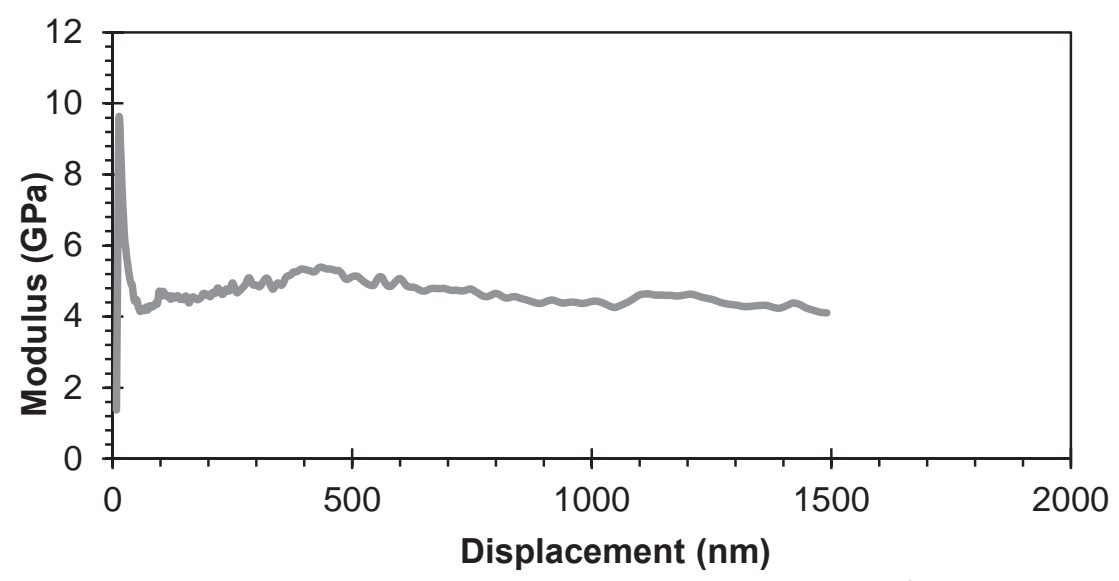

Figure B-20: Modulus vs. Displacement curve for 6 wt\% xGnP ${ }^{\circledR}-M-15$ in Epoxy Test 32

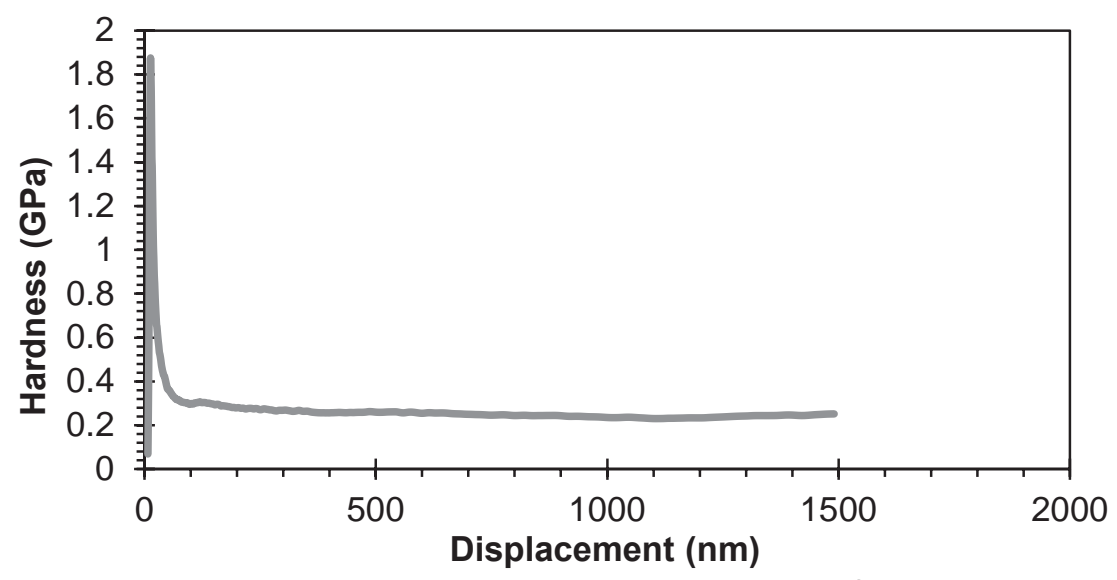

Figure B-21: Hardness vs. Displacement curve 6 wt\% xGnP ${ }^{\circledR}-M-15$ in Epoxy Test 32 
Table B-8: Nanoindentation Averages Between 500 and $1500 \mathrm{~nm}$ Depth for $1 \mathrm{wt} \%$ $x G n P^{\circledR}-M-5$ in Epoxy

\begin{tabular}{|c|c|c|c|c|}
\hline Test & $\begin{array}{c}\text { Average } \\
\text { Modulus } \\
(\mathrm{GPa})\end{array}$ & $\begin{array}{l}\text { Modulus } \\
\text { Std Dev }\end{array}$ & $\begin{array}{c}\text { Average } \\
\text { Hardness } \\
(\mathrm{GPa})\end{array}$ & $\begin{array}{c}\text { Hardness } \\
\text { Std Dev }\end{array}$ \\
\hline 4 & 3.7624 & 0.0704 & 0.2634 & 0.0063 \\
\hline 7 & 3.7480 & 0.0616 & 0.2638 & 0.0055 \\
\hline 21 & 3.7002 & 0.0536 & 0.2619 & 0.0056 \\
\hline 26 & 3.7902 & 0.1522 & 0.2592 & 0.0023 \\
\hline 29 & 3.6961 & 0.0748 & 0.2638 & 0.0053 \\
\hline 31 & 3.7501 & 0.0588 & 0.2537 & 0.0081 \\
\hline 39 & 3.7846 & 0.1071 & 0.2466 & 0.0049 \\
\hline 41 & 3.7407 & 0.0609 & 0.2593 & 0.0022 \\
\hline 42 & 3.7722 & 0.0502 & 0.2641 & 0.0059 \\
\hline 45 & 3.7248 & 0.0524 & 0.2621 & 0.0037 \\
\hline 46 & 3.7492 & 0.0608 & 0.2628 & 0.0029 \\
\hline 47 & 3.7500 & 0.0679 & 0.2697 & 0.0057 \\
\hline 49 & 3.7074 & 0.0571 & 0.2625 & 0.0040 \\
\hline 51 & 3.7385 & 0.0485 & 0.2634 & 0.0038 \\
\hline 53 & 3.8458 & 0.0664 & 0.2640 & 0.0052 \\
\hline 55 & 3.7215 & 0.0533 & 0.2566 & 0.0020 \\
\hline 56 & 3.7186 & 0.0568 & 0.2601 & 0.0025 \\
\hline 57 & 3.8032 & 0.0557 & 0.2637 & 0.0045 \\
\hline 61 & 3.7945 & 0.0516 & 0.2610 & 0.0025 \\
\hline 62 & 3.7172 & 0.0515 & 0.2584 & 0.0023 \\
\hline 63 & 3.6965 & 0.0516 & 0.2602 & 0.0026 \\
\hline 66 & 3.7982 & 0.0504 & 0.2598 & 0.0020 \\
\hline 69 & 3.7955 & 0.0896 & 0.2533 & 0.0020 \\
\hline 71 & 3.7151 & 0.0443 & 0.2605 & 0.0024 \\
\hline Mean & 3.75 & -- & 0.261 & --- \\
\hline Std Dev & 0.04 & --- & 0.005 & --- \\
\hline Count & 24 & 24 & 24 & 24 \\
\hline
\end{tabular}




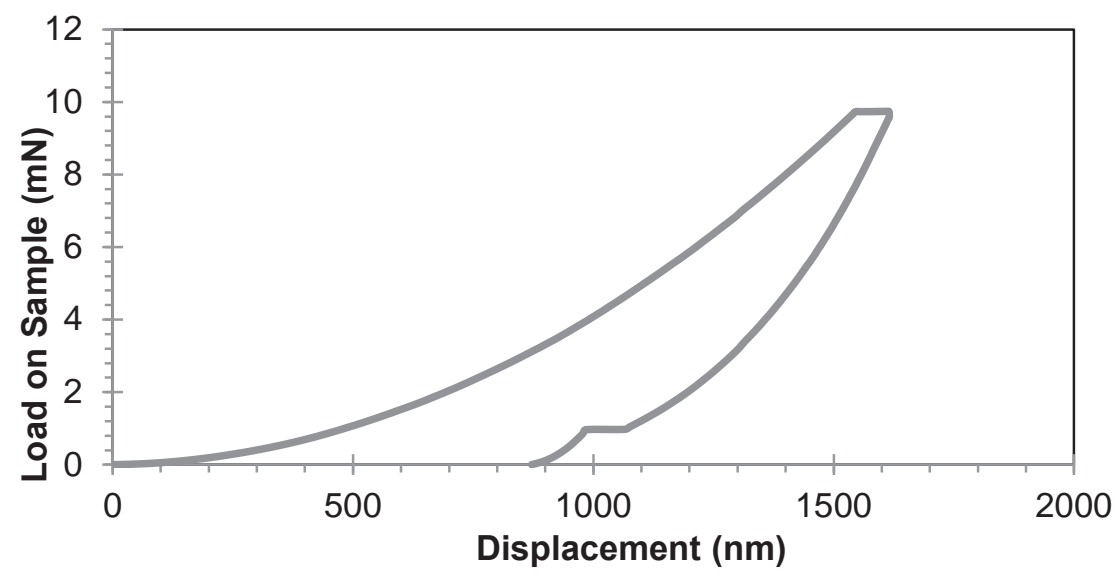

Figure B-22: Load vs. Displacement curve for 1 wt\% xGnP ${ }^{\circledR}-M-5$ in Epoxy Test 31

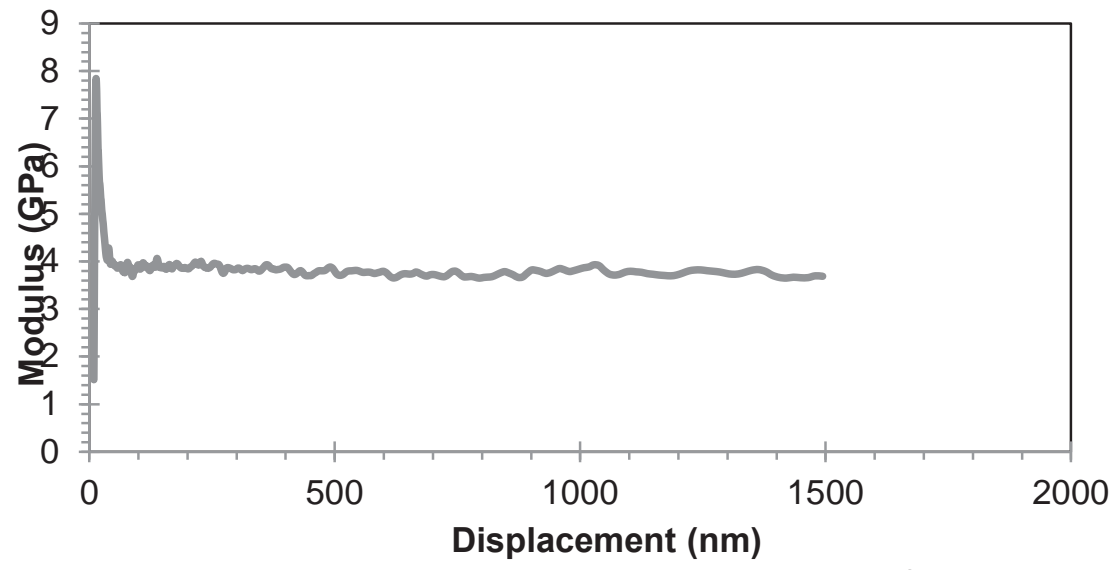

Figure B-23: Modulus vs. Displacement curve for 1 wt\% xGnP ${ }^{\circledR}-M-5$ in Epoxy Test 31

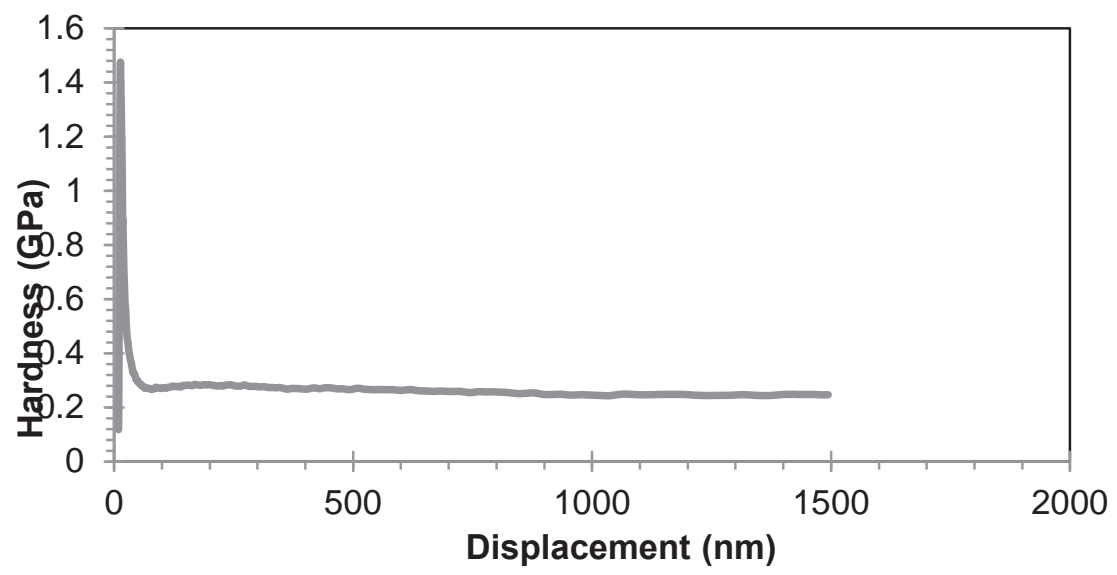

Figure B-24: Hardness vs. Displacement curve for 1 wt\% xGnP ${ }^{\circledR}-M-5$ in Epoxy Test 31 
Table B-9: Nanoindentation Averages Between 500 and $1500 \mathrm{~nm}$ Depth for $2 \mathrm{wt} \%$ $x G n P^{\circledR}-M-5$ in Epoxy

\begin{tabular}{|c|c|c|c|c|}
\hline Test & $\begin{array}{c}\text { Average } \\
\text { Modulus } \\
\text { (GPa) }\end{array}$ & $\begin{array}{l}\text { Modulus } \\
\text { Std Dev }\end{array}$ & $\begin{array}{c}\text { Average } \\
\text { Hardness } \\
(\mathrm{GPa})\end{array}$ & $\begin{array}{c}\text { Hardness } \\
\text { Std Dev }\end{array}$ \\
\hline 1 & 3.8159 & 0.0509 & 0.2555 & 0.0025 \\
\hline 2 & 3.8409 & 0.0675 & 0.2544 & 0.0024 \\
\hline 8 & 3.8699 & 0.0671 & 0.2578 & 0.0037 \\
\hline 11 & 4.0319 & 0.1107 & 0.2497 & 0.0172 \\
\hline 13 & 3.9116 & 0.0613 & 0.2603 & 0.0090 \\
\hline 14 & 3.8206 & 0.0718 & 0.2606 & 0.0042 \\
\hline 17 & 3.8613 & 0.0714 & 0.2562 & 0.0043 \\
\hline 18 & 3.9688 & 0.1510 & 0.2568 & 0.0058 \\
\hline 19 & 3.8269 & 0.0524 & 0.2534 & 0.0082 \\
\hline 21 & 3.9716 & 0.0715 & 0.2519 & 0.0053 \\
\hline 22 & 3.8216 & 0.0667 & 0.2598 & 0.0037 \\
\hline 23 & 3.9145 & 0.0595 & 0.2645 & 0.0050 \\
\hline 25 & 3.8307 & 0.0746 & 0.2545 & 0.0039 \\
\hline 26 & 3.8618 & 0.0571 & 0.2687 & 0.0045 \\
\hline 34 & 3.8745 & 0.1035 & 0.2606 & 0.0066 \\
\hline 35 & 3.8529 & 0.0773 & 0.2499 & 0.0067 \\
\hline 43 & 3.8703 & 0.0496 & 0.2589 & 0.0019 \\
\hline 54 & 3.8639 & 0.0808 & 0.2763 & 0.0072 \\
\hline 61 & 3.8515 & 0.0752 & 0.2626 & 0.0050 \\
\hline 62 & 4.0648 & 0.1506 & 0.2601 & 0.0040 \\
\hline 63 & 3.8775 & 0.0836 & 0.2647 & 0.0033 \\
\hline 65 & 3.9648 & 0.0985 & 0.2572 & 0.0023 \\
\hline 68 & 3.8381 & 0.0787 & 0.2620 & 0.0038 \\
\hline 69 & 3.8555 & 0.1415 & 0.2553 & 0.0065 \\
\hline Mean & 3.89 & -- & 0.259 & --- \\
\hline Std Dev & 0.07 & --- & 0.006 & --- \\
\hline Count & 24 & 24 & 24 & 24 \\
\hline
\end{tabular}




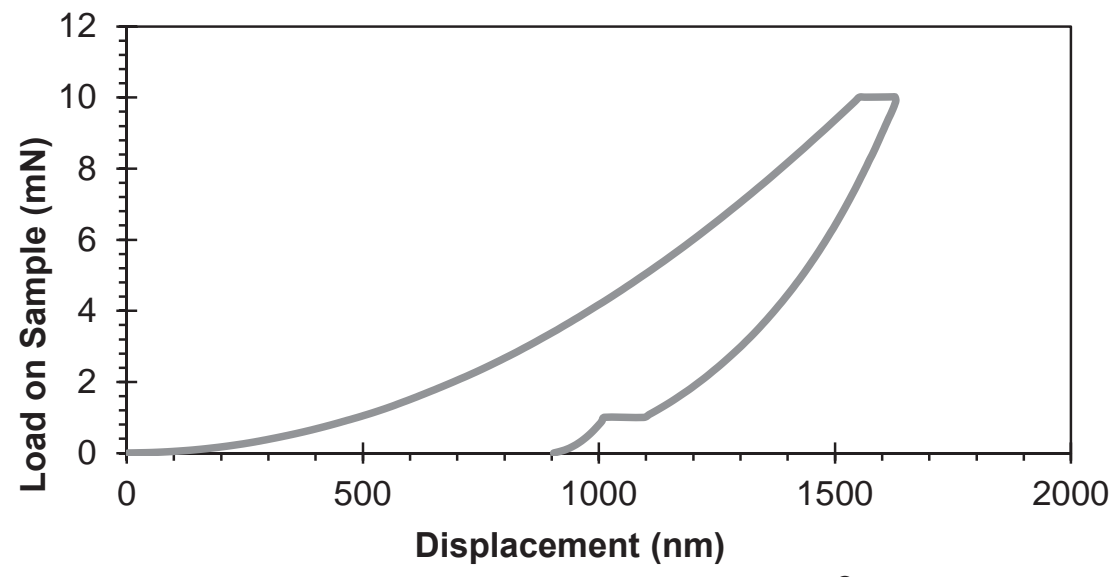

Figure B-25: Load vs. Displacement curve for $2 w t \% x G n P^{\circledR}-M-5$ in Epoxy Test 26

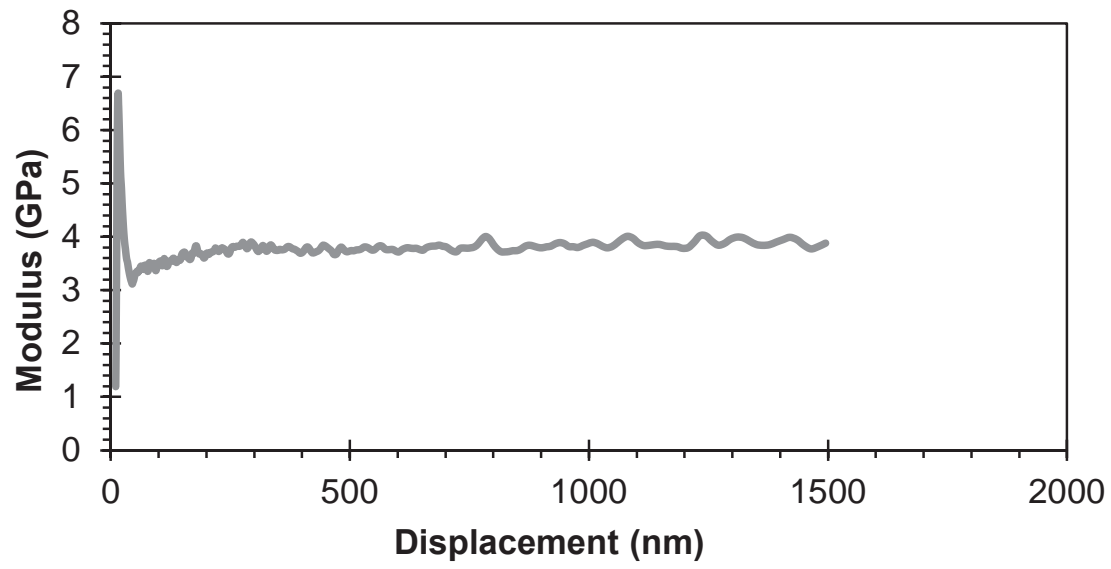

Figure B-26: Modulus vs. Displacement curve for 2 wt\% xGnP ${ }^{\circledR}-M-5$ in Epoxy Test 26

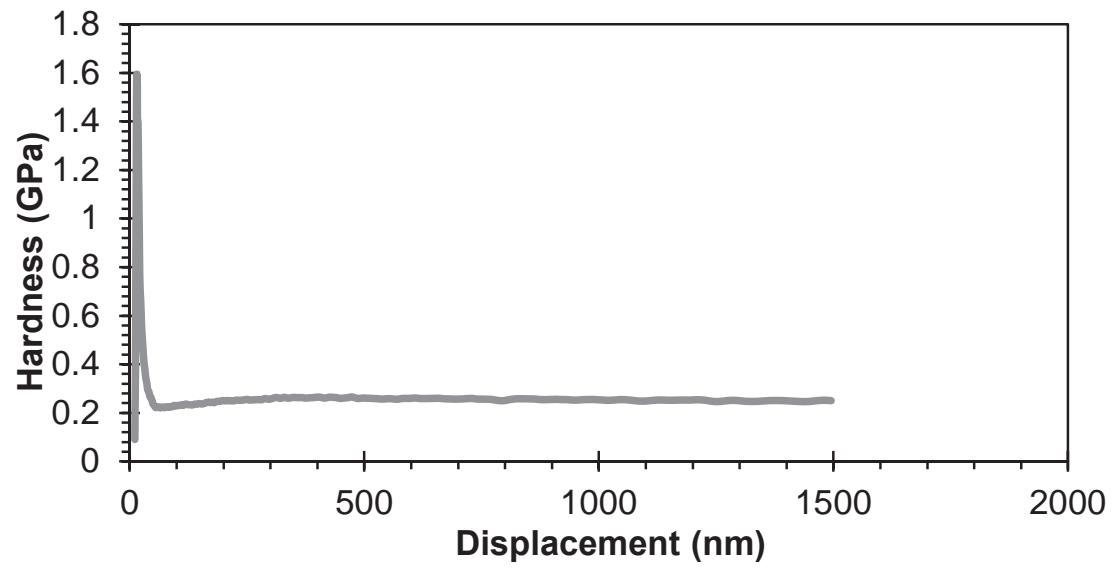

Figure B-27: Hardness vs. Displacement curve for 2 wt\% xGnP ${ }^{\circledR}-M-5$ in Epoxy Test 26 
Table B-10: Nanoindentation Averages Between 500 and $1500 \mathrm{~nm}$ Depth for 3 wt\% $x G n P^{\circledR}-M-5$ in Epoxy

\begin{tabular}{|c|c|c|c|c|}
\hline Test & $\begin{array}{c}\text { Average } \\
\text { Modulus } \\
\text { (GPa) }\end{array}$ & $\begin{array}{l}\text { Modulus } \\
\text { Std Dev }\end{array}$ & $\begin{array}{c}\text { Average } \\
\text { Hardness } \\
\text { (GPa) }\end{array}$ & $\begin{array}{l}\text { Hardness } \\
\text { Std Dev }\end{array}$ \\
\hline 2 & 4.1926 & 0.1338 & 0.2391 & 0.0099 \\
\hline 5 & 3.8800 & 0.0631 & 0.2432 & 0.0051 \\
\hline 7 & 4.1122 & 0.1230 & 0.2468 & 0.0096 \\
\hline 14 & 3.9496 & 0.1060 & 0.2543 & 0.0038 \\
\hline 15 & 3.8495 & 0.0585 & 0.2621 & 0.0069 \\
\hline 16 & 3.8466 & 0.0683 & 0.2744 & 0.0084 \\
\hline 20 & 3.9150 & 0.1178 & 0.2493 & 0.0065 \\
\hline 26 & 3.9559 & 0.0600 & 0.2440 & 0.0113 \\
\hline 32 & 3.8594 & 0.0752 & 0.2573 & 0.0036 \\
\hline 33 & 4.1934 & 0.0777 & 0.2553 & 0.0058 \\
\hline 36 & 3.9692 & 0.1440 & 0.2470 & 0.0081 \\
\hline 39 & 3.8683 & 0.1047 & 0.2577 & 0.0034 \\
\hline 40 & 3.8508 & 0.0498 & 0.2646 & 0.0042 \\
\hline 48 & 4.0644 & 0.1346 & 0.2592 & 0.0065 \\
\hline 49 & 3.8760 & 0.0718 & 0.2561 & 0.0038 \\
\hline 51 & 4.0379 & 0.1014 & 0.2381 & 0.0019 \\
\hline 53 & 3.8615 & 0.0618 & 0.2697 & 0.0051 \\
\hline 54 & 4.0143 & 0.0508 & 0.2644 & 0.0026 \\
\hline 58 & 3.8770 & 0.0666 & 0.2667 & 0.0045 \\
\hline 63 & 3.8833 & 0.1185 & 0.2532 & 0.0030 \\
\hline 65 & 3.8965 & 0.0770 & 0.2584 & 0.0024 \\
\hline 67 & 3.9119 & 0.0734 & 0.2574 & 0.0074 \\
\hline 70 & 3.9828 & 0.0838 & 0.2683 & 0.0083 \\
\hline 71 & 3.8796 & 0.0614 & 0.2639 & 0.0053 \\
\hline Mean & 3.95 & --- & 0.256 & --- \\
\hline Std Dev & 0.11 & --- & 0.010 & --- \\
\hline Count & 24 & 24 & 24 & 24 \\
\hline
\end{tabular}




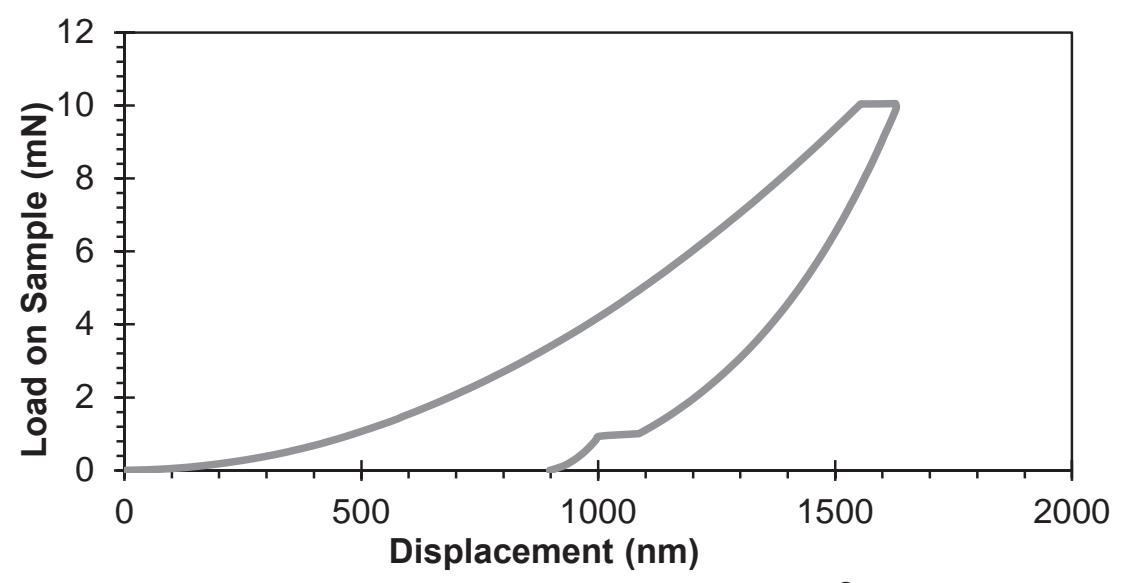

Figure B-28: Load vs. Displacement curve for 3 wt\% xGnP ${ }^{\circledR}-M-5$ in Epoxy Test 32

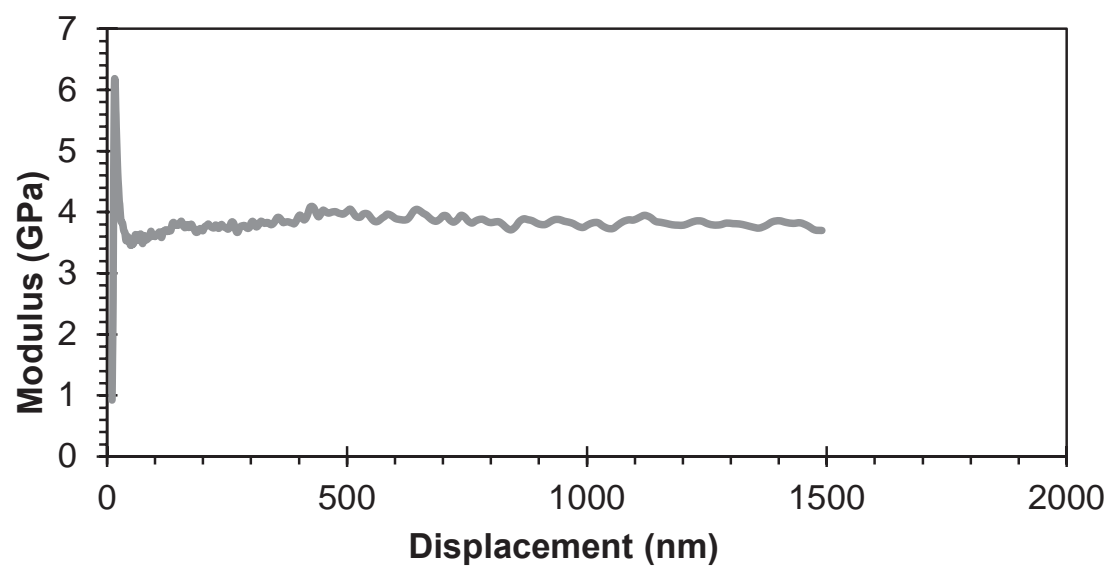

Figure B-29: Modulus vs. Displacement curve for 3 wt\% xGnP ${ }^{\circledR}-M-5$ in Epoxy Test 32

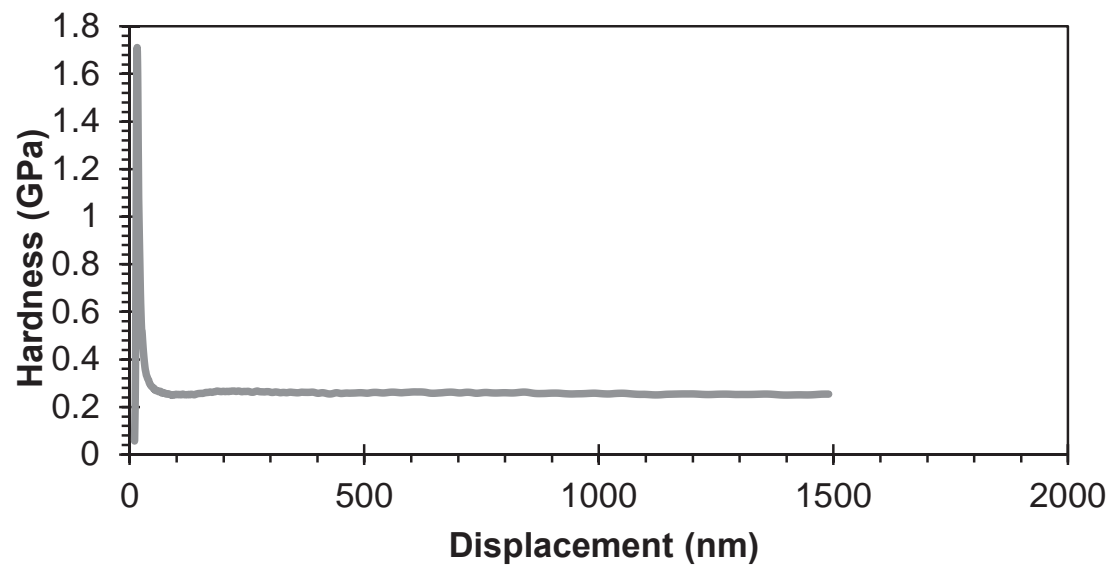

Figure B-30: Hardness vs. Displacement curve for 3 wt\% $x$ GnP $^{\circledR}-M-5$ in Epoxy Test 32 
Table B-11: Nanoindentation Averages Between 500 and $1500 \mathrm{~nm}$ Depth for 4 wt\% $x G n P^{\circledR}-M-5$ in Epoxy

\begin{tabular}{|c|c|c|c|c|}
\hline Test & $\begin{array}{c}\text { Average } \\
\text { Modulus } \\
\text { (GPa) }\end{array}$ & $\begin{array}{l}\text { Modulus } \\
\text { Std Dev }\end{array}$ & $\begin{array}{c}\text { Average } \\
\text { Hardness } \\
\text { (GPa) }\end{array}$ & $\begin{array}{l}\text { Hardness } \\
\text { Std Dev }\end{array}$ \\
\hline 3 & 4.0012 & 0.0994 & 0.2517 & 0.0059 \\
\hline 5 & 3.9648 & 0.0478 & 0.2597 & 0.0049 \\
\hline 6 & 3.9853 & 0.0580 & 0.2670 & 0.0108 \\
\hline 10 & 4.0275 & 0.0635 & 0.2582 & 0.0026 \\
\hline 16 & 3.9398 & 0.0658 & 0.2506 & 0.0069 \\
\hline 18 & 3.9353 & 0.0782 & 0.2526 & 0.0062 \\
\hline 20 & 3.9911 & 0.0596 & 0.2527 & 0.0052 \\
\hline 22 & 3.9760 & 0.1035 & 0.2580 & 0.0094 \\
\hline 24 & 4.1220 & 0.1554 & 0.2602 & 0.0041 \\
\hline 25 & 4.0621 & 0.0990 & 0.2469 & 0.0042 \\
\hline 29 & 4.1062 & 0.1738 & 0.2529 & 0.0097 \\
\hline 30 & 4.3830 & 0.1028 & 0.2566 & 0.0102 \\
\hline 35 & 4.3585 & 0.2496 & 0.2588 & 0.0028 \\
\hline 37 & 3.9667 & 0.0834 & 0.2547 & 0.0031 \\
\hline 39 & 4.0793 & 0.1253 & 0.2201 & 0.0133 \\
\hline 42 & 4.0629 & 0.0926 & 0.2678 & 0.0068 \\
\hline 45 & 4.0658 & 0.0601 & 0.2437 & 0.0042 \\
\hline 48 & 3.9505 & 0.0854 & 0.2431 & 0.0060 \\
\hline 50 & 4.3224 & 0.0799 & 0.2437 & 0.0052 \\
\hline 57 & 3.9428 & 0.0668 & 0.2552 & 0.0043 \\
\hline 60 & 4.3404 & 0.1160 & 0.2775 & 0.0089 \\
\hline 61 & 4.0017 & 0.1357 & 0.2400 & 0.0060 \\
\hline 67 & 4.3149 & 0.0659 & 0.2157 & 0.0029 \\
\hline 69 & 3.9795 & 0.0765 & 0.2582 & 0.0043 \\
\hline Mean & 4.08 & -- & 0.252 & --- \\
\hline Std Dev & 0.15 & --- & 0.013 & --- \\
\hline Count & 24 & 24 & 24 & 24 \\
\hline
\end{tabular}




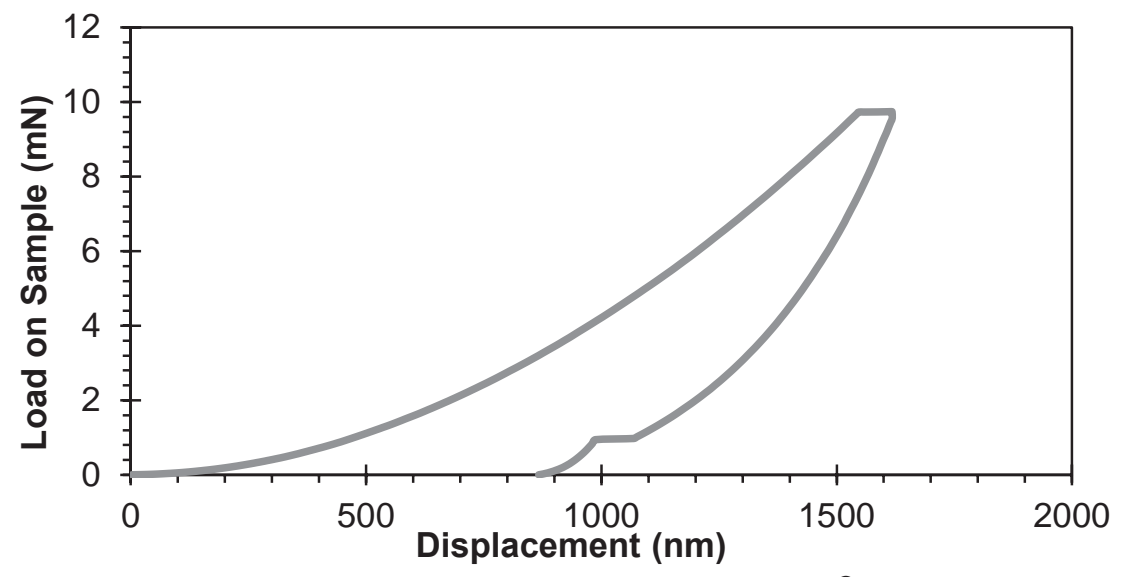

Figure B-31: Load vs. Displacement curve for 4 wt\% $x G n P^{\circledR}-M-5$ in Epoxy Test 22

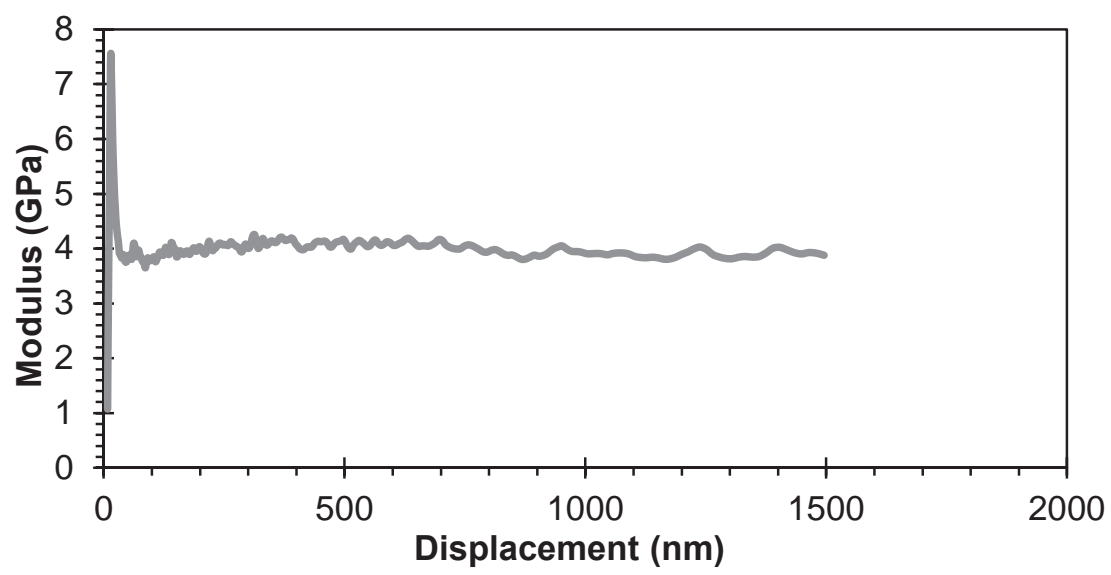

Figure B-32: Modulus vs. Displacement curve for 4 wt\% $x G n P^{\circledR}-M-5$ in Epoxy Test 22

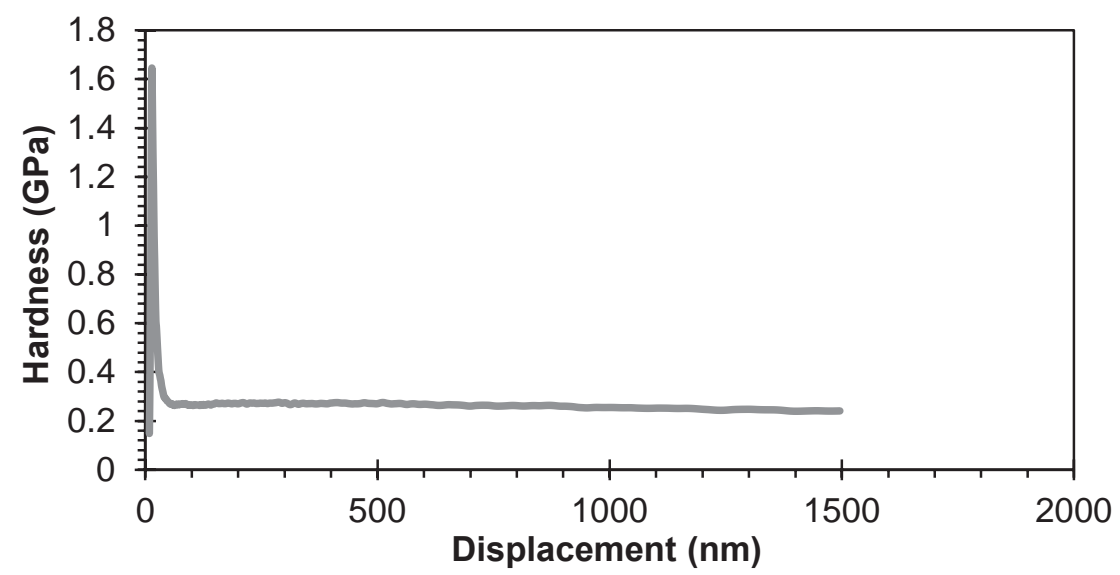

Figure B-33: Hardness vs. Displacement curve for 4 wt\% $x$ GnP $^{\circledR}-M-5$ in Epoxy Test 22 
Table B-12: Nanoindentation Averages Between 500 and $1500 \mathrm{~nm}$ Depth for 5 wt\% $x G n P^{\circledR}-M-5$ in Epoxy

\begin{tabular}{|l|c|c|c|c|}
\hline Test & $\begin{array}{c}\text { Average } \\
\text { Modulus } \\
\text { (GPa) }\end{array}$ & $\begin{array}{c}\text { Modulus } \\
\text { Std Dev }\end{array}$ & $\begin{array}{c}\text { Average } \\
\text { Hardness } \\
\text { (GPa) }\end{array}$ & $\begin{array}{c}\text { Hardness } \\
\text { Std Dev }\end{array}$ \\
\hline 2 & 4.1960 & 0.0719 & 0.2821 & 0.0063 \\
\hline 7 & 4.1514 & 0.0784 & 0.2618 & 0.0031 \\
\hline 10 & 4.2962 & 0.0729 & 0.2330 & 0.0045 \\
\hline 16 & 4.2065 & 0.0726 & 0.2605 & 0.0059 \\
\hline 20 & 4.4672 & 0.3831 & 0.2819 & 0.0110 \\
\hline 21 & 4.5421 & 0.0756 & 0.2582 & 0.0050 \\
\hline 28 & 4.3497 & 0.0566 & 0.2600 & 0.0049 \\
\hline 29 & 4.5050 & 0.2183 & 0.2430 & 0.0018 \\
\hline 30 & 4.1457 & 0.2597 & 0.2539 & 0.0117 \\
\hline 31 & 4.5166 & 0.3601 & 0.2603 & 0.0181 \\
\hline 32 & 4.5070 & 0.1128 & 0.2611 & 0.0169 \\
\hline 38 & 4.2010 & 0.1273 & 0.2037 & 0.0100 \\
\hline 41 & 4.5584 & 0.1865 & 0.2574 & 0.0051 \\
\hline 43 & 4.2835 & 0.0801 & 0.2663 & 0.0103 \\
\hline 45 & 4.1939 & 0.2538 & 0.2545 & 0.0095 \\
\hline 51 & 4.3502 & 0.0851 & 0.2402 & 0.0059 \\
\hline 54 & 4.4981 & 0.0710 & 0.2447 & 0.0103 \\
\hline 55 & 4.1311 & 0.0776 & 0.2542 & 0.0134 \\
\hline 56 & 4.1260 & 0.0549 & 0.2538 & 0.0074 \\
\hline 62 & 4.1066 & 0.1240 & 0.2594 & 0.0023 \\
\hline 64 & 4.1752 & 0.0788 & 0.2503 & 0.0061 \\
\hline 68 & 4.3757 & 0.0791 & 0.2611 & 0.0064 \\
\hline 69 & 4.3977 & 0.1745 & 0.2323 & 0.0083 \\
\hline 72 & 4.2854 & 0.0839 & 0.2525 & 0.0017 \\
\hline Mean & 4.32 & --- & $\mathbf{0 . 2 5 4}$ & --- \\
\hline Std Dev & $\mathbf{0 . 1 5}$ & --- & $\mathbf{0 . 0 1 6}$ & --- \\
\hline Count & $\mathbf{2 4}$ & $\mathbf{2 4}$ & $\mathbf{2 4}$ & $\mathbf{2 4}$ \\
\hline & & & & \\
\hline
\end{tabular}




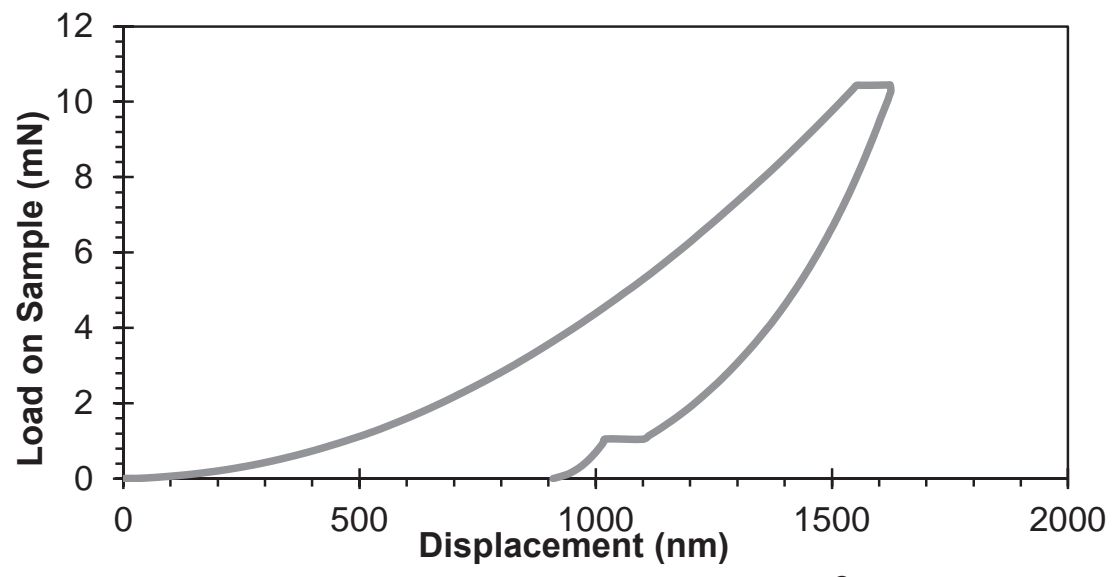

Figure B-34: Load vs. Displacement curve for 5 wt\% xGnP ${ }^{\circledR}-M-5$ in Epoxy Test 28

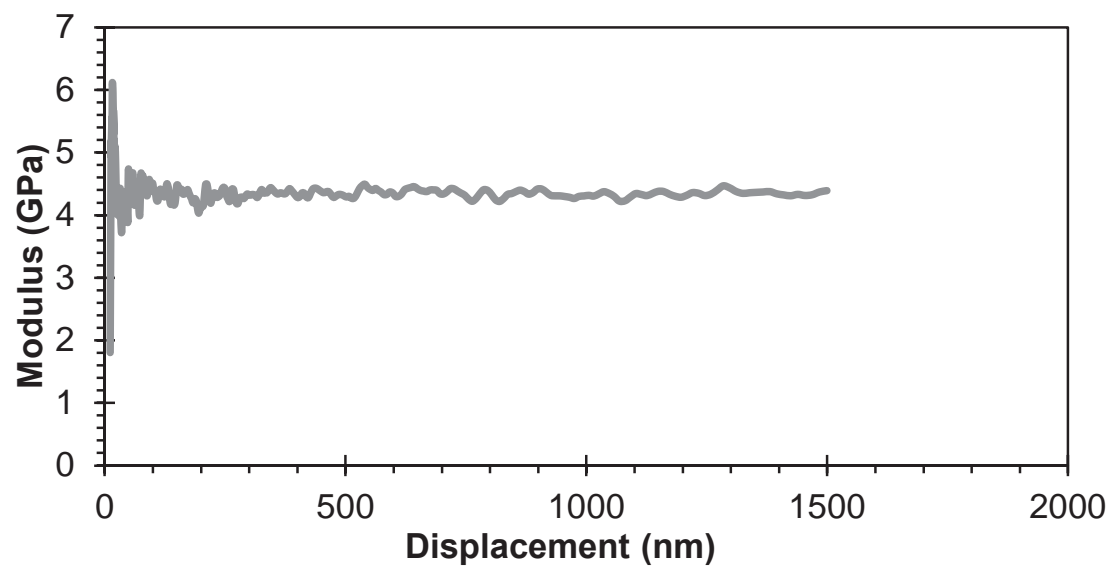

Figure B-35: Modulus vs. Displacement curve for 5 wt\% xGnP ${ }^{\circledR}-M-5$ in Epoxy Test 28

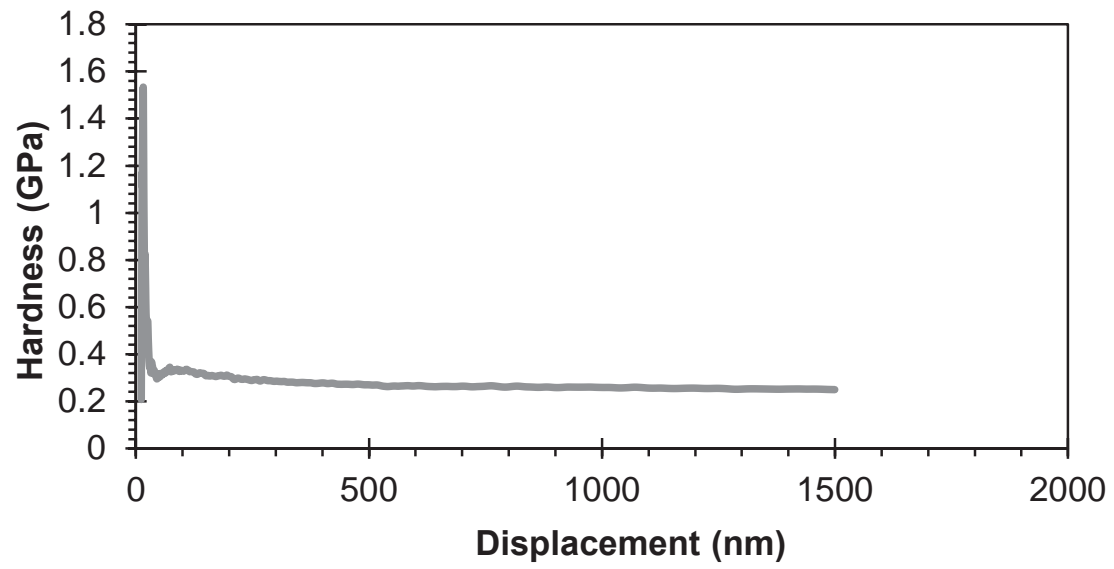

Figure B-36: Hardness vs. Displacement curve for 5 wt\% $x$ GnP $^{\circledR}-M-5$ in Epoxy Test 28 
Table B-13: Nanoindentation Averages Between 500 and $1500 \mathrm{~nm}$ Depth for 6 wt\% $x G n P^{\circledR}-M-5$ in Epoxy

\begin{tabular}{|c|c|c|c|c|}
\hline Test & $\begin{array}{c}\text { Average } \\
\text { Modulus } \\
\text { (GPa) }\end{array}$ & $\begin{array}{l}\text { Modulus } \\
\text { Std Dev }\end{array}$ & $\begin{array}{c}\text { Average } \\
\text { Hardness } \\
\text { (GPa) }\end{array}$ & $\begin{array}{l}\text { Hardness } \\
\text { Std Dev }\end{array}$ \\
\hline 4 & 4.3475 & 0.0602 & 0.2930 & 0.2930 \\
\hline 14 & 4.7146 & 0.2458 & 0.2397 & 0.2397 \\
\hline 16 & 4.4033 & 0.0641 & 0.2617 & 0.2617 \\
\hline 17 & 4.7146 & 0.2458 & 0.2397 & 0.2397 \\
\hline 18 & 4.2756 & 0.0952 & 0.2397 & 0.2397 \\
\hline 22 & 4.2705 & 0.0808 & 0.2506 & 0.2506 \\
\hline 26 & 4.4748 & 0.0762 & 0.2459 & 0.2459 \\
\hline 31 & 4.6819 & 0.1173 & 0.2475 & 0.2475 \\
\hline 38 & 4.3890 & 0.1356 & 0.2608 & 0.0041 \\
\hline 40 & 4.3250 & 0.1367 & 0.2475 & 0.0112 \\
\hline 41 & 4.6418 & 0.2774 & 0.2461 & 0.0058 \\
\hline 42 & 4.4948 & 0.0872 & 0.2639 & 0.0051 \\
\hline 44 & 4.4190 & 0.0926 & 0.2552 & 0.0070 \\
\hline 45 & 4.6027 & 0.1952 & 0.2639 & 0.0131 \\
\hline 47 & 4.4718 & 0.1258 & 0.2474 & 0.0047 \\
\hline 48 & 4.3576 & 0.1898 & 0.2651 & 0.0020 \\
\hline 52 & 4.5228 & 0.1199 & 0.2549 & 0.0054 \\
\hline 54 & 4.3385 & 0.1346 & 0.2566 & 0.0021 \\
\hline 62 & 4.5414 & 0.1499 & 0.2347 & 0.0055 \\
\hline 63 & 4.3321 & 0.2027 & 0.2459 & 0.0037 \\
\hline 66 & 4.3425 & 0.1581 & 0.2620 & 0.0040 \\
\hline 67 & 4.2930 & 0.0758 & 0.2632 & 0.0038 \\
\hline 68 & 4.4437 & 0.1949 & 0.2568 & 0.0030 \\
\hline 71 & 4.2968 & 0.1065 & 0.2662 & 0.0053 \\
\hline Mean & 4.45 & --- & 0.254 & --- \\
\hline Std Dev & 0.14 & --- & 0.012 & --- \\
\hline Count & 24 & 24 & 24 & 24 \\
\hline
\end{tabular}




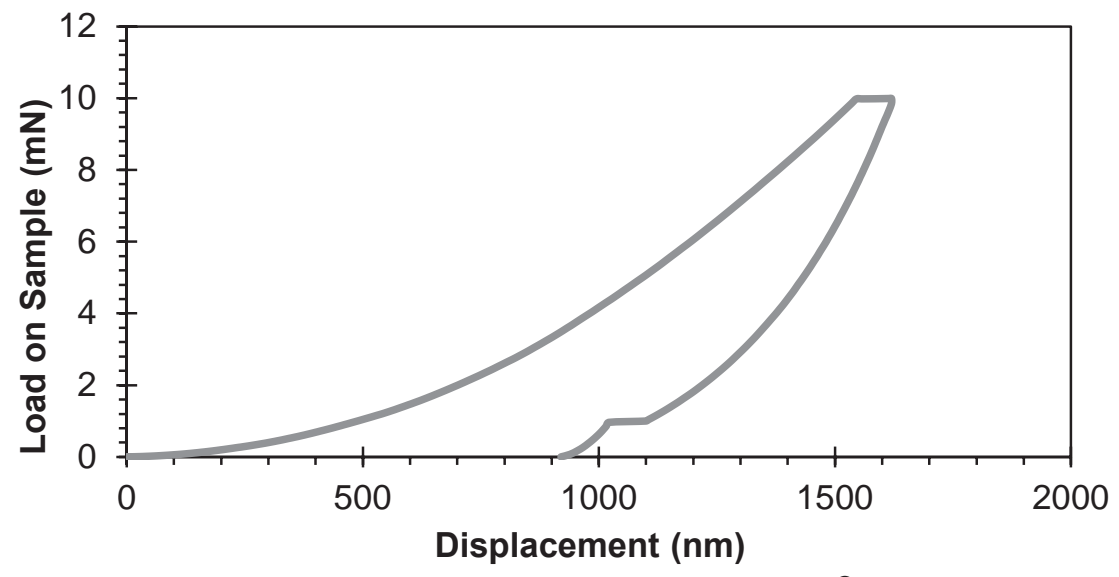

Figure B-37: Load vs. Displacement curve for 6 wt\% xGnP ${ }^{\circledR}-M-5$ in Epoxy Test 18

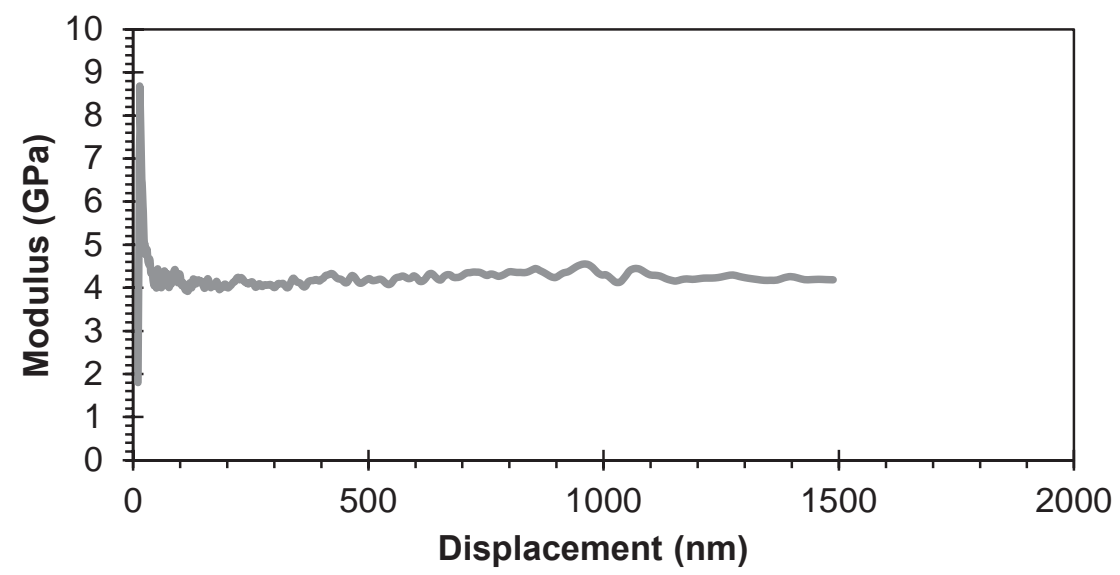

Figure B-38: Modulus vs. Displacement curve for 6 wt\% xGnP ${ }^{\circledR}-M-5$ in Epoxy Test 18

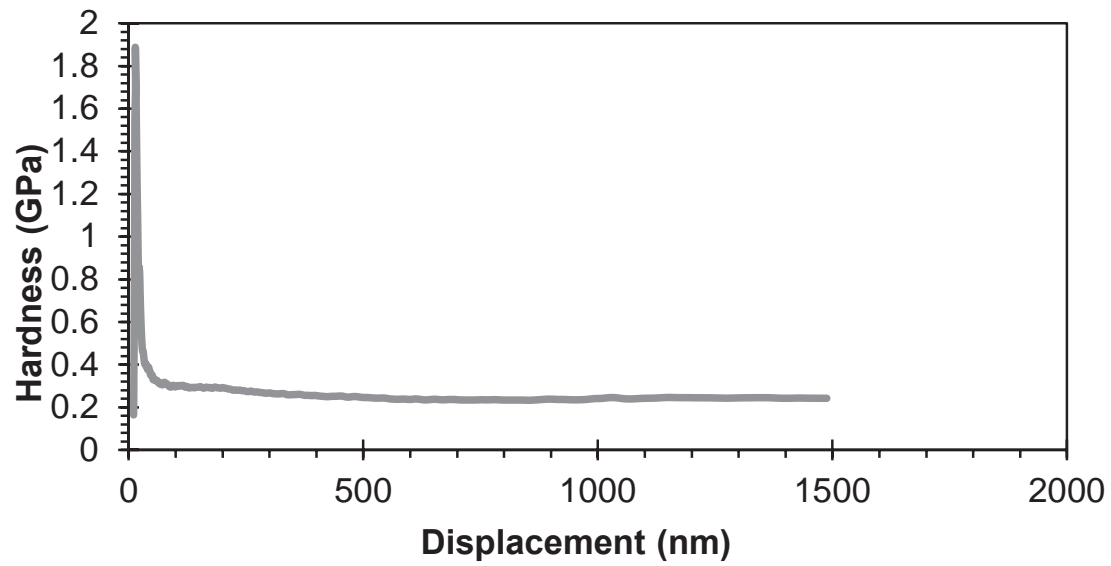

Figure B-39: Hardness vs. Displacement curve for 6 wt\% xGnP ${ }^{\circledR}-M-5$ in Epoxy Test 18 
Table B-14: Nanoindentation Averages Between 500 and $1500 \mathrm{~nm}$ Depth for $1 \mathrm{wt} \%$ $x G n P^{\circledR}-C-300$ in Epoxy

\begin{tabular}{|l|c|c|c|c|}
\hline Test & $\begin{array}{c}\text { Average } \\
\text { Modulus } \\
\text { (GPa) }\end{array}$ & $\begin{array}{c}\text { Modulus } \\
\text { Std Dev }\end{array}$ & $\begin{array}{c}\text { Average } \\
\text { Hardness } \\
\text { (GPa) }\end{array}$ & $\begin{array}{c}\text { Hardness } \\
\text { Std Dev }\end{array}$ \\
\hline 1 & 3.5861 & 0.0441 & 0.2562 & 0.0031 \\
\hline 2 & 3.5654 & 0.0517 & 0.2557 & 0.0028 \\
\hline 3 & 3.6534 & 0.0471 & 0.2653 & 0.0053 \\
\hline 4 & 3.6069 & 0.0556 & 0.2538 & 0.0020 \\
\hline 5 & 3.6568 & 0.0508 & 0.2648 & 0.0053 \\
\hline 6 & 3.6506 & 0.0558 & 0.2589 & 0.0027 \\
\hline 7 & 3.6569 & 0.0536 & 0.2615 & 0.0036 \\
\hline 8 & 3.6416 & 0.0662 & 0.2637 & 0.0050 \\
\hline 9 & 3.6312 & 0.0537 & 0.2582 & 0.0022 \\
\hline 10 & 3.6452 & 0.0626 & 0.2630 & 0.0043 \\
\hline 11 & 3.6595 & 0.0495 & 0.2617 & 0.0035 \\
\hline 12 & 3.6393 & 0.0484 & 0.2620 & 0.0050 \\
\hline 13 & 3.6388 & 0.0520 & 0.2582 & 0.0022 \\
\hline 14 & 3.7079 & 0.0704 & 0.2650 & 0.0027 \\
\hline 15 & 3.6834 & 0.0582 & 0.2641 & 0.0046 \\
\hline 16 & 3.6520 & 0.0565 & 0.2626 & 0.0040 \\
\hline 17 & 3.7064 & 0.1085 & 0.2667 & 0.0101 \\
\hline 18 & 3.6237 & 0.0471 & 0.2578 & 0.0023 \\
\hline 19 & 3.5862 & 0.0435 & 0.2538 & 0.0026 \\
\hline 20 & 3.7131 & 0.0412 & 0.2636 & 0.0039 \\
\hline 21 & 3.6062 & 0.0506 & 0.2588 & 0.0029 \\
\hline 22 & 3.6458 & 0.0634 & 0.2623 & 0.0039 \\
\hline 23 & 3.6783 & 0.0516 & 0.2625 & 0.0028 \\
\hline 24 & 3.5750 & 0.0445 & 0.2543 & 0.0017 \\
\hline 25 & 3.6258 & 0.0427 & 0.2583 & 0.0021 \\
\hline 26 & 3.7384 & 0.0752 & 0.2693 & 0.0062 \\
\hline 27 & 3.6040 & 0.0515 & 0.2577 & 0.0025 \\
\hline 28 & 3.6398 & 0.0457 & 0.2601 & 0.0026 \\
\hline 29 & 3.6396 & 0.0606 & 0.2608 & 0.0031 \\
\hline 30 & 3.7010 & 0.0643 & 0.2664 & 0.0042 \\
\hline 32 & 3.6561 & 0.0580 & 0.2629 & 0.0044 \\
\hline 33 & 3.6401 & 0.0537 & 0.2615 & 0.0034 \\
\hline 34 & 3.6620 & 0.0570 & 0.2663 & 0.0050 \\
\hline 35 & 3.6483 & 0.0567 & 0.2622 & 0.0048 \\
\hline 36 & 3.6447 & 0.0655 & 0.2587 & 0.0032 \\
\hline Mean & 3.65 & --- & $\mathbf{0 . 2 6 1}$ & --- \\
\hline Std Dev & $\mathbf{0 . 0 4}$ & --- & $\mathbf{0 . 0 0 4}$ & --- \\
\hline Count & $\mathbf{3 5}$ & $\mathbf{3 5}$ & $\mathbf{3 5}$ & $\mathbf{3 5}$ \\
\hline & & & & \\
\hline & & & \\
\hline 13 & & &
\end{tabular}




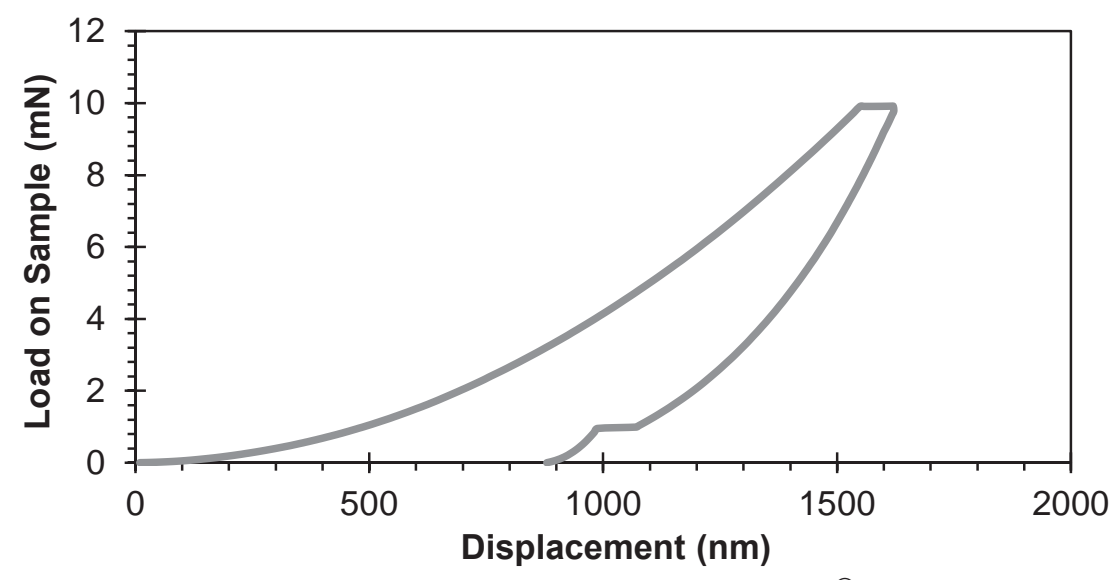

Figure B-40: Load vs. Displacement curve for 1 wt\% xGnP ${ }^{\circledR}-C-300$ in Epoxy Test 36

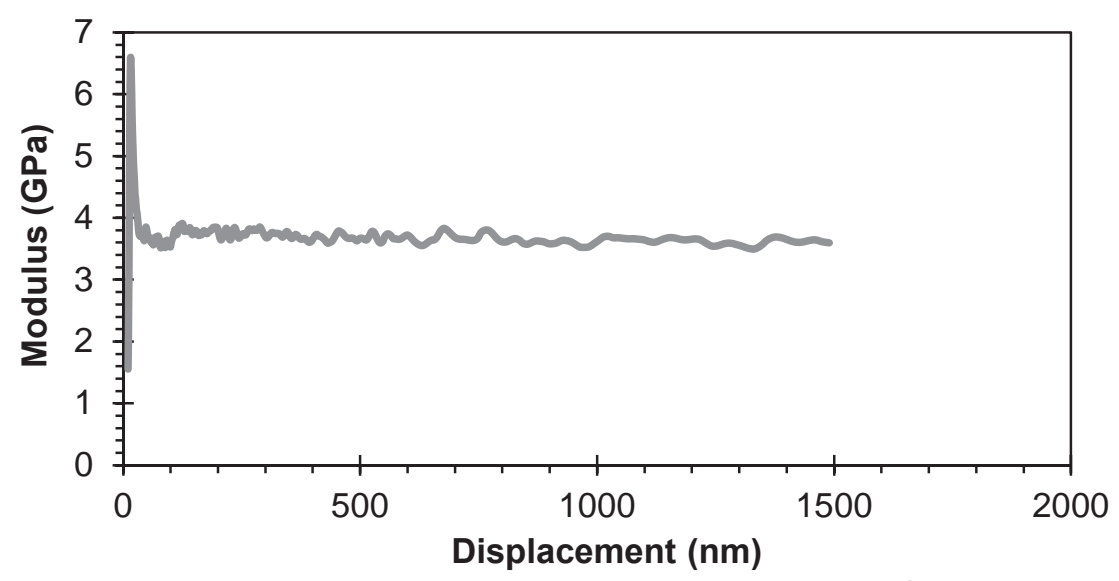

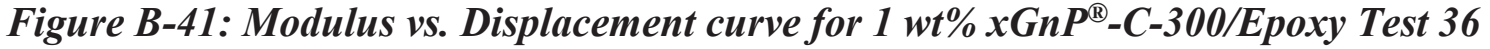

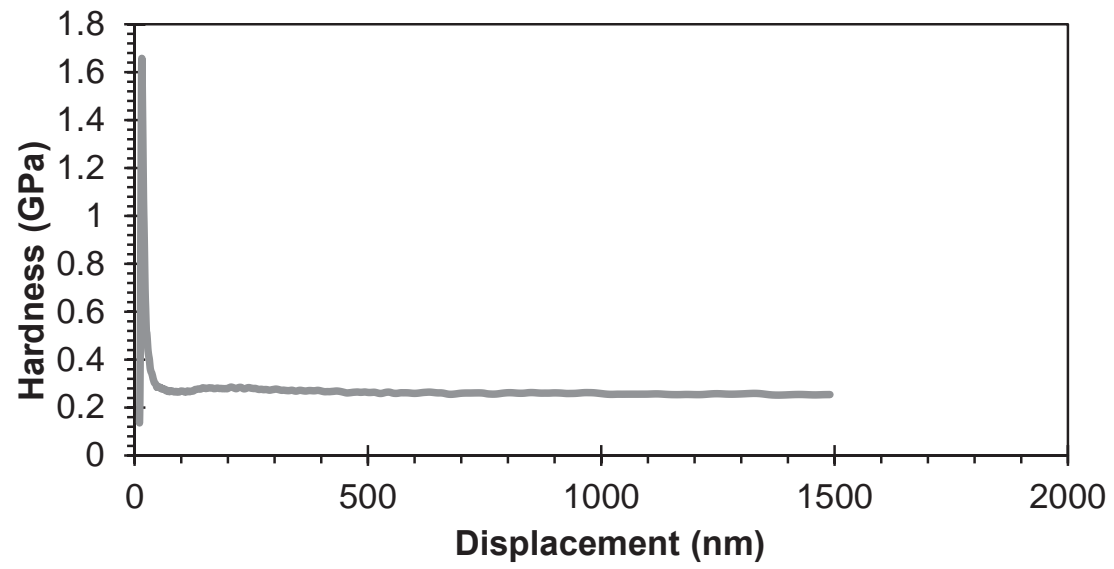

Figure B-42: Hardness vs. Displacement curve for 1 wt\% xGnP ${ }^{\circledR}-C-300 / E p o x y$ Test 36 
Table B-15: Nanoindentation Averages Between 500 and $1500 \mathrm{~nm}$ Depth for 2 wt\% $x G n P^{\circledR}-C-300$ in Epoxy

\begin{tabular}{|c|c|c|c|c|}
\hline Test & $\begin{array}{c}\text { Average } \\
\text { Modulus } \\
\text { (GPa) }\end{array}$ & $\begin{array}{l}\text { Modulus } \\
\text { Std Dev }\end{array}$ & $\begin{array}{c}\text { Average } \\
\text { Hardness } \\
\text { (GPa) }\end{array}$ & $\begin{array}{l}\text { Hardness } \\
\text { Std Dev }\end{array}$ \\
\hline 1 & 3.8225 & 0.0630 & 0.2739 & 0.0044 \\
\hline 5 & 3.8100 & 0.0564 & 0.2674 & 0.0030 \\
\hline 16 & 3.8072 & 0.0569 & 0.2721 & 0.0032 \\
\hline 18 & 3.8049 & 0.0567 & 0.2664 & 0.0024 \\
\hline 19 & 3.8076 & 0.0491 & 0.2707 & 0.0024 \\
\hline 23 & 3.7881 & 0.0465 & 0.2680 & 0.0020 \\
\hline 24 & 3.8156 & 0.0526 & 0.2690 & 0.0020 \\
\hline 26 & 3.8082 & 0.0619 & 0.2678 & 0.0030 \\
\hline 29 & 3.7508 & 0.0508 & 0.2645 & 0.0017 \\
\hline 35 & 3.8038 & 0.0450 & 0.2691 & 0.0026 \\
\hline 39 & 3.8147 & 0.0711 & 0.2679 & 0.0030 \\
\hline 42 & 3.8088 & 0.0607 & 0.2700 & 0.0026 \\
\hline 45 & 3.7681 & 0.0531 & 0.2619 & 0.0022 \\
\hline 47 & 3.8070 & 0.0548 & 0.2680 & 0.0027 \\
\hline 49 & 3.7938 & 0.0530 & 0.2653 & 0.0025 \\
\hline 56 & 3.7697 & 0.0578 & 0.2617 & 0.0024 \\
\hline 57 & 3.7930 & 0.0698 & 0.2680 & 0.0050 \\
\hline 62 & 3.7732 & 0.0508 & 0.2650 & 0.0022 \\
\hline 68 & 3.7050 & 0.0672 & 0.2436 & 0.0070 \\
\hline 76 & 3.7926 & 0.0580 & 0.2661 & 0.0020 \\
\hline 80 & 3.8215 & 0.0549 & 0.2650 & 0.0022 \\
\hline 82 & 3.7832 & 0.0494 & 0.2608 & 0.0038 \\
\hline 85 & 3.7127 & 0.0661 & 0.2418 & 0.0113 \\
\hline 88 & 3.7953 & 0.0633 & 0.2636 & 0.0022 \\
\hline 103 & 3.7524 & 0.0525 & 0.2599 & 0.0024 \\
\hline Mean & 3.79 & -- & 0.265 & --- \\
\hline Std Dev & 0.03 & --- & 0.007 & --- \\
\hline Count & 25 & 25 & 25 & 25 \\
\hline
\end{tabular}




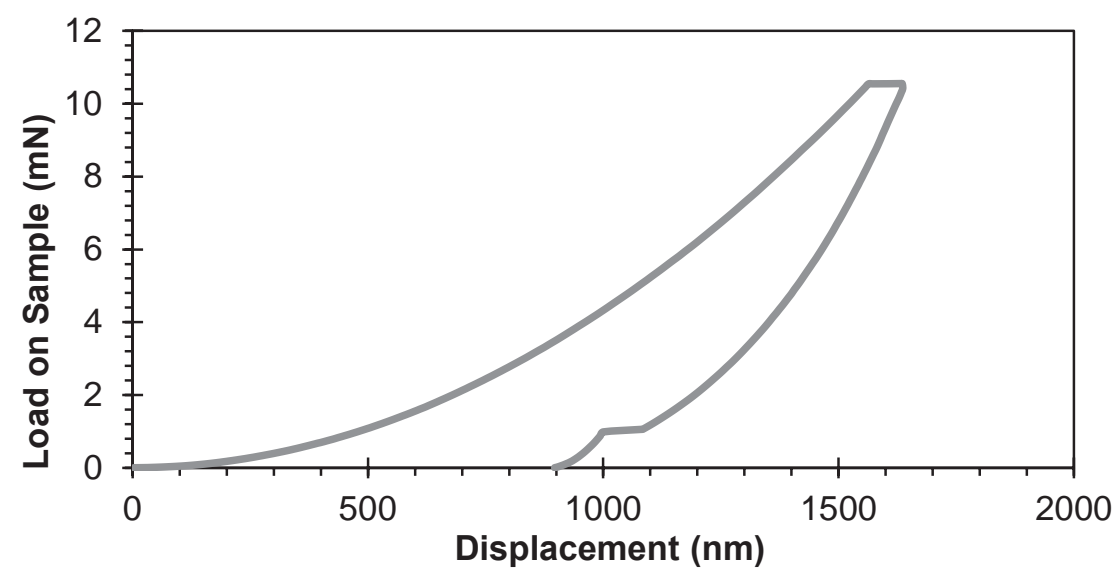

Figure B-43: Load vs. Displacement curve for 2 wt\% $x G n P^{\circledR}-C-300$ in Epoxy Test 35

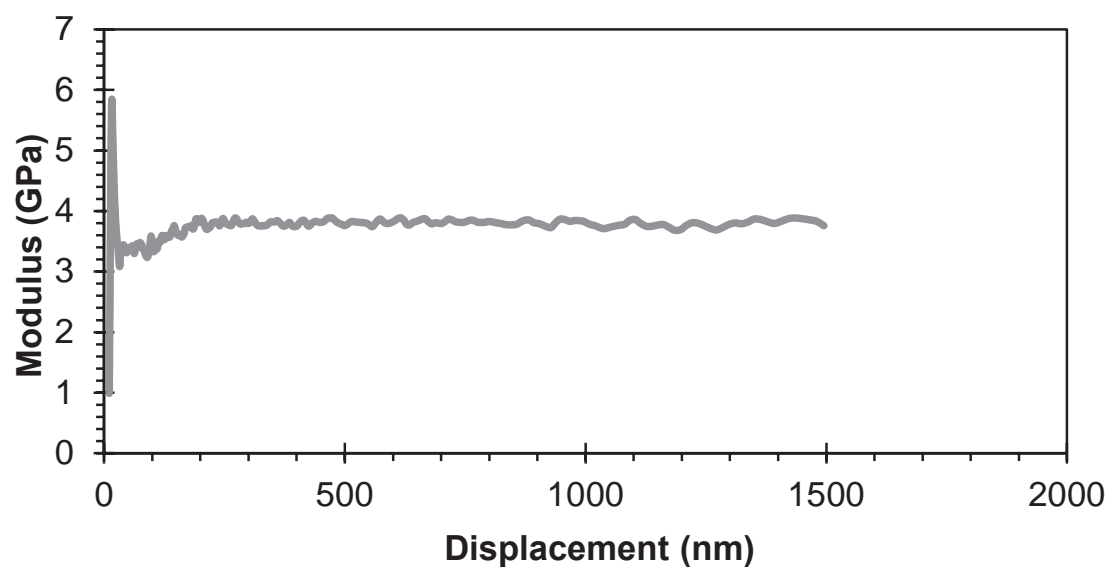

Figure B-44: Modulus vs. Displacement curve for 2 wt\% xGnP ${ }^{\circledR}-C-300 /$ Epoxy Test 35

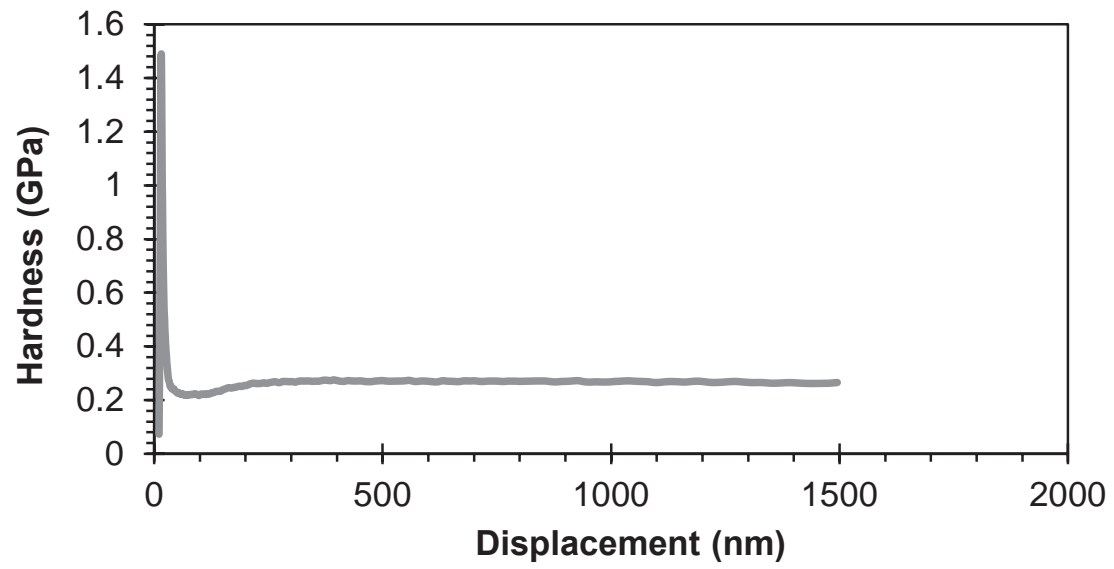

Figure B-45: Hardness vs. Displacement curve for 2 wt\% xGnP ${ }^{\circledR}-C-300 /$ Epoxy Test 35 
Table B-16: Nanoindentation Averages Between 500 and $1500 \mathrm{~nm}$ Depth for 3 wt\% $x G n P^{\circledR}-C-300$ in Epoxy

\begin{tabular}{|l|c|c|c|r|}
\hline Test & $\begin{array}{c}\text { Average } \\
\text { Modulus } \\
\text { (GPa) }\end{array}$ & $\begin{array}{c}\text { Modulus } \\
\text { Std Dev }\end{array}$ & $\begin{array}{c}\text { Average } \\
\text { Hardness } \\
\text { (GPa) }\end{array}$ & $\begin{array}{c}\text { Hardness } \\
\text { Std Dev }\end{array}$ \\
\hline 5 & 3.8713 & 0.0786 & 0.2552 & 0.0026 \\
\hline 7 & 3.7644 & 0.0468 & 0.2643 & 0.0059 \\
\hline 14 & 3.7674 & 0.0869 & 0.2601 & 0.0029 \\
\hline 16 & 3.8406 & 0.0727 & 0.2718 & 0.0078 \\
\hline 17 & 3.7809 & 0.0525 & 0.2458 & 0.0040 \\
\hline 18 & 3.8004 & 0.0617 & 0.2613 & 0.0018 \\
\hline 22 & 3.8576 & 0.0725 & 0.2504 & 0.0015 \\
\hline 23 & 3.7707 & 0.0626 & 0.2662 & 0.0626 \\
\hline 25 & 3.7572 & 0.0661 & 0.2659 & 0.0060 \\
\hline 30 & 3.8014 & 0.0530 & 0.2530 & 0.0034 \\
\hline 35 & 3.7615 & 0.0590 & 0.2711 & 0.0070 \\
\hline 37 & 3.7676 & 0.0534 & 0.2637 & 0.0033 \\
\hline 41 & 3.7827 & 0.0669 & 0.2631 & 0.0040 \\
\hline 42 & 3.7811 & 0.0678 & 0.2680 & 0.0034 \\
\hline 43 & 3.8374 & 0.0528 & 0.2672 & 0.0028 \\
\hline 49 & 3.8568 & 0.0635 & 0.2695 & 0.0034 \\
\hline 50 & 3.7737 & 0.0428 & 0.2553 & 0.0029 \\
\hline 53 & 3.8114 & 0.0702 & 0.2610 & 0.0021 \\
\hline 57 & 3.8190 & 0.0687 & 0.2746 & 0.0068 \\
\hline 58 & 3.7800 & 0.0579 & 0.2614 & 0.0021 \\
\hline 60 & 3.8282 & 0.0630 & 0.2715 & 0.0050 \\
\hline 61 & 3.7618 & 0.0657 & 0.2577 & 0.0022 \\
\hline 62 & 3.7885 & 0.0674 & 0.2664 & 0.0032 \\
\hline 63 & 3.7574 & 0.0937 & 0.2632 & 0.0042 \\
\hline 65 & 3.7778 & 0.0651 & 0.2631 & 0.0023 \\
\hline 68 & 3.7796 & 0.0650 & 0.2653 & 0.0032 \\
\hline 69 & 3.7655 & 0.0555 & 0.2599 & 0.0020 \\
\hline 70 & 3.7912 & 0.0619 & 0.2671 & 0.0050 \\
\hline 72 & 3.7706 & 0.0723 & 0.2629 & 0.0046 \\
\hline Mean & 3.79 & --- & $\mathbf{0 . 2 6 3}$ & --- \\
\hline Std Dev & $\mathbf{0 . 0 3}$ & --- & $\mathbf{0 . 0 0 7}$ & --- \\
\hline count & $\mathbf{2 9}$ & $\mathbf{2 9}$ & $\mathbf{2 9}$ & $\mathbf{2 9}$ \\
\hline & & & & \\
\hline
\end{tabular}




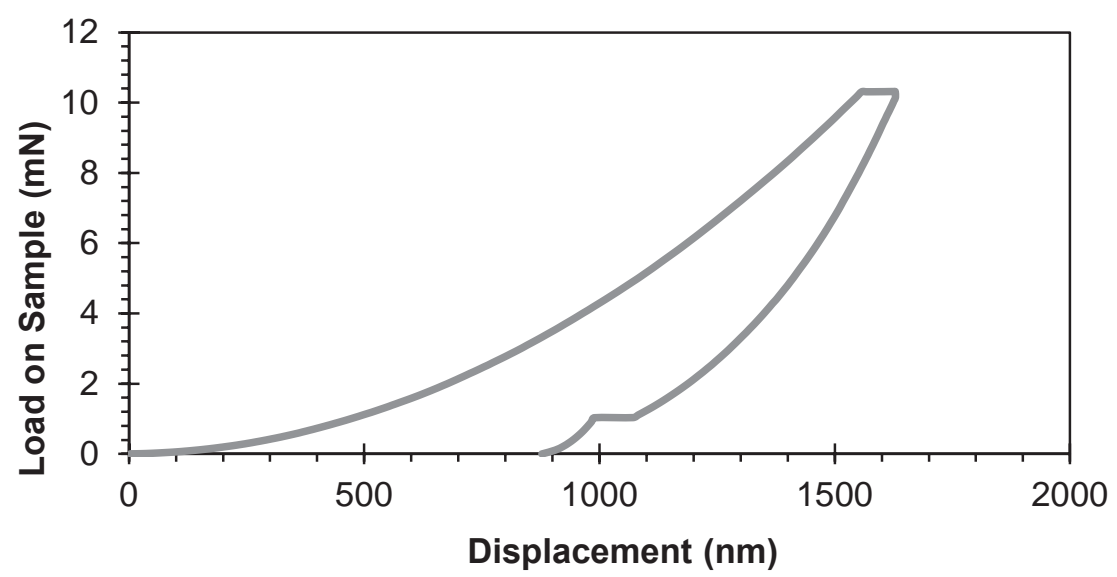

Figure B-46: Load vs. Displacement curve for 3 wt\% $x G n P^{\circledR}{ }_{-} C-300$ in Epoxy Test 35

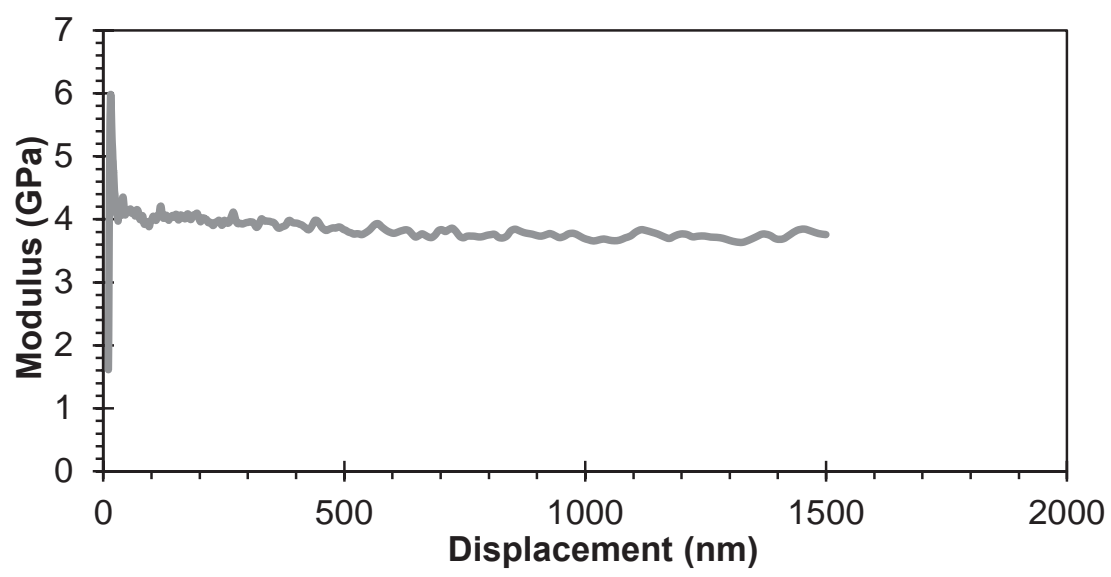

Figure B-47: Modulus vs. Displacement curve for 3 wt\% xGnP ${ }^{\circledR}-C-300 /$ Epoxy Test 35

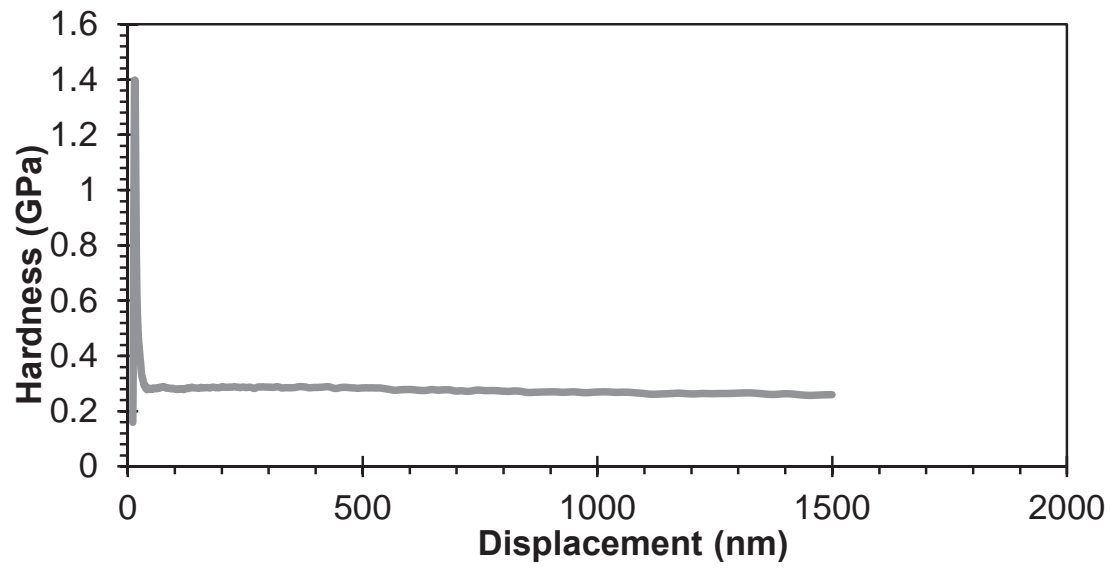

Figure B-48: Hardness vs. Displacement curve for 3 wt\% xGnP ${ }^{\circledR}-C-300 /$ Epoxy Test 35 
Table B-17: Nanoindentation Averages Between 500 and $1500 \mathrm{~nm}$ Depth for 4 wt\% $x G n P^{\circledR}-C-300$ in Epoxy

\begin{tabular}{|l|c|c|c|c|}
\hline Test & $\begin{array}{c}\text { Average } \\
\text { Modulus } \\
\text { (GPa) }\end{array}$ & $\begin{array}{c}\text { Modulus } \\
\text { Std Dev }\end{array}$ & $\begin{array}{c}\text { Average } \\
\text { Hardness } \\
\text { (GPa) }\end{array}$ & $\begin{array}{c}\text { Hardness } \\
\text { Std Dev }\end{array}$ \\
\hline 3 & 3.7926 & 0.0660 & 0.2675 & 0.0037 \\
\hline 6 & 3.9248 & 0.0627 & 0.2720 & 0.0041 \\
\hline 7 & 3.7870 & 0.0609 & 0.2675 & 0.0044 \\
\hline 9 & 3.7997 & 0.0903 & 0.2675 & 0.0083 \\
\hline 10 & 3.7904 & 0.0578 & 0.2630 & 0.0028 \\
\hline 13 & 3.8177 & 0.0760 & 0.2649 & 0.0027 \\
\hline 14 & 3.8080 & 0.0623 & 0.2724 & 0.0053 \\
\hline 16 & 3.9288 & 0.0791 & 0.2607 & 0.0053 \\
\hline 18 & 3.8590 & 0.0632 & 0.2665 & 0.0026 \\
\hline 19 & 3.8147 & 0.0684 & 0.2610 & 0.0029 \\
\hline 23 & 3.7848 & 0.0638 & 0.2612 & 0.0039 \\
\hline 27 & 3.7896 & 0.0588 & 0.2601 & 0.0020 \\
\hline 30 & 3.7863 & 0.0556 & 0.2647 & 0.0027 \\
\hline 31 & 3.7853 & 0.0552 & 0.2594 & 0.0020 \\
\hline 32 & 3.8371 & 0.0817 & 0.2669 & 0.0045 \\
\hline 34 & 3.7967 & 0.0836 & 0.2620 & 0.0027 \\
\hline 35 & 3.8554 & 0.0642 & 0.2737 & 0.0065 \\
\hline 38 & 3.7915 & 0.0595 & 0.2581 & 0.0021 \\
\hline 42 & 3.8625 & 0.0744 & 0.2598 & 0.0021 \\
\hline 45 & 3.9063 & 0.0745 & 0.2706 & 0.0031 \\
\hline 47 & 3.8001 & 0.0573 & 0.2604 & 0.0029 \\
\hline 51 & 3.8017 & 0.0558 & 0.2705 & 0.0043 \\
\hline 52 & 3.8240 & 0.0485 & 0.2608 & 0.0031 \\
\hline 56 & 3.7935 & 0.0543 & 0.2647 & 0.0022 \\
\hline 62 & 3.8408 & 0.0609 & 0.2619 & 0.0024 \\
\hline 63 & 3.8581 & 0.0605 & 0.2652 & 0.0029 \\
\hline 66 & 3.8498 & 0.0558 & 0.2725 & 0.0045 \\
\hline 67 & 3.8442 & 0.0594 & 0.2678 & 0.0043 \\
\hline 68 & 3.8903 & 0.1072 & 0.2698 & 0.0059 \\
\hline 70 & 3.8004 & 0.0586 & 0.2624 & 0.0024 \\
\hline Mean & 3.83 & --- & $\mathbf{0 . 2 6 5}$ & --- \\
\hline Std Dev & $\mathbf{0 . 0 4}$ & --- & $\mathbf{0 . 0 0 5}$ & --- \\
\hline Count & $\mathbf{3 0}$ & $\mathbf{3 0}$ & $\mathbf{3 0}$ & $\mathbf{3 0}$ \\
\hline & & & & \\
\hline
\end{tabular}




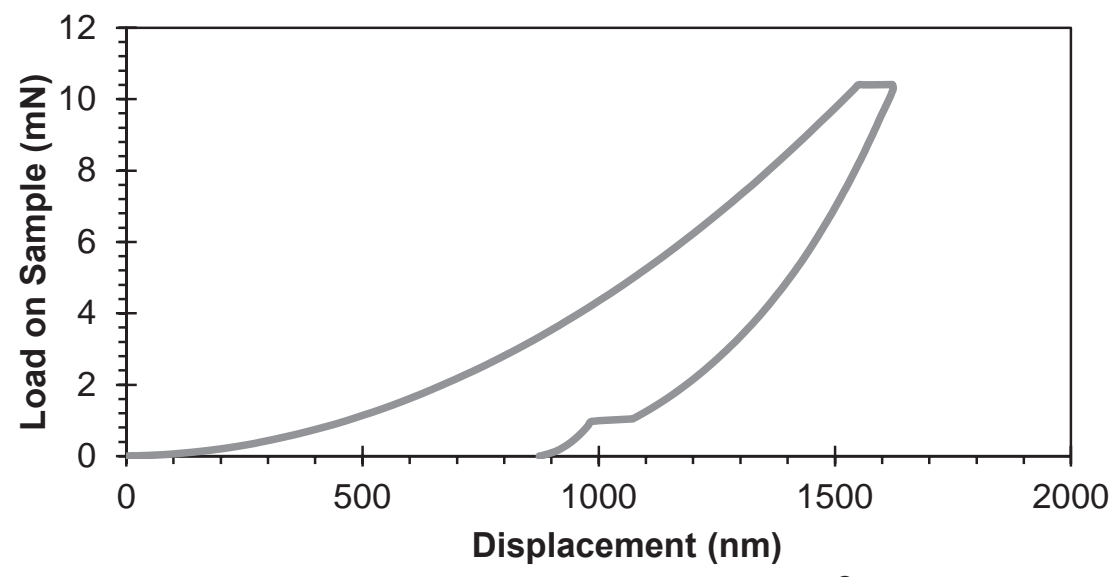

Figure B-49: Load vs. Displacement curve for 4 wt\% $x G n P^{\circledR}{ }_{-} C-300$ in Epoxy Test 35

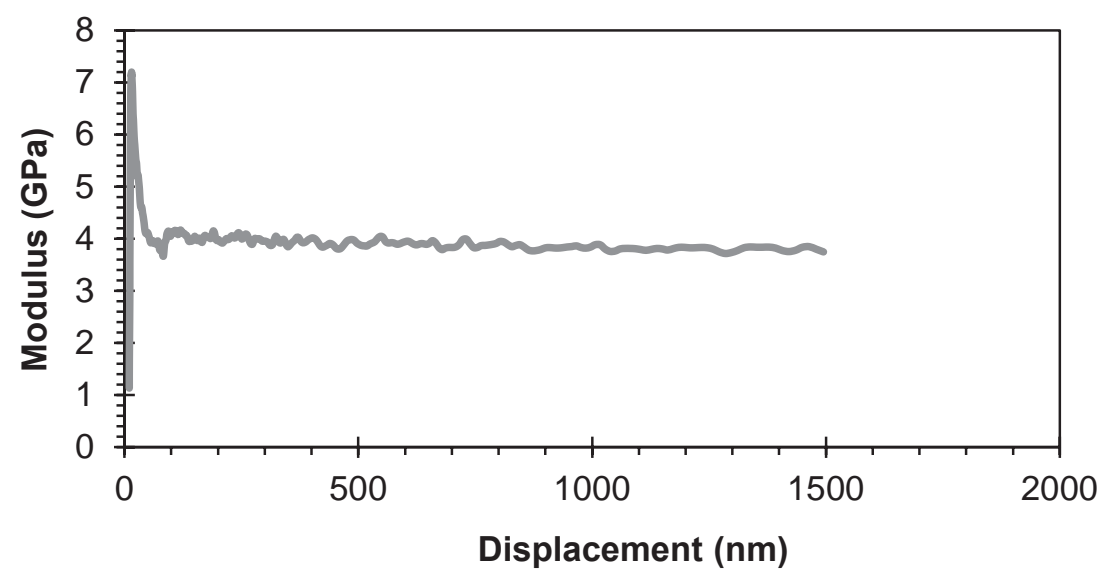

Figure B-50: Modulus vs. Displacement curve for 4 wt\% $x G n P^{\circledR}{ }_{-}$- $-300 /$ Epoxy Test 35

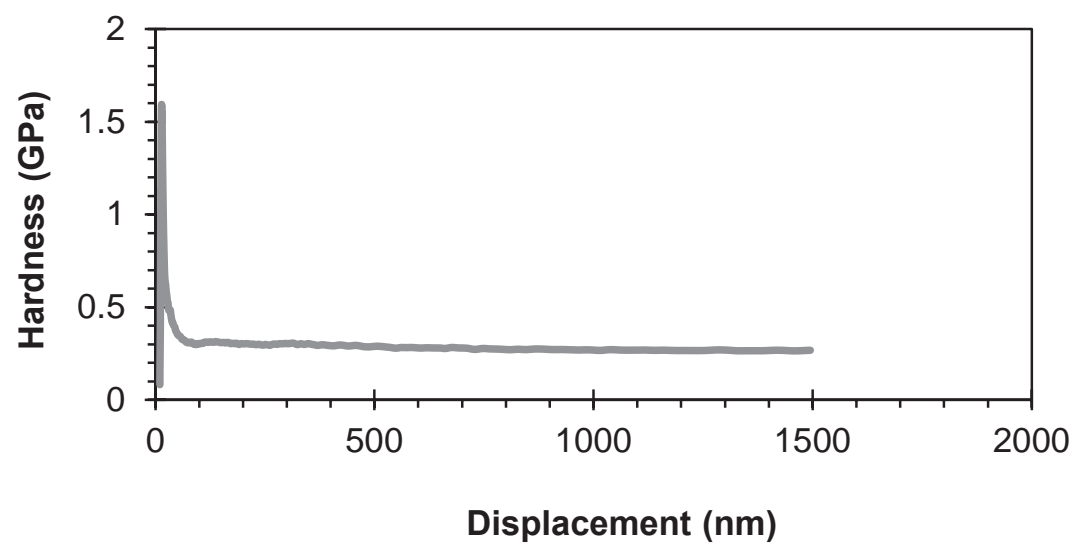

Figure B-51: Hardness vs. Displacement curve for 4 wt\% xGnP ${ }^{\circledR}-C-300 / E p o x y$ Test 35 
Table B-18: Nanoindentation Averages Between 500 and $1500 \mathrm{~nm}$ Depth for 5 wt\% $x G n P^{\circledR}-C-300$ in Epoxy

\begin{tabular}{|c|c|c|c|c|}
\hline Test & $\begin{array}{c}\text { Average } \\
\text { Modulus } \\
\text { (GPa) }\end{array}$ & $\begin{array}{l}\text { Modulus } \\
\text { Std Dev }\end{array}$ & $\begin{array}{c}\text { Average } \\
\text { Hardness } \\
\text { (GPa) }\end{array}$ & $\begin{array}{l}\text { Hardness } \\
\text { Std Dev }\end{array}$ \\
\hline 1 & 3.8176 & 0.0475 & 0.2654 & 0.0050 \\
\hline 2 & 3.8510 & 0.0574 & 0.2646 & 0.0039 \\
\hline 3 & 3.9563 & 0.0773 & 0.2605 & 0.0032 \\
\hline 5 & 3.8600 & 0.0611 & 0.2637 & 0.0043 \\
\hline 6 & 3.8601 & 0.0815 & 0.2694 & 0.0049 \\
\hline 9 & 3.9793 & 0.0833 & 0.2742 & 0.0069 \\
\hline 12 & 4.0334 & 0.0909 & 0.2713 & 0.0060 \\
\hline 15 & 3.8645 & 0.0717 & 0.2708 & 0.0068 \\
\hline 17 & 3.9625 & 0.0682 & 0.2620 & 0.0019 \\
\hline 18 & 3.8960 & 0.0778 & 0.2778 & 0.0072 \\
\hline 19 & 3.8528 & 0.0559 & 0.2587 & 0.0024 \\
\hline 21 & 3.8379 & 0.0679 & 0.2657 & 0.0057 \\
\hline 22 & 3.8028 & 0.0589 & 0.2577 & 0.0026 \\
\hline 23 & 3.9037 & 0.0516 & 0.2716 & 0.0050 \\
\hline 24 & 3.9037 & 0.0516 & 0.2716 & 0.0050 \\
\hline 25 & 3.9149 & 0.0645 & 0.2710 & 0.0059 \\
\hline 26 & 4.1250 & 0.0506 & 0.2665 & 0.0029 \\
\hline 28 & 3.8974 & 0.0711 & 0.2684 & 0.0030 \\
\hline 29 & 3.8089 & 0.0640 & 0.2624 & 0.0039 \\
\hline 30 & 3.8733 & 0.0745 & 0.2633 & 0.0032 \\
\hline 31 & 4.0875 & 0.0648 & 0.2644 & 0.0018 \\
\hline 32 & 3.8056 & 0.0628 & 0.2582 & 0.0021 \\
\hline 35 & 3.8340 & 0.0658 & 0.2650 & 0.0047 \\
\hline 36 & 3.8735 & 0.0577 & 0.2604 & 0.0024 \\
\hline Mean & 3.90 & --- & 0.266 & --- \\
\hline Std Dev & 0.09 & --- & 0.005 & --- \\
\hline Count & 24 & 24 & 24 & 24 \\
\hline
\end{tabular}




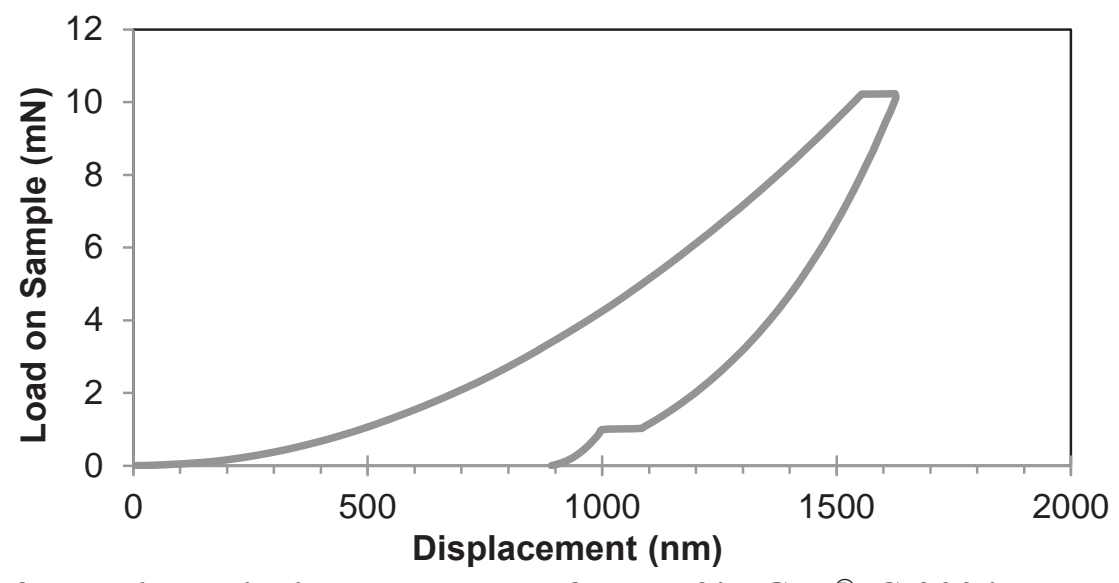

Figure B-52: Load vs. Displacement curve for 5 wt\% $x G n P^{\circledR}{ }_{-} C-300$ in Epoxy Test 36

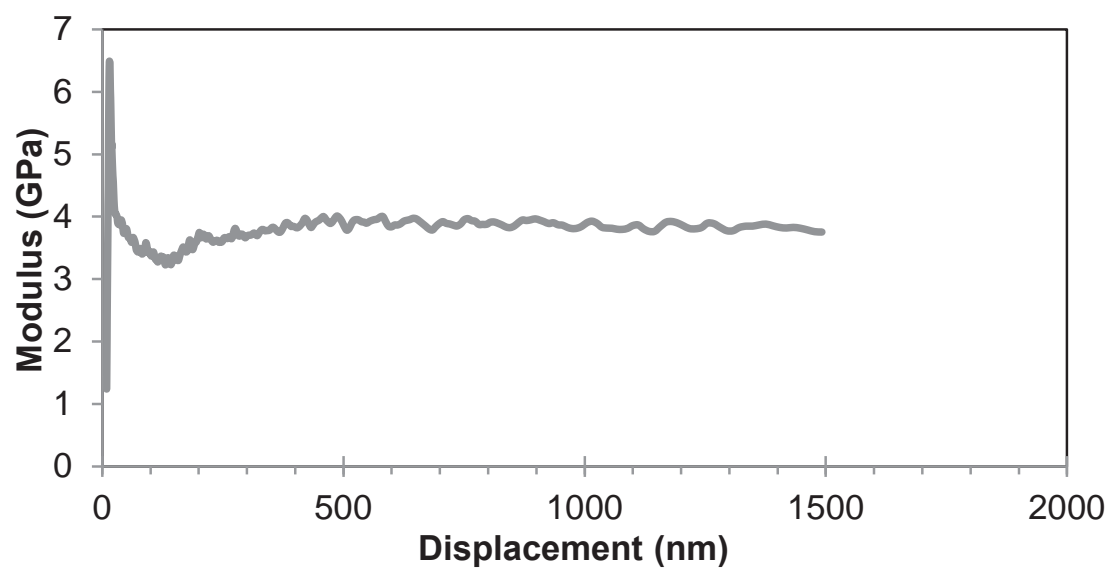

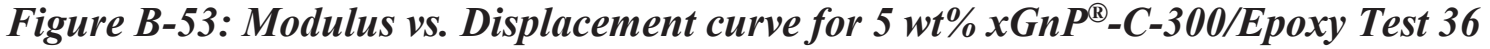

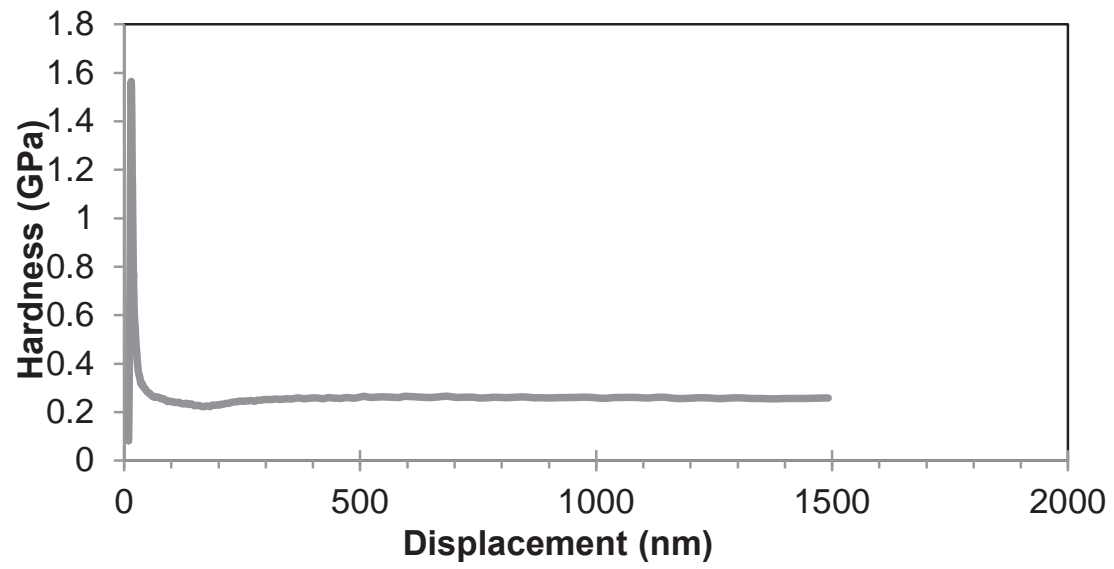

Figure B-54: Hardness vs. Displacement curve for 5 wt\% xGnP ${ }^{\circledR}-C-300 /$ Epoxy Test 36 
Table B-19: Nanoindentation Averages Between 500 and $1500 \mathrm{~nm}$ Depth for $6 \mathrm{wt} \%$ $x G n P^{\circledR}-C-300$ in Epoxy

\begin{tabular}{|l|c|c|c|c|}
\hline Test & $\begin{array}{c}\text { Average } \\
\text { Modulus } \\
\text { (GPa) }\end{array}$ & $\begin{array}{c}\text { Modulus } \\
\text { Std Dev }\end{array}$ & $\begin{array}{c}\text { Average } \\
\text { Hardness } \\
\text { (GPa) }\end{array}$ & $\begin{array}{c}\text { Hardness } \\
\text { Std Dev }\end{array}$ \\
\hline 1 & 3.8713 & 0.0579 & 0.2571 & 0.0030 \\
\hline 2 & 3.8579 & 0.0752 & 0.2694 & 0.0035 \\
\hline 3 & 3.8559 & 0.0542 & 0.2642 & 0.0017 \\
\hline 5 & 3.8568 & 0.0623 & 0.2661 & 0.0023 \\
\hline 7 & 3.9230 & 0.0642 & 0.2652 & 0.0025 \\
\hline 9 & 3.8772 & 0.0638 & 0.2639 & 0.0026 \\
\hline 10 & 3.9582 & 0.0774 & 0.2685 & 0.0028 \\
\hline 12 & 3.9858 & 0.0564 & 0.2695 & 0.0029 \\
\hline 13 & 3.8908 & 0.0528 & 0.2684 & 0.0028 \\
\hline 17 & 3.8630 & 0.0508 & 0.2681 & 0.0036 \\
\hline 20 & 3.8524 & 0.0700 & 0.2624 & 0.0026 \\
\hline 21 & 3.9717 & 0.0934 & 0.2677 & 0.0030 \\
\hline 22 & 3.8303 & 0.0544 & 0.2687 & 0.0038 \\
\hline 23 & 3.8531 & 0.0593 & 0.2618 & 0.0019 \\
\hline 24 & 3.9409 & 0.0696 & 0.2713 & 0.0026 \\
\hline 25 & 3.8511 & 0.0703 & 0.2656 & 0.0032 \\
\hline 26 & 4.0552 & 0.0761 & 0.2729 & 0.0025 \\
\hline 27 & 3.8864 & 0.0574 & 0.2659 & 0.0032 \\
\hline 29 & 3.8919 & 0.0711 & 0.2730 & 0.0047 \\
\hline 31 & 4.1289 & 0.0856 & 0.2736 & 0.0021 \\
\hline 32 & 3.8782 & 0.0553 & 0.2614 & 0.0029 \\
\hline 33 & 3.9110 & 0.0550 & 0.2739 & 0.0053 \\
\hline 34 & 3.8487 & 0.0669 & 0.2660 & 0.0025 \\
\hline 35 & 4.0282 & 0.0696 & 0.2674 & 0.0023 \\
\hline Mean & $\mathbf{3 . 9 1}$ & --- & $\mathbf{0 . 2 6 7}$ & --- \\
\hline Std Dev & $\mathbf{0 . 0 8}$ & --- & $\mathbf{0 . 0 0 4}$ & --- \\
\hline Count & $\mathbf{2 4}$ & $\mathbf{2 4}$ & $\mathbf{2 4}$ & $\mathbf{2 4}$ \\
\hline & & & & \\
\hline
\end{tabular}




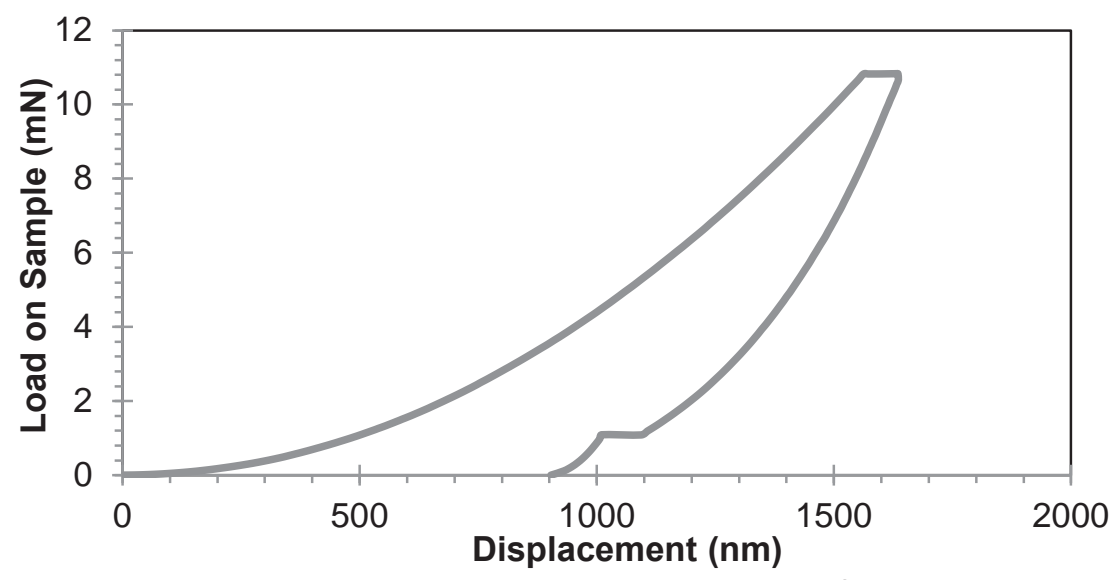

Figure B-55: Load vs. Displacement curve for $6 w t \% x G n P^{\circledR}-C-300$ in Epoxy Test 35

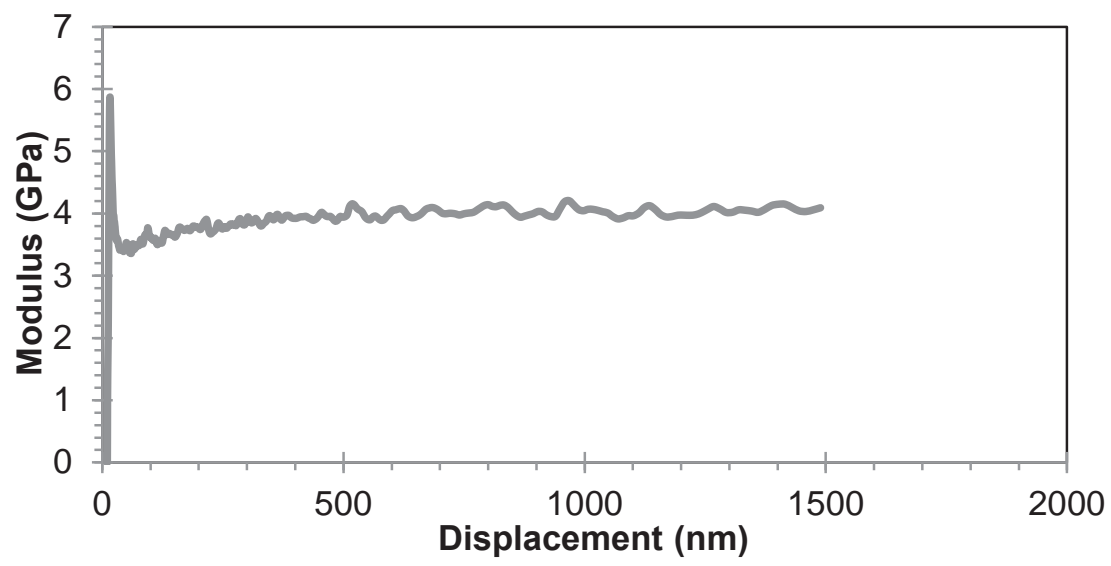

Figure B-56: Modulus vs. Displacement curve for 6 wt\% $x G n P^{\circledR}-C-300 / E p o x y$ Test 35

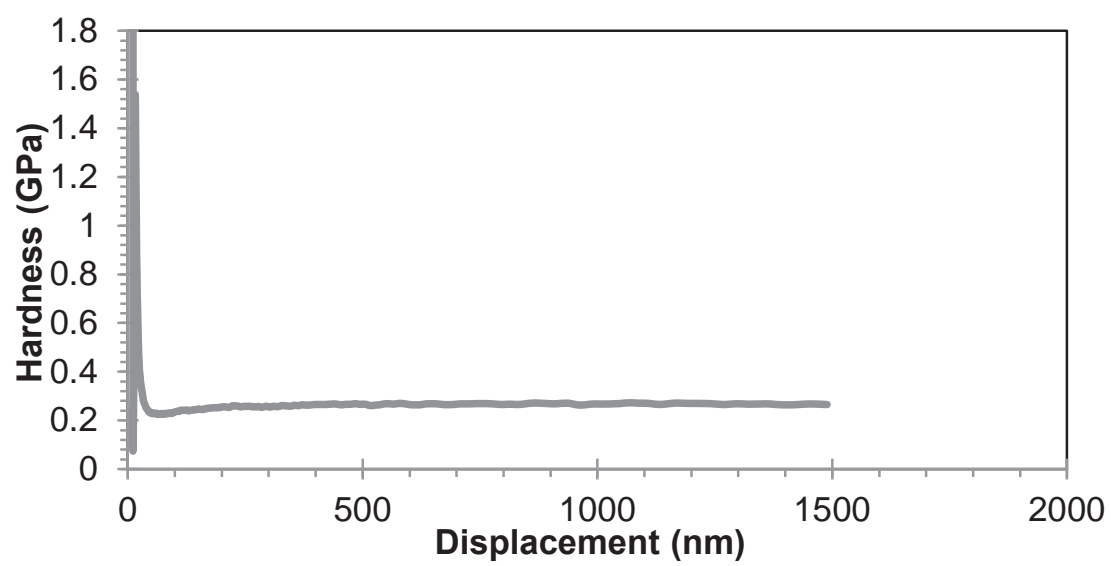

Figure B-57: Hardness vs. Displacement curve for 6 wt\% $x G n P^{\circledR}-C-300 / E p o x y$ Test 35 
Table B-20: Nanoindentation Averages Between 500 and $1500 \mathrm{~nm}$ Depth for $1 \mathrm{wt} \%$ TC307 in Epoxy

\begin{tabular}{|c|c|c|c|c|}
\hline Test & $\begin{array}{c}\text { Average } \\
\text { Modulus } \\
\text { (GPa) }\end{array}$ & $\begin{array}{l}\text { Modulus } \\
\text { Std Dev }\end{array}$ & $\begin{array}{c}\text { Average } \\
\text { Hardness } \\
\text { (GPa) }\end{array}$ & $\begin{array}{c}\text { Hardness } \\
\text { Std Dev }\end{array}$ \\
\hline 1 & 3.7239 & 0.0509 & 0.2735 & 0.0033 \\
\hline 2 & 3.6832 & 0.0568 & 0.2716 & 0.0034 \\
\hline 3 & 3.7131 & 0.0675 & 0.2736 & 0.0037 \\
\hline 4 & 3.6419 & 0.0525 & 0.2630 & 0.0018 \\
\hline 5 & 3.6929 & 0.0690 & 0.2724 & 0.0042 \\
\hline 6 & 3.6864 & 0.0532 & 0.2708 & 0.0028 \\
\hline 7 & 3.6632 & 0.0549 & 0.2721 & 0.0035 \\
\hline 8 & 3.7103 & 0.0671 & 0.2723 & 0.0039 \\
\hline 9 & 3.6564 & 0.0427 & 0.2668 & 0.0017 \\
\hline 10 & 3.7974 & 0.0775 & 0.2899 & 0.0109 \\
\hline 12 & 3.7056 & 0.0529 & 0.2744 & 0.0041 \\
\hline 13 & 3.7452 & 0.0615 & 0.2786 & 0.0059 \\
\hline 14 & 3.6778 & 0.0572 & 0.2731 & 0.0041 \\
\hline 15 & 3.7003 & 0.0524 & 0.2724 & 0.0039 \\
\hline 16 & 3.6993 & 0.0624 & 0.2745 & 0.0044 \\
\hline 17 & 3.6797 & 0.0617 & 0.2690 & 0.0030 \\
\hline 18 & 3.7769 & 0.0741 & 0.2827 & 0.0061 \\
\hline 19 & 3.6834 & 0.0561 & 0.2682 & 0.0021 \\
\hline 20 & 3.6972 & 0.0636 & 0.2759 & 0.0049 \\
\hline 21 & 3.7184 & 0.0569 & 0.2713 & 0.0025 \\
\hline 22 & 3.6674 & 0.0532 & 0.2683 & 0.0034 \\
\hline 23 & 3.7086 & 0.0493 & 0.2706 & 0.0034 \\
\hline 24 & 3.6875 & 0.0639 & 0.2712 & 0.0038 \\
\hline 25 & 3.7035 & 0.0519 & 0.2716 & 0.0028 \\
\hline 27 & 3.7174 & 0.0580 & 0.2749 & 0.0053 \\
\hline 28 & 3.7198 & 0.0691 & 0.2796 & 0.0068 \\
\hline 29 & 3.7267 & 0.0588 & 0.2756 & 0.0048 \\
\hline 30 & 3.6903 & 0.0577 & 0.2699 & 0.0051 \\
\hline 31 & 3.6979 & 0.0561 & 0.2707 & 0.0043 \\
\hline 33 & 3.6917 & 0.0595 & 0.2712 & 0.0044 \\
\hline 34 & 3.6816 & 0.0467 & 0.2704 & 0.0040 \\
\hline 35 & 3.7307 & 0.0840 & 0.2783 & 0.0057 \\
\hline 36 & 3.7006 & 0.0617 & 0.2687 & 0.0019 \\
\hline Mean & 3.70 & -- & 0.27 & -- \\
\hline Std Dev & 0.03 & -- & 0.00 & --- \\
\hline Count & 33 & 33 & 33 & 33 \\
\hline
\end{tabular}




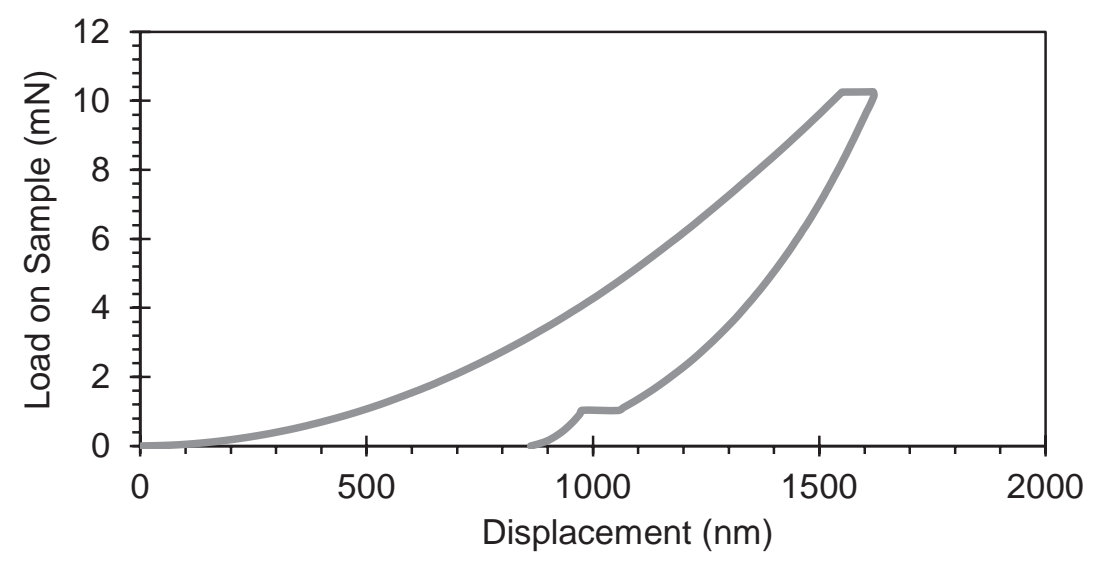

Figure B-58: Load vs. Displacement curve for 1 wt\% TC307 in Epoxy Test 36

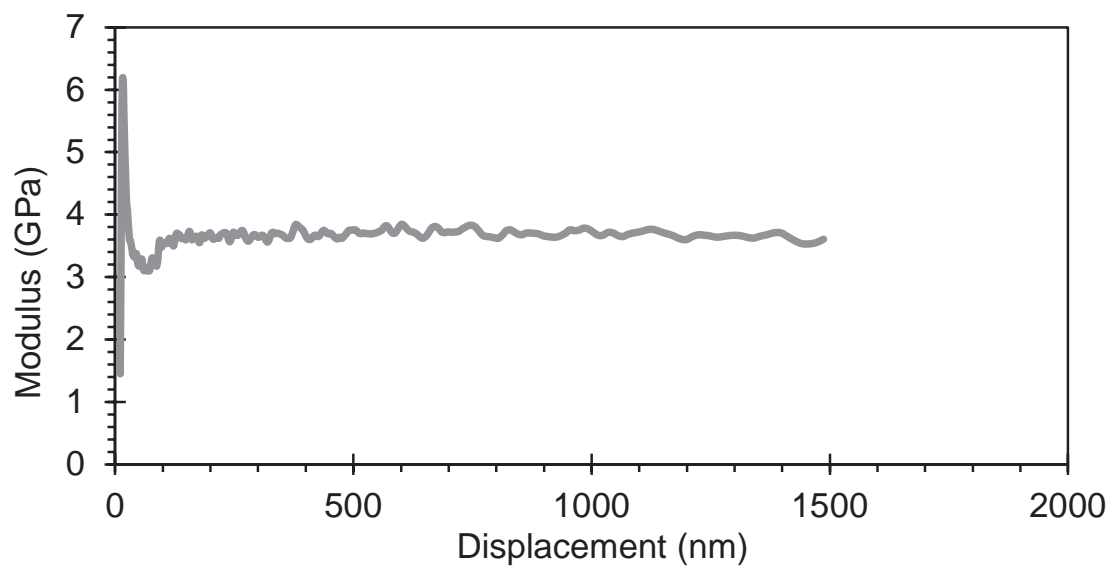

Figure B-59: Modulus vs. Displacement curve for 1 wt\% TC307 in Epoxy Test 36

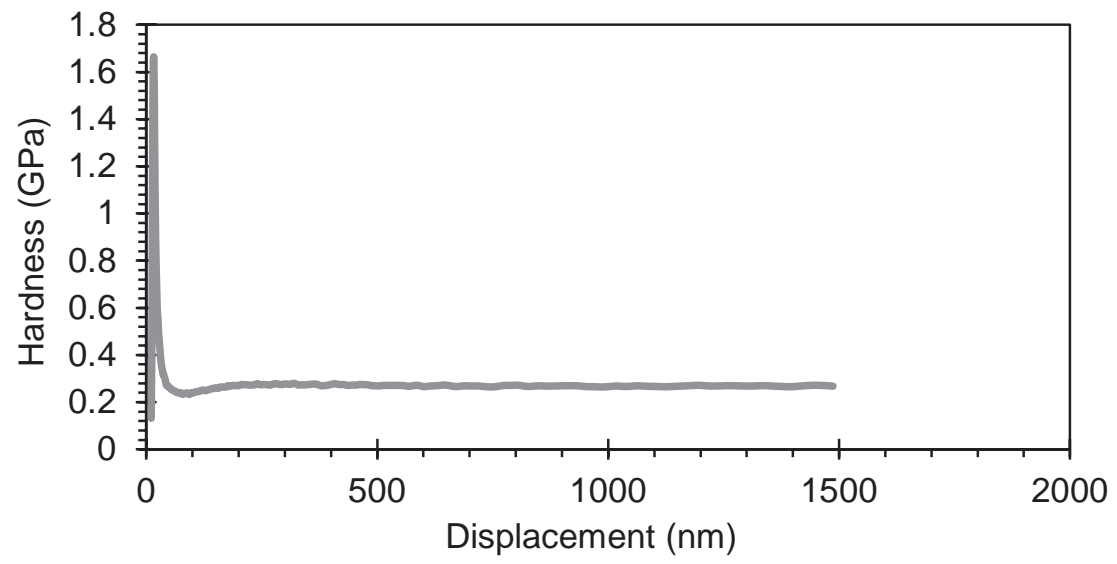

Figure B-60: Hardness vs. Displacement curve for 1 wt\% TC307 in Epoxy Test 36 
Table B-21: Nanoindentation Averages Between 500 and $1500 \mathrm{~nm}$ Depth for 2 wt\% TC307 in Epoxy

\begin{tabular}{|c|c|c|c|c|}
\hline Test & $\begin{array}{c}\text { Average } \\
\text { Modulus } \\
\text { (GPa) }\end{array}$ & $\begin{array}{l}\text { Modulus } \\
\text { Std Dev }\end{array}$ & $\begin{array}{c}\text { Average } \\
\text { Hardness } \\
\text { (GPa) }\end{array}$ & $\begin{array}{l}\text { Hardness } \\
\text { Std Dev }\end{array}$ \\
\hline 2 & 3.7162 & 0.0616 & 0.2711 & 0.0038 \\
\hline 3 & 3.6920 & 0.0648 & 0.2671 & 0.0031 \\
\hline 4 & 3.7231 & 0.0630 & 0.2692 & 0.0034 \\
\hline 5 & 3.7911 & 0.0748 & 0.2745 & 0.0052 \\
\hline 6 & 3.7813 & 0.0755 & 0.2811 & 0.0066 \\
\hline 7 & 3.5016 & 0.0676 & 0.2434 & 0.0051 \\
\hline 8 & 3.7366 & 0.0535 & 0.2753 & 0.0046 \\
\hline 9 & 3.7568 & 0.0496 & 0.2757 & 0.0047 \\
\hline 10 & 3.8141 & 0.0602 & 0.2755 & 0.0036 \\
\hline 11 & 3.7964 & 0.0635 & 0.2741 & 0.0036 \\
\hline 12 & 3.7364 & 0.0474 & 0.2739 & 0.0053 \\
\hline 13 & 3.7318 & 0.0549 & 0.2740 & 0.0035 \\
\hline 14 & 3.8237 & 0.0640 & 0.2827 & 0.0071 \\
\hline 15 & 3.7009 & 0.0575 & 0.2682 & 0.0022 \\
\hline 16 & 3.7977 & 0.0996 & 0.2767 & 0.0052 \\
\hline 18 & 3.7573 & 0.0594 & 0.2751 & 0.0039 \\
\hline 19 & 3.8009 & 0.0725 & 0.2817 & 0.0047 \\
\hline 20 & 3.7071 & 0.0497 & 0.2690 & 0.0033 \\
\hline 21 & 3.7839 & 0.0511 & 0.2748 & 0.0023 \\
\hline 22 & 3.7642 & 0.0603 & 0.2815 & 0.0062 \\
\hline 23 & 3.7547 & 0.0714 & 0.2759 & 0.0035 \\
\hline 24 & 3.7434 & 0.0562 & 0.2742 & 0.0027 \\
\hline 25 & 3.7724 & 0.0752 & 0.2750 & 0.0028 \\
\hline 26 & 3.6854 & 0.0576 & 0.2666 & 0.0028 \\
\hline 27 & 3.9585 & 0.0858 & 0.2977 & 0.0083 \\
\hline 28 & 3.7634 & 0.0579 & 0.2778 & 0.0032 \\
\hline 30 & 3.7080 & 0.0576 & 0.2697 & 0.0026 \\
\hline 31 & 3.7465 & 0.0562 & 0.2786 & 0.0027 \\
\hline 32 & 3.7323 & 0.0610 & 0.2754 & 0.0039 \\
\hline 33 & 3.5856 & 0.0787 & 0.2493 & 0.0043 \\
\hline 34 & 3.7392 & 0.0578 & 0.2748 & 0.0046 \\
\hline 35 & 3.7298 & 0.0545 & 0.2743 & 0.0046 \\
\hline 36 & 3.7157 & 0.0453 & 0.2697 & 0.0022 \\
\hline Mean & 3.74 & -- & 0.27 & -- \\
\hline Std Dev & 0.07 & -- & 0.01 & --- \\
\hline Count & 33 & 33 & 33 & 33 \\
\hline
\end{tabular}




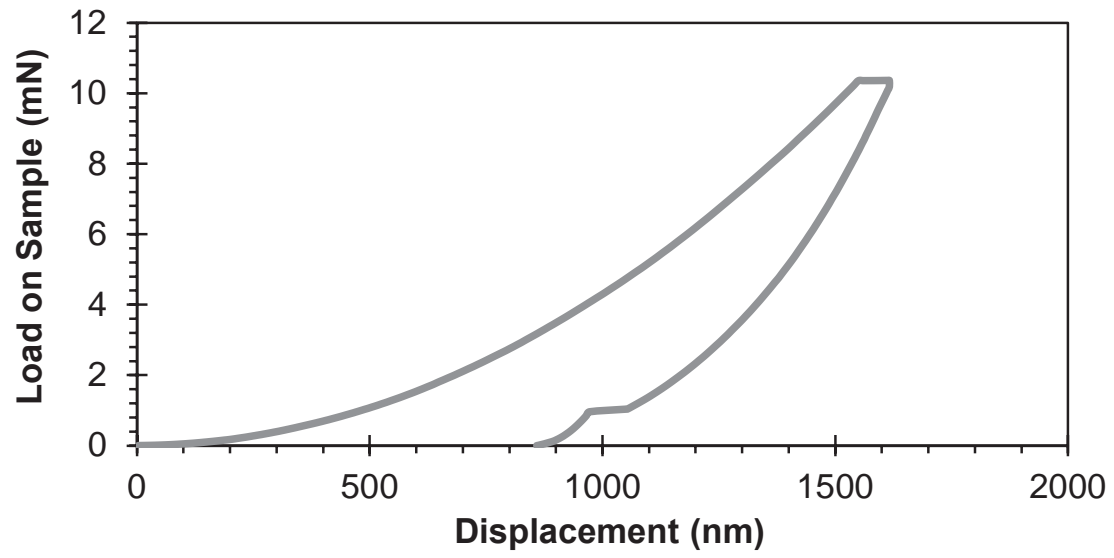

Figure B-61: Load vs. Displacement curve for 2 wt\% TC307 in Epoxy Test 36

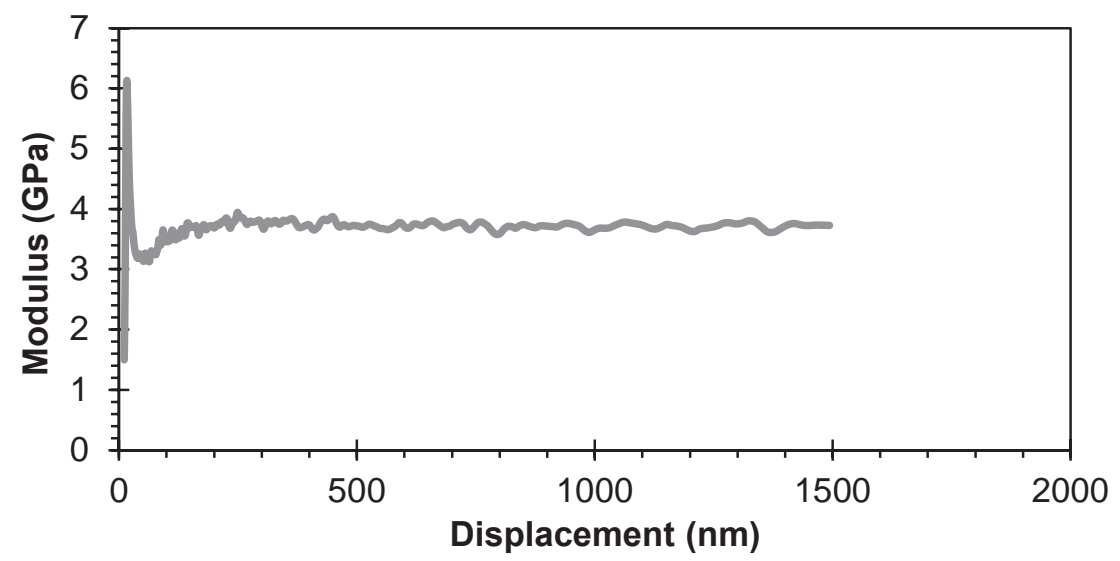

Figure B-62: Modulus vs. Displacement curve for 2 wt\% TC307 in Epoxy Test 36

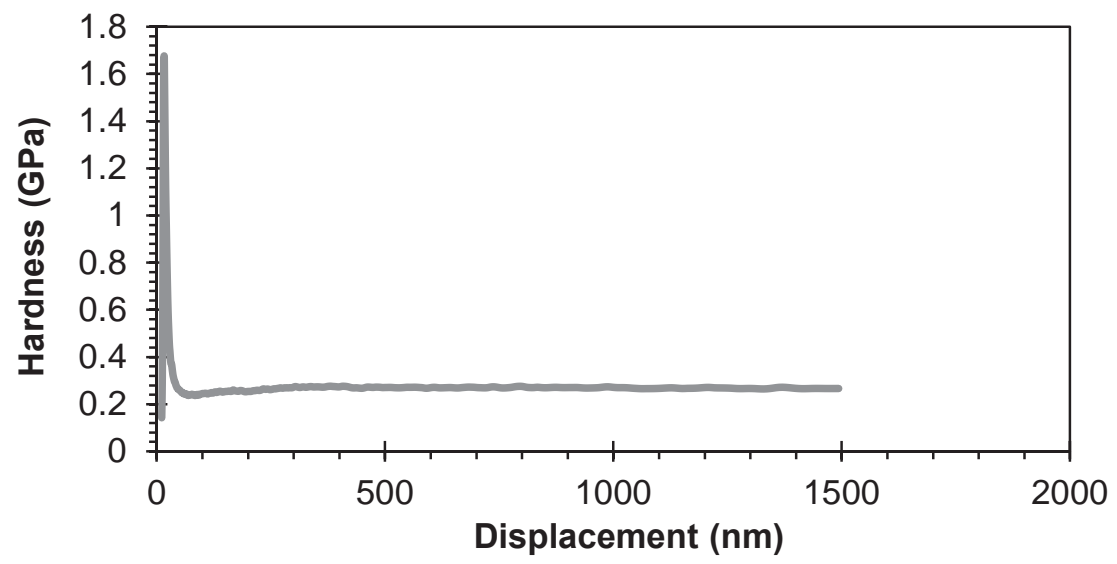

Figure B-63: Hardness vs. Displacement curve for 2 wt\% TC307 in Epoxy Test 36 
Table B-22: Nanoindentation Averages Between 500 and $1500 \mathrm{~nm}$ Depth for 3 wt\% TC307 in Epoxy

\begin{tabular}{|l|c|c|c|c|}
\hline Test & $\begin{array}{c}\text { Average } \\
\text { Modulus } \\
\text { (GPa) }\end{array}$ & $\begin{array}{c}\text { Modulus } \\
\text { Std Dev }\end{array}$ & $\begin{array}{c}\text { Average } \\
\text { Hardness } \\
\text { (GPa) }\end{array}$ & $\begin{array}{c}\text { Hardness } \\
\text { Std Dev }\end{array}$ \\
\hline 1 & 3.7613 & 0.0529 & 0.2699 & 0.0020 \\
\hline 2 & 3.8119 & 0.0463 & 0.2788 & 0.0036 \\
\hline 3 & 3.8351 & 0.0680 & 0.2805 & 0.0058 \\
\hline 4 & 3.7452 & 0.0533 & 0.2738 & 0.0023 \\
\hline 5 & 3.7956 & 0.0579 & 0.2759 & 0.0039 \\
\hline 6 & 3.7571 & 0.0594 & 0.2685 & 0.0027 \\
\hline 7 & 3.7592 & 0.0485 & 0.2717 & 0.0021 \\
\hline 8 & 3.8285 & 0.0572 & 0.2793 & 0.0060 \\
\hline 9 & 4.0016 & 0.1155 & 0.2968 & 0.0067 \\
\hline 10 & 3.8040 & 0.0511 & 0.2760 & 0.0051 \\
\hline 11 & 3.7877 & 0.0624 & 0.2743 & 0.0027 \\
\hline 12 & 3.9456 & 0.0711 & 0.2941 & 0.0074 \\
\hline 13 & 3.9006 & 0.0754 & 0.2819 & 0.0037 \\
\hline 14 & 3.9505 & 0.0653 & 0.2847 & 0.0030 \\
\hline 15 & 3.8163 & 0.0654 & 0.2801 & 0.0066 \\
\hline 16 & 3.7603 & 0.0594 & 0.2704 & 0.0028 \\
\hline 17 & 3.7614 & 0.0514 & 0.2734 & 0.0043 \\
\hline 18 & 3.7921 & 0.0623 & 0.2787 & 0.0041 \\
\hline 20 & 3.7293 & 0.0501 & 0.2717 & 0.0021 \\
\hline 21 & 3.7947 & 0.0550 & 0.2786 & 0.0051 \\
\hline 22 & 3.7835 & 0.0589 & 0.2745 & 0.0030 \\
\hline 23 & 3.8165 & 0.0608 & 0.2785 & 0.0043 \\
\hline 24 & 3.7838 & 0.0465 & 0.2755 & 0.0040 \\
\hline 26 & 3.7326 & 0.0606 & 0.2710 & 0.0031 \\
\hline 27 & 3.7919 & 0.0572 & 0.2745 & 0.0035 \\
\hline 28 & 3.8279 & 0.0580 & 0.2781 & 0.0024 \\
\hline 29 & 3.8835 & 0.0943 & 0.2851 & 0.0057 \\
\hline 30 & 3.7986 & 0.0681 & 0.2772 & 0.0072 \\
\hline 31 & 3.8531 & 0.0508 & 0.2801 & 0.0048 \\
\hline 32 & 3.8687 & 0.0615 & 0.2873 & 0.0068 \\
\hline 33 & 3.8019 & 0.0623 & 0.2769 & 0.0036 \\
\hline 34 & 3.7906 & 0.0633 & 0.2754 & 0.0047 \\
\hline 35 & 3.7765 & 0.0602 & 0.2732 & 0.0036 \\
\hline 36 & 3.7933 & 0.0647 & 0.2763 & 0.0027 \\
\hline Mean & 3.81 & --- & $\mathbf{0 . 2 8}$ & --- \\
\hline Std Dev & $\mathbf{0 . 0 6}$ & --- & $\mathbf{0 . 0 1}$ & --- \\
\hline Count & 34 & 34 & 34 & 34 \\
\hline
\end{tabular}




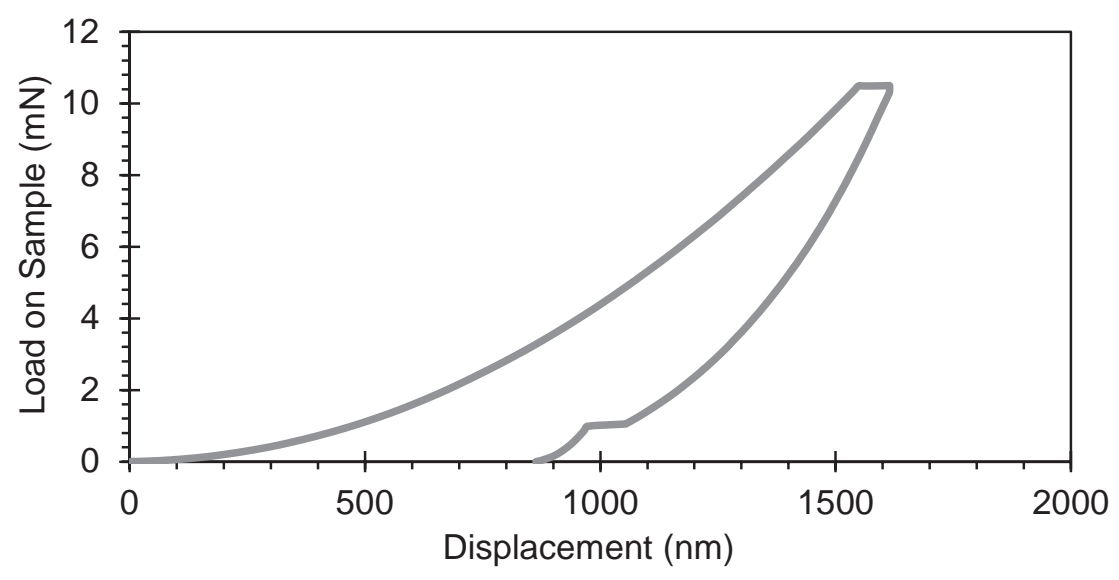

Figure B-64: Load vs. Displacement curve for 3 wt\% TC307 in Epoxy Test 36

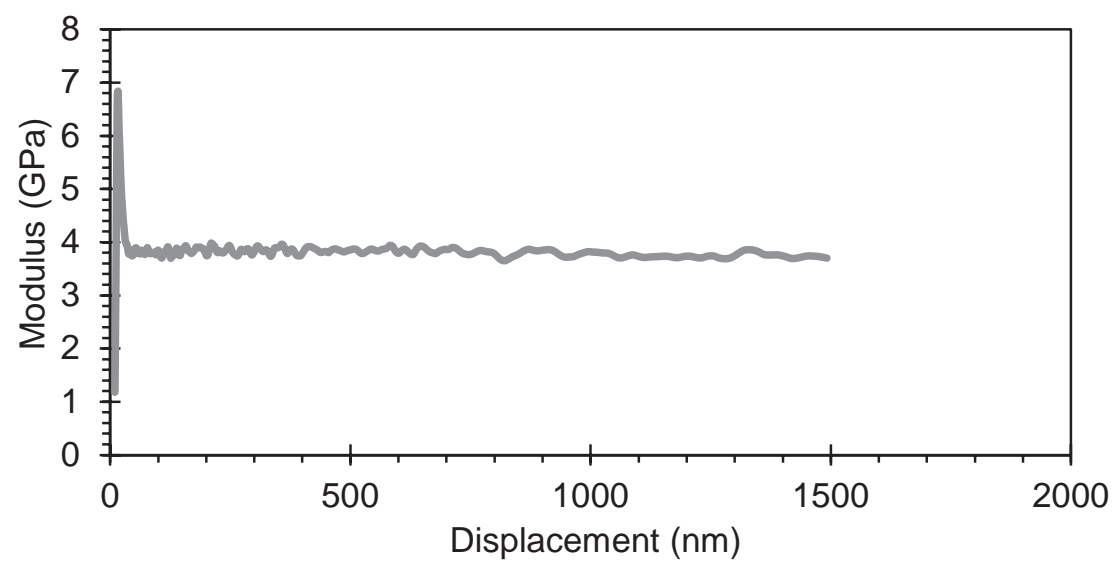

Figure B-65: Modulus vs. Displacement curve for 3 wt\% TC307 in Epoxy Test 36

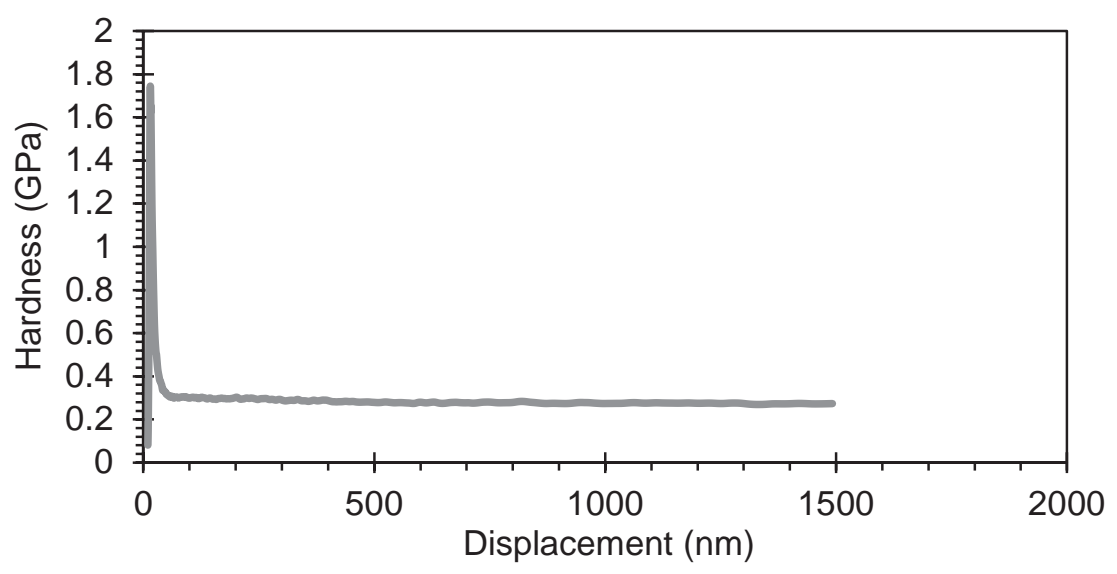

Figure B-66: Hardness vs. Displacement curve for 3 wt\% TC307 in Epoxy Test 36 
Table B-23: Nanoindentation Averages Between 500 and $1500 \mathrm{~nm}$ Depth for 4 wt\% TC307 in Epoxy

\begin{tabular}{|c|c|c|c|c|}
\hline Test & $\begin{array}{c}\text { Average } \\
\text { Modulus } \\
\text { (GPa) }\end{array}$ & $\begin{array}{l}\text { Modulus } \\
\text { Std Dev }\end{array}$ & $\begin{array}{c}\text { Average } \\
\text { Hardness } \\
\text { (GPa) }\end{array}$ & $\begin{array}{l}\text { Hardness } \\
\text { Std Dev }\end{array}$ \\
\hline 2 & 3.7709 & 0.0583 & 0.2725 & 0.0030 \\
\hline 3 & 3.8621 & 0.0742 & 0.2825 & 0.0052 \\
\hline 4 & 3.8513 & 0.0633 & 0.2805 & 0.0049 \\
\hline 5 & 3.7873 & 0.0666 & 0.2691 & 0.0057 \\
\hline 6 & 3.7898 & 0.0617 & 0.2795 & 0.0040 \\
\hline 7 & 3.7733 & 0.0541 & 0.2749 & 0.0025 \\
\hline 8 & 3.8160 & 0.0631 & 0.2736 & 0.0024 \\
\hline 9 & 3.8258 & 0.0656 & 0.2841 & 0.0047 \\
\hline 10 & 3.8387 & 0.0674 & 0.2833 & 0.0059 \\
\hline 11 & 3.7992 & 0.0604 & 0.2764 & 0.0024 \\
\hline 12 & 3.8163 & 0.0569 & 0.2732 & 0.0029 \\
\hline 13 & 3.8191 & 0.0744 & 0.2803 & 0.0069 \\
\hline 14 & 3.8472 & 0.0634 & 0.2836 & 0.0043 \\
\hline 16 & 3.7791 & 0.0537 & 0.2737 & 0.0036 \\
\hline 17 & 4.1407 & 0.2393 & 0.3171 & 0.0197 \\
\hline 18 & 3.8238 & 0.0582 & 0.2813 & 0.0031 \\
\hline 19 & 3.8016 & 0.0678 & 0.2687 & 0.0029 \\
\hline 20 & 4.0229 & 0.1110 & 0.3023 & 0.0078 \\
\hline 21 & 3.9048 & 0.0600 & 0.2773 & 0.0021 \\
\hline 22 & 3.8231 & 0.0544 & 0.2796 & 0.0044 \\
\hline 23 & 3.9114 & 0.0753 & 0.2901 & 0.0064 \\
\hline 24 & 3.7981 & 0.0595 & 0.2771 & 0.0048 \\
\hline 25 & 3.8550 & 0.0586 & 0.2825 & 0.0049 \\
\hline 26 & 3.8950 & 0.0648 & 0.2858 & 0.0054 \\
\hline 27 & 3.8688 & 0.0721 & 0.2846 & 0.0078 \\
\hline 28 & 3.8579 & 0.0642 & 0.2852 & 0.0082 \\
\hline 29 & 3.8456 & 0.0834 & 0.2865 & 0.0070 \\
\hline 30 & 3.8859 & 0.1090 & 0.2789 & 0.0041 \\
\hline 31 & 3.7992 & 0.0525 & 0.2788 & 0.0056 \\
\hline 32 & 3.8481 & 0.0611 & 0.2836 & 0.0050 \\
\hline 33 & 3.8129 & 0.0600 & 0.2767 & 0.0029 \\
\hline 34 & 3.8080 & 0.0562 & 0.2769 & 0.0033 \\
\hline 35 & 3.8226 & 0.0492 & 0.2829 & 0.0041 \\
\hline Mean & 3.85 & -- & 0.28 & -- \\
\hline Std Dev & 0.07 & -- & 0.01 & --- \\
\hline Count & 33 & 33 & 33 & 33 \\
\hline
\end{tabular}




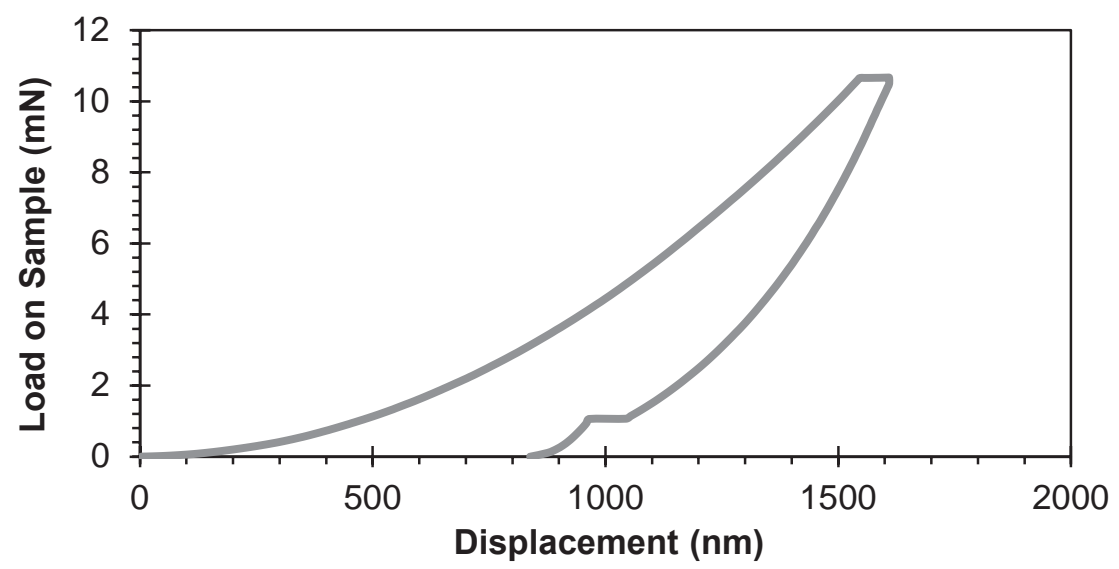

Figure B-67: Load vs. Displacement curve for 4 wt\% TC307 in Epoxy Test 36

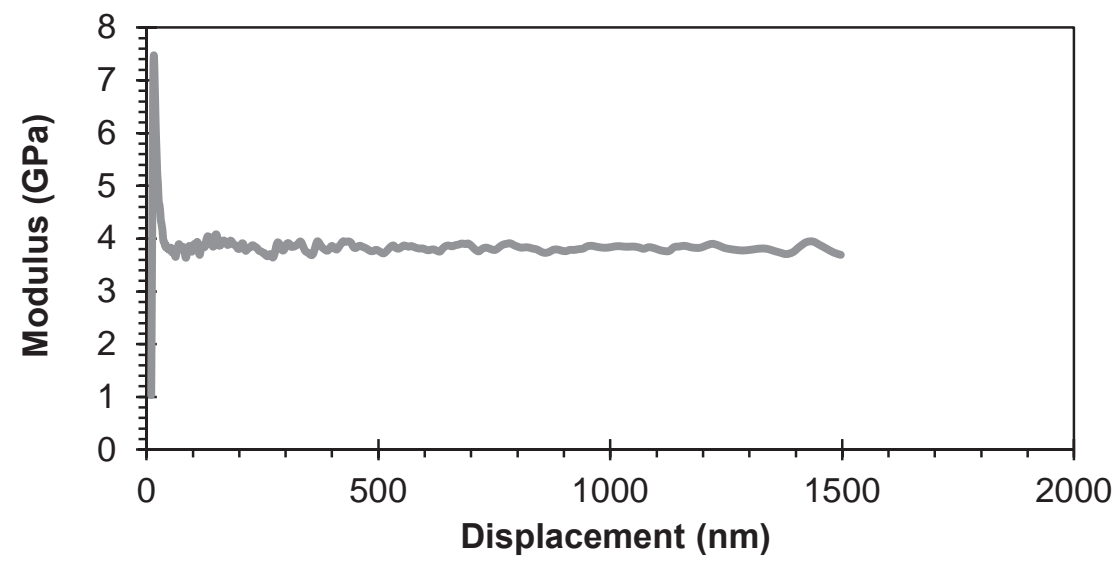

Figure B-68: Modulus vs. Displacement curve for 4 wt\% TC307 in Epoxy Test 36

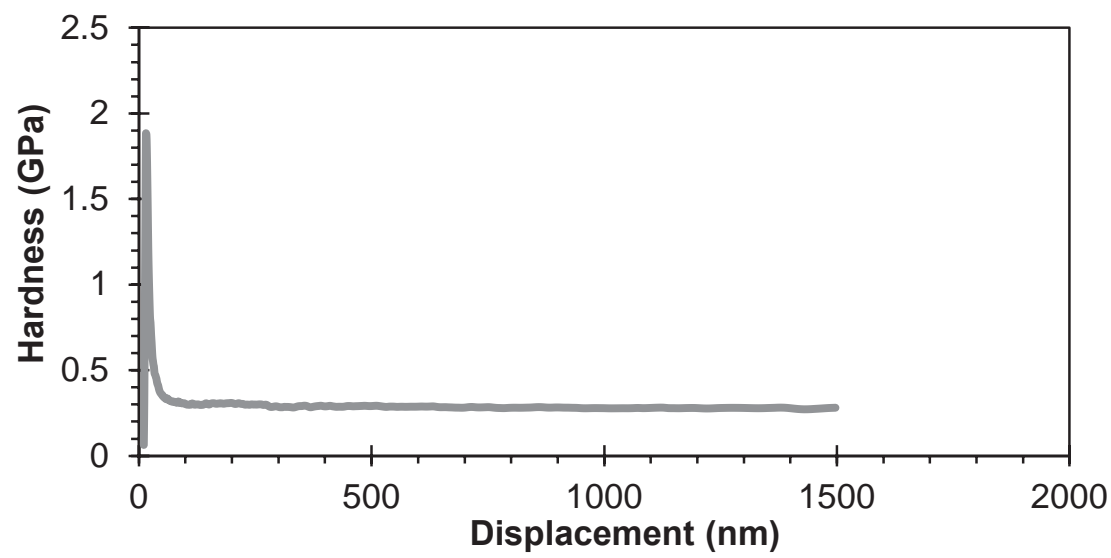

Figure B-69: Hardness vs. Displacement curve for 4 wt\% TC307 in Epoxy Test 36 


\section{Appdenix C: Electrical Resistivity Results}

Table C-1: ASTM D257 Thru-Plane Electrical Resistivity Results for Neat Epoxy

\begin{tabular}{|l|c|c|c|}
\hline \multicolumn{1}{|c|}{ Sample } & No. & $\begin{array}{c}\text { Applied } \\
\text { Voltage } \\
(\mathbf{V})\end{array}$ & $\begin{array}{c}\text { Volume Electrical } \\
\text { Resistivity }(\mathbf{\Omega}-\mathrm{cm})\end{array}$ \\
\hline A862-4-17-12 & 1 & 100 & $2.8174 \mathrm{E}+16$ \\
\hline A862-4-17-12 & 2 & 100 & $3.1263 \mathrm{E}+16$ \\
\hline A862-4-17-12 & 3 & 100 & $2.8694 \mathrm{E}+16$ \\
\hline A862-4-17-12 & 4 & 100 & $3.3570 \mathrm{E}+16$ \\
\hline A862-4-17-12 & 5 & 100 & $2.5305 \mathrm{E}+16$ \\
\hline A862-4-17-12 & 6 & 100 & $2.5670 \mathrm{E}+16$ \\
\hline Average & & $\mathbf{2 . 8 7 7 9 3 E + 1 6}$ \\
\hline Standard Deviation & & $\mathbf{3 . 2 0 0 9 9 E + 1 5}$ \\
\hline Count & & $\mathbf{6}$ \\
\hline
\end{tabular}

Table C-2: ASTM D257 Thru-Plane Electrical Resistivity Results for 1 wt\% xGnP ${ }^{\circledR}-M$ 15 in Epoxy

\begin{tabular}{|l|c|c|c|}
\hline Sample & No. & $\begin{array}{c}\text { Applied } \\
\text { Voltage } \\
(\mathrm{V})\end{array}$ & $\begin{array}{c}\text { Volume Electrical } \\
\text { Resistivity }(\Omega-c m)\end{array}$ \\
\hline A862-M15-1-5-10-12 & 1 & 100 & $6.9052 \mathrm{E}+15$ \\
\hline A862-M15-1-5-10-12 & 2 & 100 & $3.0085 \mathrm{E}+15$ \\
\hline A862-M15-1-5-10-12 & 3 & 100 & $4.754 \mathrm{E}+15$ \\
\hline A862-M15-1-5-10-12 & 4 & 100 & $7.5537 \mathrm{E}+15$ \\
\hline A862-M15-1-5-10-12 & 5 & 100 & $1.1287 \mathrm{E}+16$ \\
\hline A862-M15-1-5-10-12 & 6 & 100 & $7.1802 \mathrm{E}+15$ \\
\hline \multicolumn{3}{|c|}{ Average } & $6.78 \mathrm{E}+15$ \\
\hline Standard Deviation & & $\mathbf{2 . 8 1 E + 1 5}$ \\
\hline Count & & 6 \\
\hline
\end{tabular}


Table C-3: ASTM D4496 Two Point In-Plane Electrical Resistivity Results for 2 wt\% $x G n P^{\circledR}-M-15$ in Epoxy

\begin{tabular}{|l|c|c|c|}
\hline \multicolumn{1}{|c|}{ Sample } & No. & $\begin{array}{c}\text { Applied } \\
\text { Voltage } \\
\text { (V) }\end{array}$ & $\begin{array}{c}\text { Volume Electrical } \\
\text { Resistivity }(\mathbf{\Omega}-\mathbf{c m})\end{array}$ \\
\hline A862-M15-2-5-2-12 & 1 & 20 & $1.3453 \mathrm{E}+09$ \\
\hline A862-M15-2-5-2-12 & 3 & 20 & $2.9236 \mathrm{E}+09$ \\
\hline A862-M15-2-5-2-12 & 4 & 20 & $4.1336 \mathrm{E}+09$ \\
\hline A862-M15-2-5-2-12 & 6 & 20 & $2.4117 \mathrm{E}+09$ \\
\hline A862-M15-2-5-2-12 & 7 & 20 & $2.2122 \mathrm{E}+09$ \\
\hline Average & & $\mathbf{2 . 6 1 E + 0 9}$ \\
\hline Standard Deviation & & $\mathbf{1 . 0 3 E + 0 9}$ \\
\hline Count & & $\mathbf{5}$ \\
\hline
\end{tabular}

Table C-4: ASTM D4496 Two Point In-Plane Electrical Resistivity Results for 3 wt\% $x G n P^{\circledR}-M-15$ in Epoxy

\begin{tabular}{|l|c|c|c|}
\hline \multicolumn{1}{|c|}{ Sample } & No. & $\begin{array}{c}\text { Applied } \\
\text { Voltage } \\
\text { (V) }\end{array}$ & $\begin{array}{c}\text { Volume Electrical } \\
\text { Resistivity }(\mathbf{\Omega}-\mathbf{c m})\end{array}$ \\
\hline A862-M15-3-5-1-12 & 2 & 20 & $1.0894 \mathrm{E}+07$ \\
\hline A862-M15-3-5-1-12 & 3 & 20 & $1.5487 \mathrm{E}+08$ \\
\hline A862-M15-3-5-1-12 & 5 & 20 & $3.0470 \mathrm{E}+08$ \\
\hline A862-M15-3-5-1-12 & 6 & 20 & $1.7174 \mathrm{E}+07$ \\
\hline A862-M15-3-5-1-12 & 7 & 20 & $2.5402 \mathrm{E}+07$ \\
\hline Average & & $\mathbf{1 . 0 3 E + 0 8}$ \\
\hline Standard Deviation & & $\mathbf{1 . 2 8 E + 0 8}$ \\
\hline Count & & $\mathbf{5}$ \\
\hline
\end{tabular}


Table C-5: ASTM D4496 Two Point In-Plane Electrical Resistivity Results for 4 wt\% $x G n P^{\circledR}-M-15$ in Epoxy

\begin{tabular}{|l|c|c|c|}
\hline \multicolumn{1}{|c|}{ Sample } & No. & $\begin{array}{c}\text { Applied } \\
\text { Voltage } \\
\text { (V) }\end{array}$ & $\begin{array}{c}\text { Volume Electrical } \\
\text { Resistivity }(\mathbf{\Omega}-\mathbf{c m})\end{array}$ \\
\hline A862-M15-4-4-27-12 & 1 & 20 & $1.9267 \mathrm{E}+07$ \\
\hline A862-M15-4-4-27-12 & 2 & 20 & $1.3121 \mathrm{E}+06$ \\
\hline A862-M15-4-4-27-12 & 5 & 20 & $4.3010 \mathrm{E}+07$ \\
\hline A862-M15-4-4-27-12 & 6 & 20 & $1.5718 \mathrm{E}+07$ \\
\hline A862-M15-4-4-27-12 & 10 & 20 & $4.6043 \mathrm{E}+06$ \\
\hline Average & & $\mathbf{1 . 6 8 E + 0 7}$ \\
\hline Standard Deviation & & $\mathbf{1 . 6 5 E + 0 7}$ \\
\hline Count & & $\mathbf{5}$ \\
\hline
\end{tabular}

Table C-6: ASTM D4496 Two Point In-Plane Electrical Resistivity Results for 5 wt\% $x G n P^{\circledR}-M-15$ in Epoxy

\begin{tabular}{|l|c|c|c|}
\hline \multicolumn{1}{|c|}{ Sample } & No. & $\begin{array}{c}\text { Applied } \\
\text { Voltage } \\
(\mathbf{V})\end{array}$ & $\begin{array}{c}\text { Volume Electrical } \\
\text { Resistivity }(\mathbf{\Omega}-\mathbf{c m})\end{array}$ \\
\hline A862-M15-5-4-26-12 & 4 & 10 & $1.0092 \mathrm{E}+07$ \\
\hline A862-M15-5-4-26-12 & 7 & 10 & $1.5715 \mathrm{E}+07$ \\
\hline A862-M15-5-4-26-12 & 8 & 10 & $1.5547 \mathrm{E}+07$ \\
\hline A862-M15-5-4-26-12 & 9 & 10 & $1.8111 \mathrm{E}+05$ \\
\hline A862-M15-5-4-26-12 & 10 & 10 & $4.9666 \mathrm{E}+06$ \\
\hline Average & & $\mathbf{9 . 3 0 E + 0 6}$ \\
\hline Standard Deviation & & $\mathbf{6 . 7 6 E + 0 6}$ \\
\hline Count & & $\mathbf{5}$ \\
\hline
\end{tabular}


Table C-7: ASTM D4496 Two Point In-Plane Electrical Resistivity Results for 6 wt\% $x G n P^{\circledR}-M-15$ in Epoxy

\begin{tabular}{|l|c|c|c|}
\hline Sample & No. & $\begin{array}{c}\text { Applied } \\
\text { Voltage } \\
(\mathbf{V})\end{array}$ & $\begin{array}{c}\text { Volume Electrical } \\
\text { Resistivity }(\mathbf{\Omega}-\mathbf{c m})\end{array}$ \\
\hline A862-M15-6-4-19-12 & 1 & 20 & $4.0667 \mathrm{E}+06$ \\
\hline A862-M15-6-4-19-12 & 2 & 20 & $8.2678 \mathrm{E}+06$ \\
\hline A862-M15-6-4-19-12 & 3 & 20 & $3.3021 \mathrm{E}+06$ \\
\hline A862-M15-6-4-19-12 & 4 & 20 & $8.2510 \mathrm{E}+05$ \\
\hline A862-M15-6-4-19-12 & 7 & 20 & $7.5786 \mathrm{E}+06$ \\
\hline A862-M15-6-4-19-12 & 8 & 20 & $6.5565 \mathrm{E}+06$ \\
\hline \multicolumn{2}{|c|}{ Average } & $\mathbf{5 . 1 0 E + 0 6}$ \\
\hline Standard Deviation & $\mathbf{2 . 8 6 E + 0 6}$ \\
\hline Count & $\mathbf{6}$ \\
\hline
\end{tabular}

Table C-8: ASTM D257 Thru-Plane Electrical Resistivity Results for 1 wt\% $x G n P^{\circledR}-M-$ 5 in Epoxy

\begin{tabular}{|l|c|c|c|}
\hline \multicolumn{1}{|c|}{ Sample } & No. & $\begin{array}{c}\text { Applied } \\
\text { Voltage } \\
(\mathbf{V})\end{array}$ & $\begin{array}{c}\text { Volume Electrical } \\
\text { Resistivity }(\mathbf{\Omega}-\mathbf{c m})\end{array}$ \\
\hline A862-M5-1-9-28-12 & 1 & 100 & $2.9730 \mathrm{E}+15$ \\
\hline A862-M5-1-9-28-12 & 2 & 100 & $1.6002 \mathrm{E}+15$ \\
\hline A862-M5-1-9-28-12 & 3 & 100 & $1.7335 \mathrm{E}+15$ \\
\hline A862-M5-1-9-28-12 & 4 & 100 & $3.9281 \mathrm{E}+15$ \\
\hline A862-M5-1-9-28-12 & 5 & 100 & $3.3609 \mathrm{E}+15$ \\
\hline Average & & $\mathbf{2 . 7 2 E + 1 5}$ \\
\hline \multicolumn{2}{|l}{ Standard Deviation } & $\mathbf{1 . 0 2 E + 1 5}$ \\
\hline Count & & $\mathbf{5}$ \\
\hline
\end{tabular}


Table C-9: ASTM D257 Thru-Plane Electrical Resistivity Results for 2 wt\% xGnP ${ }^{\circledR}-M$ 5 in Epoxy

\begin{tabular}{|l|c|c|c|}
\hline \multicolumn{1}{|c|}{ Sample } & No. & $\begin{array}{c}\text { Applied } \\
\text { Voltage } \\
(\mathbf{V})\end{array}$ & $\begin{array}{c}\text { Volume Electrical } \\
\text { Resistivity }(\mathbf{\Omega}-\mathbf{c m})\end{array}$ \\
\hline A862-M5-2-8-28-12 & 1 & 100 & $6.7435 \mathrm{E}+15$ \\
\hline A862-M5-2-8-28-12 & 2 & 100 & $5.7857 \mathrm{E}+15$ \\
\hline A862-M5-2-8-28-12 & 3 & 100 & $2.8083 \mathrm{E}+15$ \\
\hline A862-M5-2-8-28-12 & 4 & 100 & $3.4980 \mathrm{E}+15$ \\
\hline Average & & $\mathbf{4 . 7 1 E + 1 5}$ \\
\hline Standard Deviation & & $\mathbf{1 . 8 6 E + 1 5}$ \\
\hline Count & & $\mathbf{4}$ \\
\hline
\end{tabular}

Table C-10: ASTM D257 Thru-Plane Electrical Resistivity Results for 3 wt\% xGnP ${ }^{\circledR}$ $M-5$ in Epoxy

\begin{tabular}{|l|c|c|c|}
\hline \multicolumn{1}{|c|}{ Sample } & No. & $\begin{array}{c}\text { Applied } \\
\text { Voltage } \\
(\mathbf{V})\end{array}$ & $\begin{array}{c}\text { Volume Electrical } \\
\text { Resistivity }(\Omega-c m)\end{array}$ \\
\hline A862-M5-3-10-3-12 & 1 & 100 & $1.0830 \mathrm{E}+15$ \\
\hline A862-M5-3-10-3-12 & 2 & 100 & $7.8721 \mathrm{E}+13$ \\
\hline A862-M5-3-10-3-12 & 3 & 100 & $1.6381 \mathrm{E}+15$ \\
\hline A862-M5-3-10-3-12 & 4 & 100 & $1.0940 \mathrm{E}+15$ \\
\hline Average & & $\mathbf{9 . 7 3 E + 1 4}$ \\
\hline Standard Deviation & & $\mathbf{6 . 5 0 E + 1 4}$ \\
\hline Count & & $\mathbf{4}$ \\
\hline
\end{tabular}


Table C-11: ASTM D4496 Two Point In-Plane Electrical Resistivity Results for 4 wt\% $x G n P^{\circledR}-M-5$ in Epoxy

\begin{tabular}{|l|c|c|c|}
\hline \multicolumn{1}{|c|}{ Sample } & No. & $\begin{array}{c}\text { Applied } \\
\text { Voltage } \\
\text { (V) }\end{array}$ & $\begin{array}{c}\text { Volume Electrical } \\
\text { Resistivity }(\boldsymbol{\Omega}-\mathbf{c m})\end{array}$ \\
\hline A862-M5-4-10-9-12 & 1 & 20 & $3.1778 \mathrm{E}+09$ \\
\hline A862-M5-4-10-9-12 & 2 & 20 & $6.0006 \mathrm{E}+09$ \\
\hline A862-M5-4-10-9-12 & 3 & 20 & $6.4053 \mathrm{E}+09$ \\
\hline A862-M5-4-10-9-12 & 4 & 20 & $1.2004 \mathrm{E}+08$ \\
\hline A862-M5-4-10-9-12 & 5 & 20 & $3.1864 \mathrm{E}+09$ \\
\hline Average & & $\mathbf{3 . 7 8 E + 0 9}$ \\
\hline Standard Deviation & & $\mathbf{2 . 5 5 E + 0 9}$ \\
\hline Count & & $\mathbf{5}$ \\
\hline
\end{tabular}

Table C-12: ASTM D4496 Two Point In-Plane Electrical Resistivity Results for 5 wt\% $x G n P^{\circledR}-M-5$ in Epoxy

\begin{tabular}{|l|c|c|c|}
\hline \multicolumn{1}{|c|}{ Sample } & No. & $\begin{array}{c}\text { Applied } \\
\text { Voltage } \\
(\mathbf{V})\end{array}$ & $\begin{array}{c}\text { Volume Electrical } \\
\text { Resistivity }(\mathbf{\Omega}-\mathbf{c m})\end{array}$ \\
\hline A862-M5-5-10-10-12 & 1 & 20 & $3.3884 \mathrm{E}+06$ \\
\hline A862-M5-5-10-10-12 & 2 & 20 & $5.0785 \mathrm{E}+06$ \\
\hline A862-M5-5-10-10-12 & 3 & 20 & $8.5093 \mathrm{E}+07$ \\
\hline A862-M5-5-10-10-12 & 4 & 20 & $2.0494 \mathrm{E}+09$ \\
\hline A862-M5-5-10-10-12 & 5 & 20 & $8.8652 \mathrm{E}+08$ \\
\hline Average & & $\mathbf{6 . 0 6 E + 0 8}$ \\
\hline Standard Deviation & & $\mathbf{8 . 8 8 E + 0 8}$ \\
\hline Count & & $\mathbf{5}$ \\
\hline
\end{tabular}


Table C-13: ASTM D4496 Two Point In-Plane Electrical Resistivity Results for 6 wt\% $x G n P^{\circledR}-M-5$ in Epoxy

\begin{tabular}{|l|c|c|c|}
\hline \multicolumn{1}{|c|}{ Sample } & No. & $\begin{array}{c}\text { Applied } \\
\text { Voltage } \\
\text { (V) }\end{array}$ & $\begin{array}{c}\text { Volume Electrical } \\
\text { Resistivity }(\mathbf{\Omega}-\mathbf{c m})\end{array}$ \\
\hline A862-M5-6-10-15-12 & 1 & 20 & $1.9957 \mathrm{E}+08$ \\
\hline A862-M5-6-10-15-12 & 2 & 20 & $1.6696 \mathrm{E}+06$ \\
\hline A862-M5-6-10-15-12 & 3 & 20 & $4.8455 \mathrm{E}+07$ \\
\hline A862-M5-6-10-15-12 & 4 & 20 & $7.9778 \mathrm{E}+08$ \\
\hline A862-M5-6-10-15-12 & 5 & 20 & $2.1487 \mathrm{E}+07$ \\
\hline Average & & $\mathbf{2 . 1 4 E + 0 8}$ \\
\hline Standard Deviation & & $\mathbf{3 . 3 6 E + 0 8}$ \\
\hline Count & & $\mathbf{5}$ \\
\hline
\end{tabular}

Table C-14: ASTM D257 Thru-Plane Electrical Resistivity Results for 1 wt\% xGnP ${ }^{\otimes_{-}}$ C-300 in Epoxy

\begin{tabular}{|l|c|c|c|}
\hline \multicolumn{1}{|c|}{ Sample } & No. & $\begin{array}{c}\text { Applied } \\
\text { Voltage } \\
\text { (V) }\end{array}$ & $\begin{array}{c}\text { Volume Electrical } \\
\text { Resistivity }(\mathbf{\Omega}-\mathbf{c m})\end{array}$ \\
\hline A862-C300-1-3-22-13 & 1 & 100 & $3.7129 \mathrm{E}+16$ \\
\hline A862-C300-1-3-22-13 & 2 & 100 & $4.4553 \mathrm{E}+16$ \\
\hline A862-C300-1-3-22-13 & 3 & 100 & $2.6489 \mathrm{E}+16$ \\
\hline A862-C300-1-3-22-13 & 4 & 100 & $2.2575 \mathrm{E}+15$ \\
\hline A862-C300-1-3-22-13 & 5 & 100 & $1.331 \mathrm{E}+16$ \\
\hline A862-C300-1-3-22-13 & 6 & 100 & $3.3842 \mathrm{E}+16$ \\
\hline Average & & $\mathbf{2 . 6 3 E + 1 6}$ \\
\hline Standard Deviation & & $\mathbf{1 . 5 8 E + 1 6}$ \\
\hline Count & & $\mathbf{6}$ \\
\hline
\end{tabular}


Table C-15: ASTM D257 Thru-Plane Electrical Resistivity Results for 2 wt\% xGnP ${ }^{\circledR}$ C-300 in Epoxy

\begin{tabular}{|l|c|c|c|}
\hline \multicolumn{1}{|c|}{ Sample } & No. & $\begin{array}{c}\text { Applied } \\
\text { Voltage } \\
(\mathbf{V})\end{array}$ & $\begin{array}{c}\text { Volume Electrical } \\
\text { Resistivity }(\mathbf{\Omega}-\mathbf{c m})\end{array}$ \\
\hline A862-C300-2-3-7-13 & 1 & 100 & $6.9635 \mathrm{E}+15$ \\
\hline A862-C300-2-3-7-13 & 2 & 100 & $2.6773 \mathrm{E}+15$ \\
\hline A862-C300-2-3-7-13 & 3 & 100 & $4.8582 \mathrm{E}+15$ \\
\hline A862-C300-2-3-7-13 & 4 & 100 & $5.8175 \mathrm{E}+15$ \\
\hline A862-C300-2-3-7-13 & 5 & 100 & $7.8765 \mathrm{E}+15$ \\
\hline A862-C300-2-3-7-13 & 6 & 100 & $2.2335 \mathrm{E}+15$ \\
\hline Average & & $\mathbf{5 . 0 7 E + 1 5}$ \\
\hline Standard Deviation & $\mathbf{2 . 2 7 E + 1 5}$ \\
\hline Count & $\mathbf{6}$ \\
\hline
\end{tabular}

Table C-16: ASTM D257 Thru-Plane Electrical Resistivity Results for 3 wt\% xGnP ${ }^{\circledR}$ C-300 in Epoxy

\begin{tabular}{|l|c|c|c|}
\hline \multicolumn{1}{|c|}{ Sample } & No. & $\begin{array}{c}\text { Applied } \\
\text { Voltage } \\
\text { (V) }\end{array}$ & $\begin{array}{c}\text { Volume Electrical } \\
\text { Resistivity }(\mathbf{\Omega}-\mathbf{c m})\end{array}$ \\
\hline A862-C300-3-3-5-13 & 2 & 100 & $5.6470 \mathrm{E}+15$ \\
\hline A862-C300-3-3-5-13 & 3 & 100 & $4.6057 \mathrm{E}+15$ \\
\hline A862-C300-3-3-5-13 & 4 & 100 & $4.1309 \mathrm{E}+15$ \\
\hline A862-C300-3-3-5-13 & 5 & 100 & $5.6662 \mathrm{E}+15$ \\
\hline A862-C300-3-3-5-13 & 6 & 100 & $9.2082 \mathrm{E}+15$ \\
\hline Average & & $\mathbf{5 . 8 5 E + 1 5}$ \\
\hline Standard Deviation & $\mathbf{1 . 9 9 E + 1 5}$ \\
\hline Count & $\mathbf{5}$ \\
\hline
\end{tabular}


Table C-17: ASTM D4496 Two Point In-Plane Electrical Resistivity Results for 4 wt\% $x G n P^{\circledR}-C-300$ in Epoxy

\begin{tabular}{|l|c|c|c|}
\hline \multicolumn{1}{|c|}{ Sample } & No. & $\begin{array}{c}\text { Applied } \\
\text { Voltage } \\
\text { (V) }\end{array}$ & $\begin{array}{c}\text { Volume Electrical } \\
\text { Resistivity }(\mathbf{\Omega}-\mathbf{c m})\end{array}$ \\
\hline A862-C300-4-7-15-13 & 1 & 20 & $4.1362 \mathrm{E}+08$ \\
\hline A862-C300-4-7-15-13 & 2 & 20 & $2.9932 \mathrm{E}+08$ \\
\hline A862-C300-4-7-15-13 & 3 & 20 & $2.7520 \mathrm{E}+08$ \\
\hline A862-C300-4-7-15-13 & 4 & 20 & $4.1075 \mathrm{E}+08$ \\
\hline A862-C300-4-7-15-13 & 5 & 20 & $3.4078 \mathrm{E}+08$ \\
\hline Average & & $\mathbf{3 . 4 8 E + 0 8}$ \\
\hline Standard Deviation & $\mathbf{6 . 3 2 E + 0 7}$ \\
\hline Count & $\mathbf{5}$ \\
\hline
\end{tabular}

Table C-18: ASTM D4496 Two Point In-Plane Electrical Resistivity Results for 5 wt\% $x G n P^{\circledR}-C-300$ in Epoxy

\begin{tabular}{|l|c|c|c|}
\hline \multicolumn{1}{|c|}{ Sample } & No. & $\begin{array}{c}\text { Applied } \\
\text { Voltage } \\
\text { (V) }\end{array}$ & $\begin{array}{c}\text { Volume Electrical } \\
\text { Resistivity }(\boldsymbol{\Omega}-\mathbf{c m})\end{array}$ \\
\hline A862-C300-5-4-1-13 & 1 & 20 & $3.8954 \mathrm{E}+08$ \\
\hline A862-C300-5-4-1-13 & 2 & 20 & $1.7501 \mathrm{E}+08$ \\
\hline A862-C300-5-4-1-13 & 3 & 20 & $2.8087 \mathrm{E}+08$ \\
\hline A862-C300-5-4-1-13 & 4 & 20 & $3.0243 \mathrm{E}+07$ \\
\hline A862-C300-5-4-1-13 & 5 & 20 & $1.1860 \mathrm{E}+08$ \\
\hline Average & & $\mathbf{1 . 9 9 E + 0 8}$ \\
\hline Standard Deviation & $\mathbf{1 . 4 0 E + 0 8}$ \\
\hline Count & $\mathbf{5}$ \\
\hline
\end{tabular}


Table C-19: ASTM D4496 Two Point In-Plane Electrical Resistivity Results for 6 wt\% $x G n P^{\circledR}-C-300$ in Epoxy

\begin{tabular}{|l|c|c|c|}
\hline \multicolumn{1}{|c|}{ Sample } & No. & $\begin{array}{c}\text { Applied } \\
\text { Voltage } \\
\text { (V) }\end{array}$ & $\begin{array}{c}\text { Volume Electrical } \\
\text { Resistivity }(\boldsymbol{\Omega}-\mathbf{c m})\end{array}$ \\
\hline A862-C300-6-4-4-13 & 1 & 20 & $1.5909 \mathrm{E}+08$ \\
\hline A862-C300-6-4-4-13 & 2 & 20 & $2.3288 \mathrm{E}+07$ \\
\hline A862-C300-6-4-4-13 & 3 & 20 & $4.6670 \mathrm{E}+06$ \\
\hline A862-C300-6-4-4-13 & 4 & 20 & $1.5175 \mathrm{E}+07$ \\
\hline A862-C300-6-4-4-13 & 5 & 20 & $1.5353 \mathrm{E}+07$ \\
\hline Average & & $\mathbf{4 . 3 5 E + 0 7}$ \\
\hline Standard Deviation & $\mathbf{6 . 4 9 E + 0 7}$ \\
\hline Count & $\mathbf{5}$ \\
\hline
\end{tabular}




\section{Appdenix D: DMA Results}

Table D-1: DMA Results for Neat Epoxy

\begin{tabular}{|c|c|c|c|c|}
\hline Sample & No. & $\begin{array}{c}\text { Storage } \\
\text { Modulus } \\
\text { Onset }\left({ }^{\circ} \mathbf{C}\right)\end{array}$ & $\begin{array}{c}\text { Loss } \\
\text { Modulus } \\
\text { Peak } \\
\left({ }^{\circ} \mathbf{C}\right)\end{array}$ & $\begin{array}{c}\text { Tan Delta } \\
\text { Peak } \\
\left({ }^{\circ} \mathbf{C}\right)\end{array}$ \\
\hline A862-3-6-13 & 1 & 139.15 & 149.40 & 155.29 \\
\hline A862-3-6-13 & 2 & 139.54 & 149.84 & 155.57 \\
\hline A862-3-6-13 & 3 & 139.76 & 149.76 & 155.48 \\
\hline A862-3-6-13 & 4 & 139.12 & 150.11 & 156.29 \\
\hline A862-3-6-13 & 5 & 138.49 & 149.61 & 155.79 \\
\hline A862-3-6-13 & 6 & 139.74 & 150.12 & 156.13 \\
\hline Average & & $\mathbf{1 3 9 . 3}$ & $\mathbf{1 4 9 . 8}$ & $\mathbf{1 5 5 . 8}$ \\
\hline Standard Deviation & & $\mathbf{0 . 5}$ & $\mathbf{0 . 3}$ & $\mathbf{0 . 4}$ \\
\hline Count & $\mathbf{6}$ & $\mathbf{6}$ & $\mathbf{6}$ \\
\hline
\end{tabular}

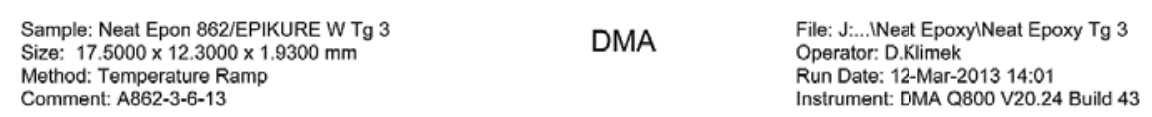

Instrument: DMA Q800 V20.24 Build 43

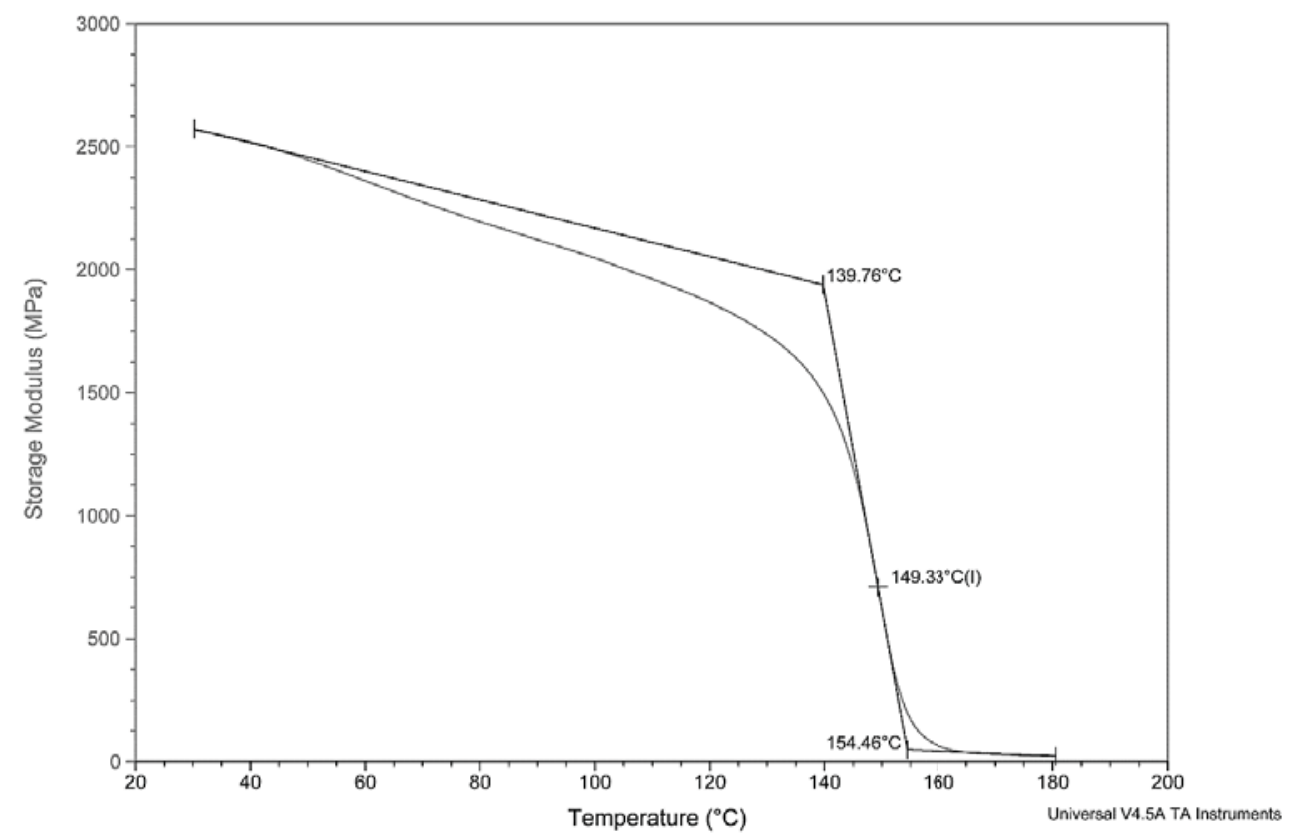

Figure D-1: Storage Modulus for Neat Epoxy Test 3 


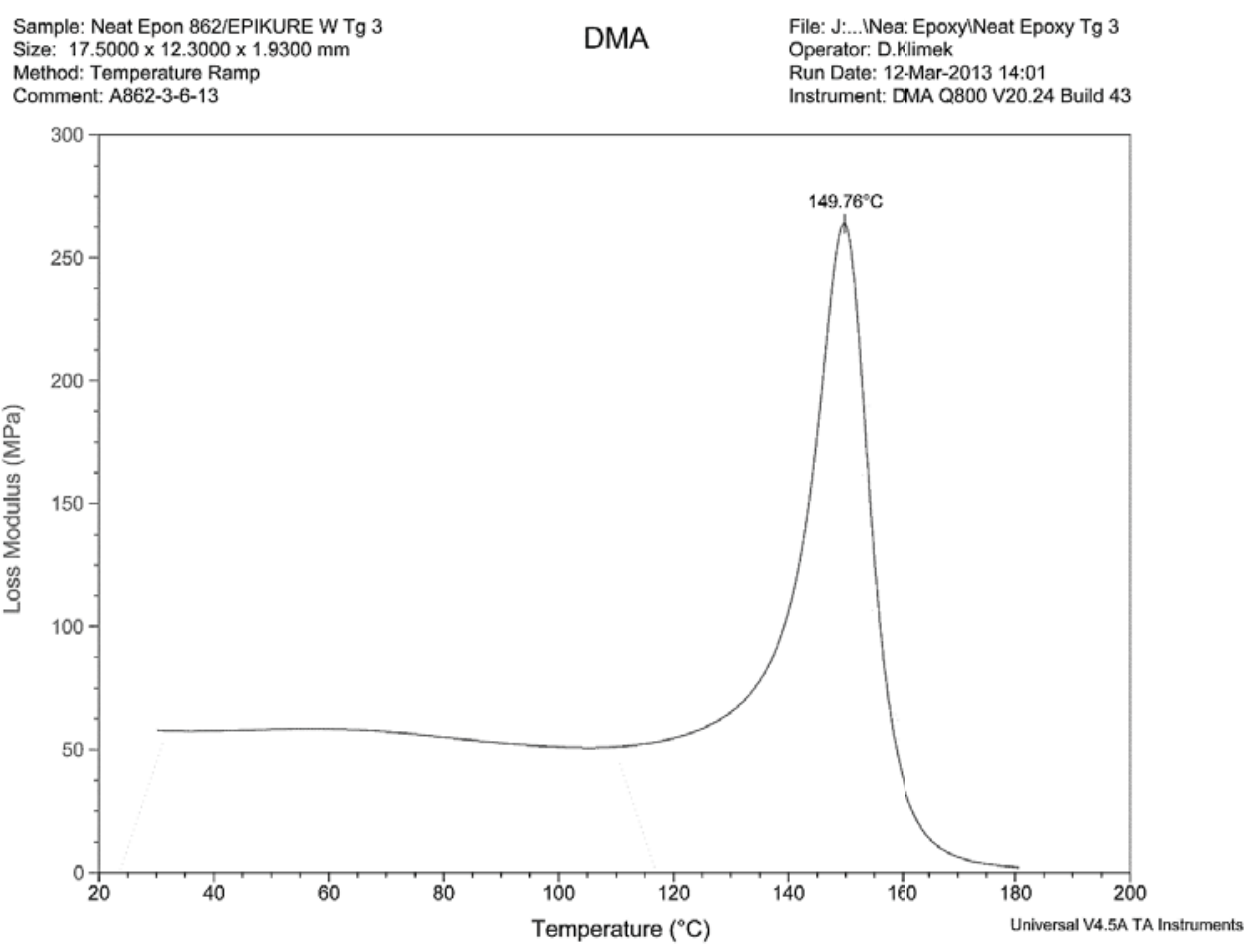

Figure D-2: Loss Modulus for Neat Epoxy Test 3

\begin{tabular}{|c|c|c|}
\hline $\begin{array}{l}\text { Sample: Neat Epon } 862 / \text { EPIKURE W Tg } 3 \\
\text { Size: } 17.5000 \times 12.3000 \times 1.9300 \mathrm{~mm} \\
\text { Method: Temperature Ramp } \\
\text { Comment: A862-3-6-13 }\end{array}$ & DMA & $\begin{array}{l}\text { File: J:...INeat EpoxylNeat Epoxy Tg } 3 \\
\text { Operator: D.Klimek } \\
\text { Run Date: } 12-\text { Mar-2013 14:01 } \\
\text { Instrument: DMA Q800 V20.24 Build } 43\end{array}$ \\
\hline
\end{tabular}

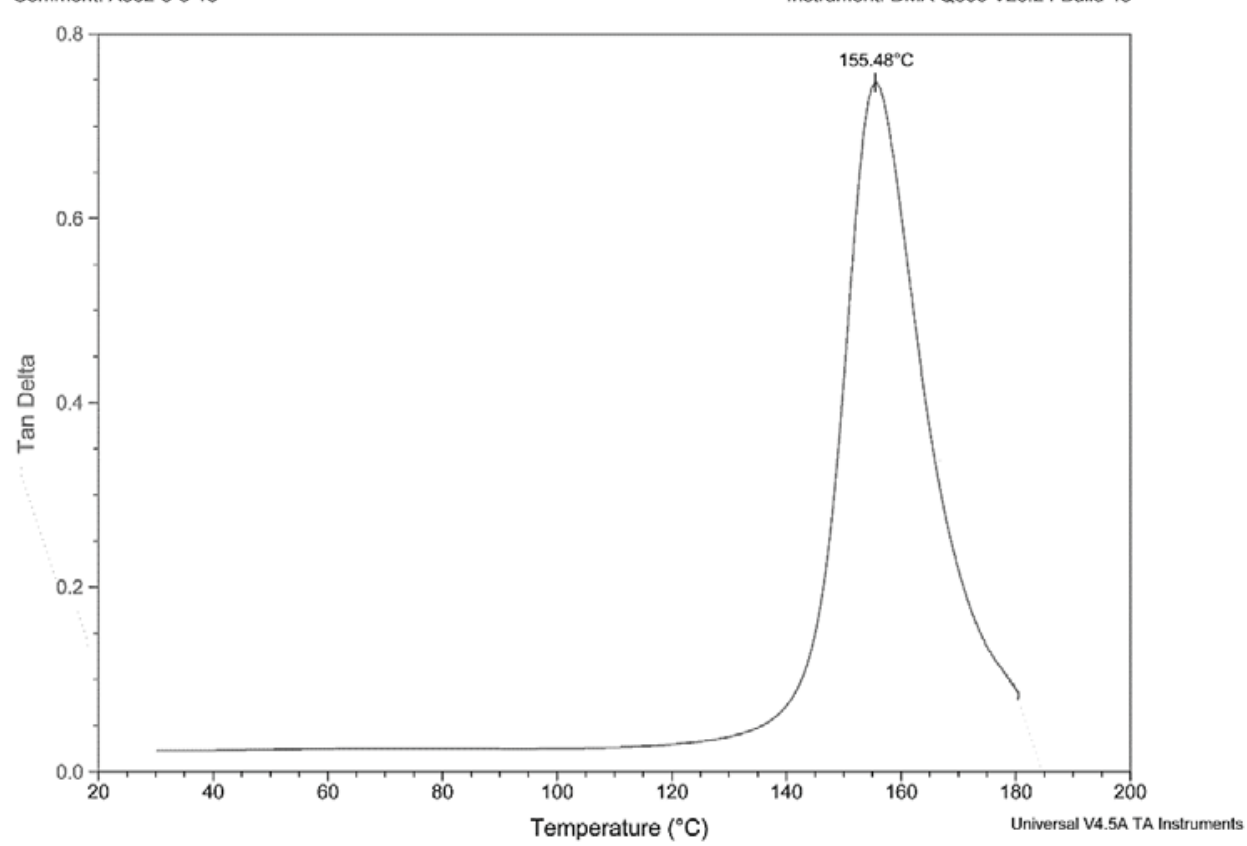

Figure D-3: Tan Delta for Neat Epoxy Test 3 
Table D-2: DMA Results for 1 wt\% $x G n P^{\circledR}-M-15$ in Epoxy

\begin{tabular}{|l|c|c|c|c|}
\hline \multicolumn{1}{|c|}{ Sample } & No. & $\begin{array}{c}\text { Storage } \\
\text { Modulus } \\
\text { Onset }\left({ }^{\circ} \mathbf{C}\right)\end{array}$ & $\begin{array}{c}\text { Loss } \\
\text { Modulus } \\
\text { Peak } \\
\left({ }^{\circ} \mathbf{C}\right)\end{array}$ & $\begin{array}{c}\text { Tan Delta } \\
\text { Peak } \\
\left({ }^{\circ} \mathbf{C}\right)\end{array}$ \\
\hline A862-M-151-3-7-12 & 1 & 130.96 & 144.97 & 152.89 \\
\hline A862-M-151-3-7-12 & 2 & 132.24 & 145.62 & 153.70 \\
\hline A862-M-151-3-7-12 & 3 & 132.55 & 145.42 & 153.83 \\
\hline Average & & $\mathbf{1 3 1 . 9}$ & $\mathbf{1 4 5 . 3}$ & $\mathbf{1 5 3 . 5}$ \\
\hline Standard Deviation & $\mathbf{0 . 8}$ & $\mathbf{0 . 3}$ & $\mathbf{0 . 5}$ \\
\hline Count & $\mathbf{3}$ & $\mathbf{3}$ & $\mathbf{3}$ \\
\hline
\end{tabular}

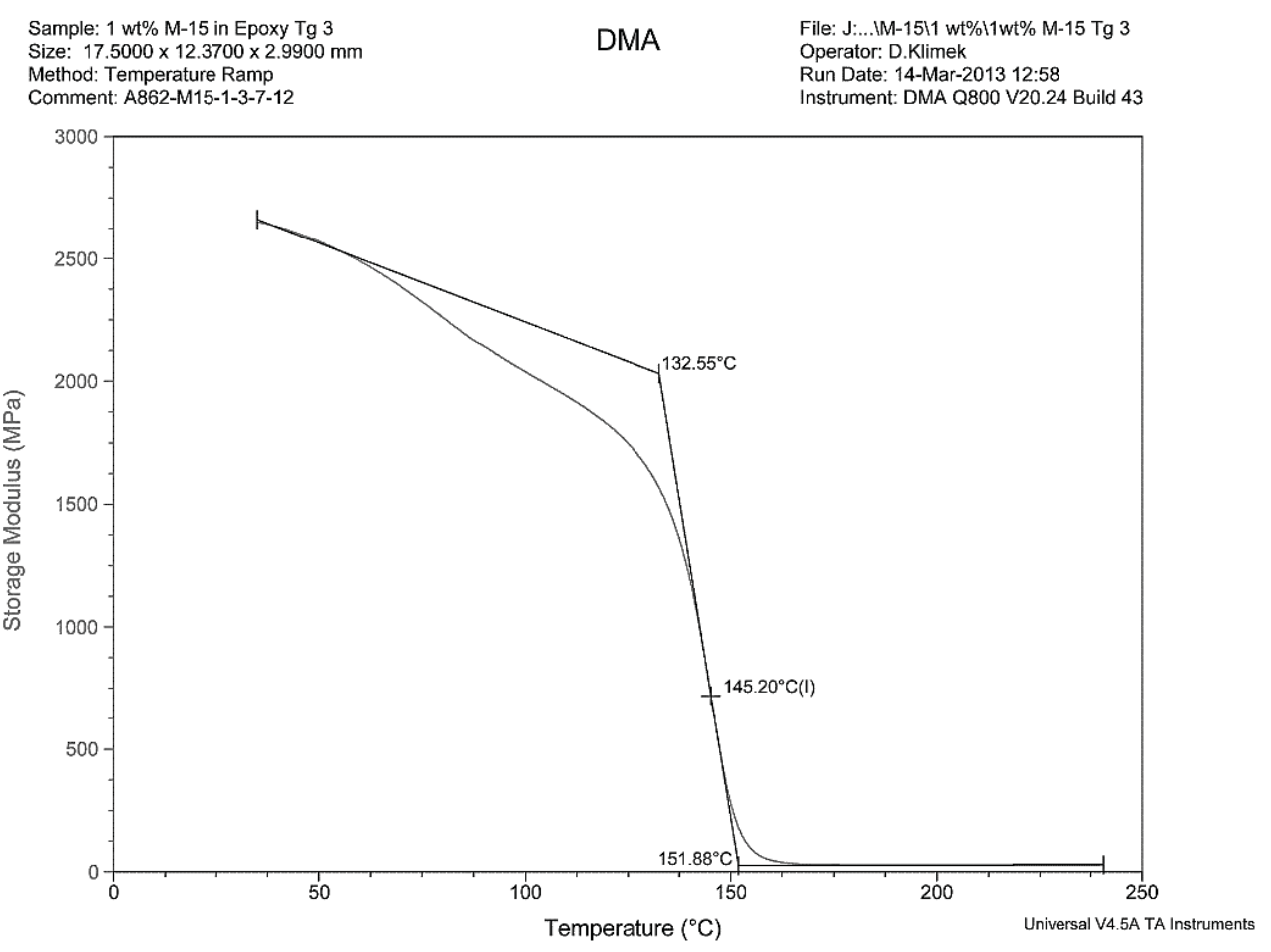

Figure D-4: Storage Modulus for $1 w t \% x G n P^{\circledR}-M-15$ in Epoxy Test 3 


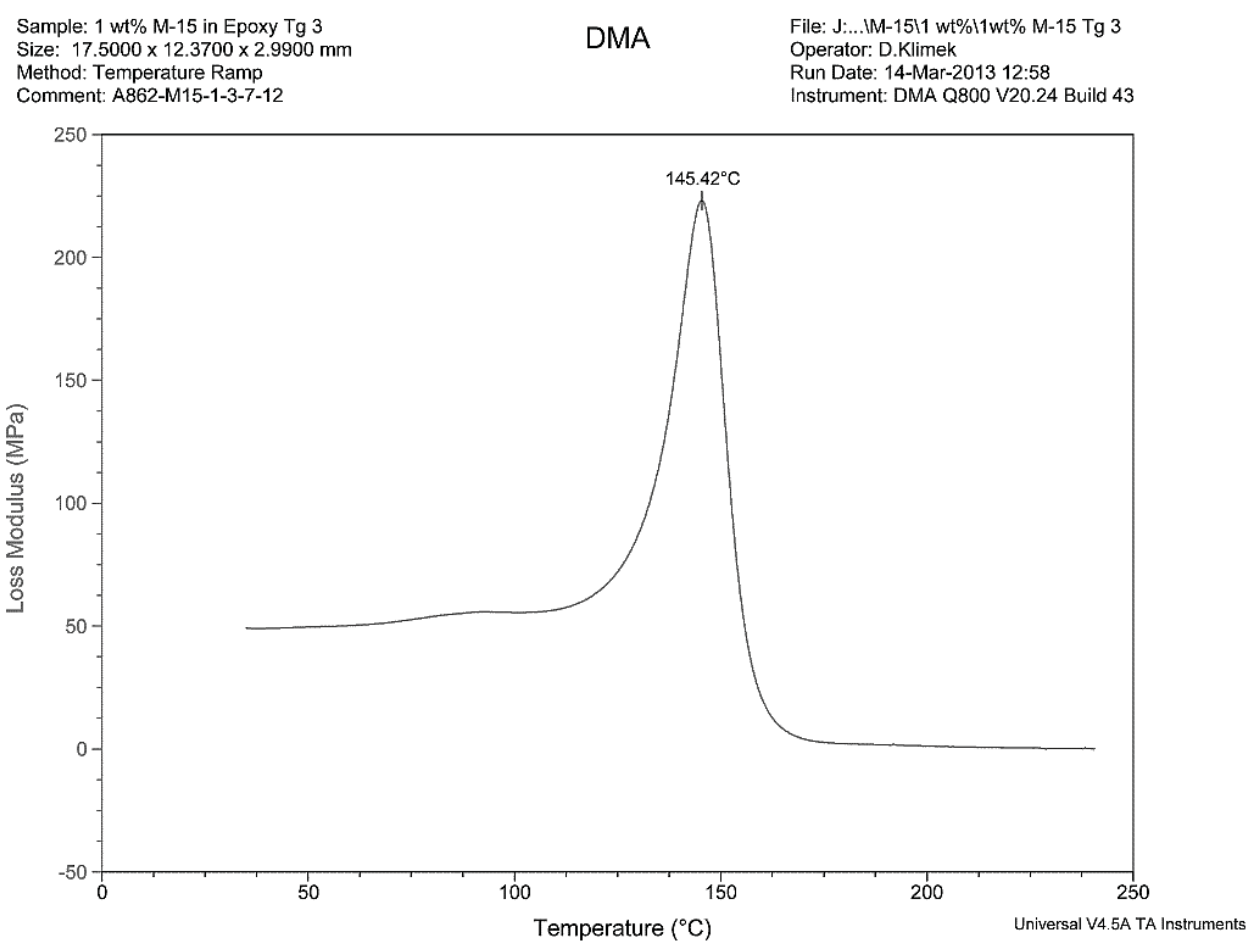

3

Figure D-5: Loss Modulus for 1 wt\% $x G n P^{\circledR}-M-15$ in Epoxy Test 3

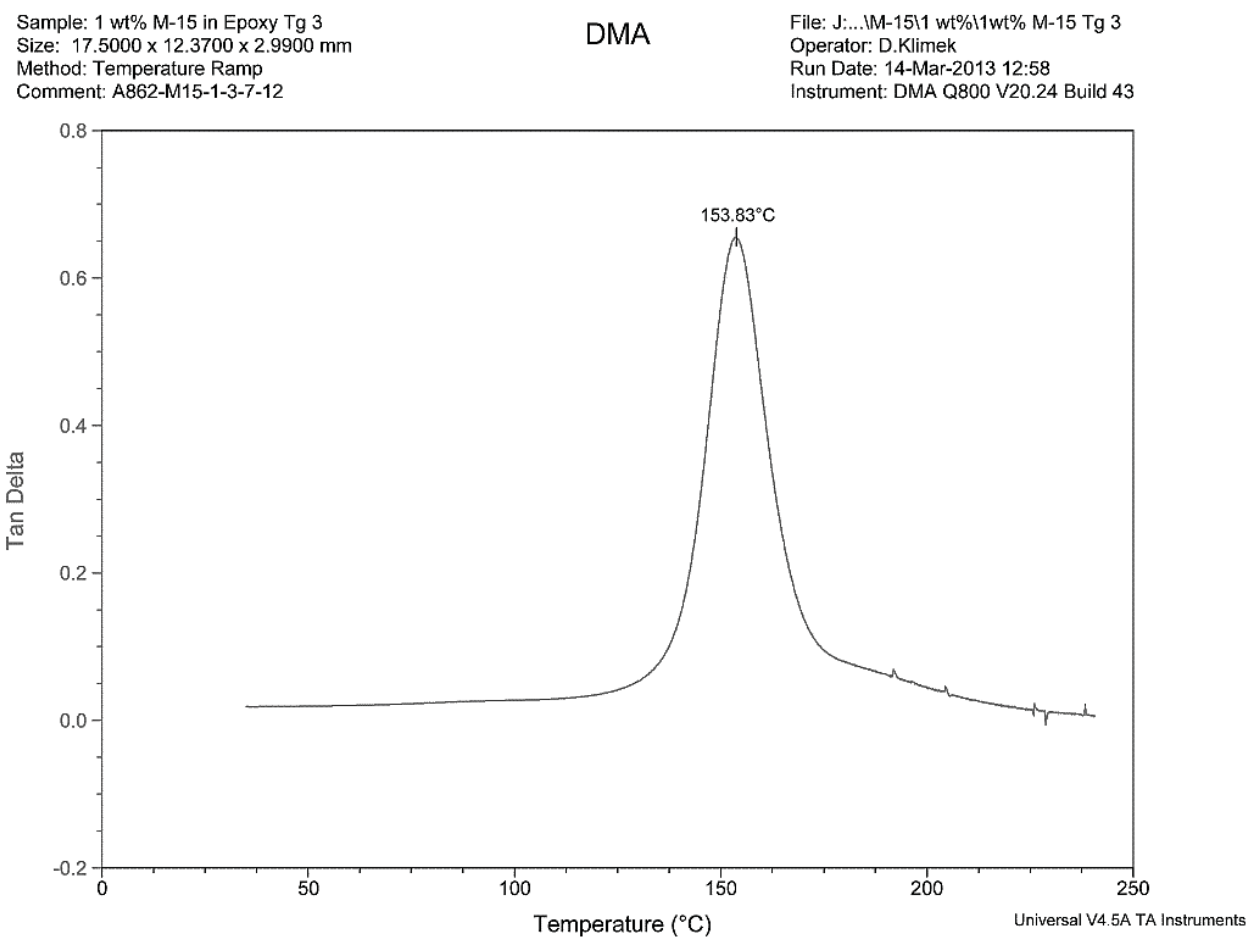

Figure D-6: Tan Delta for 1 wt\% xGnP ${ }^{\circledR}-M-15$ in Epoxy Test 3 
Table D-3: DMA Results for 2 wt\% $x G n P^{\circledR}-M-15$ in Epoxy

\begin{tabular}{|l|c|c|c|c|}
\hline \multicolumn{1}{|c|}{ Sample } & No. & $\begin{array}{c}\text { Storage } \\
\text { Modulus } \\
\text { Onset }\left({ }^{\circ} \mathbf{C}\right)\end{array}$ & $\begin{array}{c}\text { Loss } \\
\text { Modulus } \\
\text { Peak } \\
\left({ }^{\circ} \mathbf{C}\right)\end{array}$ & $\begin{array}{c}\text { Tan Delta } \\
\text { Peak } \\
\left({ }^{\circ} \mathbf{C}\right)\end{array}$ \\
\hline A862-M15-2-2-22-12 & 1 & 130.50 & 144.20 & 152.81 \\
\hline A862-M15-2-2-22-12 & 2 & 129.23 & 142.46 & 151.55 \\
\hline A862-M15-2-2-22-12 & 3 & 129.92 & 142.92 & 152.02 \\
\hline A862-M15-2-5-2-12 & 4 & 131.25 & 143.96 & 153.01 \\
\hline A862-M15-2-5-2-12 & 5 & 130.33 & 144.30 & 153.65 \\
\hline Average & & $\mathbf{1 3 0 . 2}$ & $\mathbf{1 4 3 . 6}$ & $\mathbf{1 5 2 . 6}$ \\
\hline Standard Deviation & $\mathbf{0 . 7}$ & $\mathbf{0 . 8}$ & $\mathbf{0 . 8}$ \\
\hline Count & $\mathbf{5}$ & $\mathbf{5}$ & $\mathbf{5}$ \\
\hline
\end{tabular}

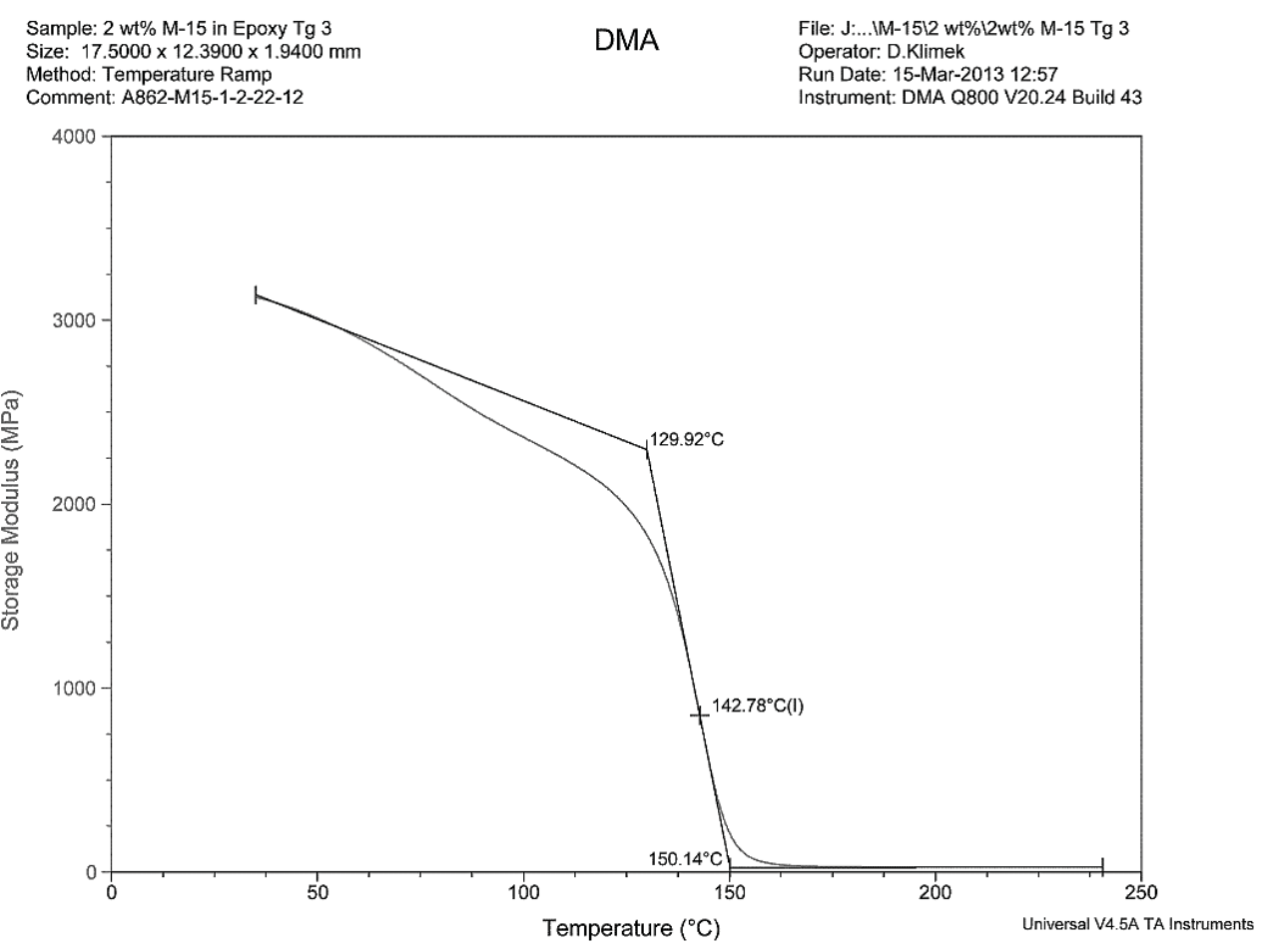

Figure D-7: Storage Modulus for 2 wt\% $x$ nnP $^{\circledR}-M-15$ in Epoxy Test 3 


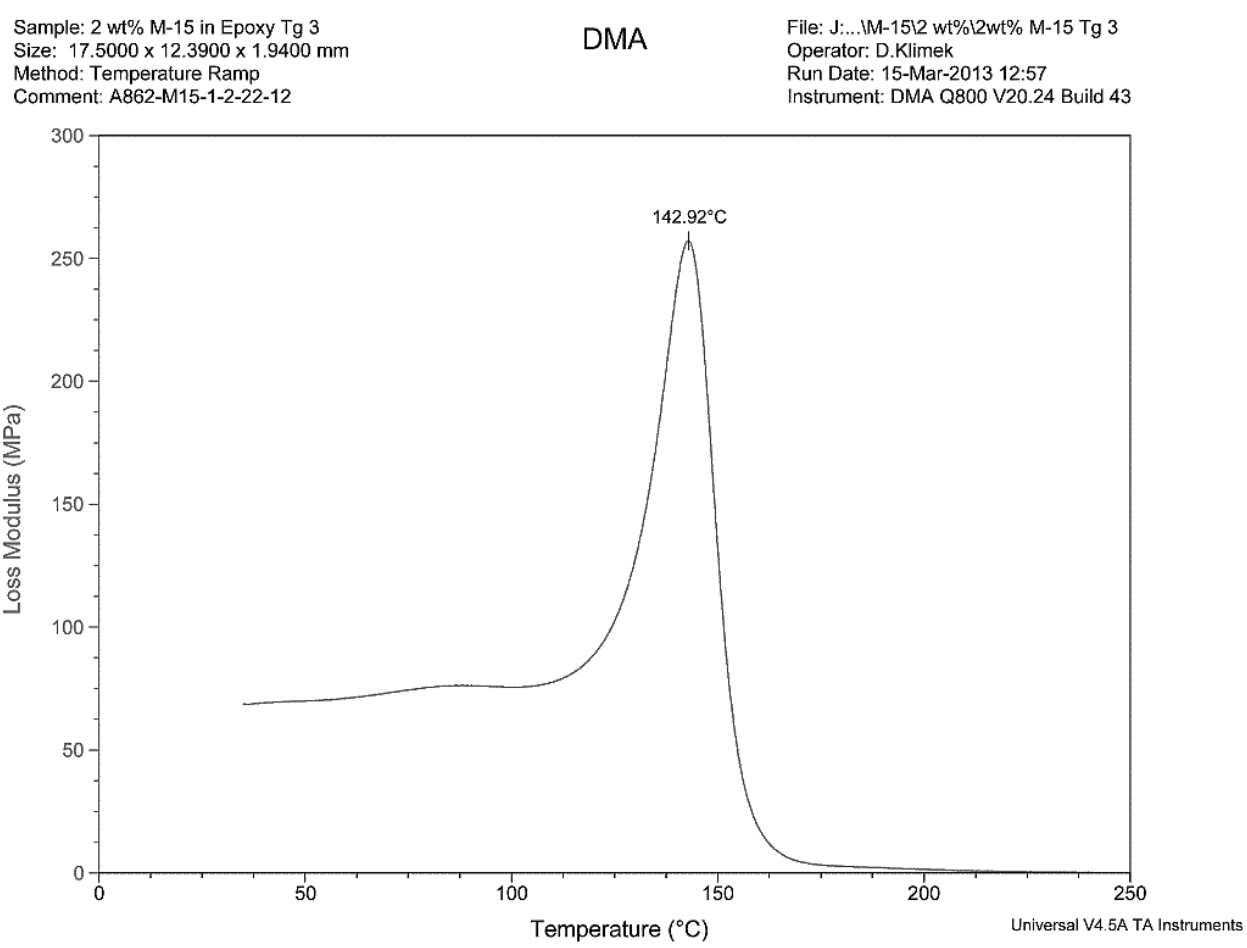

Figure D-8: Loss Modulus for 2 wt\% xGnP ${ }^{\circledR}-M-15$ in Epoxy Test 3

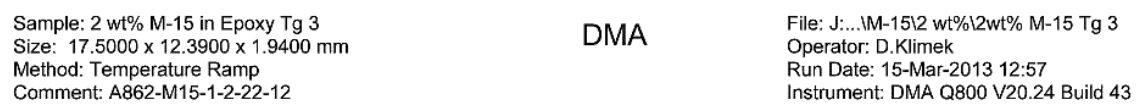

Comment: A862-M15-1-2-22-12

Operator: D.Klimek

Instrument: DMA Q800 V20.24 Build 43

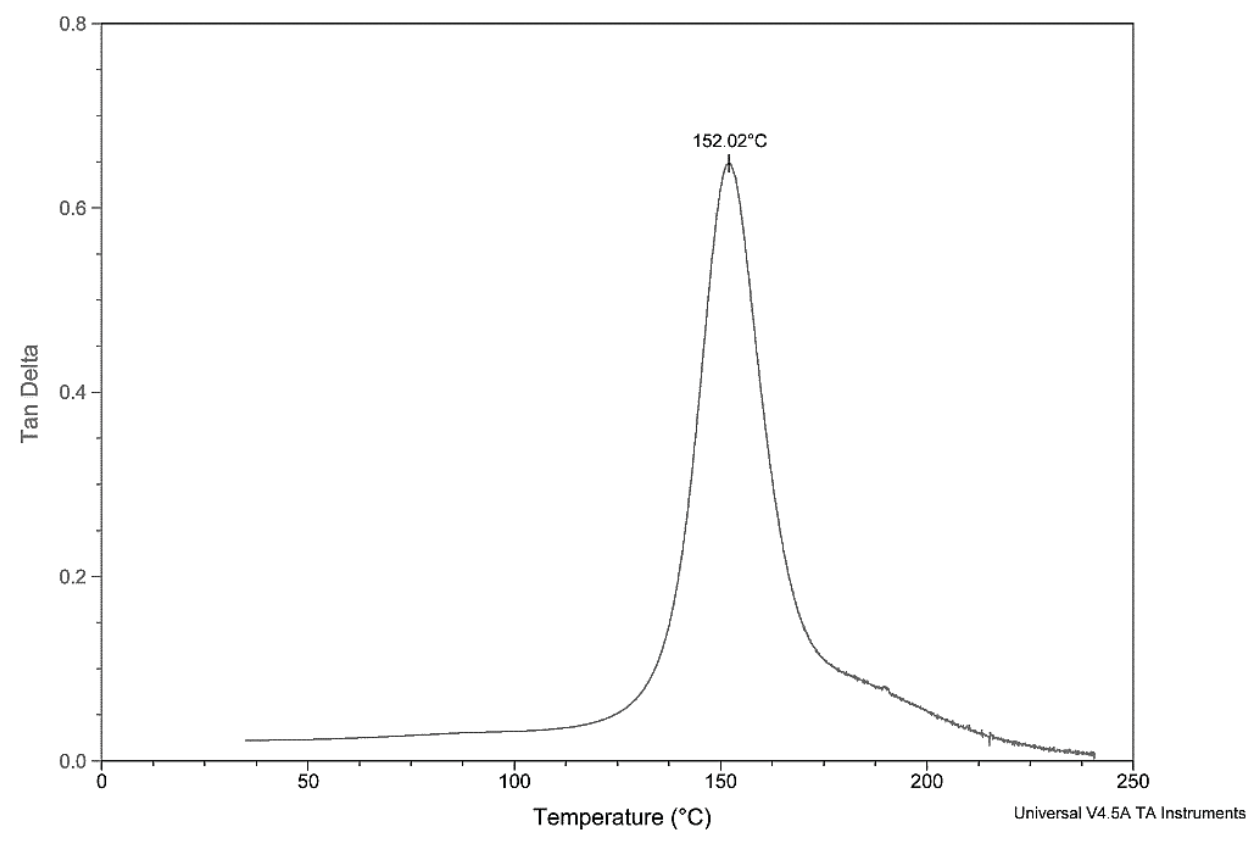

Figure D-9: Tan Delta for 2 wt\% $x G n P^{\circledR}-M-15$ in Epoxy Test 3 
Table D-4: DMA Results for 3 wt\% $x G n P^{\circledR}-M-15$ in Epoxy

\begin{tabular}{|l|c|c|c|c|}
\hline \multicolumn{1}{|c|}{ Sample } & No. & $\begin{array}{c}\text { Storage } \\
\text { Modulus } \\
\text { Onset }\left({ }^{\circ} \mathbf{C}\right)\end{array}$ & $\begin{array}{c}\text { Loss } \\
\text { Modulus } \\
\text { Peak } \\
\left({ }^{\circ} \mathbf{C}\right)\end{array}$ & $\begin{array}{c}\text { Tan Delta } \\
\text { Peak } \\
\left({ }^{\circ} \mathbf{C}\right)\end{array}$ \\
\hline A862-M15-3-3-14-12 & 1 & 130.59 & 143.70 & 150.83 \\
\hline A862-M15-3-3-14-12 & 2 & 129.92 & 142.74 & 150.22 \\
\hline A862-M15-3-3-14-12 & 3 & 130.82 & 142.77 & 150.26 \\
\hline Average & & $\mathbf{1 3 0 . 4}$ & $\mathbf{1 4 3 . 1}$ & $\mathbf{1 5 0 . 4}$ \\
\hline Standard Deviation & $\mathbf{0 . 5}$ & $\mathbf{0 . 5}$ & $\mathbf{0 . 3}$ \\
\hline Count & $\mathbf{3}$ & $\mathbf{3}$ & $\mathbf{3}$ \\
\hline
\end{tabular}

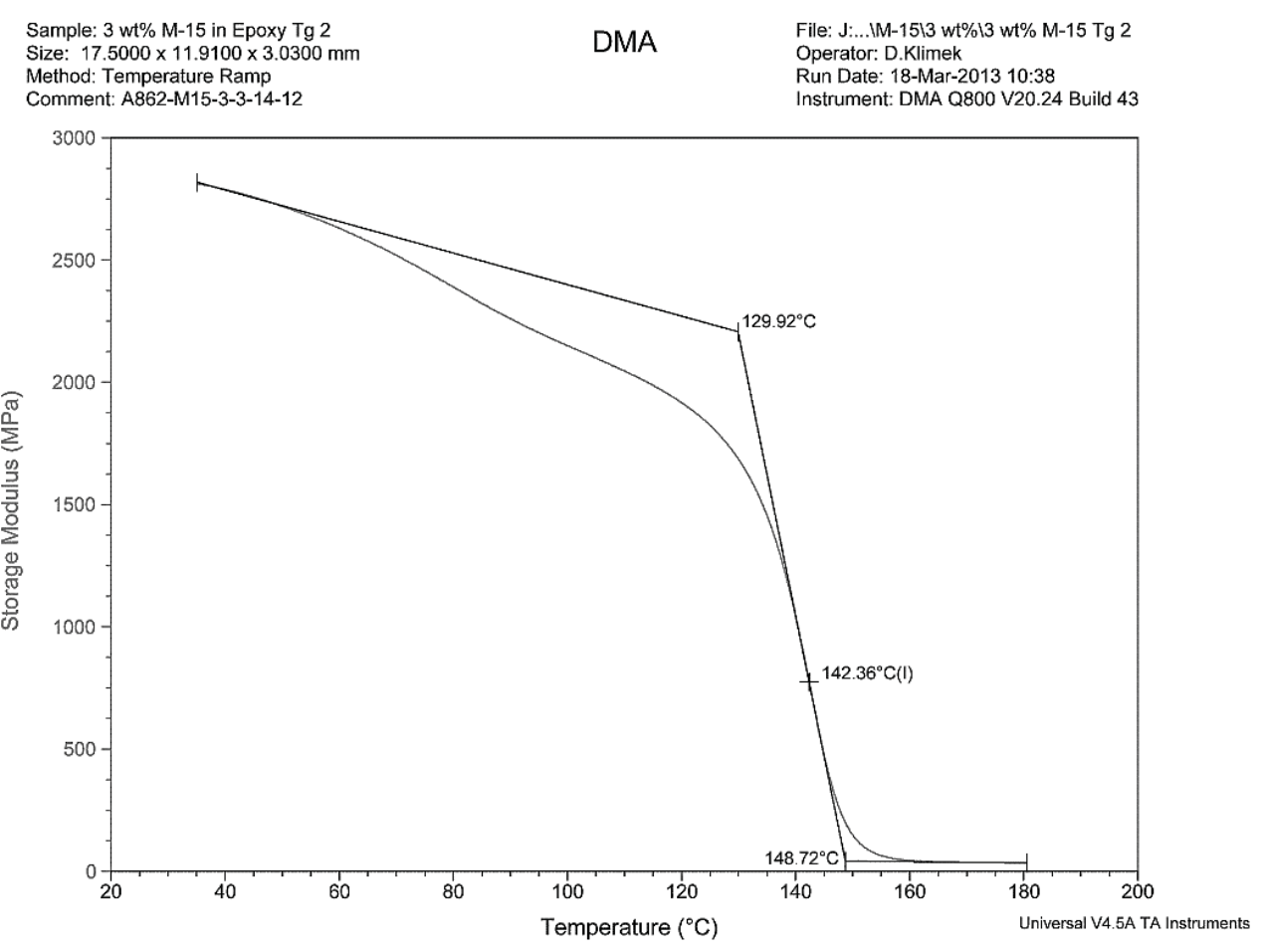

Figure D-10: Storage Modulus for 3 wt\% $x G n P^{\circledR}-M-15$ in Epoxy Test 2 


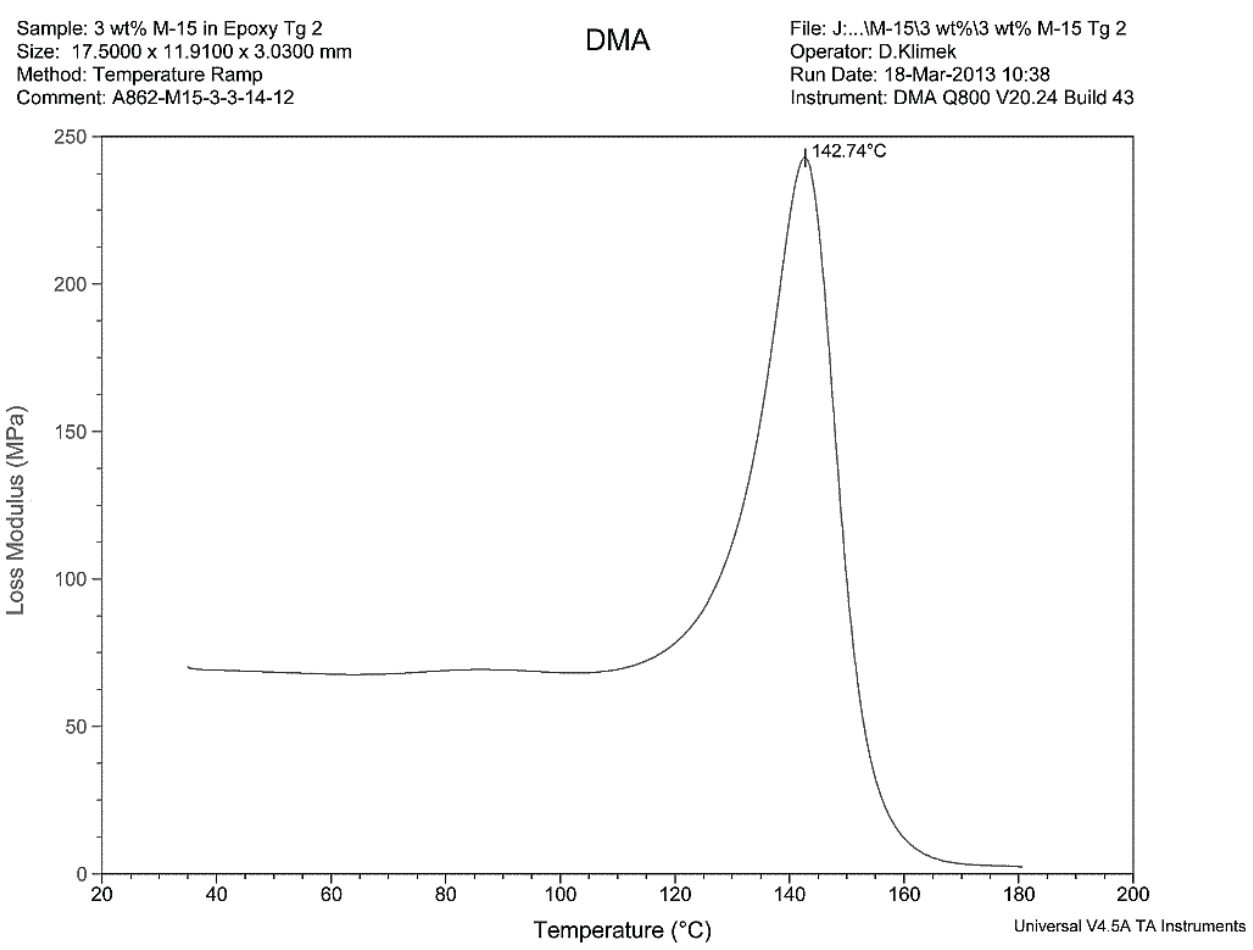

Figure D-11: Loss Modulus for 3 wt\% $x G n P^{\circledR}-M-15$ in Epoxy Test 2

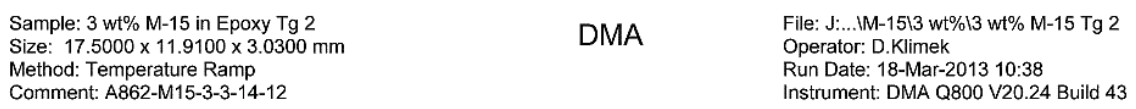

Instrument: DMA Q800 V20.24 Build 43

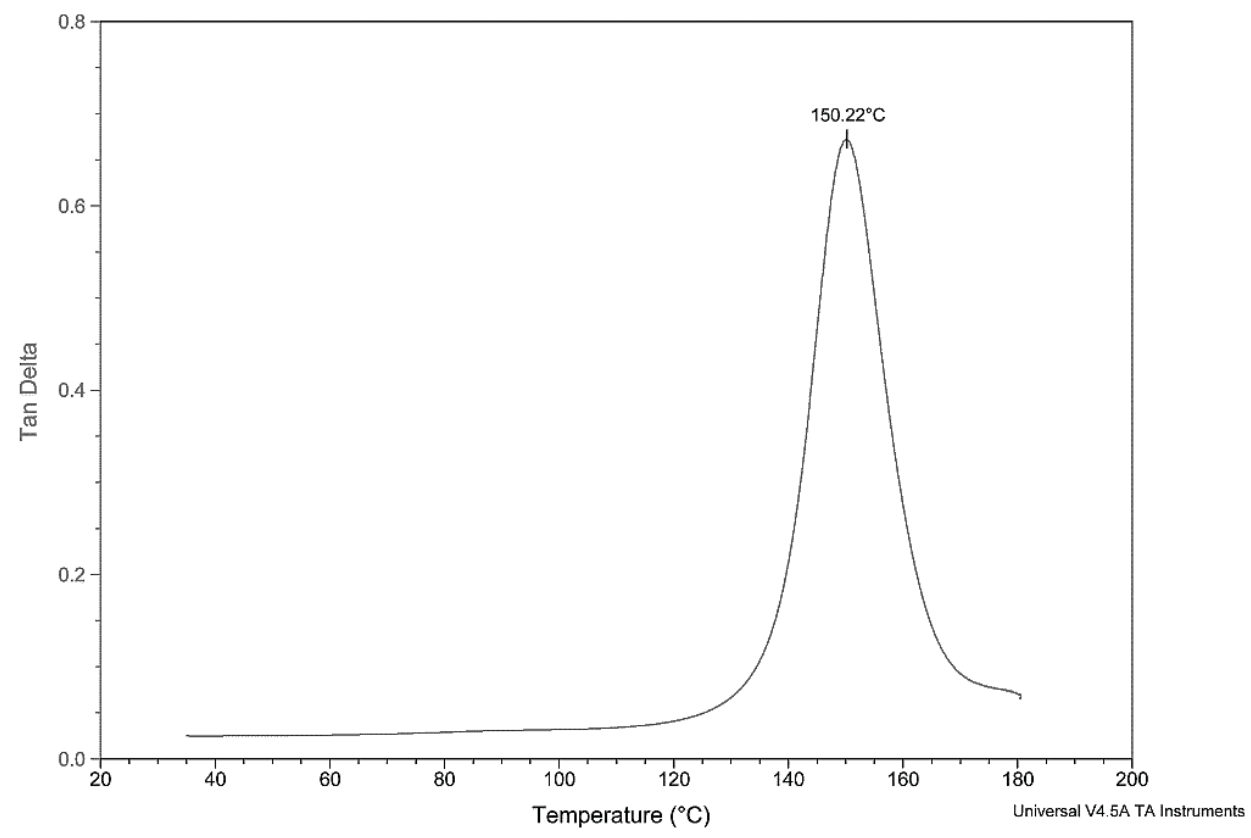

Figure D-12: Tan Delta for $3 w t \% x G n P^{\circledR}-M-15$ in Epoxy Test 2 
Table D-5: DMA Results for 4 wt\% $x G n P^{\circledR}-M-15$ in Epoxy

\begin{tabular}{|l|c|c|c|c|}
\hline \multicolumn{1}{|c|}{ Sample } & No. & $\begin{array}{c}\text { Storage } \\
\text { Modulus } \\
\text { Onset }\left({ }^{\circ} \mathbf{C}\right)\end{array}$ & $\begin{array}{c}\text { Loss } \\
\text { Modulus } \\
\text { Peak } \\
\left({ }^{\circ} \mathbf{C}\right)\end{array}$ & $\begin{array}{c}\text { Tan Delta } \\
\text { Peak } \\
\left({ }^{\circ} \mathbf{C}\right)\end{array}$ \\
\hline A862-M15-4-3-15-12 & 1 & 131.82 & 144.63 & 152.71 \\
\hline A862-M15-4-3-15-12 & 2 & 130.79 & 143.68 & 152.26 \\
\hline A862-M15-4-3-15-12 & 3 & 131.90 & 143.98 & 152.26 \\
\hline Average & & $\mathbf{1 3 1 . 5}$ & $\mathbf{1 4 4 . 1}$ & $\mathbf{1 5 2 . 4}$ \\
\hline Standard Deviation & $\mathbf{0 . 6}$ & $\mathbf{0 . 5}$ & $\mathbf{0 . 3}$ \\
\hline Count & $\mathbf{3}$ & $\mathbf{3}$ & $\mathbf{3}$ \\
\hline
\end{tabular}

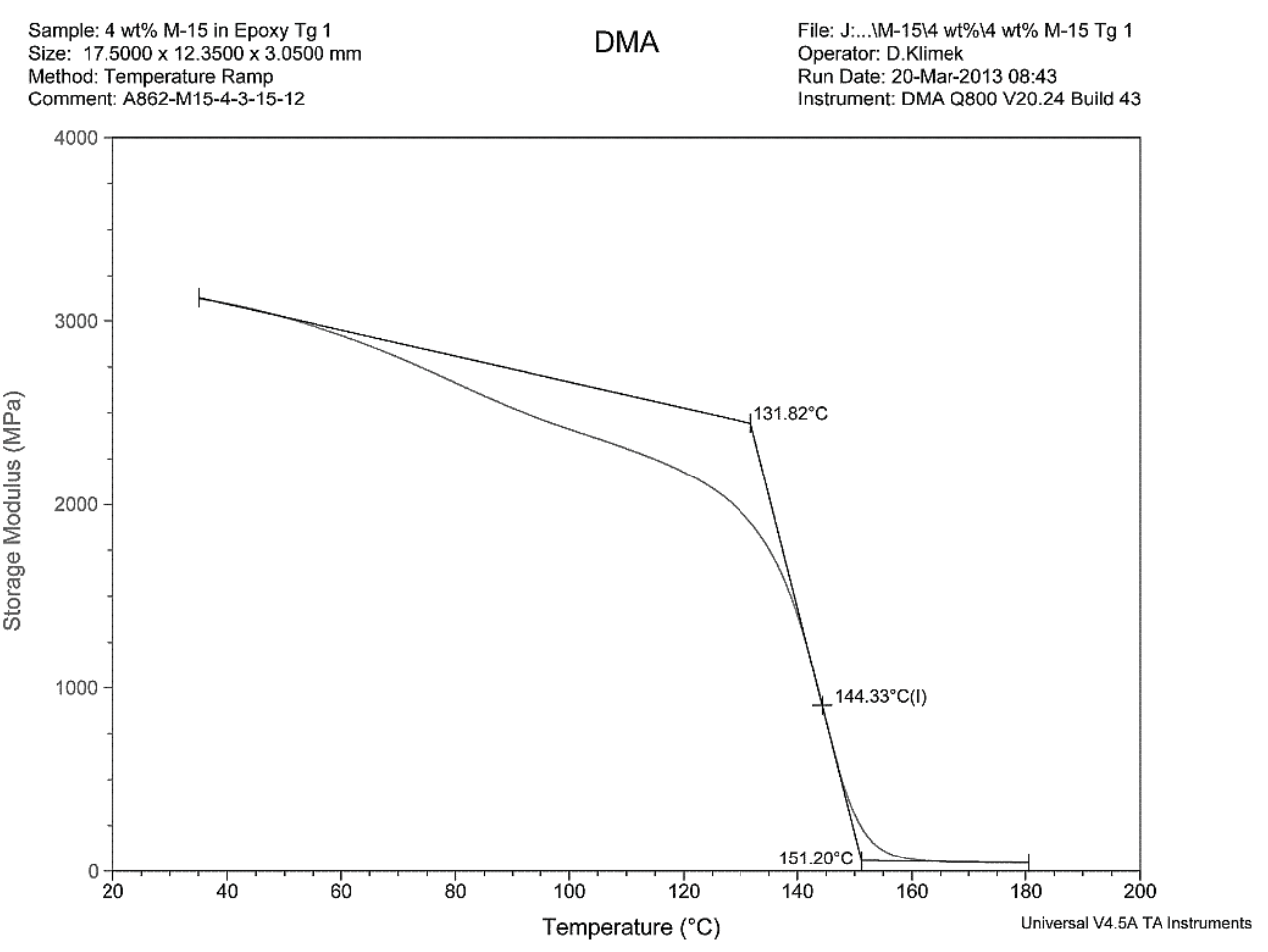

Figure D-13: Storage Modulus for 4 wt\% $x G n P^{\circledR}-M-15$ in Epoxy Test 1 


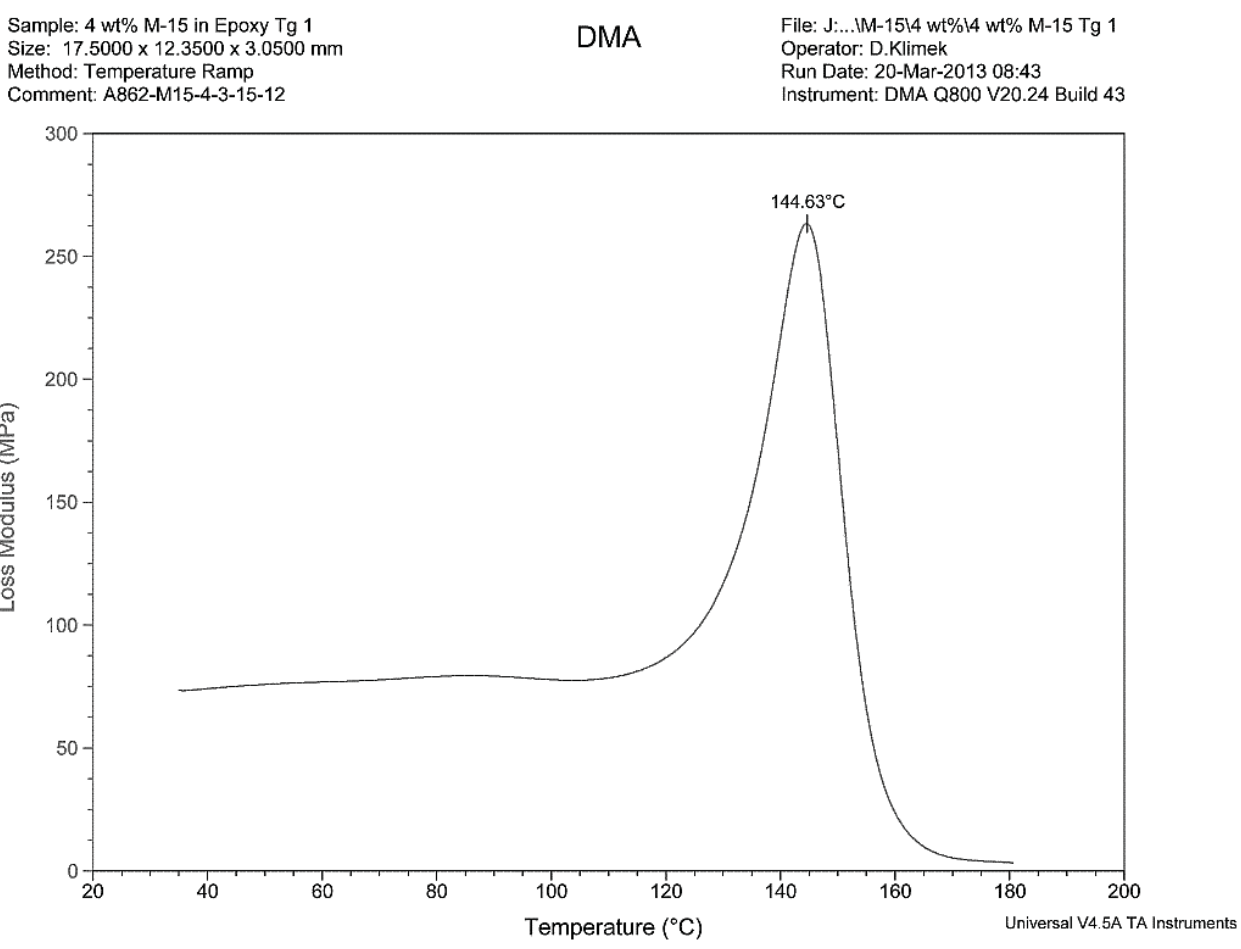

Figure D-14: Loss Modulus for 4 wt\% $x G n P^{\circledR}-M-15$ in Epoxy Test 1

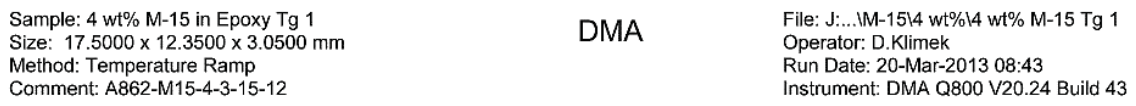

Instrument: DMA Q800 V20.24 Build 43

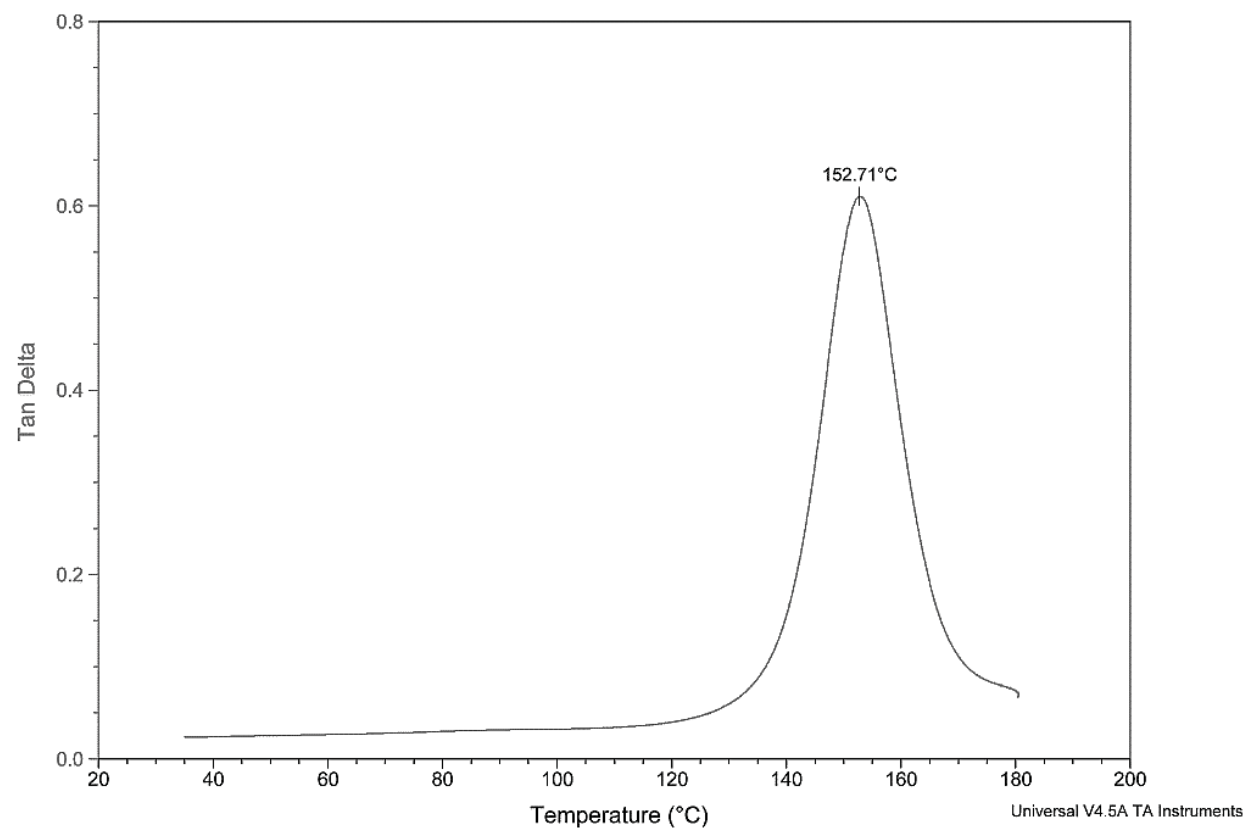

Figure D-15: Tan Delta for 4 wt\% $x G n P^{\circledR}-M-15$ in Epoxy Test 1 
Table D-6: DMA Results for 5 wt\% $x G n P^{\circledR}-M-15$ in Epoxy

\begin{tabular}{|l|c|c|c|c|}
\hline \multicolumn{1}{|c|}{ Sample } & No. & $\begin{array}{c}\text { Storage } \\
\text { Modulus } \\
\text { Onset }\left({ }^{\circ} \mathbf{C}\right)\end{array}$ & $\begin{array}{c}\text { Loss } \\
\text { Modulus } \\
\text { Peak } \\
\left({ }^{\circ} \mathbf{C}\right)\end{array}$ & $\begin{array}{c}\text { Tan Delta } \\
\text { Peak } \\
\left({ }^{\circ} \mathbf{C}\right)\end{array}$ \\
\hline A862-M15-5-3-19-12 & 1 & 137.15 & 149.59 & 156.27 \\
\hline A862-M15-5-3-19-12 & 2 & 136.60 & 149.05 & 156.04 \\
\hline A862-M15-5-3-19-12 & 3 & 137.13 & 148.75 & 155.57 \\
\hline Average & & $\mathbf{1 3 7 . 0}$ & $\mathbf{1 4 9 . 1}$ & $\mathbf{1 5 6 . 0}$ \\
\hline Standard Deviation & $\mathbf{0 . 3}$ & $\mathbf{0 . 4}$ & $\mathbf{0 . 4}$ \\
\hline Count & $\mathbf{3}$ & $\mathbf{3}$ & $\mathbf{3}$ \\
\hline
\end{tabular}

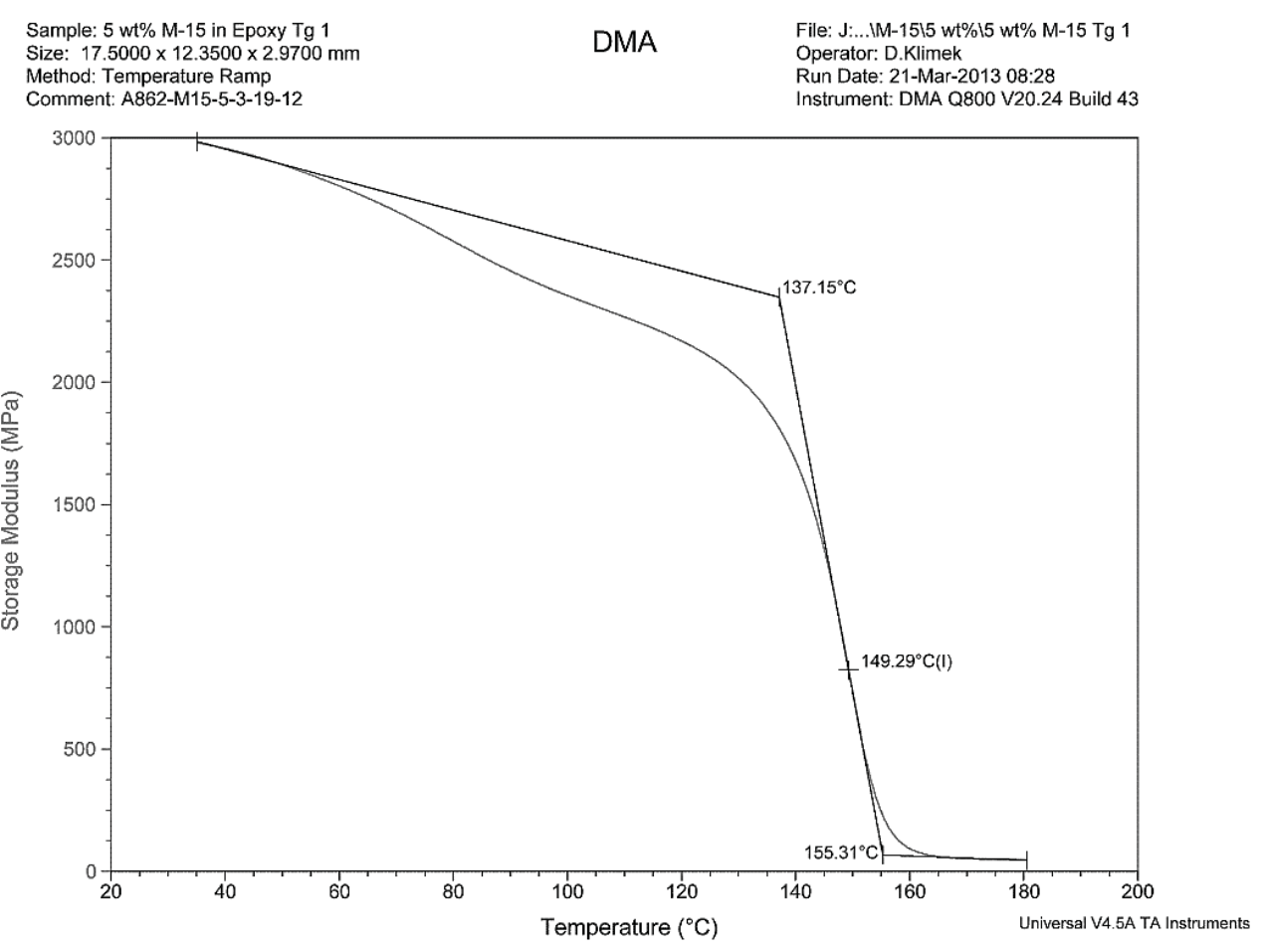

Figure D-16: Storage Modulus for 5 wt\% $x G n P^{\circledR}-M-15$ in Epoxy Test 1 


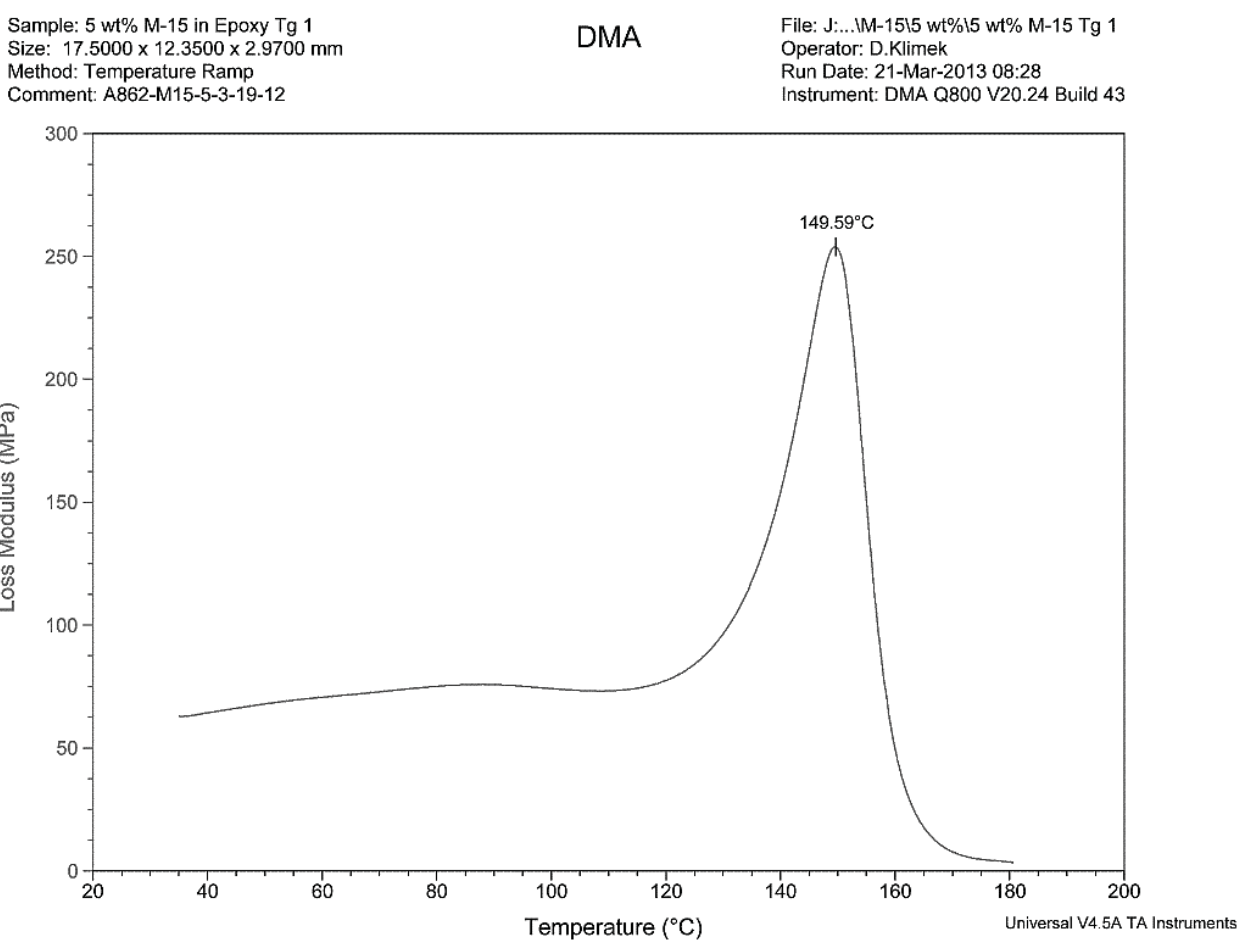

Figure D-17: Loss Modulus for 5 wt\% $x G n P^{\circledR}-M-15$ in Epoxy Test 1

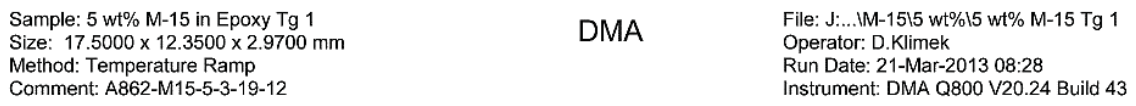

Instrument: DMA Q800 V20.24 Build 43

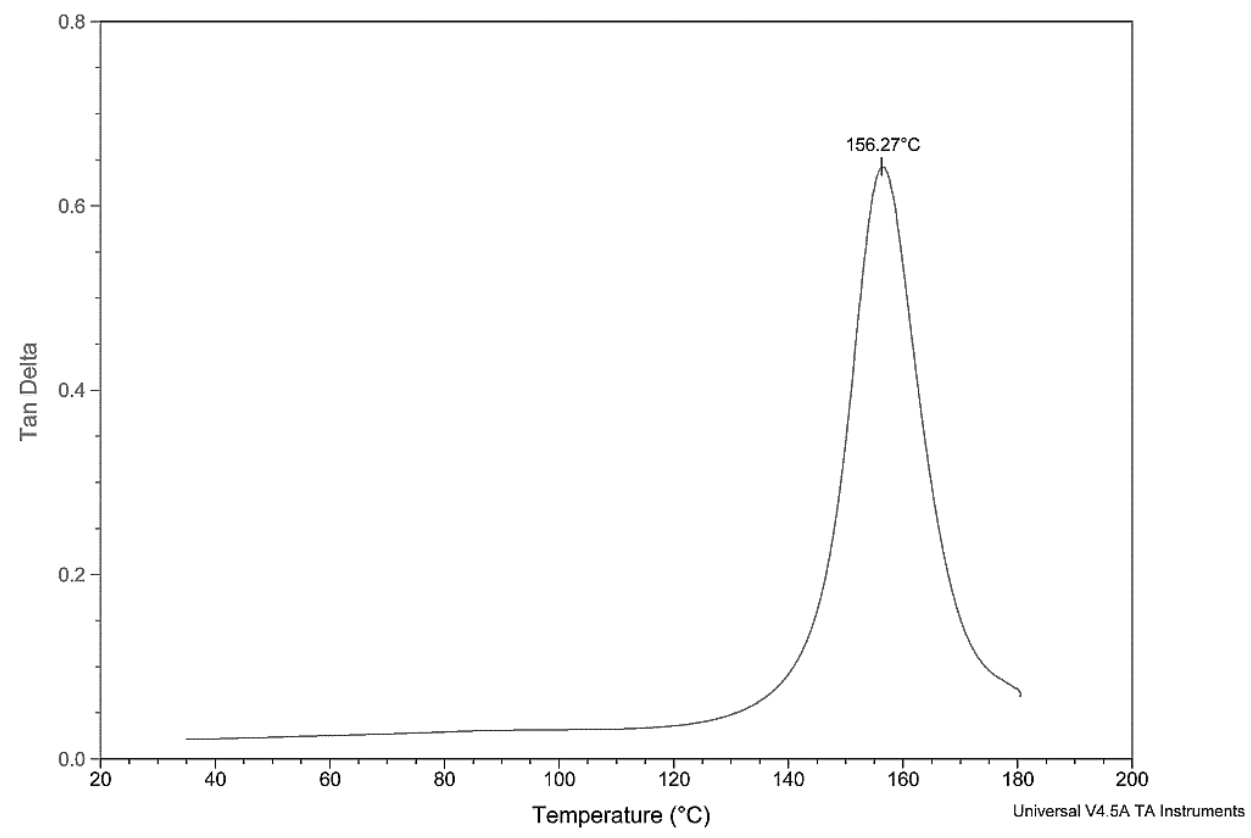

Figure D-18: Tan Delta for 5 wt\% $x G n P^{\circledR}-M-15$ in Epoxy Test 1 
Table D-7: DMA Results for 6 wt\% $x G n P^{\circledR}-M-15$ in Epoxy

\begin{tabular}{|l|c|c|c|c|}
\hline \multicolumn{1}{|c|}{ Sample } & No. & $\begin{array}{c}\text { Storage } \\
\text { Modulus } \\
\text { Onset }\left({ }^{\circ} \mathbf{C}\right)\end{array}$ & $\begin{array}{c}\text { Loss } \\
\text { Modulus } \\
\text { Peak } \\
\left({ }^{\circ} \mathbf{C}\right)\end{array}$ & $\begin{array}{c}\text { Tan Delta } \\
\text { Peak } \\
\left({ }^{\circ} \mathbf{C}\right)\end{array}$ \\
\hline A862-M15-6-3-28-12 & 1 & 136.34 & 148.60 & 155.92 \\
\hline A862-M15-6-3-28-12 & 2 & 134.71 & 147.38 & 155.20 \\
\hline A862-M15-6-3-28-12 & 3 & 135.61 & 149.02 & 156.54 \\
\hline A862-M15-6-4-19-12 & 4 & 137.37 & 148.75 & 156.11 \\
\hline A862-M15-6-4-19-12 & 5 & 136.19 & 148.31 & 155.83 \\
\hline Average & & $\mathbf{1 3 6 . 0}$ & $\mathbf{1 4 8 . 4}$ & $\mathbf{1 5 5 . 9}$ \\
\hline Standard Deviation & $\mathbf{1 . 0}$ & $\mathbf{0 . 6}$ & $\mathbf{0 . 5}$ \\
\hline Count & $\mathbf{5}$ & $\mathbf{5}$ & $\mathbf{5}$ \\
\hline
\end{tabular}

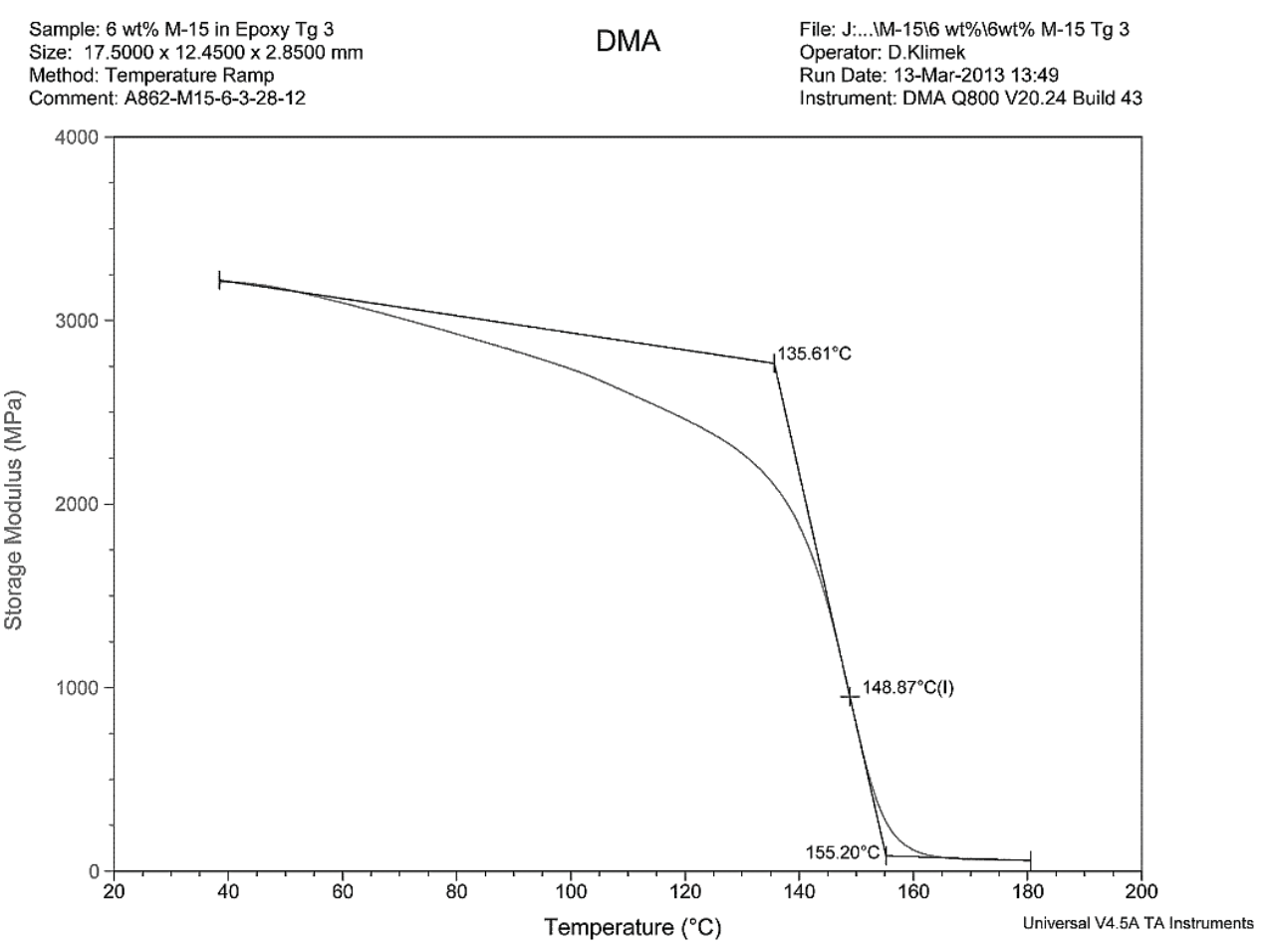

Figure D-19: Storage Modulus for 6 wt\% $x G n P^{\circledR}-M-15$ in Epoxy Test 3 


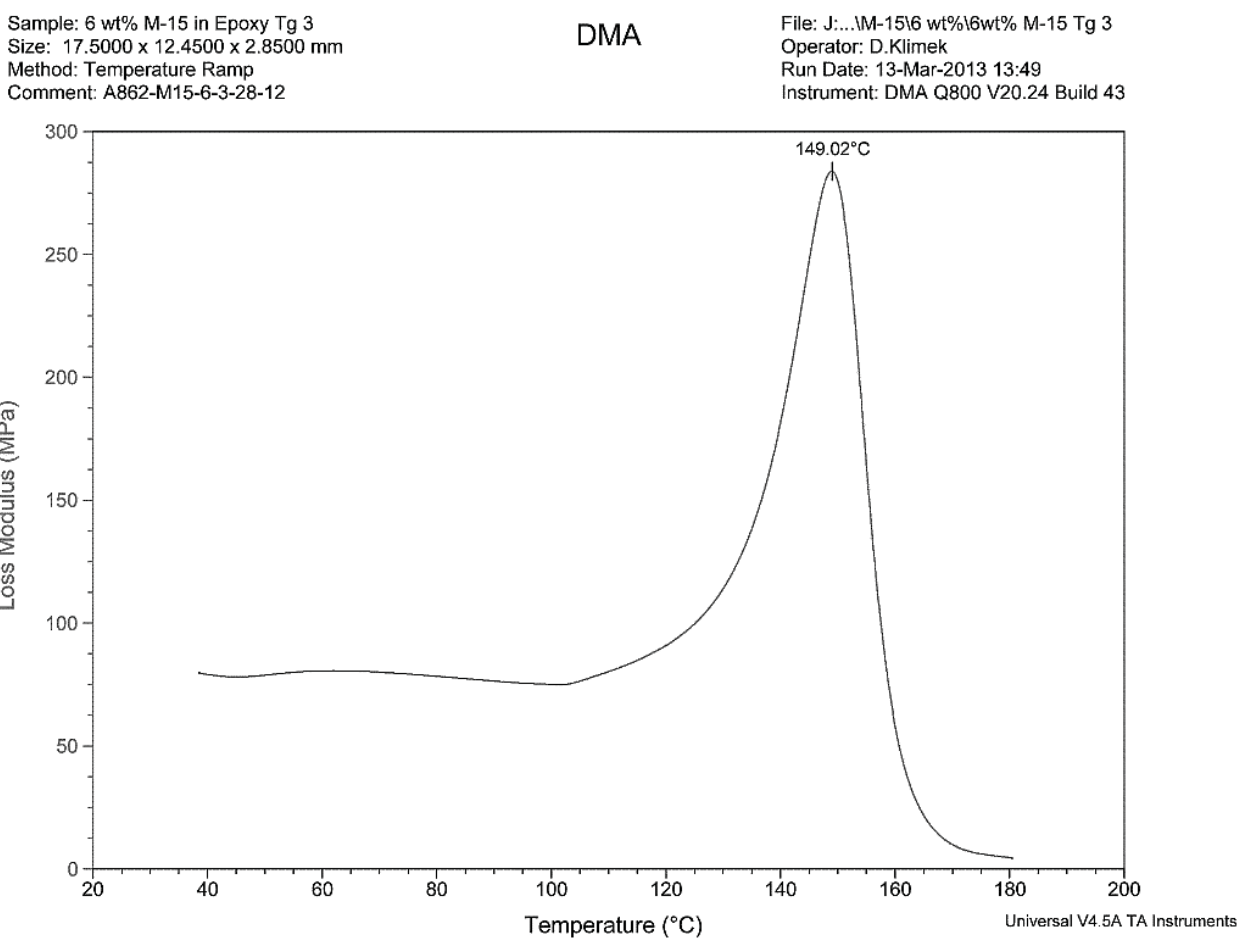

Figure D-20: Loss Modulus for 6 wt\% xGnP ${ }^{\circledR}-M-15$ in Epoxy Test 3

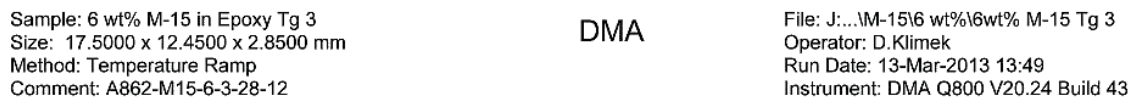

Instrument: DMA Q800 V20.24 Build 43

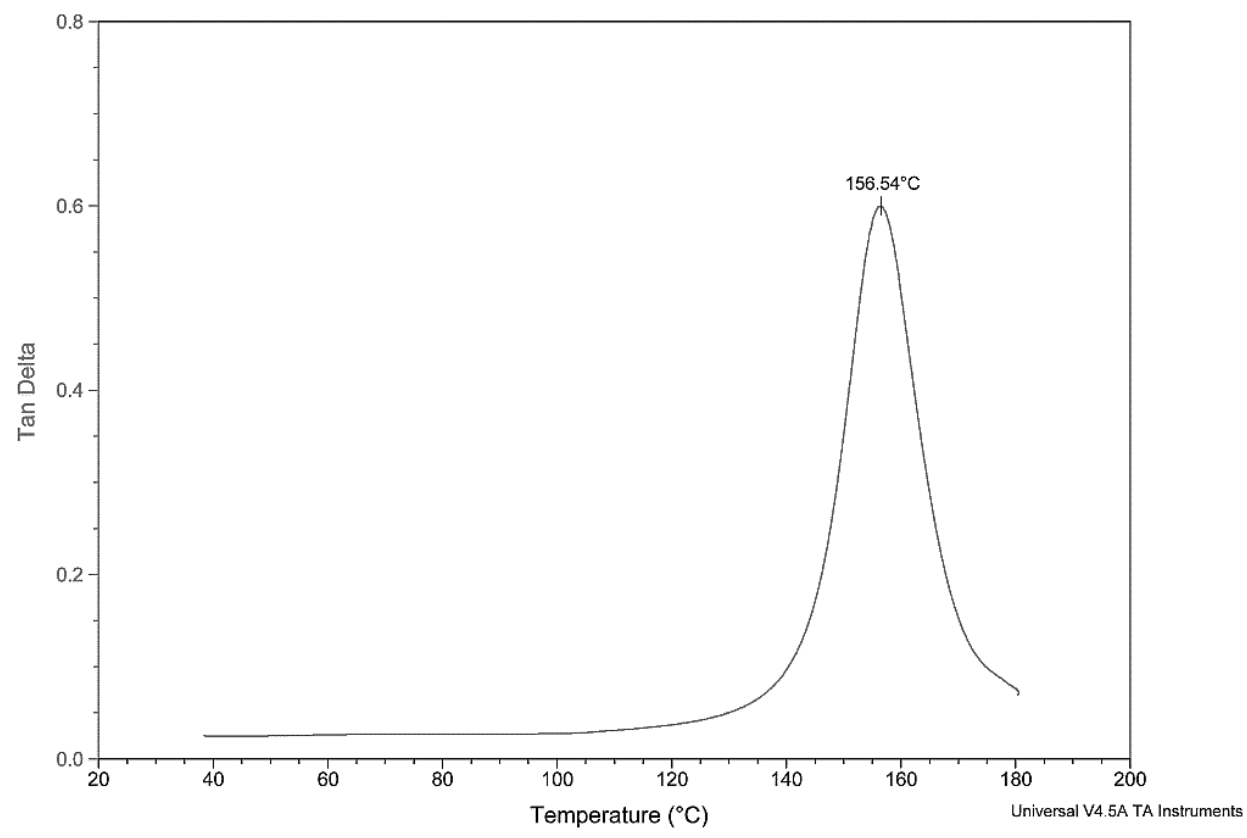

Figure D-21: Tan Delta for 6 wt\% $x G n P^{\circledR}-M-15$ in Epoxy Test 3 
Table D-8: DMA Results for 1 wt\% $x G n P^{\circledR}-M-5$ in Epoxy

\begin{tabular}{|l|c|c|c|c|}
\hline \multicolumn{1}{|c|}{ Sample } & No. & $\begin{array}{c}\text { Storage } \\
\text { Modulus } \\
\text { Onset }\left({ }^{\circ} \mathbf{C}\right)\end{array}$ & $\begin{array}{c}\text { Loss } \\
\text { Modulus } \\
\text { Peak } \\
\left({ }^{\circ} \mathbf{C}\right)\end{array}$ & $\begin{array}{c}\text { Tan Delta } \\
\text { Peak } \\
\left({ }^{\circ} \mathbf{C}\right)\end{array}$ \\
\hline A862-M5-1-9-28-12 & 1 & 136.19 & 147.80 & 154.59 \\
\hline A862-M5-1-9-28-12 & 2 & 135.77 & 147.58 & 154.17 \\
\hline A862-M5-1-9-28-12 & 3 & 136.61 & 147.29 & 154.05 \\
\hline Average & & $\mathbf{1 3 6 . 2}$ & $\mathbf{1 4 7 . 6}$ & $\mathbf{1 5 4 . 3}$ \\
\hline Standard Deviation & $\mathbf{0 . 4}$ & $\mathbf{0 . 3}$ & $\mathbf{0 . 3}$ \\
\hline Count & $\mathbf{3}$ & $\mathbf{3}$ & $\mathbf{3}$ \\
\hline
\end{tabular}

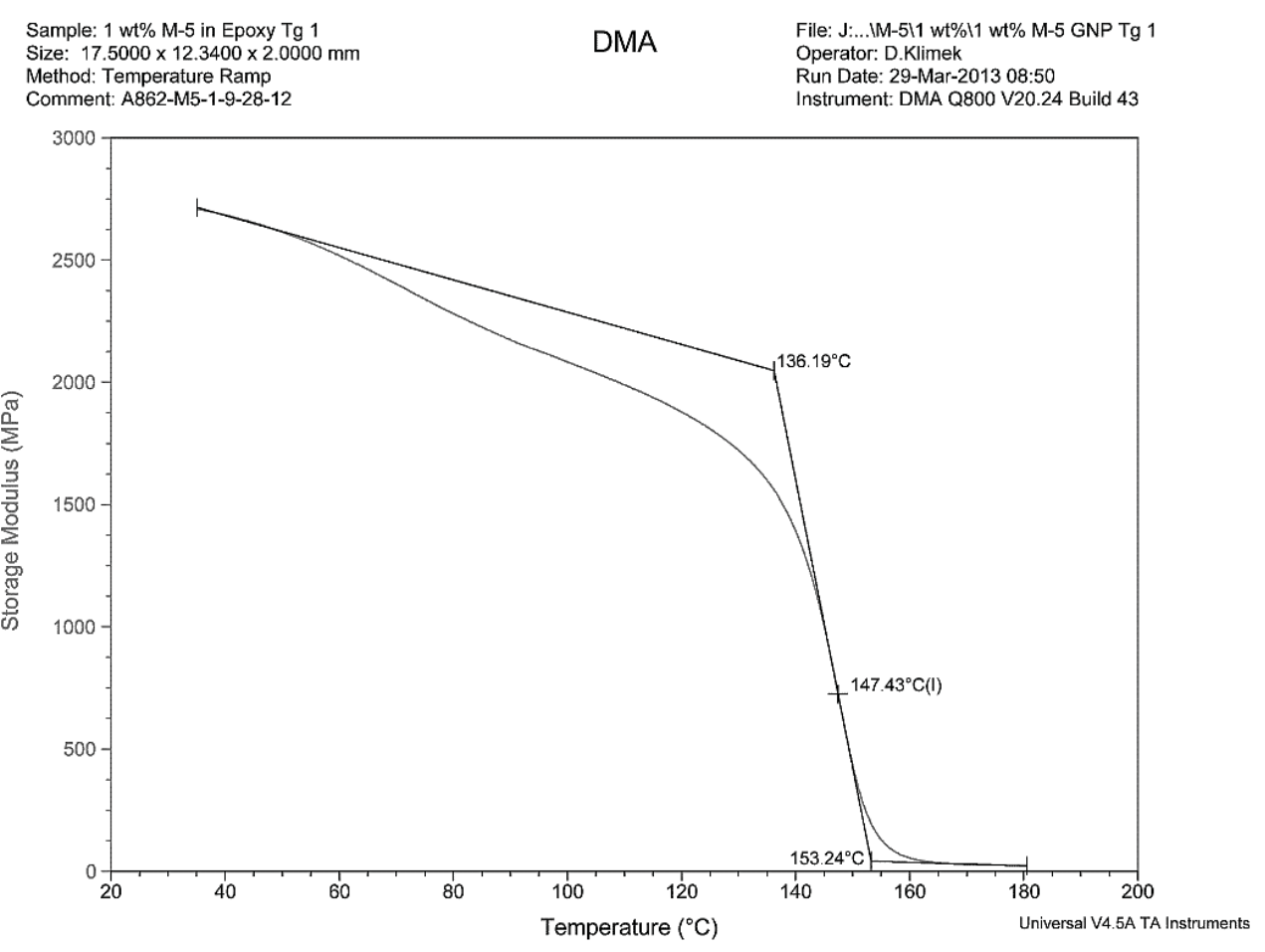

Figure D-22: Storage Modulus for 1 wt\% $x G n P^{\circledR}-M-5$ in Epoxy Test 1 


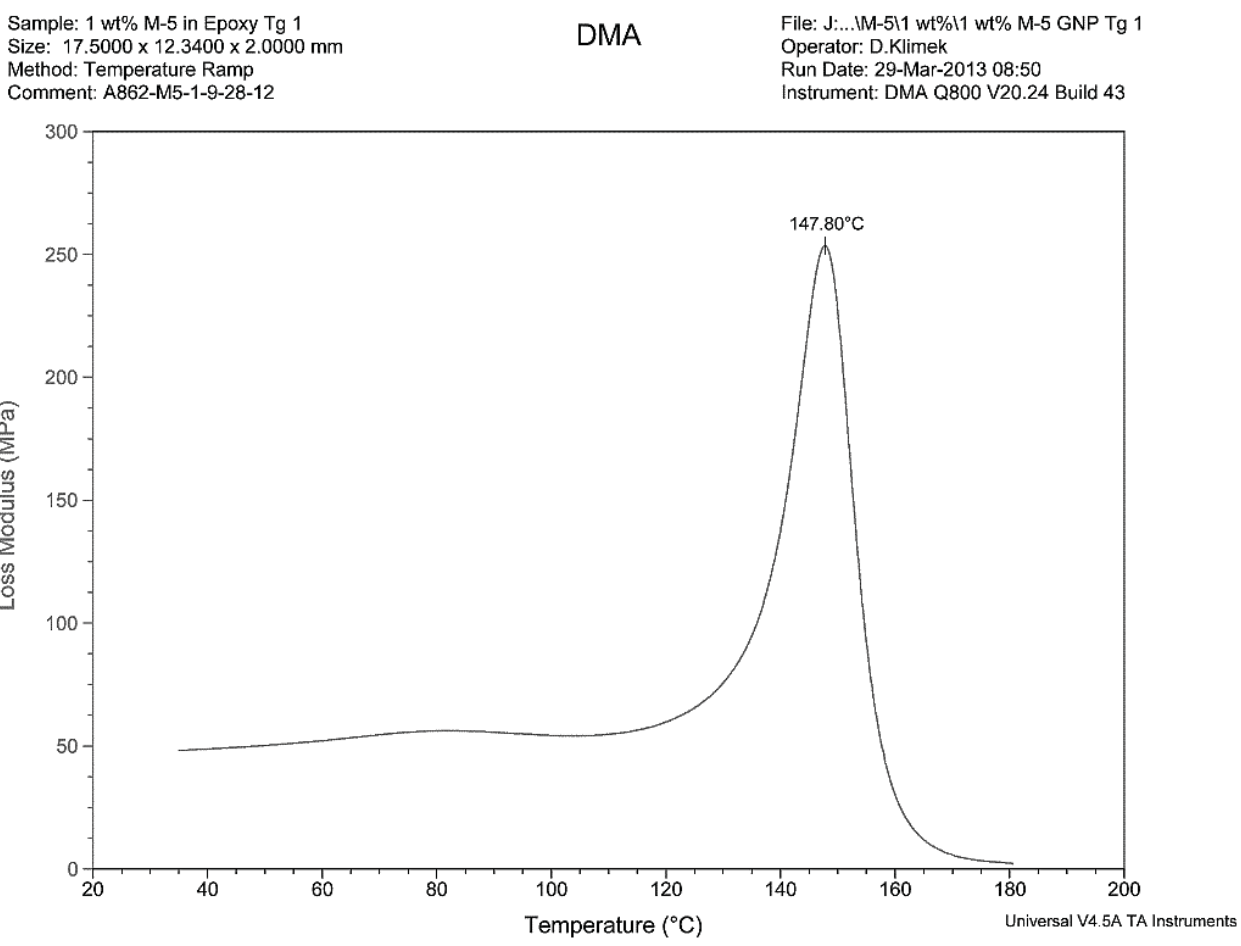

Figure D-23: Loss Modulus for 1 wt\% xGnP ${ }^{\circledR}-M-5$ in Epoxy Test 1

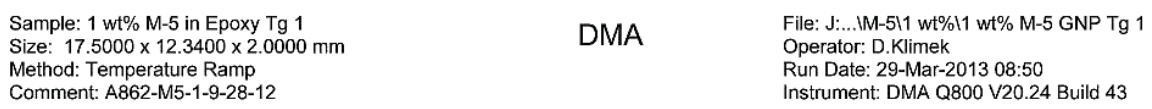

Instrument: DMA Q800 V20.24 Build 43

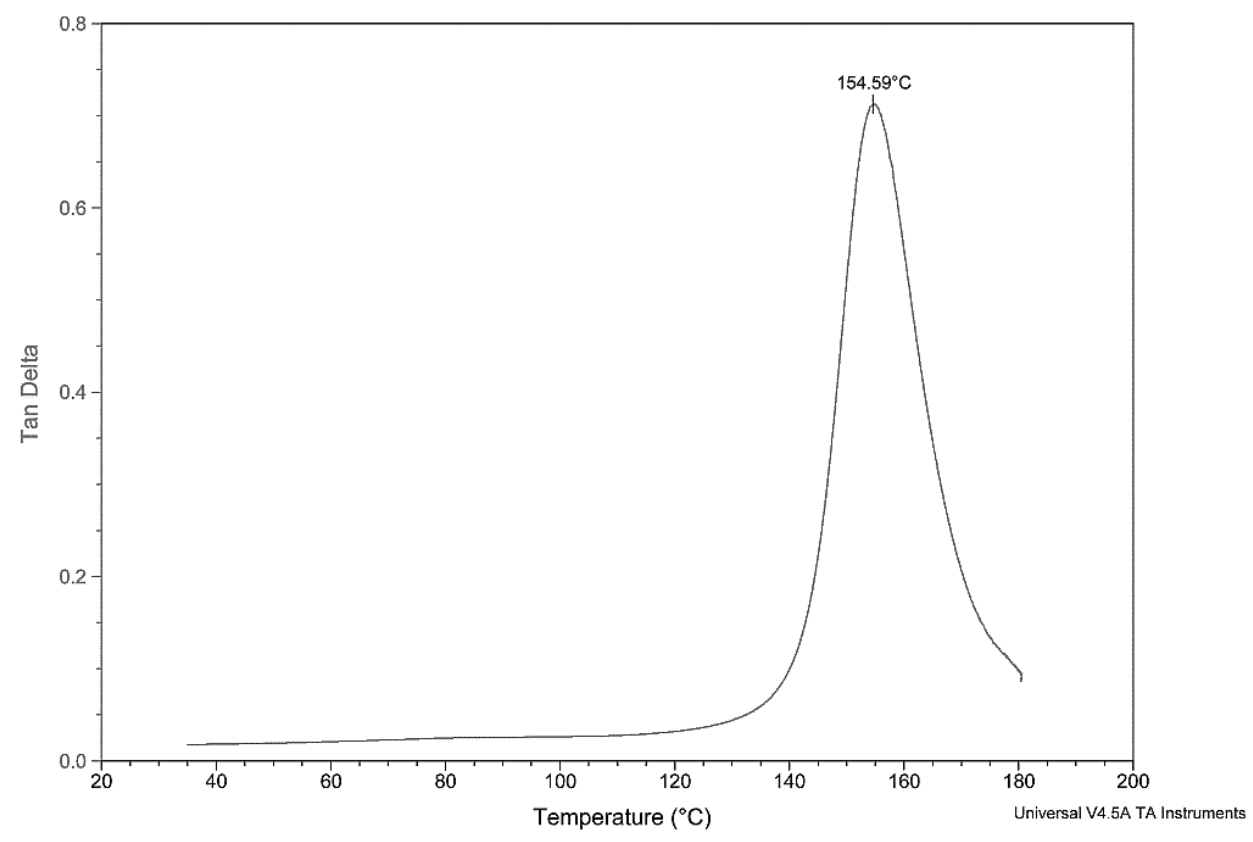

Figure D-24: Tan Delta for 1 wt\% $x G n P^{\circledR}-M-5$ in Epoxy Test 1 
Table D-9: DMA Results for 2 wt\% $x G n P^{\circledR}-M-5$ in Epoxy

\begin{tabular}{|l|c|c|c|c|}
\hline Sample & No. & $\begin{array}{c}\text { Storage } \\
\text { Modulus } \\
\text { Onset }\left({ }^{\circ} \mathbf{C}\right)\end{array}$ & $\begin{array}{c}\text { Loss } \\
\text { Modulus } \\
\text { Peak } \\
\left({ }^{\circ} \mathbf{C}\right)\end{array}$ & $\begin{array}{c}\text { Tan Delta } \\
\text { Peak } \\
\left({ }^{\circ} \mathbf{C}\right)\end{array}$ \\
\hline A862-M5-2-8-28-12 & 1 & 134.99 & 146.04 & 153.59 \\
\hline A862-M5-2-8-28-12 & 2 & 134.15 & 145.82 & 153.01 \\
\hline A862-M5-2-8-28-12 & 3 & 134.90 & 145.58 & 152.82 \\
\hline Average & & $\mathbf{1 3 4 . 7}$ & $\mathbf{1 4 5 . 8}$ & $\mathbf{1 5 3 . 1}$ \\
\hline Standard Deviation & $\mathbf{0 . 5}$ & $\mathbf{0 . 2}$ & $\mathbf{0 . 4}$ \\
\hline Count & $\mathbf{3}$ & $\mathbf{3}$ & $\mathbf{3}$ \\
\hline
\end{tabular}

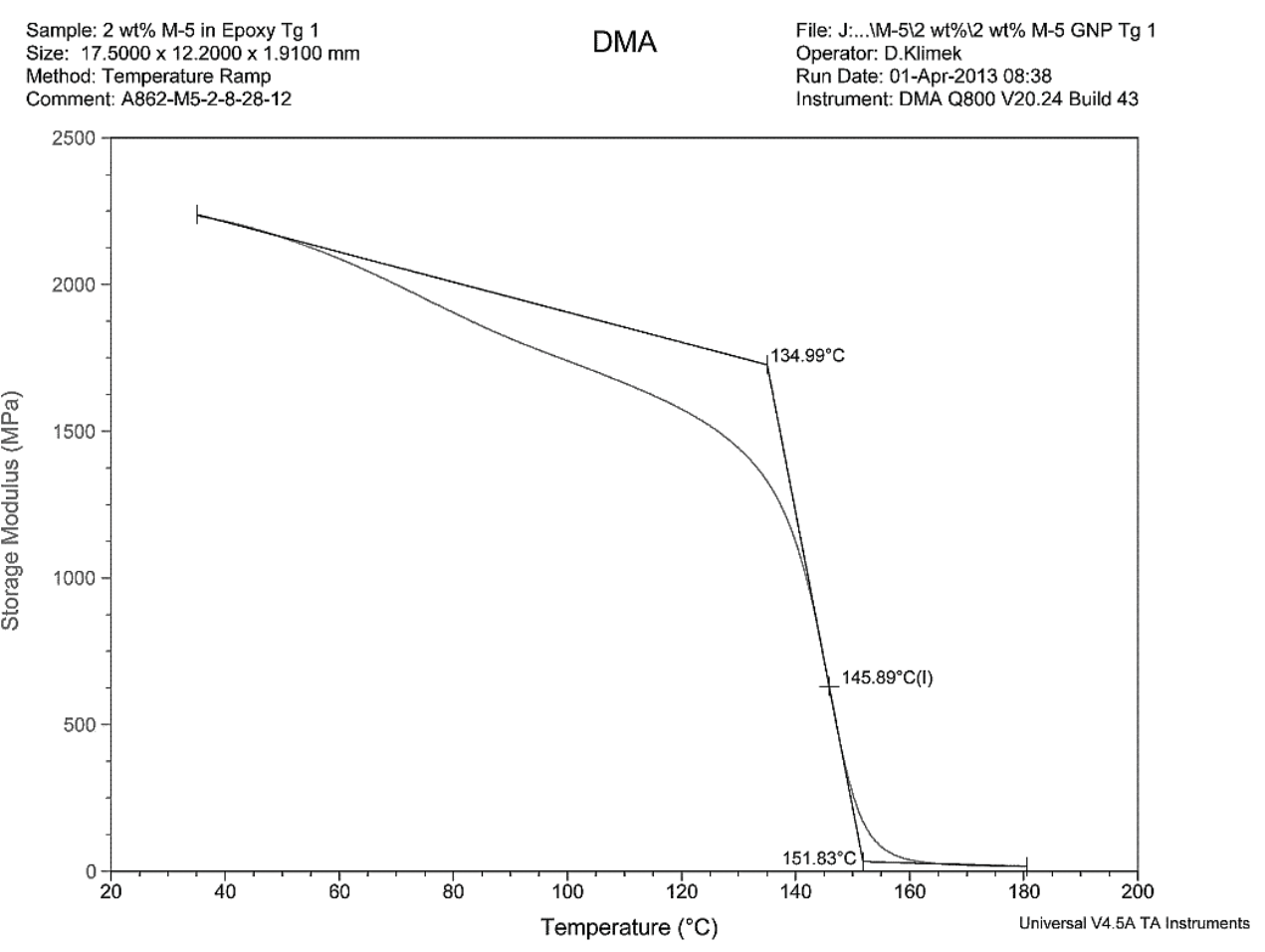

Figure D-25: Storage Modulus for $2 w t \% x G n P^{\circledR}-M-5$ in Epoxy Test 1 


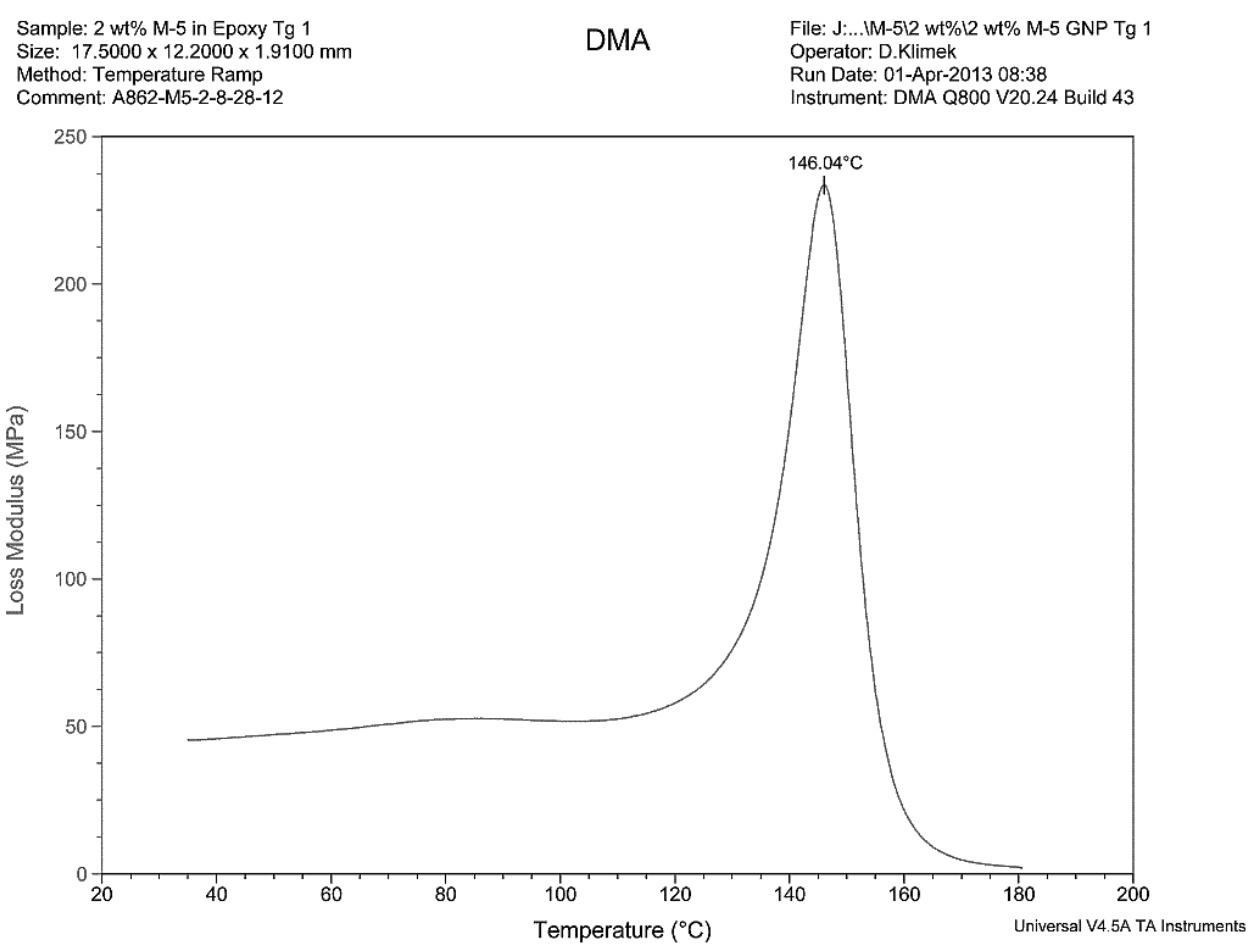

Figure D-26: Loss Modulus for 2 wt\% $x G n P^{\circledR}-M-5$ in Epoxy Test 1

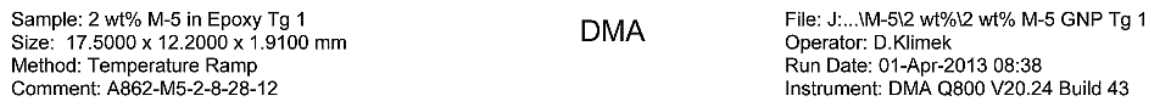

Comment: A862-M5-2-8-28-12

Operator: D.Klimek

Instrument: DMA Q800 V20.24 Build 43

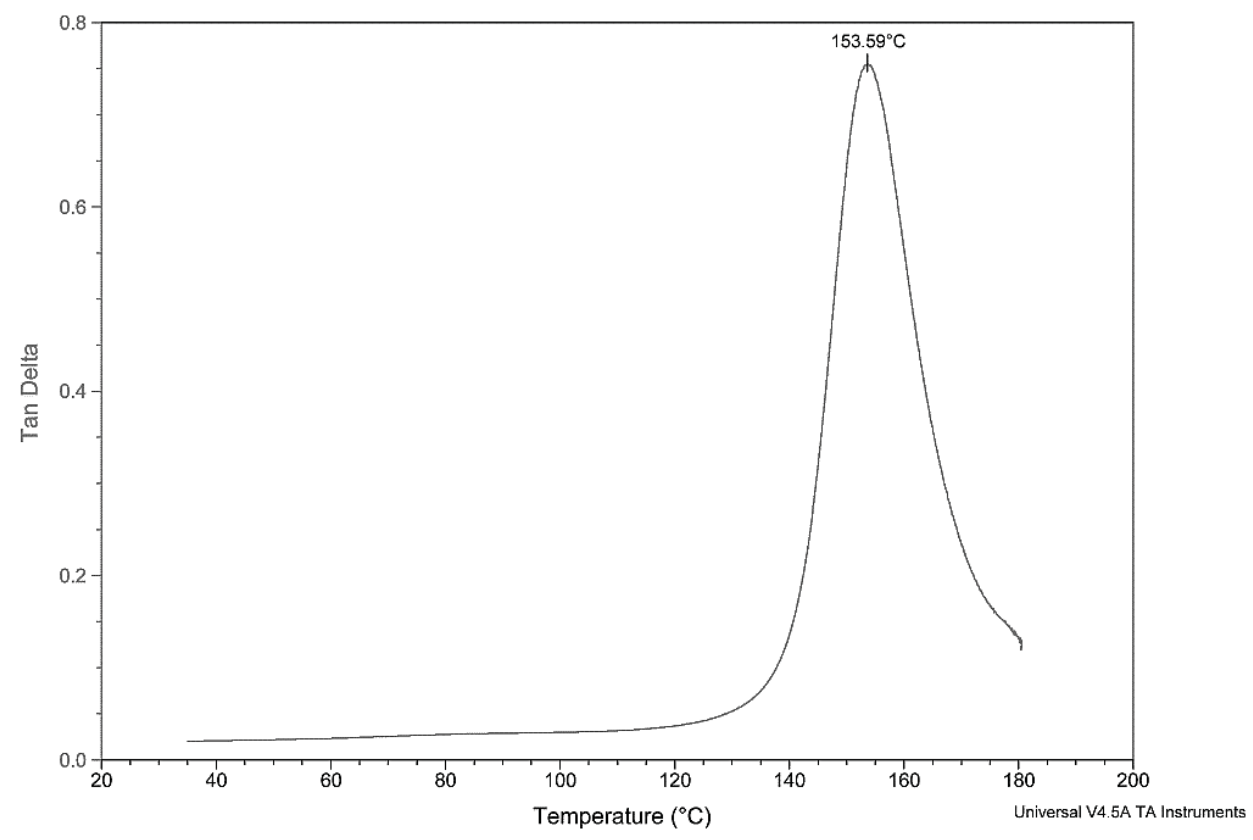

Figure D-27: Tan Delta for 2 wt\% $x G n P^{\circledR}-M-5$ in Epoxy Test 1 
Table D-10: DMA Results for 3 wt\% $x G n P^{\circledR}-M-5$ in Epoxy

\begin{tabular}{|l|c|c|c|c|}
\hline \multicolumn{1}{|c|}{ Sample } & No. & $\begin{array}{c}\text { Storage } \\
\text { Modulus } \\
\text { Onset }\left({ }^{\circ} \mathbf{C}\right)\end{array}$ & $\begin{array}{c}\text { Loss } \\
\text { Modulus } \\
\text { Peak } \\
\left({ }^{\circ} \mathbf{C}\right)\end{array}$ & $\begin{array}{c}\text { Tan Delta } \\
\text { Peak } \\
\left({ }^{\circ} \mathbf{C}\right)\end{array}$ \\
\hline A862-M5-3-10-3-12 & 1 & 137.17 & 147.87 & 154.76 \\
\hline A862-M5-3-10-3-12 & 2 & 137.53 & 147.78 & 154.34 \\
\hline A862-M5-3-10-3-12 & 3 & 137.57 & 148.51 & 154.93 \\
\hline Average & & $\mathbf{1 3 7 . 4}$ & $\mathbf{1 4 8 . 1}$ & $\mathbf{1 5 4 . 7}$ \\
\hline Standard Deviation & $\mathbf{0 . 2}$ & $\mathbf{0 . 4}$ & $\mathbf{0 . 3}$ \\
\hline Count & $\mathbf{3}$ & $\mathbf{3}$ & $\mathbf{3}$ \\
\hline
\end{tabular}

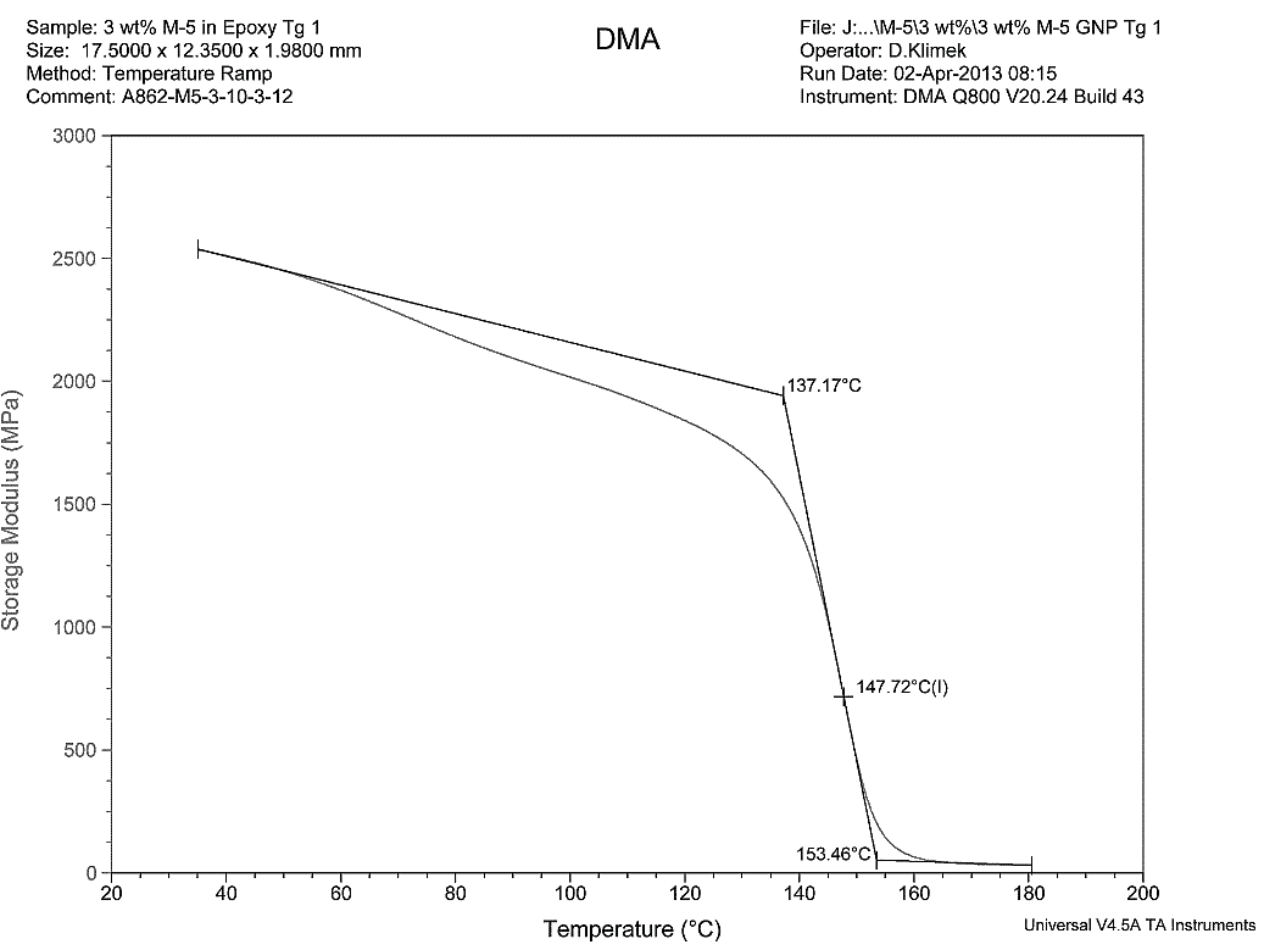

Figure D-28: Storage Modulus for $3 w t^{0} \times x_{n} P^{\circledR}-M-5$ in Epoxy Test 1 


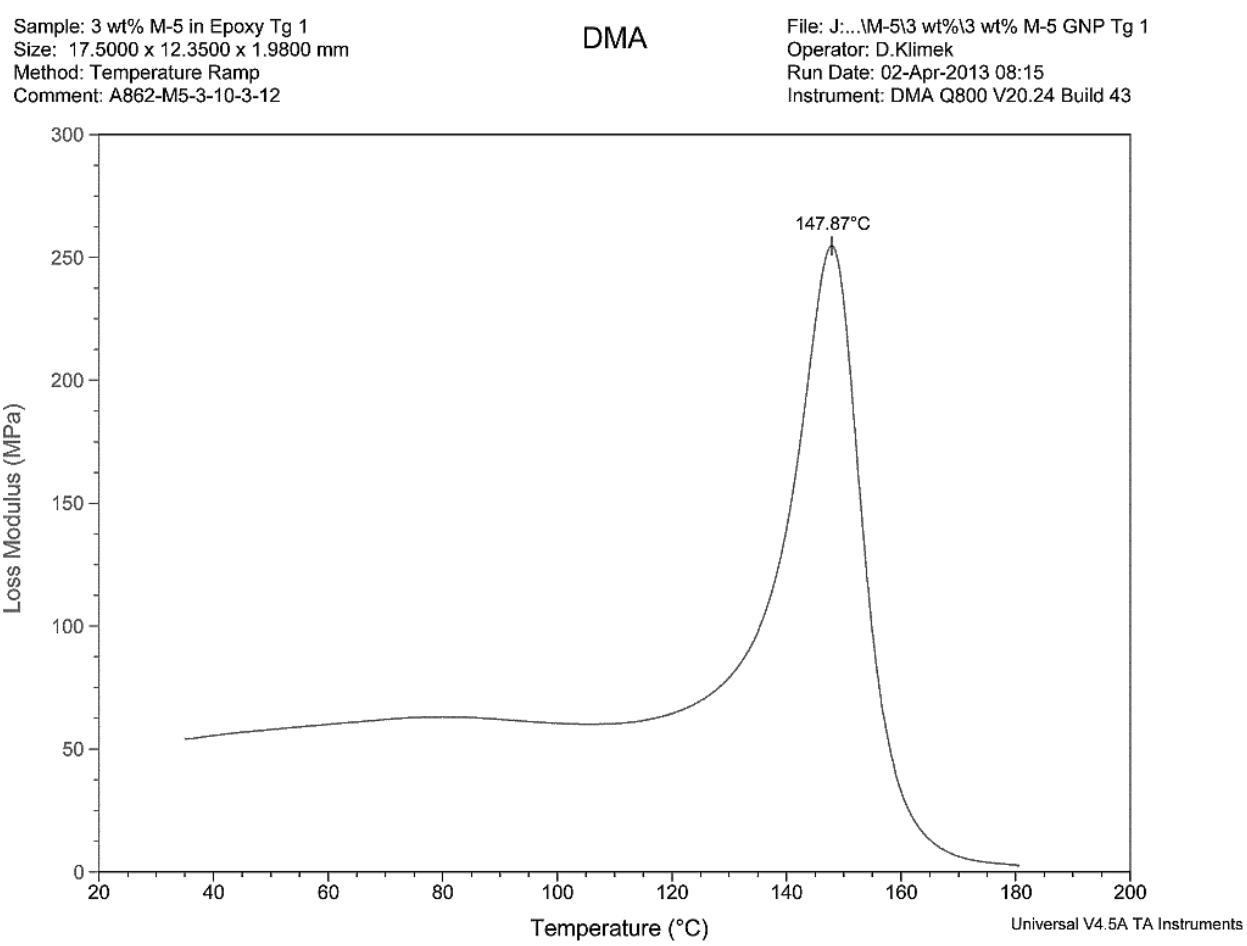

Figure D-29: Loss Modulus for 3 wt\% $x G n P^{\circledR}-M-5$ in Epoxy Test 1.

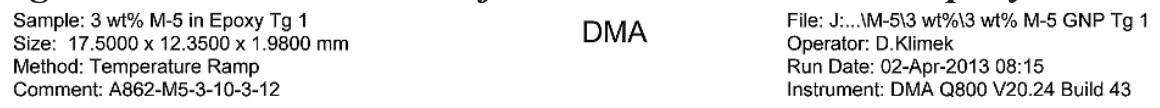

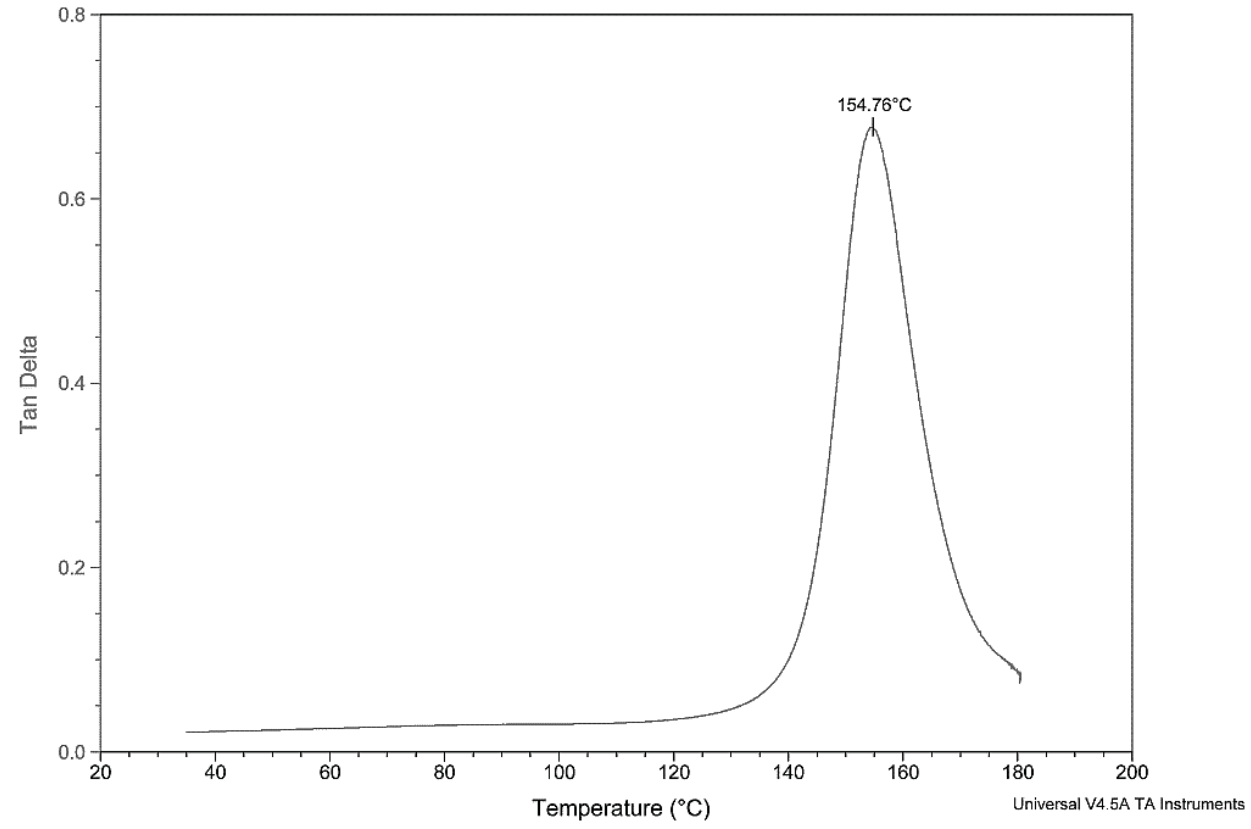

Figure D-30: Tan Delta for 3 wt\% $x G n P^{\circledR}-M-5$ in Epoxy Test 1 
Table D-11: DMA Results for 4 wt\% $x G n P^{\circledR}-M-5$ in Epoxy

\begin{tabular}{|l|c|c|c|c|}
\hline \multicolumn{1}{|c|}{ Sample } & No. & $\begin{array}{c}\text { Storage } \\
\text { Modulus } \\
\text { Onset }\left({ }^{\circ} \mathbf{C}\right)\end{array}$ & $\begin{array}{c}\text { Loss } \\
\text { Modulus } \\
\text { Peak } \\
\left({ }^{\circ} \mathbf{C}\right)\end{array}$ & $\begin{array}{c}\text { Tan Delta } \\
\text { Peak } \\
\left({ }^{\circ} \mathbf{C}\right)\end{array}$ \\
\hline A862-M5-4-10-9-12 & 1 & 139.66 & 150.42 & 156.82 \\
\hline A862-M5-4-10-9-12 & 2 & 139.34 & 150.00 & 156.58 \\
\hline A862-M5-4-10-9-12 & 3 & 139.92 & 149.50 & 156.09 \\
\hline Average & & $\mathbf{1 3 9 . 6}$ & $\mathbf{1 5 0 . 0}$ & $\mathbf{1 5 6 . 5}$ \\
\hline Standard Deviation & $\mathbf{0 . 3}$ & $\mathbf{0 . 5}$ & $\mathbf{0 . 4}$ \\
\hline Count & $\mathbf{3}$ & $\mathbf{3}$ & $\mathbf{3}$ \\
\hline
\end{tabular}

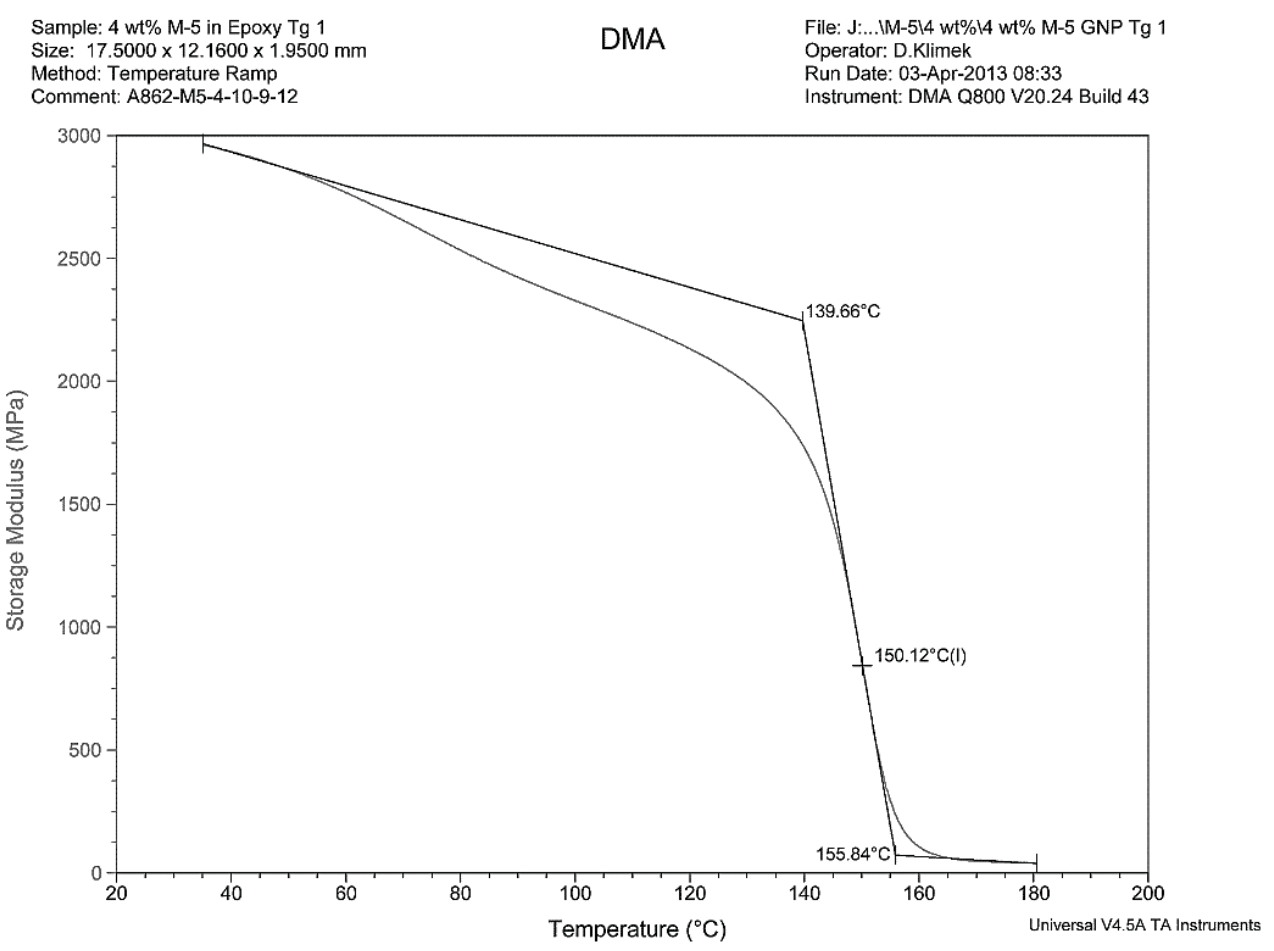

Figure D-31: Storage Modulus for 4 wt\% $x G n P^{\circledR}-M-5$ in Epoxy Test 1 


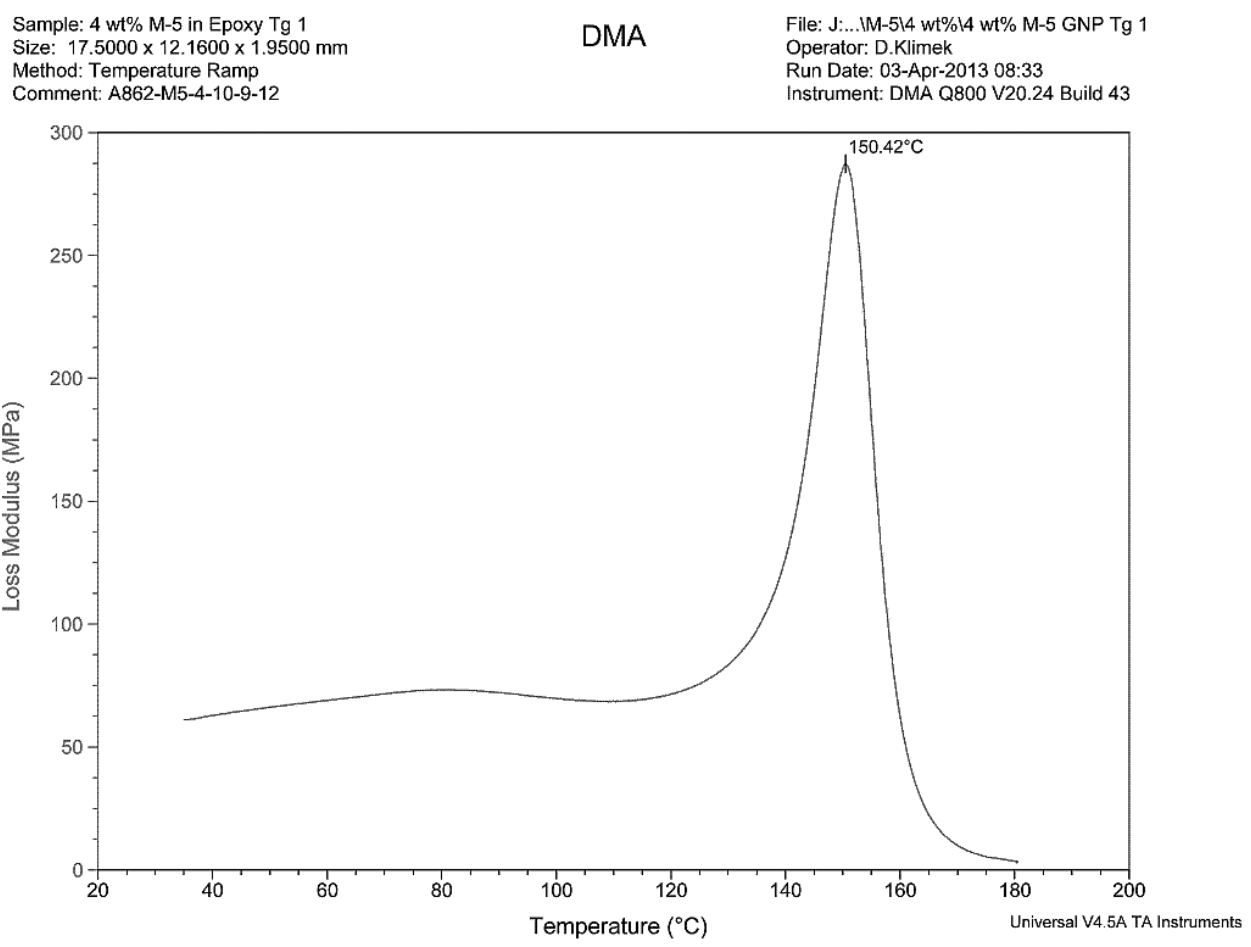

Figure D-32: Loss Modulus for 4 wt\% xGnP ${ }^{\circledR}-M-5$ in Epoxy Test 1

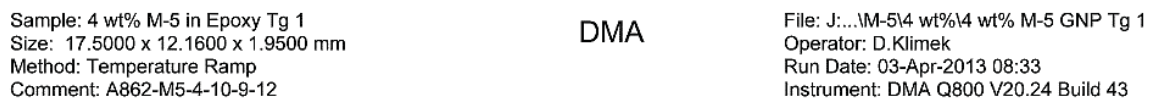

Instrument: DMA Q800 V20.24 Build 43

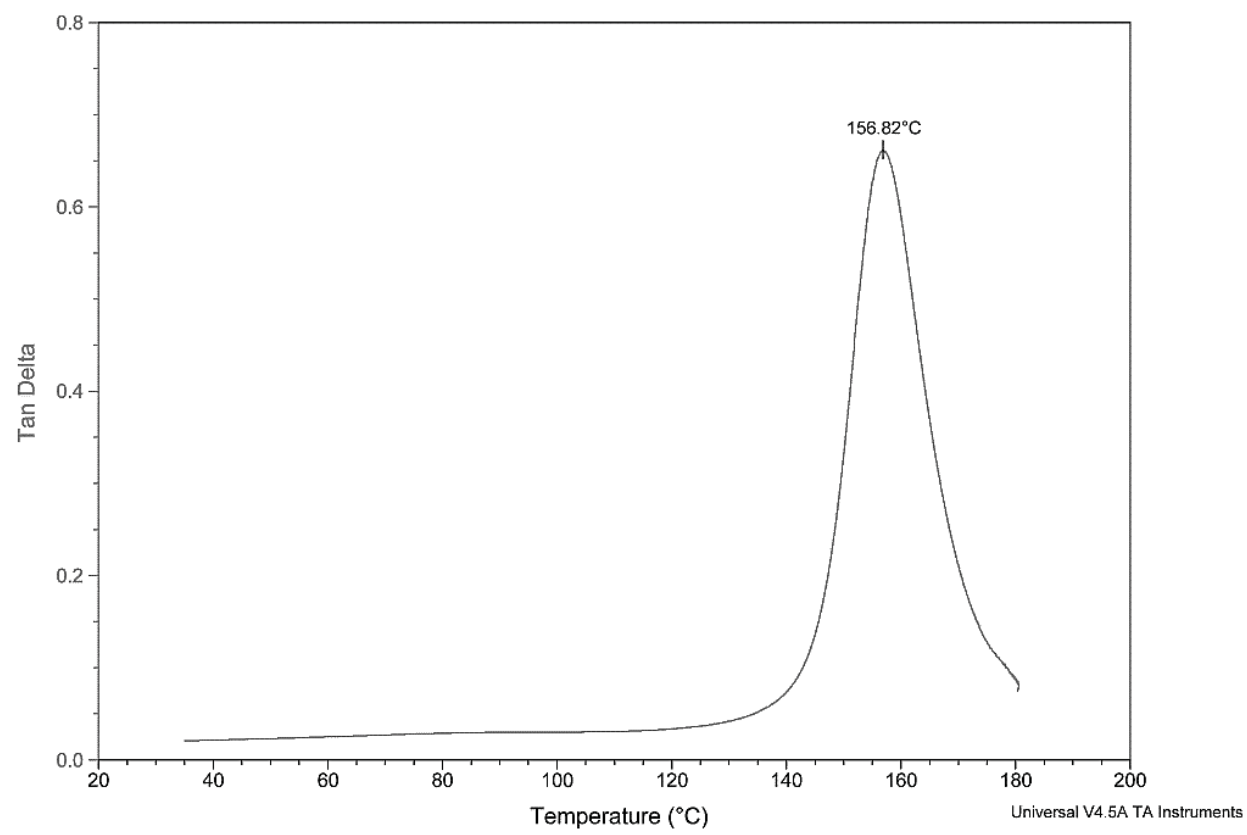

Figure D-33: Tan Delta for 4 wt\% $x$ GnP $^{\circledR}-M-5$ in Epoxy Test 1 
Table D-12: DMA Results for 5 wt\% $x G n P^{\circledR}-M-5$ in Epoxy

\begin{tabular}{|l|c|c|c|c|}
\hline \multicolumn{1}{|c|}{ Sample } & No. & $\begin{array}{c}\text { Storage } \\
\text { Modulus } \\
\text { Onset }\left({ }^{\circ} \mathbf{C}\right)\end{array}$ & $\begin{array}{c}\text { Loss } \\
\text { Modulus } \\
\text { Peak } \\
\left({ }^{\circ} \mathbf{C}\right)\end{array}$ & $\begin{array}{c}\text { Tan Delta } \\
\text { Peak } \\
\left({ }^{\circ} \mathbf{C}\right)\end{array}$ \\
\hline A862-M5-5-10-10-12 & 1 & 140.85 & 150.68 & 157.09 \\
\hline A862-M5-5-10-10-12 & 2 & 140.93 & 151.06 & 157.62 \\
\hline A862-M5-5-10-10-12 & 3 & 140.78 & 150.48 & 156.88 \\
\hline Average & & $\mathbf{1 4 0 . 9}$ & $\mathbf{1 5 0 . 7}$ & $\mathbf{1 5 7 . 2}$ \\
\hline Standard Deviation & $\mathbf{0 . 1}$ & $\mathbf{0 . 3}$ & $\mathbf{0 . 4}$ \\
\hline Count & $\mathbf{3}$ & $\mathbf{3}$ & $\mathbf{3}$ \\
\hline
\end{tabular}

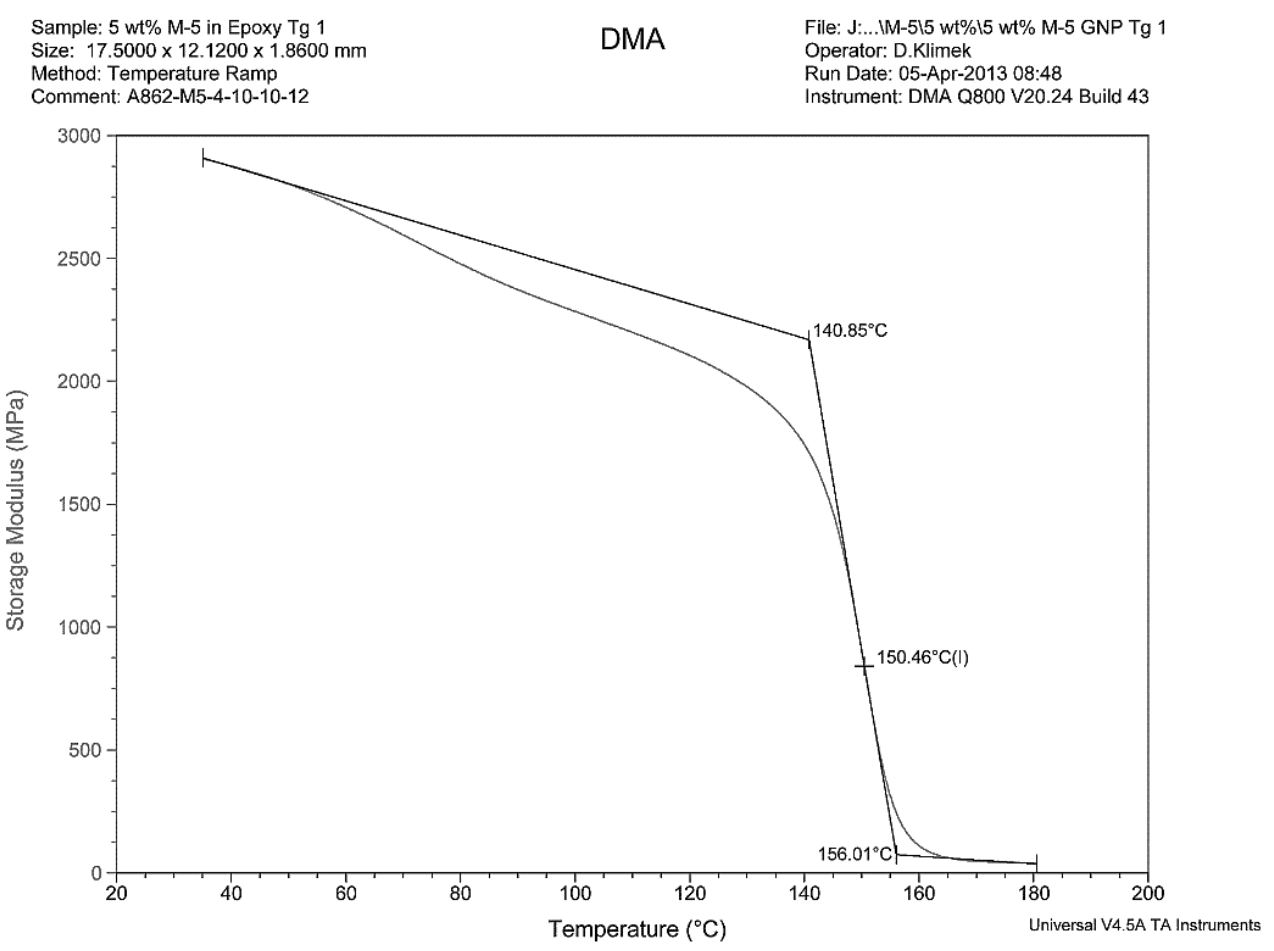

Figure D-34: Storage Modulus for $5 w t \% \times$ Gn $P^{\circledR}-M-5$ in Epoxy Test 1 


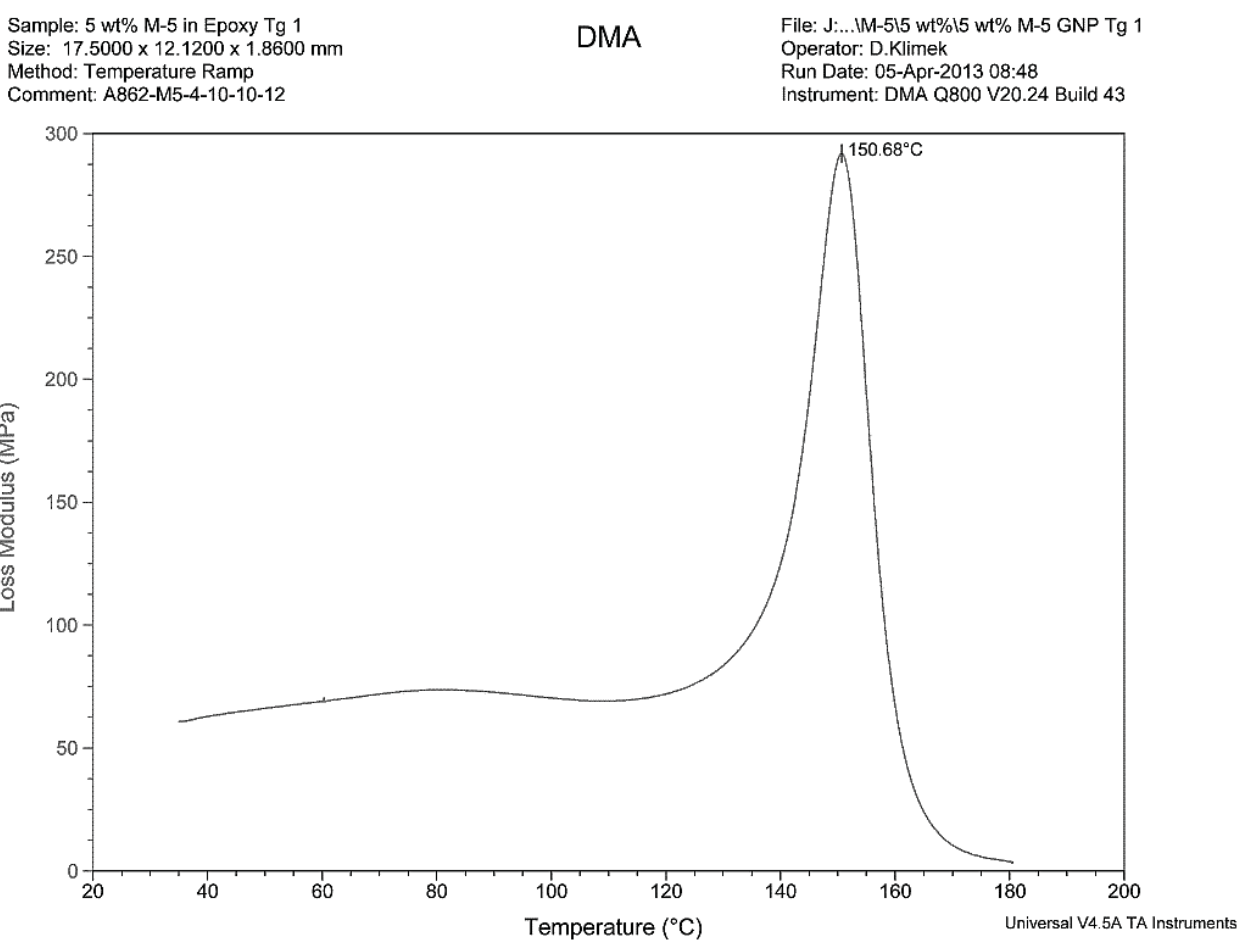

Figure D-35: Loss Modulus for 5 wt\% xGnP ${ }^{\circledR}-M-5$ in Epoxy Test 1

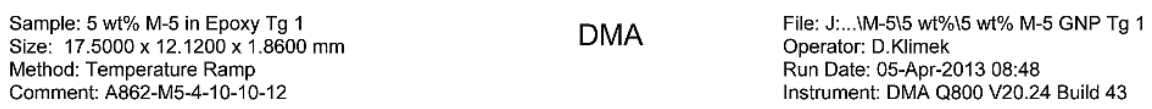

Instrument: DMA Q800 V20.24 Build 43

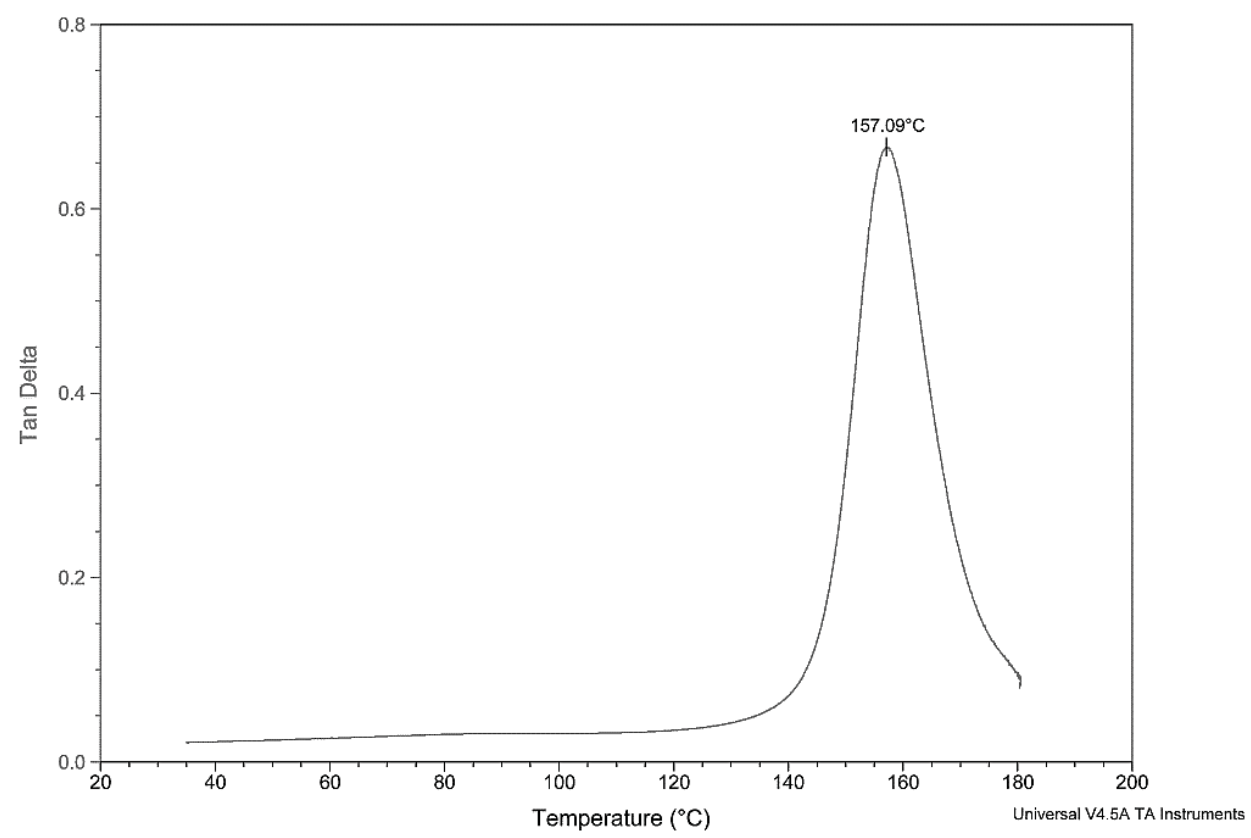

Figure D-36: Tan Delta for 5 wt\% $x G n P^{\circledR}-M-5$ in Epoxy Test 1 
Table D-13: DMA Results for 6 wt\% $x G n P^{\circledR}-M-5$ in Epoxy

\begin{tabular}{|l|c|c|c|c|}
\hline \multicolumn{1}{|c|}{ Sample } & No. & $\begin{array}{c}\text { Storage } \\
\text { Modulus } \\
\text { Onset }\left({ }^{\circ} \mathbf{C}\right)\end{array}$ & $\begin{array}{c}\text { Loss } \\
\text { Modulus } \\
\text { Peak } \\
\left({ }^{\circ} \mathbf{C}\right)\end{array}$ & $\begin{array}{c}\text { Tan Delta } \\
\text { Peak } \\
\left({ }^{\circ} \mathbf{C}\right)\end{array}$ \\
\hline A862-M5-6-10-15-12 & 1 & 139.08 & 149.76 & 156.42 \\
\hline A862-M5-6-10-15-12 & 2 & 139.20 & 149.88 & 156.38 \\
\hline A862-M5-6-10-15-12 & 3 & 139.68 & 149.85 & 156.50 \\
\hline Average & & $\mathbf{1 3 9 . 3}$ & $\mathbf{1 4 9 . 8}$ & $\mathbf{1 5 6 . 4}$ \\
\hline Standard Deviation & $\mathbf{0 . 3}$ & $\mathbf{0 . 1}$ & $\mathbf{0 . 1}$ \\
\hline Count & $\mathbf{3}$ & $\mathbf{3}$ & $\mathbf{3}$ \\
\hline
\end{tabular}

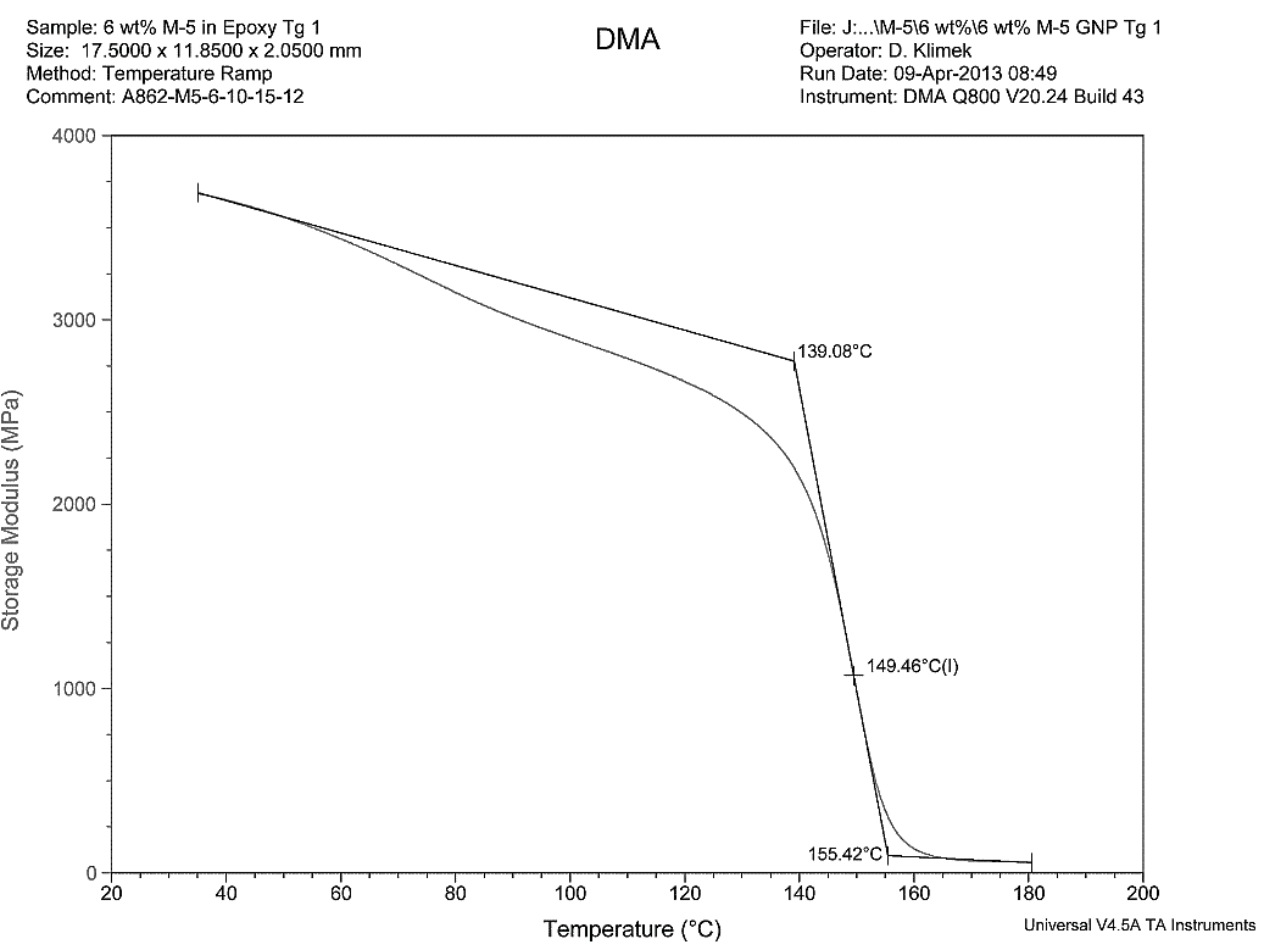

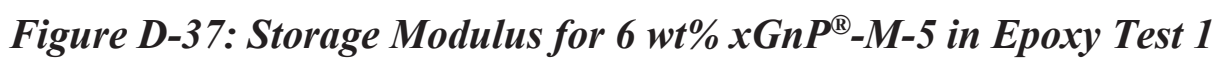




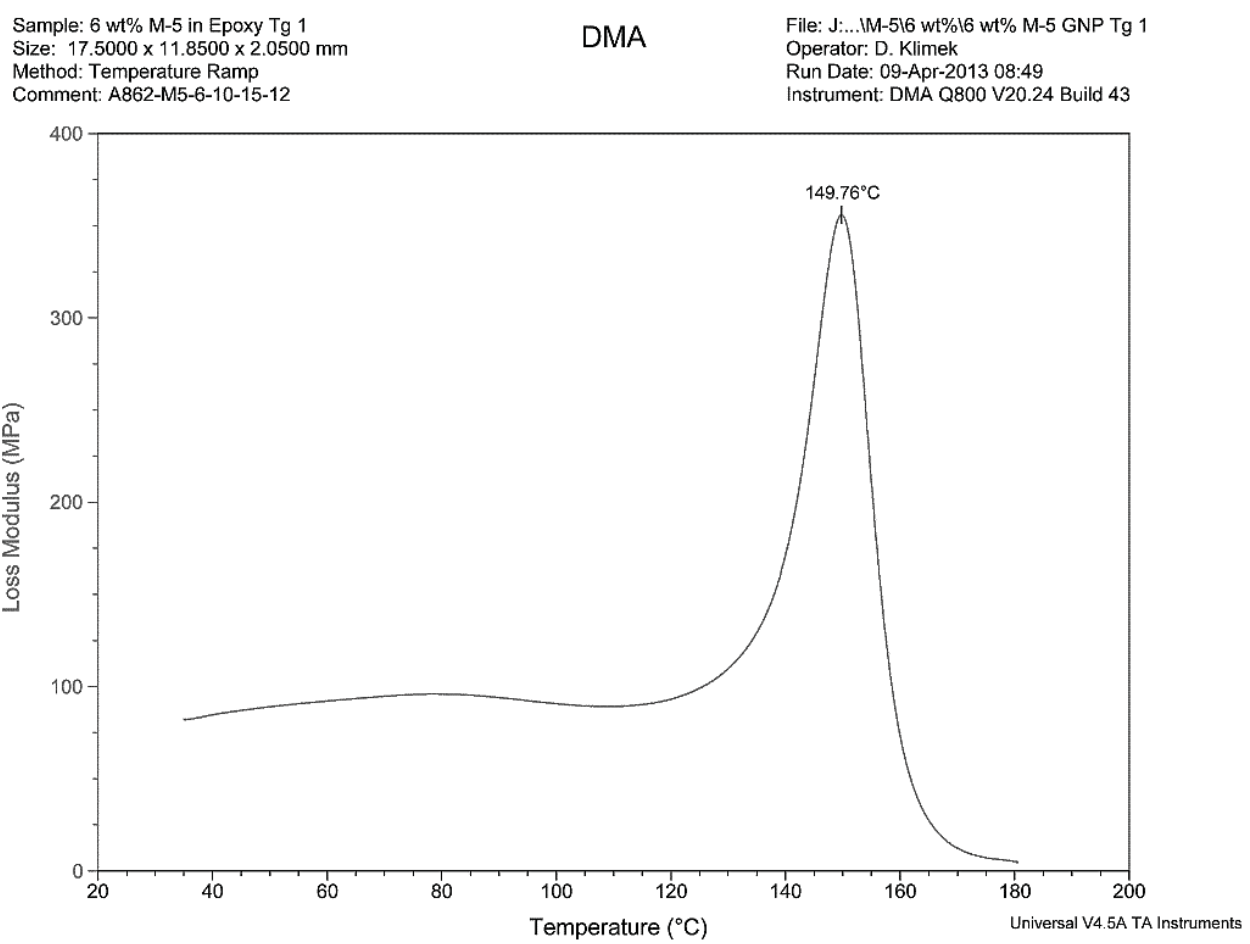

Figure D-38: Loss Modulus for 6 wt\% xGnP ${ }^{\circledR}-M-5$ in Epoxy Test 1

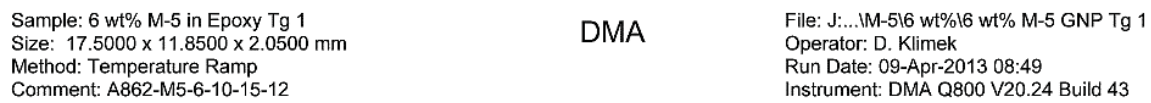

Instrument: DMA Q800 V20.24 Build 43

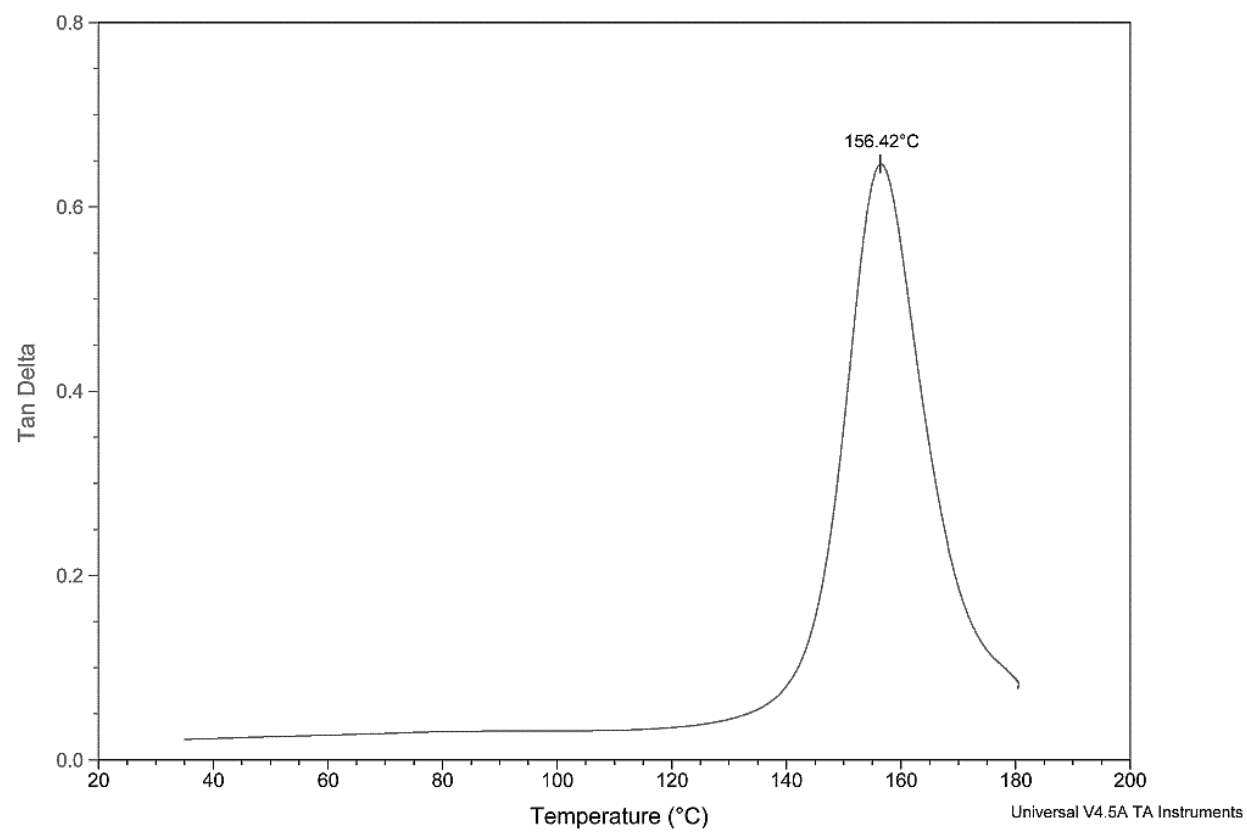

Figure D-39: Tan Delta for 6 wt\% $x$ GnP $^{\circledR}-M-5$ in Epoxy Test 1 
Table D-14: DMA Results for 1 wt\% $x G n P^{\circledR}-C-300$ in Epoxy

\begin{tabular}{|l|c|c|c|c|}
\hline \multicolumn{1}{|c|}{ Sample } & No. & $\begin{array}{c}\text { Storage } \\
\text { Modulus } \\
\text { Onset }\left({ }^{\circ} \mathbf{C}\right)\end{array}$ & $\begin{array}{c}\text { Loss } \\
\text { Modulus } \\
\text { Peak } \\
\left({ }^{\circ} \mathbf{C}\right)\end{array}$ & $\begin{array}{c}\text { Tan Delta } \\
\text { Peak } \\
\left({ }^{\circ} \mathbf{C}\right)\end{array}$ \\
\hline A862-C300-1-3-22-13 & 1 & 132.52 & 145.48 & 152.92 \\
\hline A862-C300-1-3-22-13 & 2 & 132.43 & 145.27 & 152.71 \\
\hline A862-C300-1-3-22-13 & 3 & 131.73 & 145.18 & 152.32 \\
\hline Average & & $\mathbf{1 3 2 . 2}$ & $\mathbf{1 4 5 . 3}$ & $\mathbf{1 5 2 . 7}$ \\
\hline Standard Deviation & $\mathbf{0 . 4}$ & $\mathbf{0 . 2}$ & $\mathbf{0 . 3}$ \\
\hline Count & $\mathbf{3}$ & $\mathbf{3}$ & $\mathbf{3}$ \\
\hline
\end{tabular}

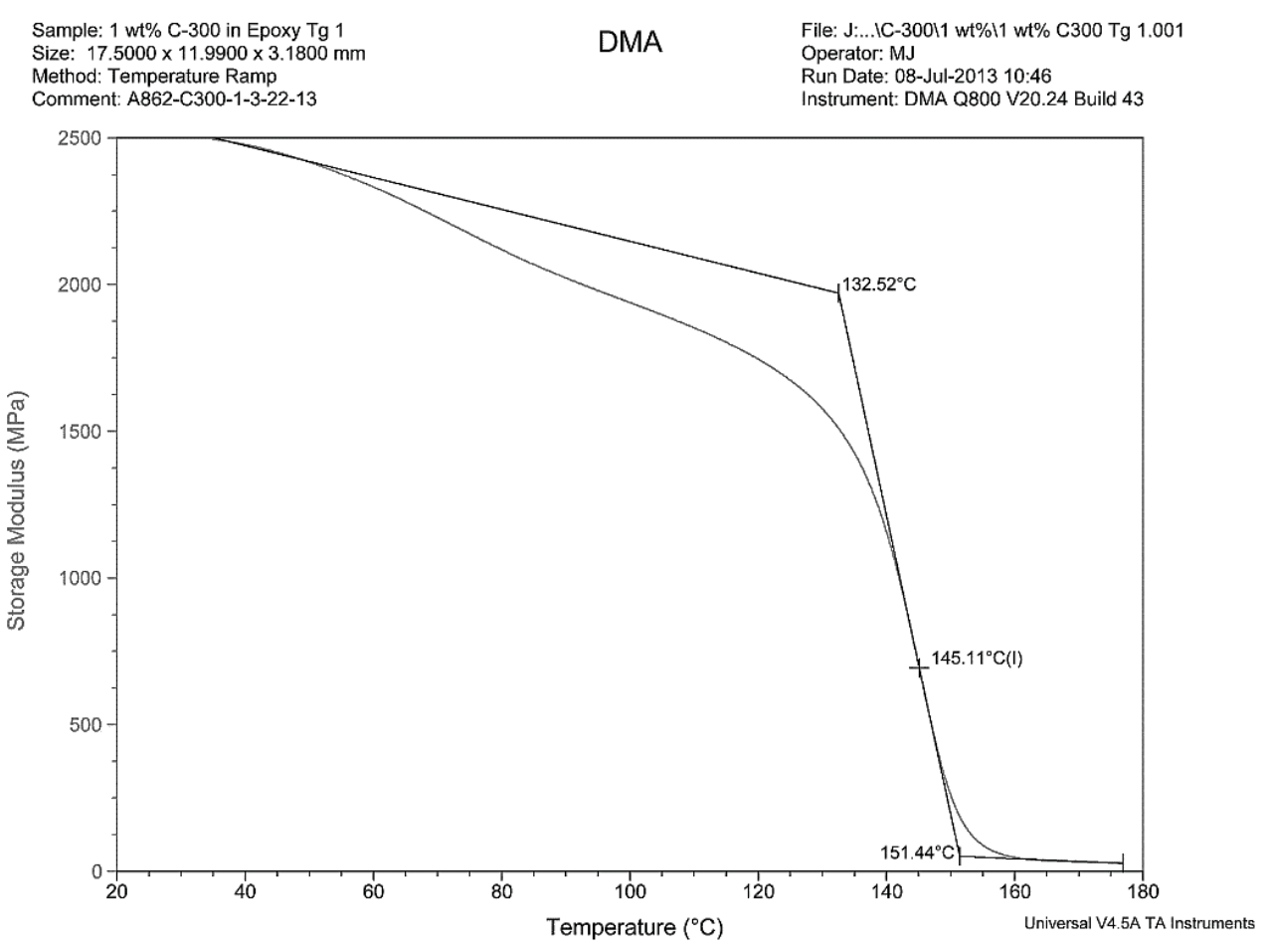

Figure D-40: Storage Modulus for 1 wt\% $x G n P^{\circledR}-C-300$ in Epoxy Test 1 


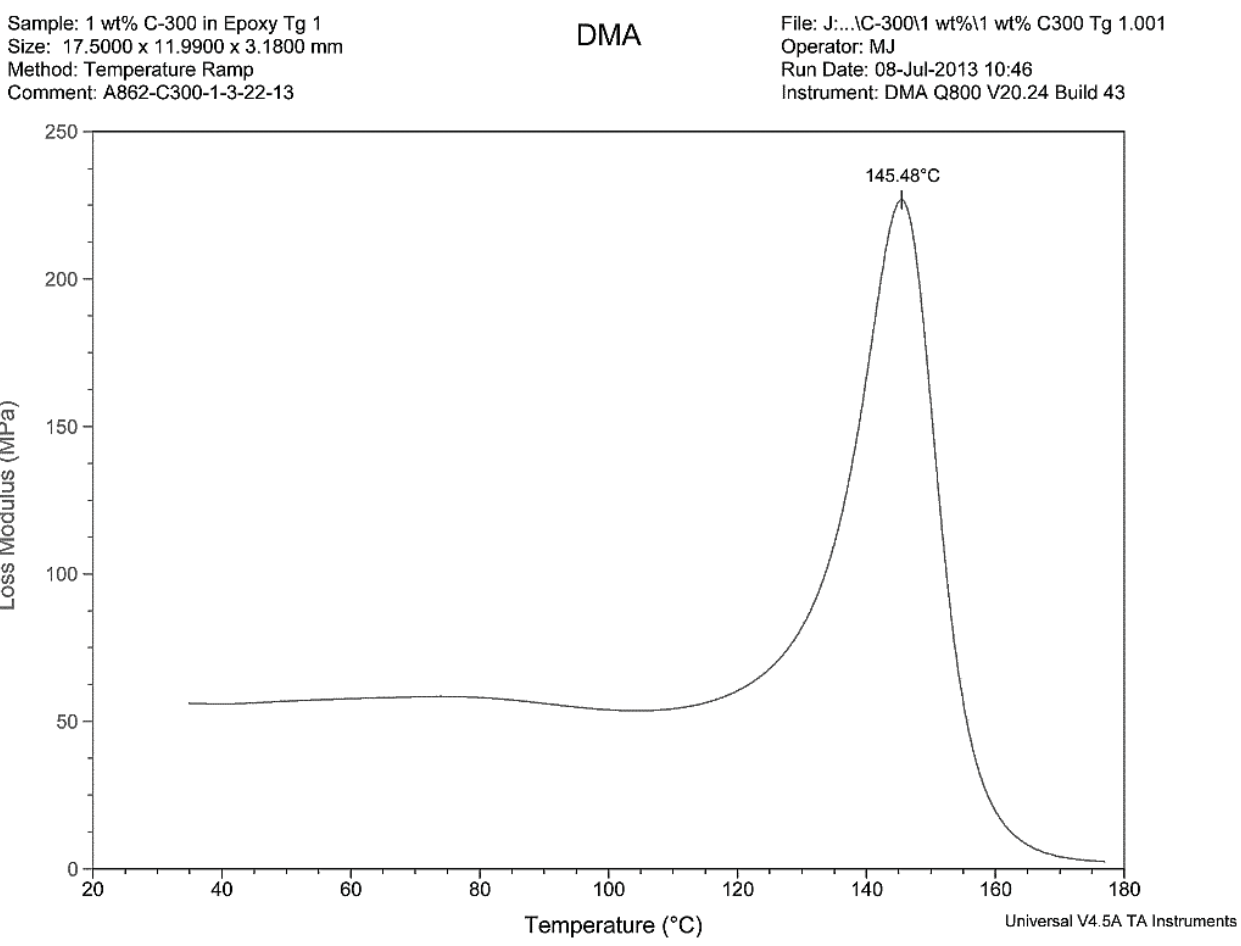

Figure D-41: Loss Modulus for 1 wt\% xGnP ${ }^{\circledR}-C-300$ in Epoxy Test 1

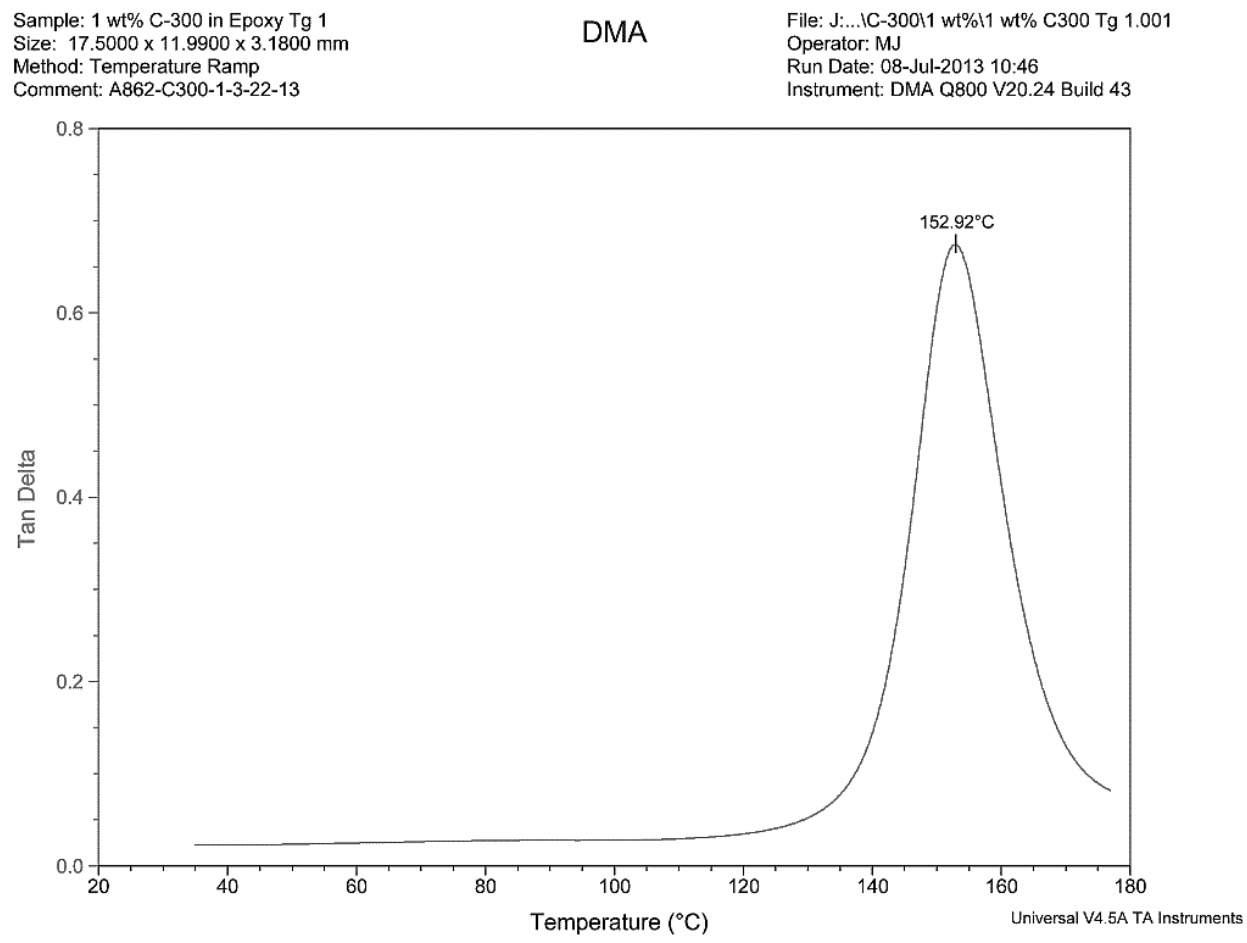

Figure D-42: Tan Delta for 1 wt\% $x G n P^{\circledR}-C-300$ in Epoxy Test 1 
Table D-15: DMA Results for 2 wt\% $x G n P^{\circledR}-C-300$ in Epoxy

\begin{tabular}{|l|c|c|c|c|}
\hline \multicolumn{1}{|c|}{ Sample } & No. & $\begin{array}{c}\text { Storage } \\
\text { Modulus } \\
\text { Onset }\left({ }^{\circ} \mathbf{C}\right)\end{array}$ & $\begin{array}{c}\text { Loss } \\
\text { Modulus } \\
\text { Peak } \\
\left({ }^{\circ} \mathbf{C}\right)\end{array}$ & $\begin{array}{c}\text { Tan Delta } \\
\text { Peak } \\
\left({ }^{\circ} \mathbf{C}\right)\end{array}$ \\
\hline A862-C300-2-3-7-13 & 1 & 120.45 & 134.87 & 143.52 \\
\hline A862-C300-2-3-7-13 & 2 & 120.21 & 134.86 & 143.50 \\
\hline A862-C300-2-3-7-13 & 3 & 121.11 & 134.67 & 143.13 \\
\hline Average & & $\mathbf{1 2 0 . 6}$ & $\mathbf{1 3 4 . 8}$ & $\mathbf{1 4 3 . 4}$ \\
\hline Standard Deviation & $\mathbf{0 . 5}$ & $\mathbf{0 . 1}$ & $\mathbf{0 . 2}$ \\
\hline Count & $\mathbf{3}$ & $\mathbf{3}$ & $\mathbf{3}$ \\
\hline
\end{tabular}

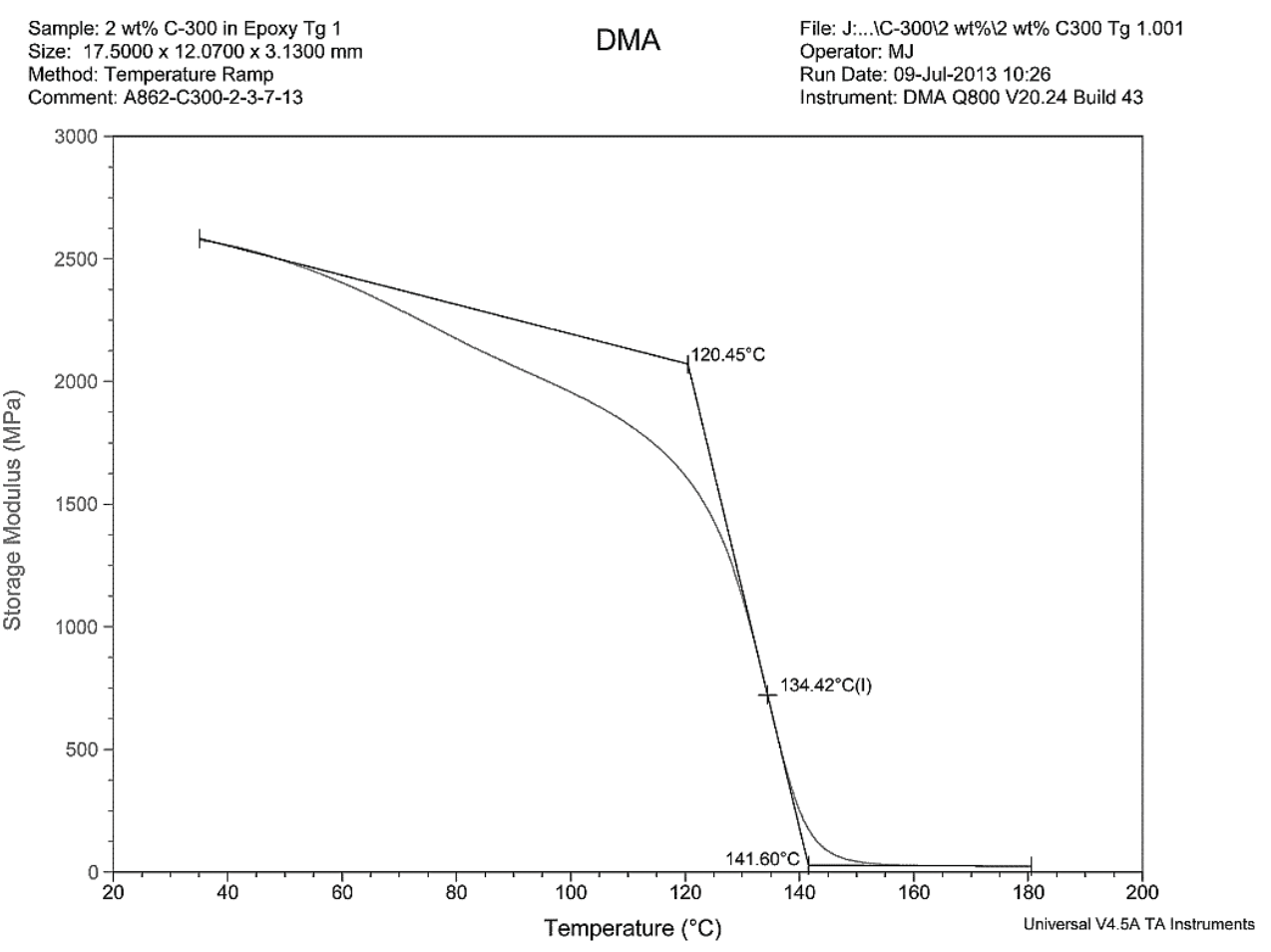

Figure D-43: Storage Modulus for $2 w t \% x G n P^{\circledR}-C-300$ in Epoxy Test 1 


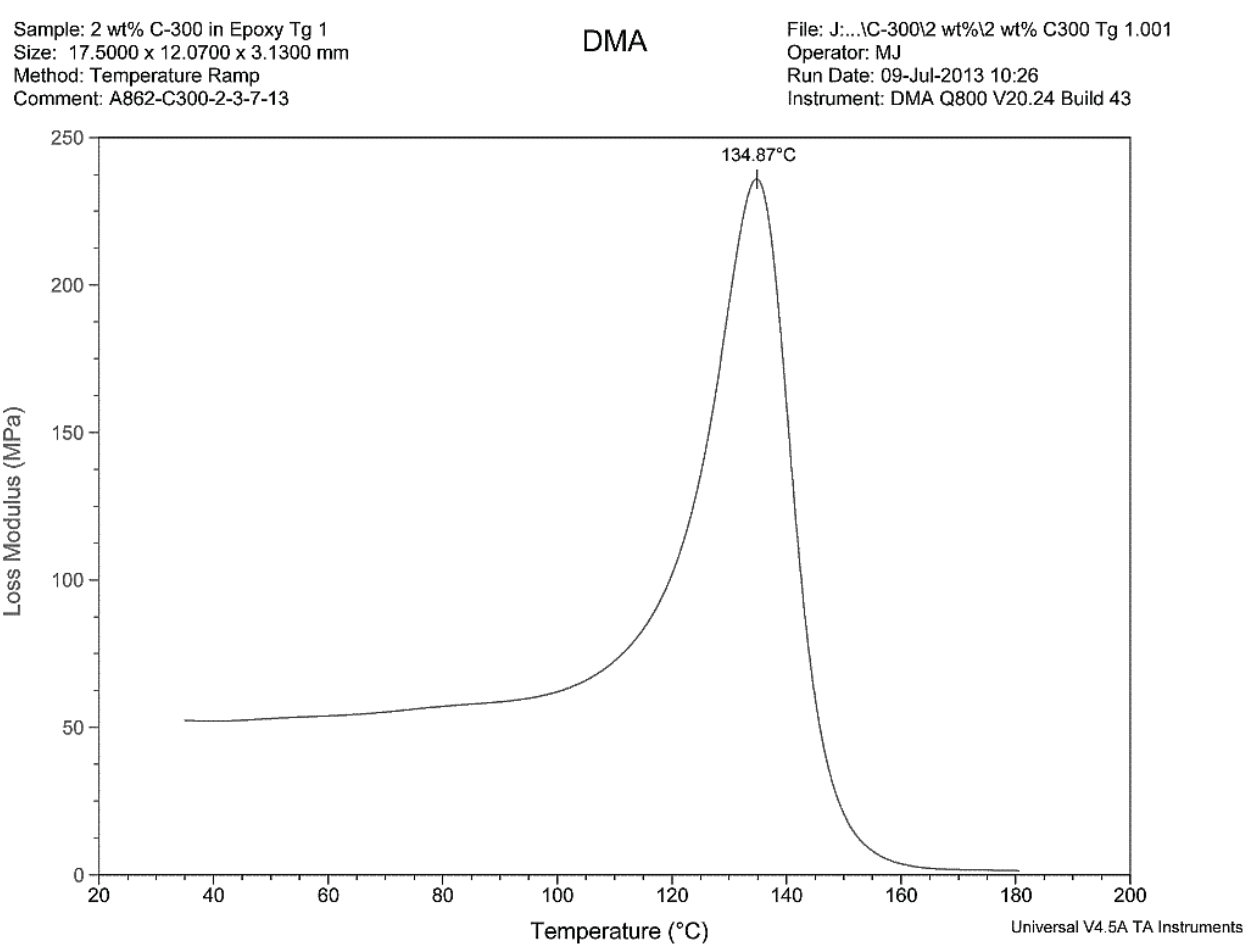

Figure D-44: Loss Modulus for $2 w t \% x G n P^{\circledR}-C-300$ in Epoxy Test 1

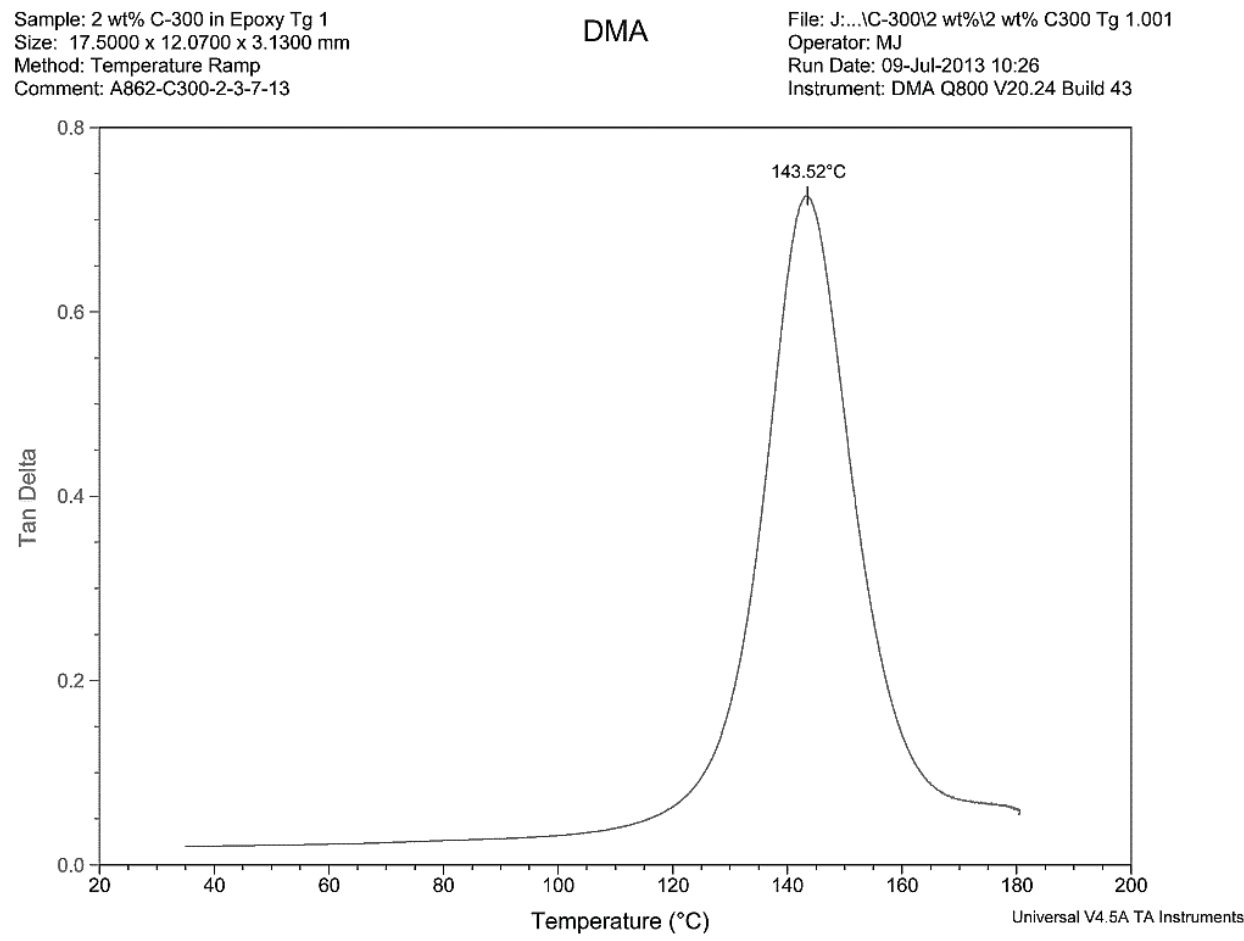

Figure D-45: Tan Delta for 2 wt\% $x$ GnP $^{\circledR}-$ C-300 in Epoxy Test 1 
Table D-16: DMA Results for 3 wt\% $x G n P^{\circledR}-C-300$ in Epoxy

\begin{tabular}{|l|c|c|c|c|}
\hline \multicolumn{1}{|c|}{ Sample } & No. & $\begin{array}{c}\text { Storage } \\
\text { Modulus } \\
\text { Onset }\left({ }^{\circ} \mathbf{C}\right)\end{array}$ & $\begin{array}{c}\text { Loss } \\
\text { Modulus } \\
\text { Peak } \\
\left({ }^{\circ} \mathbf{C}\right)\end{array}$ & $\begin{array}{c}\text { Tan Delta } \\
\text { Peak } \\
\left({ }^{\circ} \mathbf{C}\right)\end{array}$ \\
\hline A862-C300-3-3-5-13 & 1 & 132.03 & 145.15 & 152.54 \\
\hline A862-C300-3-3-5-13 & 2 & 132.33 & 144.88 & 152.47 \\
\hline A862-C300-3-3-5-13 & 3 & 133.17 & 145.12 & 153.16 \\
\hline Average & & $\mathbf{1 3 2 . 5}$ & $\mathbf{1 4 5 . 1}$ & $\mathbf{1 5 2 . 7}$ \\
\hline Standard Deviation & $\mathbf{0 . 6}$ & $\mathbf{0 . 1}$ & $\mathbf{0 . 4}$ \\
\hline Count & $\mathbf{3}$ & $\mathbf{3}$ & $\mathbf{3}$ \\
\hline
\end{tabular}

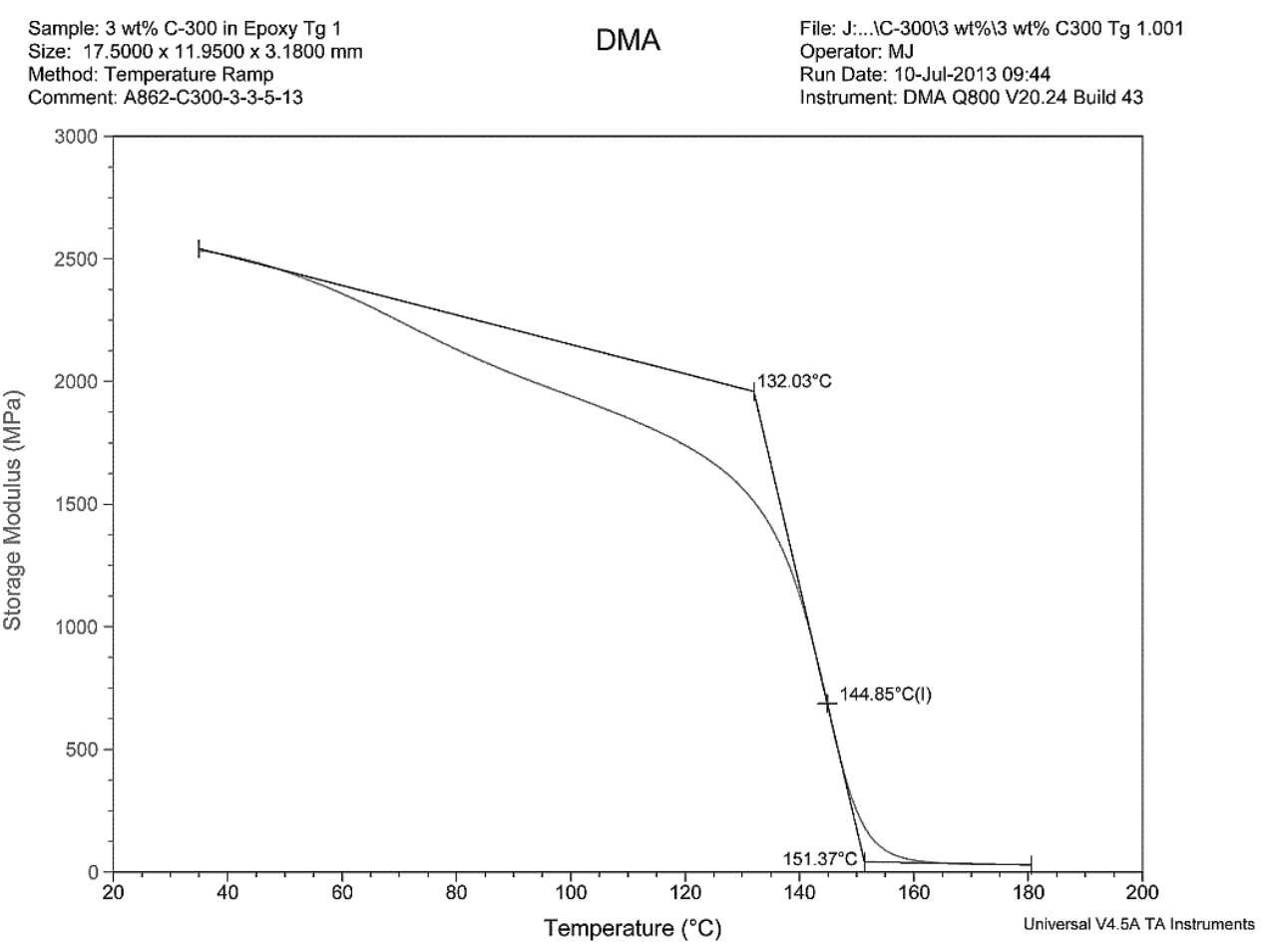

Figure D-46: Storage Modulus for 3 wt\% xGnP ${ }^{\circledR}-C-300$ in Epoxy Test 1 


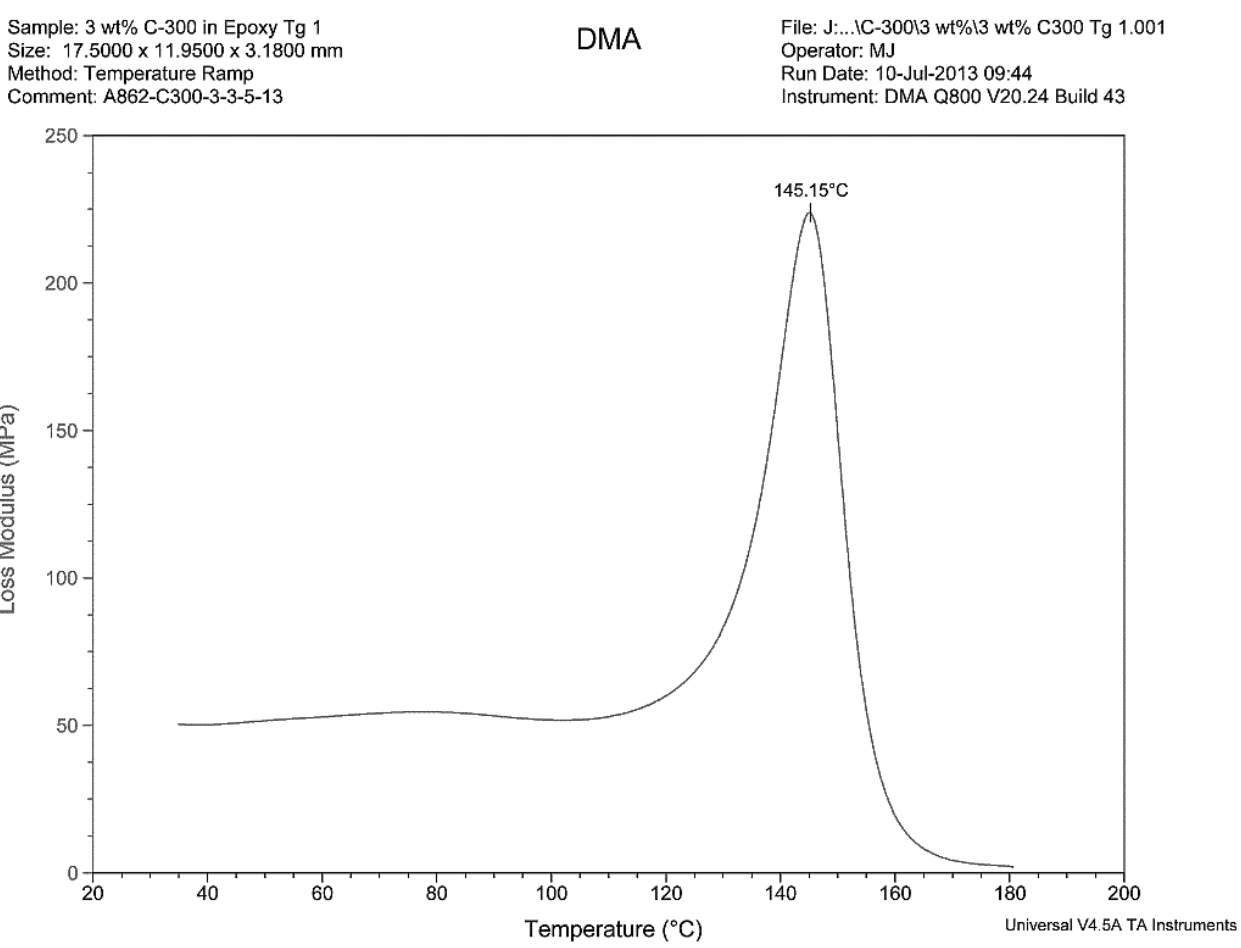

Figure D-47: Loss Modulus for $3 w t \% x G n P^{\circledR}-C-300$ in Epoxy Test 1

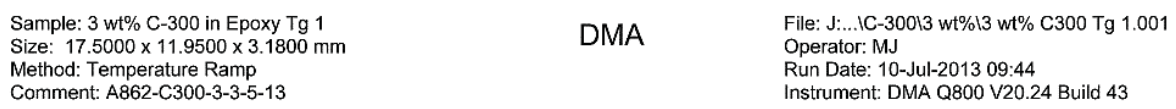

Method: Temperature Ramp
Comment: A862-C300-3-3-5-13

Instrument: DMA Q800 V20.24 Build 43

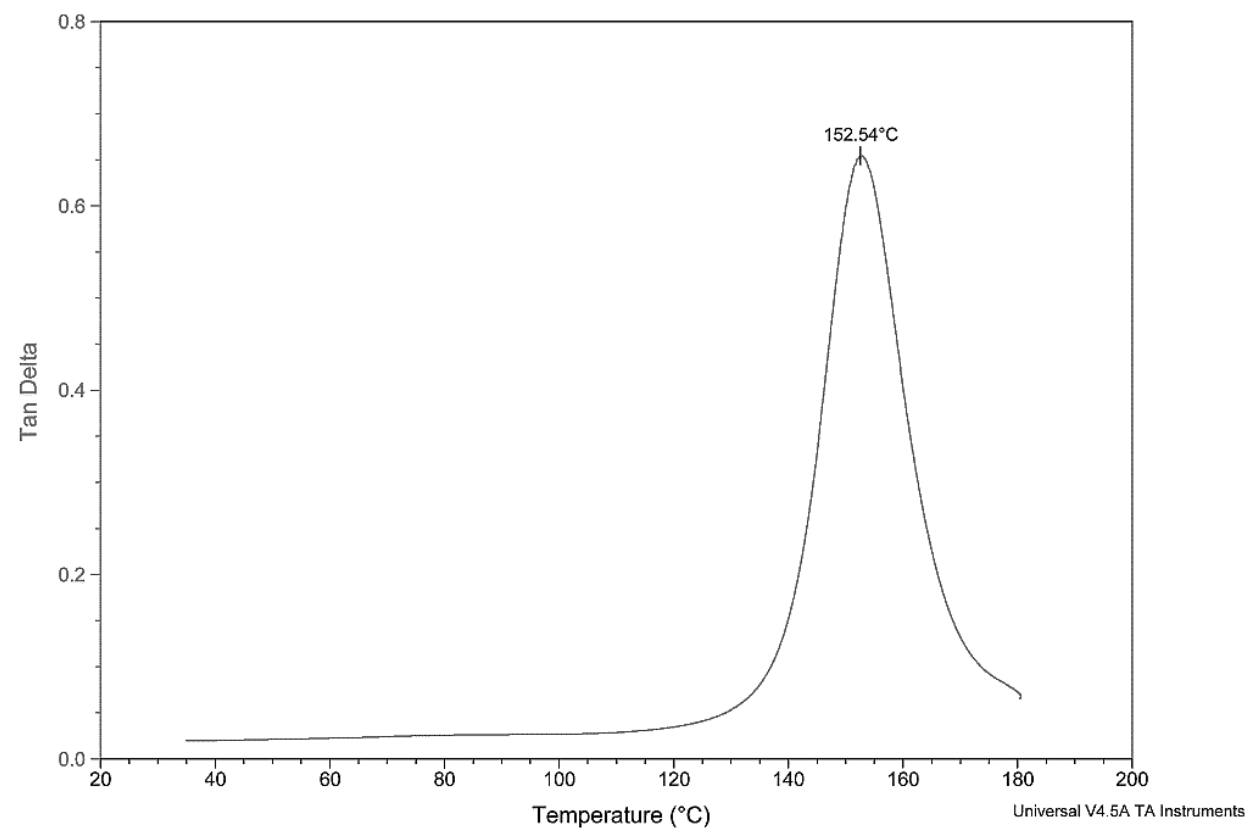

Figure D-48: Tan Delta for $3 w t \% x G n P^{\circledR}-C-300$ in Epoxy Test 1 
Table D-17: DMA Results for 4 wt\% $x G n P^{\circledR}-C-300$ in Epoxy

\begin{tabular}{|l|c|c|c|c|}
\hline \multicolumn{1}{|c|}{ Sample } & No. & $\begin{array}{c}\text { Storage } \\
\text { Modulus } \\
\text { Onset }\left({ }^{\circ} \mathbf{C}\right)\end{array}$ & $\begin{array}{c}\text { Loss } \\
\text { Modulus } \\
\text { Peak } \\
\left({ }^{\circ} \mathbf{C}\right)\end{array}$ & $\begin{array}{c}\text { Tan Delta } \\
\text { Peak } \\
\left({ }^{\circ} \mathbf{C}\right)\end{array}$ \\
\hline A862-C300-4-3-28-13 & 1 & 134.39 & 147.20 & 154.60 \\
\hline A862-C300-4-3-28-13 & 2 & 134.56 & 147.22 & 154.76 \\
\hline A862-C300-4-3-28-13 & 3 & 135.97 & 147.69 & 155.23 \\
\hline Average & & $\mathbf{1 3 5 . 0}$ & $\mathbf{1 4 7 . 4}$ & $\mathbf{1 5 4 . 9}$ \\
\hline Standard Deviation & $\mathbf{0 . 9}$ & $\mathbf{0 . 3}$ & $\mathbf{0 . 3}$ \\
\hline Count & $\mathbf{3}$ & $\mathbf{3}$ & $\mathbf{3}$ \\
\hline
\end{tabular}

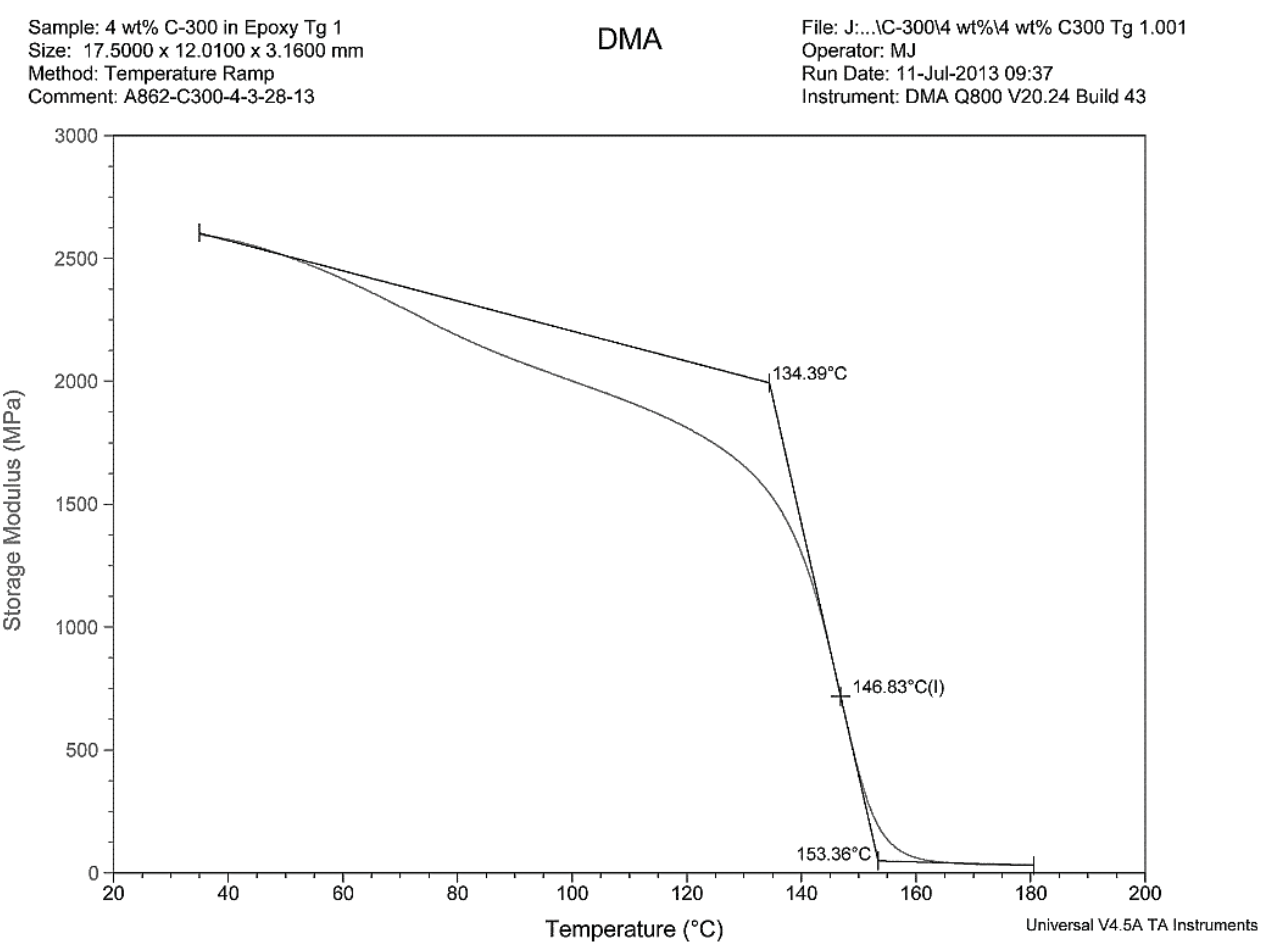

Figure D-49: Storage Modulus for 4 wt\% $x G n P^{\circledR}-C-300$ in Epoxy Test 1 


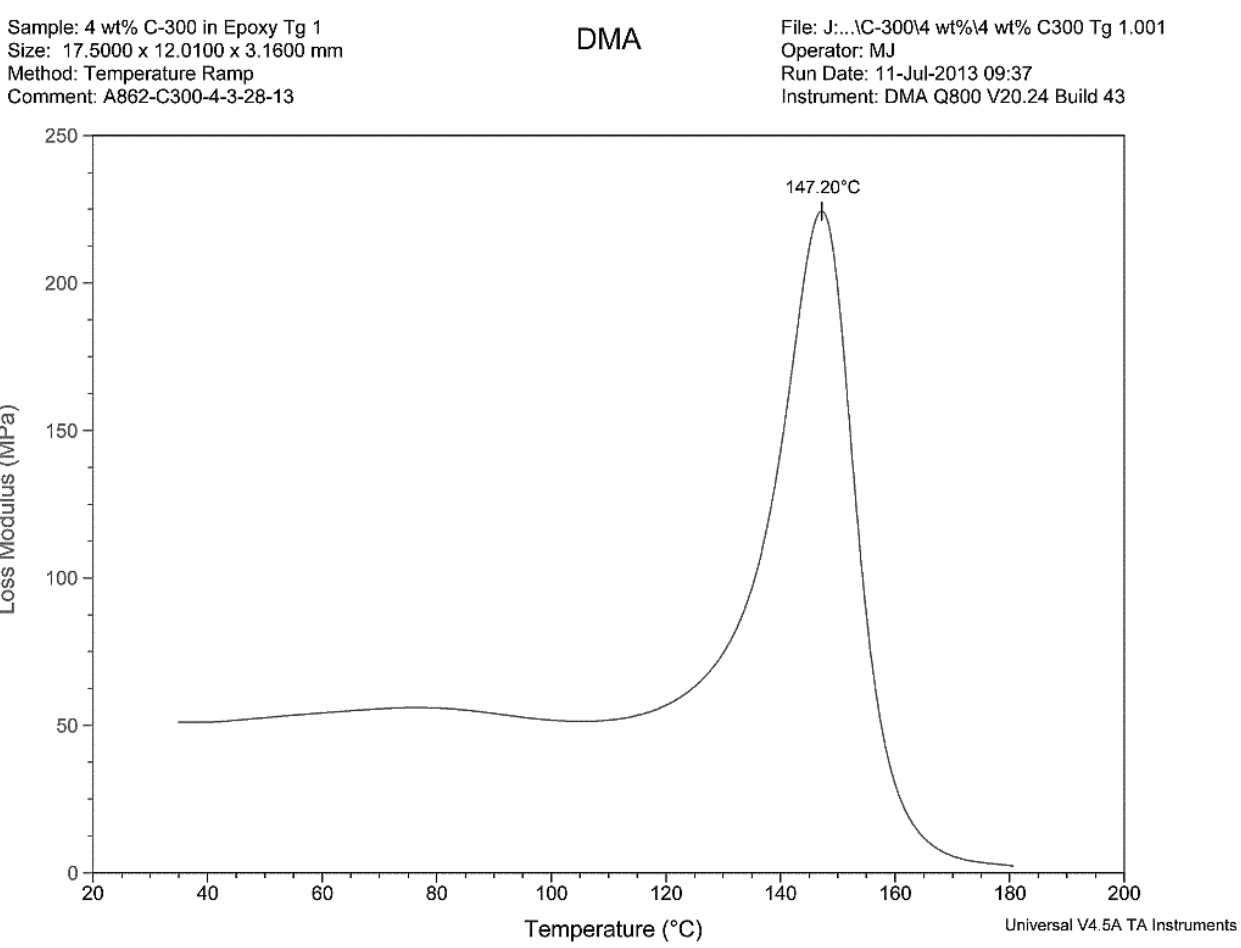

Figure D-50: Loss Modulus for 4 wt\% $x G n P^{\circledR}-C-300$ in Epoxy Test 1

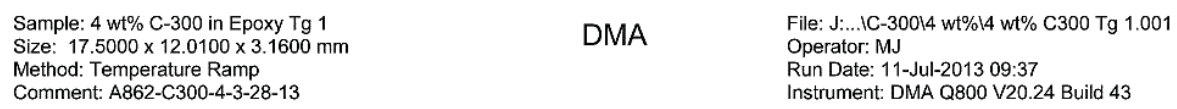

Method: Temperature Ramp

Run Date: 11 -Jul-2013 09:37

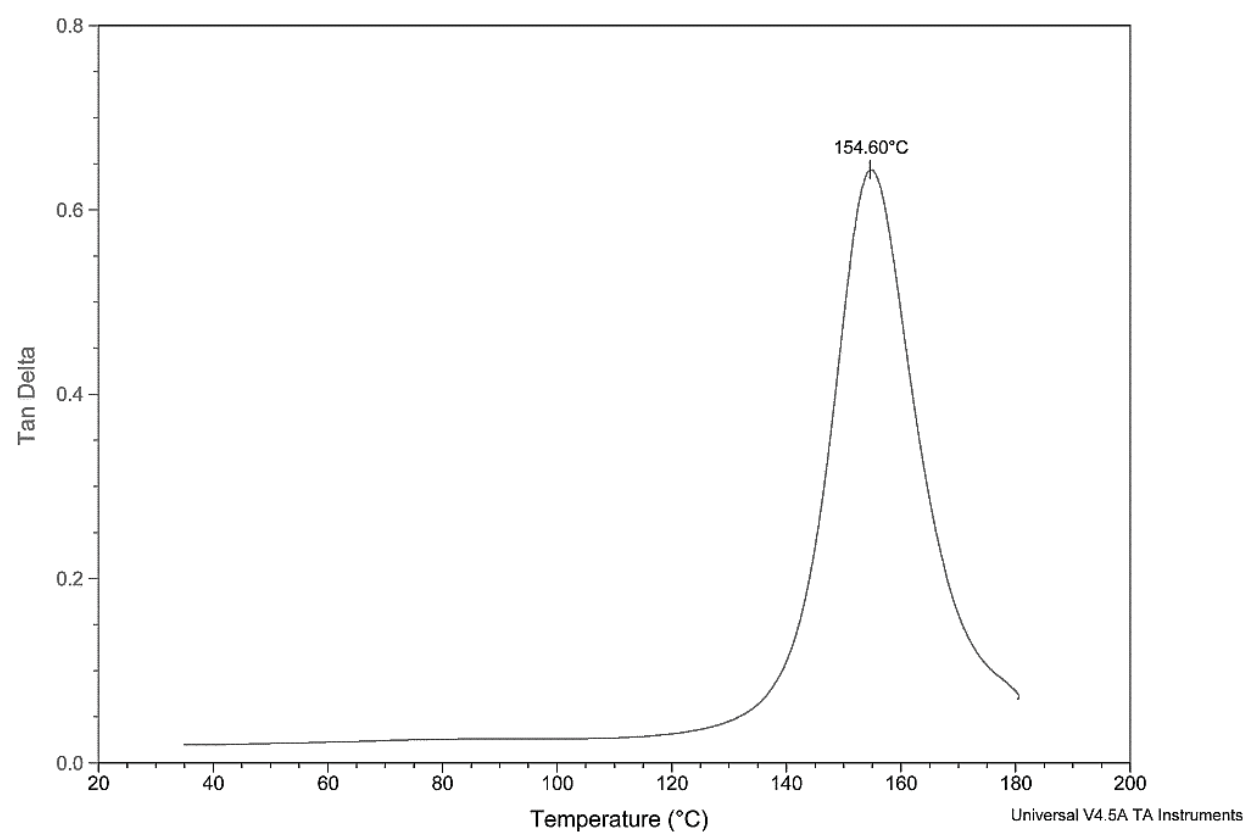

Figure D-51: Tan Delta for 4 wt\% $x$ GnP $^{\circledR}{ }_{-}$-300 in Epoxy Test 1 
Table D-18: DMA Results for 5 wt\% $x G n P^{\circledR}-C-300$ in Epoxy

\begin{tabular}{|l|c|c|c|c|}
\hline \multicolumn{1}{|c|}{ Sample } & No. & $\begin{array}{c}\text { Storage } \\
\text { Modulus } \\
\text { Onset }\left({ }^{\circ} \mathbf{C}\right)\end{array}$ & $\begin{array}{c}\text { Loss } \\
\text { Modulus } \\
\text { Peak } \\
\left({ }^{\circ} \mathbf{C}\right)\end{array}$ & $\begin{array}{c}\text { Tan Delta } \\
\text { Peak } \\
\left({ }^{\circ} \mathbf{C}\right)\end{array}$ \\
\hline A862-C300-5-4-1-13 & 1 & 133.13 & 145.77 & 153.52 \\
\hline A862-C300-5-4-1-13 & 2 & 132.29 & 145.49 & 153.02 \\
\hline A862-C300-5-4-1-13 & 3 & 133.58 & 145.61 & 153.45 \\
\hline Average & & $\mathbf{1 3 3 . 0}$ & $\mathbf{1 4 5 . 6}$ & $\mathbf{1 5 3 . 3}$ \\
\hline Standard Deviation & $\mathbf{0 . 7}$ & $\mathbf{0 . 1}$ & $\mathbf{0 . 3}$ \\
\hline Count & $\mathbf{3}$ & $\mathbf{3}$ & $\mathbf{3}$ \\
\hline
\end{tabular}

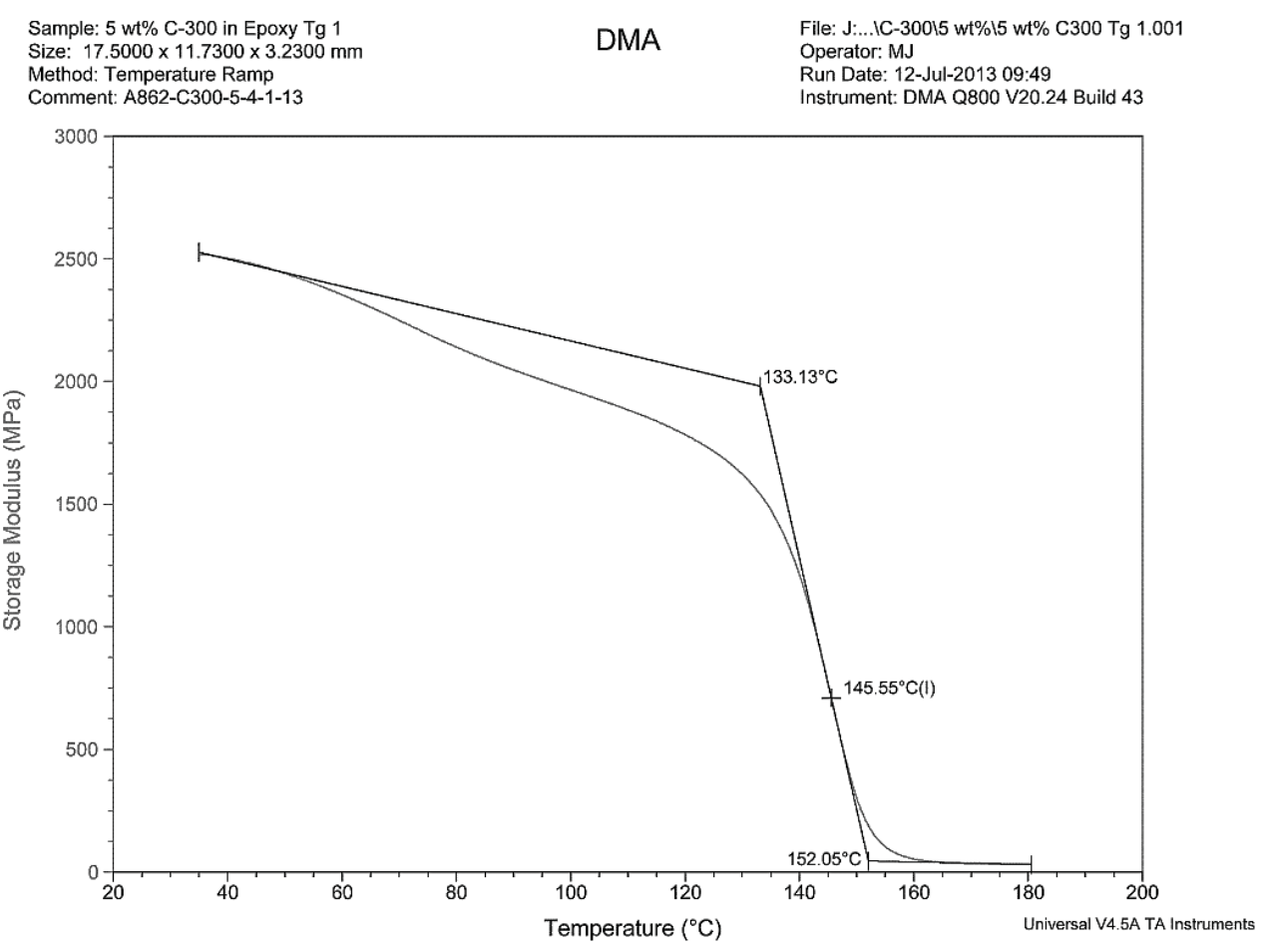

Figure D-52: Storage Modulus for 5 wt\% $x G n P^{\circledR}-C-300$ in Epoxy Test 1 


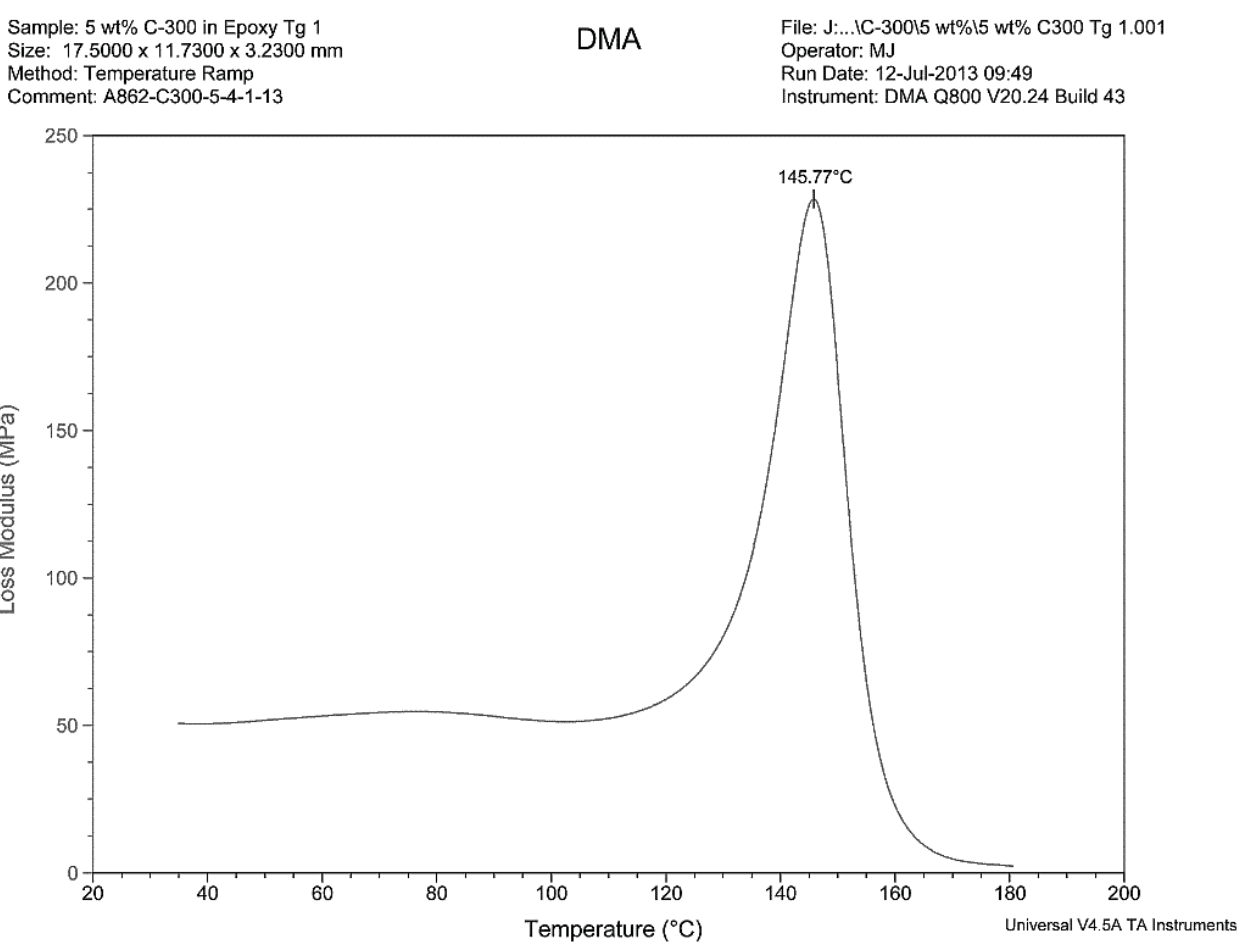

Figure D-53: Loss Modulus for 5 wt\% xGnP ${ }^{\circledR}-C-300$ in Epoxy Test 1

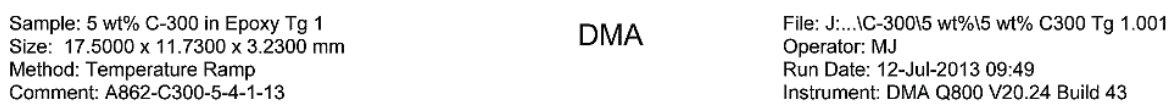

Method: Temperature Ramp
Comment: A862-C300-5-4-1-13

Run Date: 12-Jul-2013 09:49

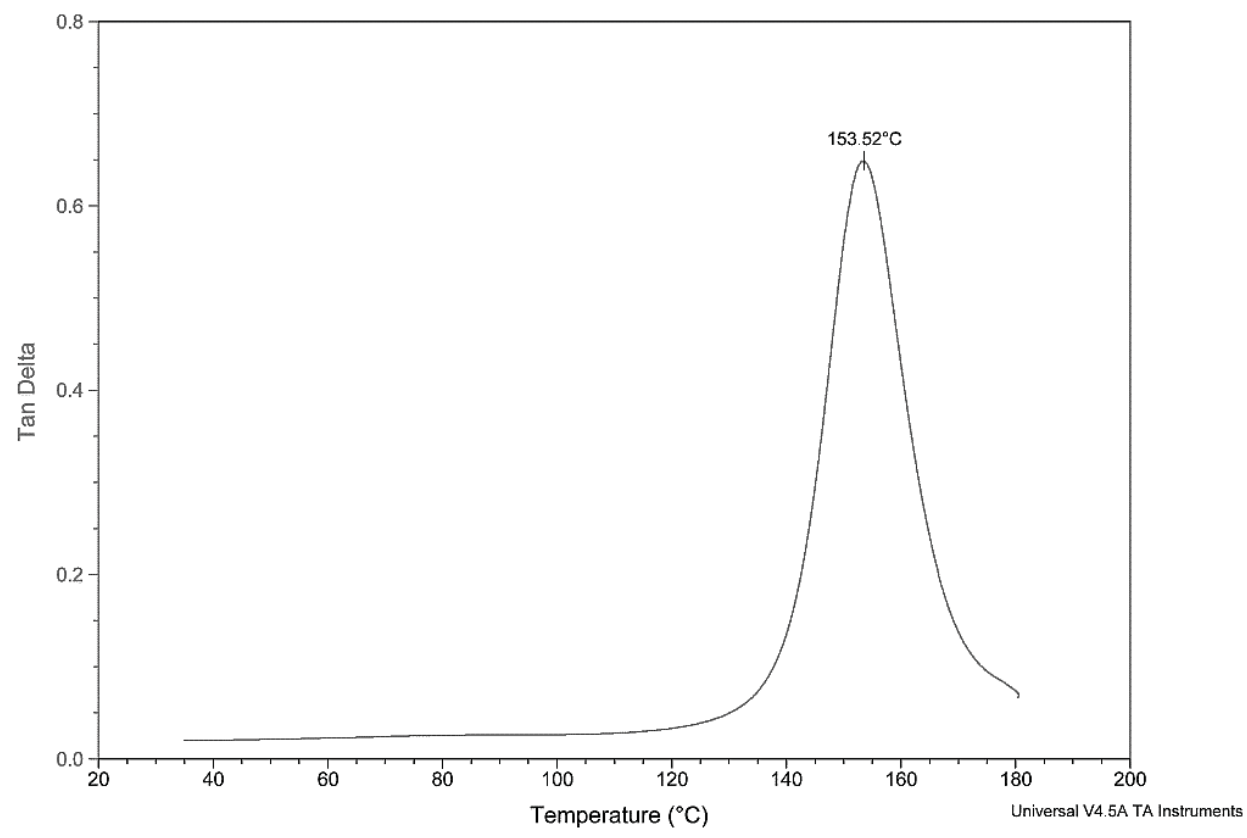

Figure D-54: Tan Delta for 5 wt\% $x G n P^{\circledR}-C-300$ in Epoxy Test 1 
Table D-19: DMA Results for 6 wt\% $x G n P^{\circledR}-C-300$ in Epoxy

\begin{tabular}{|l|c|c|c|c|}
\hline \multicolumn{1}{|c|}{ Sample } & No. & $\begin{array}{c}\text { Storage } \\
\text { Modulus } \\
\text { Onset }\left({ }^{\circ} \mathbf{C}\right)\end{array}$ & $\begin{array}{c}\text { Loss } \\
\text { Modulus } \\
\text { Peak } \\
\left({ }^{\circ} \mathbf{C}\right)\end{array}$ & $\begin{array}{c}\text { Tan Delta } \\
\text { Peak } \\
\left({ }^{\circ} \mathbf{C}\right)\end{array}$ \\
\hline A862-C300-6-4-1-13 & 1 & 132.28 & 145.33 & 153.12 \\
\hline A862-C300-6-4-1-13 & 2 & 132.98 & 145.43 & 153.49 \\
\hline A862-C300-6-4-1-13 & 3 & 133.23 & 145.32 & 153.54 \\
\hline Average & & $\mathbf{1 3 2 . 8}$ & $\mathbf{1 4 5 . 4}$ & $\mathbf{1 5 3 . 4}$ \\
\hline Standard Deviation & $\mathbf{0 . 5}$ & $\mathbf{0 . 1}$ & $\mathbf{0 . 2}$ \\
\hline Count & $\mathbf{3}$ & $\mathbf{3}$ & $\mathbf{3}$ \\
\hline
\end{tabular}

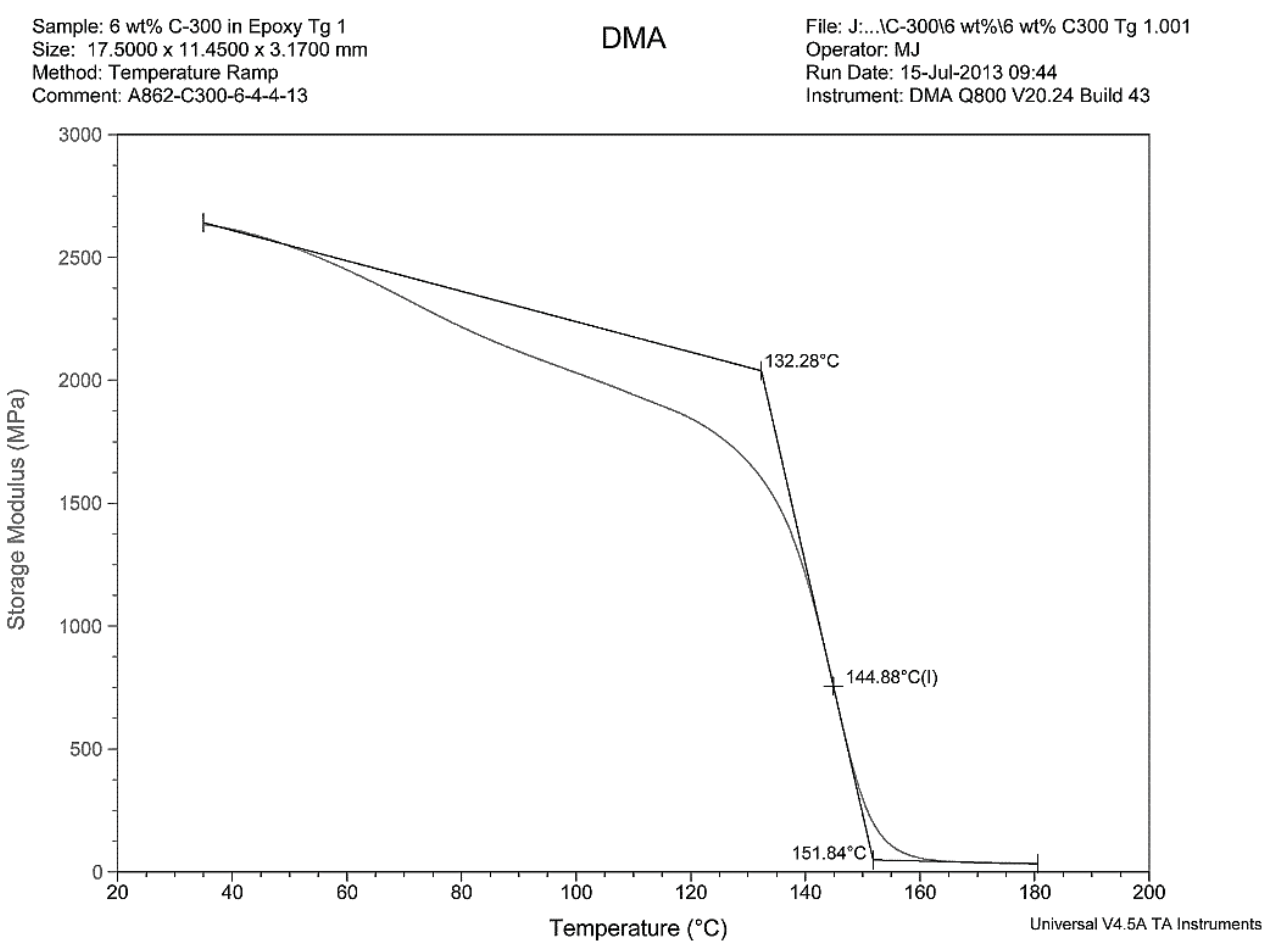

Figure D-55: Storage Modulus for $6 w t \% x G n P^{\circledR}-C-300$ in Epoxy Test 1 


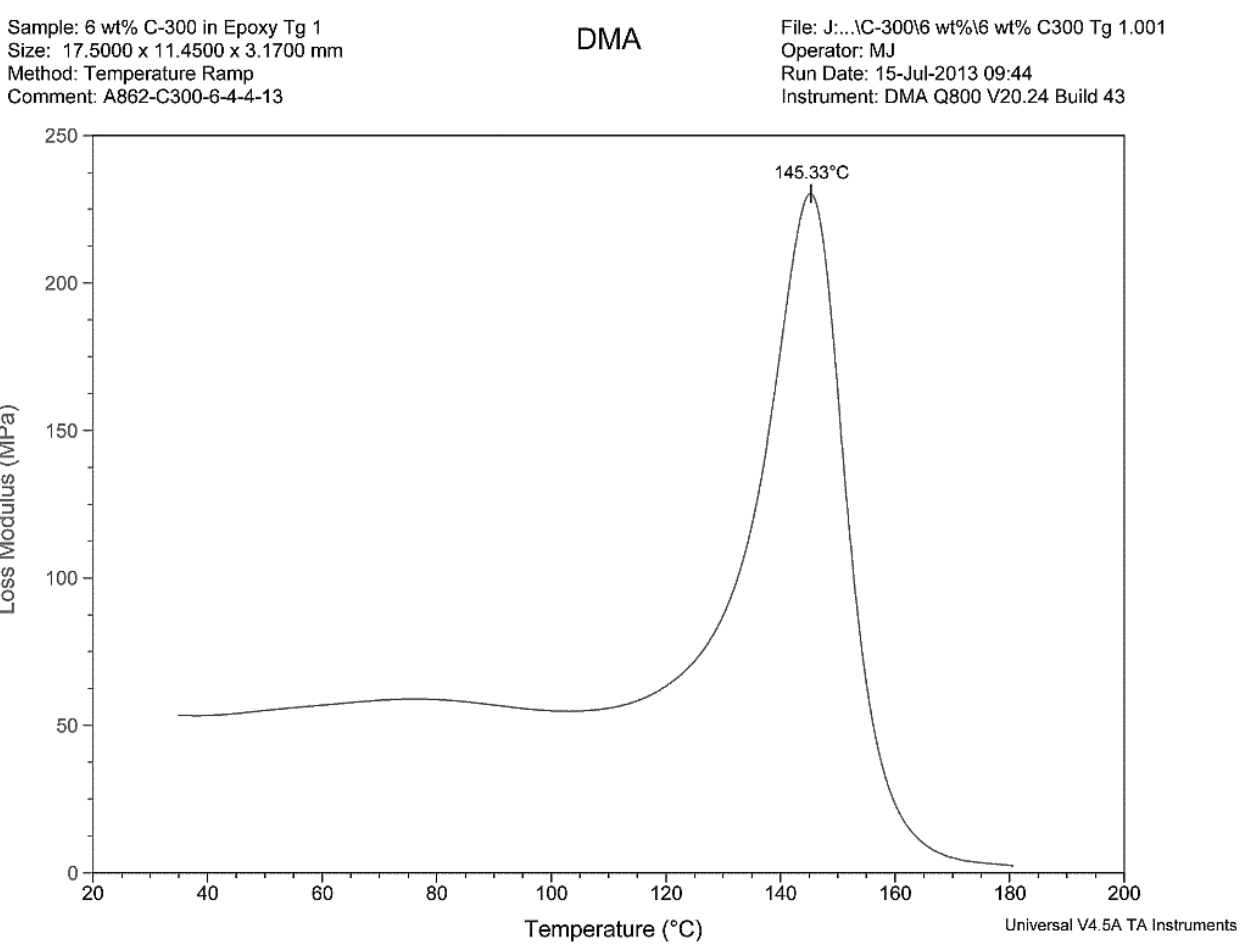

Figure D-56: Loss Modulus for 6 wt\% xGnP ${ }^{\circledR}-C-300$ in Epoxy Test 1

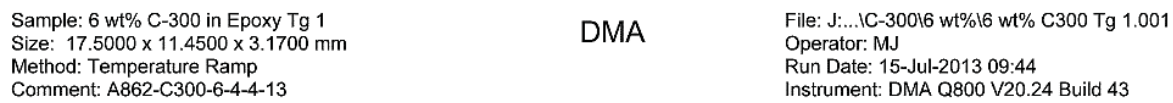

Method: Temperature Ramp
Comment: A862-C300-6-4-4

Instrument: DMA Q800 V20.24 Build 43

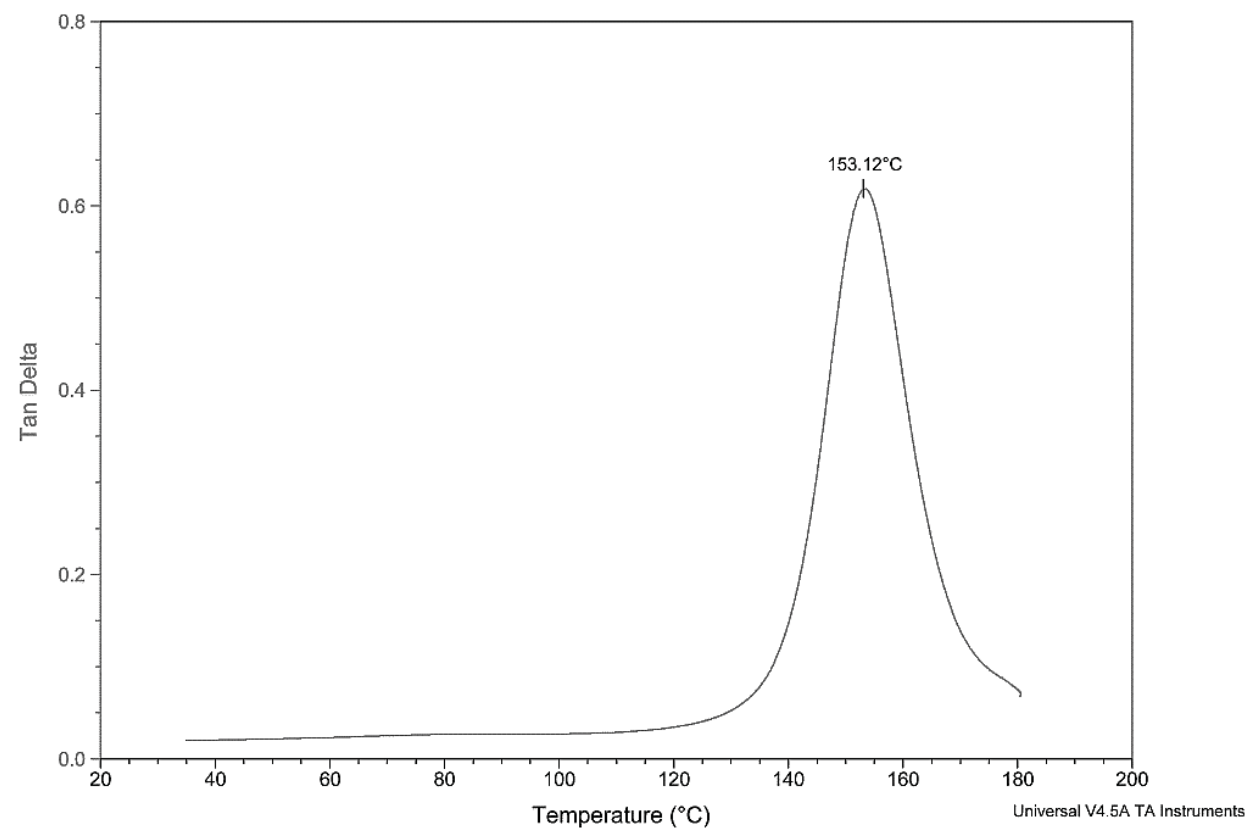

Figure D-57: Tan Delta for 6 wt\% $x G n P^{\circledR}-C-300$ in Epoxy Test 1 
Table D-20: DMA Results for 1 wt\% TC307 in Epoxy

\begin{tabular}{|l|c|c|c|c|}
\hline \multicolumn{1}{|c|}{ Sample } & No. & $\begin{array}{c}\text { Storage } \\
\text { Modulus } \\
\text { Onset }\left({ }^{\circ} \mathbf{C}\right)\end{array}$ & $\begin{array}{c}\text { Loss } \\
\text { Modulus } \\
\text { Peak } \\
\left({ }^{\circ} \mathbf{C}\right)\end{array}$ & $\begin{array}{c}\text { Tan Delta } \\
\text { Peak } \\
\left({ }^{\circ} \mathbf{C}\right)\end{array}$ \\
\hline A862-TC307-1-1-7-15 & 1 & 133.51 & 146.54 & 154.41 \\
\hline A862-TC307-1-1-7-15 & 2 & 132.46 & 146.12 & 153.67 \\
\hline A862-TC307-1-1-7-15 & 3 & 132.36 & 146.36 & 154.11 \\
\hline A862-TC307-1-1-7-15 & 4 & 132.37 & 145.7 & 153.87 \\
\hline Average & & $\mathbf{1 3 2 . 7}$ & $\mathbf{1 4 6 . 2}$ & $\mathbf{1 5 4 . 0}$ \\
\hline Standard Deviation & $\mathbf{0 . 6}$ & $\mathbf{0 . 4}$ & $\mathbf{0 . 3}$ \\
\hline Count & $\mathbf{4}$ & $\mathbf{4}$ & $\mathbf{4}$ \\
\hline
\end{tabular}

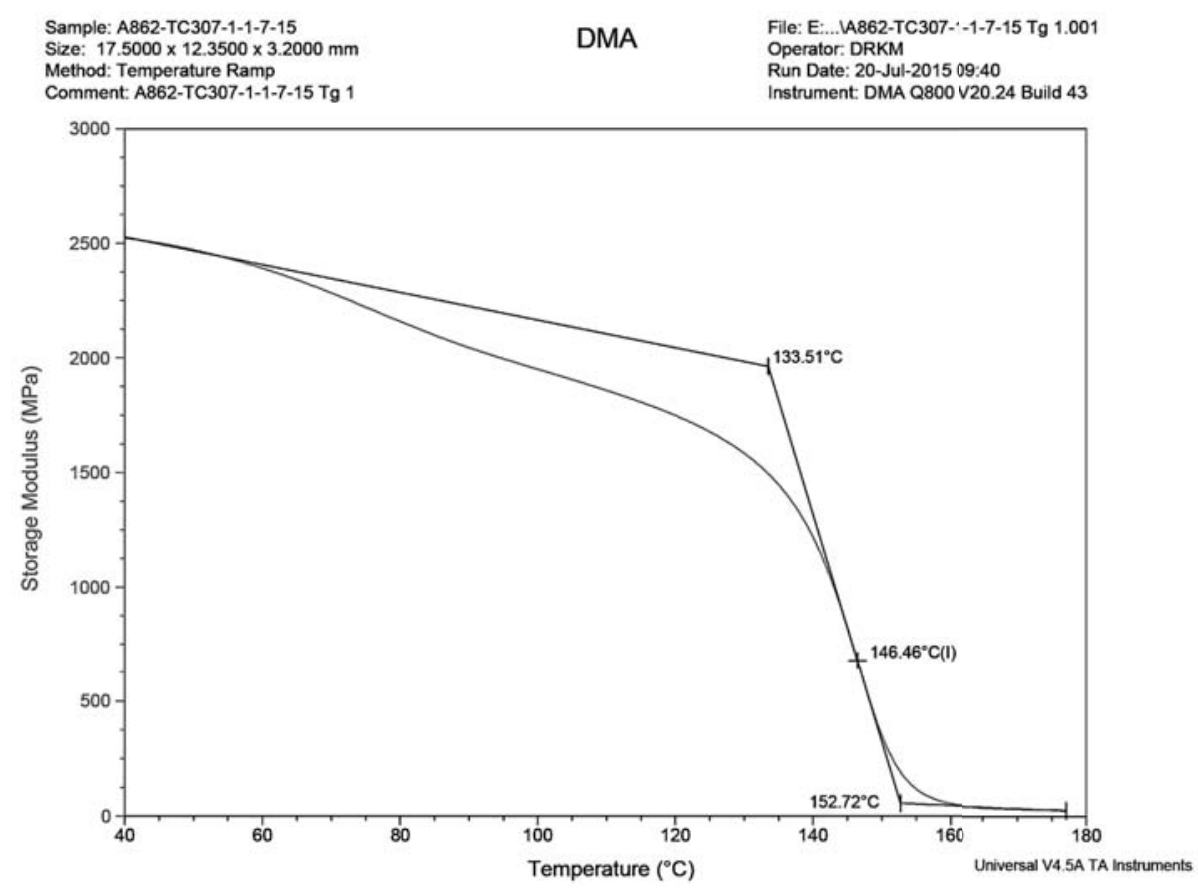

Figure D-58: Storage Modulus for 1 wt\% TC307 in Epoxy Test 1 


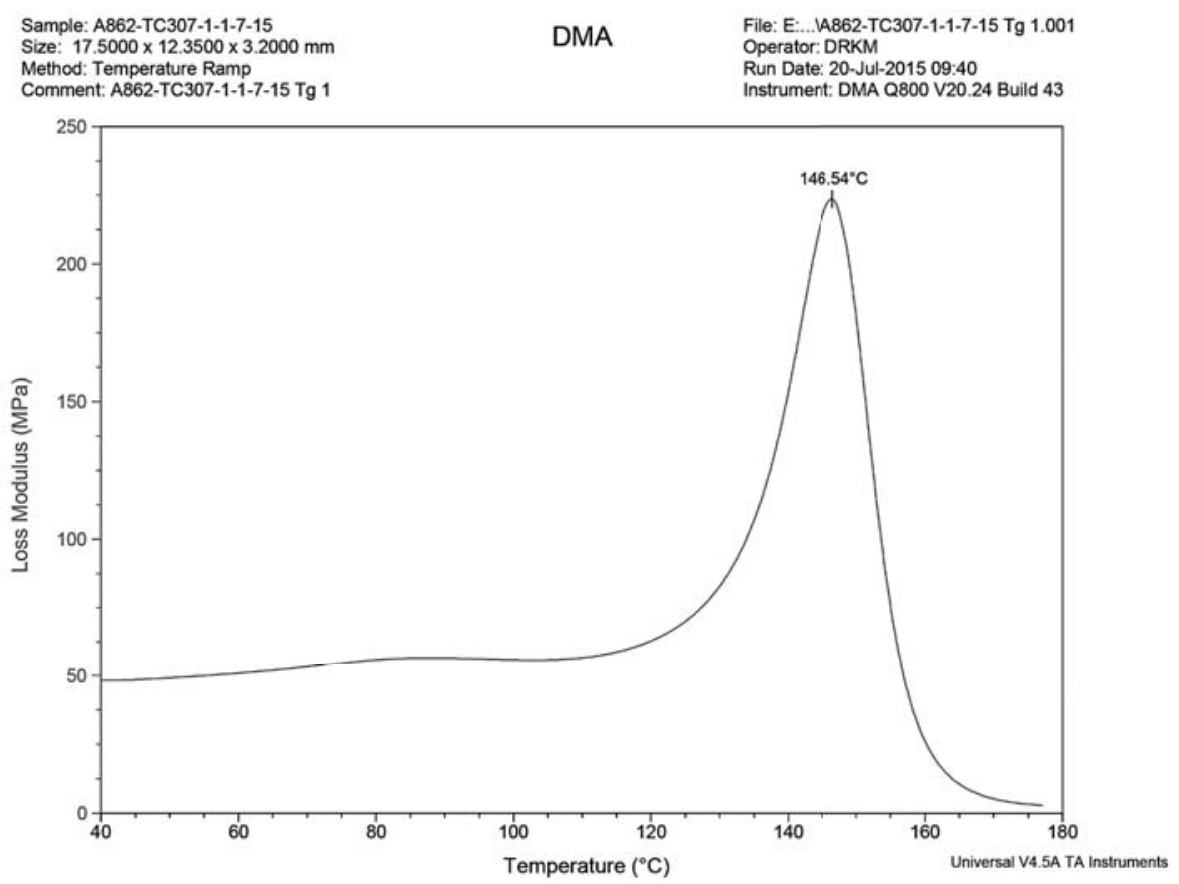

Figure D-59: Loss Modulus for 1 wt\% TC307 in Epoxy Test 1

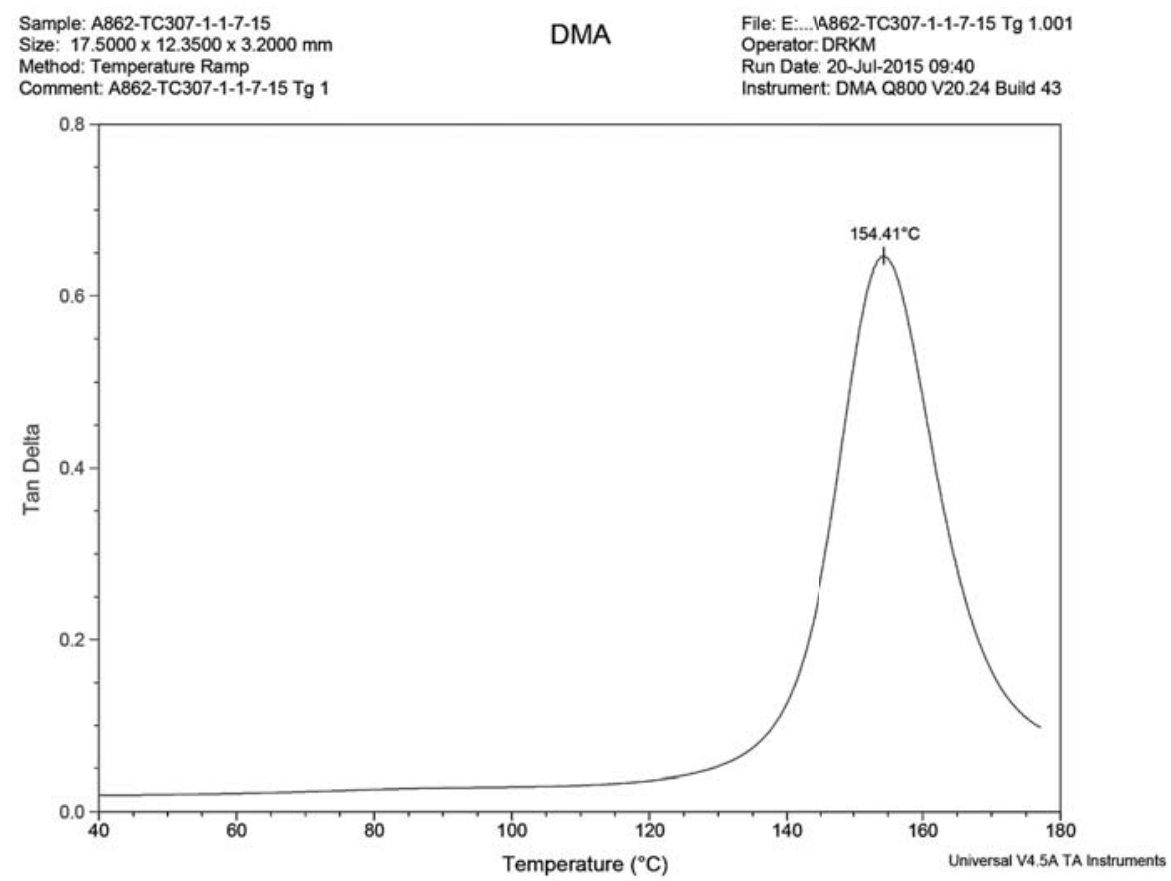

Figure D-60: Tan Delta for 1 wt\% TC307 in Epoxy Test 1 
Table D-21: DMA Results for 2 wt\% TC307 in Epoxy

\begin{tabular}{|l|c|c|c|c|}
\hline \multicolumn{1}{|c|}{ Sample } & No. & $\begin{array}{c}\text { Storage } \\
\text { Modulus } \\
\text { Onset }\left({ }^{\circ} \mathbf{C}\right)\end{array}$ & $\begin{array}{c}\text { Loss } \\
\text { Modulus } \\
\text { Peak } \\
\left({ }^{\circ} \mathbf{C}\right)\end{array}$ & $\begin{array}{c}\text { Tan Delta } \\
\text { Peak } \\
\left({ }^{\circ} \mathbf{C}\right)\end{array}$ \\
\hline A862-TC307-2-12-14-14 & 1 & 134.65 & 147.76 & 155.33 \\
\hline A862-TC307-2-12-14-14 & 2 & 135.24 & 148.25 & 155.66 \\
\hline A862-TC307-2-12-14-14 & 3 & 134.32 & 148.64 & 155.89 \\
\hline A862-TC307-2-12-14-14 & 4 & 134.31 & 148.42 & 155.84 \\
\hline Average & & $\mathbf{1 3 4 . 6}$ & $\mathbf{1 4 8 . 3}$ & $\mathbf{1 5 5 . 7}$ \\
\hline Standard Deviation & $\mathbf{0 . 4}$ & $\mathbf{0 . 4}$ & $\mathbf{0 . 3}$ \\
\hline Count & $\mathbf{4}$ & $\mathbf{4}$ & $\mathbf{4}$ \\
\hline
\end{tabular}

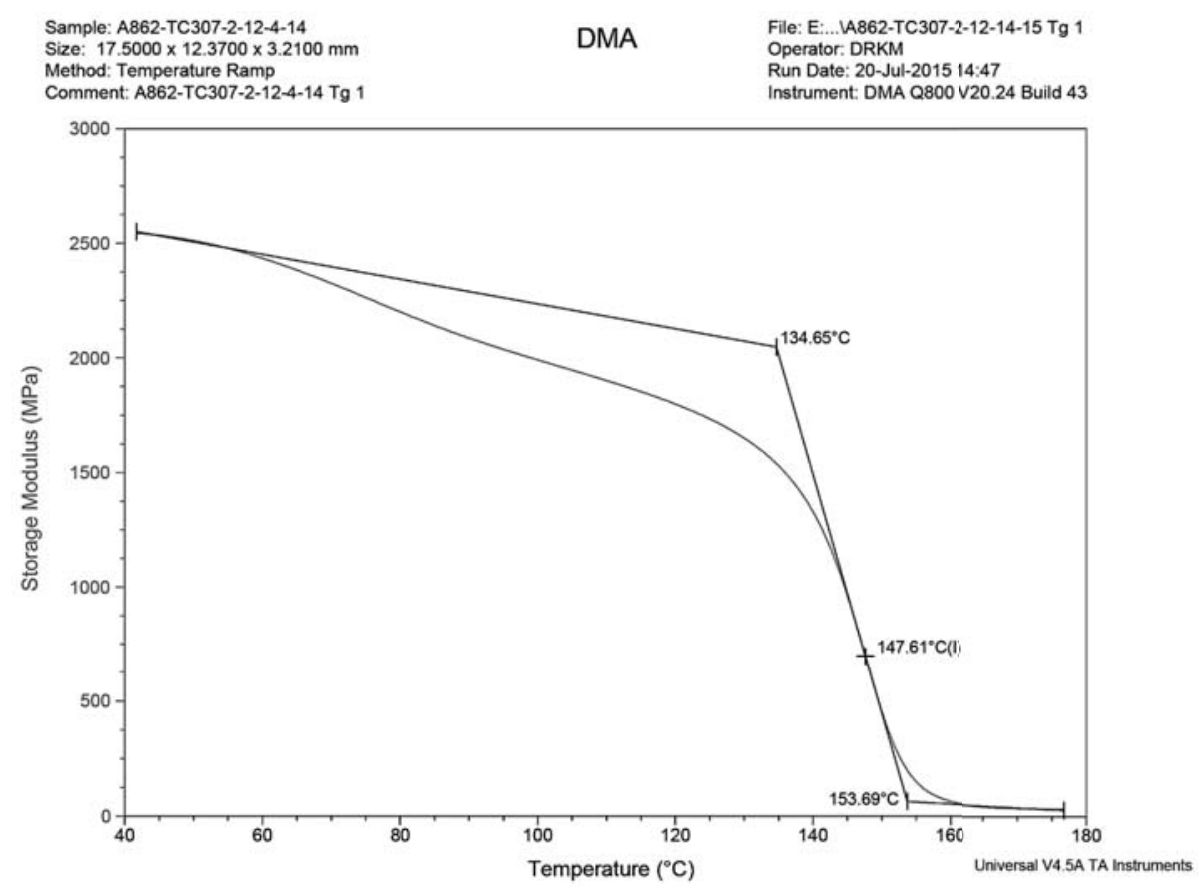

Figure D-61: Storage Modulus for 2 wt\% TC307 in Epoxy Test 1 


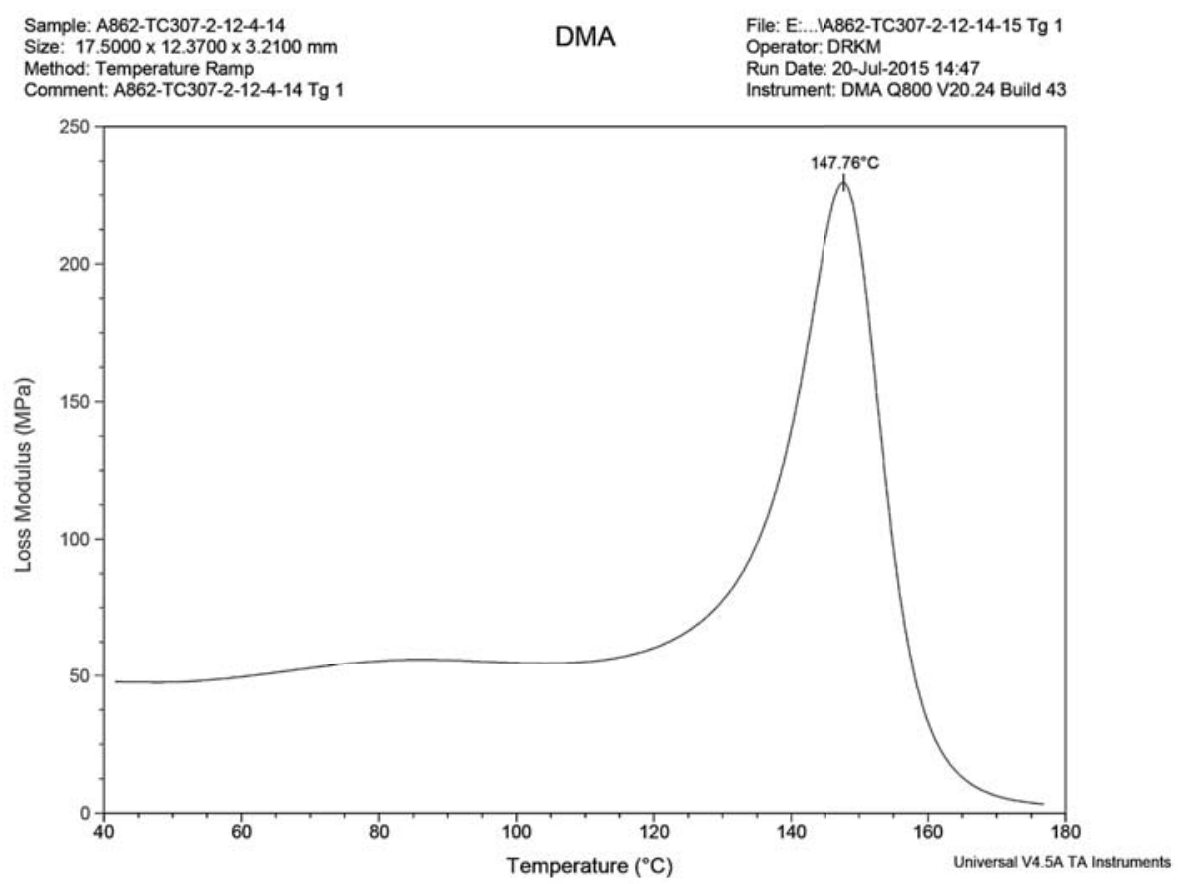

Figure D-62: Loss Modulus for 2 wt\% TC307 in Epoxy Test 1

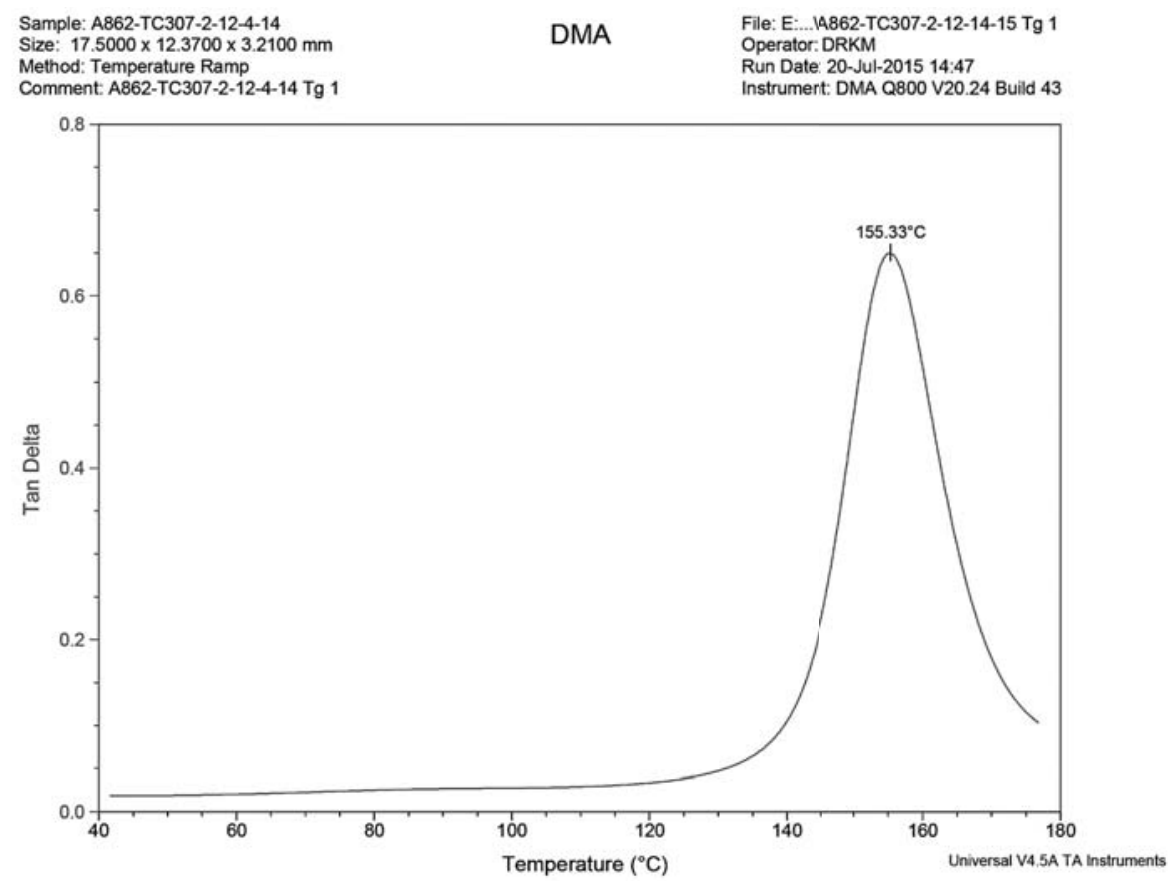

Figure D-63: Tan Delta for 2 wt\% TC307 in Epoxy Test 1 
Table D-22: DMA Results for 3 wt\% TC307 in Epoxy

\begin{tabular}{|l|c|c|c|c|}
\hline \multicolumn{1}{|c|}{ Sample } & No. & $\begin{array}{c}\text { Storage } \\
\text { Modulus } \\
\text { Onset }\left({ }^{\circ} \mathbf{C}\right)\end{array}$ & $\begin{array}{c}\text { Loss } \\
\text { Modulus } \\
\text { Peak } \\
\left({ }^{\circ} \mathbf{C}\right)\end{array}$ & $\begin{array}{c}\text { Tan Delta } \\
\text { Peak } \\
\left({ }^{\circ} \mathbf{C}\right)\end{array}$ \\
\hline A862-TC307-3-1-9-15 & 1 & 132.80 & 145.45 & 153.46 \\
\hline A862-TC307-3-1-9-15 & 2 & 131.88 & 145.49 & 153.18 \\
\hline A862-TC307-3-1-9-15 & 3 & 132.05 & 145.44 & 153.18 \\
\hline A862-TC307-3-1-9-15 & 4 & 132.96 & 145.53 & 153.39 \\
\hline Average & & $\mathbf{1 3 2 . 4}$ & $\mathbf{1 4 5 . 5}$ & $\mathbf{1 5 3 . 3}$ \\
\hline Standard Deviation & $\mathbf{0 . 5}$ & $\mathbf{0 . 0}$ & $\mathbf{0 . 1}$ \\
\hline Count & $\mathbf{4}$ & $\mathbf{4}$ & $\mathbf{4}$ \\
\hline
\end{tabular}

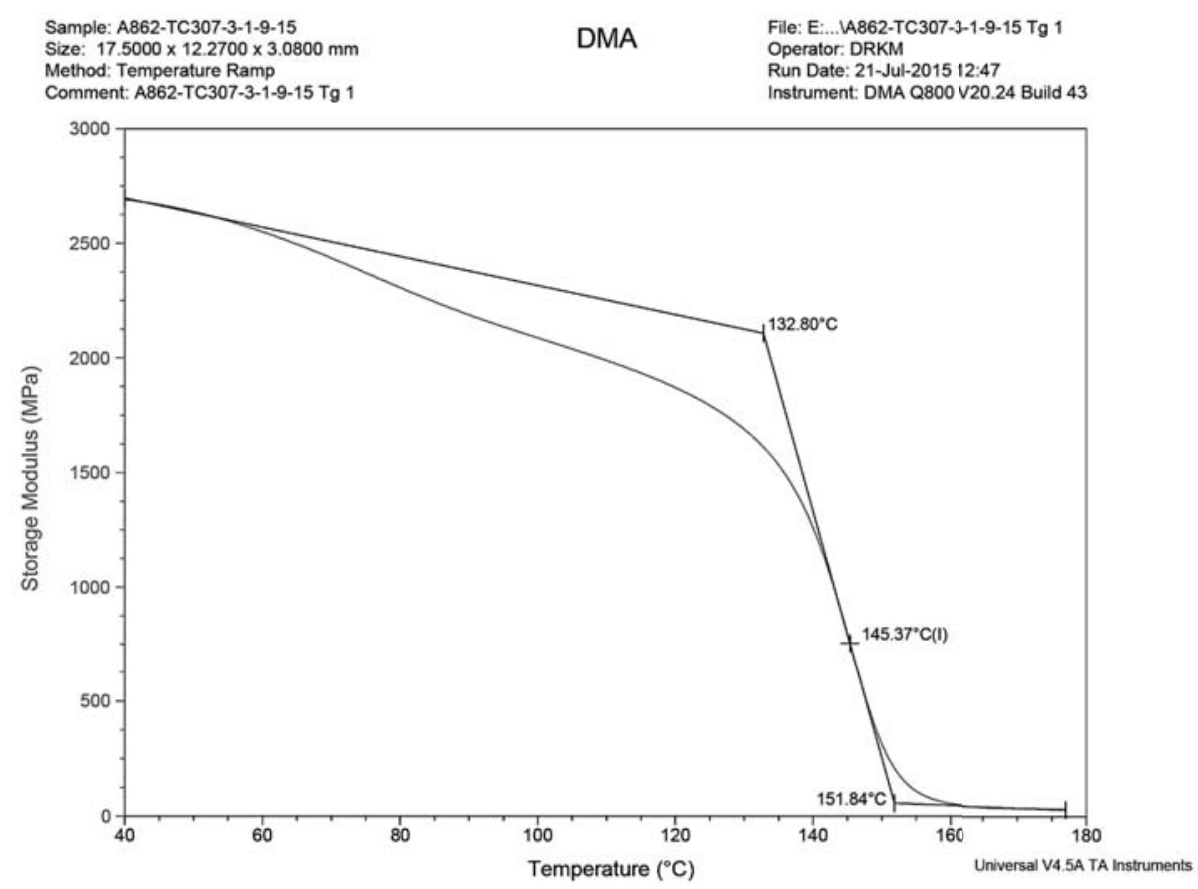

Figure D-64: Storage Modulus for 3 wt\% TC307 in Epoxy Test 1 


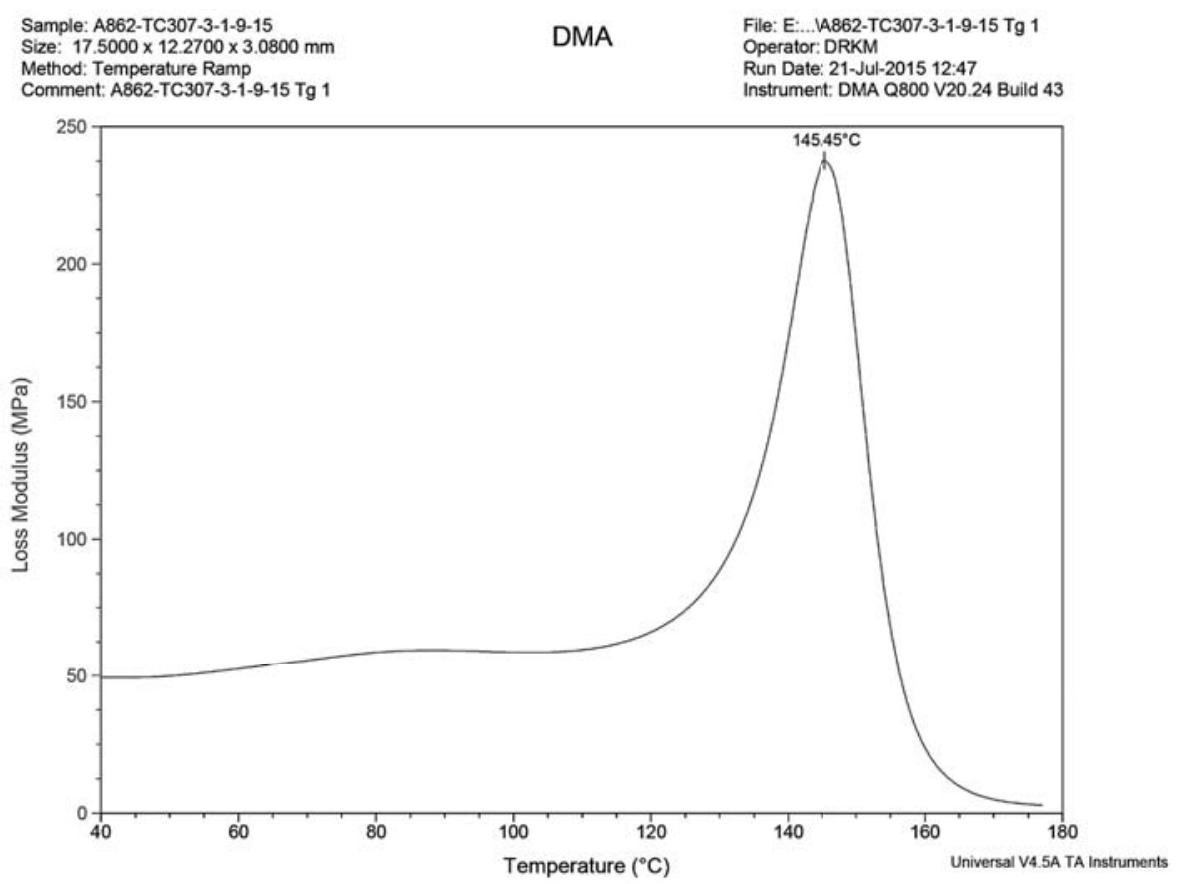

Figure D-65: Loss Modulus for 3 wt\% TC307 in Epoxy Test 1

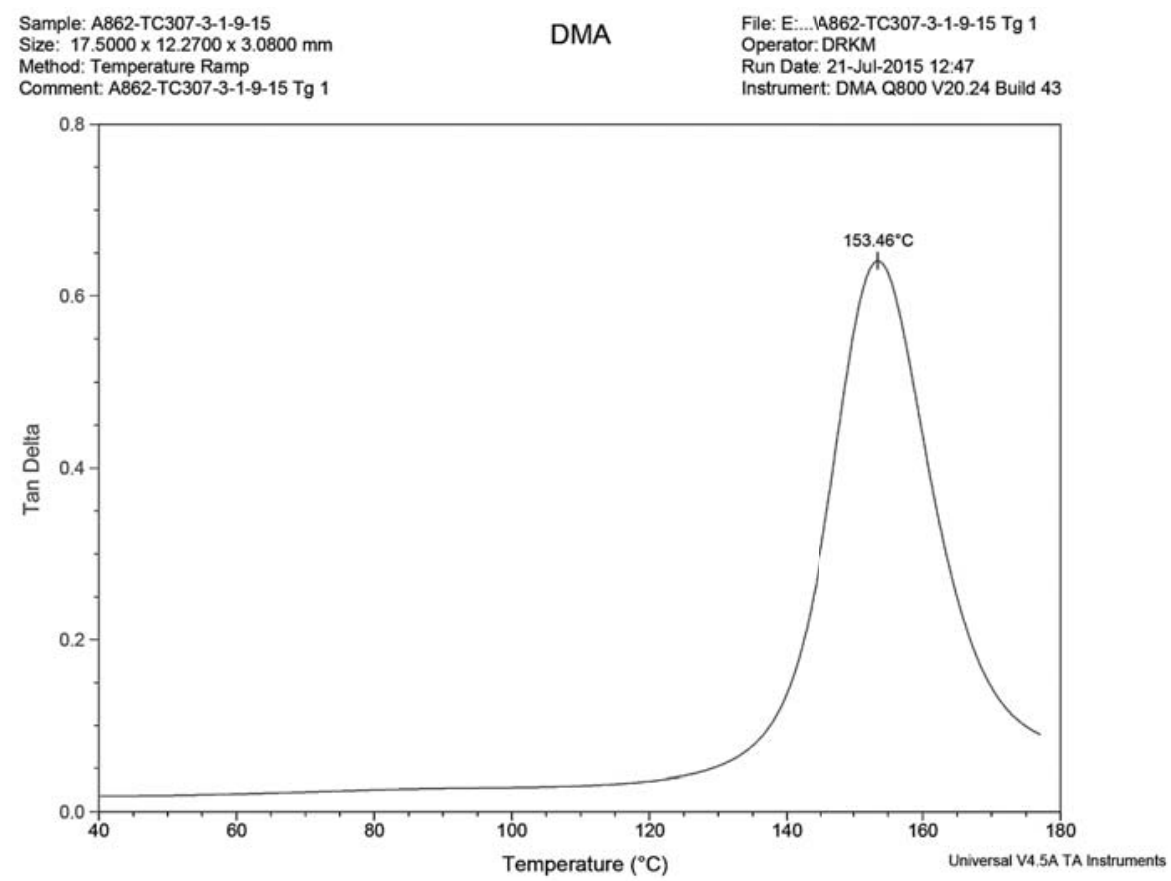

Figure D-66: Tan Delta for 3 wt\% TC307 in Epoxy Test 1 
Table D-23: DMA Results for 4 wt\% TC307 in Epoxy

\begin{tabular}{|l|c|c|c|c|}
\hline \multicolumn{1}{|c|}{ Sample } & No. & $\begin{array}{c}\text { Storage } \\
\text { Modulus } \\
\text { Onset }\left({ }^{\circ} \mathbf{C}\right)\end{array}$ & $\begin{array}{c}\text { Loss } \\
\text { Modulus } \\
\text { Peak } \\
\left({ }^{\circ} \mathbf{C}\right)\end{array}$ & $\begin{array}{c}\text { Tan Delta } \\
\text { Peak } \\
\left({ }^{\circ} \mathbf{C}\right)\end{array}$ \\
\hline A862-TC307-4-12-8-14 & 1 & 135.79 & 148.82 & 156.34 \\
\hline A862-TC307-4-12-8-14 & 2 & 135.58 & 148.71 & 156.38 \\
\hline A862-TC307-4-12-8-14 & 3 & 135.08 & 148.66 & 156.21 \\
\hline A862-TC307-4-12-8-14 & 4 & 135.14 & 148.87 & 156.57 \\
\hline Average & & $\mathbf{1 3 5 . 4}$ & $\mathbf{1 4 8 . 8}$ & $\mathbf{1 5 6 . 4}$ \\
\hline Standard Deviation & $\mathbf{0 . 3}$ & $\mathbf{0 . 1}$ & $\mathbf{0 . 1}$ \\
\hline Count & $\mathbf{4}$ & $\mathbf{4}$ & $\mathbf{4}$ \\
\hline
\end{tabular}

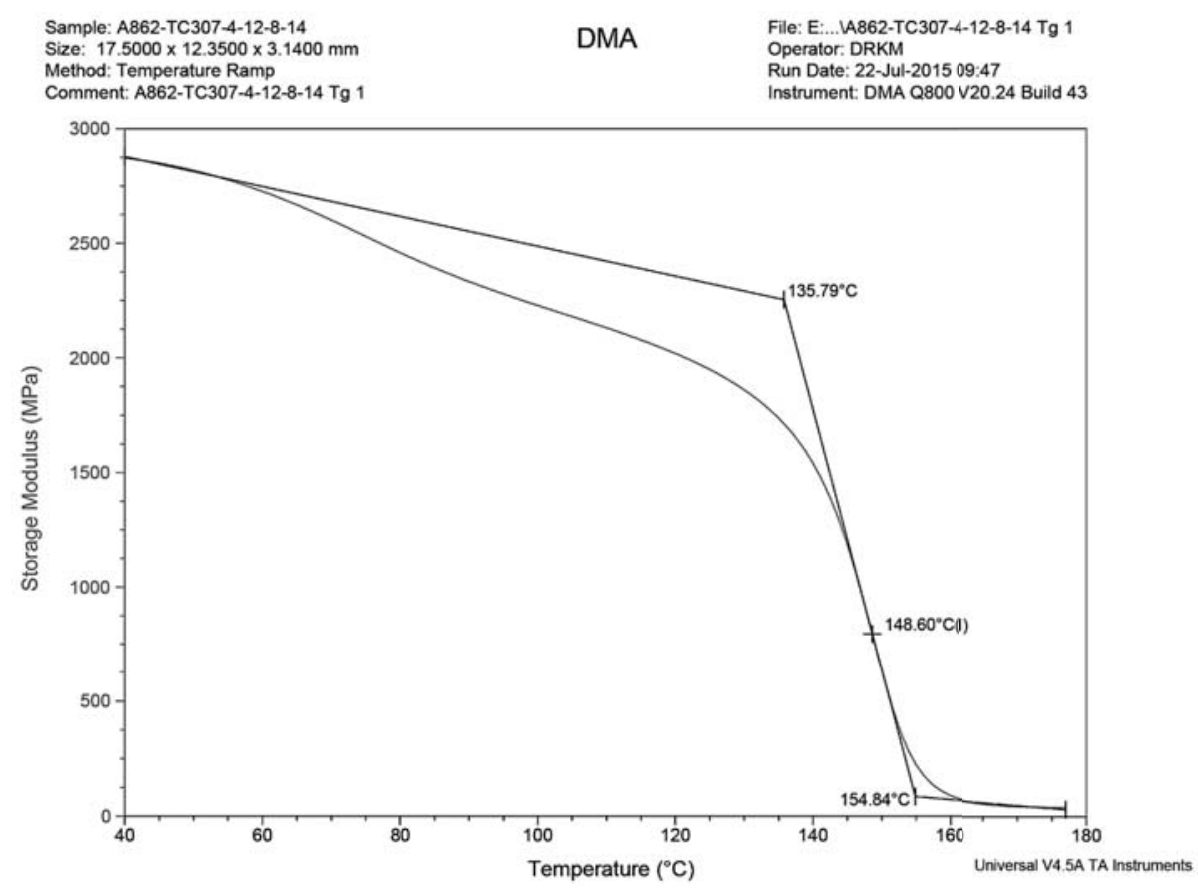

Figure D-67: Storage Modulus for 4 wt\% TC307 in Epoxy Test 1 


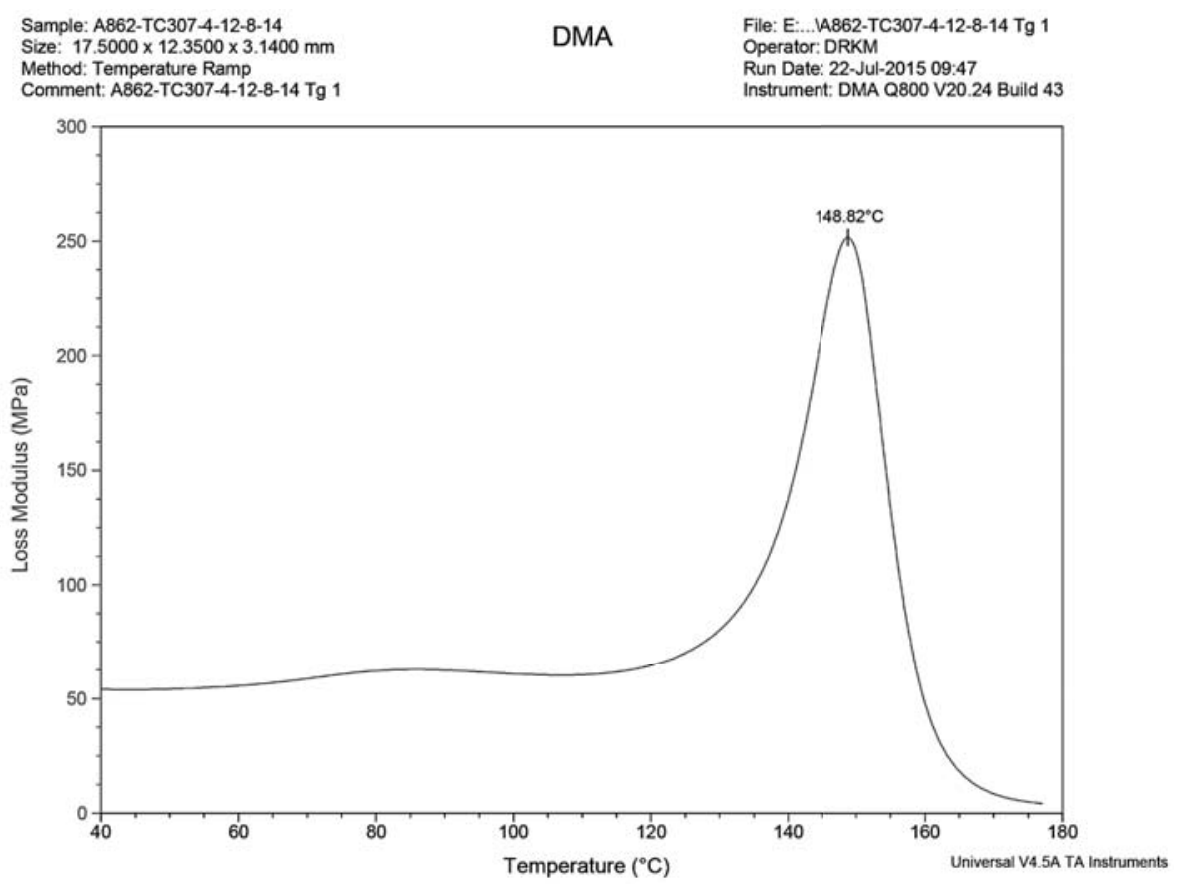

Figure D-68: Loss Modulus for 4 wt\% TC307 in Epoxy Test 1

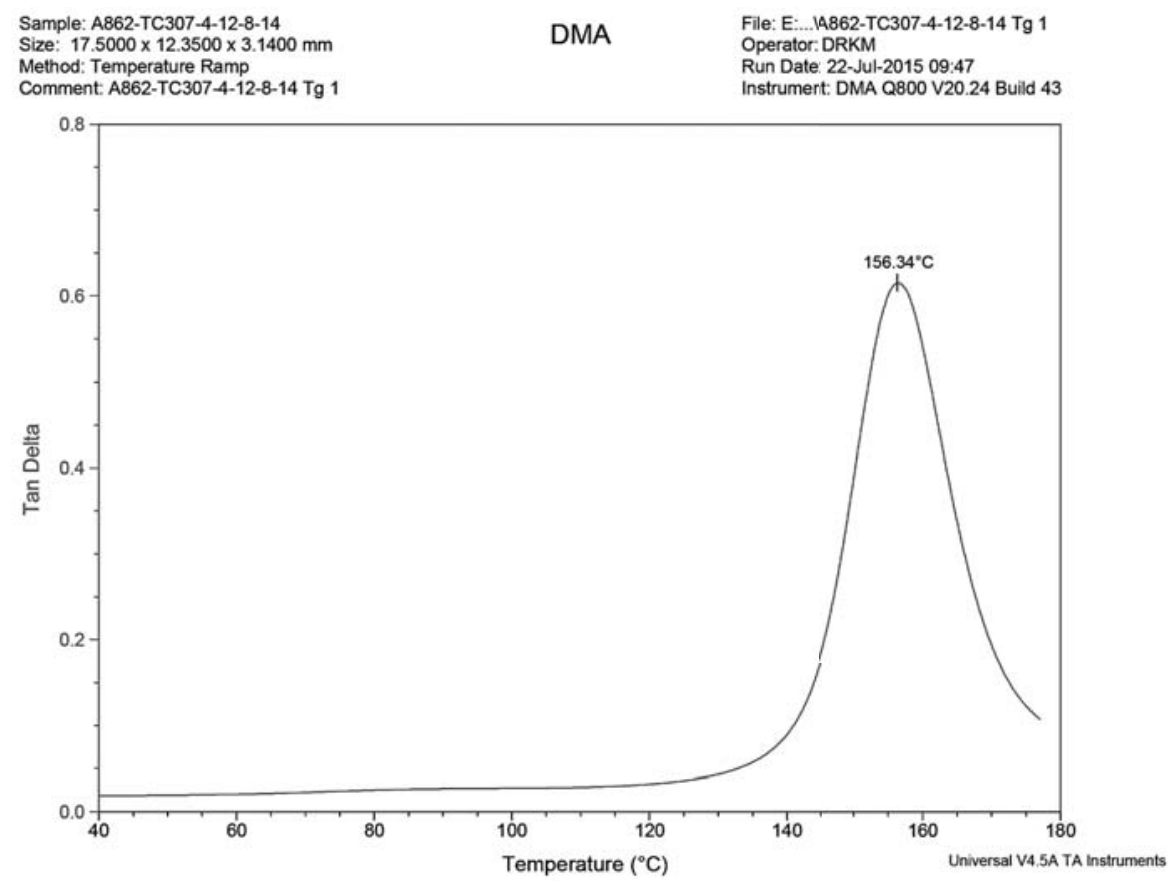

Figure D-69: Tan Delta for 4 wt\% TC307 in Epoxy Test 1 


\section{Appdenix E: DSC Results}

Table E-1: DSC Results for Neat Epoxy

\begin{tabular}{|l|c|c|}
\hline Sample & No. & $\begin{array}{c}\mathrm{Tg} \\
\left({ }^{\circ} \mathrm{C}\right)\end{array}$ \\
\hline A862-9-30-11 & 1 & 142.89 \\
\hline A862-9-30-11 & 2 & 142.95 \\
\hline A862-9-30-11 & 3 & 143.95 \\
\hline A862-12-6-11 & 1 & 142.61 \\
\hline A862-12-6-11 & 2 & 144.23 \\
\hline A862-12-6-11 & 3 & 142.58 \\
\hline A862-12-6-11 & 4 & 144.12 \\
\hline Average & & $\mathbf{1 4 3 . 3}$ \\
\hline Standard Deviation & $\mathbf{0 . 7}$ \\
\hline Count & $\mathbf{7}$ \\
\hline
\end{tabular}

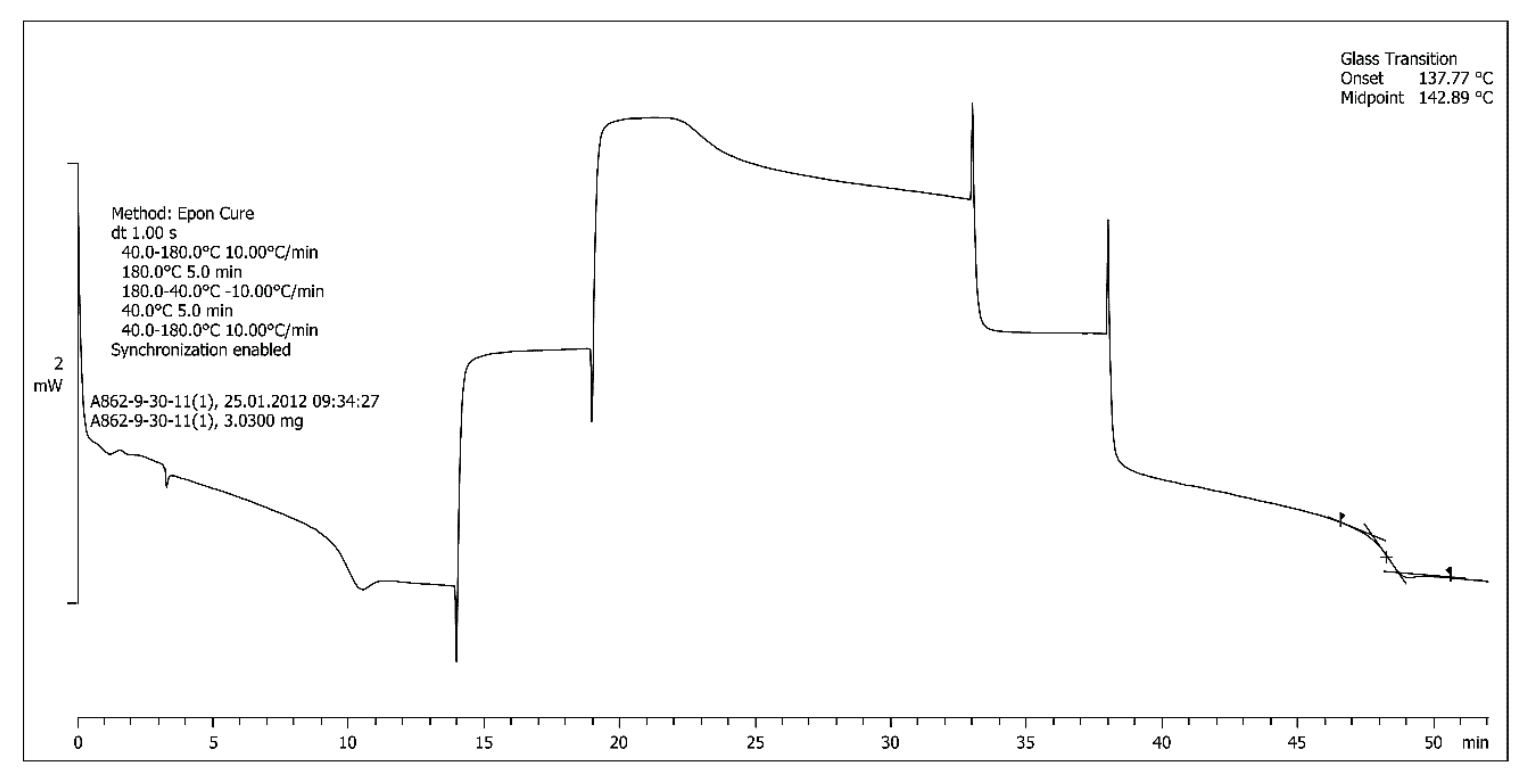

Figure E-1: DSC for Neat Epoxy (A862-9-30-11) Run 1 vs. Time 
Table E-2: DSC Results for 1 wt\% xGnP ${ }^{\circledR}-M-15$ in Epoxy

\begin{tabular}{|l|c|c|}
\hline \multicolumn{1}{|c|}{ Sample } & No. & $\begin{array}{c}\mathrm{Tg} \\
\left({ }^{\circ} \mathbf{C}\right)\end{array}$ \\
\hline A862-M15-1-10-7-11 & 1 & 146.07 \\
\hline A862-M15-1-10-7-11 & 2 & 147.00 \\
\hline A862-M15-1-10-7-11 & 3 & 143.64 \\
\hline A862-M15-1-10-7-11 & 4 & 142.63 \\
\hline A862-M15-1-12-12-11 & 1 & 144.66 \\
\hline A862-M15-1-12-12-11 & 2 & 146.34 \\
\hline A862-M15-1-12-12-12 & 3 & 146.44 \\
\hline A862-M15-1-12-12-12 & 4 & 145.95 \\
\hline Average & & $\mathbf{1 4 5 . 3}$ \\
\hline Standard Deviation & $\mathbf{1 . 5}$ \\
\hline Count & $\mathbf{8}$ \\
\hline
\end{tabular}

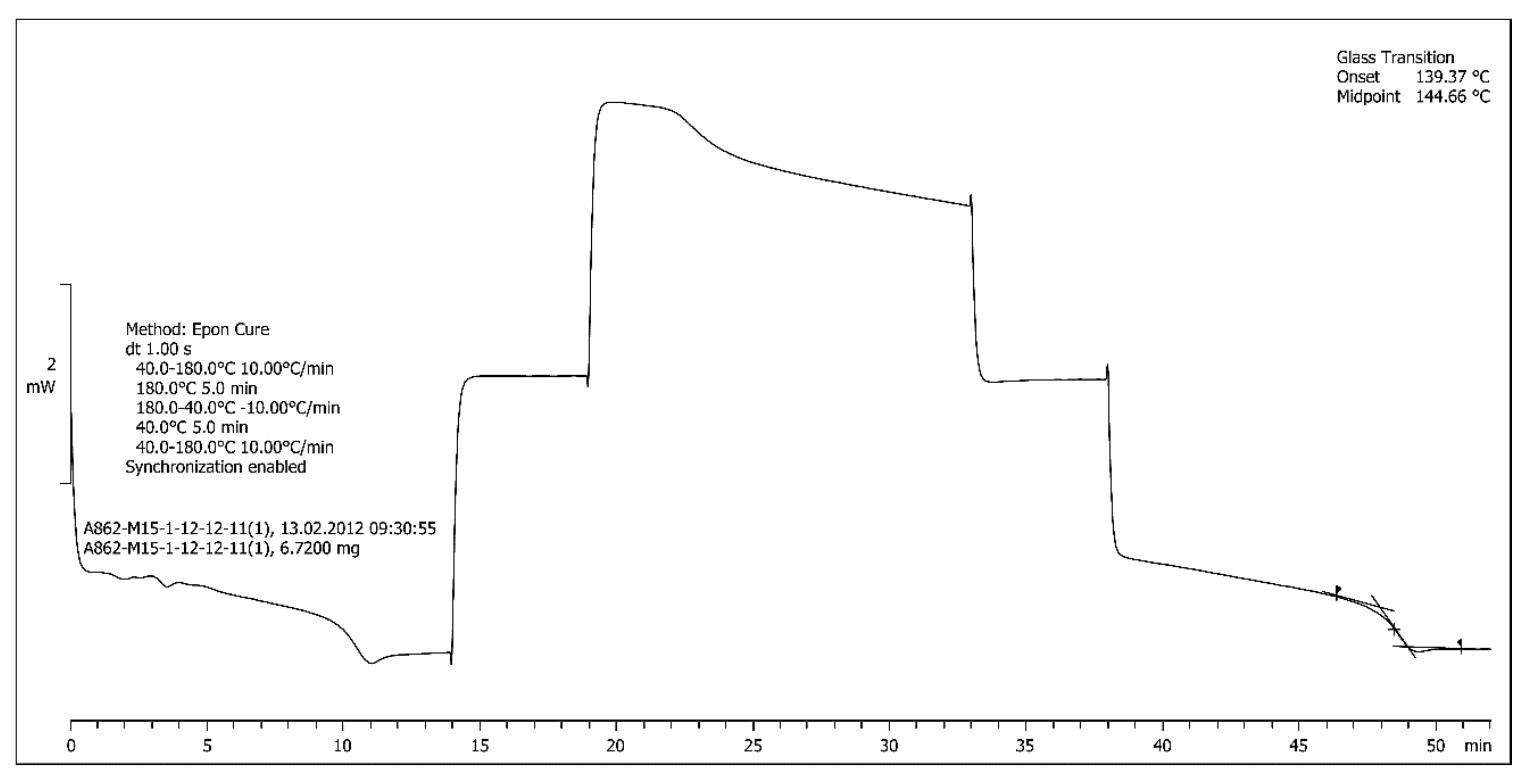

Figure E-2: DSC for 1 wt\% xGnP ${ }^{\circledR}-M-15$ in Epoxy (A862-M15-1-12-12-11) Run 1 vs. Time 
Table E-3: DSC Results for 2 wt\% $x$ GnP ${ }^{\circledR}-M-15$ in Epoxy

\begin{tabular}{|l|c|c|}
\hline \multicolumn{1}{|c|}{ Sample } & No. & $\begin{array}{c}\mathrm{Tg} \\
\left({ }^{\circ} \mathbf{C}\right)\end{array}$ \\
\hline A862-M15-2-10-4-11 & 1 & 142.45 \\
\hline A862-M15-2-10-4-11 & 2 & 142.25 \\
\hline A862-M15-2-12-13-11 & 1 & 142.64 \\
\hline A862-M15-2-12-13-11 & 2 & 144.21 \\
\hline A862-M15-2-12-13-11 & 3 & 143.76 \\
\hline A862-M15-2-12-13-11 & 4 & 143.55 \\
\hline A862-M15-2-2-22-12 & 1 & 142.30 \\
\hline A862-M15-2-2-22-12 & 2 & 144.87 \\
\hline Average & & $\mathbf{1 4 3 . 3}$ \\
\hline Standard Deviation & $\mathbf{1 . 0}$ \\
\hline Count & $\mathbf{8}$ \\
\hline
\end{tabular}

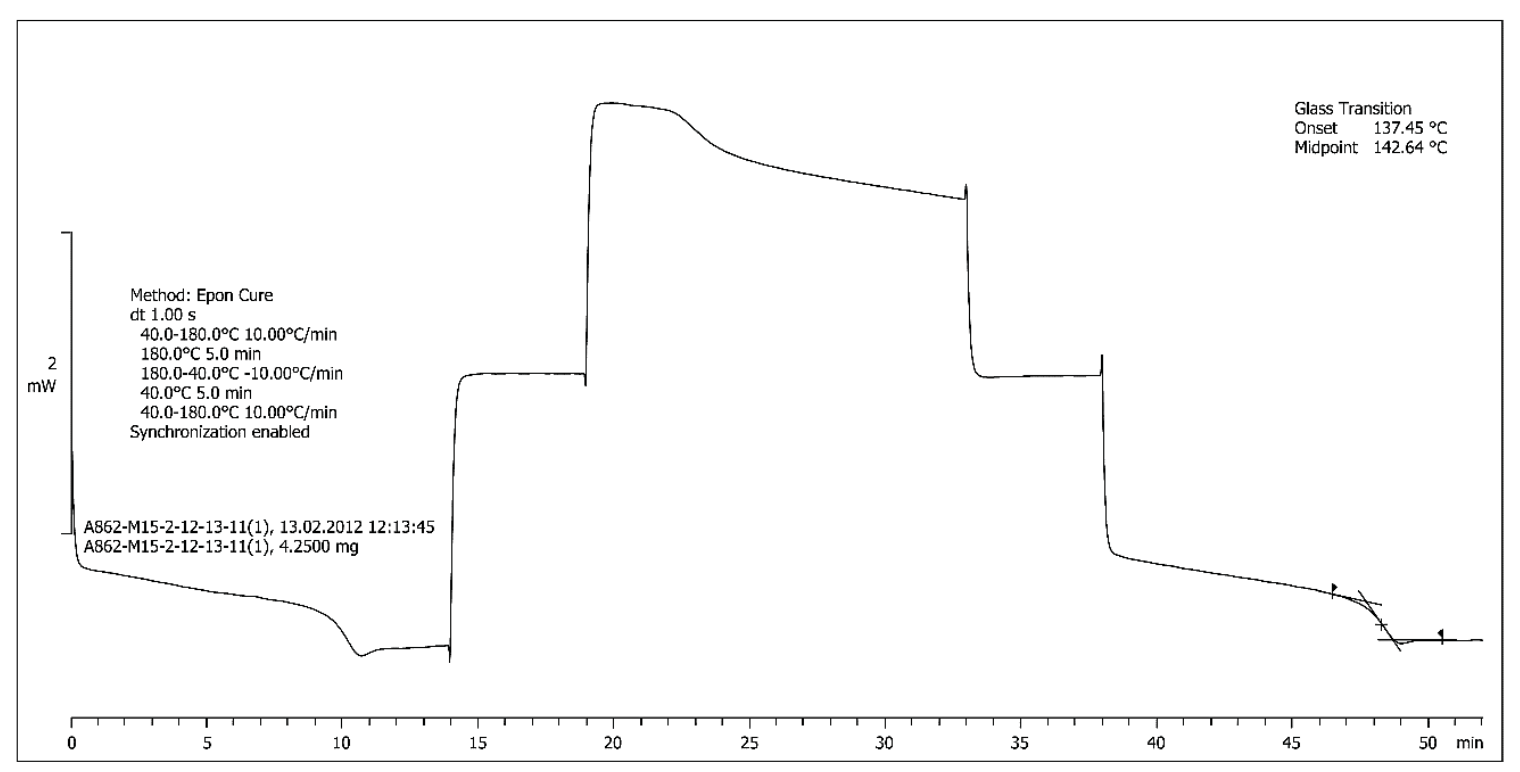

Figure E-3: DSC for 2 wt\% xGnP ${ }^{\circledR}-M-15$ in Epoxy (A862-M15-2-12-13-11) Run 1 vs. Time 
Table E-4: DSC Results for 3 wt\% $x$ GnP ${ }^{\circledR}-M-15$ in Epoxy

\begin{tabular}{|l|c|c|}
\hline \multicolumn{1}{|c|}{ Sample } & No. & $\begin{array}{c}\mathrm{Tg} \\
\left({ }^{\circ} \mathbf{C}\right)\end{array}$ \\
\hline A862-M15-3-10-11-11 & 1 & 140.04 \\
\hline A862-M15-3-10-11-11 & 2 & 142.23 \\
\hline A862-M15-3-12-14-11 & 1 & 136.07 \\
\hline A862-M15-3-12-14-11 & 2 & 137.10 \\
\hline A862-M15-3-12-14-11 & 3 & 136.71 \\
\hline A862-M15-3-12-14-11 & 4 & 136.33 \\
\hline A862-M15-3-3-14-12 & 1 & 140.73 \\
\hline A862-M15-3-3-14-12 & 2 & 140.71 \\
\hline Average & & $\mathbf{1 3 8 . 7}$ \\
\hline Standard Deviation & $\mathbf{2 . 4}$ \\
\hline Count & $\mathbf{8}$ \\
\hline
\end{tabular}

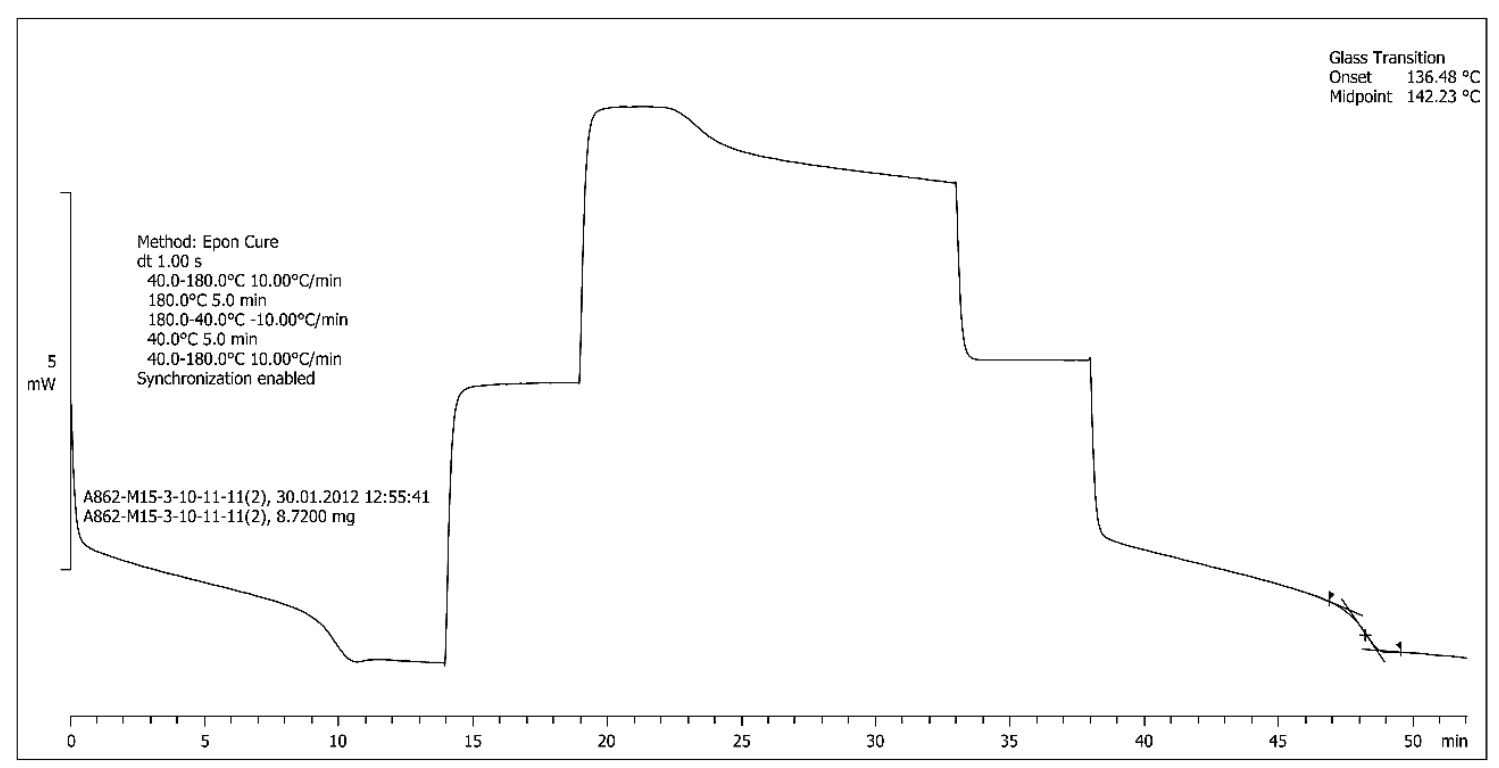

Figure E-4: DSC for 3 wt\% xGnP ${ }^{\circledR}-M-15$ in Epoxy (A862-M15-3-10-11-11) Run 2 vs. Time 
Table E-5: DSC Results for 4 wt\% $x$ GnP ${ }^{\circledR}-M-15$ in Epoxy

\begin{tabular}{|l|c|c|}
\hline \multicolumn{1}{|c|}{ Sample } & No. & $\begin{array}{c}\text { Tg } \\
\left({ }^{\circ} \mathbf{C}\right)\end{array}$ \\
\hline A862-M15-4-10-13-11 & 1 & 145.32 \\
\hline A862-M15-4-10-13-11 & 2 & 144.73 \\
\hline A862-M15-4-10-13-11 & 3 & 143.63 \\
\hline A862-M15-4-10-13-11 & 4 & 144.23 \\
\hline A862-M15-4-12-15-11 & 1 & 143.94 \\
\hline A862-M15-4-12-15-11 & 2 & 144.07 \\
\hline A862-M15-4-12-15-11 & 3 & 142.40 \\
\hline A862-M15-4-12-15-11 & 4 & 145.77 \\
\hline Average & & $\mathbf{1 4 4 . 3}$ \\
\hline Standard Deviation & $\mathbf{1 . 0}$ \\
\hline Count & $\mathbf{8}$ \\
\hline
\end{tabular}

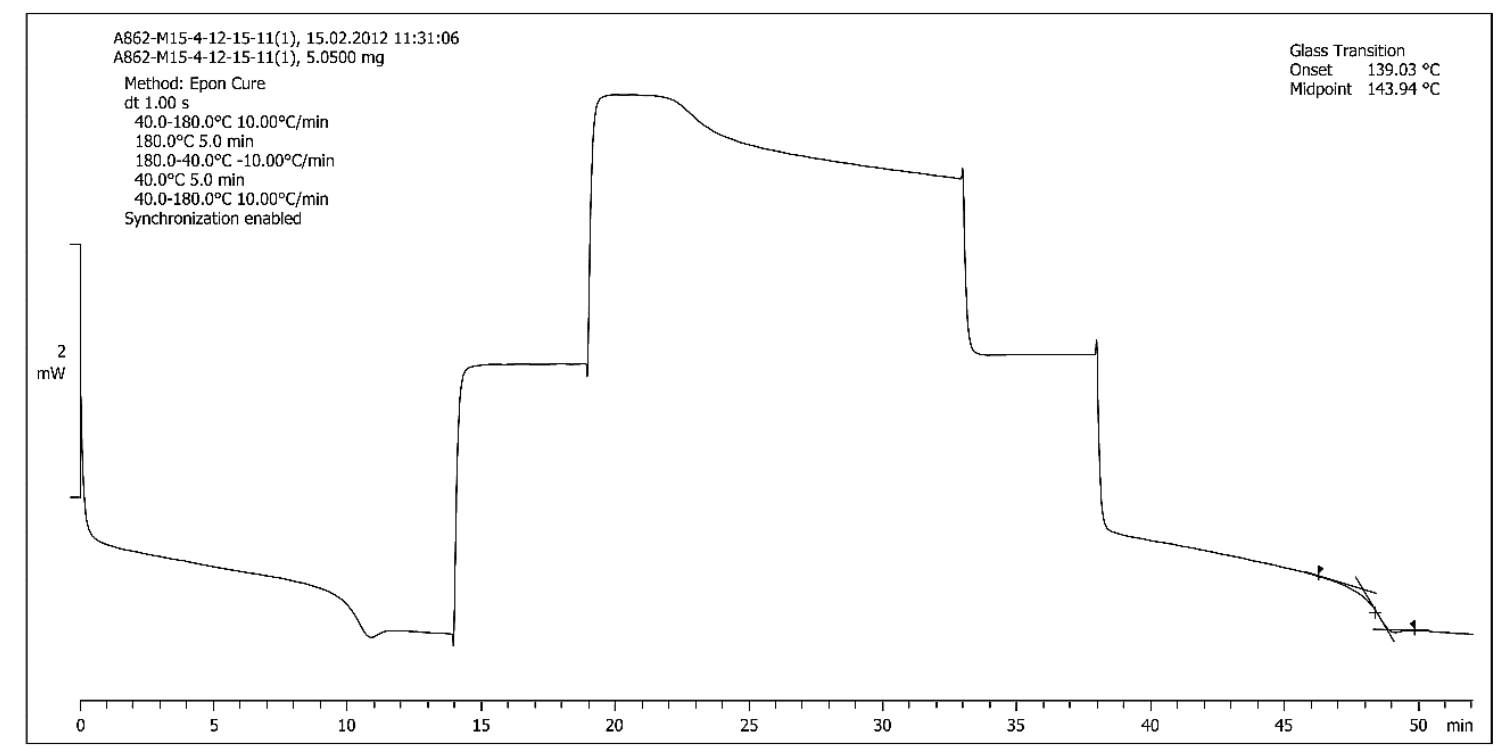

Figure E-5: DSC for 4 wt\% xGnP ${ }^{\circledR}-M-15$ in Epoxy (A862-M15-4-12-15-11) Run 1 vs. Time 
Table E-6: DSC Results for 5 wt\% $x$ GnP ${ }^{\circledR}-M-15$ in Epoxy

\begin{tabular}{|l|c|c|}
\hline \multicolumn{1}{|c|}{ Sample } & No. & $\begin{array}{c}\mathrm{Tg} \\
\left({ }^{\circ} \mathbf{C}\right)\end{array}$ \\
\hline A862-M15-5-10-18-11 & 1 & 143.58 \\
\hline A862-M15-5-10-18-11 & 2 & 143.29 \\
\hline A862-M15-5-10-18-11 & 3 & 143.59 \\
\hline A862-M15-5-10-18-11 & 4 & 143.63 \\
\hline A862-M15-5-12-16-11 & 1 & 148.27 \\
\hline A862-M15-5-12-16-11 & 2 & 146.94 \\
\hline A862-M15-5-12-16-11 & 3 & 145.84 \\
\hline A862-M15-5-12-16-11 & 4 & 146.55 \\
\hline Average & & $\mathbf{1 4 5 . 2}$ \\
\hline Standard Deviation & $\mathbf{1 . 9}$ \\
\hline Count & $\mathbf{8}$ \\
\hline
\end{tabular}

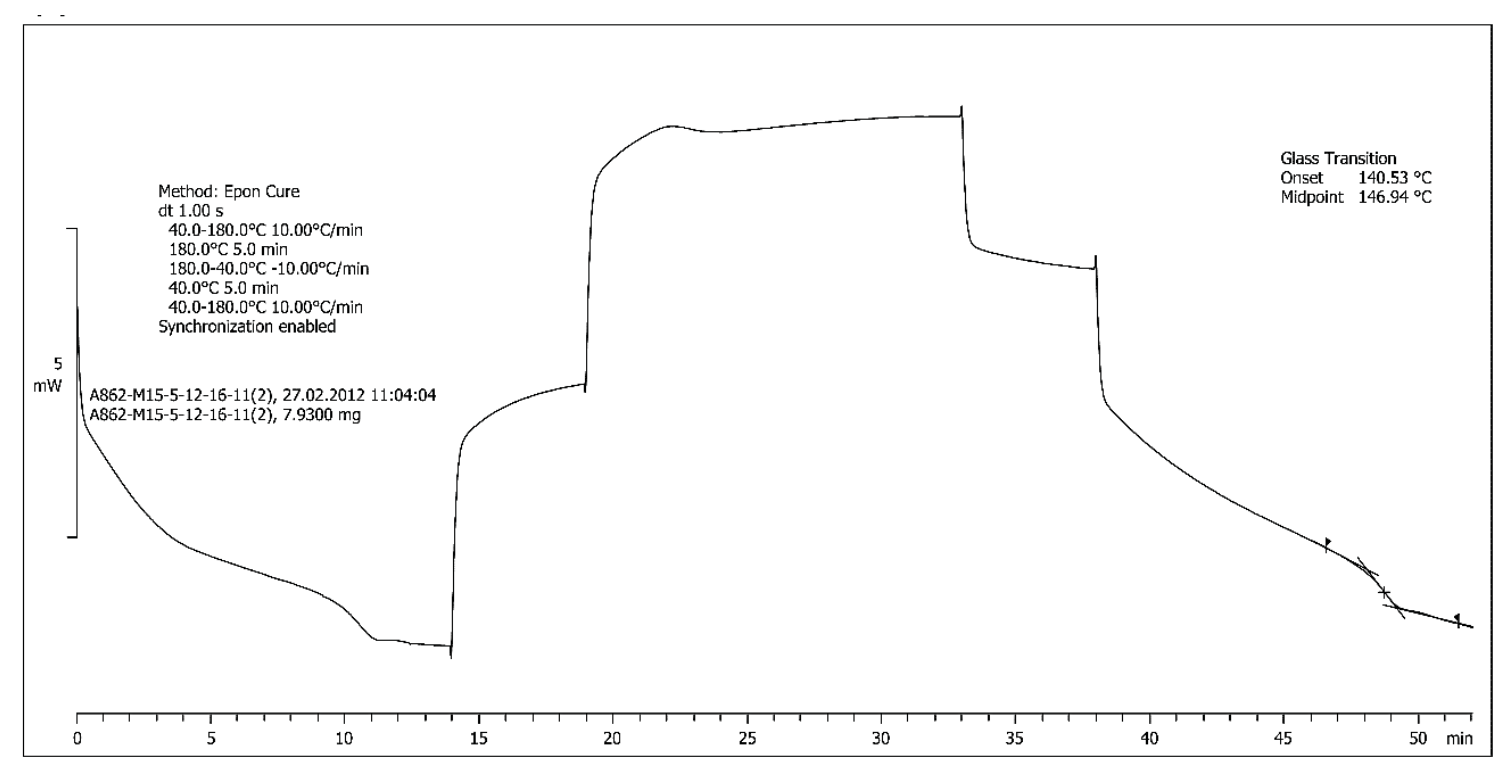

Figure E-6: DSC for 5 wt\% xGnP ${ }^{\circledR}-M-15$ in Epoxy (A862-M15-5-12-16-11) Run 2 vs. Time 
Table E-7: DSC Results for 6 wt\% $x$ GnP ${ }^{\circledR}-M-15$ in Epoxy

\begin{tabular}{|l|c|c|}
\hline \multicolumn{1}{|c|}{ Sample } & No. & $\begin{array}{c}\mathrm{Tg} \\
\left({ }^{\circ} \mathbf{C}\right)\end{array}$ \\
\hline A862-M15-6-10-26-11 & 1 & 141.08 \\
\hline A862-M15-6-10-26-11 & 2 & 143.07 \\
\hline A862-M15-6-1-19-12 & 1 & 147.12 \\
\hline A862-M15-6-1-19-12 & 2 & 145.44 \\
\hline A862-M15-6-1-19-12 & 3 & 146.19 \\
\hline A862-M15-6-1-19-12 & 4 & 147.47 \\
\hline A862-M15-6-1-19-12 & 5 & 148.04 \\
\hline A862-M15-6-1-19-12 & 6 & 146.05 \\
\hline Average & & $\mathbf{1 4 5 . 6}$ \\
\hline Standard Deviation & $\mathbf{2 . 4}$ \\
\hline Count & $\mathbf{8}$ \\
\hline
\end{tabular}

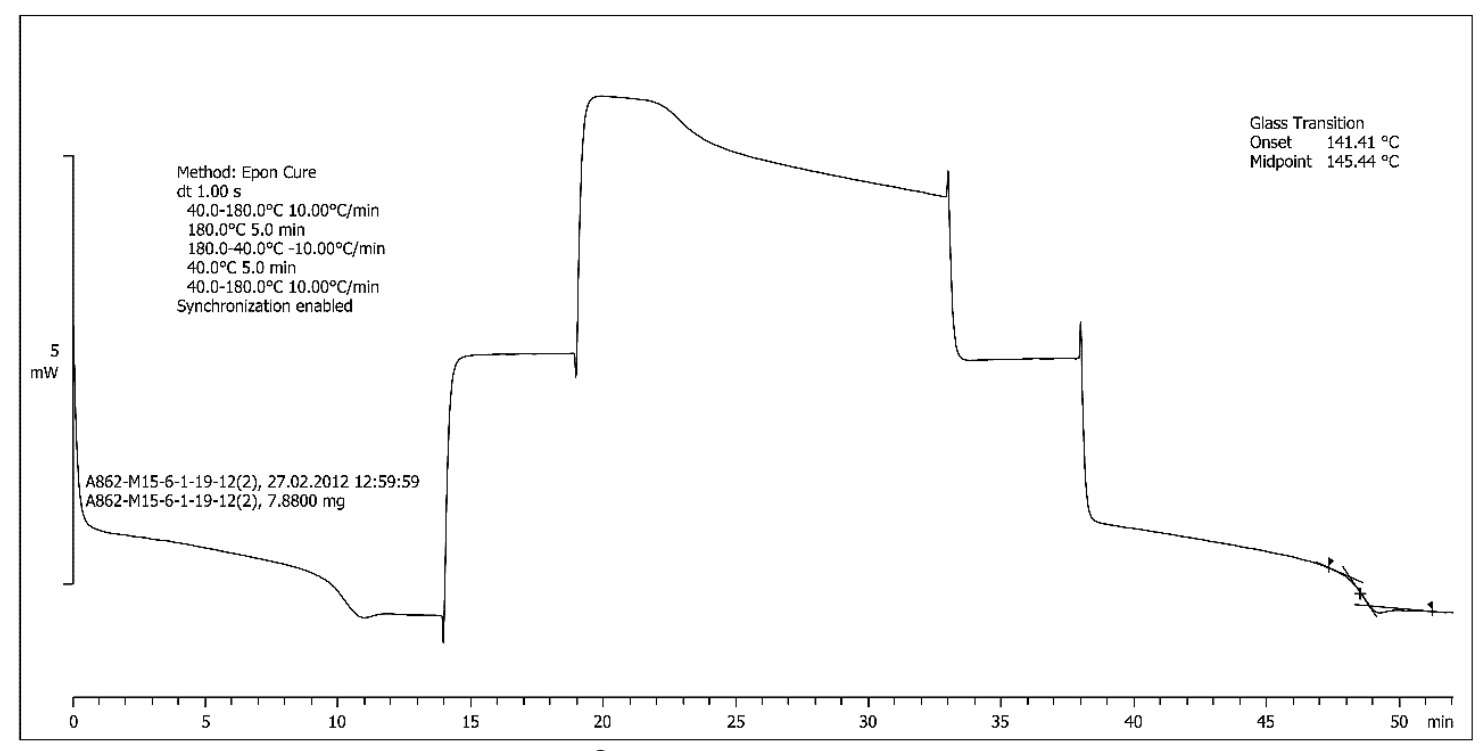

Figure E-7: DSC for 6 wt\% $x$ GnP ${ }^{\circledR}-M-15$ in Epoxy (A862-M15-6-1-19-12) Run 2 vs. Time 


\section{Appdenix F: Acoustic Absorption}

\section{F.1 Impedance Tube Method}

The standard used is ASTM E1050, this is an impedance tube method [1]. This method was chosen because the set up at Michigan Technological University was capable of testing in the frequency range of interest. The measurement of interest is acoustic absorption coefficient at a frequency range of $500-6400 \mathrm{~Hz}$, this frequency was chosen because it shows the most absorption as opposed to lower frequencies, i.e. $50-500 \mathrm{~Hz}$, even highly absorptive foams do not absorb much in this range. How much the sample absorbs will directly indicate how well the materials will dampen sound at the frequency of interest.

The impedance tube consists of a ridged tube with a specimen holder at one end and a speaker at the other with two microphones in between. There are a few different places for the microphones to be placed into depending on what frequency range is of interest. The speaker is connected to a white noise generator the microphones are connected to a computer with a MatLab graphical user interface (GUI) for the data acquisition. Figure F-1 below shows the setup of the tube.

First the microphones must be calibrated, a highly absorptive foam is used to do this. In the MatLab GUI use the normal configuration calibration first, then switch the microphones and use the switched configuration calibration, the configuration is based on the frequency desired for testing. To test the composite samples, the samples' edge is coated with petroleum jelly to keep any sound waves from escaping. The microphones are placed back into the normal position. The MatLab GUI takes data measurements at 
all the frequencies between 500 and $6400 \mathrm{~Hz}$. The measurements recorded are absorption coefficient, the real and imaginary parts of the reflection coefficient, the real and imaginary parts of the specific impedance ratio, and the real and imaginary parts of the specific admittance. Only the absorption coefficient is used to indicate dampening.

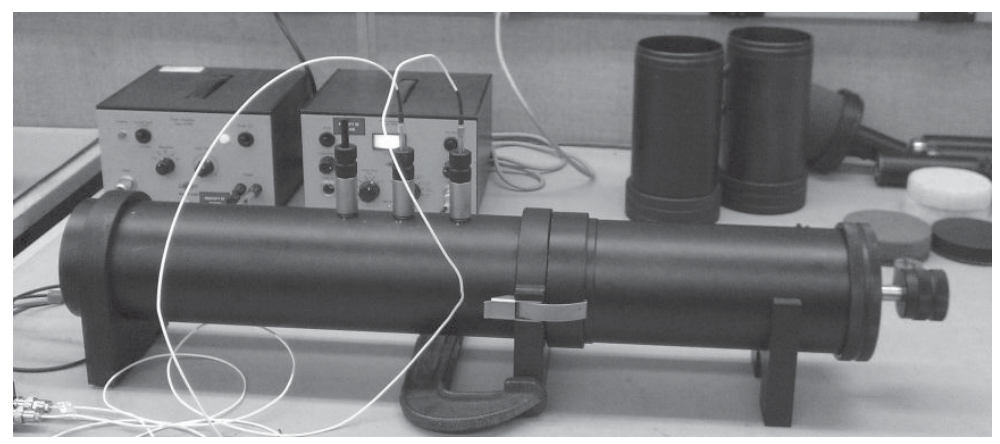

Figure F-1: Impedance tube set up

\section{F.2 Dynamic Mechanical Analysis Method [2]}

Dynamic mechanical analysis (DMA) can be used to measure tan delta. Tan delta is the measure of maternal damping, such as acoustic damping. Acoustic dampening is dominated by the polymer $\mathrm{T}_{\mathrm{g}}$. Equation F-1 shows the relationship between acoustic absorption $(\alpha \lambda$, units of $\mathrm{dB})$ and $\tan \delta$.

$$
\alpha \lambda=8.686 * \pi * \tan \delta
$$

Acoustic damping is dependent on the temperature and the frequency of the measurements. The measurements were done at a frequency of $1 \mathrm{~Hz}$ over a temperature range of $40{ }^{\circ} \mathrm{C}$ to $180{ }^{\circ} \mathrm{C}$. 


\section{F.3 Acoustic Absorption Results}

The impedance tube method works well for porous foam-like materials since they have a high absorption coefficient. The acoustic absorption for solid polymers and polymer composites have a very low absorption coefficient, with this method the acoustic absorption for the polymer could not be differentiated from the absorption of the impedance tube. Figure F-2 shows the sound absorption coefficient over a frequency range of 500-6400 Hz for the empty impedance tube and Figure F-3 shows the absorption coefficient over the same frequency range for neat epoxy and 1-6 wt $\% \mathrm{xGnP}^{\circledR}-\mathrm{M}-15$. The profile of the empty tube is very similar to the profile obtained for the epoxy and the GNP/epoxy composites.

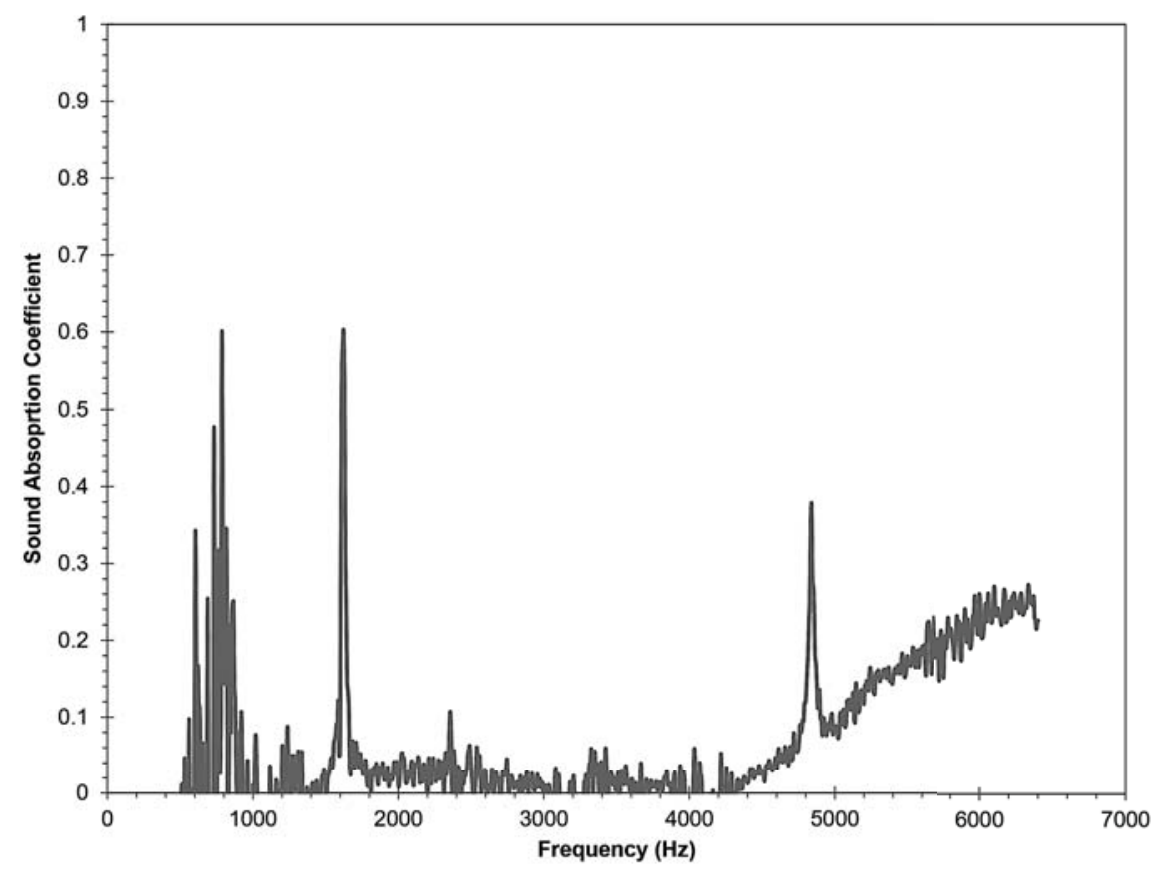

Figure F-2: Sound Absorption Coefficient for the empty impedance tube $500-6400 \mathrm{~Hz}$ 


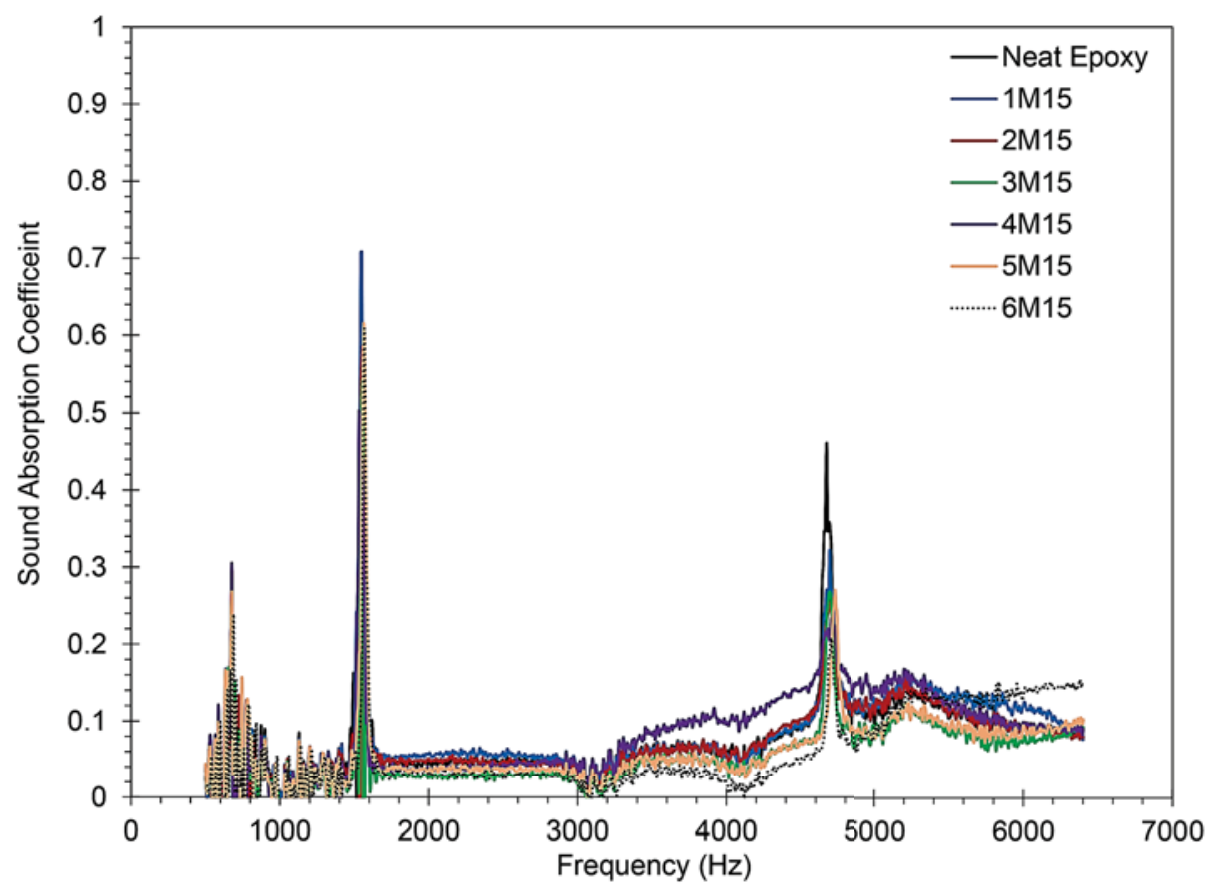

Figure F-3: Sound Absorption Coefficient for neat epoxy and 1-6 wt\% xGnP ${ }^{\circledR}-M-15$ in epoxy 500-6400 Hz

Since directly measuring the sound absorption was not possible, a DMA was used to try to relate mechanical properties to sound properties. Table F-1 shows the alphalambda (acoustic absorption) at $1 \mathrm{~Hz}$ frequency for neat epoxy and 1-6 wt $\% \mathrm{xGnP}^{\circledR}-\mathrm{M}-$ 15/epoxy, $x G n P^{\circledR}-M-5 / e p o x y$ and $x G n P^{\circledR}-C-300 /$ epoxy. The acoustic absorption measured at $1 \mathrm{~Hz}$ did not have a very clear trend. The results are scattered, but the overall trend is a decrease in acoustic absorption as more GNP was added to the epoxy, 6 wt $\%$ for all three GNPs had the lowest alpha-lambda. 
Table F-1: Maximum alpha-lambda with tan delta $T_{g}$ results for $x G n P^{\circledR}-M-15$ in epoxy, $x G n P^{\circledR}-M-5$ in epoxy and $x G n P^{\circledR}-C-300$ in epoxy measured at $1 \mathrm{~Hz}$

\begin{tabular}{|c|c|c|}
\hline Formulation & $\begin{array}{l}\text { Max Alpha- } \\
\text { Lambda (dB) }\end{array}$ & $\begin{array}{c}\text { Tan Delta Peak } \\
\mathbf{T}_{\mathrm{g}}\left({ }^{\circ} \mathbf{C}\right)\end{array}$ \\
\hline Neat Epoxy & $20.69 \pm 0.17 n=6$ & $155.8 \pm 0.4 n=6$ \\
\hline \multicolumn{3}{|l|}{$x G n P^{\circledR}-M-15$} \\
\hline $1 \mathrm{M15}$ & $17.99 \pm 0.09 \mathrm{n}=3$ & $153.5 \pm 0.5 n=3$ \\
\hline $2 M 15$ & $17.30 \pm 0.46 n=5$ & $152.6 \pm 0.8 \mathrm{n}=5$ \\
\hline $3 \mathrm{M} 15$ & $18.28 \pm 0.15 n=3$ & $150.4 \pm 0.3 n=3$ \\
\hline $4 \mathrm{M} 15$ & $16.81 \pm 0.14 n=3$ & $152.4 \pm 0.3 \mathrm{n}=3$ \\
\hline 5M15 & $17.40 \pm 0.12 n=3$ & $156.0 \pm 0.4 n=3$ \\
\hline $6 \mathrm{M} 15$ & $16.61 \pm 0.13 n=5$ & $155.9 \pm 0.5 n=5$ \\
\hline \multicolumn{3}{|l|}{$x G n P^{\circledR}-M-5$} \\
\hline $1 \mathrm{M5}$ & $19.36 \pm 0.14 \mathrm{n}=3$ & $154.3 \pm 0.3 n=3$ \\
\hline $2 \mathrm{M5}$ & $20.00 \pm 0.67 n=3$ & $153.1 \pm 0.4 n=3$ \\
\hline $3 M 5$ & $18.52 \pm 0.09 n=3$ & $154.7 \pm 0.3 n=3$ \\
\hline 4M5 & $18.40 \pm 0.31 n=3$ & $156.5 \pm 0.4 \mathrm{n}=3$ \\
\hline $5 \mathrm{M5}$ & $18.20 \pm 0.02 \mathrm{n}=3$ & $157.2 \pm 0.4 n=3$ \\
\hline $6 \mathrm{M5}$ & $17.55 \pm 0.11 n=3$ & $156.4 \pm 0.1 \mathrm{n}=3$ \\
\hline \multicolumn{3}{|l|}{$\mathrm{xGnP}^{\circledR}-\mathrm{C}-300$} \\
\hline $1 \mathrm{C} 300$ & $18.46 \pm 0.14 \mathrm{n}=3$ & $152.7 \pm 0.3 n=3$ \\
\hline $2 \mathrm{C300}$ & $19.75 \pm 0.11 \mathrm{n}=3$ & $143.4 \pm 0.2 \mathrm{n}=3$ \\
\hline $3 \mathrm{C300}$ & $18.02 \pm 0.30 \mathrm{n}=3$ & $152.7 \pm 0.4 \mathrm{n}=3$ \\
\hline $4 \mathrm{C300}$ & $17.40 \pm 0.17 n=3$ & $154.9 \pm 0.3 \mathrm{n}=3$ \\
\hline $5 C 300$ & $17.60 \pm 0.16 n=3$ & $153.3 \pm 0.3 n=3$ \\
\hline $6 C 300$ & $16.87 \pm 0.06 n=3$ & $153.4 \pm 0.2 \mathrm{n}=3$ \\
\hline
\end{tabular}

\section{F.4 References}

[1] American Society for Testing and Materials, Standard Test Methods for Impedance and Absorption of Acoustical Materials Using a Tube, Two Microphones and a Digital Freqency Analysis System:ASTM Standard E1050-08, (2008).

[2] Carsaro, R. D., Sperling, L. H., Sound and Vibration Damping with Polymers. Washington DC: American Chemical Society, (1990) In print. 


\section{Copyright Agreements and Permissions}

\section{Permission to use Figure 2-5}

Danielle Klimek-McDonald <drklimek@mtu.edu> to Julia :-

巴e Mar 20 th 4 i

All I need is something from XG Sciences saying that they give me (Danielle Klimek-McDonald) permission to use their picture in my dissertation.

...

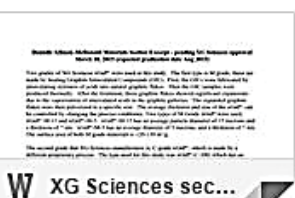

W XG Sciences sec...

¿ Julia King <jaking@mtu.edu>

to Hiroyuki, me :-

๔ Mar 20

Hiroyuki

$\mathrm{Hi}$. It is Julie King, from Michigan Tech University. One of my PhD students is writing her dissertation and plans to graduate in Aug 2015. We need your permission to use the information on the attached file about your GNP's we used and your permission to use the 2 TEM images of $x G n P$ that used to be on your $X G$ Sciences website in this dissertation. Can you please email me back with your approval.

Thanks!

Julie

- Hiroyuki Fukushima <fukushima@xgsciences.com> to Julia, me :

Mar 26 故

Hi Julie,

Yes, it is O.K. to use those images, as long as they are quoted as XG Sciences' copy right.

Regards,

Hiroyuki 


\section{Permission to use Figure 2-6}

\section{Asbury Carbons section of dissertation}

Albert V. Tamashausky <ALBERT@asbury.com>

Mon, $\operatorname{Mar} 23,2015$ at 8:12 AM

To: Julia King <jaking@mtu.edu>

Cc: Danielle Klimek-McDonald <drklimek@mtu.edu>

Hello Julie and Danielle,

I have attached your description of TC307, with a few edits. Feel free to use them or lose them.

Regarding the TEM you have selected, I have attached a few more TEM of TC307 that may work better. These images are higher resolution. The image currently in the section except is a lower res TEM. Take a look at the attached images and feel free to use any or all of them.

Thank you,

Albert

Albert V. Tamashausky

Attachments: Asbury TEM section for dissertation, TC307 TEM images.

Director of Research and Technical Services

Asbury Carbons

PO Box 144

405 Old Main Street

Asbury, NJ 08802

908-537-2155, ext 2236 


\section{Permission for Sections 4.1.1, 4.2.1, 4.3.1, 4.6.1, and 5.1 \\ Copyright Agreement for Journal of Applied Polymer Science JOHN WI LEY AND SONS LI CENSE TERMS AND CONDITIONS}

Mar 17, 2015

This Agreement between Danielle R KlimekMcDonald ("You") and John Wiley and Sons ("John Wiley and Sons") consists of your license details and the terms and conditions provided by John Wiley and Sons and Copyright Clearance Center.

License Number 3591490294127

License date Mar 17, 2015

Licensed Content Publisher John Wiley and Sons

Licensed Content Publication J ournal of Applied Polymer Science

Licensed Content Title Mechanical properties of graphene nanoplatelet/epoxy composites Licensed Content Author Julia A. King, Danielle R. Klimek, Ibrahim Miskioglu, Greg M.

Odegard

Licensed Content Date Oct 18, 2012

Pages 7

Type of use Dissertation/Thesis

Requestor type Author of this Wiley article

Format Electronic

Portion Full article

Will you be translating? No

Title of your thesis / Dissertation MECHANICAL PROPERTIES OF GRAPHENE

NANOPLATELET/EPOXY COMPOSITES

Expected completion date Aug 2015

Expected size (number of pages) 250

Requestor Location Danielle R KlimekMcDonald

1400 Townsend Dr

203 Chemical Sciences and Engineering

Chemical Engineering Department

HOUGHTON, MI 49931

United States

Attn: Danielle R KlimekMcDonald

Billing Type Invoice

Billing Address Danielle R KlimekMcDonald 


\section{Townsend Dr}

203 Chemical Sciences and Engineering

Chemical Engineering Department

HOUGHTON, MI 49931

United States

Attn: Danielle R KlimekMcDonald

Total 0.00 USD

Terms and Conditions

\section{TERMS AND CONDITIONS}

This copyrighted material is owned by or exclusively licensed to John Wiley \& Sons, Inc. or one of its group companies (each a"Wiley Company") or handled on behalf of a society with which a Wiley Company has exclusive publishing rights in relation to a particular work (collectively "WILEY"). By clicking accept in connection with completing this licensing transaction, you agree that the following terms and conditions apply to this transaction (along with the billing and payment terms and conditions established by the Copyright Clearance Center Inc., ("CCC's Billing and Payment terms and conditions"), at the time that you opened your Rightslink account (these are available at any time at http://myaccount.copyright.com).

\section{Terms and Conditions}

- The materials you have requested permission to reproduce or reuse (the "Wiley Materials") are protected by copyright.

- You are hereby granted a personal, nonexclusive, nonsub licensable (on a standalone basis), nontransferable, worldwide, limited license to reproduce the Wiley Materials for the purpose specified in the licensing process. This license is for a onetime use only and limited to any maximum distribution number specified in the license. The first instance of republication or reuse granted by this licence must be completed within two years of the date of the grant of this licence (although copies prepared before the end date may be distributed thereafter). The Wiley Materials shall not be used in any other manner or for any other purpose, beyond what is granted in the license. Permission is granted subject to an appropriate acknowledgement given to the author, title of the material/book/journal and the publisher. You shall also duplicate the copyright notice that appears in the Wiley publication in your use of the Wiley Material. Permission is also granted on the understanding that nowhere in the text is a previously published source acknowledged for all or part of this Wiley Material. Any third party content is expressly excluded from this permission.

- With respect to the Wiley Materials, all rights are reserved. Except as expressly granted by the terms of the license, no part of the Wiley Materials may be copied, modified, adapted (except for minor reformatting required by the new Publication), translated, reproduced, transferred or distributed, in any form or by any means, and no derivative works may be made based on the Wiley Materials without the prior permission of the 
respective copyright owner. You may not alter, remove or suppress in any manner any copyright, trademark or other notices displayed by the Wiley Materials. You may not license, rent, sell, loan, lease, pledge, offer as security, transfer or assign the Wiley Materials on a standalone basis, or any of the rights granted to you hereunder to any other person.

- The Wiley Materials and all of the intellectual property rights therein shall at all times remain the exclusive property of John Wiley \& Sons Inc, the Wiley Companies, or their respective licensors, and your interest therein is only that of having possession of and the right to reproduce the Wiley Materials pursuant to Section 2 herein during the continuance of this Agreement. You agree that you own no right, title or interest in or to the Wiley Materials or any of the intellectual property rights therein. You shall have no rights hereunder other than the license as provided for above in Section 2. No right, license or interest to any trademark, trade name, service mark or other branding ("Marks") of WILEY or its licensors is granted hereunder, and you agree that you shall not assert any such right, license or interest with respect thereto.

- NEITHER WILEY NOR ITS LICENSORS MAKES ANY WARRANTY OR REPRESENTATION OF ANY KIND TO YOU OR ANY THIRD PARTY, EXPRESS, IMPLIED OR STATUTORY, WITH RESPECT TO THE MATERIALS OR THE ACCURACY OF ANY INFORMATION CONTAINED IN THE MATERIALS, INCLUDING, WITHOUT LIMITATION, ANY IMPLIED WARRANTY OF MERCHANTABILITY, ACCURACY, SATISFACTORY QUALITY, FITNESS FOR A PARTICULAR PURPOSE, USABILITY, INTEGRATION OR NONINFRINGEMENT AND ALL SUCH WARRANTIES ARE HEREBY EXCLUDED BY WILEY AND ITS LICENSORS AND WAIVED BY YOU

- WILEY shall have the right to terminate this Agreement immediately upon breach of this Agreement by you.

- You shall indemnify, defend and hold harmless WILEY, its Licensors and their respective directors, officers, agents and employees, from and against any actual or threatened claims, demands, causes of action or proceedings arising from any breach of this Agreement by you.

- IN NO EVENT SHALL WILEY OR ITS LICENSORS BE LIABLE TO YOU OR ANY OTHER PARTY OR ANY OTHER PERSON OR ENTITY FOR ANY SPECIAL, CONSEQUENTIAL, INCIDENTAL, INDIRECT, EXEMPLARY OR PUNITIVE DAMAGES, HOWEVER CAUSED, ARISING OUT OF OR IN CONNECTION WITH THE DOWNLOADING, PROVISIONING, VIEWING OR USE OF THE MATERIALS REGARDLESS OF THE FORM OF ACTION, WHETHER FOR BREACH OF CONTRACT, BREACH OF WARRANTY, TORT, NEGLIGENCE, INFRINGEMENT OR OTHERWISE (INCLUDING, WITHOUT LIMITATION, DAMAGES BASED ON LOSS OF PROFITS, DATA, FILES, USE, BUSINESS OPPORTUNITY OR CLAIMS OF THIRD PARTIES), AND WHETHER OR NOT THE PARTY HAS BEEN ADVISED OF THE POSSIBILITY OF SUCH DAMAGES. THIS LIMITATION SHALL APPLY NOTWITHSTANDING ANY FAILURE OF ESSENTIAL PURPOSE OF ANY LIMITED REMEDY PROVIDED HEREIN. 
- Should any provision of this Agreement be held by a court of competent jurisdiction to be illegal, invalid, or unenforceable, that provision shall be deemed amended to achieve as nearly as possible the same economic effect as the original provision, and the legality, validity and enforceability of the remaining provisions of this Agreement shall not be affected or impaired thereby.

- The failure of either party to enforce any term or condition of this Agreement shall not constitute a waiver of either party's right to enforce each and every term and condition of this Agreement. No breach under this agreement shall be deemed waived or excused by either party unless such waiver or consent is in writing signed by the party granting such waiver or consent. The waiver by or consent of a party to a breach of any provision of this Agreement shall not operate or be construed as a waiver of or consent to any other or subsequent breach by such other party.

- This Agreement may not be assigned (including by operation of law or otherwise) by you without WILEY's prior written consent.

- Any fee required for this permission shall be nonrefundable after thirty (30) days from receipt by the CCC. These terms and conditions together with CCC's Billing and Payment terms and conditions (which are incorporated herein) form the entire agreement between you and WILEY concerning this licensing transaction and (in the absence of fraud) supersedes all prior agreements and representations of the parties, oral or written. This Agreement may not be amended except in writing signed by both parties. This Agreement shall be binding upon and inure to the benefit of the parties' successors, legal representatives, and authorized assigns.

- In the event of any conflict between your obligations established by these terms and conditions and those established by CCC's Billing and Payment terms and conditions, these terms and conditions shall prevail.

- WILEY expressly reserves all rights not specifically granted in the combination of (i) the license details provided by you and accepted in the course of this licensing transaction, (ii) these terms and conditions and (iii) CCC's Billing and Payment terms and conditions.

- This Agreement will be void if the Type of Use, Format, Circulation, or Requestor Type was misrepresented during the licensing process.

- This Agreement shall be governed by and construed in accordance with the laws of the State of New York, USA, without regards to such state's conflict of law rules. Any legal action, suit or proceeding arising out of or relating to these Terms and Conditions or the breach thereof shall be instituted in a court of competent jurisdiction in New York County in the State of New York in the United States of America and each party hereby consents and submits to the personal jurisdiction of such court, waives any objection to venue in such court and consents to service of process by registered or certified mail, return receipt requested, at the last known address of such party. 


\section{WILEY OPEN ACCESS TERMS AND CONDITIONS}

Wiley Publishes Open Access Articles in fully Open Access Journals and in Subscription journals offering Online Open. Although most of the fully Open Access journals publish open access articles under the terms of the Creative Commons Attribution (CC BY) License only, the subscription journals and a few of the Open Access Journals offer a choice of Creative Commons Licenses:: Creative Commons Attribution (CCBY) license Creative Commons Attribution NonCommercial (CCBYNC) license and Creative Commons Attribution NonCommercialNoDerivs (CCBYNCND) License. The license type is clearly identified on the article.

Copyright in any research article in a journal published as Open Access under a Creative Commons License is retained by the author(s). Authors grant Wiley a license to publish the article and identify itself as the original publisher. Authors also grant any third party the right to use the article freely as long as its integrity is maintained and its original authors, citation details and publisher are identified as follows: [Title of Article/Author/Journal Title and Volume/Issue. Copyright (c) [year] [copyright owner as specified in the Journal]. Links to the final article on Wiley's website are encouraged where applicable.

\section{The Creative Commons Attribution License}

The Creative Commons Attribution License (CCBY) allows users to copy, distribute and transmit an article, adapt the article and make commercial use of the article. The CCBY license permits commercial and noncommercial reuse of an open access article, as long as the author is properly attributed.

The Creative Commons Attribution License does not affect the moral rights of authors, including without limitation the right not to have their work subjected to derogatory treatment. It also does not affect any other rights held by authors or third parties in the article, including without limitation the rights of privacy and publicity. Use of the article must not assert or imply, whether implicitly or explicitly, any connection with, endorsement or sponsorship of such use by the author, publisher or any other party associated with the article.

For any reuse or distribution, users must include the copyright notice and make clear to others that the article is made available under a Creative Commons Attribution license, linking to the relevant Creative Commons web page.

To the fullest extent permitted by applicable law, the article is made available as is and without representation or warranties of any kind whether express, implied, statutory or otherwise and including, without limitation, warranties of title, merchantability, fitness for a particular purpose, noninfringement, absence of defects, accuracy, or the presence or absence of errors.

\section{Creative Commons Attribution NonCommercial License}

The Creative Commons Attribution NonCommercial (CCBYNC) License permits use, distribution and reproduction in any medium, provided the original work is properly cited and is not used for commercial purposes.(see below)

\section{Creative Commons Attribution NonCommercialNoDerivs License}


The Creative Commons Attribution NonCommercialNoDerivs License (CCBYNCND) permits use, distribution and reproduction in any medium, provided the original work is properly cited, is not used for commercial purposes and no modifications or adaptations are made. (see below)

\section{Use by noncommercial users}

For noncommercial and nonpromotional purposes, individual users may access, download, copy, display and redistribute to colleagues Wiley Open Access articles, as well as adapt, translate, textand data-mine the content subject to the following conditions:

- The authors' moral rights are not compromised. These rights include the right of "paternity" (also known as "attribution" the right for the author to be identified as such) and "integrity" (the right for the author not to have the work altered in such a way that the author's reputation or integrity may be impugned).

- Where content in the article is identified as belonging to a third party, it is the obligation of the user to ensure that any reuse complies with the copyright policies of the owner of that content.

- If article content is copied, downloaded or otherwise reused for noncommercial research and education purposes, a link to the appropriate bibliographic citation (authors, journal, article title, volume, issue, page numbers, DOI and the link to the definitive published version on Wiley Online Library) should be maintained. Copyright notices and disclaimers must not be deleted.

- Any translations, for which a prior translation agreement with Wiley has not been agreed, must prominently display the statement: "This is an unofficial translation of an article that appeared in a Wiley publication. The publisher has not endorsed this translation."

\section{Use by commercial "forprofit" organisations}

Use of Wiley Open Access articles for commercial, promotional, or marketing purposes requires further explicit permission from Wiley and will be subject to a fee. Commercial purposes include:

- Copying or downloading of articles, or linking to such articles for further redistribution, sale or licensing;

- Copying, downloading or posting by a site or service that incorporates advertising with such content;

- The inclusion or incorporation of article content in other works or services (other than normal quotations with an appropriate citation) that is then available for sale or licensing, for a fee (for example, a compilation produced for marketing purposes, inclusion in a sales pack)

- Use of article content (other than normal quotations with appropriate citation) by forprofit organisations for promotional purposes 
- Linking to article content in emails redistributed for promotional, marketing or educational purposes;

- Use for the purposes of monetary reward by means of sale, resale, licence, loan, transfer or other form of commercial exploitation such as marketing products

- Print reprints of Wiley Open Access articles can be purchased from: corporatesales@wiley.com

Further details can be found on Wiley Online Library

http://olabout.wiley.com/WileyCDA/Section/id410895.html

Other Terms and Conditions:

v1.9

Questions? customercare@copyright.com or +18552393415 (toll free in the US) or +19786462777 .

Gratis licenses (referencing $\$ 0$ in the Total field) are free. Please retain this printable license for your reference. No payment is required. 


\title{
Permission for Sections 4.1.2, 4.2.2, 4.6.2, 5.2, and 5.3
}

\section{Copyright Agreement for Journal of Composite Materials}

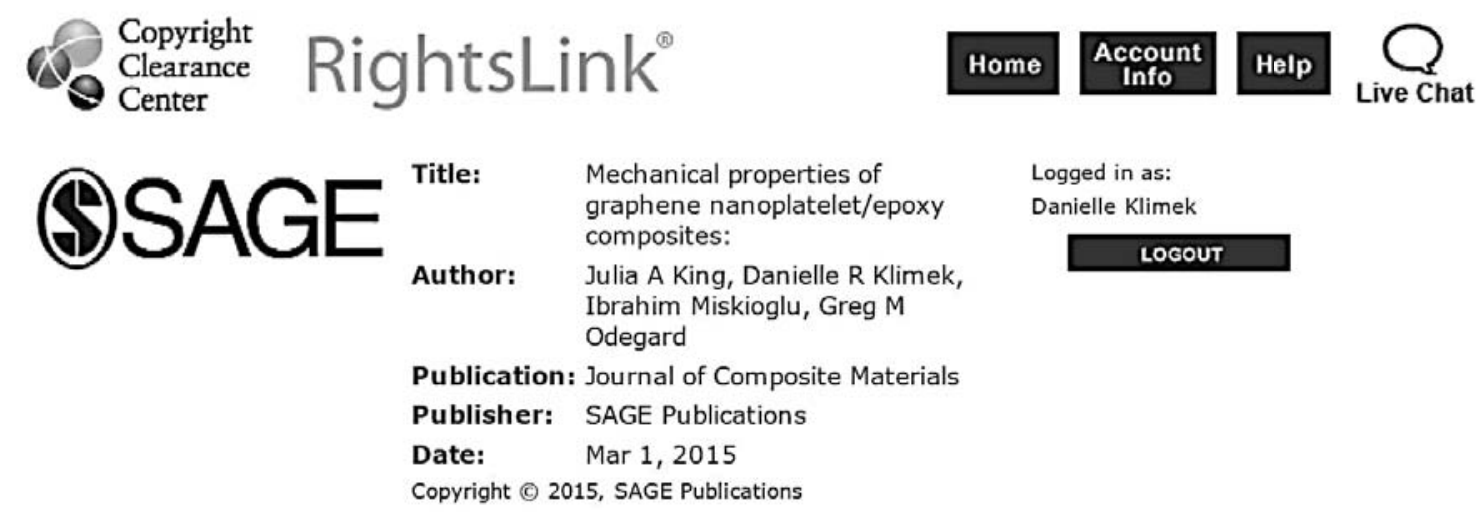

\begin{abstract}
Redirected Request
If you are an Author inquiring about the re-use of your journal article, please note that after publication of the journal article, Authors may re-use their content in any later work written or edited by the Author or for the Author's classroom use, without seeking permission from SAGE. For any other use of your work, please contact the publisher. For additional information see www.sagepub.com/repository/binaries/iournals/permissions/author use.doc.
\end{abstract}

\section{Journal Authors}

The following SAGE's Journal Author Reuse Policy, effective as of March 20, 2013:

- You may do whatever you wish with the version of the article you submitted to the journal (Version 1).

- Once the article has been accepted for publication, you may post the accepted version (Version 2) of the article on your own personal website, your department's website or the repository of your institution without any restrictions.

- You may not post the accepted version (Version 2) of the article in any repository other than those listed above (i.e. you may not deposit in the repository of another institution or a subject-matter repository) until 12 months after publication of the article in the journal.

- You may use the published article (version 3) for your own teaching needs or to supply on an individual basis to research colleagues, provided that such supply is not for commercial purposes.

- You may use the article (version 3) in a book authored or edited by you at any time after publication in the journal.

- You may not post the published article (version 3) on a website or in a repository without permission from SAGE. 
- When posting or re-using the article please provide a link to the appropriate DOI for the published version of the article on SAGE Journals (http://online.sagepub.com)

All commercial or any other re-use of the published article should be referred to SAGE. More information can be found at: http://www.sagepub.com/journalsPermissions.nav. 